\title{
ARCHITECTURE OF EXCESS: NAVIGATING BEYOND THE SUPERFICIAL
}

\author{
by \\ Rebecca Tsang \\ B.Arch.Sc., Ryerson University, 2010.
}

\author{
A Design Thesis Project \\ presented to Ryerson University \\ in partial fulfillment of the requirements for the degree of \\ Master of Architecture \\ in the program of \\ Architecture
}

Toronto, Ontario, Canada, 2016

() Rebecca Tsang 2016 



\section{AUTHOR'S DECLARATION}

I hereby declare that I am the sole author of this thesis. This is a true copy ot the thesis, including any required final revisions, as accepted by my examiners.

I authorize Ryerson University to lend this thesis project to other institutions or individuals for the purpose of scholarly research.

I further authorize Ryerson University to reproduce this thesis project by photocopying or by other means, in total or in part, at the request of other institutions or individuals for the purpose of scholarly research.

I understand that my thesis may be electronically available to the public.

Rebecca Tsang 



\section{ABSTRACT}

Contemporary architecture has become increasingly superficial as it relies on capricious visual excitement for appeal in the 21st Century. Architectural semiotics have been appropriated to become massively branded images in the urban landscape that aim for instant gratification, lacking experiential depth and qualities beyond visual delight. The aim for iconic and instant appeal in any building typology limits our understanding of architecture's relationship to use, users, and context. Working both within and beyond the same culture of consumption and excess in the experience economy, this thesis posits that characteristics and values of entertainment architecture provide engaging experiential qualities for architectural design beyond superficial appeal. Entertaining values of educational leisure, themed environments, and consumption can in fact generate a more integrated and authentic relationship between architecture, people, and place in our society of the spectacle. 



\section{ACKNOWLEDGEMENTS}

The completion of this thesis would not have been possible without the support and encouragement of a number of people. First of all, I thank my family for their support and trust, for never doubting my decisions. I would also like to thank my fiancée for his love, patience and never-ending supply of snacks and hugs. A special thanks to my thesis supervisor, Vincent Hui, for his brutally honest guidance and mentorship. I have grown to enjoy our weekly meetings and conversations. His attention and commitment to my thesis, studies, and beyond have been immensely encouraging throughout my years at Ryerson. I would also like to thank my second reader, Baruch Zone, for constantly reminding me to have fun. I would also like to extend my thanks to the last of my committee members, Jenn McArthur, for her insight and critique at each presentation. Lastly, I would like to thank my fellow classmates for filling the past two years with love, laughter, and amazing memories. 



\title{
DEDICATION
}

\author{
For Maggie
}

for always putting a smile on my face. 


\section{TABLE OF CONTENTS}

Author's Declaration ....................................................................ii

Abstract ....................................................................................................

Acknowledgements ............................................................................vii

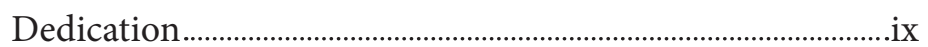

Table of Contents

List of Figures...........................................................................................

List of Appendices ........................................................................................Xxxiii

Introduction $\ldots$

Chapter 1. The Commodification of Architecture ..............09

1.1 An Appropriation of Architectural Semiotics......11

1.2 The Mediation of Images in Society.............................15

1.3 The Dominance of Economy Over Society...........19

1.4 Globalization and Competition ...................................29

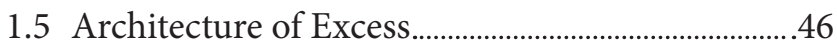

Chapter 2. Beyond Entertainment ..............................................49

2.1 The Rise of Entertainment Architecture ..................50

2.2 Entertainment as Experience...........................................

2.3 The Appeal of the Theme Park ....................................54

2.4 Still Learning from Las Vegas.......................................68

2.5 Scale and Rhythm of the City.......................................80

2.6 Beyond Superficial Entertainment.............................94

\section{Chapter 3. Design I:}

Defining Project Background, Scope, and Site .....................97

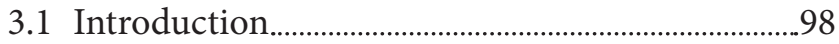

3.2 Design Research and Design Project........................102

3.3 Redefining the Animal Shelter in Toronto.............117 


\section{Chapter 4. Design II:}

Design Strategies and Tactics Exploration ………………..... 119

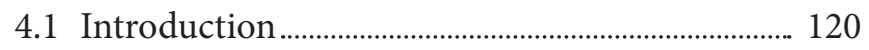

4.2 An Architecture of Work ................................................ 121

4.3 The Context as Theme ............................................... 144

4.4 Social Scale and Rhythm of Users .......................... 168

4.5 Strategies and Tactics Applied to the

Animal Shelter.

\section{Chapter 5. Design III:}

Rescue, Rehabilitate, Rehome: Redefining the Shelter... 179

\section{Conclusion}

Appendix

Bibliography 


\section{LIST OF FIGURES}

Chapter 1. The Commodification of Architecture

Figure 1.1 Proposed Apple Headquarters by Foster + Partners. Cupertino, California. http://static.dezeen.com/uploads/2011/08/dezeen_AppleCampus-2-by-Foster-Partners_2.jpG

Figure 1.2 Roman Colosseum, 1st Century AD. Rome, Italy. http://www.crystalinks. com/colosseumaerialview.jpg

Figure 1.3 Pantheon, 1st Century AD. Rome, Italy. http://romeonsegway.com/wpcontent/plugins/widgetkit/cache/gallery/738/old-pantheon-rome-onsegway-33c909baa4.jpg

Figure 1.4 St Peter's Basilica, 1626. Vatican City. https://romesoyouseeit.files. wordpress.com/2014/05/60096195_vatican_aerial_g.jpg?w=592\&h=332

Figure 1.5 London, UK. http://www.beingbrunel.com/wp-content/uploads/2014/12/ london-skyline.jpg

Figure 1.6 Bilbao, Spain. http://f.ptcdn.info/006/017/000/1395504553-1201guggen-o. jpg

Figure 1.7 Selfridges Store, Birmingham, UK. http://www.bedandbreakfastsguide. com/ArticleImages/ArticleImage_233_444.jpg

Figure 1.8 Plato's Allegory of the Cave. http://mejialangcomp.weebly.com/ uploads/1/7/7/0/17702677/5126781_orig.jpg

Figure 1.9 Preference of Images and Imagery in Society

Figure 1.10 Progression of Economic Value. Joseph Pine and James Gilmore. Welcome to the Experience Economy. 1998. https://hbr.org/1998/07/ welcome-to-the-experience-economy

Figure 1.11 Audi A4 and Audi Brand Building. http://www.topgear.com/sites/ default/files/styles/fit_1960x1102/public/cars-car/carousel/2016/07/4105. jpg?itok=mo4zS0uG; http://images.adsttc.com/media/images/5616/f59f/ e58e/ce94/b800/0156/newsletter/Schmidhubuer_Audi_IAA_2015_01. jpg?1444345229

Figure 1.12 BMW 7 Series and BMW Welt and Museum. http://www.telegraph.co.uk/ content/dam/motoring2/2015/12/02/1-2016-BMW-7-series-front-xlargelarge_trans++rWYeUU_H0zBKyvljOo6zlkYMapKPjdhyLnv9ax6_too.jpg; http://cdn.bmwblog.com/wp-content/uploads/bmw-welt-162.jpg

Figure 1.13 Mercedes Benz C Class and Mercedes Benz Museum. http://i.ndtvimg. com/i/2014-11/new-c-class-1_625x300_61416885167.jpg; http://www. benzinsider.com/wp-content/uploads/2010/12/mercedes-benz-museum. jpg 


\section{LIST OF FIGURES}

Figure 1.14 Prada Epicenter, Tokyo by Herzog \& de Meuron. Exterior. https:// c1.staticflickr.com/9/8144/7522601992_cd231baf6d_b.jpg Interior. http://retaildesignblog.net/wp-content/uploads/2011/07/Pradastore-by-Herzog-and-De-MeuronTokyo-02.jpg

Figure 1.15 Prada Epicenter, New York by Rem Koolhaas. Interior. https://s-mediacache-ak0.pinimg.com/236x/6b/48/10/6b4810d0135a8f19a1b68482 1f270991.jpg; http://cdn.archinect.net/images/1200x/7t/7tf7h31cueujk 6v2.jpg

Figure 1.16 Louis Vuitton Flagship Stores (from left to right) Hong Kong, Bahamas, New York, Shenzhen, Shanghai, Tokyo, Paris, Singapore.

Hong Kong: http://www.aokijun.com/wp-content/uploads/2005/12/01_ lvhk_0211-704x554.jpg

Bahamas: http://www.mundoflaneur.com/wp-content/uploads/2012/12/ Louis-Vuitton-Punta-del-Este-\%C2\%A9-Gal-Oppido-03.jpg New York: http://www.bellecour.fr/wp-content/uploads/2014/04/StFi_ Louis_Vuitton_NEW_YORK_5TH_AVENUE_410_WM4.jpg

Shenzhen: https://s-media-cache-ak0.pinimg.com/originals/4b/ea/f6/4bea f618f444b43dc7db2d84e81852e9.jpg

Shanghai: http://www.hypemeanseverything.com/wp-content/ uploads/2011/05/LV-shanghai.png Tokyo: https://s-media-cache-ak0.pinimg.com/originals/99/d5/ab/99d5ab 7958d721454a1bdb7f2c9751d6.jpg

Paris: http://static.flickr.com/192/484713634_b45b9626fb.jpg

Singapore: http://www.designboom.com/weblog/images/images_2/ lauren/louis\%20vuitton\%20island\%20maison/lv01.jpg

Figure 1.17 Top 20 Global Cities 2014. ATKearney. 2014. Global Cities, Present and Future: 2014 Global Cities Index and Emerging Cities Outlook. April. Accessed Dec 14, 2015. https://www.atkearney.com/research-studies/ global-cities-index/2014.

Figure 1.18 Shanghai Tower by Gensler, 2015. Shanghai, China. http://static2.gensler. com/uploads/hero_element/3916/thumb_desktop/thumbs/shangai_tower _1600x900_01_1399498850_1600x900.jpg

Figure 1.19 Burj Khalifa by SOM Architects, 2010. Dubai, UAE. http://foundtheworld. com/burj-khalifa

Figure 1.20 Taipei 101 by CY Lee and Partners, 2004. Taipei, Taiwan. https://upload. wikimedia.org/wikipedia/commons/0/05/Taipei_101_from_afar.jpg

Figure 1.21 Figure 1.21: Abraj Al Bait by Shair and Partners, 2012. Mecca, Saudi Arabia. http://images.china.cn/attachement/jpg/site1007/20120727/00137 2a9ae05117c7fdc50.jpg 


\section{LIST OF FIGURES}

Figure 1.23 Guggenheim Museum by Frank Gehry Architects, 1997. Bilbao, Spain. Interior. http://images.guggenheim-bilbao.es/src/uploads/2012/05/ enguggenheim-bilbao-museo-atrio-2-480x480.jpeg

Figure 1.24 Guggenheim Museum by Frank Gehry Architects, 1997. Bilbao, Spain. Exterior. https://upload.wikimedia.org/wikipedia/commons/1/1d/ Guggenheim_Museum,_Bilbao,_July_2010_(06).jpg

Figure 1.25 Walt Disney Concert Hall by Frank Gehry Architects, 2003. Los Angeles, California. http://www.joshbustosphotography.com/data/ photos/7_1disneyconcerthall2.jpg

Figure 1.26 Sydney Opera House Re-Branded Type Face, 2016 http://editorial. designtaxi.com/editorial-images/news-sydneyrebrand260216/1.jpg

Figure 1.27 Sydney Opera House by Jorn Utzon, 1973. Sydney, Australia. https:// upload.wikimedia.org/wikipedia/commons/7/75/Sydney_Opera_House,_ botanic_gardens_1.jpg

Figure 1.28 Sydney Opera House Re-Branded Signage, 2016 https://d3ui957tjb5bqd. cloudfront.net/uploads/2016/02/bad-or-rad-soh-\%E2\%80\%94-004.jpg

Figure 1.29 'Libeskind Buildings'

Royal Ontario Museum, 2007. Toronto, Canada. http://libeskind.com/ work/royal-ontario-museum/

Denver Art Museum Extension, 2006. Denver, Colorado. http://libeskind. com/work/extension-to-the-denver-art-museum-frederic-c-hamiltonbuilding/

The Run Run Shaw Creative Media Centre, 2010. Hong Kong, China. http://libeskind.com/work/the-run-shaw-creative-media-centre/ Military History Museum, 2011. Dresden, Germany. http://libeskind.com/ work/military-history-museum/

Figure 1.30 'Zaha Buildings'

Collins Park Place, under construction. Miami Beach, USA. http://www. zaha-hadid.com/architecture/miami-car-park/

King Abdullah Financial District Metro Station, under construction. Riyadh, Saudi Arabia. http://www.zaha-hadid.com/architecture/kingabdullah-financial-district-metro-station/ Guangzhou Opera House, 2010. Guangzhou, China. http://www.zahahadid.com/architecture/guangzhou-opera-house/ Wangjing Soho, 2014. Beijing, China. http://www.zaha-hadid.com/ architecture/wangjing-soho/ 


\section{LIST OF FIGURES}

Figure 1.31 'Gehry Buildings'

Lou Ruvo Centre for Brain Health, 2010. Las Vegas, Nevada. https:// en.wikipedia.org/wiki/Lou_Ruvo_Center_for_Brain_Health\#/media/ File:Lou_Ruvo_Brain_Institute.jpg

Walt Disney Concert Hall, 2003. Los Angeles, California. http://www. joshbustosphotography.com/data/photos/7_1disneyconcerthall2.jpg Weisman Art Museum, 1993. Minneapolis, Minnesota. http://www. morgansheffphotography.com/data/photos/244_1weisman_new_small_ scaler.jpg

IAC Building, 2007. New York, USA. http://rolfgross.dreamhosters. com/2014Gehry/Gehry2/Gehry-2_html_16e377fc.jpgg

Figure 1.32 Proposed Culture and Art Centre of Qingdao by Steven Holl. Qingdao, China. 2013. http://www.dezeen.com/2013/10/30/steven-holl-museumcomplex-china/

Figure 1.33 Proposed Shenzhen Art Museum and Library by KSP Jürgen Engel Architekten. Shenzhen, China. 2015. http://www.dezeen.com/2015/11/27/ ksp-jurgen-engel-architekten-wins-competition-design-shenzhen-artmuseum-library-china/

Figure 1.34 Proposed expansion to National Art Museum of China Interior by Jean Nouvel. Beijing, China. 2014. http://www.dezeen.com/2014/09/19/jeannouvel-national-art-museum-of-china-construction-begins/; http://cdn. pursuitist.com/wp-content/uploads/2015/04/Jean-Nouvel-and-the-NewNational-Museum-Of-China.jpg

Figure 1.35 Yinchuan Art Museum by Beijing firm We Architech Anonymous. Yinchuan, China. 2015. http://www.dezeen.com/2015/08/06/museumcontemporary-art-yinchuan-moca-waa-china-yellow-river-undulatingfacade/

Figure 1.36 Qujing History Museum by Atelier Alter and Hordor Design Group. Qujing, China. 2015. http://www.dezeen.com/2015/08/12/qujing-historymuseum-yunnan-province-china-roof-shaped-upside-down-staircaseatelier-alter-hordor-design-group/

Figure 1.37 Minsheng Contemporary Art Museum by Studio Pei-Zhu. Beijing, China. 2015. Interior and Exterior. http://www.dezeen.com/2015/09/10/studiopei-zhu-converts-beijing-factory-minsheng-art-museum-china

Figure 1.38 Proposed Apple Headquarters by Foster + Partners. Cupertino, California. http://static.dezeen.com/uploads/2011/08/dezeen_AppleCampus-2-by-Foster-Partners_2.jpg 


\section{LIST OF FIGURES}

Figure 1.39 Proposed Google Headquarters by Bjarke Ingles Group and Heatherwick Studios. North Bayshore, California. http://i0.wp.com/aasarchitecture. com/wp-content/uploads/Google-Mountain-View-Campus-by-BIGand-Heatherwick-Studio-00.jpg? resize=672\%2C372 http://4.bp.blogspot. com/-DiRoTY1kLuY/VYCxVkEVo-I/AAAAAAAB_i4/UWP22OyBDCk/ s1600/BIG\%2B.\%2BHeatherwick\%2BStudios\%2B.\%2BCharleston\%2 BPark\%2BGoogle\%2BHQ\%2B.\%2BCalifornia\%2B\%25281\%2529.jpg http://static.dezeen.com/uploads/2015/05/Robotic-cranes-BIG-andHeatherwick-Google-HQ_dezeen_784.jpg

Figure 1.40 8 Spruce Street by Frank Gehry Architects, 2010. New York, USA. https:// upload.wikimedia.org/wikipedia/commons/8/84/Beekman_Tower_fr_ BB_jeh.jpg

Figure 1.41100 11th Avenue by Ateliers Jean Nouvel, 2010. New York, USA. http://www.architravel.com/architravel_wp/wp-content/ uploads/2013/05/100_11th_Avenue_Jean_Nouvel_2.jpg

Figure 1.42 Proposed Via at West 57th Street by Bjarke Ingles Group, 2015. New York, USA. http://www.big.dk/\#projects-w57

Figure 1.43 Proposed 520 West 28th Street interior and exterior by Zaha Hadid, 2016. New York, USA.

Figure 1.44 China's "London" Thamestown (Songjiang District) in Shangai, China. 2006. http://www.theguardian.com/cities/gallery/2014/oct/22/venicechina-dalian-copy-canals-palaces-gondoliers\#img-2

Figure 1.45 China’s "Paris" Tianducheng in Hangzhou, China. 2007. http://www. theguardian.com/cities/gallery/2014/oct/22/venice-china-dalian-copycanals-palaces-gondoliers\#img-2

Figure 1.46 China's "Venice" in Dalian, China. 2014. http://www.theguardian.com/ cities/gallery/2014/oct/22/venice-china-dalian-copy-canals-palacesgondoliers\#img-2

Figure 1.47 Louis Vuitton Singapore Marina Bay by FTL Design Engineering Studio. 2012. Singapore. http://www.archdaily.com/277610/louis-vuitton-insingapore-ftl-design-engineering-studio 


\section{LIST OF FIGURES}

Chapter 2. Beyond Entertainment

Figure 2.1 Spectators gather at the Roman Coliseum for a day of entertainment: eating, cooking, drinking, fighting, watching the spectacle as well as being the spectacle. http://wandering-through-time-and-place.me/2013/04/29/ romes-colosseum-where-hippos-and-rhinos-once-fought/

Figure 2.2 English Pleasure Gardens. Vauxhall Gardens Aerial View 1751. http://1.bp.blogspot.com/-KRFn-sdKslg/VlYbJ6f1tHI/ AAAAAAAAAeE/46YE386iu20/s1600/vauxhall-gardens-prospect.jpg

Figure 2.3 Vauxhall Gardens. 1751. http://www.historytoday.com/sites/default/files/ vauxhall_grandwalk_0.jpg

Figure 2.4 Central Park. New York. Fredrick Law Olmstead. 1857. http://assets. fodors.com/destinations/1128/central-park-manhattan-new-york-citynew-york-usa_main.jpg

Figure 2.5 1893 Chicago World's Fair. Electrical Building. https://i.kinja-img.com/ gawker-media/image/upload/s--2Id5zcIC--/c_scale,fl_progressive,q_80,w _800/18tjviifqc47rjpg.jpg

Figure 2.6 1893 Chicago World's Fair. Electrics Showcase. https://i.kinja-img.com/ gawker-media/image/upload/s--VZbLq2zZ--/c_scale,fl_progressive,q_80, w_800/18tk3x3tj72qhjpg.jpg

Figure2.7 1893 Chicago World's Fair. Moving Walkways. https://i.kinja-img.com/ gawker-media/image/upload/s--VZbLq2zZ--/c_scale,fl_progressive,q_80, w_800/18tk3x3tj72qhjpg.jpg

Figure 2.8 Coney Island. Steeple Chase Amusement Park. 1900s. http://i62.tinypic. com/14lrqsg.jpg

Figure 2.9 Coney Island. Luna Park. http://excitingny.com/oldconey/images/ LunaSurfAvenue.jpg

Figure 2.10 Coney Island Cyclone Rollercoaster. 1927. http://untappedcities. wpengine.netdna-cdn.com/wp-content/uploads/2015/06/coney-islandcyclone-vintage-photo-NYC-Untapped-Cities.jpg

Figure 2.11 Disneyland. 1955. http://cdn.history.com/sites/2/2015/07/hith-disneyGettyImages-158939470.jpg

Figure 2.12 Walt Disney's vision for Disneyland. 1940s. http://www.nametagmuseum. com/walt_1953.jpg

Figure 2.13 Model for original plans for EPCOT. 1966. https://sites.google.com/site/ theoriginalepcot/_/rsrc/1392542371682/the-florida-project/the-originalepcot-F-4x3-750.jpg 


\section{LIST OF FIGURES}

Figure 2.14 Transportation System in Original EPCOT Vision. 1966. https:// sites.google.com/site/theoriginalepcot/_/rsrc/1392542076657/ the-florida-project/092712_FS_FromTheArchives_EpcotOrigins_ WaltsEpcot_5.1tag750.jpg

Figure 2.15 Map of Disney's MGM Studios. https://s-media-cache-ak0.pinimg. com/736x/85/e7/d8/85e7d8b135f398e30dd05c388540a349.jpg

Figure 2.16 Diagram of Studio Backlot Tour in Disney’s MGM Studios.

Figure 2.17 BMW Central Building Aerial View. Leipzig, Germany. 2005. Zaha Hadid Architects. http://cfile21.uf.tistory.com/ image/2522174F5214C3BB0370BD

Figure 2.18 Diagram of Space Relations and Production Flow.

Figure 2.19 BMW Central Building Exterior. Leipzig, Germany. 2005. Zaha Hadid Architects. http://www.jebiga.com/wp-content/uploads/2013/07/BMW_ Central_Building_Leipzig_Zaha_Hadid_Architects_8.jpg

Figure 2.20 BMW Central Building Interior. Leipzig, Germany. 2005. Zaha Hadid Architects. http://www.jebiga.com/wp-content/uploads/2013/07/BMW_ Central_Building_Leipzig_Zaha_Hadid_Architects_4.jpg

Figure 2.21 Ripley's Aquarium of Canada. Toronto, Canada. 2013. B+H Architects. http://www.acoustical-consultants.com/wp-content/uploads/2013/11/ ripleys_aquarium_4-390x245.jpg; http://www.bestoftoronto.net/wpcontent/uploads/2013/10/Ripleys-Aquarium-BestofToronto-2013-022.jpg

Figure 2.22 California Academy of Sciences. San Francisco, California. 2008. Renzo Piano. http://www.etudierasanfrancisco.com/wp-content/ uploads/2014/02/california-academy-of-sciences-720x340.jpg

Figure 2.23 California Academy of Sciences Section. San Francisco, California. 2008. Renzo Piano. http://expeditionworkshed.org/assets/13-CaliforniaAcademy-of-Sciences-Section.jpg

Figure 2.24 Disneyland's Sleeping Beauty Castle. http://i0.wp.com/www.isitpacked. com/wp-content/uploads/disneyland_fi.jpg?fit=1200\%2C801

Figure 2.25 Upper Strip, Las Vegas, Nevada. 1972. Learning from Las Vegas. Venturi, Robert, Denise Scott-Brown, and Steven Izenour. 1977. Learning from Las Vegas. Cambridge: The MIT Press.

Figure 2.26 Duck and Decorated Shed. Venturi, Robert, Denise Scott-Brown, and Steven Izenour. 1977. Learning from Las Vegas. Cambridge: The MIT Press 


\section{LIST OF FIGURES}

Figure 2.27 Monument by signification. Venturi, Robert, Denise Scott-Brown, and Steven Izenour. 1977. Learning from Las Vegas. Cambridge: The MIT Press.

Figure 2.28 Las Vegas 1970s. http://www.gizmoweb.org/wp-content/uploads/2010/12/ las-vegas-car-view-of-strip-14-1024x657.jpg; http://images.adsttc.com/ media/images/5589/5b60/e58e/cef4/b500/0111/large_jpg/1024pxFremont_Street_1952.jpg?1435065179

Figure 2.29 Contemporary Las Vegas. http://travelchannel.sndimg.com/content/ dam/images/travel/fullset/2014/12/11/las-vegas-adventures-strip. jpg.rend.tccom.1280.960.jpeg; http://www.fly.com/blog/wp-content/ uploads/2014/11/Las-Vegas.jpg; http://ichef-1.bbci.co.uk/news/624/ cpsprodpb/3CBF/production/_87315551_63298237-3f9f-4899-ad4546f8b56ecbe8.jpg

Figure 2.30 Paris Las Vegas Hotel. http://i.imgur.com/GFcqJox.jpg Luxor Las Vegas. http://www.lasvegastours.nl/wp-content/ uploads/2012/06/Luxor-Hotel-Las-Vegas-Lobby.jpg Caesars Palace Las Vegas Hotel and Casino. http://img.lasvegasdirect. com/caesars-palace-las-vegas-07.jpg

The Venetian Las Vegas. http://www.venetian.com/content/dam/lasvegas/ venetian/master/main/home/activities-events/gondola-rides/gondola500x340.jpg

Excalibur Hotel and Casino. https://horsetrotting.files.wordpress. com/2015/05/dsc_0197.jpg

New York New York Hotel and Casino. http://robbinsbecher.com/wpcontent/uploads/2015/03/NYLVSkylineMediumView8x10.jpg Bellagio Las Vegas. http://www.hotel-r.net/im/hotel/us/bellagio-20.jpg MGM Grand Las Vegas. http://www.arrakeen.ch/usamex/152\%20\%20 MGM\%20Grand.jpg

Figure 2.31 New York New York Hotel and Casino Exterior. http://robbinsbecher. com/wp-content/uploads/2015/03/NYLVSkylineMediumView8x10.jpg

Figure 2.32 New York Skyline. http://www.newyorker.com/wp-content/ uploads/2015/12/Veix-Goodbye-New-York-Color-1200.jpg

Figure 2.33 New York New York Hotel and Casino Exterior. http://xahlee.org/ Periodic_dosage_dir/las_vegas/vegas/nyny_bridge.jpg

Figure 2.34 Brooklyn Bridge. http://www.bigonion.com/wp-content/uploads/2015/05/ big-onion-brooklyn-bridge-7social.jpg

Figure 2.35 New York New York Hotel and Casino Interior. https://everywhereonce. files.wordpress.com/2012/12/las-vegas-new-york-hotel.jpg 


\section{LIST OF FIGURES}

Figure 2.36 New York Streetscape. http://s3-media4.fl.yelpcdn.com/bphoto/ ZzwqAL2E7EkLtjqy3myKCg/348s.jpg

Figure 2.37 30 St Mary Axe "The Gherkin". London, UK. 2001. Foster + Partners. https://encrypted-tbn1.gstatic.com/images?q=tbn:ANd9GcSsff6bCm0WBsezo_9Gc75QWWz5szDpM_XjY97ShbJNT_vfegR

Figure 2.38 Enigmatic Signifiers for "The Gherkin". Jencks, Charles. 2006. "The Iconic Building is Here to Stay." City (Routledge)

Figure 2.39 Guggenheim Museum Bilbao. Bilbao, Spain. 1997. Frank Gehry Associates. https://s-media-cache-ak0.pinimg.com/originals/3d/69/c6/3d 69c672c573daf9b4fcced18e1b3590.jpg

Figure 2.40 Enigmatic Signifiers for Guggenheim Bilbao. Jencks, Charles. 2006. “The Iconic Building is Here to Stay." City (Routledge)

Figure 2.41 Ontario College of Art and Design. Sharp Centre for Design. Toronto, Canada. 2004. Robbie/Young + Wright Architects and Alsop Architects. http://media.hgtv.ca/blogimages/up-and-coming-industrial-designtalent-ocad-video-and-exhibition-0.jpg

Figure 2.42 Enigmatic Signifiers for the Sharp Centre for Design OCAD.

Figure 2.43 Roots Canada branding and store designs emulate cottage lifestyle. http://www.vancitybuzz.com/wp-content/uploads/2015/06/10516791 _10152570098511871_13073553840442388_n.jpg; http://blogs.ubc.ca/ saudersgrace104/files/2015/09/img_5655.jpg

Figure 2.44 Between themed replicas and ambiguous and enigmatic signifiers.

Figure 2.45 Mountain Equipment Co-op Store. North Vancouver, British Columbia. http://www.proscenium.ca/wp-content/uploads/2013/08/MEC-NV-001780x516.jpg

Mountain Equipment Co-op Retail and Warehouse. Burlington, Ontario. http://www.sabmagazine.com/blog/wp-content/uploads/2010/03/mec01. jpg

Mountain Equipment Co-op Retail Store. Toronto, Ontario. http://www. blogto.com/upload/2012/03/20120307-MEC-1.jpg

Figure 2.46 Horton Plaza. San Diego, California. 1985. Jon Jerde Partnership. http://www.jerde.com/cms/media/experimental/horton_ph_int_sports_ chan.jpg; http://photos.wikimapia.org/p/00/00/50/82/38_big.jpg

Figure 2.47 Prada Epicenter, New York. http://acdn.architizer.com/thumbnailsPRODUCTION/86/ab/86abffc7fbee21e8ad5be5e1181c12f8.jpg

Figure 2.48 Sanlitun Village Shopping Center. Beijing, China. http://payload288. cargocollective.com/1/2/77014/8060662/Sanlitun-south2_875.jpg 


\section{LIST OF FIGURES}

Figure 2.49 The Grove Shopping Center. Los Angeles, California. http://www. rvgoddess.com/POSTCARDS/2010/Deja/Photos/April/042510-04.jpg

Figure 2.50 The Distillery District. Toronto, Canada. https://upload.wikimedia.org/ wikipedia/commons/5/5e/Busy_festival_at_the_Gooderham_\%26_ Worts_Distillery_District,_Toronto.jpg

Figure 2.51 Bazaar of Athens. https://upload.wikimedia.org/wikipedia/ commons/7/75/Bazar_of_Athens.jpg

Palais Royale, La Galerie d'Orleans Arcade, 1830. http://informationsdocuments.com/environnement/coppermine15x/albums/gallerie $\% 20$ illustrations/histoire/Illustrations\%20de\%20Paris\%20de\%201831\%20 a\%201870/Illustrations_de_Paris_de_1831_a_1870_-_2_259_le_PalaisRoyal_-_galerie_d_Orleans.jpg

Vakil Bazaar, 1881. https://upload.wikimedia.org/wikipedia/ commons/4/45/Bazar_Shiraz_as_seen_by_Jane_Dieulafoy,_1881.jpg

Galleria Vittorio Emanuele II, 1877. https://upload.wikimedia.org/ wikipedia/commons/b/bb/Brogi,_Giacomo_(1822-1881)_-_n._4608_-_ Milano_-_Ottagono_della_Galleria_Vittorio_Emanuele_ca._1880.jpg

Figure 2.52 Southdale Mall, Minnesota. https://i.ytimg.com/vi/Q-c7IqDxukE/ maxresdefault.jpg

Figure 2.53 Trafford Centre. Manchester, UK. https://upload.wikimedia.org/ wikipedia/commons/8/89/Trafford_centre_6.jpg

Figure 2.54 Mercato Shopping Mall. Dubai, UAE. http://www.timeoutdubai.com/ images/outlets/mercato_mall/innerbig/mercato1_innerbig.jpg

Figure 2.55 West Edmonton Mall. Edmonton, Alberta. http://www.wem.ca/ ImageGen.ashx?image=/media/198895/FINAL-2.jpg\&class=slider

Figure 2.56 La Defense Quatre Temps Mall. Paris, France. http://www.molon.de/ galleries/France/Paris/La_Defense/images01/22\%20Shopping\%20 mall\%20interior.jpg

Figure 2.57 Third Street, Santa Monica, California. 1965. Prior to redevelopment. https://www.kcet.org/sites/kl/files/atoms/article_atoms/www.kcet.org/ updaily/socal_focus/third\%2520street\%2520from\%2520wilshire\%252019 65\%2520smpl.jpeg

Figure 2.58 Third Street Promenade. Santa Monica, California. https://385e281c53d80c958c4a-d460ce610c7fad6b3cb1da8c31b5ee8e.ssl. cf2.rackcdn.com/photos/Los\%20Angeles/935McK8Zo6HeEODQGbB4xg bV5wvoN7Qe.jpg; 


\section{LIST OF FIGURES}

Figure 2.59 Third Street Promenade Street Performances. Santa Monica, California. https://gotravelleh.files.wordpress.com/2011/10/pa012020.jpg

Figure 2.60 Sync of Retail Actors - Lowe's Toronto Christmas Market 2012. Toronto, Canada http://blog.lokafy.com/wp-content/uploads/2014/06/torontochristmas-market-2012-8.jpg

Figure 2.61 Sync of Flows and Movements - Yorkdale Mall at the interchange of highways. 1964. Toronto, Canada. https://c1.staticflickr. com/9/8711/16979030102_ae7449d146.jpg

Figure 2.62 Sync of Cultural Events and Special Occasions - Maryvale Toronto Public Library inside Parkway Mall. Toronto, Canada. https://localwiki.org/ media/pages/files/ocvo30hyek1gp439.jpg

Figure 2.63 Sync of Activities - Shopping at the Hong Kong International Airport. http://www.gakei.com/clk/clkma02.jpg

Figure 2.64 Sync of Bodily Rhythms - Food Court at Siam Center. Bangkok, Thailand. http://bk.asia-city.com/sites/default/files/imagecache/item_image/ food4862_0.jpg

Figure 2.65 Sync of Collectives - Creative and Meeting Place Co-working Space inside MAYA Mall. Chiang Mai, Thailand. http://toomanyadapters.com/ wp-content/uploads/2015/04/tma-chiang-mai-coworking-1-600x400.jpg

Figure 2.66 Issues and Strategies Relationship. R.Tsang 2016 


\section{LIST OF FIGURES}

Chapter 3. Design I - Defining project site, scope, and background

Figure 3.1

Figure 3.2

Figure 3.3

Figure 3.4

Figure 3.5

Figure 3.6

Figure 3.7
Don Valley, Toronto. http://static.theglobeandmail.ca/3a7/incoming/ article863423.ece/ALTERNATES/w620/web-river-don16nw1.jpg

Map of Canada. Made with Mapbox Studio.

Map of Downtown Toronto. Made with Mapbox Studio

Some of Toronto's different neighbourhoods.

Chinatown: https://c2.staticflickr.com/4/3699/10056398335_12a0cce728

_b.jpg

Little Italy: https://belocchio.files.wordpress.com/2010/05/img_1688.jpg

Distillery: https://c1.staticflickr.com/9/8160/7111262281_8be4d7c863_b. jpg

Financial: https://upload.wikimedia.org/wikipedia/commons/c/cb/ Skyline_Toronto.JPG

Bloor St: http://andrewfare.com/UTB/mytoronto14/bloortrees.jpg

Cityplace: http://vikpahwa.com/wp-content/

uploads/2014/06/20140606_5407.jpg

Annex: https://upload.wikimedia.org/wikipedia/commons/4/45/Annex_ houses.JPG

Art Gallery of Ontario by Frank Gehry, 2008. Toronto, Canada. http:// www.obe.com/sites/default/files/project/images/curtain_wall_art_toronto. jpg

Royal Ontario Museum by Daniel Libeskind and B+H Architects, 2007. Toronto, Canada. http://libeskind.com/wp-content/uploads/the-rom-lights-up-bloor-streetc-royal-ontario-museum-2280x1900.jpg

National Ballet of Canada by KPMB, 2005. Toronto, Canada. http://www. kpmb.com/index.asp?navid=30\&fid $1=\&$ fid $2=12 \&$ fid $3=\&$ minyear $x=\& m a$ xyearx

Canadian Opera House Four Seasons Centre by Diamond Schmitt Architects, 2006. Toronto, Canada. http://dsai.ca/projects/four-seasonscentre-for-the-performing-arts-canadian-opera-company/

Sharp Centre for Design (OCAD) by Will Alsop and Robbie/Young + Wright Architects Inc., 2004. Toronto, Canada. http://wvs.topleftpixel. com/photos/2013/06/ocad-lightning-storm_clouds_005.jpg

Typical Animal Shelter Facilities.

First Headquarters of the Toronto Humane Society. https:// upload.wikimedia.org/wikipedia/commons/thumb/c/ ca/TorontoHumaneSocietyBuildingOld.jpg/220pxTorontoHumaneSocietyBuildingOld.jpg 


\section{LIST OF FIGURES}

Figure 3..8 Current Toronto Humane Society Facility at Queen Street E and River Street. Photograph.

Figure 3.9 Existing Site Plan

Figure 3.10 Aerial view looking northeast. Google Maps.

Figure 3.11 South facade of THS along Queen St E. Photograph.

Figure 3.12 THS entrance and drop off. http://www.digitaljournal.com/ img/9/5/5/2/8/2/i/8/5/5/p-large/DMB_1094.JPG

Figure 3.13 Westbound 501 Queen streetcar stop in front of the THS. Photograph.

Figure 3.14 View looking northeast at the corner of Queen and River Streets. Photograph.

Figure $3.15 \quad 1800-1840$ plans for government reserve

Figure $3.16 \quad 1850-1880$ industrial and rural landscapes

Figure $3.17 \quad 1886$ "taming" of the river and introduction of rail infrastructure

Figure 3.18 1890-1940 Ashbridges Bay Marsh filled to reduce spread of disease in stagnant waters

Figure 3.19 1950-1960 introduction of the Don Valley Parkway as a civilizing force and transportation corridor that allowed expansion into the suburbs

Figure 3.20 Today - reintroduced recreational landscapes along the valley. Future -Renaturalize river mouth for flood protection and habitat creation

Figure 3.21 Former Don Brewery on current THS Site. http://www.blogto.com/ upload/2012/07/201273-don-brewery.jpg

Figure 3.22 Map of Site prior to River Straightening | Map of Site today. http://www. blogto.com/upload/2012/04/20121130-don-river.jpg

Figure 3.23 Historical Drawing of Don River and Area

Figure 3.24 Don River Straightening Plan, 1886. http://www.blogto.com/ upload/2012/04/20120414-Don-Map.jpg

Figure 3.25 Construction of Don Valley Parkway 1950s http://www.blogto.com/ city/2013/08/that_time_toronto_opened_the_don_valley_parkway/ 


\section{LIST OF FIGURES}

Figure 3.26 Don Valley Parkway 2014 http://static.theglobeandmail.ca/3a7/incoming/ article863423.ece/ALTERNATES/w620/web-river-don16nw1.jpg

Figure 3.27 Aerial View of Lower Don River and Valley. Google Maps.

Figure 3.28 THS Adoption Kennel. http://www.jeffreyalanpayne.com/wp-content/ uploads/2014/08/Toronto-Humane-Society-Kennels.jpg 


\section{LIST OF FIGURES}

Chapter 4. Design II - Design Strategies and Tactics Exploration

Figure 4.1 Strategies applied to design project. R. Tsang 2016

Figure 4.2 Aerial Map of Contextual Conditions and Site Access Diagram (NTS). Google Maps 2015.

Figure 4.3 Circulation and Site Access of Existing THS Facility (NTS). Google Maps 2015.

Figure 4.4 Diagram of Public versus Private Spaces of the Existing THS. R.Tsang 2016

Figure 4.5 Photos and summary of THS Shelter Tour, taken Feb 3 2016, comparing public versus private spaces. R.Tsang 2016

Figure 4.6 Shelter Layout Diagrams Summary. R.Tsang 2016.

Figure 4.7 Dog Pound and Shelters.

https://apitome.files.wordpress.com/2011/10/animalshelter.jpg

Figure 4.8 Dog Daycare and Boarding Facilities

http://www.bdaarc.com/images/uploads/galleryphotos/j03-Luxury-Dog-

Boarding.jpg

https://s-media-cache-ak0.pinimg.com/originals/8c/13/80/8c13801773c1

5e0f673d2f2fd408f0da.jpg

http://www.gannett-cdn.com/-mm-/

be8a144383d573ab3769e88ebacd2b47342e9d8f/c=0-87-2000-

$1212 \& \mathrm{r}=\mathrm{x} 633 \& \mathrm{c}=1200 \times 630 / \mathrm{local} /-/ \mathrm{media} / 2015 / 05 / 29 /$ DetroitNews/

B99274711Z.1_20150529182526_000_G3JH10EC.2-0.jpg

Figure 4.9 Operational Workflow from Intake to Adoption and Public Spay/Neuter Clinic.

Figure 4.10 Intake Workflow and Associated Spaces. Based on guidelines in Appendix F.

Figure 4.11 Additional Support Spaces. R. Tsang 2016.

Figure 4.12 Workflow is identified as a process of Rescue, Rehabilitate, and Re-Home. R. Tsang 2016.

Figure 4.13 Overall Workflow and Theme of Shelter. R. Tsang 2016.

Figure 4.14 Subversion of Workflow as Architectural Narrative. R. Tsang 2016.

Figure 4.15 Program Spaces. R. Tsang 2016.

Figure 4.16 Program Spaces Organized Around Overall Architectural Narrative. R. Tsang 2016. 


\section{LIST OF FIGURES}

Figure 4.17 Program Adjacencies - Subverting "Rehabilitation" Spaces into "Re-home" Spaces. R. Tsang 2016.

Figure 4.18 Program Adjacencies - Circulation, and Visual Connections. R. Tsang 2016.

Figure 4.19 Program Organization and Circulation. R. Tsang 2016.

Figure 4.20 Existing Site Plan (NTS). Made with Mapbox Studio 2015.

Figure 4.21 Contextual indicators

Queen St Bridge https://upload.wikimedia.org/wikipedia/commons/f/f0/

Queen_St_Don_River_bridge_in_Toronto.jpg

Toronto: https://upload.wikimedia.org/wikipedia/commons/3/3a/

Toronto_skyline_(2012).jpg

Davies Brewery

Don Valley

Figure 4.22 Existing Aerial Map (Google Maps 2015) and E-W Site Section along Queen St E looking north. R.Tsang 2016.

Figure 4.23 Massing Study Diagrams. R.Tsang 2016.

Figure 4.24 Map of Site prior to River Straightening | Map of Site today. http://www. blogto.com/upload/2012/04/20121130-don-river.jpg

Figure 4.25 Don River Straightening Plan, 1886. http://www.blogto.com/ upload/2012/04/20120414-Don-Map.jpg

Figure 4.26 New Building Footprint on Site, showing original river course. R.Tsang 2016.

Figure 4.27 Existing Site Plan with Circulation Patterns. R.Tsang 2016. Based on Google Maps 2015.

Figure 4.28 Program Distribution - Rescue, Rahabilitate, and Re-Home Programs. R.Tsand 2016.

Figure 4.29 Overall Architectural Narrative. R.Tsang 2016.

Figure 4.30 Overall Program Distribution. R.Tsang 2016.

Figure 4.31 Overall Massing on site. Aerial view looking northeast. R.Tsang 2016.

Figure 4.32 The Davies Brewing \& Malting Co. 1890s Drawing. Aerial View looking northwest.

Figure 4.33 Current Aerial View of Former Davies Brewery Site looking northwest. Google Maps 2015. 


\section{LIST OF FIGURES}

Figure 4.34 Queen City Vinegar Co. Front Elevation; Along River Street with THS in the background http://www.realestatebram.com/wp-content/ uploads/2011/10/DSC_0099.jpg; Interior https://www.jeffreyteam.com/ wp-content/uploads/2016/04/Queen-City-Vinegar-Co.-Lofts-19-RiverStreet-6.jpg.

Figure 4.35 The Malthouse Lofts. Aerial View looking northwest; South Elevation facing THS https://www.jeffreyteam.com/wp-content/uploads/2016/01/ Malthouse-Loft-Towns-35-39-Old-Brewery-Lane-4.jpg; https://www. jeffreyteam.com/wp-content/uploads/2016/01/Malthouse-Loft-Towns-2939-Old-Brewery-Lane-5.jpg; Entrance along Old Brewery Lane.

Figure 4.37 Queen Street Viaduct throughout the years:

Queen St Bridge 1880s

Queen St Bridge 1910 https://www.jeffreyteam.com/wp-content/ uploads/2016/01/Queen-Street-bridge-in-1910-looking-west-with-theDon-Brewery-on-the-right-Rivervilla-in-the-center.jpg Queen St Bridge today after 1996 Renovation and Artwork Addition. http://www.riverside-to.com/wp-content/uploads/2014/06/bridge-photo. jpg

Figure 4.38 Queen Street Bridge from the THS. (Top to Bottom): Structural Support Below the Queen Street Bridge; Lower Level of the THS adjacent to the Queen Street Bridge. Photographs by Author.

Figure 4.39 Reclaimed Industrial Interiors, featuring wood beams and ceilings.

Figure 4.40 The Don River. Photograph by author.

Figure 4.41 The Don Valley Parkway, Valley, Trail, and River Landscape

Figure 4.42 Hierarchy of Spaces defined by materials. R.Tsang 2016.

Figure 4.43 Breakdown of Program Spaces and Material Palette. R.Tsang 2016.

Figure 4.44 Animal Spaces, Daily Activities, and Desired Behaviours in the Spaces. R.Tsang 2016.

Figure 4.45 Daily Routines and Activities of Canines, Felines, and Small Animals. R.Tsang 2016.

Figure 4.46 Typical Double Compartment Canine Kennel Layouts. R.Tsang 2016.

A. Individual or Small Dogs Unit.

B. Group or Big Dogs Unit

Figure 4.47 Canine Kennels

Figure 4.48 Canine Kennels 


\section{LIST OF FIGURES}

Figure 4.49 Typical Cattery Layout with Ledge. A. Individual Unit. B Group Unit.

Figure 4.50 Cattery https://7468669c0013a7dae459-4d0fcf8d315d40f305ee2ebb6c32f7 9c.ssl.cf1.rackcdn.com/3768679_1434328574.1686_updates.jpg

Figure 4.51 Cattery http://www.catteries.org.uk/images/Greenbarn12_l.jpg

Figure 4.52 Small Animal Primary Enclosures

Rabbit House http://media.zooplus.com/bilder/3/400/232443_ kleintierkaefig_lounge2_3.jpg guinea pigs http://s7d1.scene7.com/is/ image/PETCO/1491873-right-1

Hamster cage http://static.zoomalia.com/prod_img/18072/la_928d045c59 a90d7587d8d671b5f5aec4e7c1381235135.jpg

Bird Cage http://funkybirdcages.yolasite.com/ resources/1250011663liberta-parrot-play-cage_jpg.jpg Kennel https://s-media-cache-ak0.pinimg.com/564x/54/92/54/549254ca8 51efacba98c61a8c06d954d.jpg

Figure 4.53 Socialization Spaces - Canine. Photograph of Model. R.Tsang 2016.

Figure 4.54 Socialization Spaces - Feline. Photograph of Model. R.Tsang 2016.

Figure 4.55 1:20 Scale Model - Canine Screen. Photograph of Model. R.Tsang 2016.

Figure 4.56 1:20 Scale Model - Feline Screen. Photograph of Model. R.Tsang 2016.

Figure 4.57 1:20 Scale Model - Small Animals Screen. Photograph of Model. R.Tsang 2016.

Figure 4.58 1:20 Scale models of the different animal type screens. Photograph of Model. R.Tsang 2016.

Figure 4.59 Strategies applied to design project. Diagram. R.Tsang 2016. 


\section{LIST OF FIGURES}

Chapter 5. Design III - Rescue, Rehabilitate, Rehome: Redefining the Shelter

Figure 5.1 Project Site and Surroundings. Google Maps 2015.

Figure 5.2 Project Site and Context (NTS). Made with Mapbox Studio 2015.

Figure 5.3 Project Site Plan. Plan. R.Tsang 2016.

Figure 5.4 Overall Program Distribution. Diagram. R.Tsang 2016.

Figure 5.5 Aerial View Looking Northeast. Exterior Rendering. R.Tsang 2016.

Figure 5.6 Aerial View Looking Northwest. Exterior Rendering. R.Tsang 2016.

Figure 5.7 View from Street Corner. Exterior Rendering. R.Tsang 2016.

Figure 5.8 Main Entrance. Exterior Rendering. R.Tsang 2016.

Figure 5.9 Public Park. Exterior Rendering. R.Tsang 2016.

Figure 5.10 Public Park. Exterior Rendering. R.Tsang 2016.

Figure 5.11 Public Park. Sectional Perspective through park looking west. R.Tsang 2016.

Figure 5.12 South Elevation. Rendered Elevation. R.Tsang 2016.

Figure 5.13 North Elevation. Rendered Elevation. R.Tsang 2016.

Figure 5.14 East Elevation. Rendered Elevation. R.Tsang 2016.

Figure 5.15 West Elevation. Rendered Elevation. R.Tsang 2016.

Figure 5.16 First Floor Plan. R.Tsang 2016.

Figure 5.17 Lower Level Floor Plan. R.Tsang 2016.

Figure 5.18 Second Floor Plan. R.Tsang 2016.

Figure 5.19 Third Floor Plan. R.Tsang 2016.

Figure 5.20 Section AA - Through Adoptions lobby. Section. R.Tsang 2016.

Figure 5.21 Section BB - Through Clinic \& Play Area. Section. R.Tsang 2016.

Figure 5.22 Section CC - Through Canine \& Small Animals. Section. R.Tsang 2016.

Figure 5.23 Section DD - Longitudinal Section Through Entrance and Park. R.Tsang 2016. 


\section{LIST OF FIGURES}

Figure 5.24 Section EE - Longitudinal Section Through Adoptions Hall. R.Tsang 2016.

Figure 5.25 Main Adoptions Lobby. Interior Rendering. R.Tsang 2016.

Figure 5.26

Main Adoptions Lobby. Interior Rendering. R.Tsang 2016.

Figure 5.27

Sectional Perspective through Entrance and Clinic. Sectional Perspective. R.Tsang 2016.

Figure 5.28 Sectional Perspective through Main Canine Area and Public Park. Sectional Perspective. R.Tsang 2016.

Figure 5.29 Adoption Hall - First Floor. Interior Rendering. R.Tsang 2016.

Figure 5.30 Sectional Perspective Through Canine Areas. Sectional Perspective. R.Tsang 2016.

Figure 5.31 Canine Kennels and Training Area. Interior Rendering. R.Tsang 2016.

Figure 5.32 Private Dog Park. Exterior Rendering. R.Tsang 2016.

Figure 5.33 Small Animal Area on Second Floor. Section. R.Tsang 2016.

Figure 5.34 Adoptions Hall - Second Floor. Interior Rendering. R.Tsang 2016.

Figure 5.35 Canine Scales. Diagram. R.Tsang 2016.

Figure 5.36 Small Animals Scales. Diagram. R.Tsang 2016.

Figure 5.37 Feline Scales. Diagram. R.Tsang 2016.

Figure 5.38 Adoptions Hall and Reception on First Floor. Interior Rendering. R.Tsang 2016. 



\section{LIST OF APPENDICIES}

Appendix A. Design Research. Iterations and Lessons Learned ccxxiii

Appendix B. History and Relevance of Don River and Valley ccxlv

Appendix C. The Toronto Humane Society. cclxv

Appendix D. Site Visit to the Toronto Humane Society. cclxxix

Appendix E. Animal Shelter Precedent Studies ccxciii

Appendix F. Shelter Design Guidelines and Operational Efficiencies ccciii 



\section{ARCHITECTURE OF EXCESS:}

NAVIGATING BEYOND THE SUPERFICIAL 


\section{Introduction}

"We shape our buildings, and thereafter our buildings shape us" - In Sir Winston Churchill's observation of this cycle of mutual dependency, the increasingly superficial architecture in society is symptomatic of a superficial and homogenized culture. Contemporary architectural solutions have tended towards the instant gratification of the spectacle, losing its value and connection with people and place. The rise of an ocular-centric society, the dominance of economy, and the effects of globalization have pushed architecture into a commodified object that is insular and alienating. Iconic landmarks of any typology challenge the traditional architectural monument, and more often than not, these capricious spectacles only briefly capture our attention to forge superficial relations with people and context, diminishing architecture's cultural role in the process.

Traditionally we understand and navigate our cities through its built forms in a legible urban hierarchy. A hierarchy of public worth could be read through a city's architectural manifestations, where civic or religious monuments are most prominent in both form and scale to express its importance. These monuments expressed local traditions and social needs that gave it authenticity and purpose. The architecture of cathedrals, for example, does not only signify a place for religious worship, but communicates its importance through its formal expression. Its elaborately ornamented forms and facades allow the monument to stand out from its surroundings, serving as a reminder of the power of divinity through its iconographic and symbolic expressions.

The rise of logic, rational, and scientific thought in the process of modernization, however, has shifted power from religion to, essentially, anything by the increasing secularization of culture. Architectural theorist Charles Jencks notes in The Iconic Building (2005) that the secularization of 
culture pushes society to believe in anything, thus allowing other typologies to replace the monument. The loss of belief systems and declining connection with religious icons lends people to support the democratic icon, alluding to powers of corporate or individual pretensions in our contemporary society. In our increasingly global society without common religious beliefs or shared cultures, anything can be a monument. The excessive and unnecessary spectacles in the contemporary age only appeals to our visual sense and the imagery provokes a superficial emotional connection to a brand or product rather than to an understanding of culture, place, or use.

It is then essential that we re-evaluate the way we design such that architectural relevance and experiences beyond superficial delight are not lost in that process. Yet, if architecture is shaped by its culture and surroundings, we must also develop an understanding of the current culture of consumption that is pushing architecture into superficial spectacles, rather than simply proposing opposite conditions.

Taking a look at the mediation of images and imagery in society, authors including Guy Debord (1977), Jean Baudrillard (1988), and Juhani Pallasmaa (2011) are explored. The focus on imagery and artifice forges superficial relationships between people with each other and their environments. Critical of the dominance of the visual realm in society, they propose a satisfaction of other senses beyond visual delight. Driven by the appeal of imagery and the spectacle, the concepts of conspicuous consumption and conspicuous leisure, developed by sociologist Thorstein Veblen in The Theory of the Leisure Class (1899), are also explored to understand our excessive consumption patterns and its effects on architectural design and consumption. Within the context of the Experience Economy, described by economists Pine and Gilmore (1998), and expanded upon by brand architect and theorist Anna Klingmann (2007), the appropriation of architecture as a brand signifier and a tool for adding economic value places architecture at the service of economy. As such, architecture and even individual architects have become commodities of international trade and attention, and the Bilbao Effect epitomizes this trend. Architectural theorist Charles Jencks describes the Bilbao Effect as an equation of economic revival or prosperity by use of cultural institutions with unique iconic forms designed by signature architects, reducing architecture to a tourist attraction that is only expected to draw crowds and publicity. 
This effect, however, has expanded beyond cultural institutions to any and all typologies, using excessive forms and scales for capricious visual impact. The proliferation of iconic buildings in our cities start to desensitize its audience and homogenize our environments, diminishing the impact and success with each new project. Contemporary designs continue the superficial cycle to be increasingly ostentatious to recapture public attention, regardless of demand, typology, or location.

This culture of excess and consumption has also propelled the success and proliferation of entertainment architecture. Often neglected of architectural value because of its temporary and superficial nature, this thesis reveals how entertainment architecture successfully provokes and engages enjoyable architectural experiences beyond the superficial. The focus on imagery and spectacle of contemporary architecture takes its roots from entertainment architecture, and thus, an analysis in entertainment typologies form the basis for strategies outlined in the thesis. In this context, entertainment and leisure can be considered the same pursuit, where it is an essential element to life. Just as we require sleep to physically rest for a new day, we also need entertainment and leisure to re-charge and re-gain energy for work and productivity in society. Taking a break or a vacation simply allow us to be productive again.

Three typologies are explored in the thesis: theme parks, casinos, and retail spaces. Although criticized as inauthentic, superficial and mindless escapes, it can also be seen that these typologies meaningfully address the needs and desires for leisure and entertainment of the general public, engaging its users in more immersive and enjoyable environments. As places for entertainment, its architecture is in fact conducive to its use.

The need and desire for leisure and entertainment has existed since antiquity. The Roman Coliseum, for example, was a venue for public spectacles, but also a useful mechanism to keep civil unrest under control. Keeping the population well fed and entertained ensured loyalty and prosperity in the city, giving citizens no reason to rebel. Later, European Pleasure Gardens in the 16th Century gave the leisure class a picturesque and restorative landscape for picnics, performances, and entertainment. As cities modernized, these public gathering places then became a showcase for new and foreign technologies, 
evolving into giant World's Fairs and Expositions of the 18th Century, giving people the chance to congregate, socialize, and explore new products and technologies of the times. Industrialization also offered both the working class and leisure class more free time to "escape the bewilderments of everyday life". As city life became more structured and mundane, the need for entertainment became an essential pursuit to restore productivity. The development of the amusement park in the early 1900s offered mechanical rides and shows that transported the leisure-seeker far from everyday life. As an amalgamation of the pleasure gardens, world expositions, and amusement park, the theme park typology emerged as a response to the demands and desire for safe leisure fun fairs. Manufactured landscapes, new technologies, and mechanical rides became the ingredients for visionary Walt Disney's theme parks. Although numerous theme parks have since replicated Disney's formula, Walt Disney had set the precedent and his parks continue to influence themed environments, architectural storytelling, and contemporary branding worldwide, and as such, the ambitions, inception, and social relevance of Disneyland will be explored.

The works of architecture critic Beth Dunlop (1996) and art historian Karal Ann Marling (1997) explore the art and architecture of Disney to reveal an architecture of reassurance and wonderment. Walt Disney's founding intentions value hard work and perseverance that was the American Dream in order to inspire optimism and reassurance needed in the post-war years. Art historian Norman Klein compares the techniques of special effects used in Disney's theme parks with Baroque theatre to understand its methods of story-telling. Its themed environments are not means to replace reality, but are environments that tells a story. The parks use architecture and space as textual devices that tell a story of the values of work and struggle before the happily-ever-after. As Marling explores in Designing Disney's Theme Parks: The Architecture of Reassurance (1997), Disney believed in the value of hard work, and this idea of work itself also becomes a story and themed attraction in later years. A ride that reveals and exposes some of Disney's behind-thescenes spaces to its guests, the tour allows an appreciation of the real sound stages and workshops at Disney and MGM Studios, acknowledging the work and effort in the production of consumption spaces. In the context of the experience economy, architectural theorist Brian Lonsway identifies this as the built environment designed to make leisure work, merging work and 
leisure into the same space to provide a more immersive and educational experience beyond mindless consumption. This spatialization of operations or production, then, becomes an organizational strategy for architectural design that can communicate and provoke an authentic understanding of its use and function in a world of consumption, encouraging a productive journey of discovery and revelation beyond themed facades.

A city continuously remodeled for the sole purpose of entertainment, Las Vegas' commercial vernacular reveals trends and consumption patterns that are still worth investigating. Venturi, Scott-Brown, and Izenour's Learning from Las Vegas (1977) rediscovered the power of symbolism and iconography in post-modernism as a critique of modernism's elitist ideals. Today, however, as Klingmann (2007) suggests, the signs and symbols have intensified and evolved into complete themed replicas of other places, spatializing a desire for fantasy but also for familiarity of place. Casinos and resorts essentially provide the same type of entertainment, so to stay competitive, casinos have to engage users in other ways. Anthropologist and themed space academic Scott Lukas (2007) points out, places that are more intensely themed are more immersive and engaging to the guest, communicating at many different levels and senses. This in turn successfully captures their attention and spending. Sociologist Mark Gottdiener (2001) also explores the desire, implications, and trends of themed environments in the context of consumer space. One trend, the theme of the city, takes icons, landmarks, and symbols of other cities and juxtaposes them into a consistently engaging environment. These symbols allow guests to connect to already-established images of other places, and because a city is by nature diverse, the theme also provides diversity and surprise while being familiar at the same time. Theming, then, works to coherently connect architecture with people and places. Beyond Las Vegas, however, the same idea of city theming can be used to reference an authentic context and history instead, where the architectural design emerges from and references placebased symbols of its surroundings relevant to its location and culture. Site conditions, history, and local materials form a coherent theme for architectural design.

Traditionally a space for public gatherings and trade, the marketplace has evolved into completely private and internalized spaces that encloses 
consumers in an environment dedicated to the act of shopping. However, in our globalized world where standardized products replace local handicraft and can be purchased anywhere, malls and shopping remains relevant by designing engaging environments in the interstitial spaces. By replicating traditional town plazas and pedestrianized public spaces, simulated streetscapes supplement the act of shopping to satisfy the desire for social intimacy that has been lost to suburban and big box developments. As Rem Koolhaas notes in The Harvard Design School Guide to Shopping, shopping has become the most recent form of public activity, where malls or shopping districts are the new public space for social and community interaction through the familiarity of shopping and consumption. The design of these spaces simulate the scales and rhythms of city life. Beyond the act of shopping, a study of scale and rhythm reveal a strategy for design that accommodates social values of interaction and intimacy for an appropriately-scaled and authentic relation to users.

By navigating beyond the flaws and superficiality of entertainment architecture, the thesis finds that enjoyable leisure experiences can provoke an understanding of use and function, be related to and complimentary to its context, and engage appropriate scale and rhythm of users to inform more authentically engaging and integrated architecture in our society of the spectacle. The strategy of work as an architectural narrative understands operation and production processes as essential elements to architectural and spatial organization. The theme of the city strategy looks at using contextuallybased icons, symbols, materials, and construction for architectural expression. Lastly, the scale and rhythm of shopping strategy looks at users and their daily routines to establish patterns of movement and intimate relations between architecture and people.

These strategies are then explored and presented in a design project that reveals an architecture that is appropriate in expressing its function, is connected to its context, and engages its users in our contemporary society of the spectacle. 


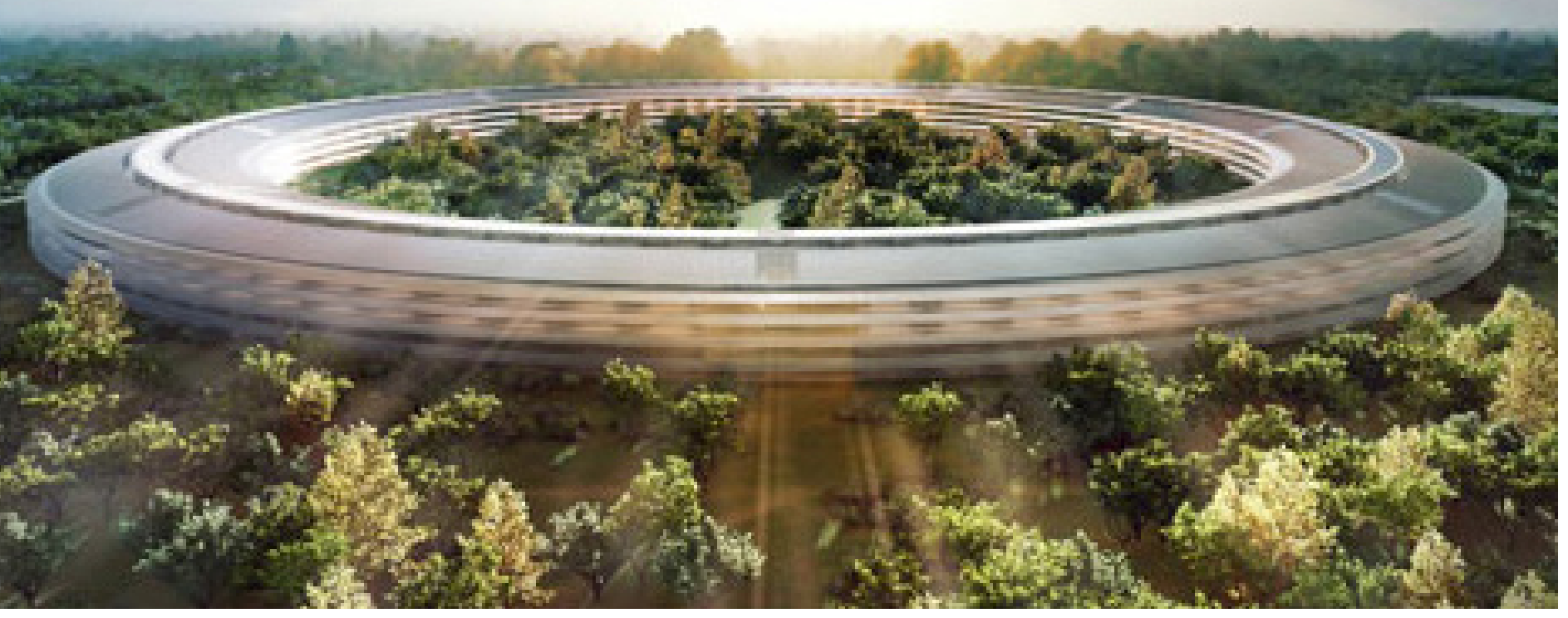

Figure 1.1 
CHAPTER 1

THE COMMODIFICATION OF ARCHITECTURE 


\subsection{An Appropriation of Architectural Semiotics}

Semiotics, as defined by the Oxford Dictionary, is the study of signs and symbols and their use or interpretation. A sign is made up of the 'signifier' and the 'signified', where the 'signifier' is the form and the 'signified' is the interpreted content or meaning. Architecture is a signifier that can be interpreted, decoded or read beyond its fundamental function as shelter for human activities. Architecture, as semiotian Umberto Eco notes, is a cultural object that is a form of mass communication (Eco 1997). This form of communication allows us to interpret cultural intentions and ambitions in history, becoming a mechanism for us to interpret the built environment around us. Where the form of the signifier is constant, the 'signified', or the interpreted meaning, is transient and changes with time (Eco 1997). Meanings and messages are never finite or fixed, but changes as different cultures attach different interpretations, changing its semantics over time. A signifier communicates, or signifies, based on culturally established signs even when it is not being used. For instance, a cave would signify shelter and suggest an inhabitation of it, despite it being inhabited or not. The cave, then, can be seen as a signifier that promotes the act of taking shelter, communicating the function that is to be fulfilled (Eco 1997).

There is a play between a building's primary function (denotative use) and secondary function (connotative message) as society progresses. Beyond its fundamental role, or primary function, of being a shelter for human activities, architecture's secondary function can be more significant and relevant as a means of communication. It has the power to signify and represent something else, and this communicative power of architecture has manifested itself throughout history as a means of expressing power. It gains authenticity, however, by embodying local culture and construction, becoming a symbol of its cultural identity. It allows us to read and understand power

(Previous Page) Figure 1.1: Proposed Apple Headquarters by Foster + Partners. Cupertino, California. relations throughout history where the physical product of architecture is both a reflection and a projection of the social, economic, and political realities of its time and culture. Relationships of power and a hierarchy of public worth could 
traditionally be read in the urban landscape, where meaning and significance were conveyed through well-known conventions (Jencks, The Iconic Building 2005). Important religious and public monuments expressed its status by standing out from its surroundings, being grander and more ornamented than the rest of the city (Figures 1.2-1.4).

The monumentality of the Roman Coliseum, for example, provided a venue in the first century for public spectacles. Apart from its programmatic value though, the sheer size and dominance of the amphitheatre in the urban landscape legibly expresses the power and ability of the Roman Empire to both its citizens and enemies, becoming an icon and legacy of its greatness. Architecture of cathedrals not only represent a place for worship, but also serves as a reminder of the power of divinity through its iconographic and symbolic expressions. Elaborately ornamented interiors and visual devices communicate religious fables and stories that symbolically reinforce and represent images of religious significance. Alternatively, expressions of power can also be appropriated negatively as well, as seen in the architecture of Nazi Germany. Albert Speer's Reich Chancellery, for instance, took Hitler's visitors on a journey of intimidation and fear by manipulating the scale, proportions, and orientation of the architecture to impose a sense of helplessness (Sudjic 2005). It serves to communicate the totalitarian context as an expression of complete control and power of the Nazi regime. As such, the communicative power of architecture has long been appropriated beyond its fundamental role as a shelter for human activities. These monuments are understood to be important expressions of power that allow us to understand and navigate the city.

However, the appropriation of architectural semiotics in contemporary society has diluted our cities with monuments to anything. Buildings of any typology are now aiming to be expressive iconic landmarks, which upsets the traditional urban hierarchy. The most expressive buildings today are no longer important public places of civic or religious significance. Stores, offices, and houses were traditionally buildings of modest expressions that made up the city's fabric as it connects important public places. Today however, these relatively banal typologies are trying to become the center of attention, upstaging buildings of social or cultural significance. The skyline of the city of London, for example, once dominated by church spires and clock towers, is now identified by office towers like Sir Norman Foster's "Gherkin", Renzo Piano's "Shard", and Rafael Vinoly's "Walkie-Talkie" (Figures 1.5-1.7). New York's traditional skyline of commerce on the other hand, is slowly being replaced by residential towers by Frank Ghery, Jean Nouvel, Bjarke Ingles Group, and Zaha Hadid. These conspicuous icons have become the attention of the city. Yet, beyond an instant of recognisability, these buildings lack any real connection to its use, context, or users, devoid of meaning and experiences beyond its exterior form. They are private spaces that reject or exclude the public, alluding to superficial expressions of power instead. 


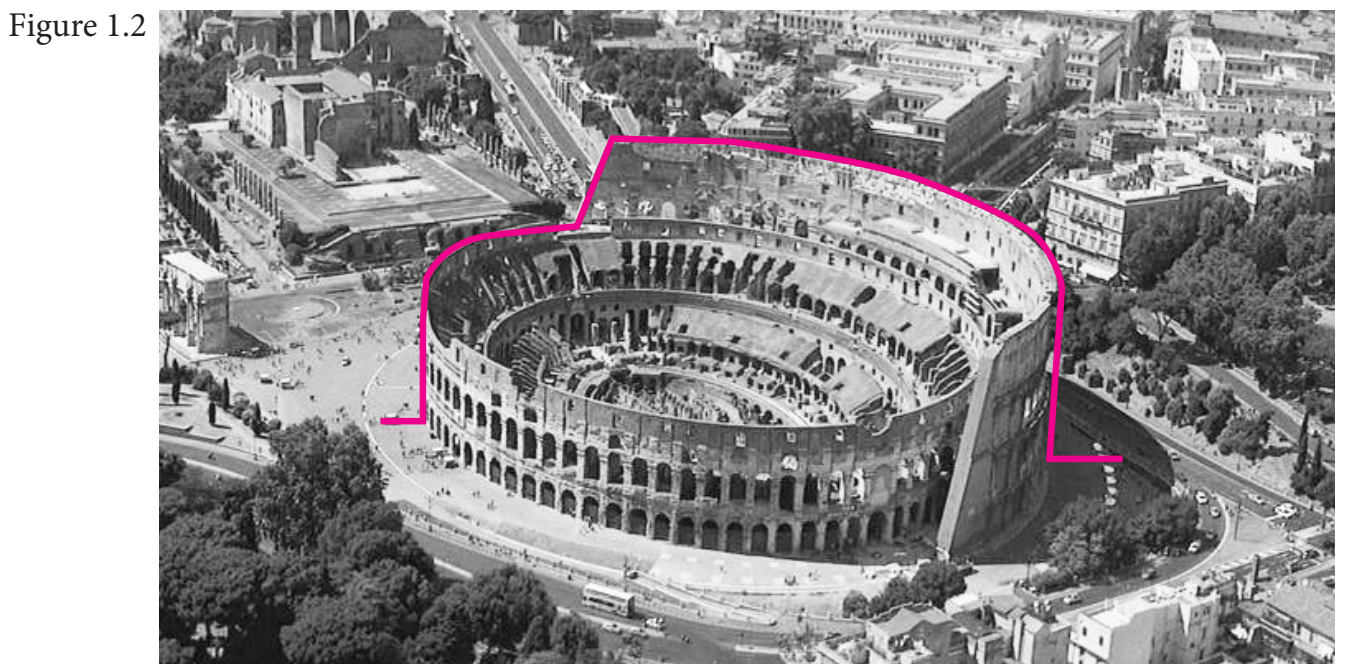

Figure 1.3

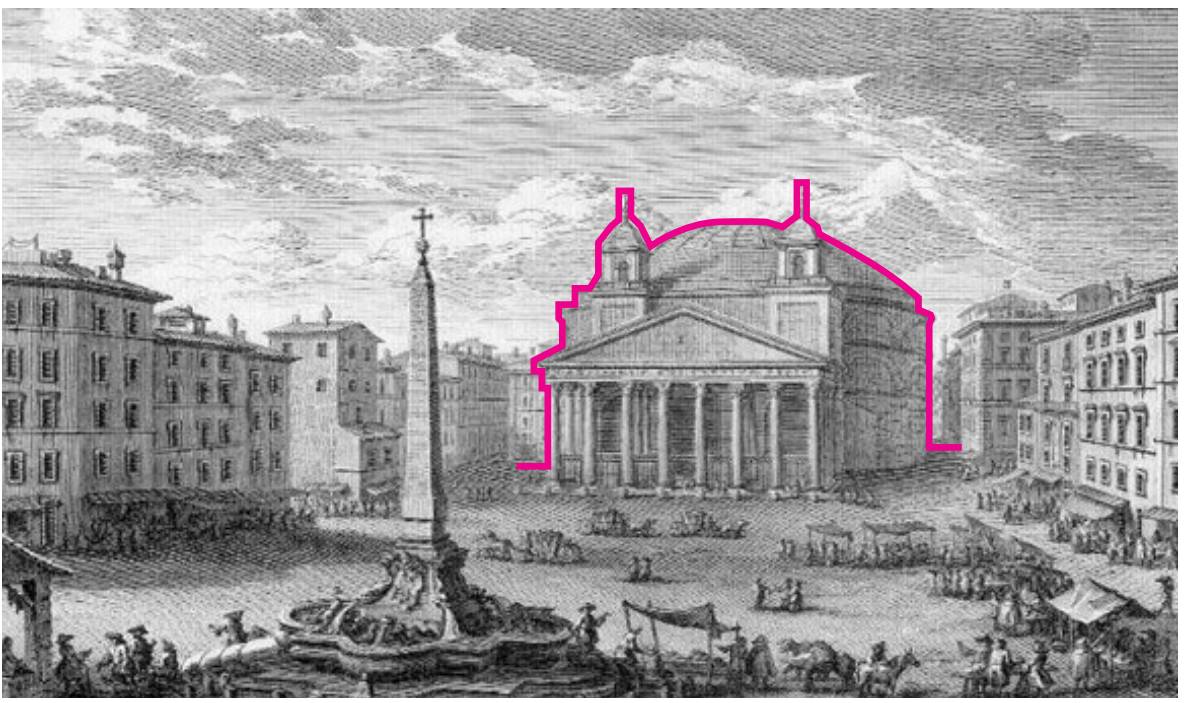

Figure 1.2: Roman Colosseum, 1st Century AD. Rome, Italy.

Figure 1.3: Pantheon, 1st Century AD. Rome, Italy.

Figure 1.4: St Peter's Basilica, 1626. Vatican City

Figure 1.4

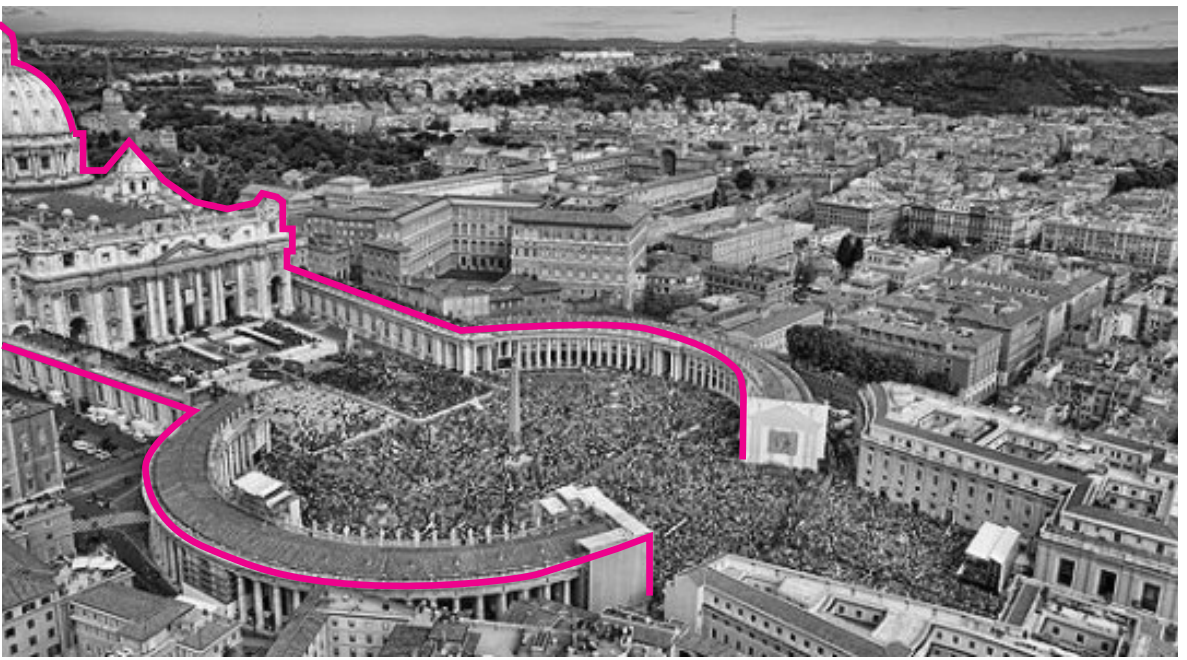


Figure 1.5
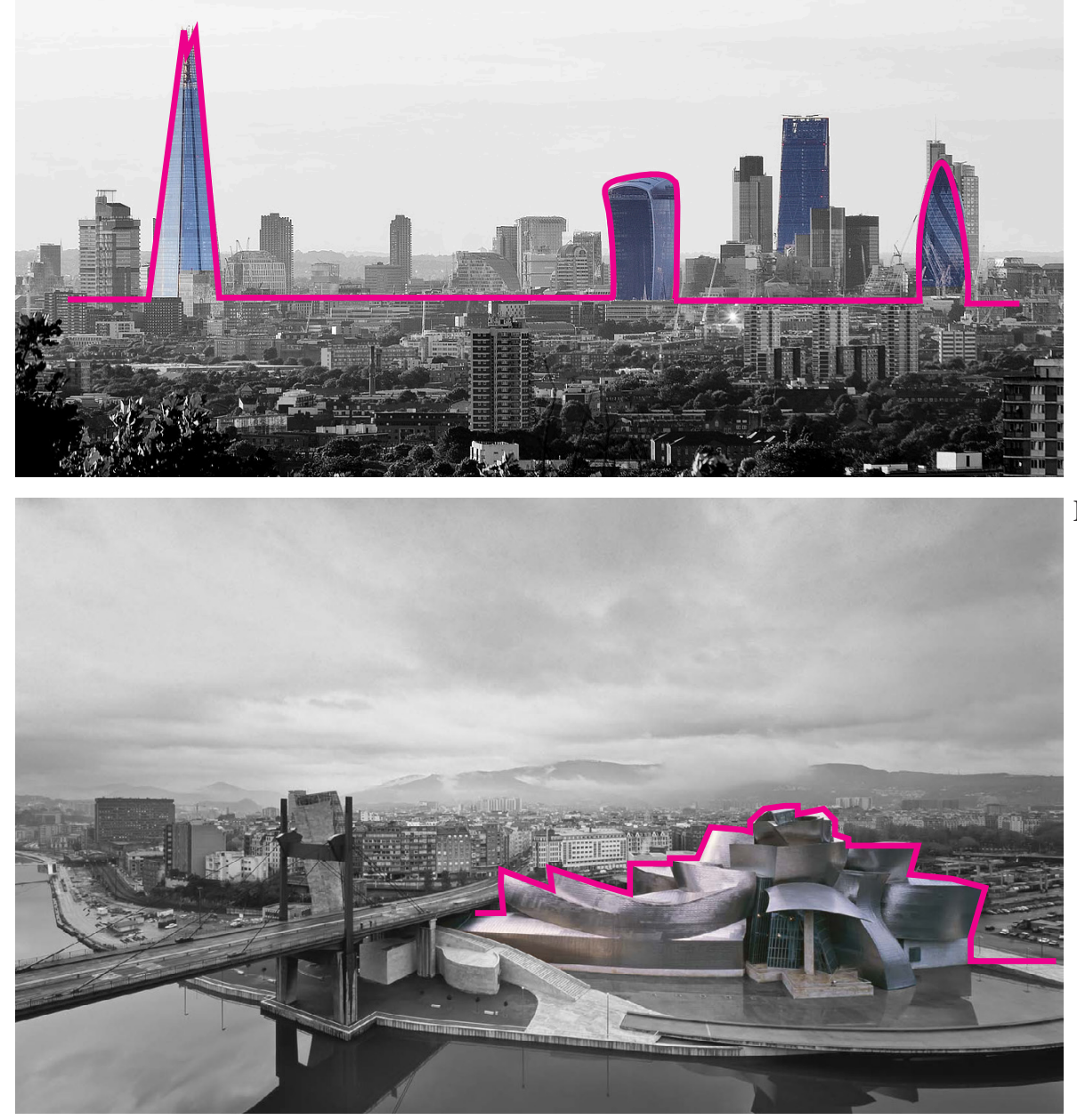

Figure 1.6

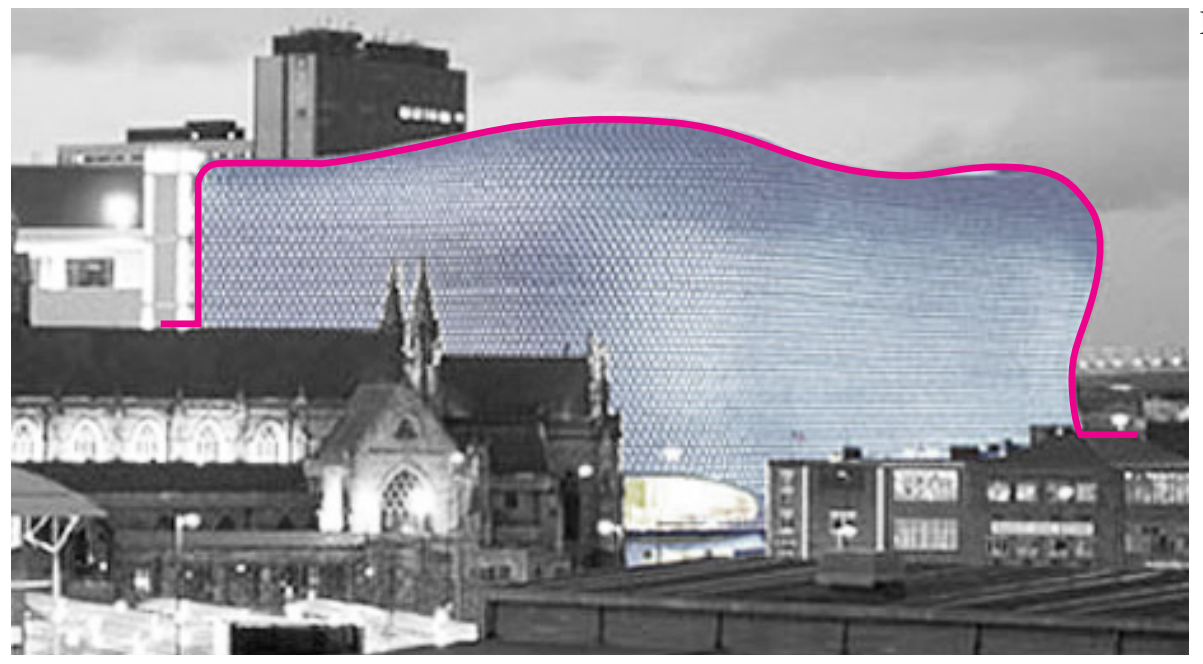

Figure 1.7

Figure 1.5: London, UK

Figure 1.6: Bilbao, Spain

Figure 1.7: Selfridges Store, Birmingham, UK 
The ease of adapting any building into an icon is precipitated by the increasing secularization of culture. The rise of logic, rational, and scientific thought in the process of modernization shifted power from religion to, essentially, anything. Architectural theorist Charles Jencks notes that the secularization of culture pushes society to believe in anything. The loss of belief systems and declining connection with religious icons lends people to support the democratic icon, an image free of religious or civic associations, alluding to powers of corporate or individual pretensions in our contemporary society (Jencks, The Iconic Building is Here to Stay 2006). In our increasingly global society without common religious beliefs or shared cultures, the trend of democratic icons continues. It allows and encourages any and every typology to be an expressive and iconic landmark that aims to generate capricious excitement and attention. Driven by the demands of economy, the building as spectacle aims to attract attention, publicity, and outrage to impact the contemporary consumer. As such, we can no longer understand the use and appropriateness of these built forms in the city. Beyond an instant of shock and awe, its effect wears off as it has no relation to its use, context, or users, and leaves us desensitized to these superficial and homogenized surroundings. Jencks notes this double-bind situation, where we, as a society, are upset and critical of this trend, yet we can't stop producing iconic buildings either (Jencks, The Iconic Building is Here to Stay 2006). Attention and publicity are part of the iconic experience. In this process, architecture's relevance and ability to communicate appropriate use and locality is thus lost, alluding instead to the brief satisfaction of the spectacle.

The increasing appearance of superficial and spectacular architecture desensitizes our understanding of conventional and traditional signs, and architecture itself to has lost its ability to embody cultural identity and meaningful experiences for people, being increasingly superficial and insensitive in the 21 st Century. Its semiotics are progressively driven by commercial interests and pretentious marketing ambitions that encourage an ostentatious demonstration of wealth and power. Arguably, these pretentious buildings reflect our time and culture of the consumer society. However, there is a cycle of mutual dependency that needs to be addressed, and to quote Sir Winston Churchill: "we shape our buildings, and thereafter our buildings shape us", the increasingly superficial architecture in society is symptomatic of a superficial and homogenized culture. It is then essential that we re-evaluate the way we design such that architectural relevance and experiences beyond superficial delight are not lost in this process. Yet, if architecture is shaped by its cultural context, we must also develop an understanding of the current culture of consumption that is pushing architecture into superficial spectacles. The preference and demand for spectacles is precipitated and perpetuated by a few interconnected factors: the mediation of images in society, the domination of economy over society, and increasing globalization and competition. 


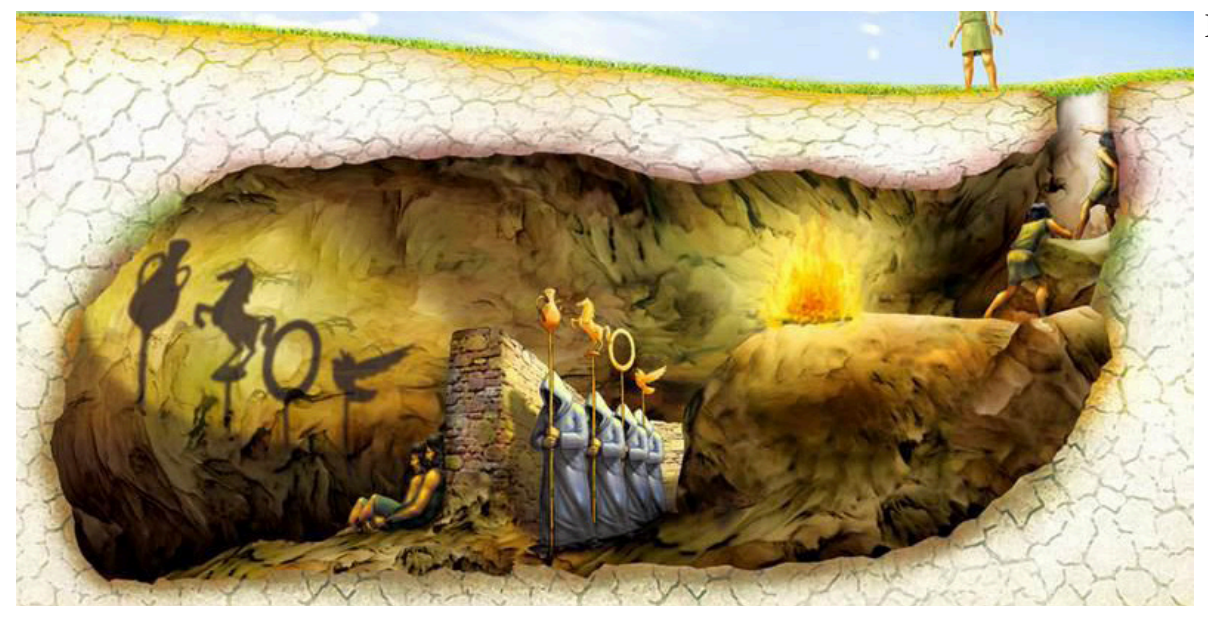

\subsection{The Mediation of Images in Society}

We understand and interpret primarily though the visual realm, and as such, it is the easiest sense to appropriate. However, it is not always true that what we see is in fact reality. Plato's allegory of the cave suggests that perception and reality are two different things. In Plato's Republic, Socrates describes a situation where a group of people have been chained in a cave and forced to stare at the wall in front of them. Behind them a fire is lit to cast shadows of puppets onto the wall. The prisoners can't see what lies behind them and thus perceive the shadows on the wall as reality (Figure 1.8). They don't realize the 'objects' they see are in fact images of objects beyond their visual realm. The perceived images constitute their reality. However, as Plato's allegory continues, experience and knowledge changes perception when a prisoner is freed and is able to see what lies beyond the cave. Reality shifts from the shadows to the fire and puppets. Thus, what we see may not be reality, but it makes us believe that it could be reality. Architecture's projective qualities, then, has the ability to communicate both reality and an image of reality.

\subsection{1 | Images and Imagery}

In exploring the origins and power of the image, architectural theorist Juhani Pallasmaa argues that image is linked directly to imagination, where embodied images and experiences inform and allows us to understand and interpret what we see (Pallasmaa 2011). Things are 'images' rather than 'objects' because they have an impact on our feelings and behaviour beyond their primary functions. For instance, a brick wall evokes imagery of earth and fire, warmth and stability, and is not simply a divider of space. Imagery is thus embodied in images and objects to evoke feelings and emotions associated with certain materials or forms. However, this allusion of imagery has been appropriated in contemporary branding to express superficial intentions

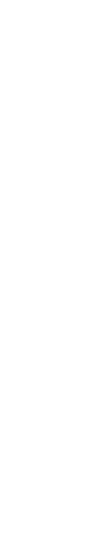




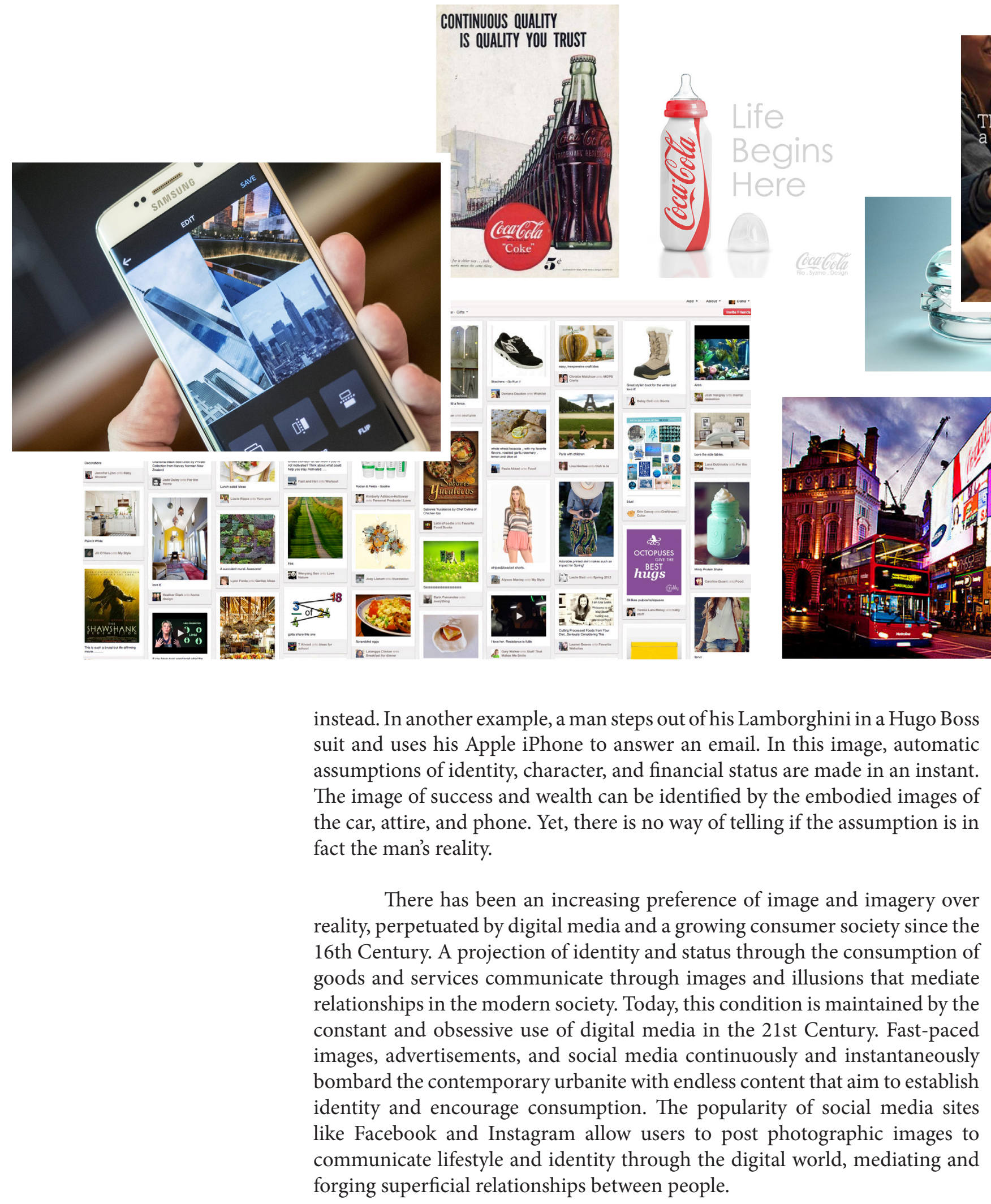


architectural form becomes an extremely persuasive and manipulative device. The material form of the object (architecture) and the produced image have become inseparable simulacra, blurring the distinctions between image and reality (Boudrillard, Mass. Identity. Architecture. Architectural Writings of Jean Boudrillard 2006).

The appropriation and preference of image has become inherent in our culture and continues to blur the distinctions between fantasy and reality, confusing our understanding of our surroundings. The capricious images attract attention and publicity, where spectacular forms evoke a sense of newness, excitement, and wonderment. This dominance and appropriation of the visual realm manipulates architecture's message and imagery to allude to superficial icons and expectations. Architecture has been reduced to easily consumable images in a time Jencks calls the "Age of the Icon" (Jencks, 2006). Beyond the easily consumable imagery however, it's unclear how the buildings relate to its use, context, or people.

"Architecture in this new society is only concerned with beauty... it has lost the reciprocity between people and their inherited artifacts (architecture), and the result is a loss of enchantment in the environment of real architecture. One more concerned with the satisfaction of excess, less of cultural exchanges" (Baudrillard, 2006, p. 26).

\subsection{3 | Society of the Spectacle}

In The Society of the Spectacle, Guy Debord discusses the same unrealism inherent in our society through the mediation of images and illusions that Pallasmaa describes. Debord argues that society has degraded from 'being' into 'having', and from 'having' into 'appearing', placing an emphasis on illusory visual imagery over mental, physical, and social wellbeing (Debord 1977). This degradation of social life (reality) into mere representation (spectacle) mediates and creates a fake, inauthentic society of the spectacle. The authentic social life in contemporary society has been lost to the inauthentic relations forged by the commodity and spectacle through the mediation of images. Appearance and imagery turns us into consumers of illusions that emphasize superficial egos, distancing people from each other. Based on Maslow's Hierarchy of Needs, the satisfaction of self-esteem and selfworth has become prevalent in our contemporary age after our basic needs are provided for by society. Debord's observation of social life degrading from 'being' into 'having' points out the tendency and goal of society to constantly acquire material goods. The 'having' then alludes to 'appearing', which projects certain imagery using the same material goods, becoming spectacles of a superficial nature. This shift from 'being' into 'having' has been propelled and sustained by the growing consumer economy, and the effects of this can be seen in contemporary architectural design. 


\section{3 | The Dominance of Economy over Society}

\subsubsection{The Consumer Economy}

Consumer economies have existed throughout history in marketplaces, agoras, and bazaars, where the exchange of goods and services allowed a civilization to properly function. Today however, consumerism as a phenomenon has proliferated our current generation at a scale of a global epidemic. Our modern consumer society and consumption patterns emerged shortly after the industrial revolution, where mass production not only met the material needs of society, but has exceeded it, leading to an excess of wealth and products. Prosperity and social mobility of the middle class then allowed more people to afford a large variety of goods. With more options available, there was growing interest in acquiring goods to improve quality of life: more clothes, more food, more everything. The post-war period of the 1950s-80s really propelled consumerism and mass consumption as it continuously marketed and advertised that the quality of life was quantifiable through the possession of material goods (Veblen 2005). Mentioned in the previous section, the obsession with image and appearance makes consumption an important aspect of defining social status and identity. Recognizing this as an important part of our culture, consumer-driven architecture has dominated all aspects of society, and our economy is thus driven by demands of conspicuous consumption.

\subsubsection{Conspicuous Consumption}

Termed in 1899 by economist and sociologist Thorstein Veblen conspicuous consumption describes the consumer behaviour of acquiring material goods to gain and publically signify social and economic status (Veblen 2005). He suggests that such behaviours are inherent and survived from our predatory and barbaric pasts. It was a social condition that came out of a stratified society, where the division of labour established social status. High-status, low-labour occupations (like conquerors and warriors) were 
economically unproductive, but were established as leaders and protectors of society. The high-status and freedom from physical labour constituted the leisure class. On the other hand, low-status, high-labour occupations (like farming and manufacturing) were economically productive but relied on the leisure class for protection. Within the leisure class, the maintenance of status was communicated by conspicuous material consumption of "Veblen goods". Defined as any consumer good that is valued for being expensive to make, sell, and buy, Veblen goods are an indicator of high socio-economic status.

"In order to gain and to hold the esteem of men it is not sufficient merely to possess wealth or power. The wealth or power must be put in evidence, for esteem is awarded only on evidence." - Thorstein Veblen, The Theory of the Leisure Class (2005 ed.), p.36.

The lower classes engaged in what Veblen calls "pecuniary emulation" instead, the tendency to conspicuously consume or imitate spending habits of the upper class in order to appear as a member of the upper class. These behaviours, Veblen notes, are useless activities that do not contribute to neither the economy nor the production of useful goods and services required for the proper functioning of society. It only serves to satisfy the esteems and egos of the consumer. However, this tradition of conspicuous consumption has continued to our present day, where the desire for status symbols and the image of wealth and power actually drives global economic trends and architectural design. As Debord had pointed out, society has shifted from 'being' into 'having' into 'appearing. The practice of conspicuous consumption has pushed companies to producing and promoting products that have become excessive and conspicuous beyond its basic functionality. Items are branded as 'luxury items' to enhance the aura of wealth. Examples include designer fashion (Yves Saint Laurent, Louis Vuitton), designer watches (Cartier), jewelry (Tiffany's), and luxury cars (Bentley, Rolls-Royce). Beyond its pragmatic functions, these items are only used to promote superficial displays of wealth and power. Thus, what we choose to own, use, and wear has become an indicator of lifestyle, wealth, and power.

In our contemporary society, the conspicuous consumption of goods has evolved to include a conspicuous consumption of experiences as well. The act of owning a Veblen good is no longer enough to satisfy esteems. The entire experience of consumption attempts to satisfy other emotions to project uniqueness and status instead. This can be summarised as the Experience Economy. 


\section{Progression of Economic Value}

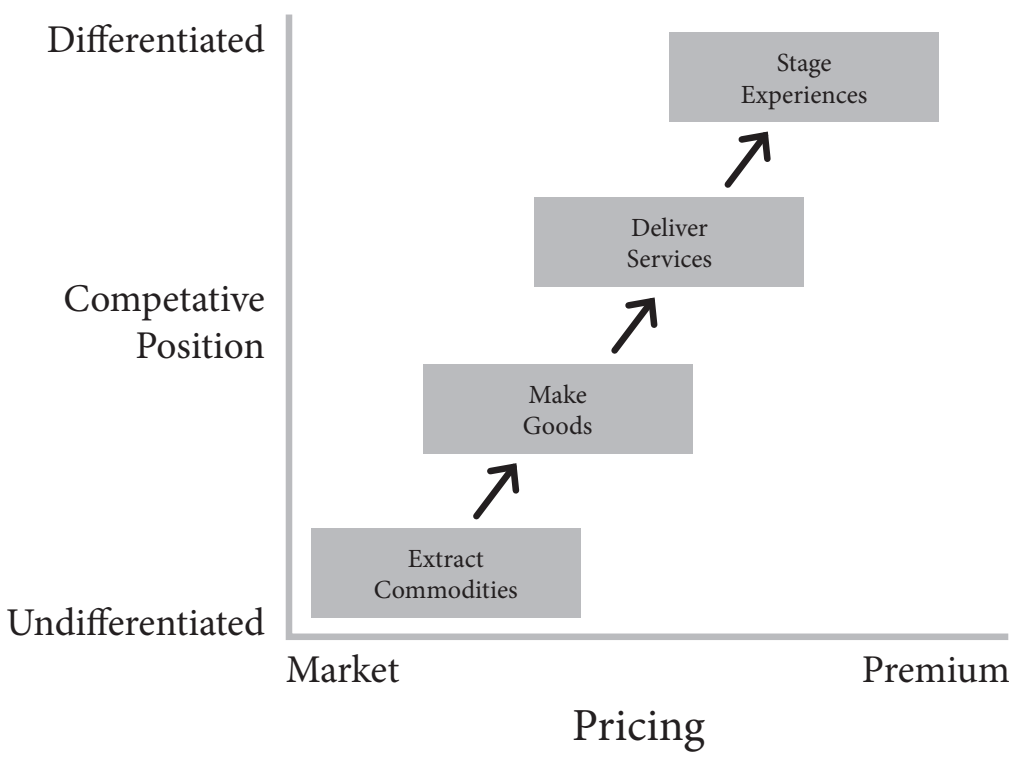

Figure 1.10

\subsection{3 | The Experience Economy}

First described in the late $90 \mathrm{~s}$ by business consultants and economists Joseph Pine II and James Gilmore, the Experience Economy describes the global business culture of the 21st Century, where the symbolic aspects of goods and services has overshadowed its intrinsic use-value (Pine and Gilmore 1999). Instead of simply acquiring more material goods, there has been a shift in the retail experience to cater to the immaterial and symbolic aspects of consumerism to provide additional emotional fulfilment for users. Pine and Gilmore synthesise retail psychology, emotional marketing, and commercial place-making to spatial production for commercial interests. "Companies stage an experience [for their customers]... connecting them in a personable, memorable way" (quoted in Klingmann, 2007). Retailers package the environment along with their products, creating unique social indicators that cater to particular lifestyles. This shift to a consumption of lifestyle-based experiences reflect social needs of self-fulfillment and identification, where every activity becomes an indicator of personal style and social attitude (Klingmann 2007). Recognizing the importance of the design of the image, the success of multi-national corporations like Starbucks, Disney, MercedesBenz, and Apple rely on the construction of particular lifestyle experiences as imagery (Klingmann 2007). This culture of manufactured experience appropriates architecture as a tool for creating these experiences (Figures 1.11-1.13). From an economic standpoint, Pine and Gilmore describe that successful business (or retail) 'full experience' has entertaining qualities, but also educational, aesthetic, and escapist qualities as well (Lonsway 2009).
Figure 1.10: Progression of Economic Value (Pine and Gilmore, 1999) 


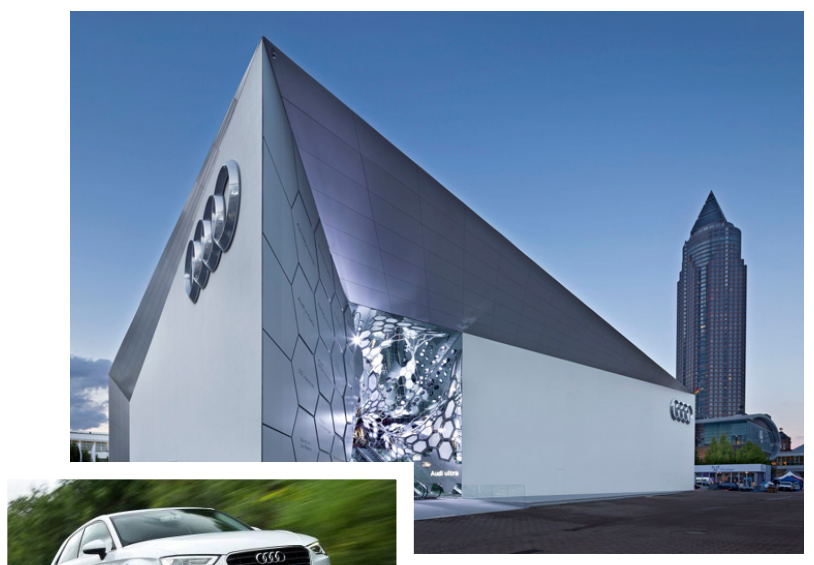

Figure 1.11
Figure 1.11: Audi A4 and Audi Brand Building.

Figure 1.12: BMW 7 Series and BMW Welt and Museum.

Figure 1.13: Mercedes Benz C Class and Mercedes Benz Museum.
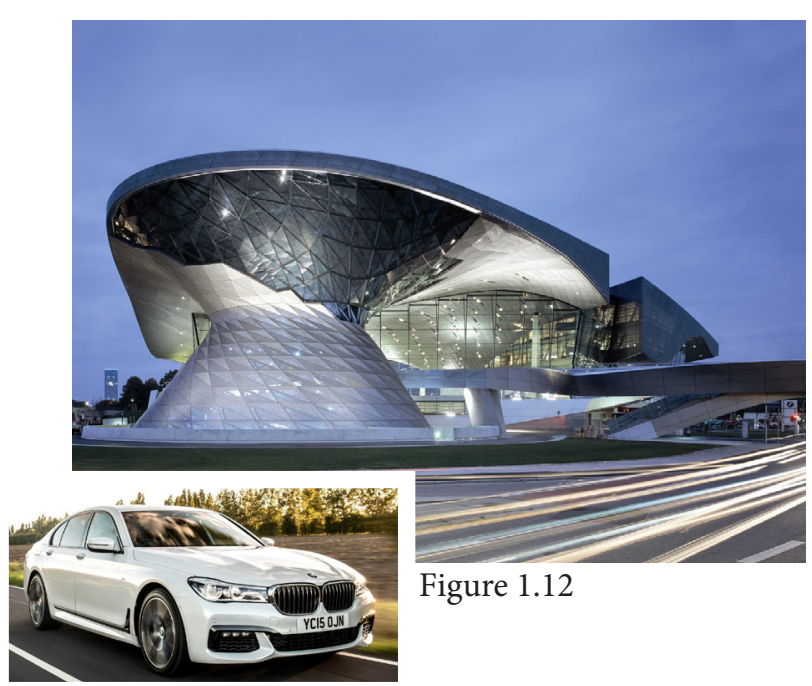

Figure 1.12

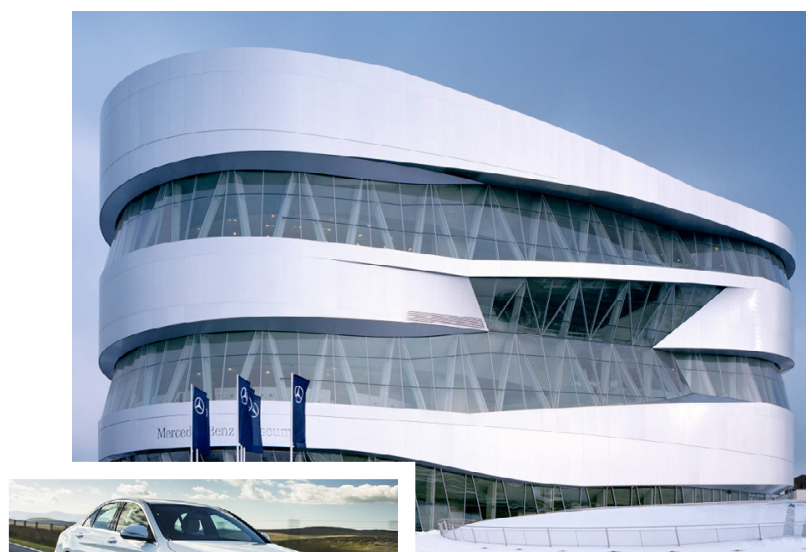

Figure 1.13 
The success of Starbucks, for example, is not simply in its effective commodification of coffee, but its ability to package and promote a particular brand and lifestyle that appeals to the senses and egos of a young and hip generation. The design of their café interiors, storefronts, décor, music, and even aroma communicates a particular ambience that identifies with young artists, students, and professionals. It differentiates Starbucks from a simple coffee provider, justifying its higher prices. Having coffee at Starbucks, then, can be seen as an act of conspicuous consumption that elevates the status of the consumer. Conspicuous consumption, as a consumer behaviour, then, fuels the representational nature of the society of the spectacle.

\subsection{4 | Architecture and Conspicuous Consumption}

In this system of value, architecture is not simply a container for the products and program, but something that advertises and shapes the entire experience of consumption, giving more value to the act of consumption. Architecture of the experience economy is an architecture of persuasion. It becomes something that persuades us to buy more through the mediation of images and experiences. Companies invest in "communication buildings" to convey its brand and set itself apart from its competitors, creating a new, unique and distinctive brand identity and tourist attraction in the process (Klingmann 2007). If every brand attempts to create newer and more unique buildings than its competitors, then our environments will become increasingly homogenized with superficial spectacles. Beyond an instant of recognisability, the buildings communicate prestige and status that, as Veblen says, is unproductive and useless to society. This superficial connection to products and brands only encourage the conspicuous consumption of both goods and architecture. Its architectural expression is often removed from and insensitive to its context.

The Selfridges store in the city of Birmingham, for example, is a conspicuous undulating form that dominates the street corner and puts the local church in its shadows (Figure 1.7, page 13). Simulating the image of a female body in a tight-fitting dress, the form of the building curves and undulates across the corner, covered in a skin of reflective disks. The building strikingly stands out from its modest surroundings, capturing attention to communicate its brand image. Not simply a store to sell goods, the building itself has become the image for consumption.

Other brands like Prada, for example, work with architects like Rem Koolhaas and Herzog \& deMeuron to create high culture shopping destinations instead of typical 'flagship stores'. Branded as an 'epicenter', each store is differentiated in different cities and features an exhibit or showroom 'public space, creating a hub identity for each city (Figures 1.14 and 1.15). Through 
its unique architecture, the brand effectively merges low brow shopping with high fashion culture to communicate its luxury status.

In our globalized world, conspicuous consumption transcends national boundaries and social classes to become universal signifiers through successful brand marketing. The continuous practice of conspicuous consumption in society allows the dominance and prevalence of consumer economy over society. The sale of images are the new items of trade in the 21 st Century. The economy is no longer judged by productivity and necessity, but by the satisfaction of excess. The same brands, whether it be clothing, jewelry, or purses, like Louis Vuitton, can be found in Toronto, New York, Paris, Shanghai, Singapore, and Marrakesh, with architectural expressions that disregard any local or cultural distinctions (Figure 1.16). They are inappropriate, insular and unwelcoming, only encouraging the behaviour of conspicuous consumption. And thus, architecture itself has become a commodified object that can be conspicuously and internationally consumed. 

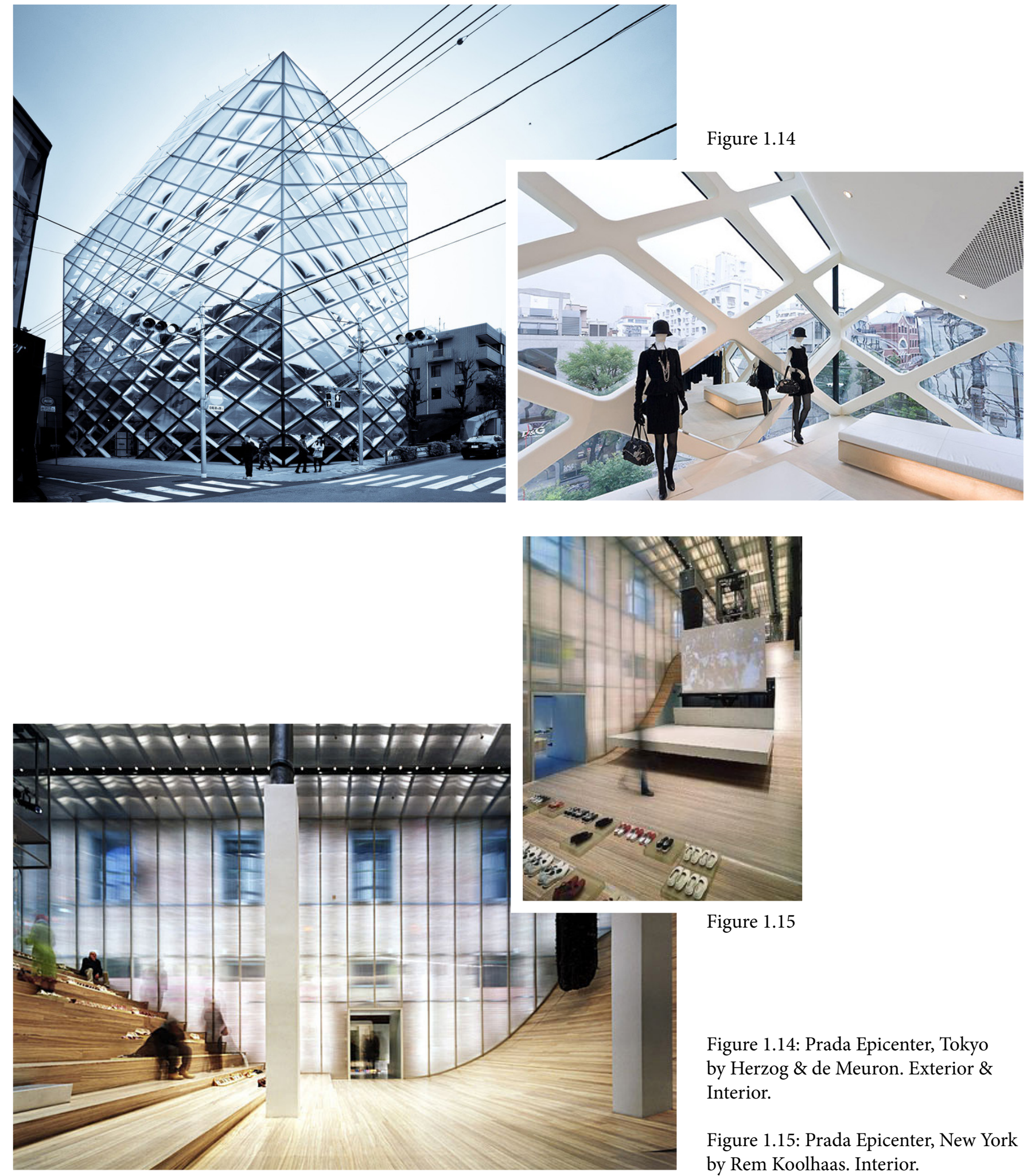

Figure 1.15

Figure 1.14: Prada Epicenter, Tokyo by Herzog \& de Meuron. Exterior \& Interior.

Figure 1.15: Prada Epicenter, New York by Rem Koolhaas. Interior. 

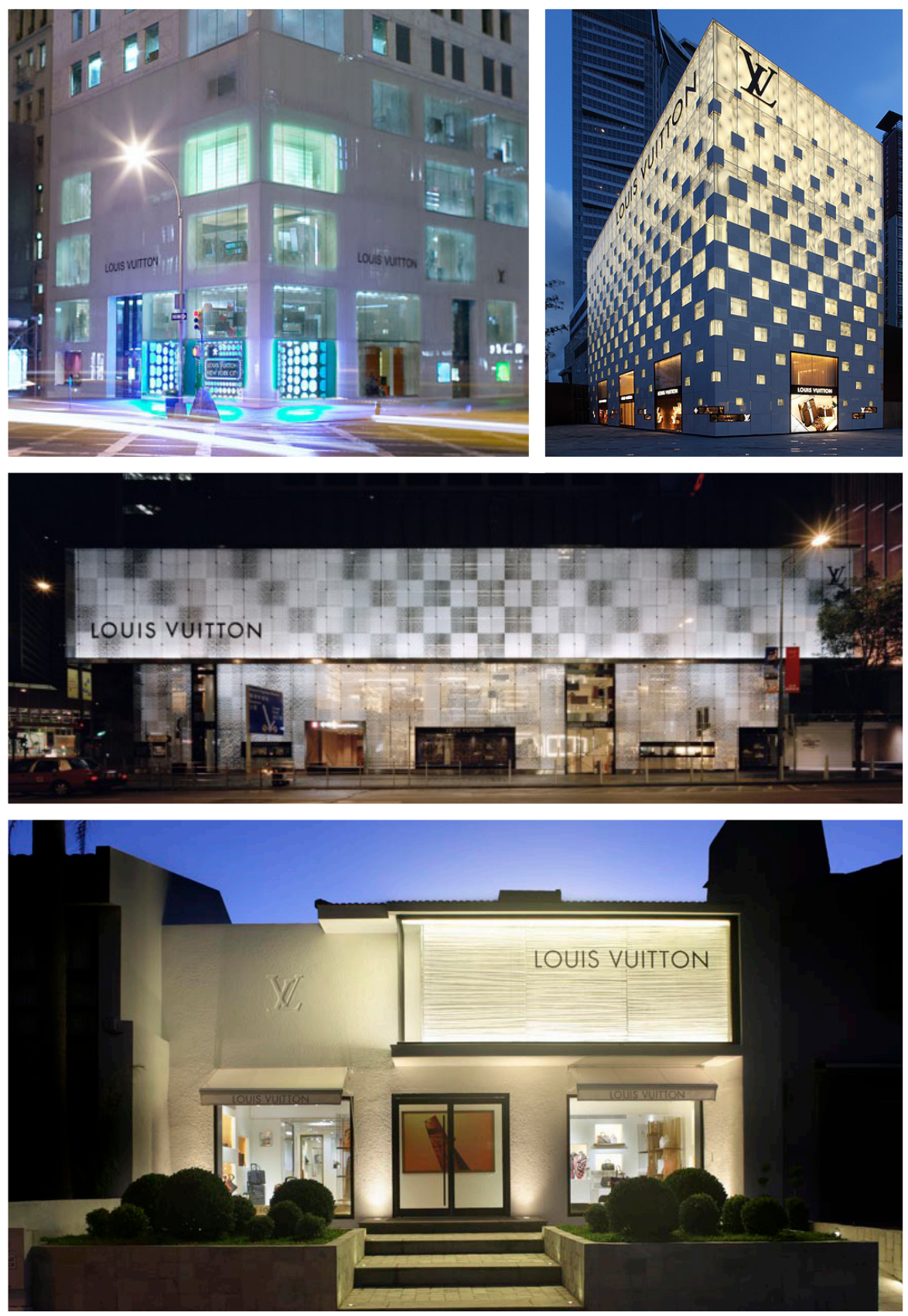

Figure 1.16: Louis Vuitton Flagship Stores (from left to right, top to bottom) LV New York, LV Shenzhen, LV Hong Kong, LV Bahamas 

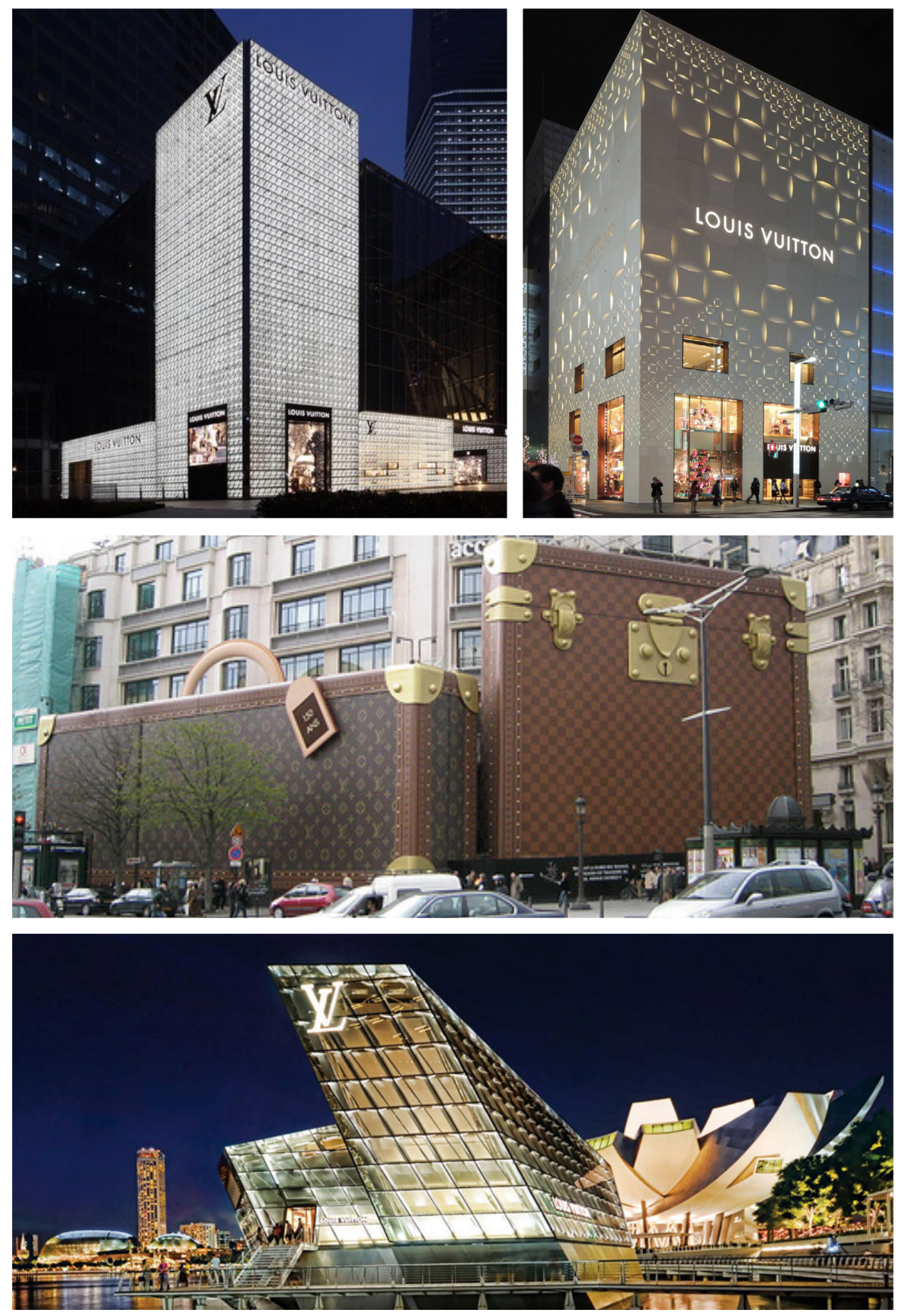

Figure 1.16 con't: Louis Vuitton Flagship Stores (from left to right, top to bottom) LV Shanghai, LV Tokyo, LV Paris, LV Singapore 


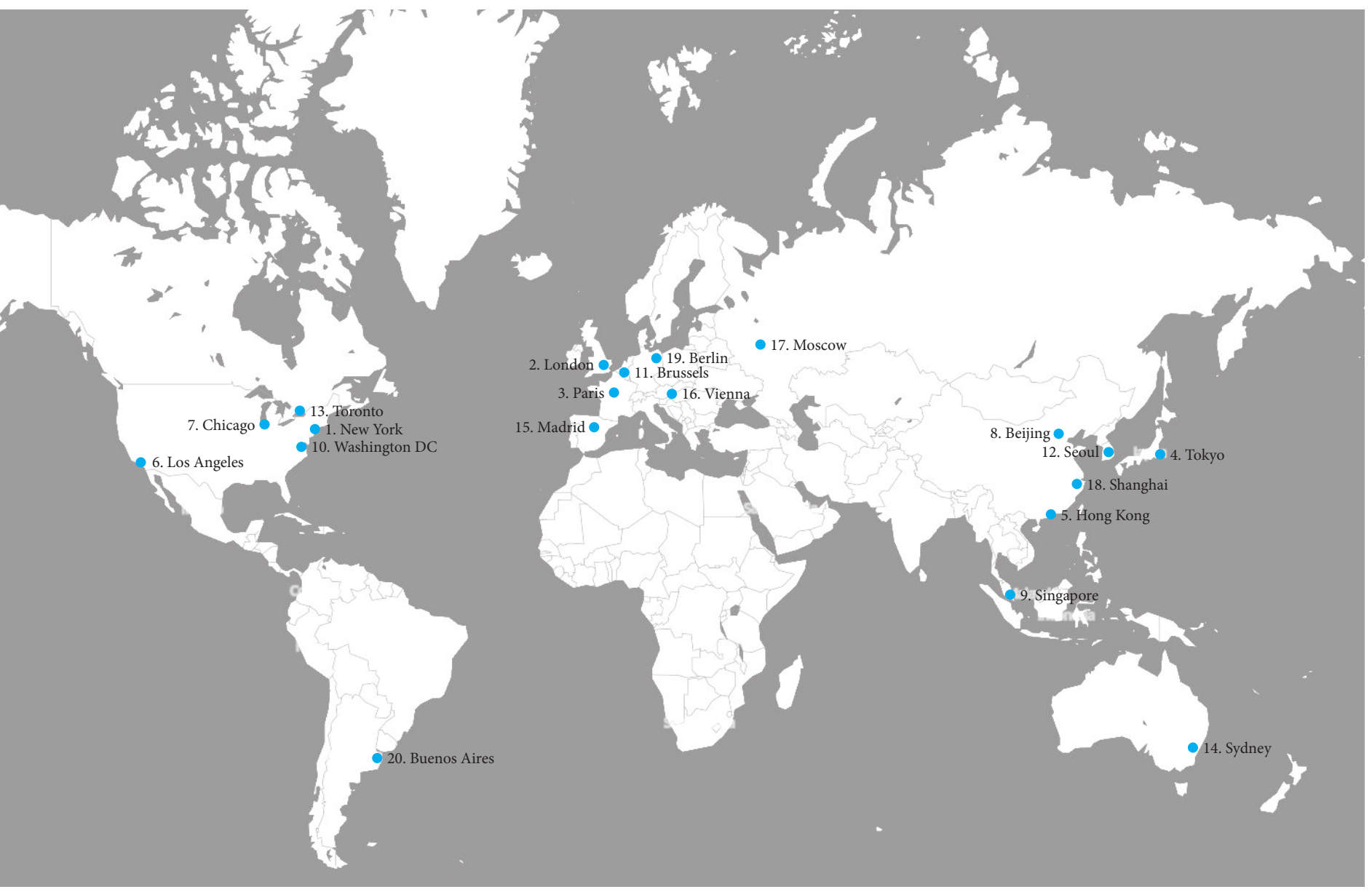

Figure 1.17: Top 20 Global Cities in 2014. 


\section{4 | Globalization and Competition}

The global integration of people and economies in the world has undoubtedly led to an increased flow and exchange of ideas and culture, broadening our understanding of places, processes, and people. At the same time, however, the built environment suffers by becoming diluted with homogeneous buildings that lack a connection to the specifics of place and people. International expansion brings with it foreign traditions and construction methods, imposing new ways of building in developing cities, often insensitive to local traditions of construction and use. The standardization of appearance and methods in different cities and countries eventually creates homogenous environments that lack specificities of place.

Globalization promotes the exchange of social, economic, political, and cultural information at an international level. Propelled by economic trade and now with increasing advances in information technology, cities, countries and continents are becoming more economically (and subsequently socially, politically, and culturally) intertwined and interdependent than ever before. Global cities are cities that have direct and influential roles in global affairs, determined by a number of criteria that form the Global Cities Index (ATKearney 2014). These cities are the most interconnected and have the most power such that they can set social, economic, or environmental agendas on a global scale as well as act as hubs of global integration. Based on numerous indicators, these cities are beneficial and desirable as places to live, work, or travel to, bringing in more economic and financial prosperity for the local population. As such, cities are always striving to become global cities for the influential power and opportunities for economic prosperity. In this context, cities are in constant competition with each other, striving for economic success and tourist attention on the international stage. To stand out, cities, like companies and brands, are investing in iconic landmarks that give it instant recognisability. Architecture in this context has become another item that can be conspicuously created. It is used to project the image of wealth and status of a city. 


\subsection{1 | Architecture as Conspicuous Consumption}

As in the past, the amount of time, resources, and money spent on architectural landmarks is an indicator of economic success and architecture is appropriated as symbols of cultural status. Today these symbols attempt to communicate at an international scale, expressing wealth and status of a city relative to the rest of the world, often disregarding any connection to its social context or necessity of function. The icons are merely signifiers of success, competing for taller, grander, and more conspicuous forms to generate a legible urban skyline.

Figure 1.18: Shanghai Tower by Gensler, 2015. Shanghai, China.

Figure 1.19: Burj Khalifa by SOM Architects, 2010. Dubai, UAE.

Figure 1.20: Taipei 101 by CY Lee and Partners, 2004. Taipei, Taiwan.

Figure 1.21: Abraj Al Bait by Shair and Partners, 2012. Mecca, Saudi Arabia.

Figure 1.22: Petronas Towers by César Pelli, 1996. Kuala Lumpur, Malaysia.

Particularly in rising markets of Asia and the Middle East, conspicuous architecture becomes a very prominent display to the world of their economic statuses. The race for tallest skyscraper is still seen as a symbol of national power. Buildings like the Burj Khalifa (Dubai), Shanghai Tower (Shanghai), Abraj Al-Bait Towers (Mecca), Taipei 101 (Taipei), and the Petronas Towers (Kuala Lumpur) dominate their respective city skylines, becoming symbols of the city itself (Figures 1.18-1.22). The sheer scale and engineering requirements conspicuously demonstrate a level of wealth associated with these nations. These buildings are not only grossly out of scale, but the tall steel and glass structures in the hot climate also disregard any environmental concerns. They simply emulate the image of success of the western world, which is epitomized by the skyscraper. 


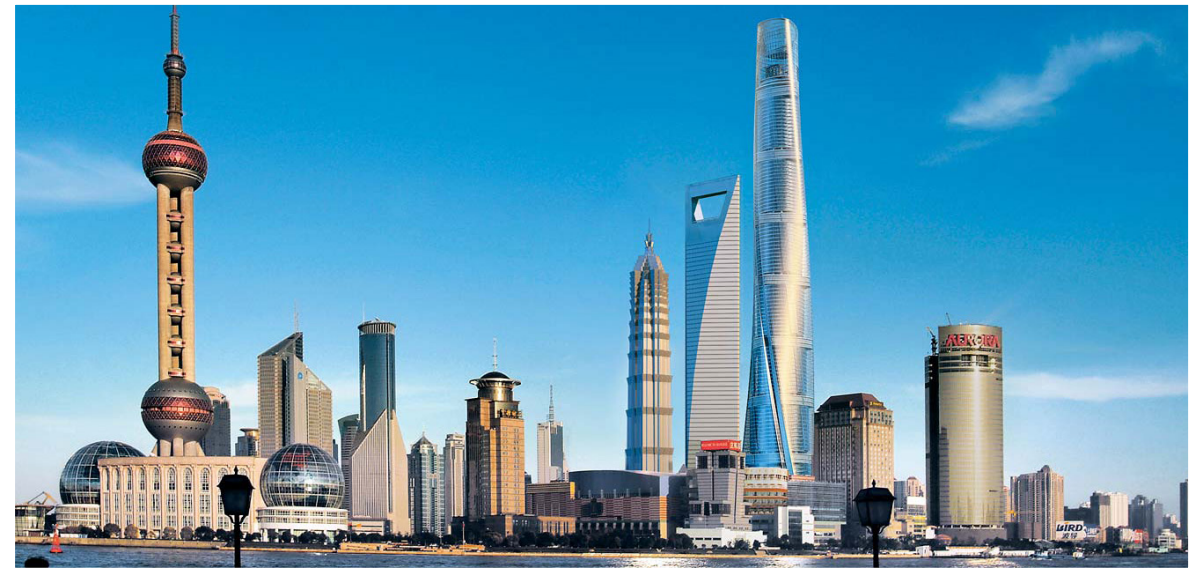

Figure 18
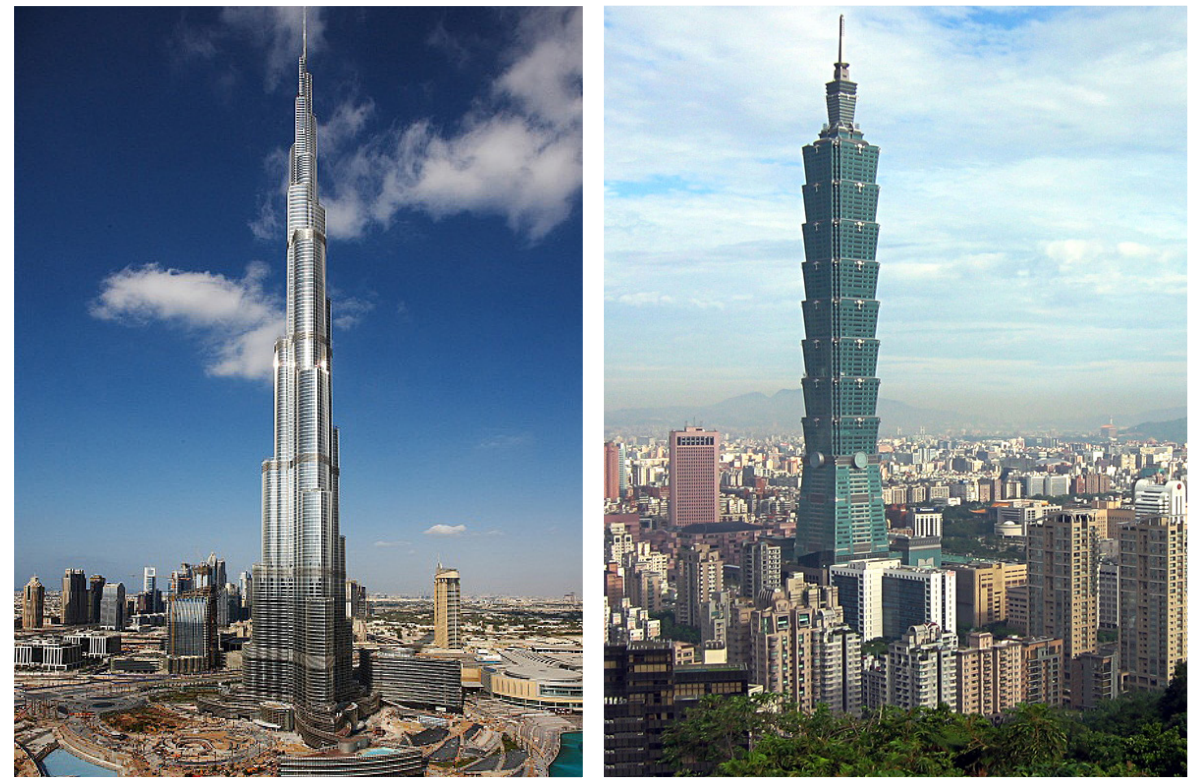

Figues 19, 20
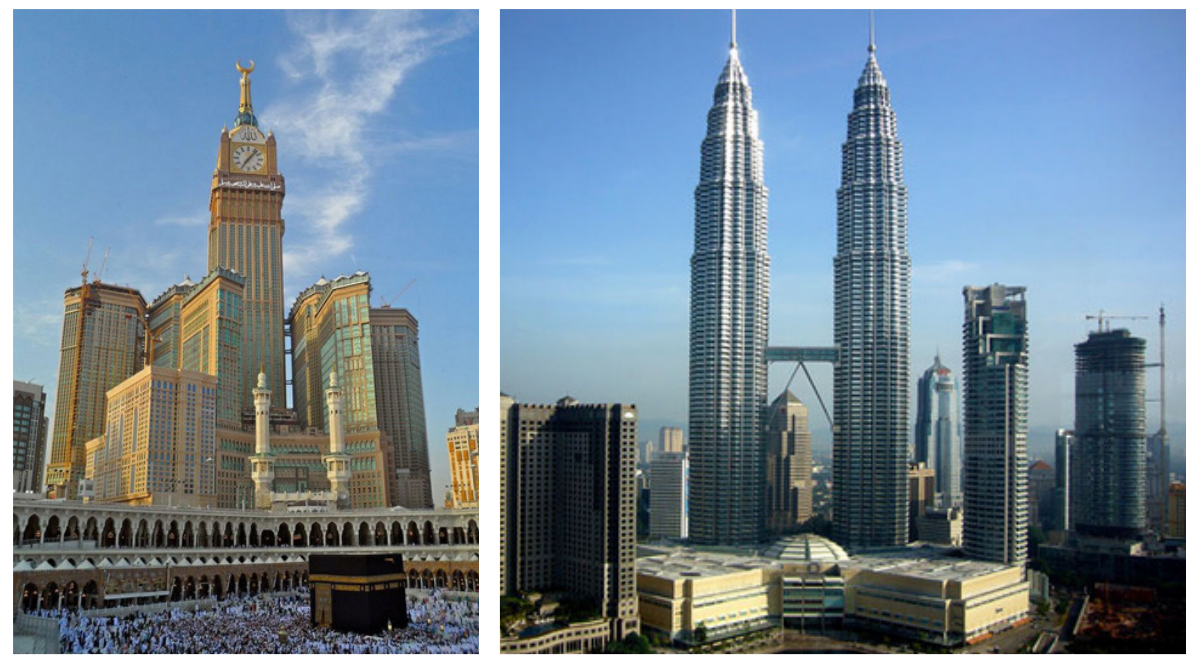

Figues 21, 22 


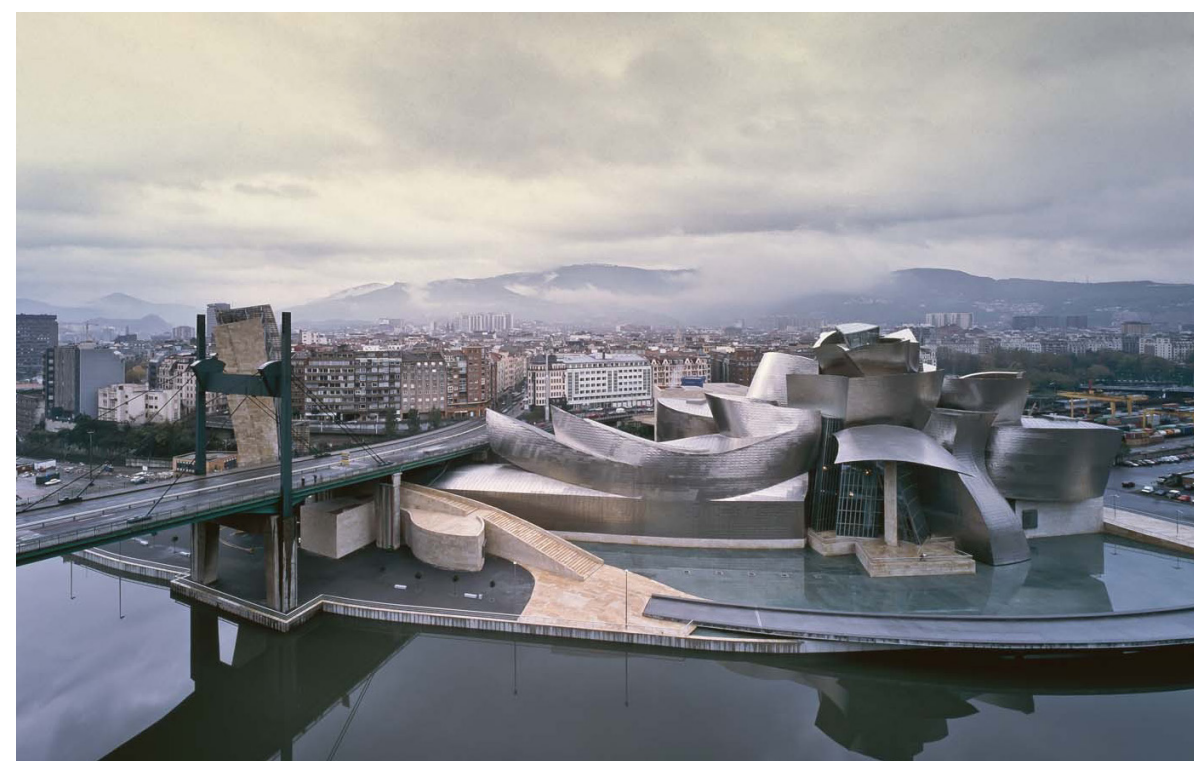

\subsubsection{The Bilbao Effect}

Apart from building taller skyscrapers, cities are also investing in unique architectural monuments to further elevate that status and competitive edge. Understood within the context of global economic competition, identifiability and iconic status become the most important aspects of architecture's place in the urban fabric. The 'branding' of a city and the merging of culture and economy attempt to both boost international reputation and attract tourists and knowledge through the medium of architecture (Jenkins 2005). The Guggenheim Museum in Bilbao, Spain began and epitomizes the trend of the iconic architectural landmark as a catalyst for reinventing urban identity and revitalizing the economy, subsequently termed the Bilbao Effect.

Figure 1.23: Guggenheim Museum by Frank Gehry Architects, 1997. Bilbao, Spain. Exterior.

Figure 1.24: Guggenheim Museum by Frank Gehry Architects, 1997. Bilbao, Spain. Exterior

Figure 1.25: Walt Disney Concert Hall by Frank Gehry Architects, 2003. Los Angeles, California.
The city of Bilbao, then a declining industrial town in the rising markets of Spain, wanted to redefine itself as a new cultural hub that could drive tourist traffic and economic investments. The Guggenheim brand museum, supplemented by Frank Gehry's unique architectural forms were seen as the driving agents for economic revival. The museum opened in 1997 and the uniqueness of architectural form did indeed draw critical acclaim, public attention, and tourists to revitalize the city, attracting 1.3 million visitors in the first year, 1.1 million in the second, and tourist spending of over $\$ 400$ million in two years (Jencks, The Iconic Building 2005). With the project costing the city $\$ 100$ million, the museum had already paid for itself in two short years. These measures of success proved extremely attractive to other declining cities hoping to reinvent their images. It gave rise to the importance of a 'wow-factor' in architecture, putting 'iconic architecture' in the forefront of economic revival, as well reaffirming the celebrity status of architects (Klingmann 2007). 


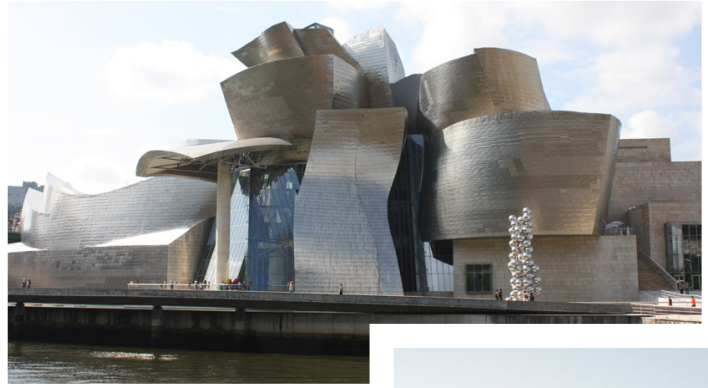

Figure 1.24

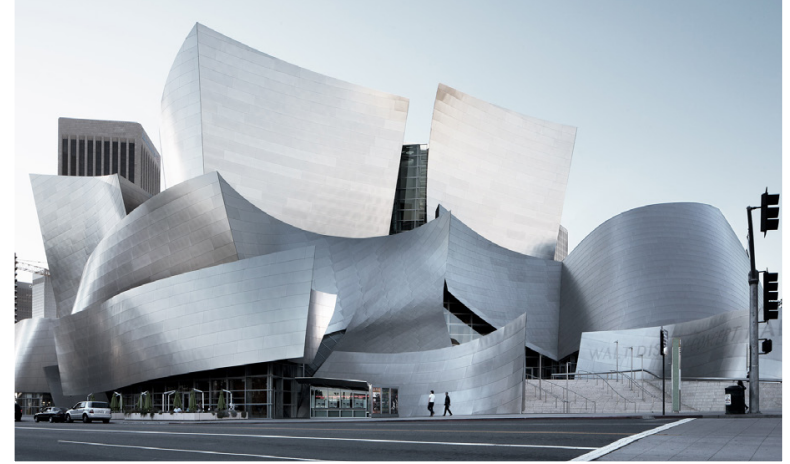

The museum itself works moderately well as an exhibition space, but is obviously out of scale and form with the rest of the city. It is clad in titanium, which is not a local material, and the curvaceous form distorts the program into its awkward spaces, overshadowing the content of the museum itself. The architectural icon simply functions as a visual magnet, a conspicuous tool for economic revival and does not necessarily or adequately respond to its context and program. Yet, the Bilbao Effect is not judged by its appropriateness to function or context, but in its ability to revitalize the surrounding area through a redefined image for the city and its means of attracting subsequent tourist dollars. Looking beyond its functional shortcomings, Gehry and Bilbao become the critical benchmark for urban revitalization. The attraction itself communicates cultural innovation to put Bilbao on the map as a world-class cultural city. It also confirms architecture's position as the new aesthetic of global economic competition.

In her book Brandscapes: Architecture in the Experience Economy, brand architect Anna Klingmann describes the success of Bilbao as the amalgamation of three ingredients: the emblematic icon, global trademark, and signature architect, simplifying urban renewal into a formula reliant on architectural spectacles and world reknowned architects (Klingmann 2007). The "wow-factor" of shock and surprise pushes for architecture to become a spectacle to attract tourists. Yet, the danger is that it sees buildings in isolation, disregarding the specificities of program, place and culture as a whole. 


\subsection{3 | Architects as Brands}

The economic success of Bilbao not only turns architecture into worldwide commodities, but also turns architects into commodities as well. The global demand for 'Gehry buildings' seek the same international attention as Guggenheim Bilbao, but only focuses on formal expression to create visual excitement. And thus, a repackaged form of Bilbao exists in Los Angeles as the Walt Disney Concert Hall, as well as in Minneapolis as the Weisman Art Museum.

Apart from Frank Gehry, other star architects (starchitects) of our generation have also become consumable items of conspicuous consumption. Each name can be attached to an architectural image: Zaha Hadid's fluid, organic forms; Daniel Libeskind's angular 'crystals'; or Santiago Calatrava's lightweight structural aesthetic (Figures 1.29-1.31, pages 36-37). Their 'signature styles' are employed and replicated everywhere for any typology, losing its specificity to site and function. The demand for "Gehry buildings" attempt to rebrand cities as unique, forward-thinking, and cultured, using architecture as a conspicuous icon.

\section{Becoming Too Iconic}

Before Bilbao, however, this effect put had also put Sydney, Australia on the map in the 1970s with Jorn Utzon's iconic Sydney Opera House. It established a new identity for Australia in the post-war years, drawing in tourists and investment to the city and surrounding area. The image of the performance venue has since become synonymous with the city itself. Over 8 million people a year take a photo in front of its arching forms, but only 350,000 actually walk through and experience the building and its performances (Brownlee 2016). Some long term effects and problems of the iconic building can be seen here. The building exterior has become more important than the cultural institution it was designed to promote, in line with Baudrillard's claim that icon has become more important than the building itself. There is a disconnection between the building's interior functions and exterior form and the building is only known in the context of Sydney rather than relating to its arts program. Recognizing this problem as "a building that has become too iconic", the institution has recently rebranded its program and image by introducing a new typographic brand that attempts to reconnect the exterior and interior, hoping to attract audiences into the building (Figures 1.26-1.28). With the startling amount of iconic buildings being completed in recent years, the briefness of visual excitement leaves many buildings as giant billboards only noticed from the exterior. 


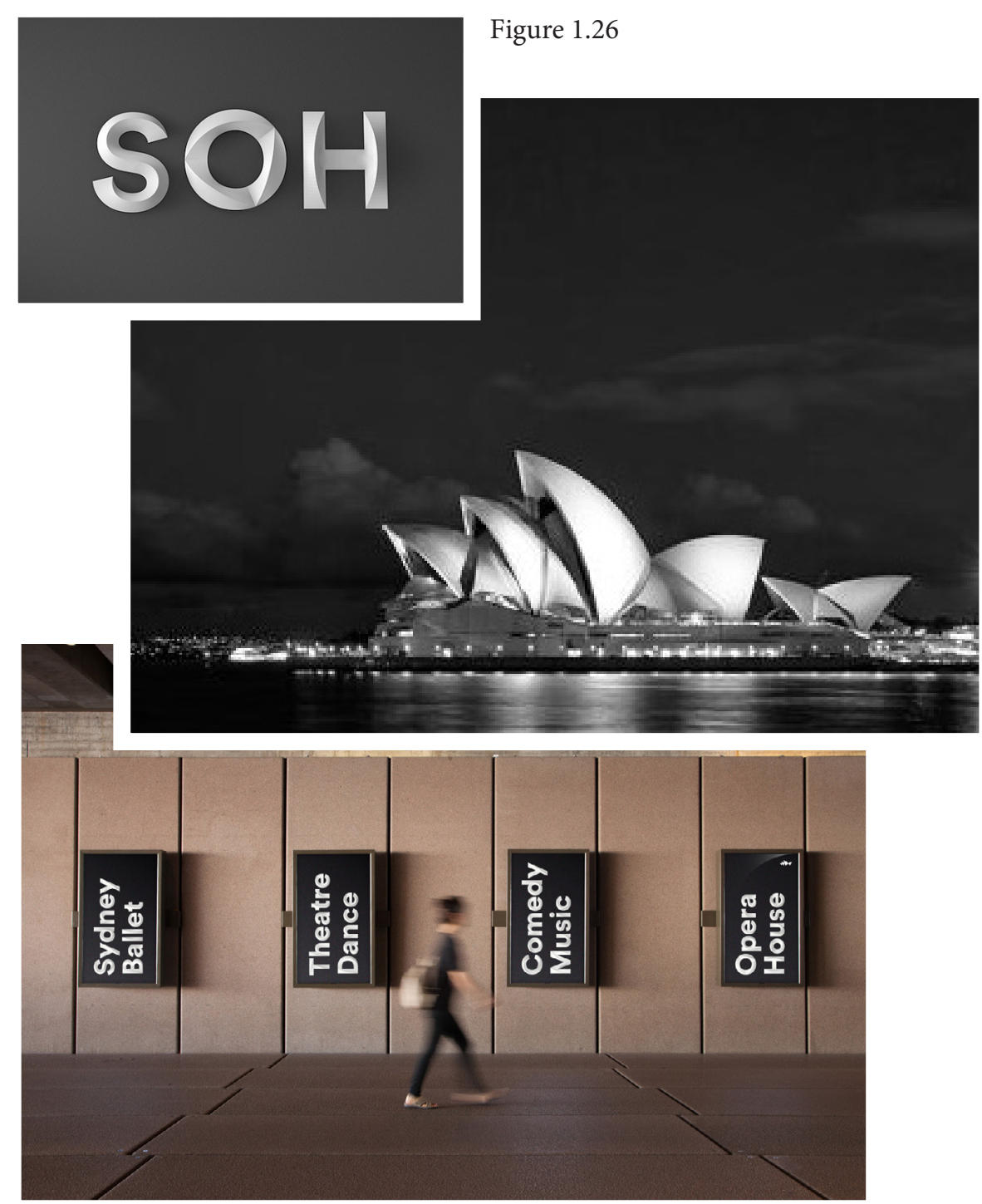

Figure 1.28
Figure 1.27

Figure 1.26: Sydney Opera House ReBranded Type Face, 2016

Figure 1.27: Sydney Opera House by Jorn Utzon, 1973. Sydney, Australia.

Figure 1.28: Sydney Opera House ReBranded Signage, 2016

Following pages:

Figure 1.29: 'Libeskind Buildings' Royal Ontario Museum, 2007.

Toronto, Canada. Denver Art Museum Extension, 2006. Denver, Colorado. Military History Museum, 2011. Dresden, Germany. The Run Run Shaw Creative Media Centre, 2010. Hong Kong, China.

Figure 1.30: 'Zaha Buildings'

Collins Park Place, under construction. Miami Beach, USA.

King Abdullah Financial District Metro Station, under construction. Riyadh, Saudi Arabia.

Guangzhou Opera House, 2010.

Guangzhou, China.

Wangjing Soho, 2014. Beijing, China.

Figure 1.31: 'Gehry Buildings'

Lou Ruvo Centre for Brain Health, 2010.

Las Vegas, Nevada.

Walt Disney Concert Hall, 2003. Los

Angeles, California.

Weisman Art Museum, 1993.

Minneapolis, Minnesota.

IAC Building, 2007. New York, USA. 

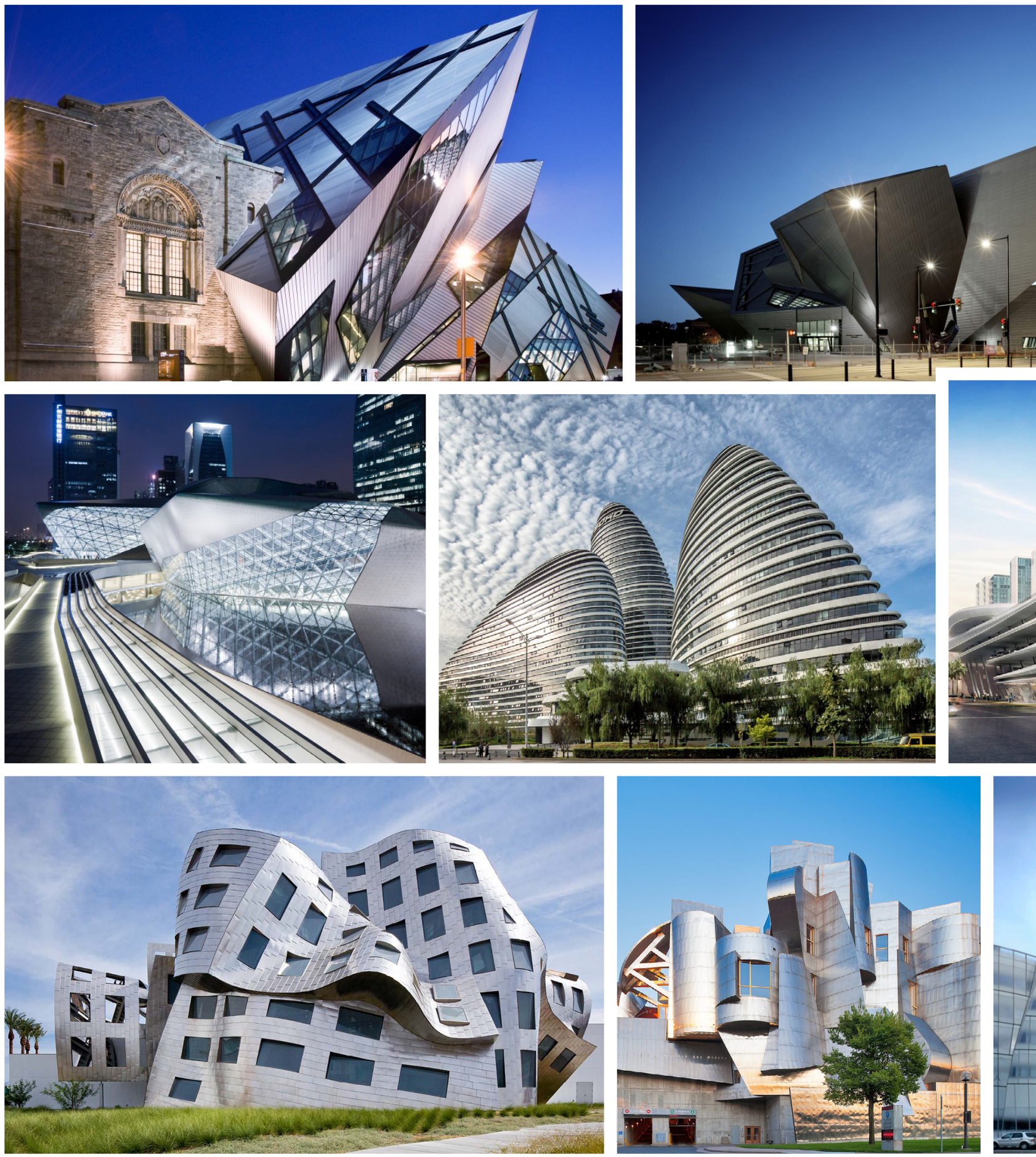


\subsection{4 | If You Build It, They Might Come}

After the success of Bilbao, the museum typology is now expected to act as catalytic agents of urban transformation. The role of culture has shifted in our capitalist world, changing it into a commodity that symbolizes and projects a sense of vibrancy and creativity (Jenkins 2005). The cultural

(Page 39)

Figure 1.32: Proposed Culture and Art Centre of Qingdao by Steven Holl. Qingdao, China. 2013.

Figure 1.33: Proposed Shenzhen Art Museum and Library by KSP Jürgen Engel Architekten. Shenzhen, China. 2015.

Figure 1.34: Proposed expansion to National Art Museum of China Interior by Jean Nouvel. Beijing, China. 2014.

Figure 1.35: Proposed expansion to National Art Museum of China Exterior by Jean Nouvel. Beijing, China. 2014.

Figure 1.36: Yinchuan Art Museum by Beijing firm We Architech Anonymous. Yinchuan, China. 2015. Interior and Exterior.

Figure 1.37: Qujing History Museum by Atelier Alter and Hordor Design Group. Qujing, China. 2015.

Figure 1.38: Minsheng Contemporary Art Museum by Studio Pei-Zhu. Beijing, China. 2015. Interior and Exterior. economy has since become a highly valued sector that is used to elevate national identity and tourist attraction. The iconic cultural building is used as a means of enhancing the economy and attracting creative industries and people to develop the cultural base needed for revival. Economist and social scientist Richard Florida discusses the importance of the 'creative class' - high-tech workers, artists, designers, etc. - for a culturally vibrant city (Florida 2002). This population is a mix of culturally diverse and highly educated individuals, and the iconic cultural building attempts to act as a cultural amenity to attract this creative class.

An entire country hoping to diversity its economy from a reliance on manufacturing and exports to domestic culture consumption, China's museum boom is symptomatic of a reliance on building typology. 3500 new museums have been built throughout China in the past 40 years, many of which are excessively scaled, poorly built, and lack exhibits and collections to qualify as a 'cultural building. A mix of government planning and private sector funding, many of the museums are designed by international architects in both rural and dense urban areas in China. Investors are building iconic spectacles to hopefully "buy culture" through museum-building (Dezeen 2015). With a focus on the spectacle and exterior forms, the museums offer immense square footage and obnoxious designs (Figures 1.32-1.38, page 39). They lack any thoughtfulness to content, program, and context appropriateness, becoming only an empty shell in the landscape, proving that statement iconic buildings do not necessarily equate to culture and tourism. Florida suggests instead that a vibrant cultural scene is more effective when cultural activities develop more organically, such as a vibrant street scene, rather than 'big ticket' attractions (Florida 2002). 

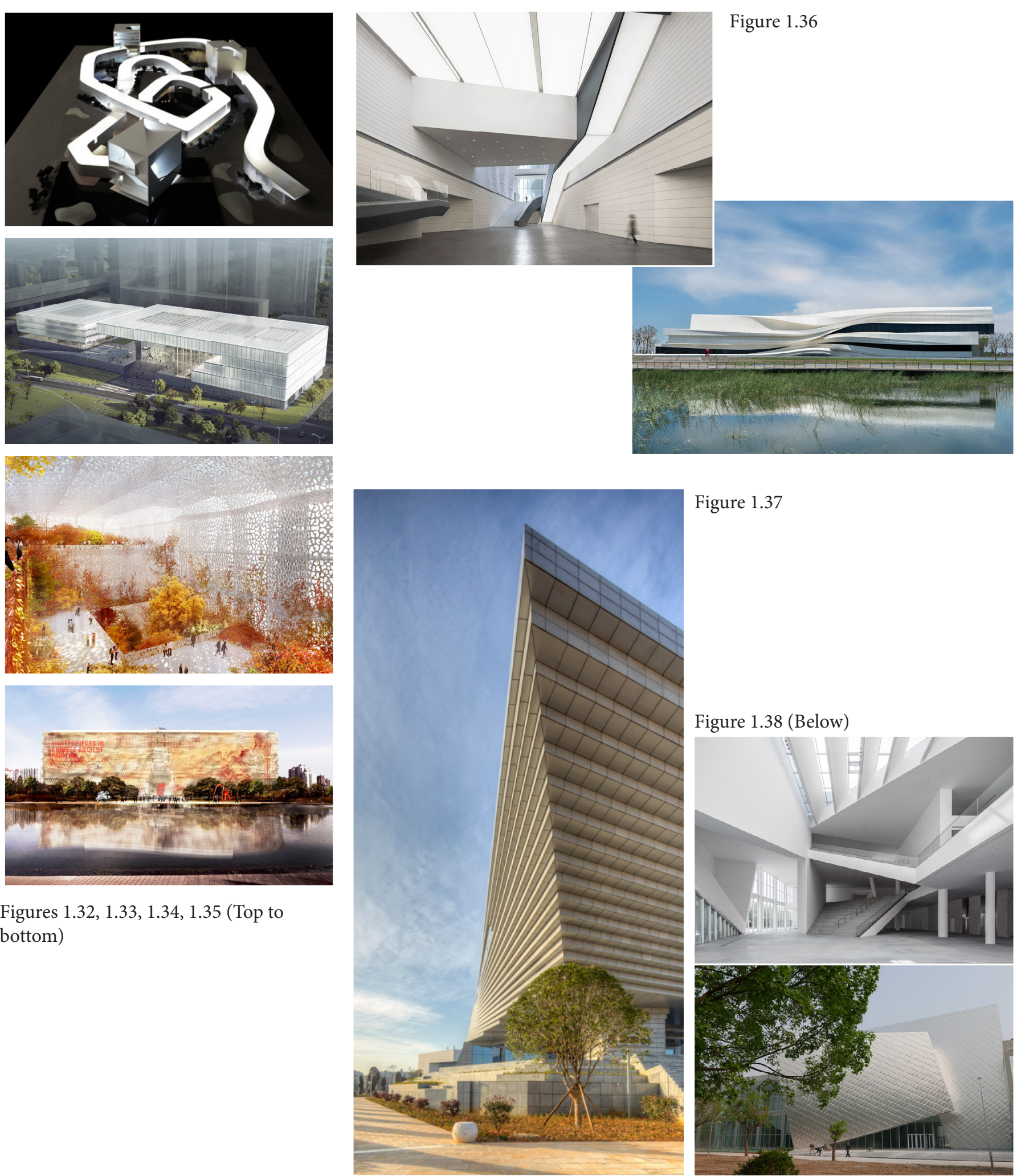

Figure 1.37

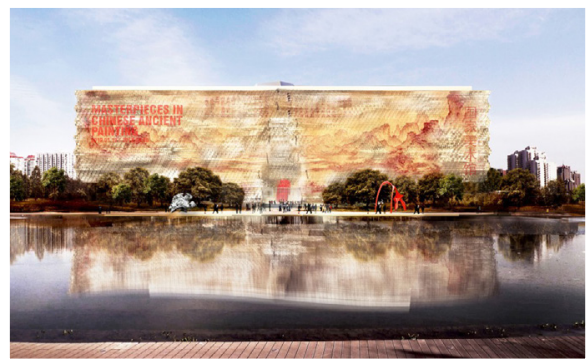

Figures 1.32, 1.33, 1.34, 1.35 (Top to bottom) 


\subsection{5 | Iconic in Any and Every Typology}

Iconic buildings thrive on excess, controversy, and publicity, infiltrating any and every typology. Beyond iconic cultural buildings, individual corporations are also drivers of capricious and conspicuous architectural forms, aiming to elevate their own economic statuses. These iconic landmarks express the hierarchy of money instead, allowing the relatively banal typologies of commercial or residential architecture to outshine public buildings.

\section{An Architectural Arms Race}

Companies are redefining its work environments through architectural interventions as a means of improving workflow, but also used as conspicuous displays of power and brand equity that appeal to global markets. The rising tech companies in Silicon Valley, for instance, are looking for architectural expressions of their own, breaking away from its traditions of suburban garages and business parks (Goldberger 2014). Corporate headquarters for Apple, Facebook and Google present ambitious architectural expressions designed by starchitects (Sir Norman Foster for Apple, Frank Gehry for Facebook, Bjarke Ingles Group and Heatherwick Studios for Google - Figures 1.38 and 1.39, page 41). Each of these tech companies are looking to redefine and out-do one another's offices in what architecture critic Paul Goldberger calls the Silicon Valley "Architectural Arms Race", where office campuses are becoming increasingly spectacular as a part of their brand recognition and identity. Apple Campus is envisioned as a continuous glass donut of office space and recreational grounds rivaling the size of the Pentagon in Washington, becoming a self-contained campus within the sprawling suburb of Cupertino. Google offices have long been entertaining spectacles from the inside, but its newest North BayShore addition by BIG and Heatherwick propose four glass canopies that span across multiple buildings, blurring the inside and out at a massive scale, making an impressive spectacle out of its new office. The effects of these new business campuses seek to blur work with amusement, maintaining productivity by providing entertaining environments. These reinvented office parks take on a tabula rasa approach, emerge in entirely new suburbs, disconnecting people from their surroundings and ignores any cultural or local tradition in the process. Due to the nature of the businesses being mostly digital and immaterial products, they become self-contained cities of their own. 

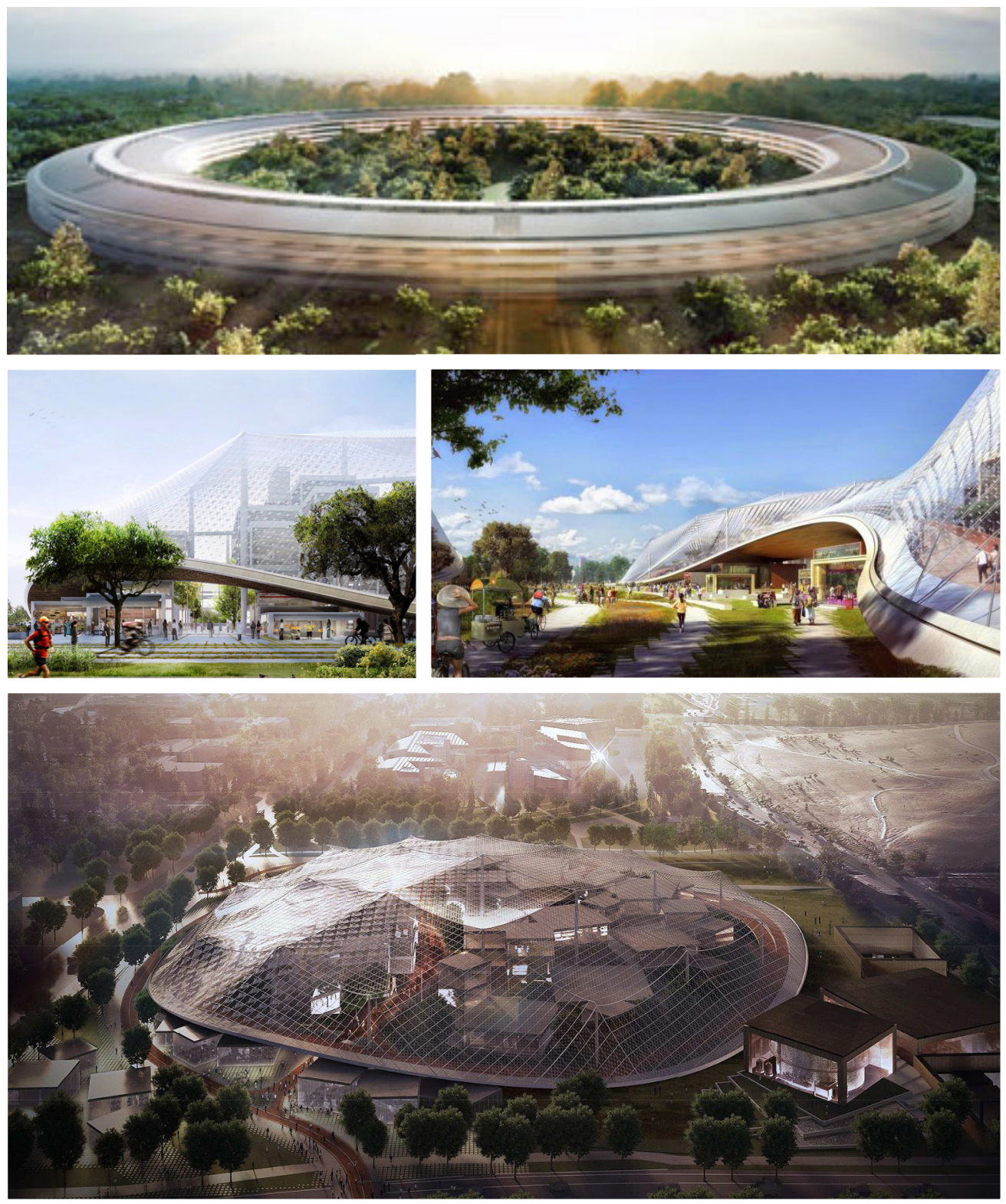

Figure 1.38 (Top Image): Proposed Apple

Headquarters by Foster + Partners.

Cupertino, California.

Figure 1.39: Proposed Google Headquarters by Bjarke Ingles Group and Heatherwick Studios. North Bayshore, California. 


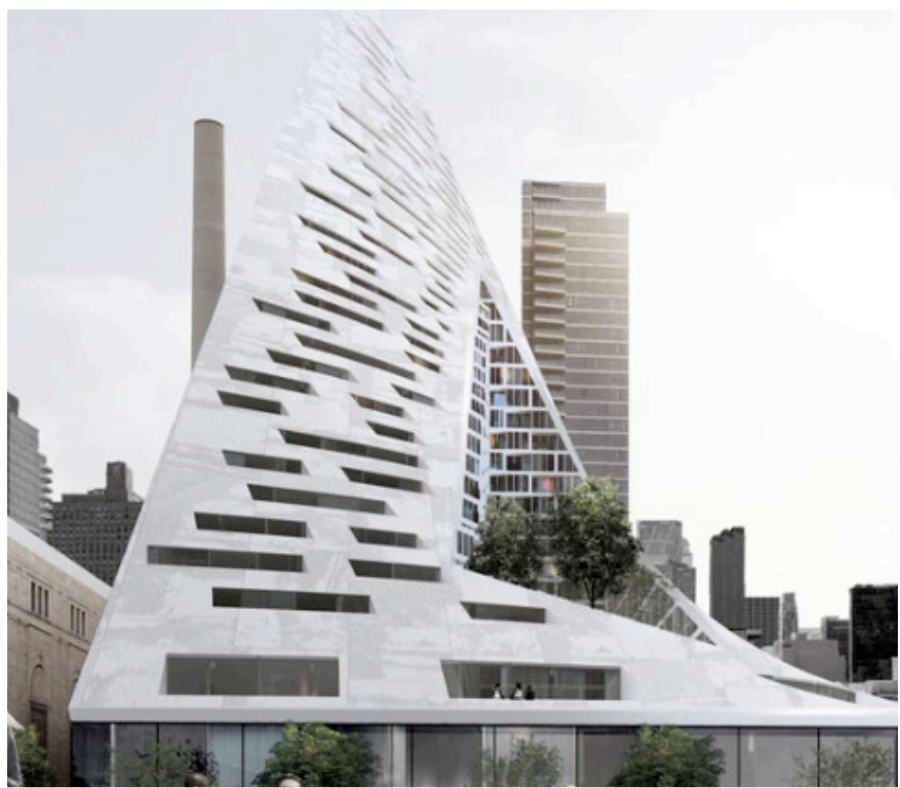

Figure 1.40

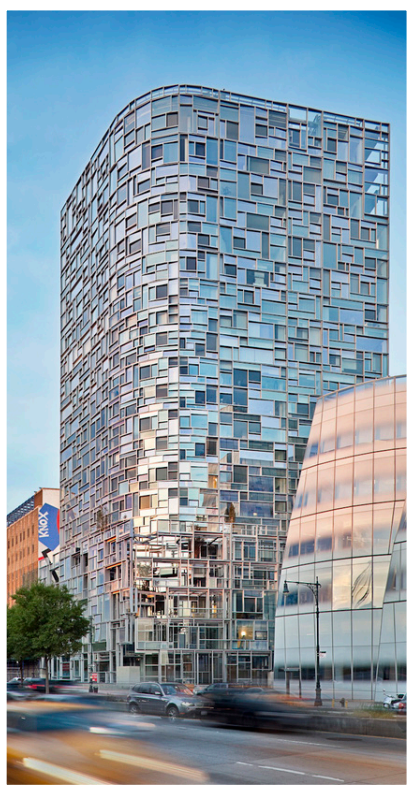

Figure 1.41

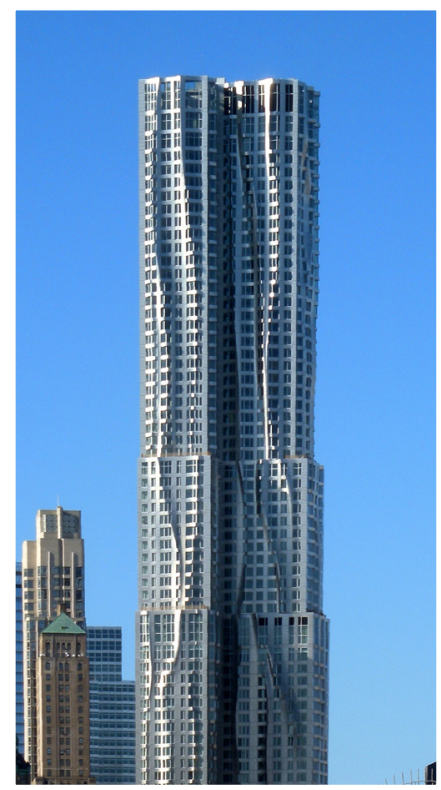

Figure 1.42

Figure 1.43
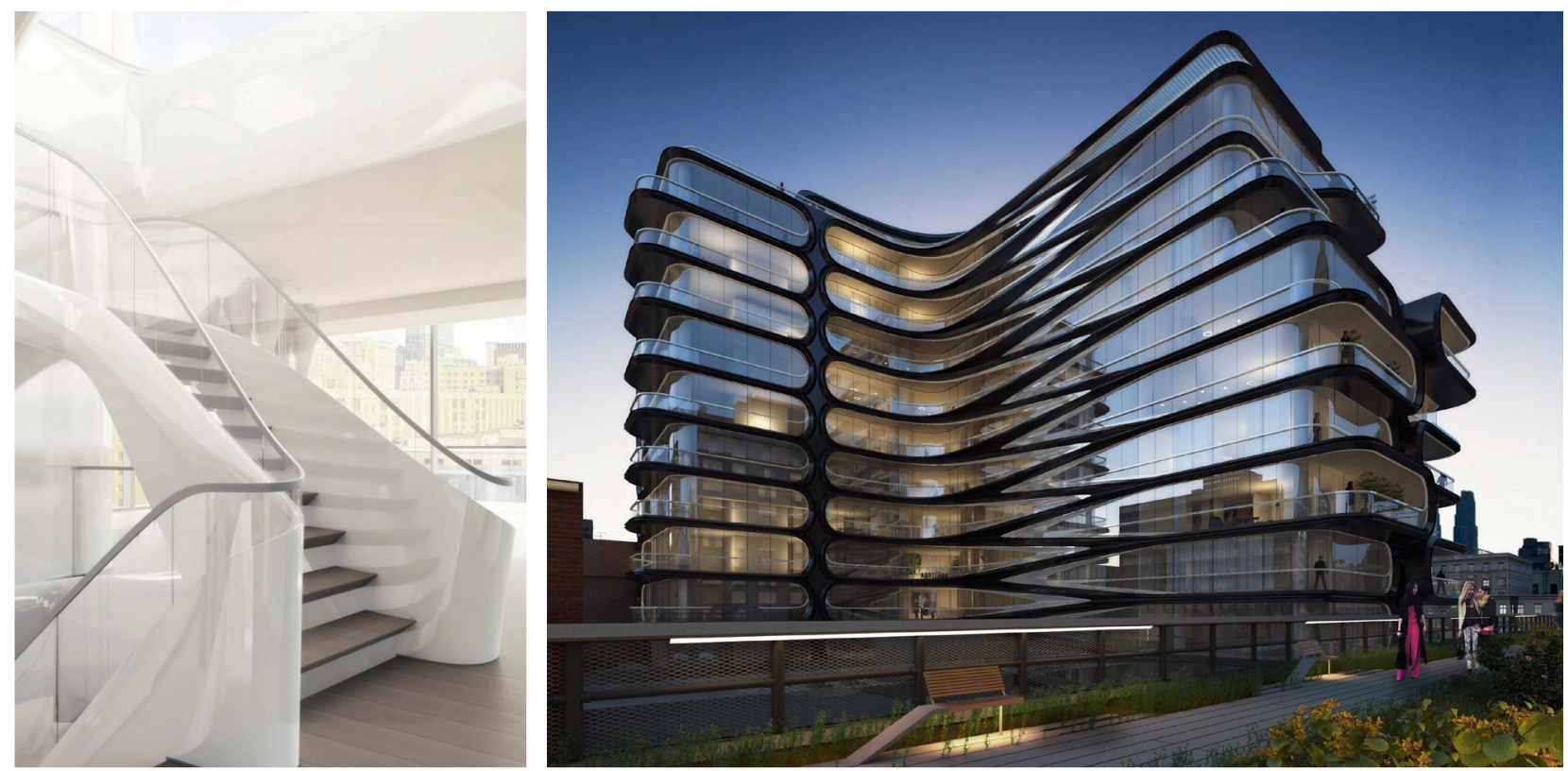
Conspicuous Living

Perhaps the most prized possession of an individual's is the residential dwelling. Apart from the excessively oversized 'McMansions' or customdesigned houses of the suburbs, residential buildings in urban centres are also employing starchitects to create iconic buildings to sell its units at a premium. Regardless of residential needs, the 'luxury condominium' becomes a symbol for the individual as another item of conspicuous consumption.

Manhattan Island was once dominated by skyscrapers for commerce, establishing its status and power as a centre for capitalism and world trade in the 1920s-30s (Heathcote 2015). Today, however, new residential towers designed by Frank Gehry, Jean Nouvel, Bjarke Ingles, Zaha Hadid and such starchitects are invading its skyline, shifting power from commerce to individual wealth (Figures 1.40-1.43, page 42). This concentration of global starchitect buildings, aiming to out-do one another's designs, not only dilutes New York's architectural identity of small scale brownstone row houses, but pushes spectacular forms as superficial displays of wealth, catering only to the elite class. The added-value of a starchitect's name adds a premium to the real estate value of the condominiums. Zaha Hadid's condominium at 520 West 28th Street at the High Line, for example, is marketed as 'designed by architect Zaha Hadid' although she is not licenced to practice architecture in New York (Related Companies 2014). Working with local architects, Ismael Leyva Architects, Hadid is credited as 'designer', and the architecture depicts her signature style of swooping curves and fluid shapes. These starchitect designed buildings, although generators of economic investment, does not address local identity or social conditions of New York. They are simply architectural manifestations of individual wealth that create a false sense of uniqueness and identity dictated by architect's signature style and not indicative of identity of residents and tenants or local culture (Klingmann 2007).
(Page 42)

Figure 1.40: 8 Spruce Street by Frank Gehry Architects, 2010. New York, USA.

Figure 1.41: 100 11th Avenue by Ateliers Jean Nouvel, 2010. New York, USA.

Figure 1.42: Proposed Via at West 57th Street by Bjarke Ingles Group, 2015. New York, USA.

Figure 1.43: Proposed 520 West 28th Street interior and exterior by Zaha Hadid, 2016. New York, USA. 
On the other hand, residential developments in China are communicating status and wealth in a different way. Themed residential communities have emerged in rural China in the form of complete copies of European cities. Paris and Venice can be found in Hangzhou, the Austrian village of Hallstatt in Guangdong, and London just out of Shanghai (Figures 1.44-1.46). Contrary to the entertainment appeal of replicas found in in Las Vegas however, European towns in China are meant to communicate the image of success, power, and achievement associated with the western world. For the developing world, these themed communities are commodities of conspicuous consumption that attempt to celebrate and display their social achievements and ability to live a western lifestyle (Bosker 2013). They are completely manufactured developments in satellite suburbs, marketed as luxury gated communities free from the pollutions of the city. They are only affordable to the upper-middle class, and the conspicuous consumption of the images of Europe become their symbols of success. It attempts to address China's housing crisis, but instead appeals to the superficial image of success and luxury. Yet, those who can afford to own a unit in these communities often choose not to live in the community, turning these 'European cities' into 'ghost towns' (Lonsway 2009). The developments are in itself a simulacra which takes on additional meaning beyond luxury housing for China's growing middle class, rather "is it a monument to China, which has become so rich and mighty it can figuratively 'own' its own City of Lights, or Manhattan, or Venice" (Bosker 2013).

Thus, regardless of typologies, contemporary architecture has been reduced to images that allude to wealth and power at an international scale. The Bilbao Effect has set the precedent for iconic buildings and urban renewal, upstaging and disregarding existing contextual relationships and social conditions. The obsession with brand name architects and ostentatious forms impose these styles globally, defeating the purpose of uniqueness and specificity. Similar building forms can be found anywhere in the world, acting as items of conspicuous consumption in the society of the spectacle. It has reduced architecture to a commodified global product. 


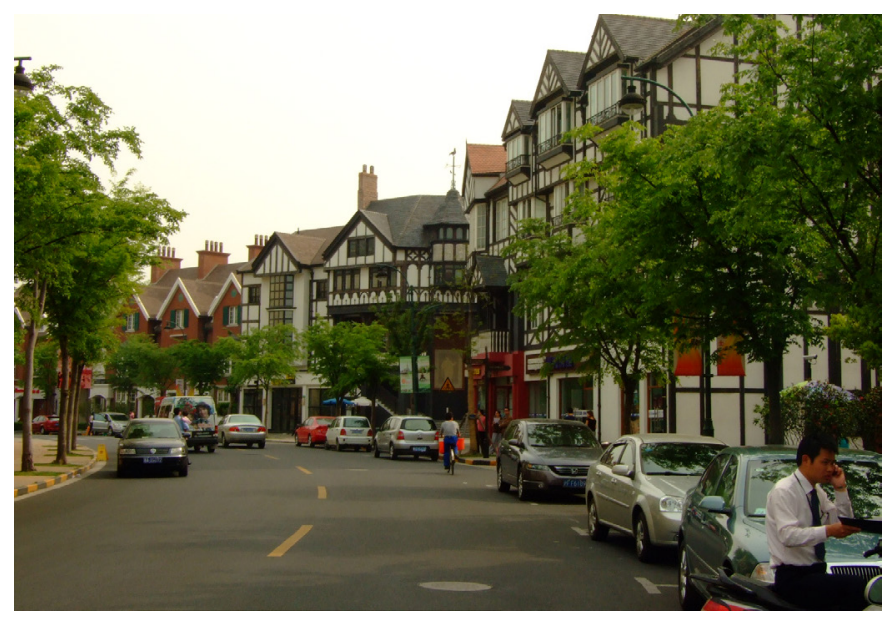

Figure 1.44

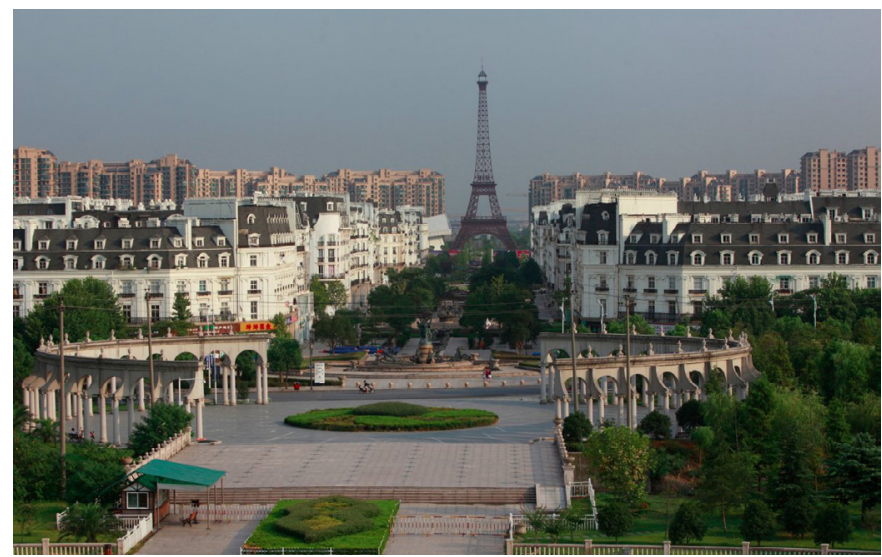

Figure 1.45

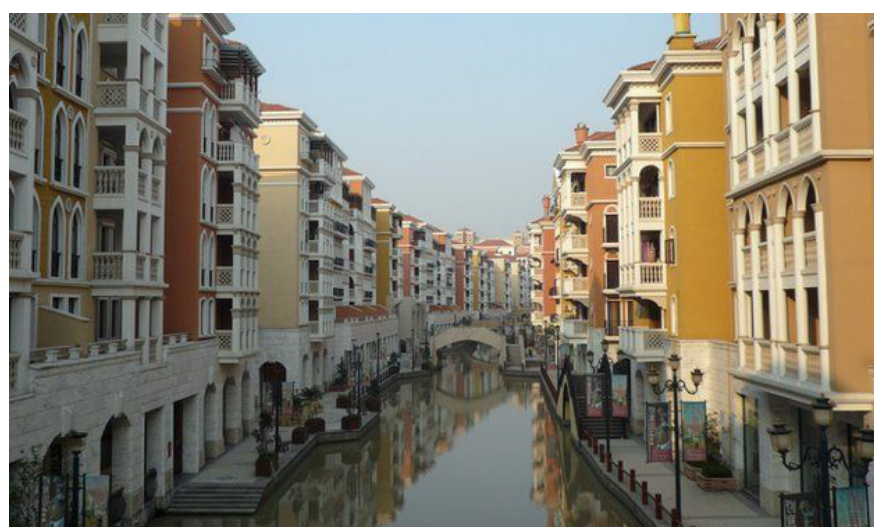

Figure 1.46

Figure 1.44: China's "London" Thamestown (Songjiang District) in Shangai, China. 2006.

Figure 1.45: China’s "Paris" Tianducheng in Hangzhou, China. 2007.

Figure 1.46: China’s "Venice” in Dalian, China. 2014. 


\section{5 | Architecture of Excess}

We currently live in an age of extreme architectural spectacles that forge superficial relationships between people and their built environments. These relationships fall short at visual excitement and capriciousness, are dominated and driven by the economy, and has been diluted in the process of globalization. On one end, iconic landmarks express and impose corporate power into the urban landscape. These buildings only aim for mass publicity and media attention, simply becoming visual marketing tools that focus on its surface relations. Instant recognisability helps the city, company, or individual project status, but at the same time, does not adequately connect the building with its locality, culture, and people. On the other end, entertainment architecture submits purely to popular culture and demand, creating themed fantasy environments that promote mindless escape. The construction of images and illusions continue to blur the distinctions between reality and fantasy, confusing our understanding of authentic versus constructed histories. Both of these conditions have transform our buildings and cities into what Klingmann calls 'brandscapes': corporately planned, themed and branded buildings or districts that allude to conspicuous consumption and power display (Klingmann 2007).

The superficial allusions to wealth and power creates mediated relationships in the society of the spectacle, and as Thorstein Veblen notes, this behaviour is unnecessary and unproductive in society. When the economy is favoured over society and culture, its architecture only aims to encourage consumption, induce brand loyalty and attract repeat customers, lacking depth and meaning beyond consumption. Architecture in this context serves to encourage the behaviour of conspicuous consumption. On the other hand, cities attempt to communicate wealth and success at international scales, and architecture in this context has been appropriated as items of conspicuous consumption. The competition of skyscrapers, iconic buildings, and star architects attempt to communicate success and wealth for an entire city or nation, disregarding the real needs and desires of its population. Following the success of Bilbao, the trend of iconic buildings has spread to any and all typologies to attract attention and publicity. Thus, the increasing proliferation of iconic buildings in the 21st Century will eventually commodify and homogenize our built environments into a landscape of instantly gratifying spectacles. 
Conspicuous consumption thrives on the excess, equating value with iconic status and uniqueness that satisfy superficial egos. The excessiveness of form, scale and themes in contemporary architecture challenge our understanding of urban hierarchy and disconnects architecture from its cultural role. If architecture is the ultimate artefact of culture, it should be able to communicate and relate to its use, context, and users. The superficiality of some contemporary buildings deprives us of these understandings as it constantly tries to become the center of attention. As such, it is essential that we re-evaluate the way we design to accommodate today's realities and consumer desires without resorting to clichés and architectural spectacles.
Figure 1.47: Louis Vuitton Singapore Marina Bay by FTL Design Engineering Studio. 2012. Singapore.

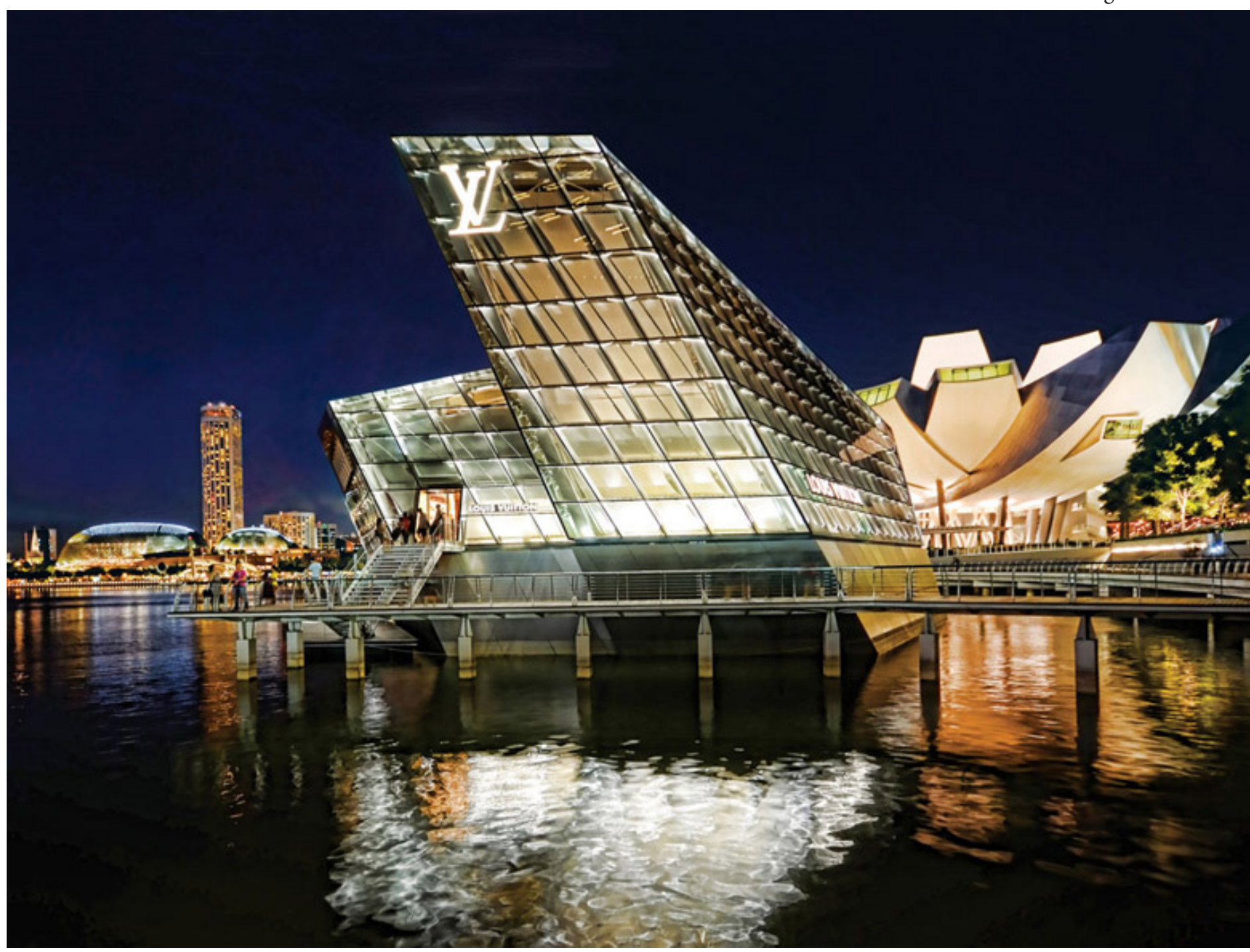




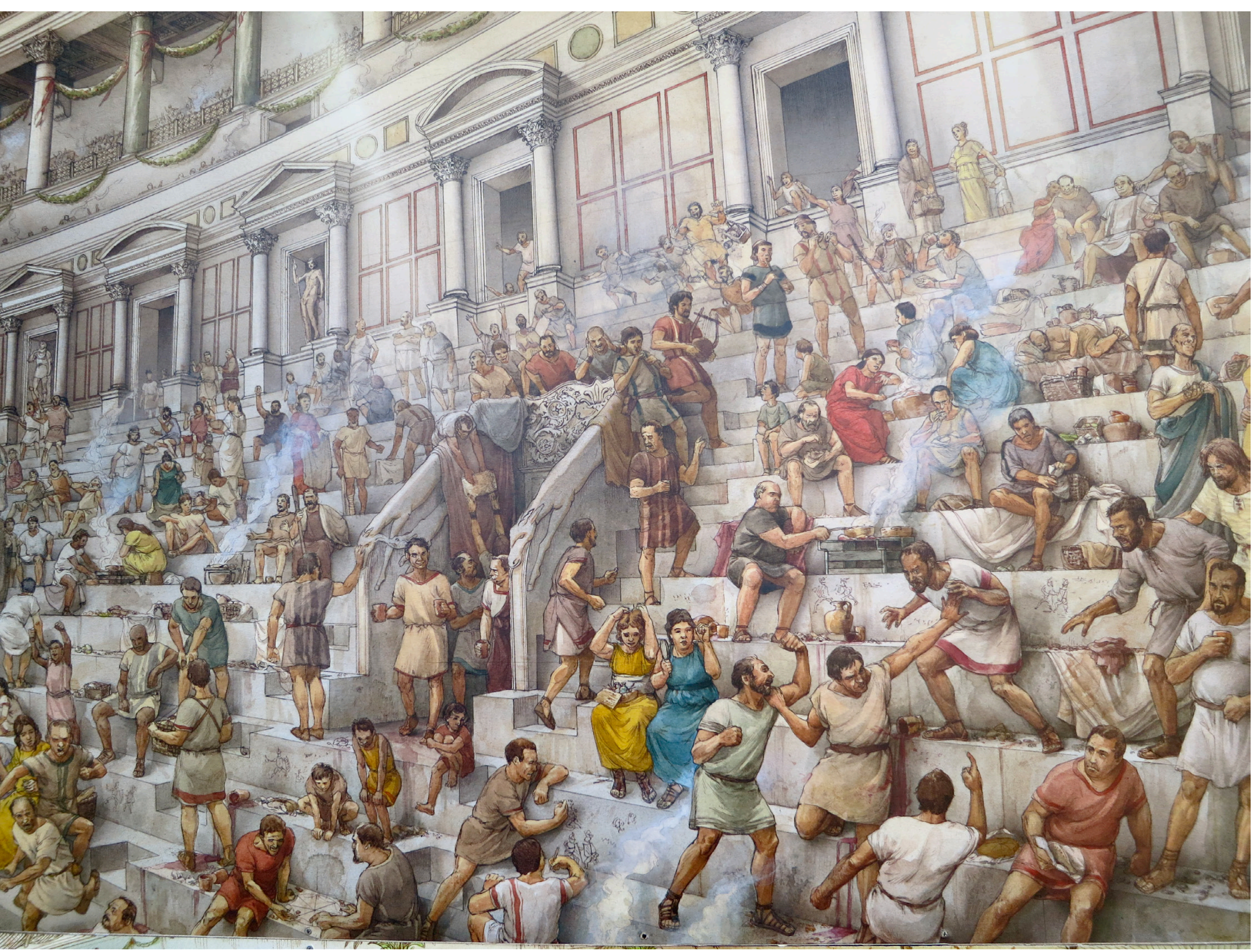

Figure 2.1 


\subsection{Rise of Entertainment Architecture}

\subsection{1 | Entertainment, Leisure, and Culture}

Our environments and architecture mirror the desires of our culture, yet also has the capacity to shape it. The culture of excess and consumption has also propelled the success and proliferation of entertainment architecture. Often neglected of architectural value because of its temporary and superficial nature, entertainment architecture can in fact provoke and engage enjoyable architectural experiences beyond the superficial. The focus on imagery and spectacle of contemporary architecture takes its roots from entertainment architecture, and thus, an analysis in entertainment architecture is essential.

Entertainment architecture can be traced as far back as the public spectacles and gladiatorial combats in the Coliseum. The monumentality of the arena was necessary to accommodate the growing population of Rome, providing a place for the public to enjoy entertaining spectacles. This necessity for a performance venue not only symbolized Roman achievement and power, but recognizes the power of entertainment to maintain social order and stability (Herwig 2006). The formula was simple: keep the population well fed and entertained and they will have no reason to rebel. Entertainment in this case worked to control public unrest, combining power and leisure together for public benefit (Lonsway 2009).

In his book Leisure, The Basis of Culture, German philosopher Josef Pieper describes leisure as an essential element to culture. He states that leisure is a non-work environment, a contemplative space that is the "foundation of Western culture" (Pieper 1952). Origins of this trace back to Greek society and the ideals of Aristotle. Leisure in Greek is skole and in Latin is scola, both root words for school. Thus, the place where we are educated stems from leisure (Murphy 1974). Leisure was the cultural ideal in Greek society where one was free from the need to labour so they can engage in contemplation, an enjoyment of self in search of knowledge. It was historically reserved for the elite, where a select few in society were free to pursue cultural discourses on math, art, music, education, and of course, architecture. Thus, leisure made way for contemplation, and subsequently higher intellect and education.

We often consider leisure as a non-work activity, something apart from work, which implies that leisure can be anything from taking a nap to non-stop entertainment. It can be seen as a supplement to work, being an activity that

Figure 2.1 (Previous Page): Spectators gather at the Roman Coliseum for a day of entertainment: eating, cooking, drinking, fighting, watching the spectacle as well as being the spectacle. we need to engage in, like sleep, to re-charge and re-energize us for more work. Leisure is a mental and spiritual attitude when a man is at one with himself, a receptive state in which the soul has the power to "answer the realities of the world", which differentiates leisure from simply the act of not working 
(i.e. idleness). This receptiveness state is imperative to phenomenological experience our environments (Brightbill 1961). There is often a distinction of work and leisure, yet the two work hand in hand: without work we cannot enjoy leisure, and without leisure we cannot support work. Aristotle notes that "we are unleisurely in order to have leisure", that is, we work in order to not have to work (Murphy 1974). In the pre-industrial ages, being free from the need to perform physical labour meant that one was of an elite class and free to engage instead in cultural and intellectual pursuits. Being able to engage in leisure symbolized wealth and power of the minority elite class of the time. As leisure-work relationships changed over time, however, the intellectual aspect of leisure has been overshadowed by mindless consumerist leisure that satisfies the trend of conspicuous leisure instead.

\subsection{2 | Conspicuous Leisure}

Another concept that Veblen studies in tandem to conspicuous consumption is that of 'conspicuous leisure', where the conspicuous act of engaging in leisure demonstrates a freedom from the need to work to earn a living (Veblen 2005). This is then associated with a level of disposable income used beyond acquiring material goods. Veblen notes: "conspicuous abstention from labour becomes the conventional mark of pecuniary achievement". Being able to engage in leisure activities, then, is another measure of status and wealth, projecting the image of happiness and success.

This escape from work and public display of it has since led to the emergence of countless typologies for leisure and entertainment. The proliferation of movie theatres, concert halls, shopping malls, hotels, resorts, theme parks, and the entire city of Las Vegas, all target the conspicuous leisure class. Vacation packages are thus increasingly standardized and all-inclusive, requiring minimal effort on the leisure consumer. It transforms the act of leisure from an elitist high culture privilege to escapist leisure for popular culture. However, beyond simply a public display of wealth and status, sometimes these leisure spaces are enjoyed for the sake of enjoyment, as ridiculous entertaining spaces that authentically engage our emotions beyond the superficial. 


\section{2 | Entertainment as Experience}

\subsection{1 | Entertainment, Leisure, and Culture}

The sustained popularity of entertainment architecture provides us with a variety of places for escape and entertainment in the 21 st Century. The need for leisure is a global phenomenon that transcends cultural and geographical differences to appeal to people of all social classes. Examining the development and evolution of other typologies in the contemporary age, buildings continuously add entertainment as an experience to remain competitive and relevant in the marketplace. In an economy of increasing competition, adding entertainment content to non-entertaining facilities add distinction to the brand and sets the company apart (Lonsway 2009). Beyond its basic function, buildings are increasingly mixed use by injecting entertainment into its program, turning them into destinations and community spaces. Libraries, for example, are not simply places to store and lend collections of books, but are diversified to include event spaces, reading rooms, and community spaces, acting as community hubs in an increasingly digital age. Museums as cultural institutions are also reaching out to expand their revenue streams, turning into wedding and clubbing venues in the evening after the exhibits are closed.

Yet, entertainment architecture is often misunderstood and criticized as superficial artefacts of mindless mass consumption. However, their ability to continuously and successfully provide leisure and entertaining experiences for people indicates that it has meanings and functions in society that are worth investigating. Beyond mere spaces for entertainment and leisure, entertainment architecture both represents and spatializes the demands of society. These spaces, as destinations, are visited by millions of people a year, communicating cultural needs and intentions beyond a need for escape. These spaces are in fact cultural creations. Thus, by understanding how entertainment architecture spatializes these needs, we can understand the appeal and benefits that can inform contemporary architectural design.

Entertainment has value in society at an experiential and productive level. The balance between work and leisure ensures that we get an escape from reality when we need it, provoking enjoyable emotions that later allow us to be productive again, similar to the effects of taking a break or a vacation from the regular workday. Entertainment architecture attempts to address our experiential realm such that the distinctions between authentic and inauthentic becomes irrelevant. From an experiential perspective, experiences are always authentic, where any means that provokes the experience is, by default, staged (Klingmann 2007). Desired authentic effects rely on both tangible and intangible materials, and architecture becomes an agent in provoking these experiences. 
Although criticized as inauthentic, superficial and mindless escapes, entertainment architecture can in fact meaningfully address the needs and desires for leisure and entertainment, engaging users in more immersive and enjoyable experiences beyond the superficial. As places for entertainment, its architecture is thus conducive to its use, and can inform contemporary architectural design. Authentic emotions and joyful experiences can be activated in 'inauthentic' environments, and these effects can in turn affect architectural design and experience.

Three typologies are explored in the thesis: theme parks, casinos, and retail spaces. Often considered the most inauthentic and superficial spaces, these typologies have in fact set the precedent for entertainment and themed spaces that proliferate our contemporary age. Although entertainment architecture is one of fantasy and consumption, there are some lessons to be learned from an experiential perspective that successfully satisfies the desires of general population. An analysis of these typologies of consumption looks beyond the superficial conspicuousness to reveal some authenticity and experiential values beneath the inauthentic façades. As an amalgamation of various entertainment experiences, the theme park environment spatializes the desire for fantasy and fun. It is choreographed in a way that guides and directs experiences but also gives visitors the choice to wander, explore, and learn. Las Vegas casinos have become increasingly grand and extravagant with their theming and messaging in the past few decades such that it becomes the most ostentatious form of leisure. Its trends indicate a focus on themes that cater to a visitor's craving for experiential consumption. The themes in fact work to create memorable experiences that are both fun and familiar at the same time. Finally, retail spaces are so ingrained in our everyday environments and change so rapidly that it becomes the best indicator of changing needs and desires of the general public. It has easily infiltrated and adjusted to the schedules of our everyday lives and its architecture is indicative of a scale and rhythm that we are familiar with. Architectural strategies are derived from these typologies that are then used as a basis for design. 


\subsection{The Appeal of the Theme Park}

\subsubsection{Emergence of the Theme Park}

1955 is usually credited as the founding year for theme parks based on Disney's conception of this recreational model, which has been copied, emulated, and replicated worldwide ever since its opening (Clave 2007). However, its origins can be traced to European pleasure gardens, fun fairs, and world expositions. The theme park itself is a manifestation and amalgamation of different periods and cultures of entertainment.

"across time and space, people have created a place within which they gathered in large numbers to participate in ritual, entertainment, amusements and spectacles, while consuming and exchanging foods, goods, and services. The theme park is the contemporary manifestation of fairs, carnivals, and amusement parks - a class of phenomenon ... [called] the amusementscape" - Botterill, 1997 quoted in Clave 2007.

\section{Pleasure Gardens}

The manufactured landscapes of theme parks can be found in the design and domestication of gardens in 16th Century Europe. The taming of landscapes created places for leisure, sports, concerts, picnics and performances (Figures 2.2 and 2.3, page 55). Called 'pleasure gardens', these parks were created for the leisure class specifically for the enjoyment of leisure time (Clave 2007). The parks were later opened to the public by the 18th Century, where they were able to enjoy the same attractions for a fee. Flora and fauna were imported from other regions of the world, simulating foreign landscapes. Zoological gardens were also introduced for the study and display of wild animals. Modern theme parks like SeaWorld use this domestication of nature

(Page 55)

Figure 2.2: English Pleasure Gardens. Vauxhall Gardens Aerial View 1751.

Figure 2.3: Vauxhall Gardens. 1751.

Figure 2.4: Central Park. New York. Fredrick Law Olmstead. 1857. as theme for entertainment value, but also a means to connect people with nature. Nature was seen as a restorative, curative, and educational force for the escape from the busyness of industrial towns. Yet, at the same time, areas in urban centers were also being cleared to create parks for the emerging middle class. New York's Central Park, for example, is a completely manufactured landscape that provided New Yorkers a "harmonizing influence" in the centre of the city (Figure 2.4, page 55). 


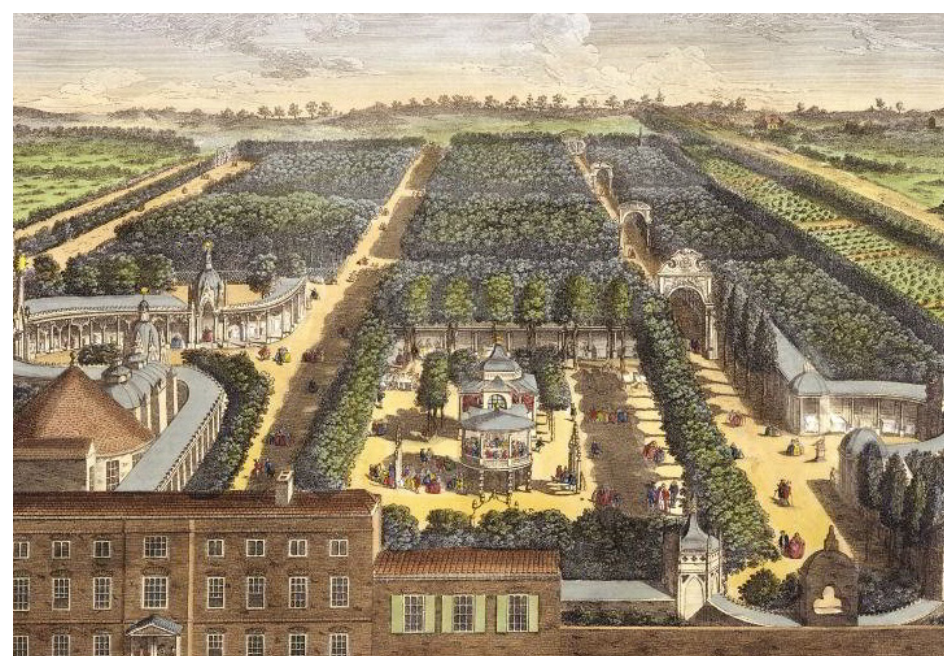

Figure 2.2

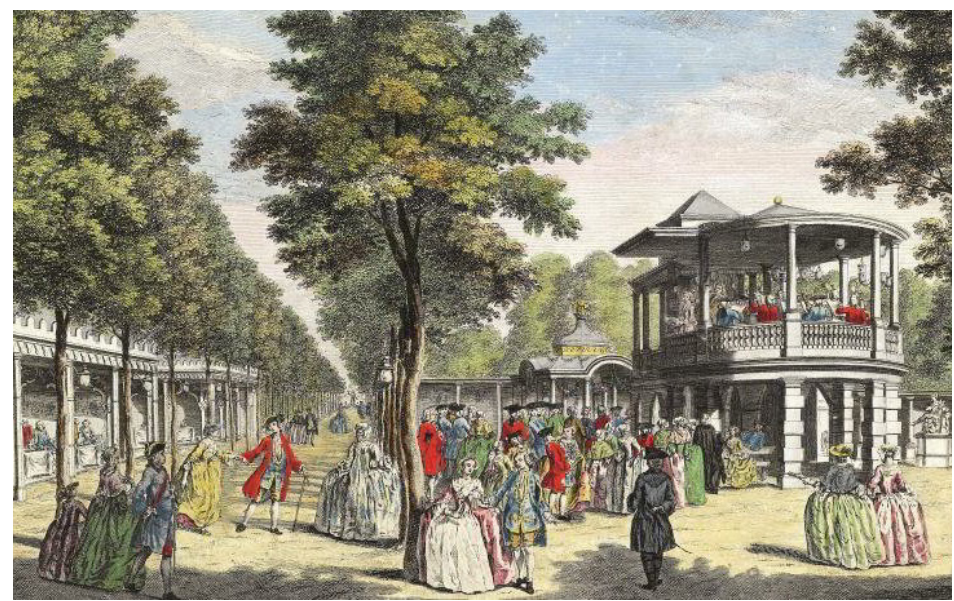

Figure 2.3

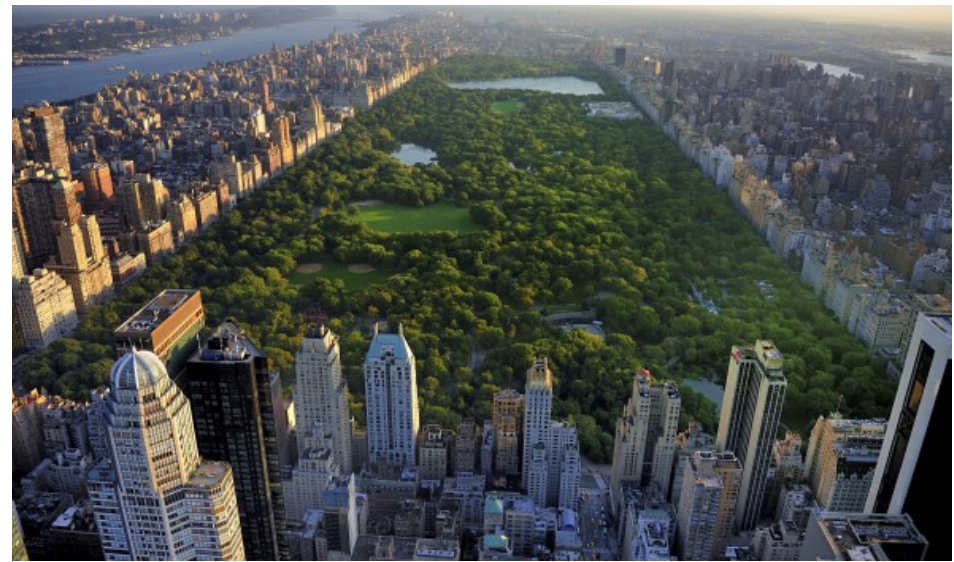

Figure 2.4 


\section{Expositions}

Industrialization had also merged the carnival, fair, and marketplace together into industrial expositions and later universal expositions. These expos were a means to display and showcase progress and modernization, but had also shifted the leisure goer from a spectator to a consumer. Tourism geographer Salvador Clave, notes that the 1893 Chicago Universal Exposition in particular, was a laboratory of experimentation, in areas like hygiene and sanitation, mechanical transport systems, international advertising campaigns, etc (Figures 2.5-2.7). These technologies helped shape the ideas for Walt Disney's "place for people to find happiness and knowledge". The expos were not simply places of escape and consumption, but a meeting place for art, inspiration, education, good living, and social participation. Later, the New York exposition of 1939 centered on the theme of the future, using total design of architecture, atmosphere and space to make its pavilions "look" modern. The pavilions weren't meant to shelter and house items of the theme but to communicate the theme itself (S. A. Lukas 2008).

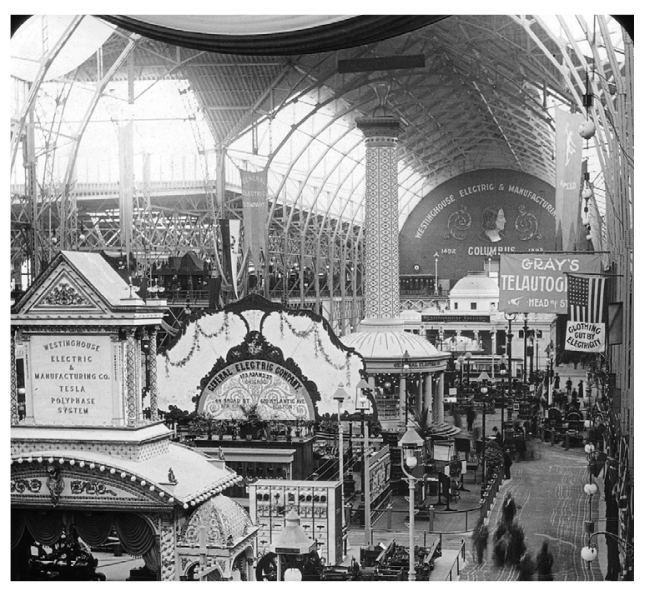

Figure 2.5

Figure 2.5: 1893 Chicago World's Fair. Electrical Building.

Figure 2.6: 1893 Chicago World's Fair. Electrics Showcase.

Figure 2.7: 1893 Chicago World's Fair. Moving Walkways.

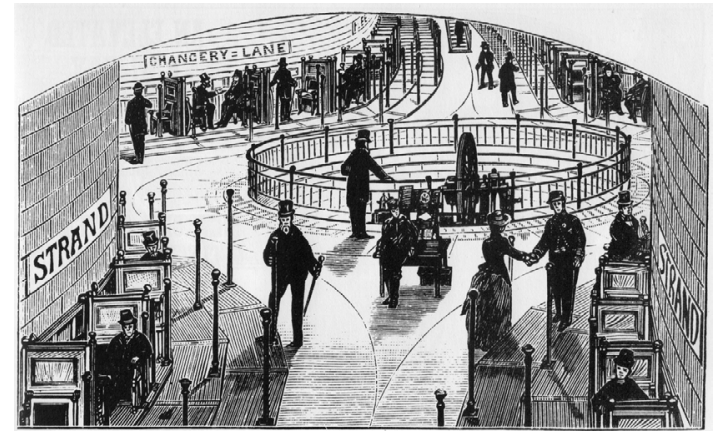

Figure 2.7 


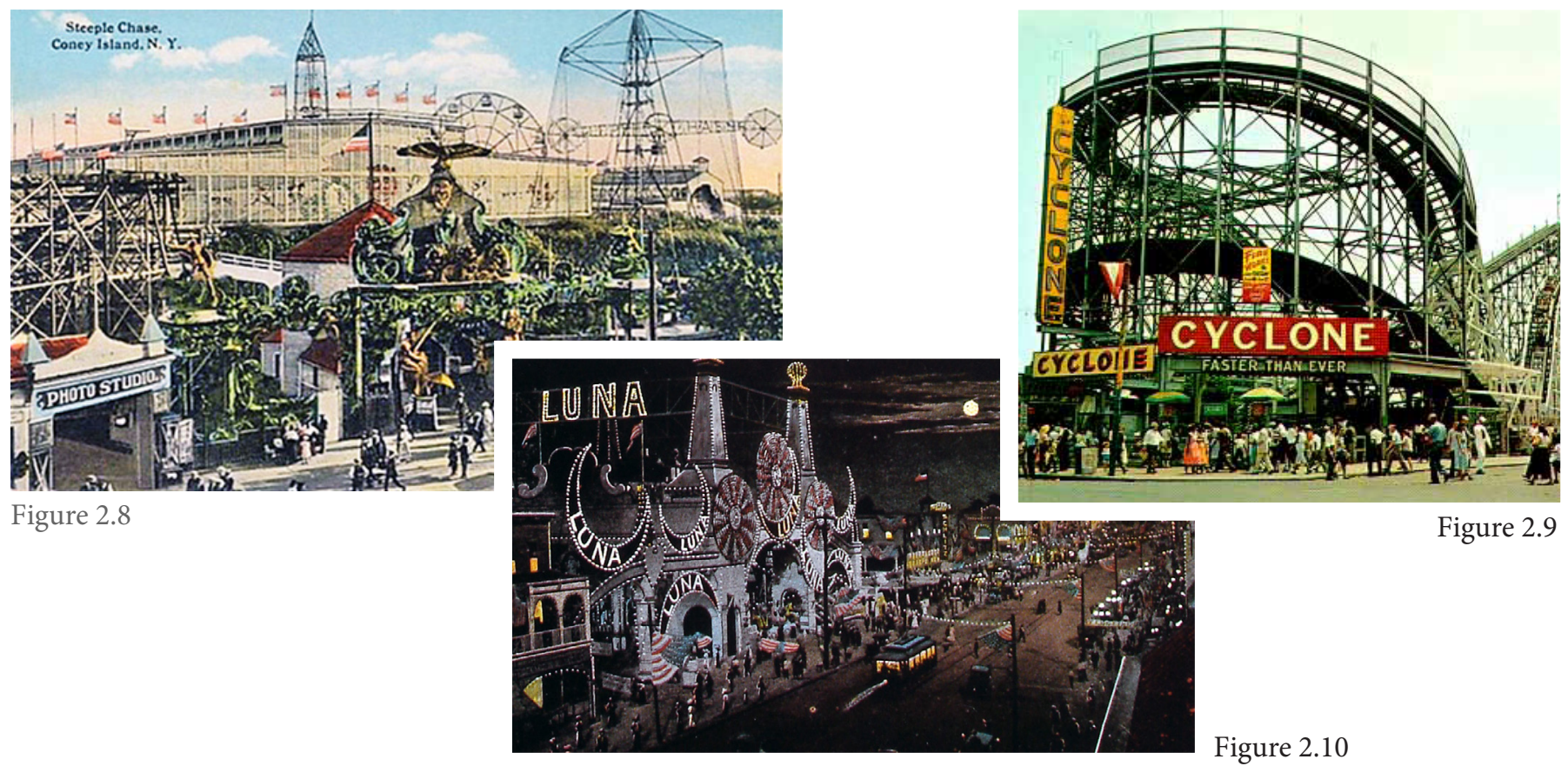

Amusement Parks

Fairs were the predecessors to amusement parks. Entertainment in fairs was provided by communities gathering together to perform shows and spectacles (freak shows, magicians, acrobats, musicians and dancers), constituting a shared experience of performers. Amusement parks, however, shifted the production of entertainment from individuals to an enterprise, changing the nature of entertainment "produced by communities" to "produced for individuals" (Clave 2007). Centralizing production meant that bigger and more expensive forms of entertainment could be offered. The availability of electricity, mechanical breakthroughs and increasing free time of the working class spurred the growth of the amusement park. Amusement parks became popular in the early 1900s as recreational areas for escaping the mundane city and work life. Offering a quick escape from the city, enterprises could attract the masses with specially designed mechanical rides and bright lights. Coney Island in New York was the epitome of amusement parks of the era. A series of different parks and rides, Coney Island turned the leisure experience into something beyond the day-to-day. Spectacles and shows caught the eye and mechanical rides, like Ferris wheels and roller coasters, offered new thrills and sensations (Figures 2.8-2.10). It transported the everyday worker into extraordinary and fantasy places with exotic and foreign experiences, relieving the tensions of everyday life. Amusement parks declined in popularity however after the Second World War, where changing demographics and affluence changed people's lifestyle and entertainment choices. The parks also failed to keep up with new trends, falling into disrepair and sameness.

Figure 2.8: Coney Island. Steeple Chase Amusement Park. 1900s.

Figure 2.9: Coney Island. Luna Park.

Figure 2.10: Coney Island Cyclone Rollercoaster. 1927. 
As the amalgamation of the pleasure gardens, expositions, and amusement parks, the theme park typology successfully merges the cultural forces and appeal of each leisure experience. The desire for domesticated and tamed landscapes for leisure is now the manufactured landscapes of theme "parks". World expositions propelled the consumption nature of the theme park, but its inspirational and educational nature also gave it significance beyond consumption. Amusement parks offered rides, shows, and thrills to transport the leisure consumer into fantasy spaces. By integrating all of these leisure experiences together, Walt Disney created a safe leisure fun fair for the masses. Its success sparked numerous other theme parks around the world, and thus Disneyland and Disneyworld are important precedents that embody the intentions and purpose of theme parks, but also acts as the benchmark for theme park innovation. Thus, an analysis of Disney's intentions can reveal an authentic connection to use and social purpose.

\subsection{2 | Disney's Utopian Visions}

Since its opening in 1955, Disneyland has been a recognized symbol of the American consumer culture. The parks and their purpose have profoundly changed since its inception in the 1950s, and it has come to epitomize the idea of capitalism and the American Dream, often criticized for its corporate domination and creation of fantasies. However, studying the initial conception and principles for Disneyland reveals Walt Disney's utopian visions of creating a better society is very much informed by its social and cultural context.

Conceived during the post-war era, Disneyland was a reaction to the paranoia and uncertainties in America at the time, alongside the rise of the middle class and the automobile. Walt Disney envisioned Disneyland to be a safe, progressive leisure fun fair as well as a civic centre of cultural exchange (Marling 1997) (Figures 2.11 and 2.12). It was an invitation for escaping the perceived dangerous urban centres, but also a journey of discovery and experience that was made possible by working with the culture of industry (or later, capitalism). Walt Disney understood the power of working with industry and corporations to inspire and provide a better society. It was intended that industry would inspire the leisure class, not simply a means to entertain and escape reality (Dunlop 1996). Fantasy and the imaginary were tools for inspiration and optimism rather than tools to mask reality. Walt Disney wanted to create a safe haven for the enjoyment of leisure and culture that draws inspiration from his own motion pictures as well as the idea of a mini World's Fair. Corporations would 'exhibit' their products as a means of showcasing new materials and technologies to the general public.

The concept for EPCOT (Experimental Prototype Community of Tomorrow) in Disneyworld was envisioned as a fully functional residential 


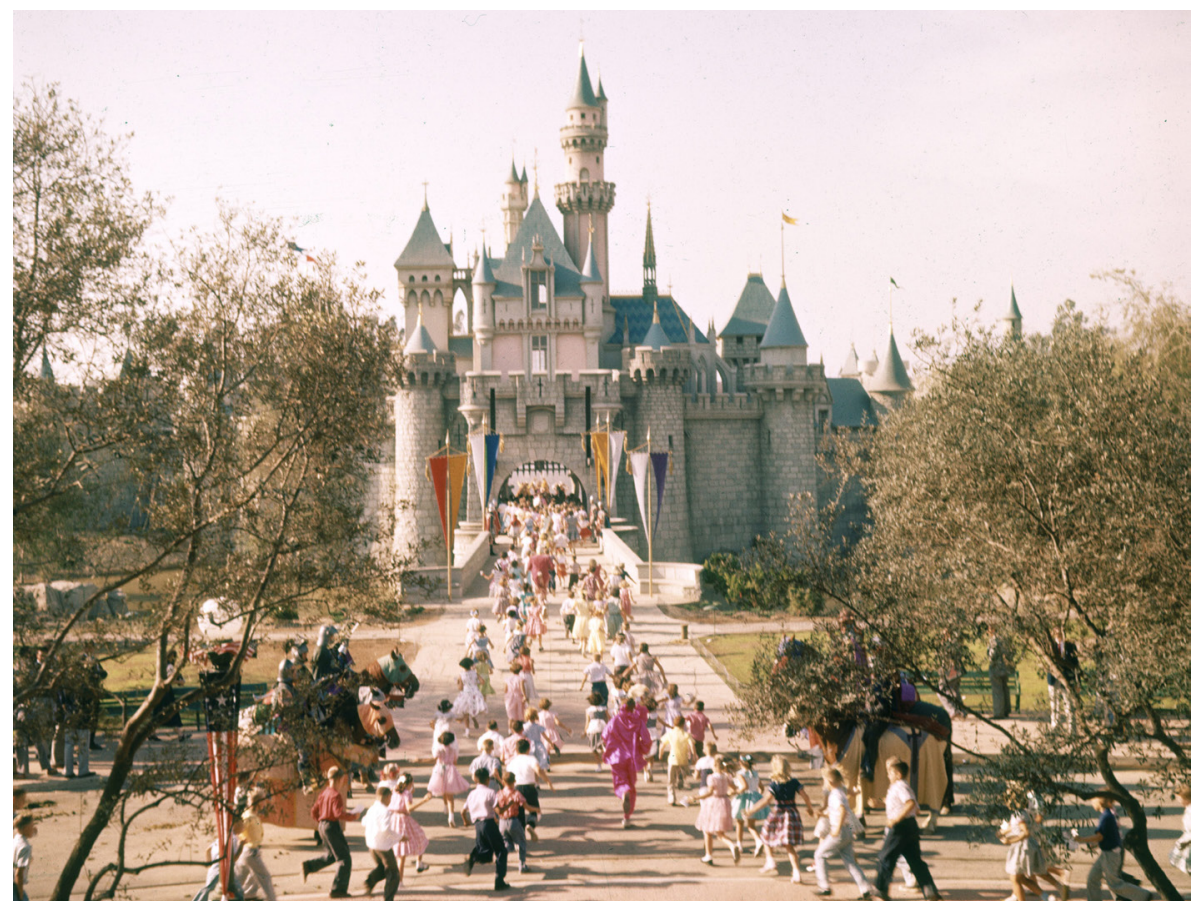

Figure 2.11

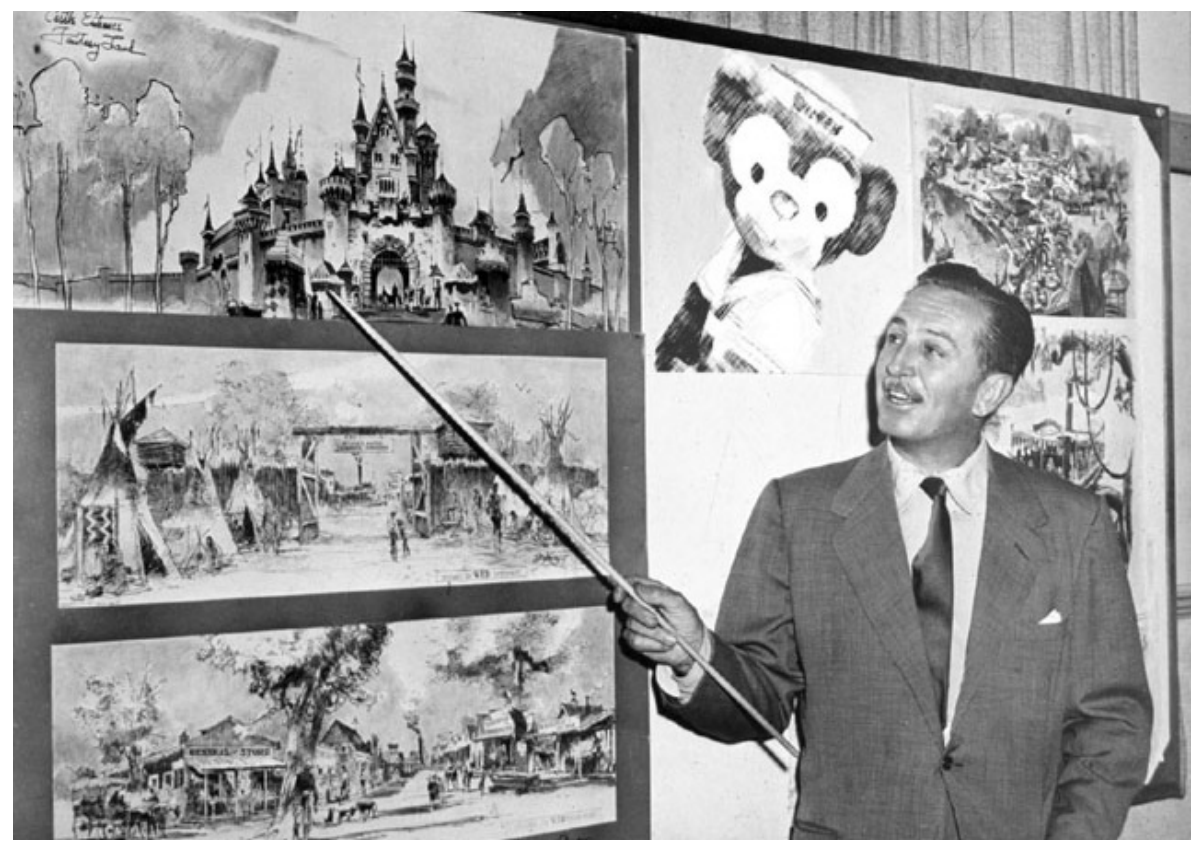

Figure 2.12

"Disneyland is your land. Here age relives fond memories of the past... and here youth may savor the challenge and promise of the future. Disneyland is dedicated to the ideals, the dreams, and the hard facts that have created America... with the hope that it will be a source of joy and inspiration to all the world."

- Walt Disney, 1955

Figure 2.11: Disneyland. 1955.

Figure 2.12: Walt Disney's vision for Disneyland. 1940s. 
community that married industry and new technologies, continuously advancing civilization through corporate sponsorship and development. Walt Disney wanted to address and improve social and environmental concerns with EPCOT, including that of suburban sprawl and ecologically conscious living, issues which are still pertinent to our times today (Figures 2.13 and 2.14). Following Walt Disney's death in 1966, however, this vision lost its ambitious and inspirational direction and has simply become another themed attraction in Disneyworld, resorting to stereotypical and cliché representations of a World's Showcase (Dunlop 1996). The drivers for the construction of Disneyland can said to be utopian and pragmatic during its conception, responding to the culture and insecurities of its time. It is an 'architecture of reassurance': the reassurance of optimism, security, and leisure, concepts that were fragmented and inadequate in the post-war era (Marling 1997).

Figure 2.13

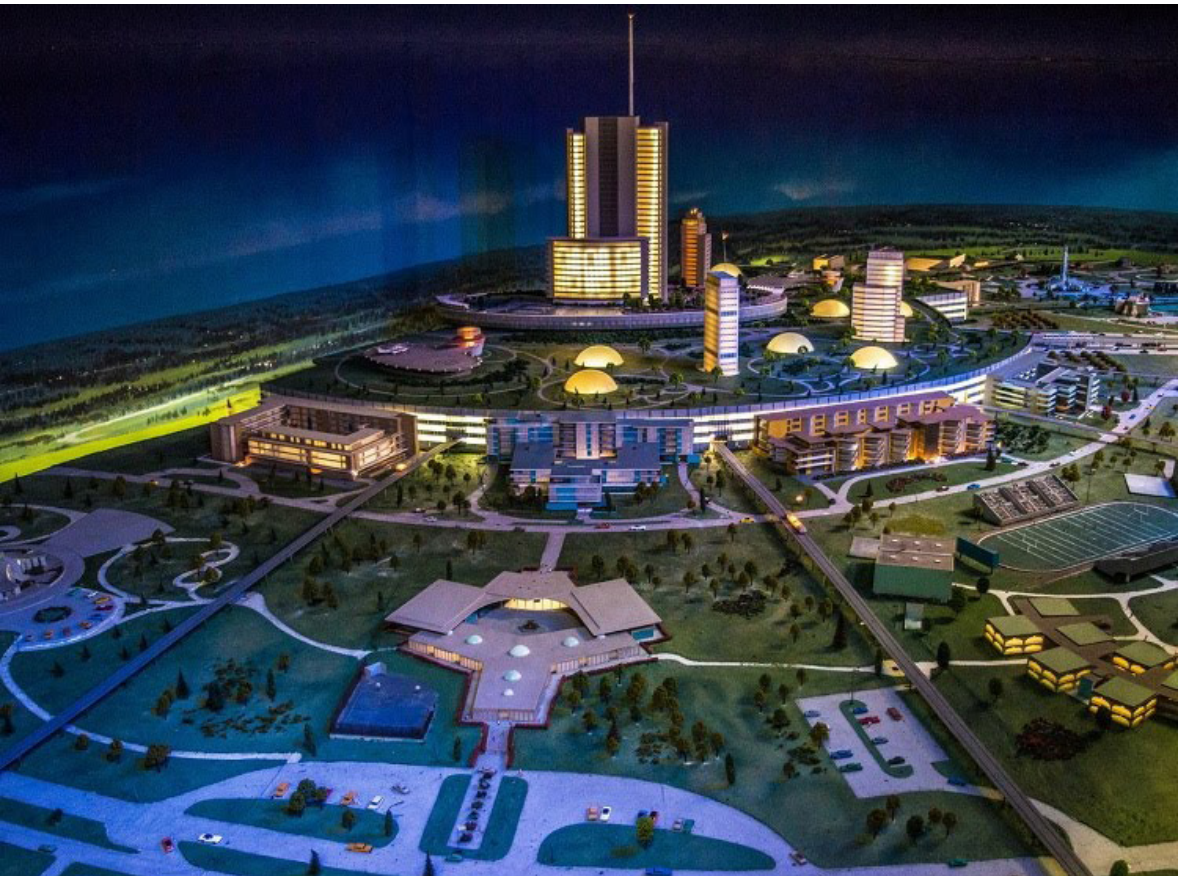

Figure 2.14

Figure 2.13: Model for original plans for EPCOT. 1966.

Figure 2.14: Transportation Systems in Original EPCOT Vision. 1966.

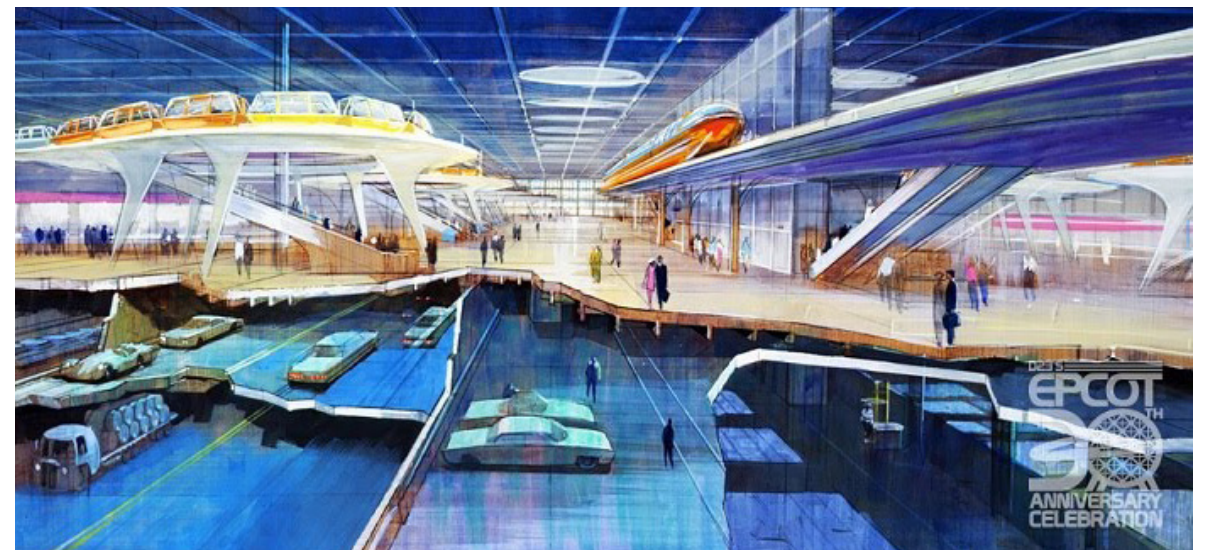




\subsection{3 | Architecture with a Plot}

Strategies to achieve Walt Disney's vision relied on an architecture of persuasion, employing spatial and special effects in its construction. Disney's theme park architecture is supplemental to its overarching social concerns and storylines. It is a place that sells the belief of fantasy and storytelling, and thus, its architectural relevance is in its attention to narrative and user experience. It is not concerned with modernist's elitist morals and discourse of the time. This recognition of the power of popular culture and storytelling sustains its appeal to mass populations, whereas modernist ideals only appealed to an elitist architectural community, eventually rejected by the general public.

Storytelling is one of our most basic and earliest forms of communication. It is our method of learning about the world. Beyond the themed facades of Disney architecture contains an underlying story waiting to be read. The park spatializes a sense of fantasy, animation, and wonderment. Space becomes a textual device employed to tell a theme's story, using the potentials of architecture to tell that story (Dunlop 1996). The Disney experience evokes our memory of childhood stories and fantasies; authentic experiences that satisfy a playful and nostalgic yearning (Marling 1997). Disney uses architecture quite explicitly not simply to imitate buildings in their stories, but scripts and choreographs the right ambiance in space to support it. The stylistically coherent architecture gives the visitor a scripted experience throughout the park, waiting in line, and during the rides. Urban historian Norman Klein describes Disney's scripted spaces as labyrinths of happy imprisonment. We enjoy getting lost in the story of shock and surprise, within safety and reassurance, with revelation and discovery at the end: we get cheerfully disoriented (N. Klein 2004). However, although the spaces are pre-determined and choreographed to tell a story, the visitor is still given the freedom to wander and navigate at their own pace. The stories behind Disney's themes and worlds often follow the recurring themes of optimism and good conquers evil. They are stories that should inspire and motivate, not simply escape from reality. 


\subsection{4 "Before there can be magic, there must be work"}

Another fundamental American belief that Walt Disney promoted through the construction of his parks was the idea of 'hard work' (Marling 1997). Hard work, perseverance, and maintenance was needed to succeed and achieve the American Dream. In the case of the theme parks, hard work keeps the Disney magic alive. Although often criticized for the active concealment of back of house services in tunnels or the masking of trash cans with themes, it can also be seen as an expression and communication of hard work. Anything that is not related to the theme or storyline in Disney parks is considered a visual intrusion (Lonsway 2009): an intruder in the story that must be concealed in order to preserve the integrity of the story. Thus, the scale and effort that is put into concealing visual intrusions expresses the idea that hard work is an essential element in any endeavour.

Disneyland in Anaheim, California was constructed in the suburbs among fields of orange groves in 1955. The park spurred such growth in the area that Disneyland is now surrounded by a city, or in other words, by 'reality'. Disney then built an extensive artificial berm around the park to 'hide' the reality that surrounds it (Lonsway 2009). In Disneyworld, though, Disney avoided this problem by purchasing enough land such that physical distance becomes the concealing factor. In some cases, 'hard work' is scripted into the theme itself. For example, in Adventureland, an expansion joint is 'disguised' as a thematic crack in the concrete pavement. In this way, the expansion joint becomes less visibly intrusive, and also anticipates future cracks in the concrete. This scripting of wear and tear into the overall theme is also present in the American small town-inspired Main Street, USA. Main Street, USA is the main avenue in Disneyland designed to resemble a nostalgic idealized version of Walt Disney's hometown. The curbs in Main Street, USA have painted marks of a grinding carriage wheel against the curb, becoming a thematic signifier and reduces the need for maintenance.

Beyond the active concealing of pragmatic devices and visual intruders, the recognition of hard work also becomes a theme and attraction in and of itself. Disney-MGM Studios Backlot Tour takes visitors on a guided tram ride through its soundstages and backlots of their film studios, choreographing the behind-the-scenes experience as one of their attractions. It exposes the real soundstages and workspaces of the designers of sets, costumes, and props to reveal the extensive work behind the magic. It reveals an authentic part of the

(Page 62)

Figure 2.15: Map of Disney's MGM Studios.

Figure 2.16: Diagram of Studio Backlot Tour in Disney's MGM Studios. theme park even though it is packaged and choreographed into an attraction ride. 

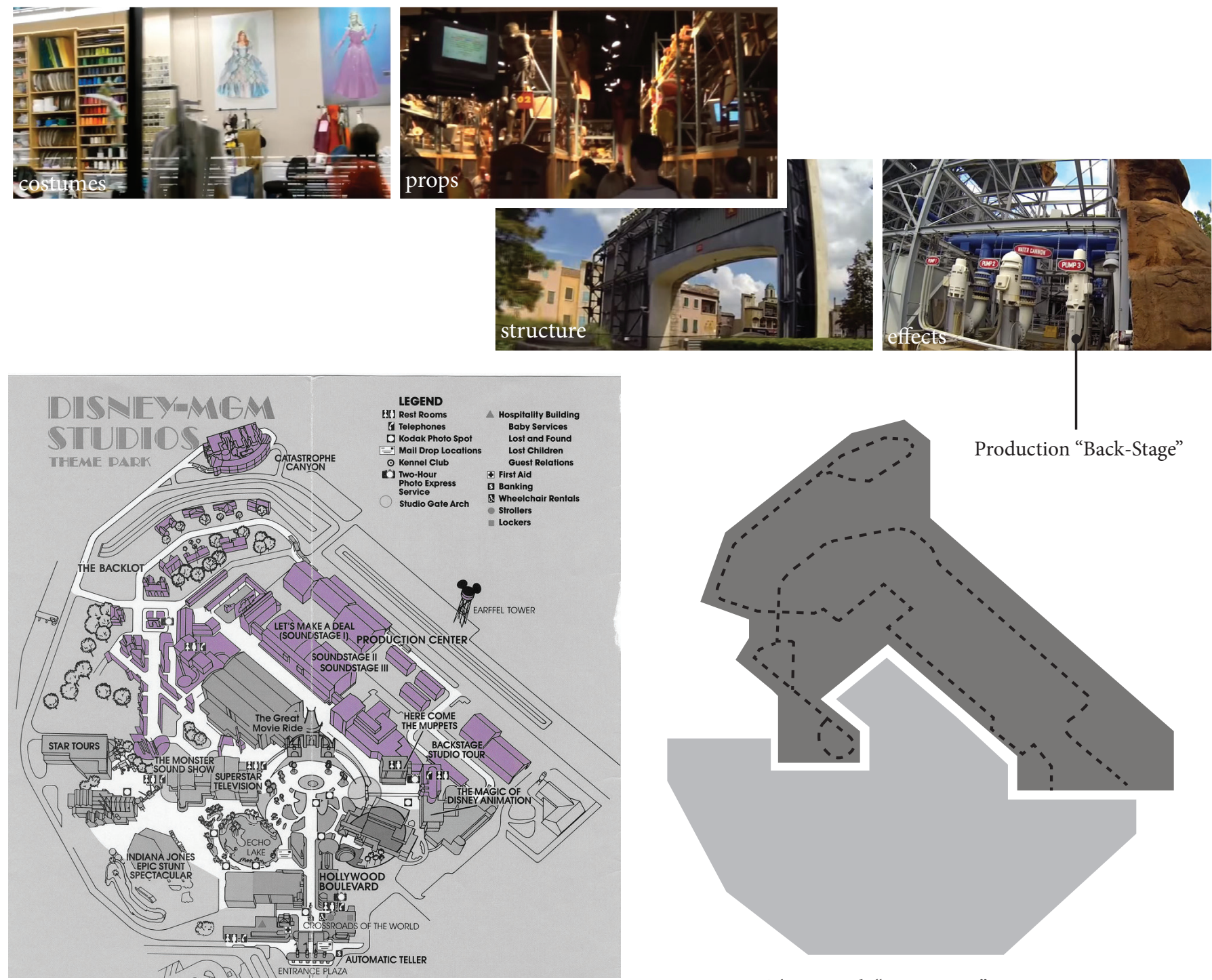

Figure 2.15

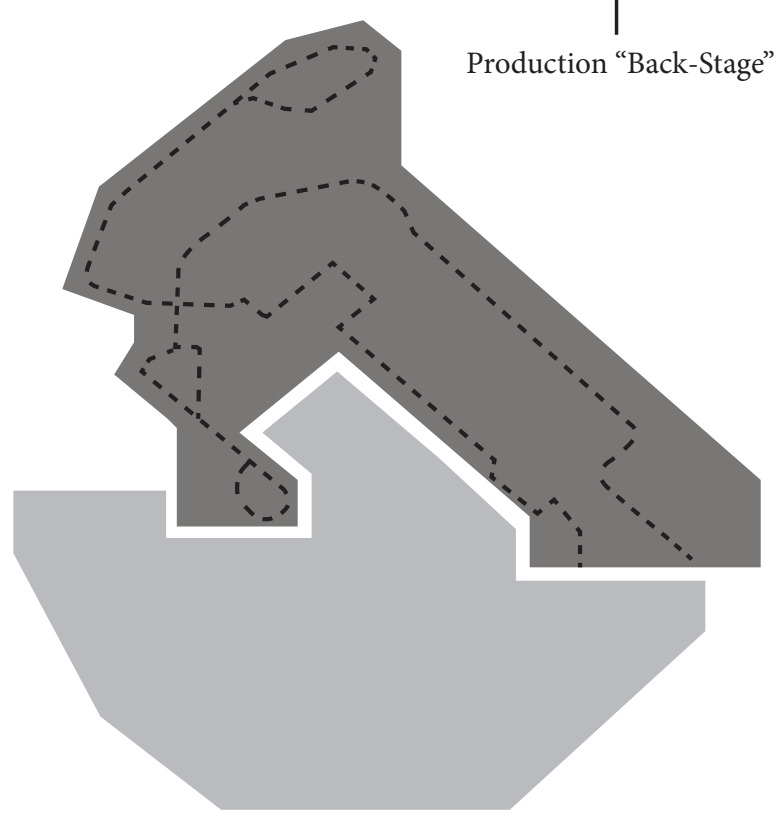

Theme Park "Front-Stage"
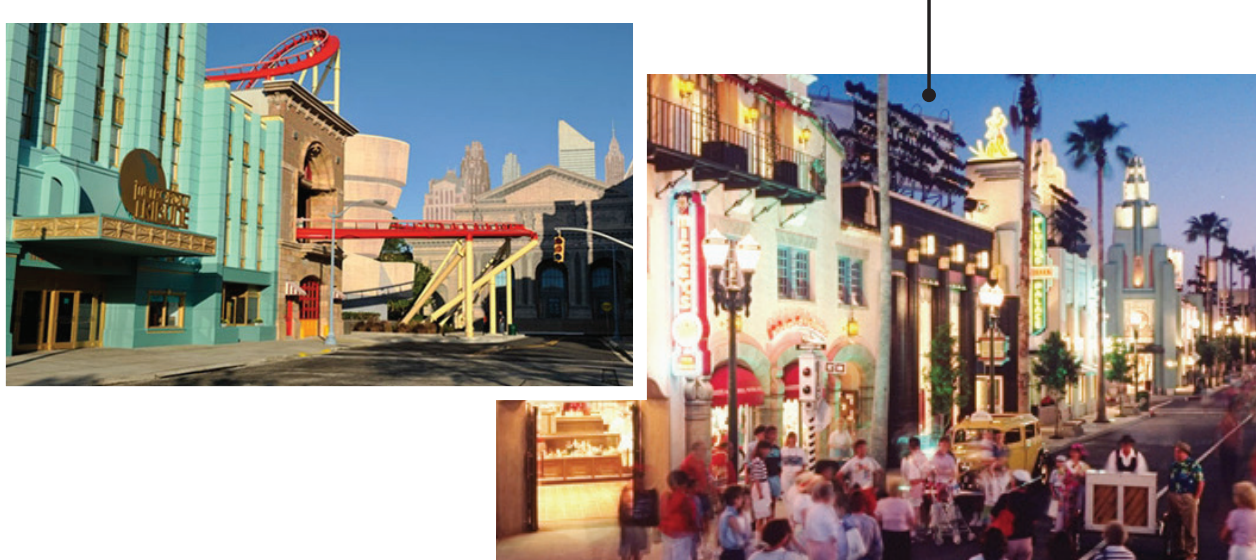

Figure 2.16 
Figure 2.17: BMW Central Building Aerial View. Leipzig, Germany. 2005. Zaha Hadid Architects.

Figure 2.18: Diagram of Space Relations and Production Flow.

Figure 2.19: BMW Central Building Exterior. Leipzig, Germany. 2005. Zaha Hadid Architects.

Figure 2.20: BMW Central Building Interior. Leipzig, Germany. 2005. Zaha Hadid Architects.

Figure 2.17

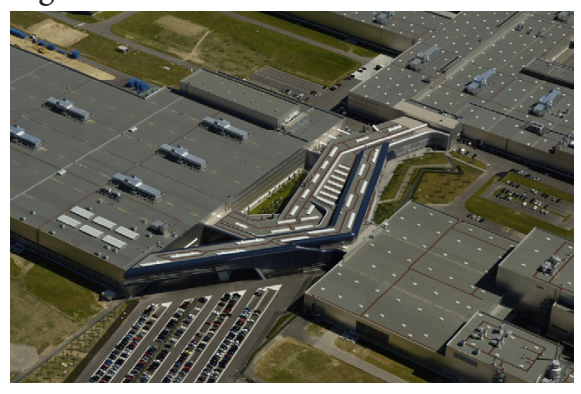

\subsection{5 | Merging Work and Leisure}

Beyond the theme park ride, however, this relationship between work and leisure can also be found subtly in coffee shops and restaurants, with exposed kitchens that connect diners and chefs, exposing production in a world of consumption. On the other hand, Zaha Hadid's BMW Central building in Leipzig, Germany, completed in 2005, integrates its factory buildings (body shop, paint shop, and assembly line) with office space, centralizing both production and work in the same environment (Figures 2.17-2.20). It redefines the relationship between the different sectors, allowing a better connection between design and product, while at the same time expresses the sleek brand identity of BMW. Centre Pompidou expresses instead the mechanical systems that are at work to maintain the buildings function, exposing its pipes and ducts as an architectural facade. However, this expression of internal ductwork hides the building's actual function as a gallery and explicitly stands out from its Parisian context. Ripley's aquarium on the other hand, exposes its systems internally, incorporating it at the end of the journey as an exhibit, revealing the many pumps, heaters, and generators needed to maintain the different aquariums (Figure 2.21, page 65). Renzo Piano's California Academy of Science uses sustainable features and natural systems to express its program of natural history museum, planetarium, and research and education centre, allowing the building form to conform to the exhibits, but can also seen as an exhibit in itself (Figures 2.22 and 2.23, page 65).
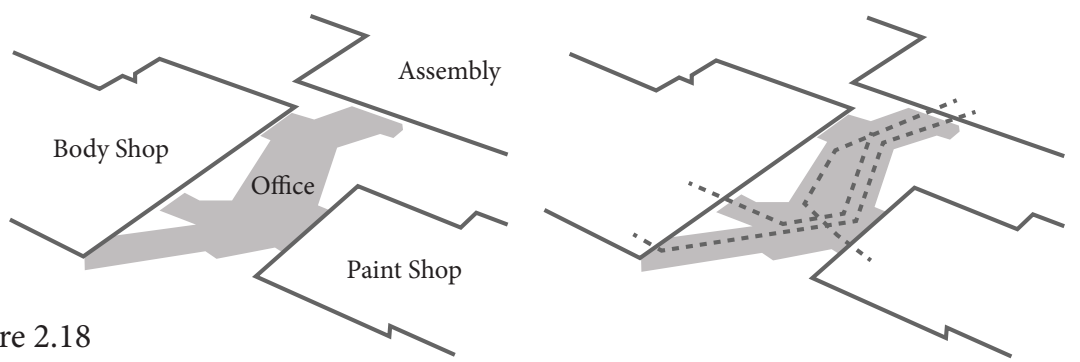

Figure 2.20

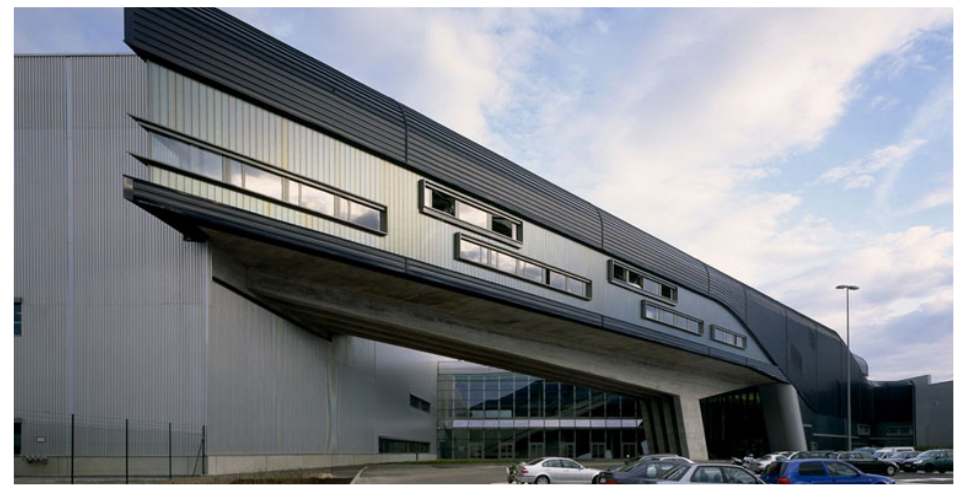

Figure 2.19

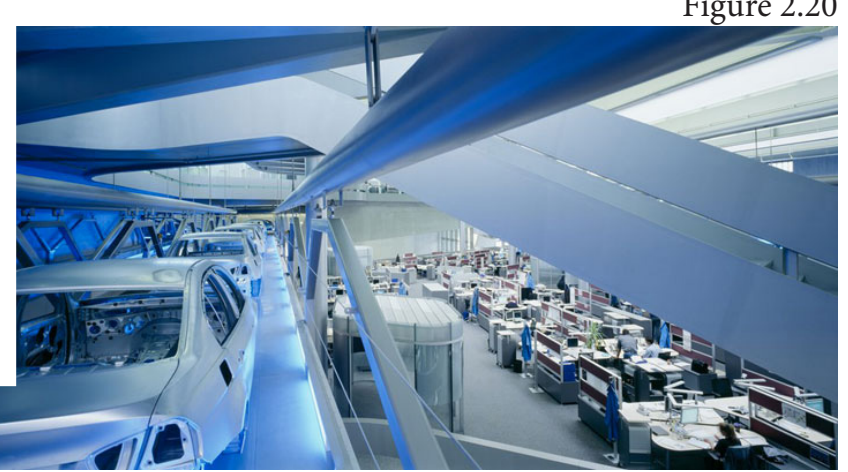



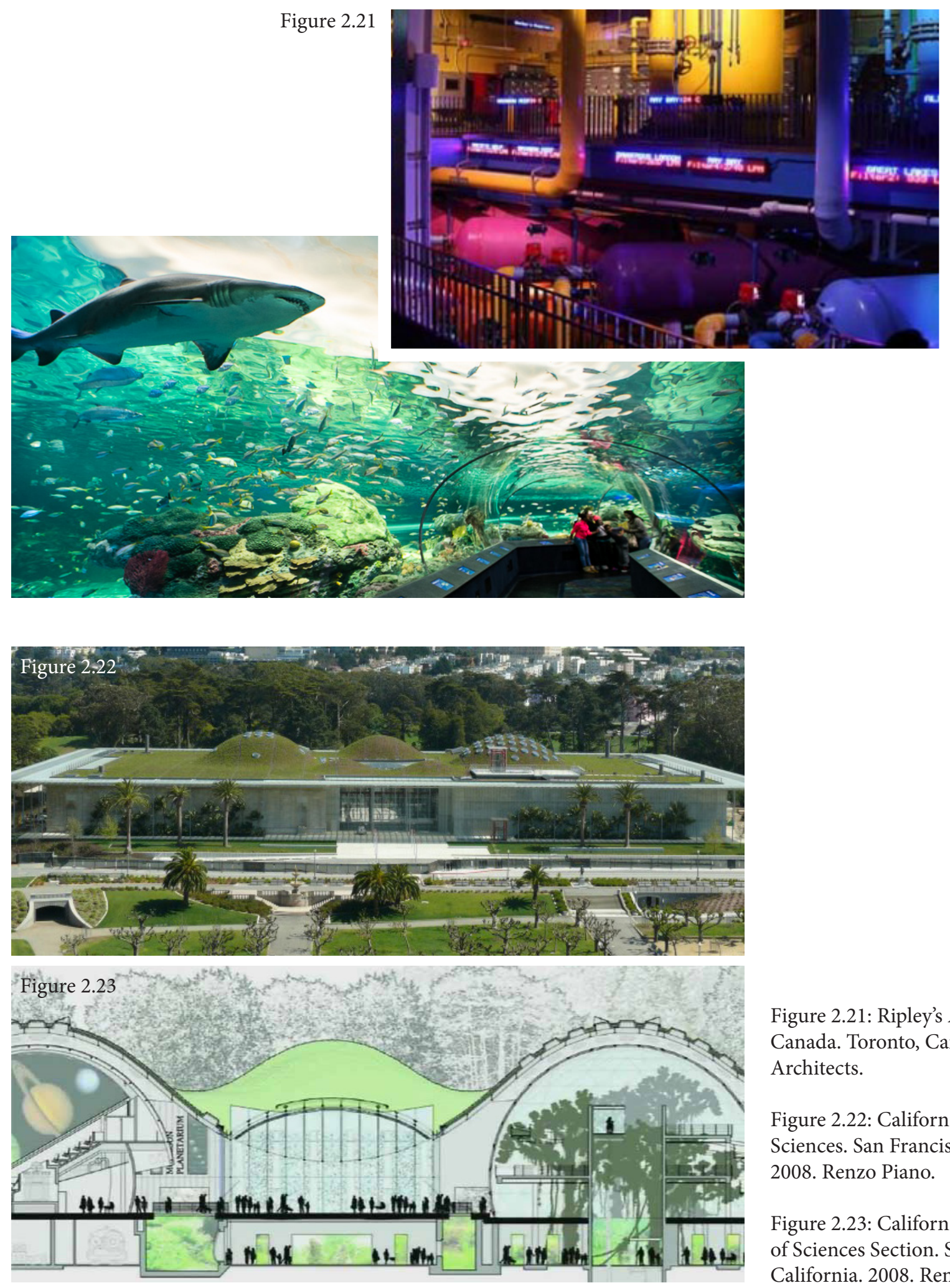

Figure 2.21: Ripley's Aquarium of Canada. Toronto, Canada. 2013. B+H Architects.

Figure 2.22: California Academy of Sciences. San Francisco, California. 2008. Renzo Piano.

Figure 2.23: California Academy of Sciences Section. San Francisco, California. 2008. Renzo Piano. 
Thus, "work" has also become a commodified spectacle in itself in our contemporary society, merging work and leisure into a consumable experience. However, this experience addresses the value of production in a world of consumption, working within the same system and culture to add value to an experience, making it a more sincere and authentic relationship. The spatialization of production then becomes an authentic architectural narrative that provokes an understanding of the building's function by subverting the process of production as an architectural experience.

The spatial effects found in Disney theme parks are choreographed to provide an immersive and convincing experience that reinforces the stories of Disney. However, criticism toward the Disney experience target its inauthentic concealing of reality or blatantly obvious forms corporate branding which negates or distorts reality into fantasy through conspicuous consumption. What we tend to forget is Walt Disney's original intentions of fairy tale optimism and social purpose when conceiving the parks. The artifices and inauthentic representations are similar to the special effects produced in Baroque theatrics, and now digital cinematics, in works of fiction to relay an underlying narrative that can be socially and culturally relevant. Reality can be conceived from the imaginary, and there can be authentic lessons from inauthentic settings.

Questioning the idea of authenticity in inauthentic environments, this thesis proposes that the spatialization of production can in fact communicate an authentic architectural narrative that is pertinent to context and culture through entertainment architecture. It attempts to expose and express 'hard work' and production in a world of escape and consumption to merge work and leisure into the same environment in order for us to better understand our consumption spaces. The narrative is derived from use or program, communicating a more authentic relationship between work and leisure, culture and entertainment. Architectural space becomes the framework for inspiring and encouraging education and leisure beyond superficial visual delight.

Going beyond the precedents presented in the previous pages, the understanding and reorganization of work or 'program' should inform the spatial and formal expression of architectural design. As such, the narrative becomes a journey of discovery and revelation that helps establish a connection between architecture and its use or program beyond a superficial showcasing of work. 


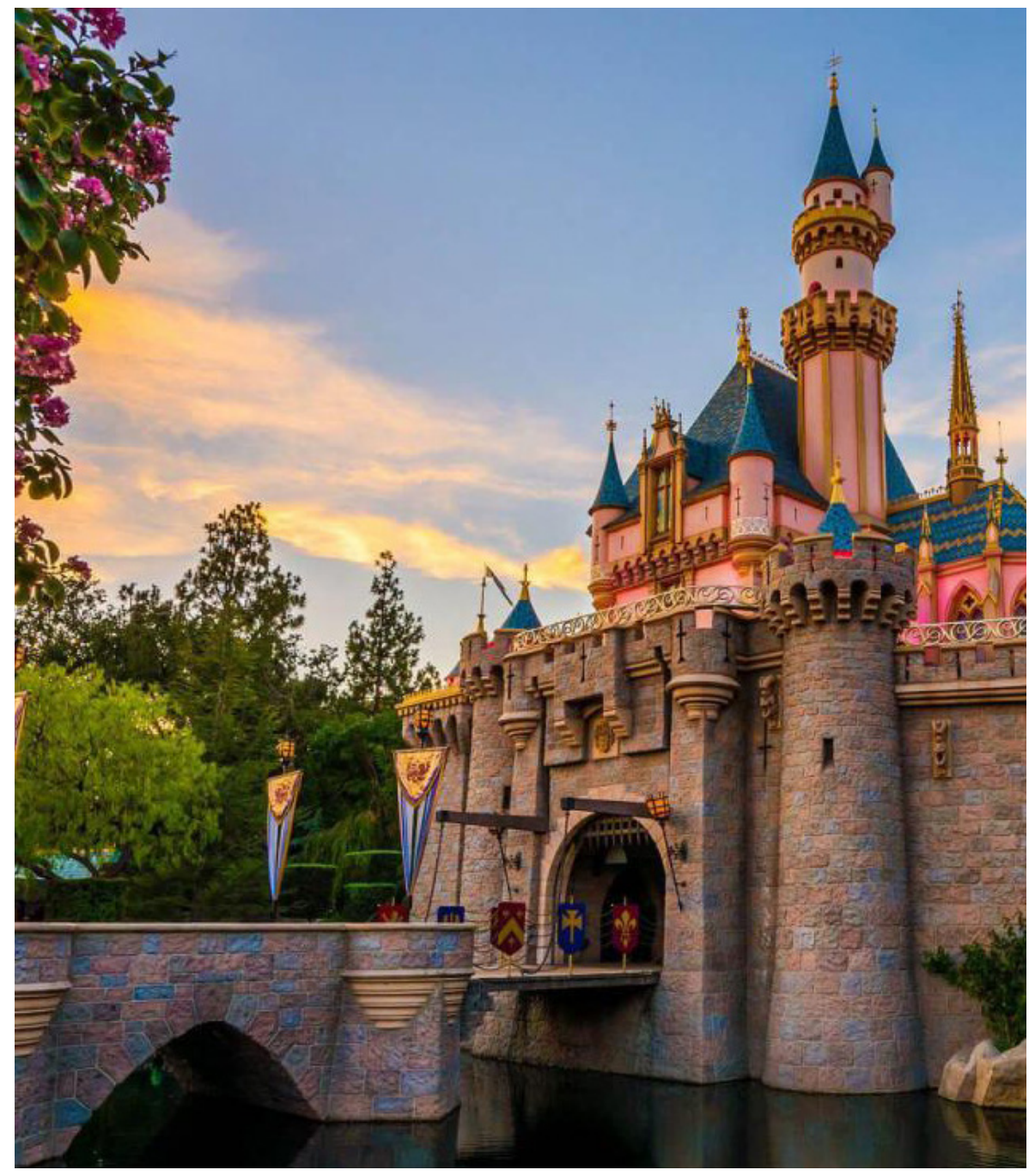

Figure 2.24

Figure 2.24: Disneyland's Sleeping Beauty Castle. 


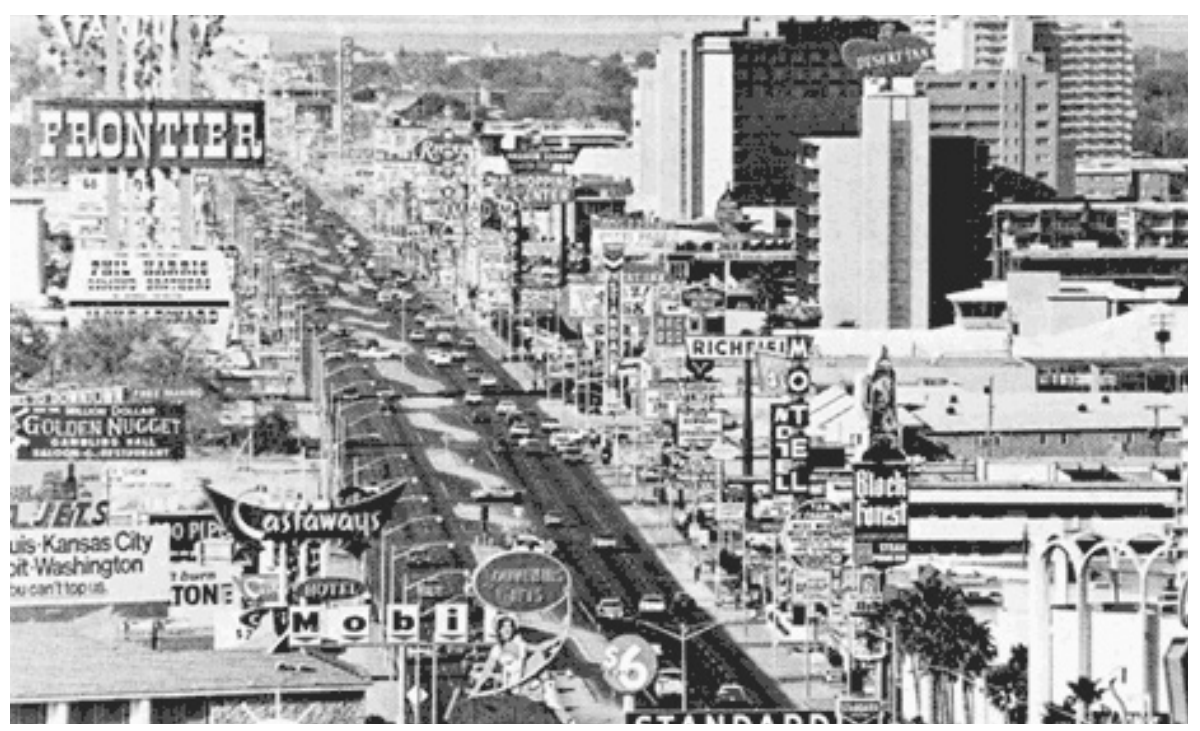

Figure 2.25

\section{4 | Still Learning from Las Vegas}

Although similar in style and appearance, Las Vegas can be interpreted as the opposite of Disney's utopian journey of discovery. Las Vegas is a place that is constructed purely for the spectacle of indulgence and pleasure, where many of the world's largest hotels, casinos, and resorts can be found in Las Vegas. Entertainment trends emerge and fade quickly on The Strip. Casinos thus have a very short life span, needing to continuously remodel every few decades to maintain mass appeal, becoming experimental grounds for all sorts of consumer-driven architecture. It is a place where the most extravagant and conspicuous forms of consumption is embraced and marketed, and its built environment also reflects this very culture. Driven by the demands of spectacle and consumption, its commercial vernacular becomes the precedent for entertainment architecture, but as Venturi, Scott-Brown and Izenour have illustrated, can also be a model for architectural theory and practice.

\subsubsection{Signs, Symbols and the Spectacle}

Venturi et al's analysis of the commercial vernacular of Las Vegas in the 1970s Learning from Las Vegas was primarily a critique of the failures of elitist modernist approach and a rediscovery of the power of symbolism and iconography in architecture. Critical of the modernist obsession of 'total design' of forms in space, denying of the use of ornament and symbols, resulting in boring, unwelcoming buildings, Venturi et al accuse modernists of creating 

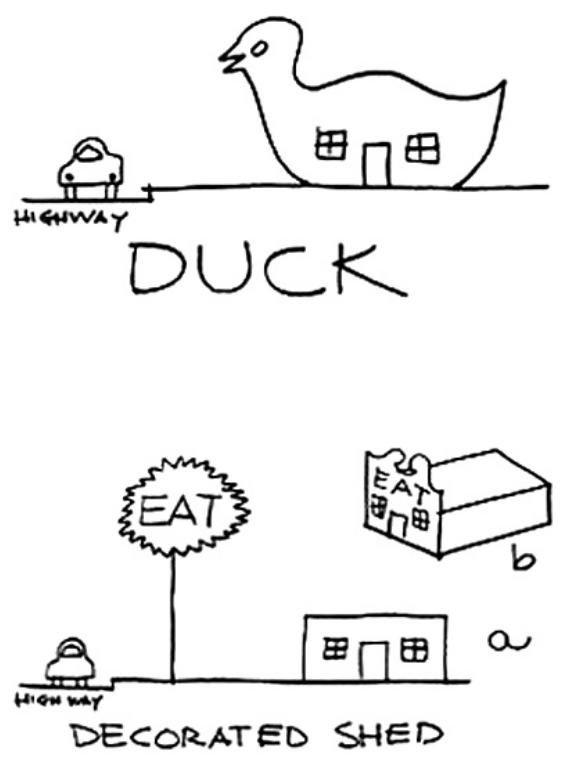

Figure 2.26

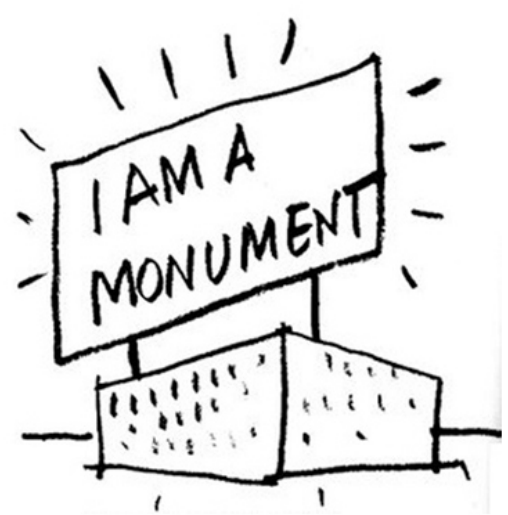

Figure 2.27 buildings that were giant symbols in and of themselves. The duck is a building that is itself a symbol, where the decorated shed is a conventional shelter that applies symbols. Their 'dead duck' analogy claims that modern buildings, in their attempts to deny symbolic associations, have instead submerged and distorted program and structure into an overall symbolic form (Venturi, ScottBrown and Izenour, Learning from Las Vegas 1977). Modernism's truth to materials and 'form follows function' rely on connotative, abstract meanings derived from purely architectural qualities, which eventually became elitist and removed from desires of the mass population, creating architecture for 'man', not buildings for 'people', insensitive and superficial to real needs of the population. However, despite modernist denial of symbolism, Venturi et al expose modernism's inherent use of symbolism as well, communicating contradictory messages between image and substance. Modernists' expression of industrial and machine aesthetic subconsciously acquired the symbolic and representative qualities of the industrial revolution, referring to its recent past of technological advancement (Venturi, Scott-Brown and Izenour, Learning from Las Vegas 1977). Thus, the image of industry became the symbol of progress in modernism. Venturi et al advocated instead for the 'ugly and ordinary' decorated shed of applied symbols on conventional buildings which draw from associative symbolism and iconography of pop culture, suburban middle class taste, and the commercial vernacular, epitomized by The Las Vegas Strip (Figure 2.25, page 68). There is an acceptance of populous taste
Figure 2.25: Upper Strip, Las Vegas, Nevada. 1972. Learning from Las Vegas. Venturi et al.

Figure 2.26: Duck and Decorated Shed. Venturi et al.

Figure 2.27: Monument by signification. Venturi et al. 
for imagery and symbols on conventional materials and engineering in postmodernism, providing fast, sound, and economic construction pertinent to their times. The re-introduction of ornament and past styles appeal to the desire for familiarity, but also for newness and excitement. Where the duck is the symbol, the decorated shed applies symbols and icons independent of program and structure, making it easily replaceable and adaptable to changing demand (Figure 2.26, page 69). These signs then symbolically transform the shed into a monument by signification (Figure 2.27, page 69).

Yet, this post-modern rejection of modernism has resulted in its own superficiality, carrying eclectic and contradictory messages in the process. Catering to popular preference of imagery, applied decorations of postmodern buildings have carried into our contemporary age, focusing purely on the exterior façade of a building for expression. Eventually a mix of superficial ducks and decorated sheds proliferate our environment. The former creates increasingly abstract sculptures and iconic buildings, and the latter creates superficial buildings with confusing meanings.

\subsubsection{Signs, Symbols and the Experience Economy}

40 years post-Venturi, Klingmann indicates that contemporary Vegas has shifted from ducks and decorated sheds to 'inverted ducks' and 'inverted sheds' in the context of the Experience Economy (Klingmann 2007). Where Venturi, Scott-Brown and Izenour's decorated shed and ducks emphasized 2-dimensional billboards and giant symbols that appealed to high-speed cars in space (Figure 2.28), contemporary casinos have transformed into a 3 -dimensional messaging system appealing to people in cars, passersby, and patrons inside at various different scales (Figure 2.29). The sign is no longer simply decorative symbols on the outside of a generic box, but a 3-dimensional experience that stitches inside and out, public and private to provide a thorough and immersive experience.

Contemporary Vegas has turned into 3-dimensional stage sets for conspicuous leisure. Overpriced luxury and extravagance proliferate The Strip, becoming the most ostentatious form of leisure. Architecture in this context mirrors the extravagance of some of its patrons as another signifier of wealth and power. All of the casinos and resorts essentially provide the same type of entertainment, but as anthropologist and themed space academic Scott Lukas points out, those that are intensely themed are more immersive and engaging to the guest, communicating at many different levels and senses. He explores the relevance and authenticity of theming for creating immersive spaces, where theming is an authentic projection of desire, controlling imagination with recognizable illusions (Lukas 2007). Guests willingly and enjoyably suspend their disbelief to connect to recognizable symbols of a theme. 


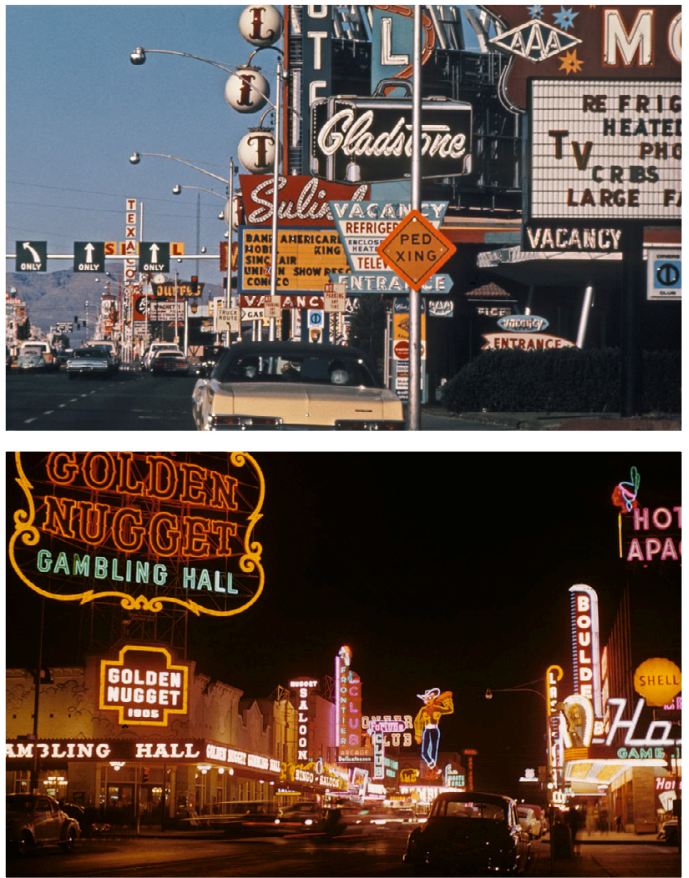

Figure 2.28
Figure 2.28: Las Vegas 1970s.

Figure 2.29: Contemporary Las Vegas.
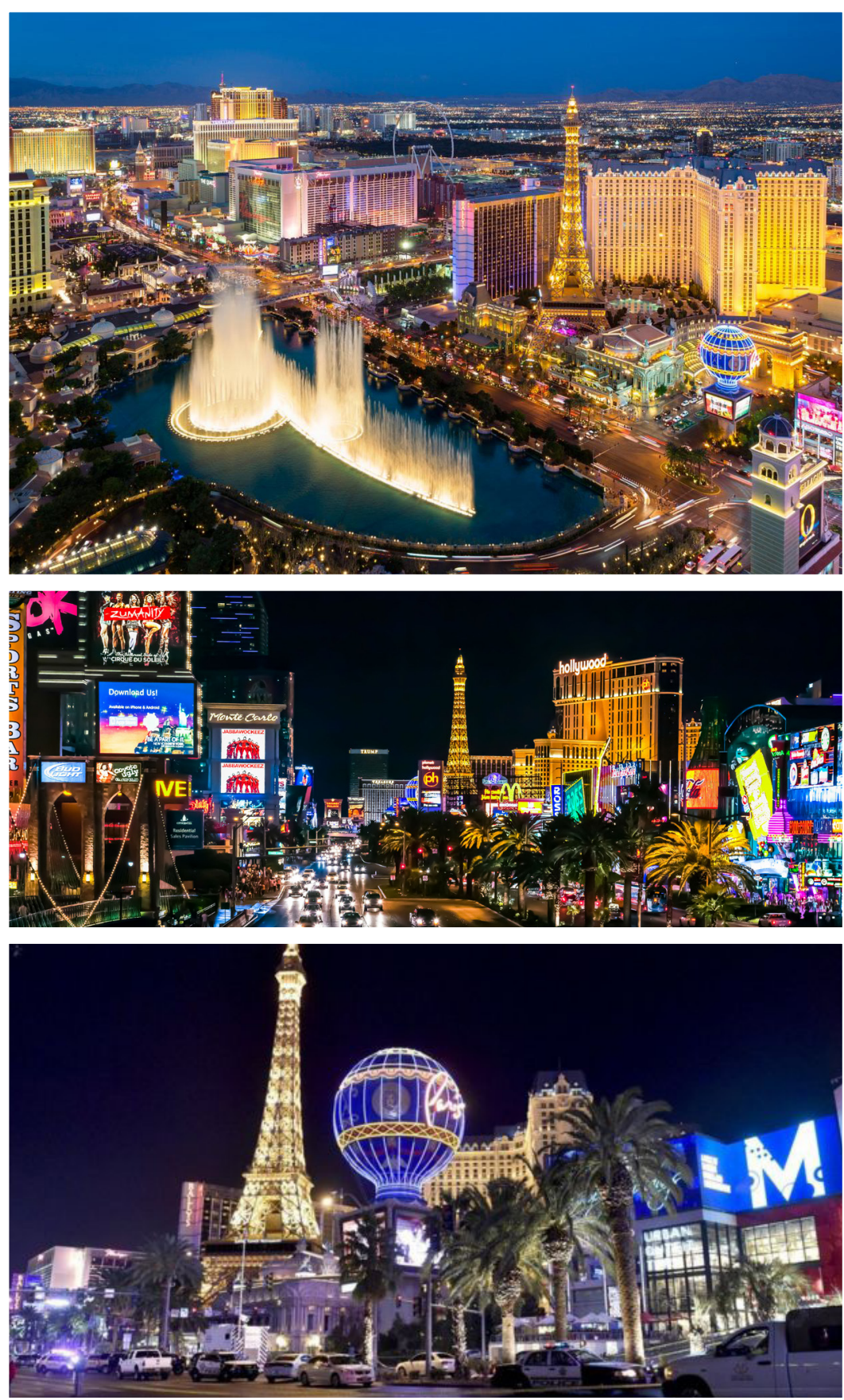
The theming speaks to different fantasies in American culture. Urban sociologist Mark Gottdeiner explores the use of themes in his book Theming of America, and identifies dominant themes found in Las Vegas: Status, Tropical Paradise, Wild West, Classical Civilization, Nostalgia or Retro, Desert, Urban Motif, Fortress, Modernism and Progress, and Representing the Unrepresentable (Gottdiener 2001). Most of these themes take visual cues from other places, whether real or mythical, current or ancient, but are all embedded in world culture that is meant to evoke and satisfy consumers' desires for rootedness and place, but also of excitement and surprise (Klingmann 2007). The idea of place marketing, or "the urban motif", is worth investigating further because rather than using invented fantasies and utopias as themes, it imitates real places and cities instead, which suggests a strategy for referencing an established sense of place. The Urban Motif uses the image of a city as a theme that places recognizable landmarks as anchors for the leisure experience to unravel. These landmarks are universal signifiers and icons of places that already have mass recognisability. However, the order and sequence in which they are experienced in reality is irrelevant to the sequencing found in Las Vegas. The icons here are re-scaled, replicated, and collaged into a fragmented and hyper-condensed experience of the city that satisfies the desires of the Experience Economy.

From afar the New York-New York Hotel and Casino is instantly identifiable by its cluster of towers resembling the New York skyline, the Statue of Liberty in the corner, and the nostalgic Coney Island rollercoaster weaving across its length. We are familiar with and recognize each of these individual references as iconic landmarks of New York, yet the location and juxtaposition of each element in relation to one another in the real New York does not try to be a true representation in this context. The landmarks work here as thematic anchors and visual indicators for the extreme and simulated experience of the city (Gottdiener 2001). Beyond instant recognisability, the complex curates an experience from outside in, thematically connecting the street to the hotel to the casino. Transitioning from one space to another simulates moving through the city, where visitors are presented with a multitude of images of New York (Figures 2.31-2.36). One can cross the Brooklyn Bridge, enjoy the streetscapes and facades of iconic New York apartments, or dine at a café or diner patio. This condensed version simulates the diversity found in the city, which in fact effectively masks the enormous scale of the hotel and casino complex. By creating different places within a place, the city as theme constantly keeps visitors engaged in the experience of the city and although it's known that the "buildings" are "fake", the simulacra provides the visitor with a memorable and enjoyable experience of being in another city using existing symbols and imagery. Because a city is by nature diverse, the theme also provides diversity and surprise while being familiar at the same time. Theming, then, works to coherently connect architecture with people and places. 

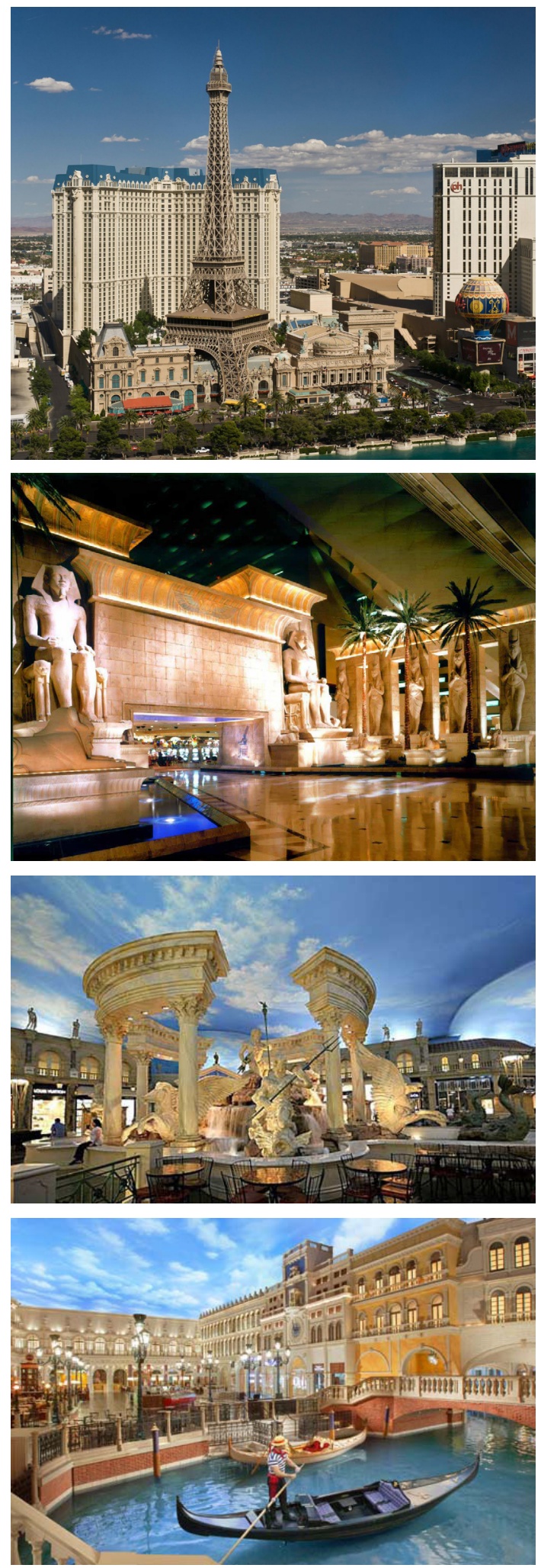
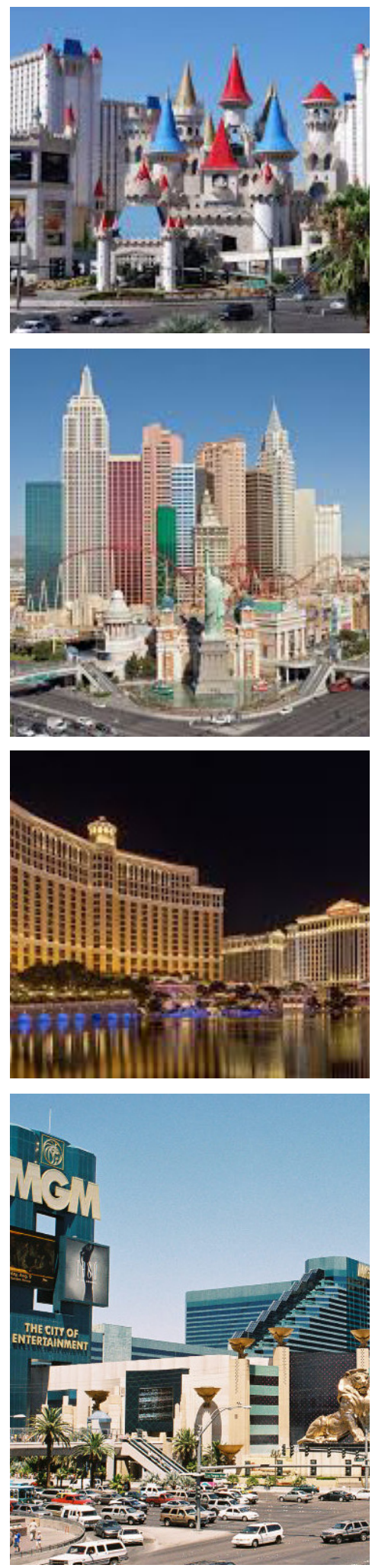

Figure 2.30

Figure 2.30: (Top to bottom, left to right) Paris Las Vegas Hotel; Luxor Las Vegas; Caesars Palace Las Vegas Hotel and Casino; The Venetian Las Vegas; Excalibur Hotel and Casino; New York New York Hotel and Casino; Bellagio Las Vegas; MGM Grand Las Vegas.

(Following Pages)

Figure 2.31: New York New York Hotel and Casino Exterior.

Figure 2.32: New York Skyline.

Figure 2.33: New York New York Hotel and Casino Exterior.

Figure 2.34: Brooklyn Bridge.

Figure 2.35: New York New York Hotel and Casino Interior.

Figure 2.36: New York Streetscape. 
Figure 2.31
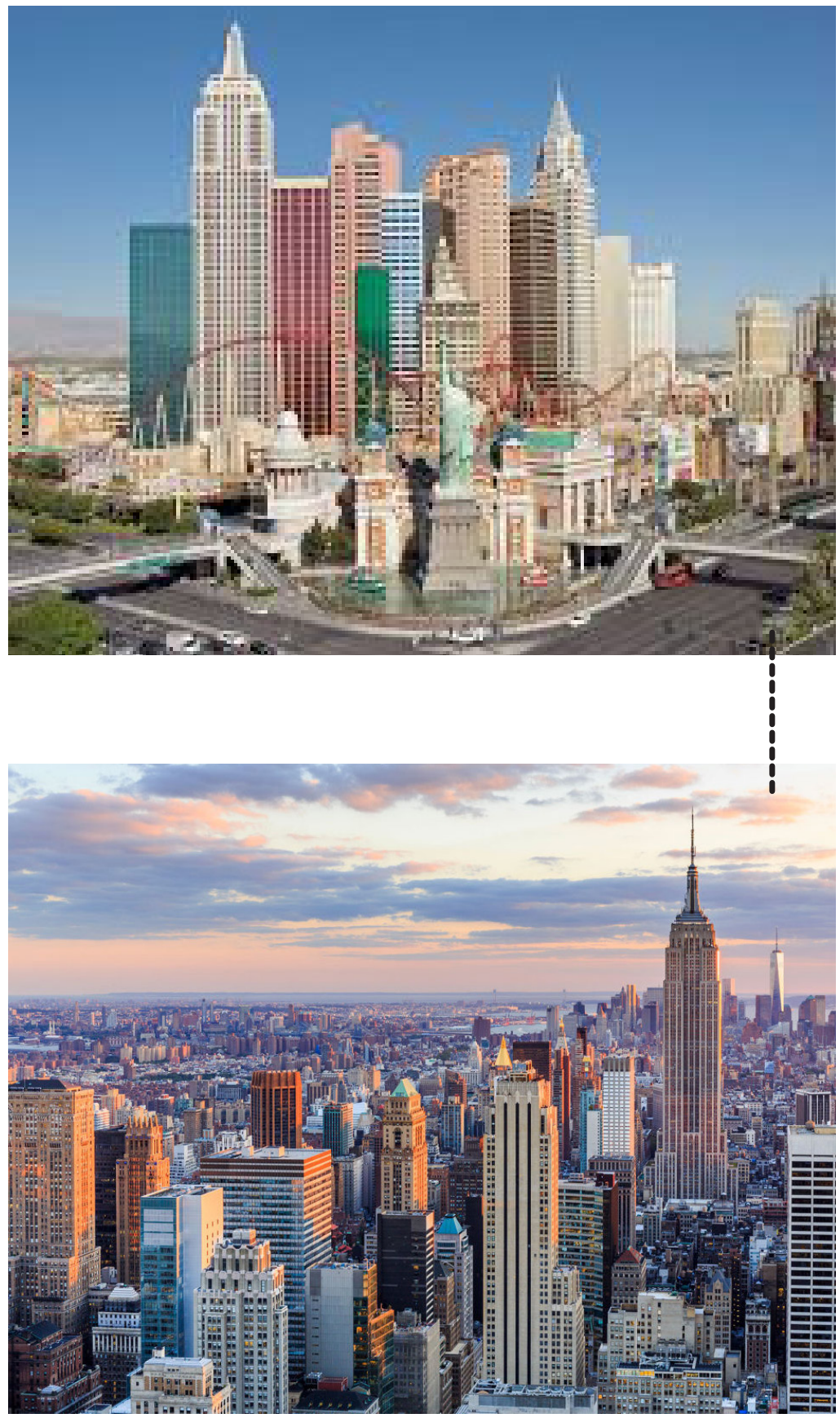

Figure 2.32
Figure 2.33
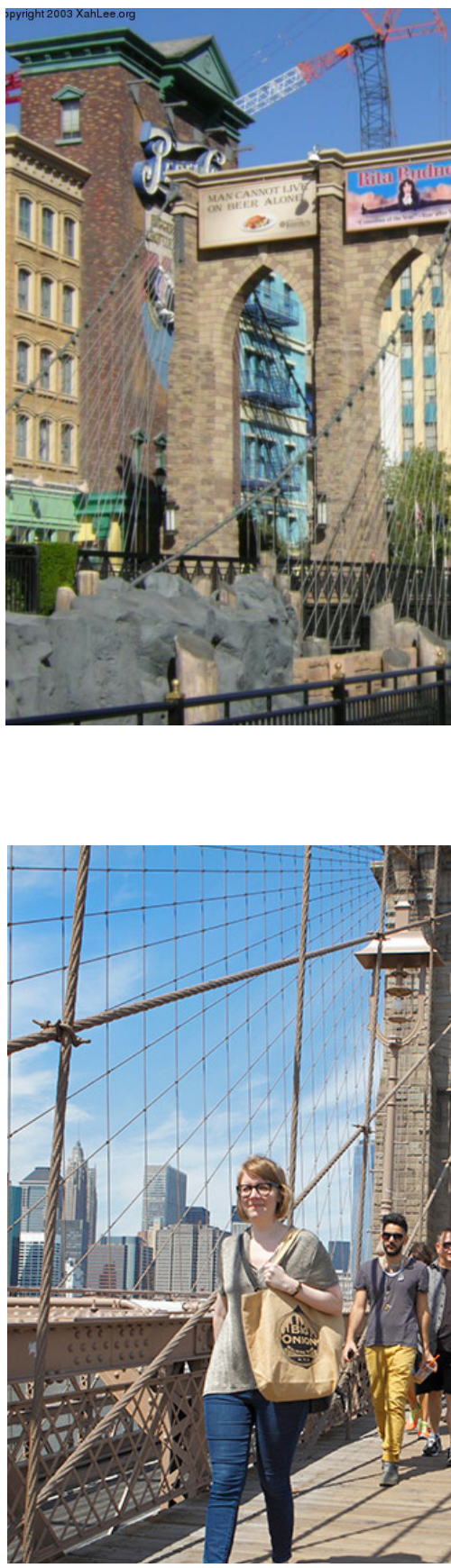

Figure 2.34 


\section{(Page 77)}

Figure 2.37: 30 St Mary Axe "The Gherkin”. London, UK. 2001. Foster + Partners.

Figure 2.38: Enigmatic Signifiers for "The Gherkin".

Figure 2.39: Guggenheim Museum Bilbao. Bilbao, Spain. 1997. Frank Gehry Associates.

Figure 2.40: Enigmatic Signifiers for Guggenheim Bilbao.

Figure 2.41: Ontario College of Art and Design. Sharp Centre for Design. Toronto, Canada. 2004. Robbie/Young + Wright Architects and Alsop Architects.

Figure 2.42: Enigmatic Signifiers for The Sharp Centre for Design OCAD.

\subsection{3 |The Enigmatic Signifier}

On the other end of the spectrum of architectural signs and symbols, the contemporary iconic building references multiple and ambiguous meanings and objects rather than replicating established symbolism or iconography of other places. Their themes and iconic appeal confuse our understanding of its place within its context. An icon, by definition, is a likeness, image, similitude, or a sign with some factor in common with the thing it represents (Jencks, The Iconic Building 2005). An iconic building often has an intentional likeness to bizarre and contradictory things, provoking and competing for attention through capricious excitement. Charles Jencks describes the iconic building as an "enigmatic signifier", an ambiguous sculptural form that lends itself to multiple meanings meant to provoke curiosity and publicity (Figures 2.372.42 , page 77 ). The ambiguity of allusion acts as a form of promotion for the building or organization it represents, where anger, outrage, and publicity are all part of the iconic experience, generating fear and attraction, love and hate at the same time (Jencks, The Iconic Building 2005). Explicitness and cliché render many icons conspicuous one-liners, but a successful icon, Jencks notes, works best when its metaphorical comparisons are both obvious and revealed, relating to the building's symbolic program and meaning.

The enigmatic signifier alludes to unusual codes where multiple interactions of meanings and metaphors serve to spark interest and conversation (Jencks, The Iconic Building is Here to Stay 2006). These ambiguous signs and allusions pose a problem in the way we understand architecture's relation to the city because there isn't a consistent understanding of its intentions. 


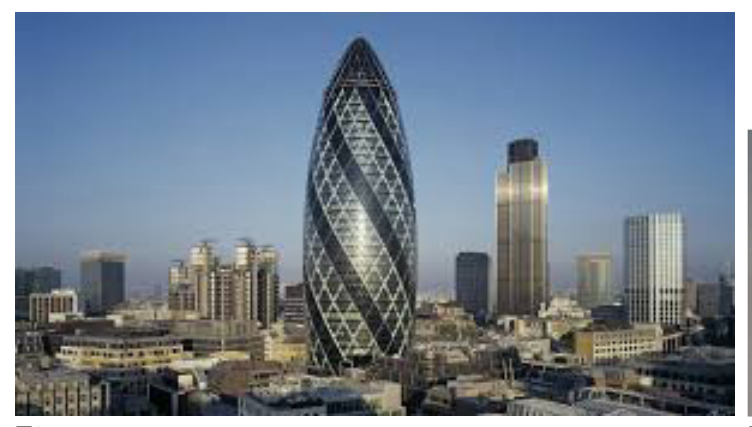

Figure 2.37

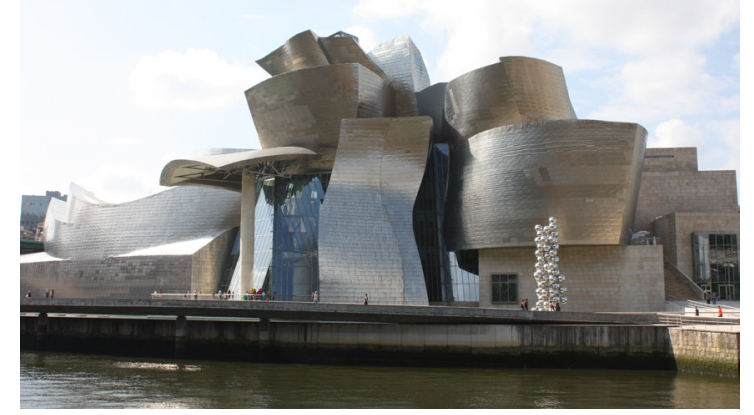

Figure 2.39

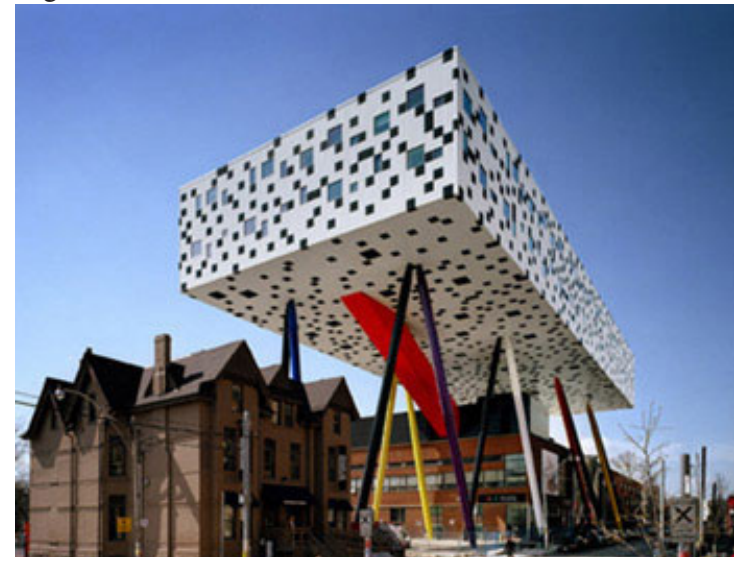

Figure 2.41

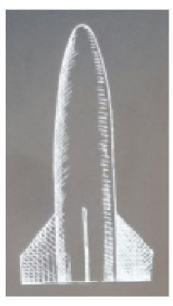

Figure 2.38
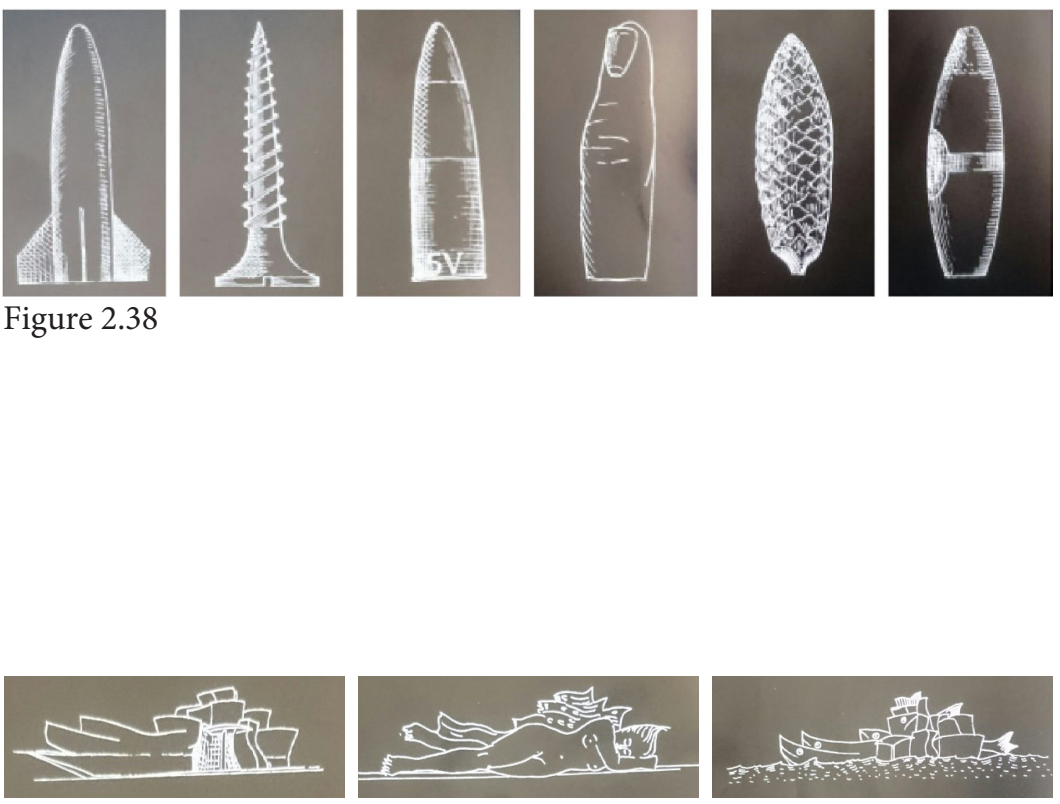

Figure 2.40
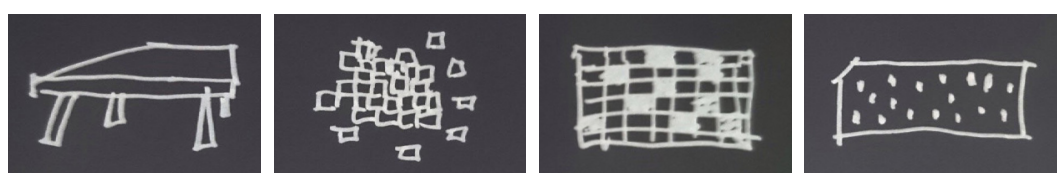
(Page 79)

Figure 2.43: Roots Canada branding and store designs emulate cottage lifestyle.

Figure 2.44: Between themed replicas and ambiguous and enigmatic signifiers.

Figure 2.45: (left to right) Mountain Equipment Co-op Store. North Vancouver, British Columbia.

Mountain Equipment Co-op Retail and Warehouse. Burlington, Ontario.

Mountain Equipment Co-op Retail Store. Toronto, Ontario.

\subsubsection{Curating a Sense of Place}

As opposed to the open-ended system of signification of iconic landmarks, Las Vegas's symbolism and architecture draw from other preestablished places as themes, and its inauthentic facades are a means to replicate sense of place both inside and out, enjoyably providing an experience of another city. However, the visual identifiers can evoke a sense of place that references an authentic history, context, or product instead. In the context of the culture of consumption, some brands use themed visual identifiers to evoke a sense of place that in turn expresses and defines their brand identity.

Roots Canada, for instance, successfully translates symbols of Ontario parks and cottage life into their products and store designs, evoking a lifestyle that is place-based and an authentic reference to the products' history and place. Their store designs can be considered "cottage" or "back-country"themed (Figure 2.43). Mountain Equipment Co-op also uses the same strategy, where their products and architecture reflect the landscape and wilderness of British Columbia. Sustainable initiatives and the use of local materials evoke imagery and appreciation of outdoor activities and landscapes. The resulting architectural environments communicate and visually tie an authentic reference to the history and place of the products.

To navigate between themed clichés and enigmatic signifiers, placebased symbols that reference a building's immediate context and history forms a strategy for an authentic architectural expression. This strategy of place-based symbolism uses the theme of the city to address the desire for familiarity and authenticity that connects people to their environments for an architecture that is site-specific and contextually connected. Using the city or context as a theme, the architectural expression embodies local culture and sense of place for an appropriate relationship to the city. Beyond thematic ties, however, site conditions should also offer opportunities for physical and visual connections for a more integrated architecture in the city. 

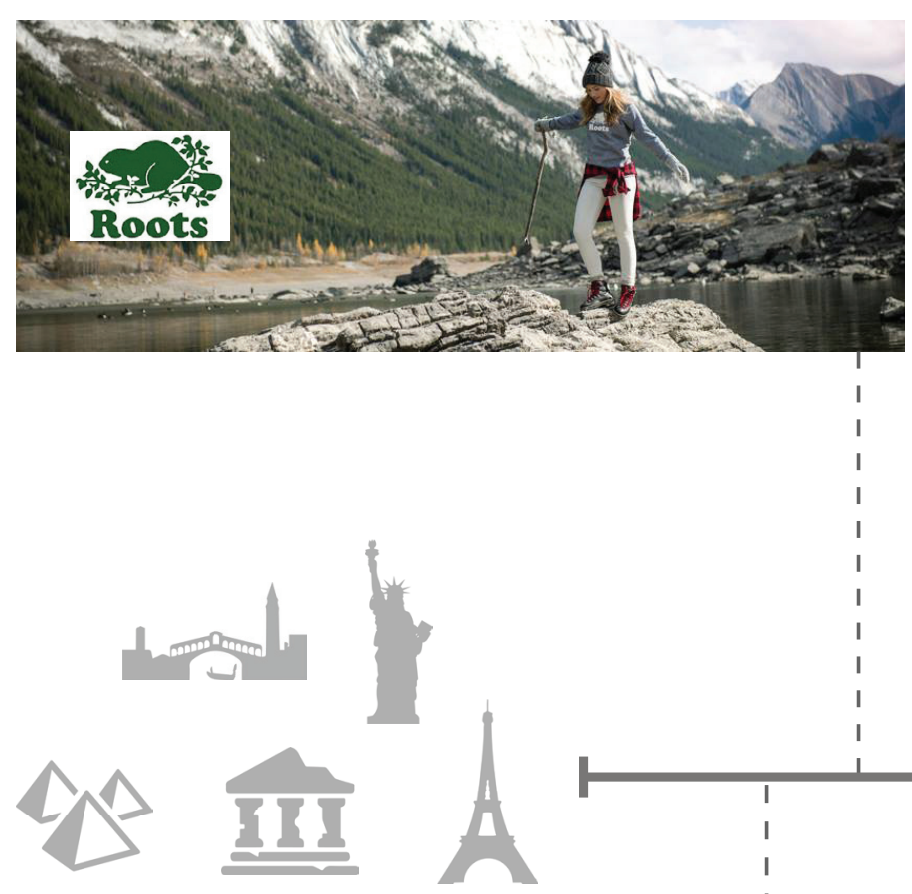

Overt \& Explicit Replication

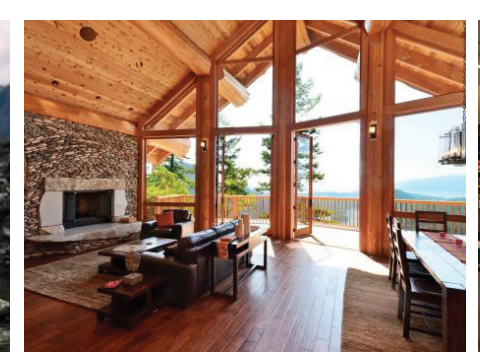

Figure 2.43
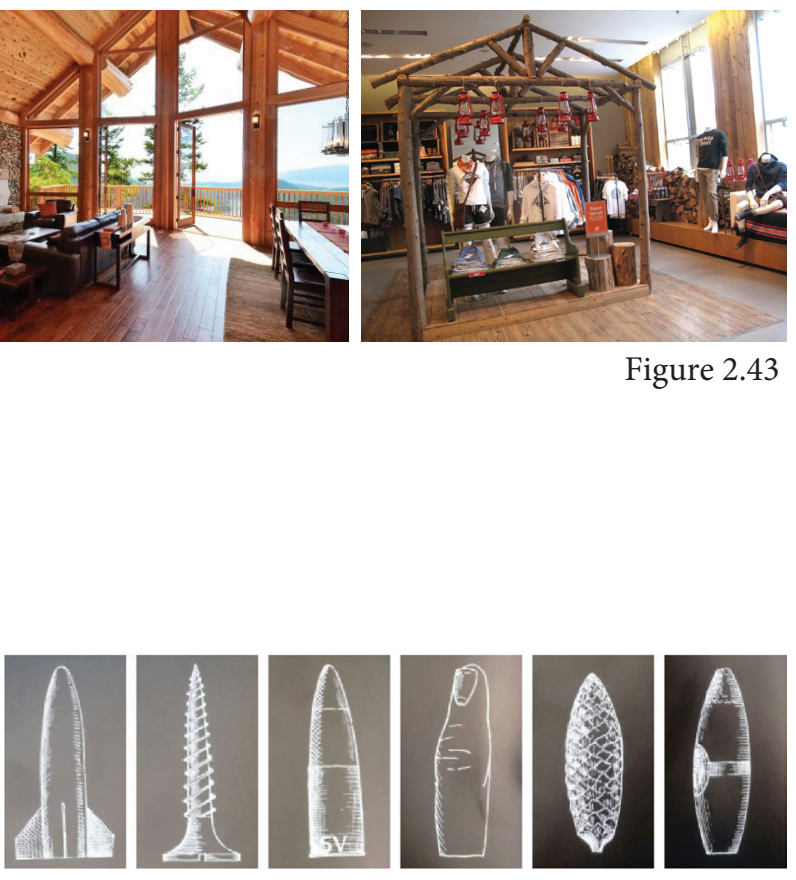

"Enigmatic Signifier"

Figure 2.44
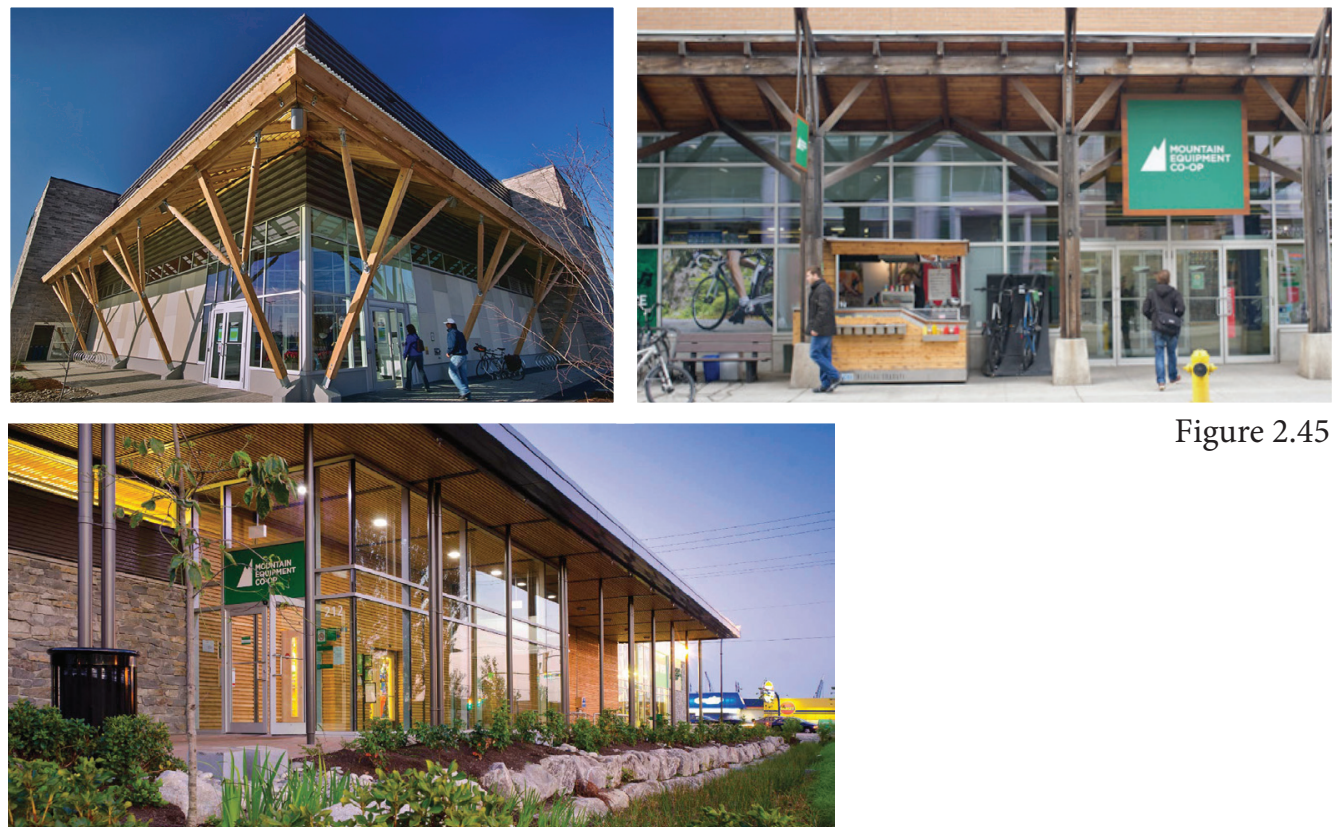

Figure 2.45 


\section{5. | Scale and Rhythm of the City}

\subsection{1 | Shopping and the City}

Cities have been known to grow and evolve around the marketplace. Archaeologist Peter Carelli suggests that the evolution of consumer culture, the act of buying and selling, actually parallels the process of urbanization (Kärrholm 2012). Beyond simply trading goods out of necessity, the accumulation of wealth and customers attracted more people, both traders and consumers, into urban centers. Consumerism and cities grew hand in hand. The town square, marketplaces, agoras, and bazaars were important places of consumption necessary for basic functions of life and were also places where urban life and public liveliness developed (Herwig 2006). Consumption was thus a form public activity, giving people the opportunity to congregate and socialize outside of their home.

It wasn't until the industrial revolution that our modern consumer society and consumption patterns emerged. Mass production, prosperity and social mobility allowed more people to afford a variety of goods, and the trend of mass consumption began. Discussed in previous chapters, Veblen's concept of conspicuous consumption describes the consumer behaviour of acquiring material goods to signify and publically gain social status (Veblen 2005). The growth of the leisure class, with more disposable income and more options for consumption, then led to the modern phenomenon of "shopping", where the act of browsing and buying becomes a leisure activity in itself. Urban theorist Sharon Zukin notes that cities have shifted from 'landscapes of production' to 'landscapes of consumption' to satisfy the need for increasing consumption (Zukin 1991). In a western context, factories and industries used to dominate the city's landscape, generating economic prosperity as well as its own products and services. With products being sourced from developing nations in the east, the city's landscape is now dominated by consumption space only, shifting power and focus from production to consumption.

This rising interest in shopping propelled the development of numerous types of retail spaces, from the arcades and galleries of Europe to the globalized shopping malls and big box stores we are familiar with today. As Rem Koolhaas claims, in The Harvard Design School Guide to Shopping (2001), shopping has become the primary mode of urban life, replacing traditional leisure and activity in public space. Shopping has undoubtedly become a part of our everyday practice and it is hard to imagine a city functioning without retail spaces. Grocery stores, cafes, barber shops, hardware stores and bookstores are just some of the places we'd frequently visit. It has become a pervasive and inescapable aspect of our everyday life that continuously shapes and reshapes our physical environments. 


\subsection{2 | Retail as Driver of Change}

Venturi, Scott-Brown, and Izenour's study of Las Vegas' commercial vernacular was seminal in understanding and acknowledging this trend

Figure 2.46: Horton Plaza. San Diego, California. 1985. Jon Jerde Partnership. and preference of consumption in architectural discourse. The diversity, complexity, and symbolism of retail architecture formed the basis for postmodernist notions of re-introducing ornament and symbols in architectural language. The merging of high and low culture through the use of applied signs and symbols of pop culture and historical references appealed and connected to the masses in both new and familiar ways.

A firm specializing in designing shopping malls, Jerde Partnership, while designing Horton Plaza in San Diego, understood the demands of consumers and the desire for complexity and variety of public space. Jon Jerde created an outdoor mall in the post-modern mode of clashing styles that emphasized "the bottom 20 feet", where bright colours, forms, and rhythms engage the consumers at a scale they can relate to, but also becomes a backdrop to public life (Figure 2.46). The mall was meant to simulate the cheerful disorientation of wandering through European streets (Herwig 2006). Horton Plaza, since its opening in 1985, has become an important and successful hub of entertainment and urban life that revitalized downtown San Diego, rebranding the experience of urban shopping (Klingmann 2007). It provided an alternative to the enclosed suburban shopping malls of the time.

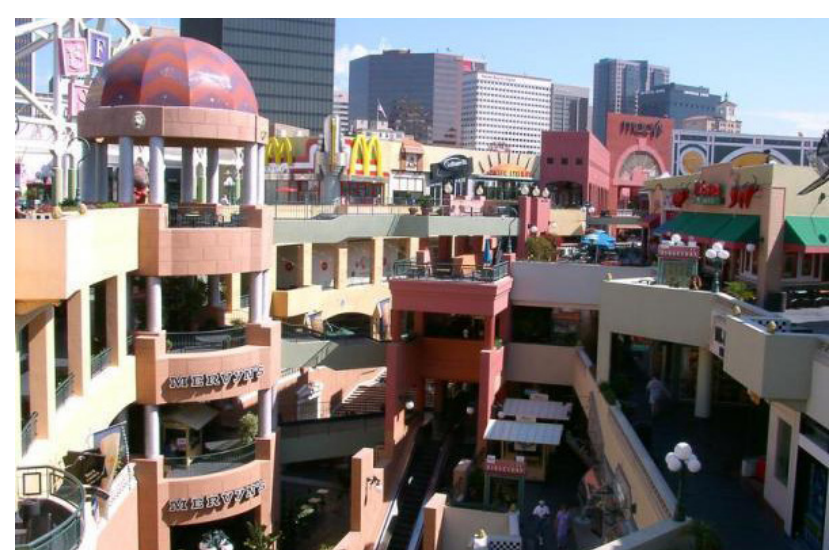

Figure 2.46 (left and bottom)

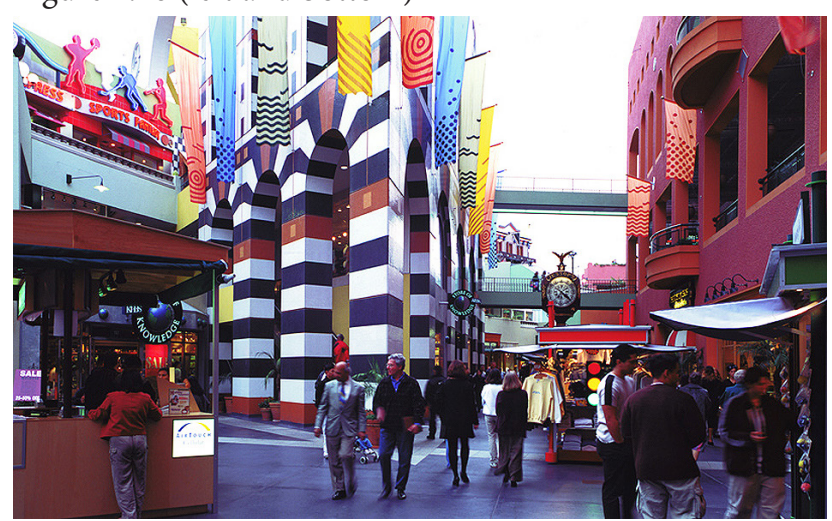




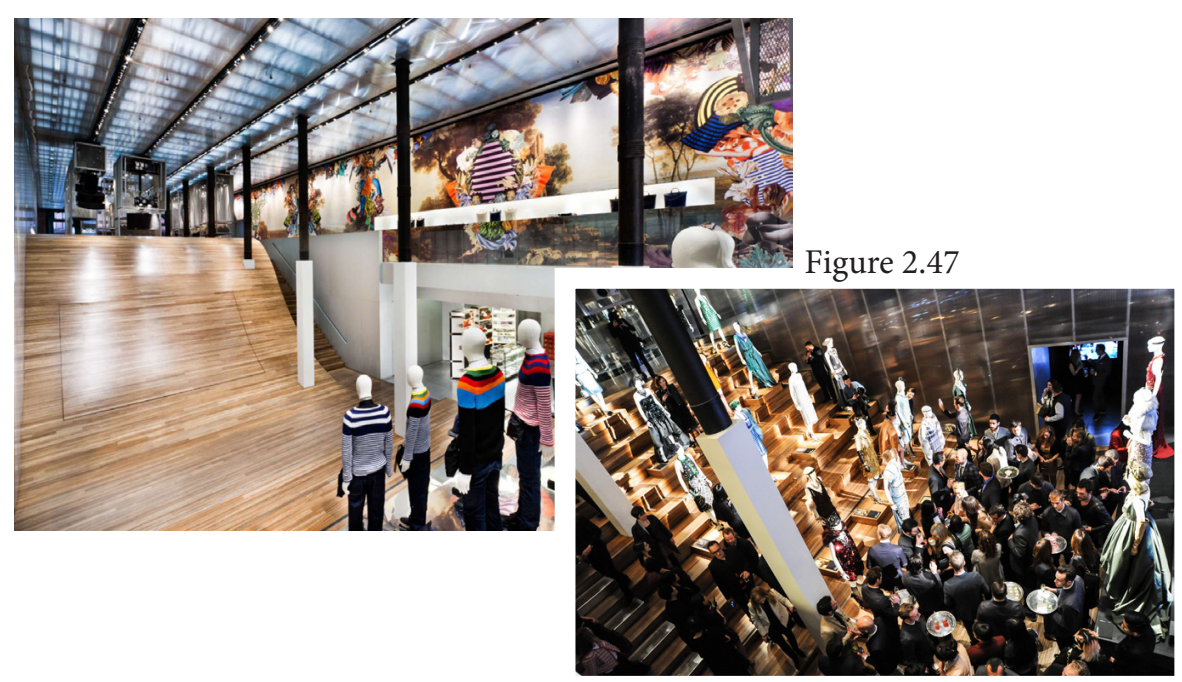

Figure 2.47: Prada Epicenter, New York.

(Page 83)

Figure 2.48: Sanlitun Village Shopping Center. Beijing, China.

Figure 2.49: The Grove Shopping Center. Los Angeles, California.

Figure 2.50: The Distillery District. Toronto, Canada.

Shopping is thus an important driver of change in our built environment. The constant change and proliferation of retail typologies reflect the desires of this culture of consumption, replacing yet replicating traditional urban public space and activity. Retail architecture, although criticized for encouraging temporary and superficial connections with brands and products, offers a contemporary type of public space and user engagement that is informed by the scale and rhythms of city life. Examining the evolution of retail spaces and their relationship with public liveliness, it can be seen that strategies for retail spaces create more engaging environments beyond the act of shopping by understanding the scale and rhythm of shoppers. This same study of user rhythm can be used as a strategy for architectural design that can encourage engaging spaces for its users and the public. 

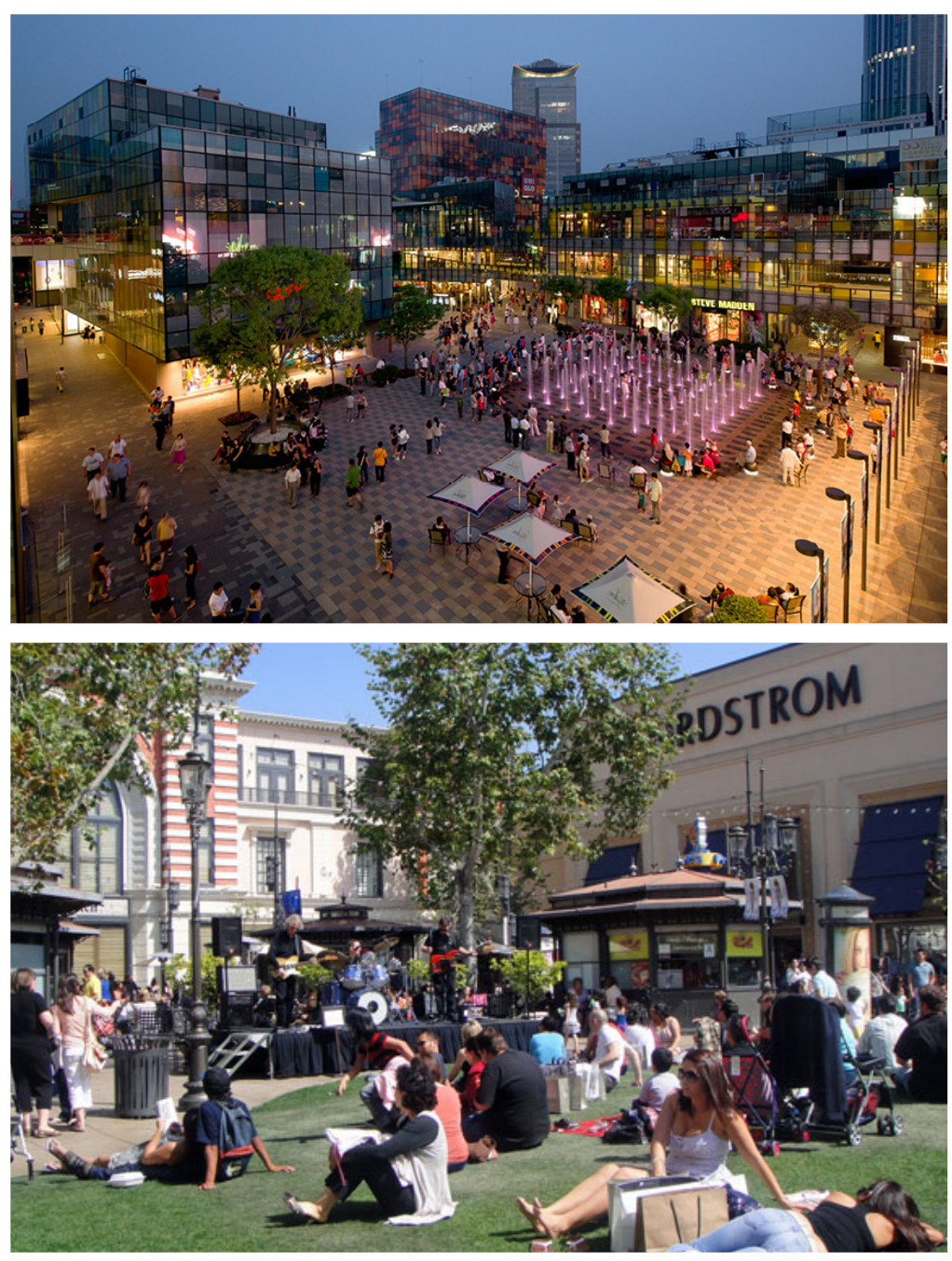

Figure 2.48

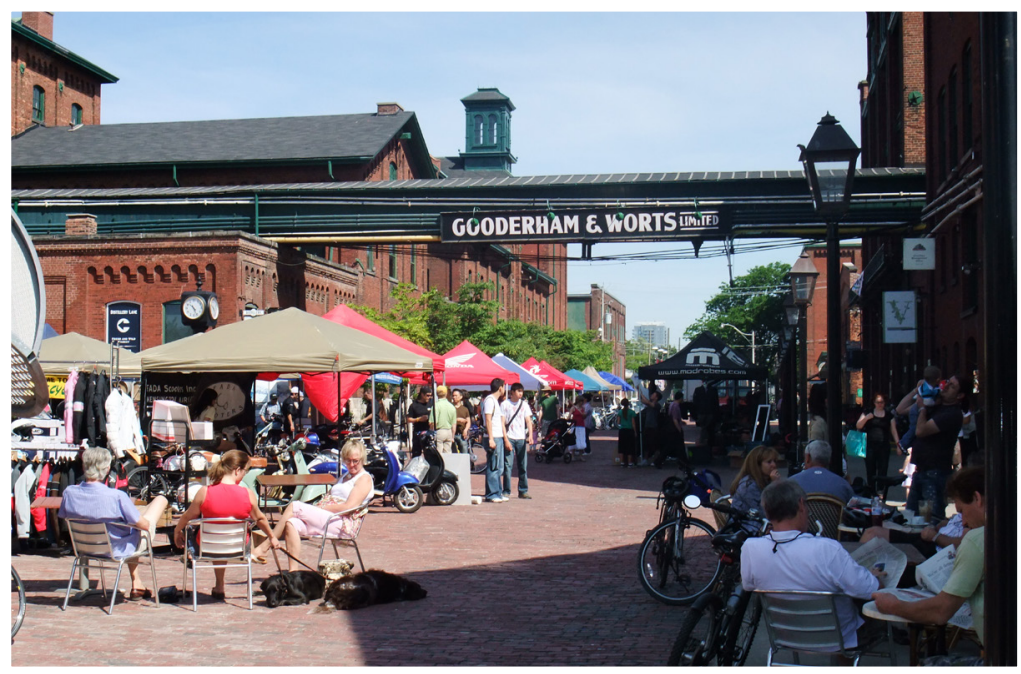

Figure 2.49

Figure 2.50 


\subsection{3 | Evolution of Retail Space and Public Space}

Throughout history, public space is closely linked to retail spaces (Kärrholm 2012). Marketplaces and agoras were public gathering places that also was a convenient place for the sale of goods and services (Figure 2.51). Shopping was thus a backdrop to street life and social life. As retail spaces evolved, however, we see the shifting of public space from a truly public domain to privatized "open-to-public" space. Architectural theorist Mattias Karrholm identifies it as a constant re- and de-territorialization of public space. He observes that retail architecture (particularly the shopping mall, shopping center, and urban shopping districts) increasingly invades and redefines, or territorializes, the experience and use of public space in our cities. These spaces work at the scale of a large city block, but simulates the small-scale rhythm and intimacy of the street. Arguably, however, this invasion and infiltration of retail in our everyday spaces creates opportunities for social and public street life that actually benefits the city and its people beyond the act of shopping. Examining the evolution of retail spaces in modern history, it can be seen that these spaces continuously use the same strategy of scale and rhythm to imitate urban streets and public life.

\section{The Galleria}

The modern western shopping mall typology can be found as early as the 1700s. The Palais Royal in central Paris can be seen as the first prototypical interior mall, becoming the focus of public commercial activity after the French Revolution. Formerly the palace of Cardinal Richelieu, the residence was converted into a commercial centre with the expansion and construction of grand arcades along its perimeter (Lonsway 2009). The new covered arcade was an accumulation of business, consumerism, entertainment, and residences in a space protected from traffic and weather at a scale of intimacy that fostered commercial activity as well as public life. Evolving beyond the ad-hoc street-level arcades, its commercial popularity spurred developments in more monumental spaces specific for consumption, becoming its own architectural typology of the galleria. The Galleria Vittorio Emanuele in Milan, for instance (built in 1866), is one of the oldest "shopping malls", internalizing streetscapes and offers protection from weather, transforming shopping and urban street life into a comfortable experience. Although covered, the entrance to gallerias were open-air and aligned with major streets, public places and monuments in the city, maintaining an axial connection to its context. 

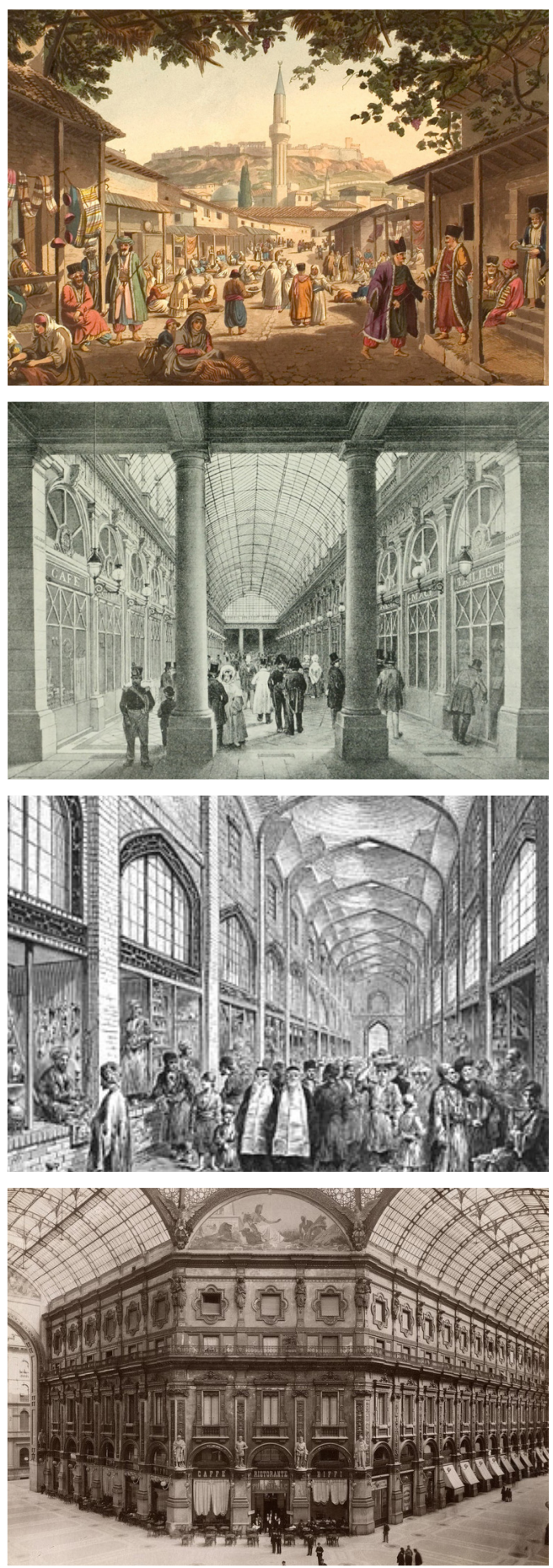

Figure 2.51: (top to bottom) Bazaar of Athens

Palais Royale, La Galerie d'Orleans Arcade, 1830 Vakil Bazaar, 1881

Galleria Vittorio Emanuele II, 1877 
Figure 2.52

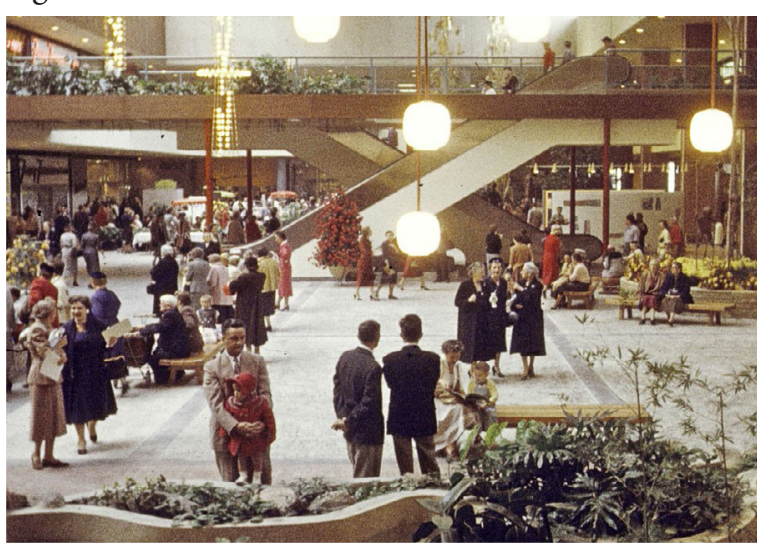

Figure 2.53

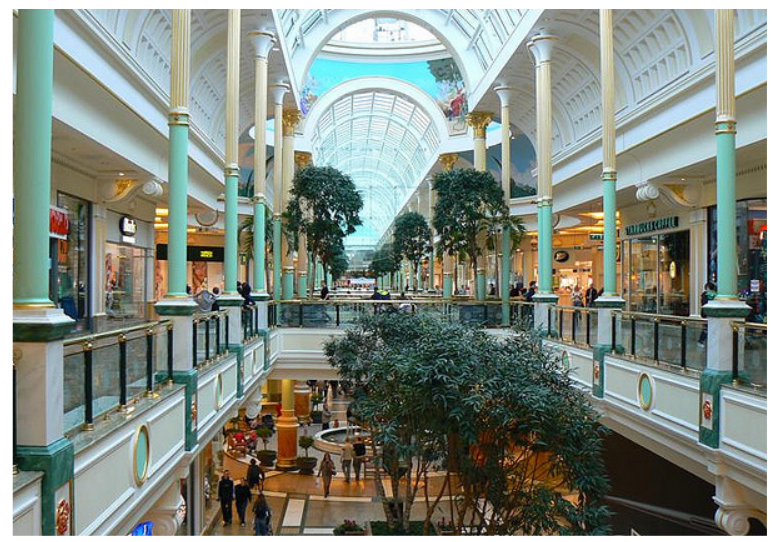

Figure 2.54

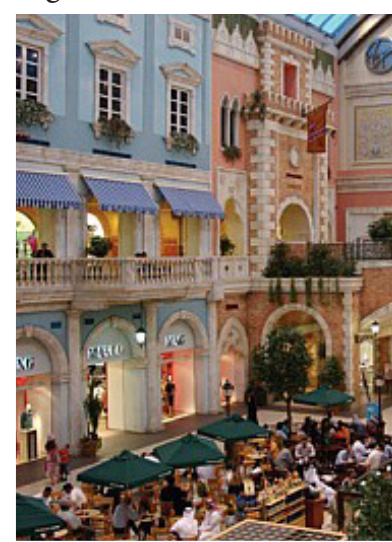

Figure 2.52. Southdale Mall, Minnesota.

Figure 2.53. Trafford Centre.

Manchester, UK.

Figure 2.54. Mercato Shopping Mall. Dubai, UAE.

Figure 2.55. West Edmonton Mall. Edmonton, Alberta.

Figure 2.56. La Defense Quatre Temps Mall. Paris, France.

\section{The Shopping Mall}

The completely internalized shopping mall was introduced in America by Austrian architect, Victor Gruen, often called the father of the American shopping mall. The mall was a reaction to his hatred toward the growing reliance of cars in suburban America. (Hardwickall 2003). He described cars as noisy and antisocial machines responsible for the downfall of American cities and public life. Coming from Vienna, Gruen was inspired by the organic diversity of European shops, markets and greenery that fostered community belonging and connection that he found was lacking in America. Acknowledging the American reliance on cars though, Gruen wanted to create a destination people had to drive to, subsequently abandon their cars, and then proceed on foot. Southdale Mall in Edina, Minnesota opened in 1956 as the first fully enclosed pedestrian shopping mall containing over 70 shops, 2 department stores, and a massive center courtyard that was skylit with a year round temperature of 24 degrees, simulating the streets and plazas of European cities (Hardwickall 2003). As an architectural object in the suburban landscape, Gruen intentionally left the exterior blank and ominous, and the interior spaces become the draw, awing visitors as they transitioned from outside to inside. Consumers were given a safe, climatically comfortable "city-like" alternative to spend their leisure time in, becoming the new "public space" of suburbia. Strategies of successful mall designs reduce storefronts to modest scales and proportions that encourage slow movement and browsing through simulated diversity. The simulation of diversity is created by designing 
Figure 2.55

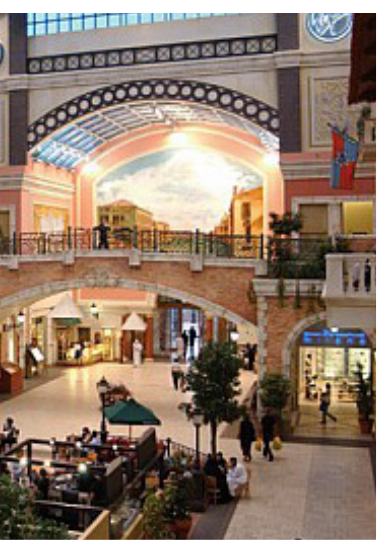

Figure 2.56

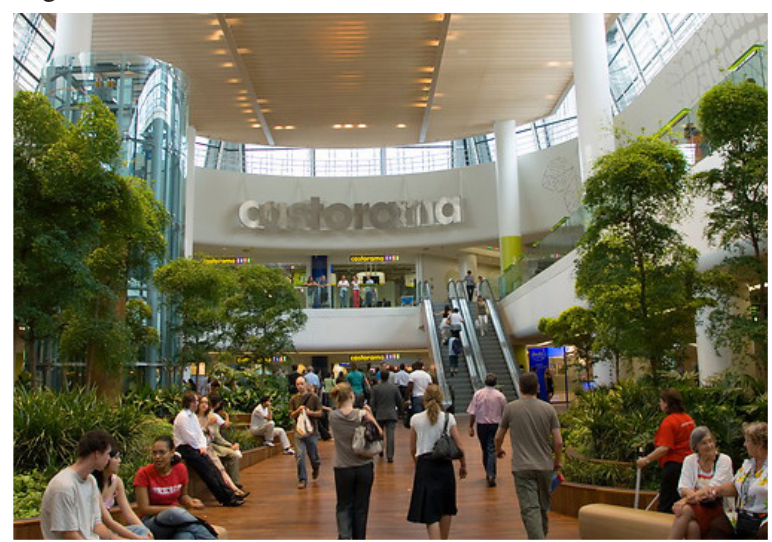

separate districts and zones within the mall to create different places within a place that breaks down its behemoth reality. Small scale storefronts and kiosks in the "streets" evoke the small town marketplace to become not only places for consumption, but social spaces, spatializing a desire for the public activity and liveliness in the traditional marketplace. Further simulation of outdoor spaces replicate nature itself, incorporating real and fake greenery that attempts to soften and exteriorize the internalized spaces. These simulated spaces allow the consumer to experience the liveliness and social aspects of the traditional urban marketplace in a comfortable, clean, and safe environment. It was common to see social groups of all ages forming in the food court or people walking the mall for exercise and not simply there for shopping (Lonsway 2009).

Ironically though, this new suburban destination, although inspired by densely populated city centers, were draining life from the city itself. By the 1980s, the proliferation American shopping malls, in America and beyond, only encouraged more driving and an abandonment of city centers in favour of the internalized, climate-controlled simulated city. This popular typology grew exponentially and expanded to the rest of the world, where shopping malls in European cities look and function the same as ones in Asian and Middle Eastern cities. 


\section{Pedestrianized Outdoor Malls}

Since the 1990s however, following the success of Jerde's Horton Plaza, the suburban mall has declined in popularity in America. Where the initial suburban mall was a safe haven for middle-class white Americans fleeing the perceived dangers of a racially diverse city centre, increasing immigrant populations in suburbs are now driving affluent populations back into the downtown core, drawn by the lure of shopping once again (Hardwickall 2003). As mentioned earlier, suburban expansion and exportation of production has left many urban districts derelict in favour of convenient and automobilefriendly shopping malls. As a result, urban centres become neglected areas prone to crime, contributing to its perceived dangers and unattractiveness. In attempts to revitalize urban environments, shopping becomes a strategic tool for organization and re-planning. "Lifestyle Centers" or "Urban Entertainment Centres" are commercially driven developments that attempt to rebrand city districts and promote urban revitalization (Klingmann 2007). With a renewed desire for being outdoors, these new shopping centres are open-air malls disguised as romanticised town centres, similar to Disney's Main Street, USA. Karrholm describes them as "malls without walls" (Kärrholm 2012). They contain all the functions of a mall without lookinglike one. Instead, they simulate and copy the appearance of familiar downtown character. These shopping centers combine and overlap four consumer activities: entertainment, retail, dining, and culture into a themed and pedestrianized attraction (Klingmann 2007). These separate components cater to various levels of consumption and entertainment to form a centre of branded consumer experiences.

A desire for such urban redevelopment transformed Santa Monica's Third Street Promenade from a regular side street into festive outdoor mall. Following numerous failed attempts at revitalizing this area of the downtown core, public and private investment in the late 1980s transformed the area by strategically and thematically re-planning the nine-block area. Large cinema complexes and retail flagship stores serve as anchors that encouraged returning customers, while streets were re-paved to encourage cart vendors and street performers to enliven the pedestrian realm. A variety of programs and mix of retail types simulate urban density, where local shops and major chains operated side by side. Bookshops and cafes would encourage lingering and outdoor dining areas increases the intimacy of space, giving the development an illusion of diversity and actively encouraged street life. In recent years though, major franchises have pushed out local brands, losing its unique balance and social diversity, becoming yet another shopping venue in the area. 


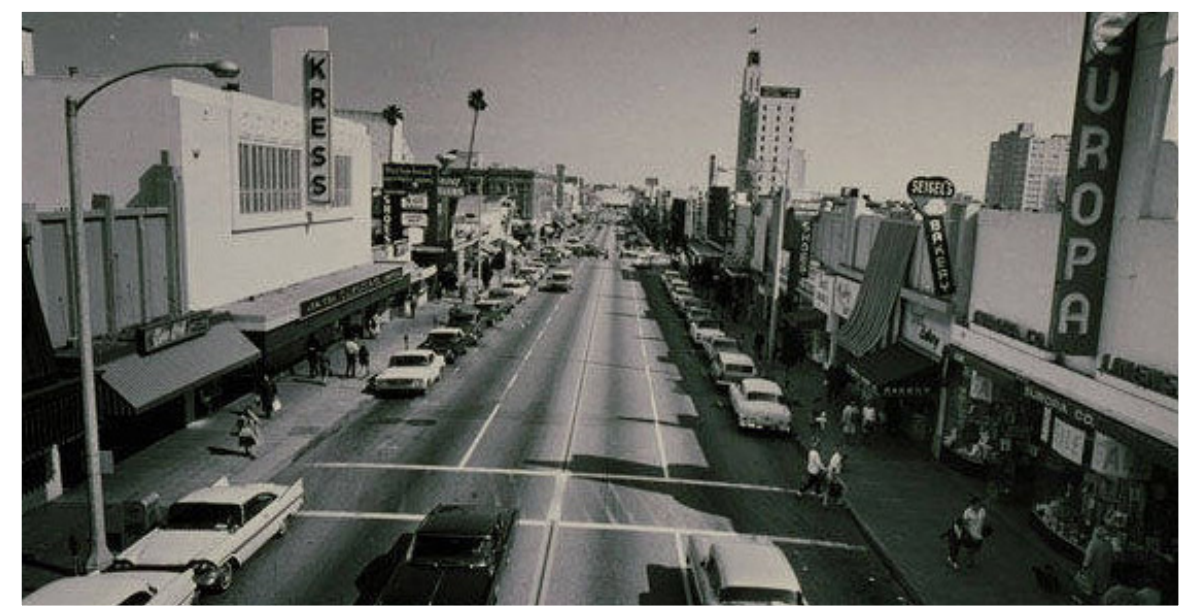

Figure 2.57
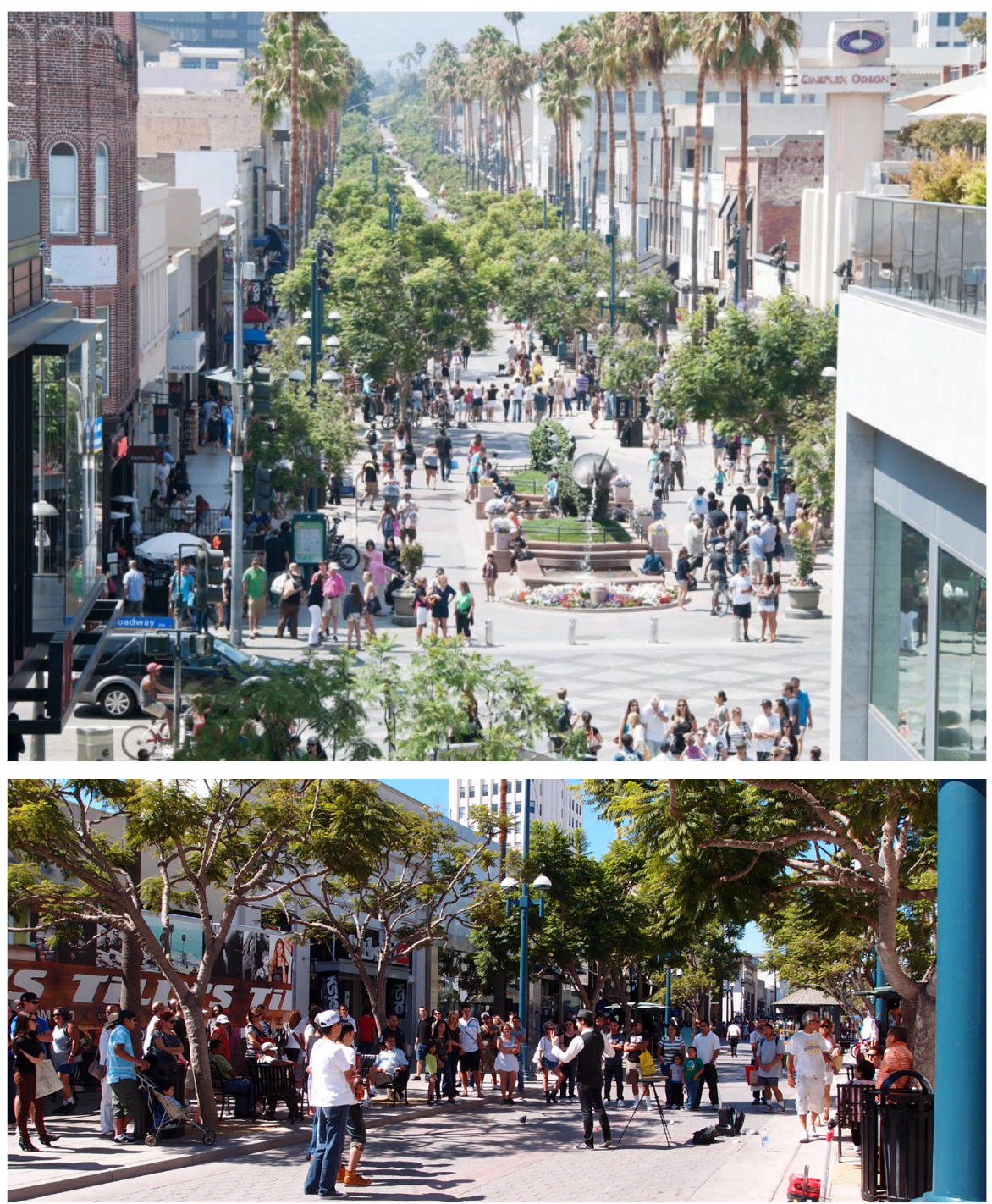

Figure 2.59

Figure 2.57: Third Street, Santa Monica, California. 1965. Prior to redevelopment.

Figure 2.58. Third Street Promenade. Santa Monica, California.

Figure 2.59: Third Street Promenade Street Performances. Santa Monica, California. 


\subsection{4 | A Rhythm of Life}

Figure 2.60: Sync of Retail Actors -

Lowe's Toronto Christmas Market 2012.

Toronto, Canada.

Figure 2.61: Sync of Flows and

Movements - Yorkdale Mall at the interchange of highways. 1964. Toronto, Canada.

Figure 2.62: Sync of Cultural Events and Special Occasions - Maryvale Toronto Public Library inside Parkway Mall. Toronto, Canada.

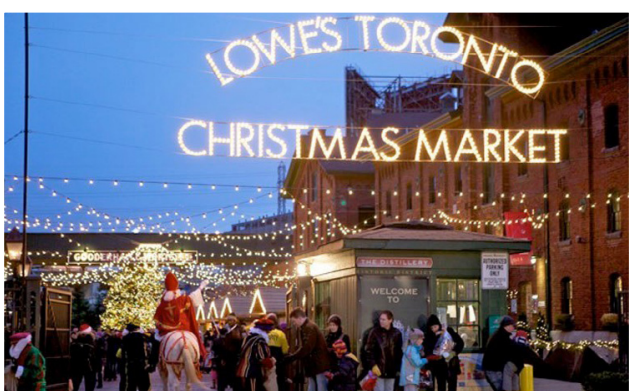

Figure 2.60
In the evolution of retail typologies, it can be seen that retail spaces, indoor or outdoor, is constantly and continuously used as public space. There is a replication of streetscapes and scales in its design and organization that appeal to the desire for urban public street life. Beyond shopping centers, however, shopping and retail has proliferated and infiltrated all typologies, syncing up with the rhythms of urban life itself (Kärrholm 2012). The integration of retail with everyday life is seen through a process of commercial synchronization, and Karrholm identifies 6 types of rhythms that lead to the proliferation of retail in our everyday lives:

1. Synchronization of Retail Actors - By retail actors, Karrholm means any organization that is involved with the promotion of retail sales, including the city government itself. Joint ventures and commercial sponsorships organize and fund "free public events" in the city as a means to encourage public liveliness and attractiveness, but ultimately to gain tourists and consumers.

2. Synchronization of Flows and Movements - Since retail is dependent on a steady flow of people, it adjusts to urban flows and movements to maximize exposure to passers-by, both pedestrians and vehicular. These include nodes of inter-city or inter-regional traffic flows, positioning retail near transit stops or highway exits.

\section{Synchronization of Cultural Events and Special Occasions - Retail} also uses rhythms of events or occasions to organize operations. Stores are open later during Christmas season to accommodate the cultural traditions of gift-hunting. But special occasions also adjust to the convenience of shopping. We can vote, get our taxes done, borrow books, and even get married in the shopping mall.

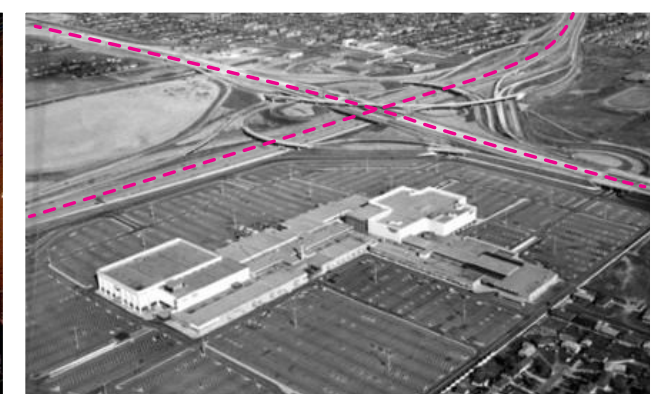

Figure 2.61

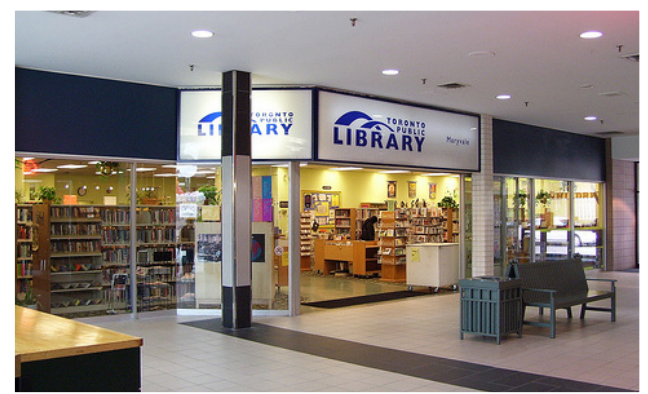

Figure 2.62 
4. Synchronization of Activities - Also known as the hybridization of environments, where retail is inserted or merged with other nonretail activities we would engage in such as museums, libraries, airports, and railway stations.

5. Synchronization of Bodily Rhythms - To keep customers engaged longer, retail is set to adjust to people's bodily rhythms of pace, hunger, thirst, and fatigue. It allows consumers to easily switch from one rhythm to the next. For example, shopping for commodities can switch to shopping for food instead.

6. Synchronization of Collectives - Syncing schedules with certain types of people, such as car owners, retired people, students, etc. These collectives may not be a social group or community, but have aspects of life that are common between them. This allows retail to target specific lifestyles to influence shopper identity.

This proliferation and synchronization of retail to urban life has considered all aspects and rhythms of the way people use, move through, and live in the city. Retail architecture has thus successfully integrated itself into the everyday by engaging users at appropriate scales and rhythms. Beyond a logic of retail placement throughout the city, the architectural environment is used to communicate and induce certain rhythms. Horizontal or vertical planes divide or articulate facades in a rhythmic fashion, setting rhythm and flow by localizing openings, entrances, and windows to encourage lingering (Kärrholm 2012).
Figure 2.63: Sync of Activities - Shopping at the Hong Kong International Airport.

Figure 2.64: Sync of Bodily Rhythms Food Court at Siam Center. Bangkok, Thailand.

Figure 2.65: Sync of Collectives Creative and Meeting Place Co-working Space inside MAYA Mall. Chiang Mai, Thailand.

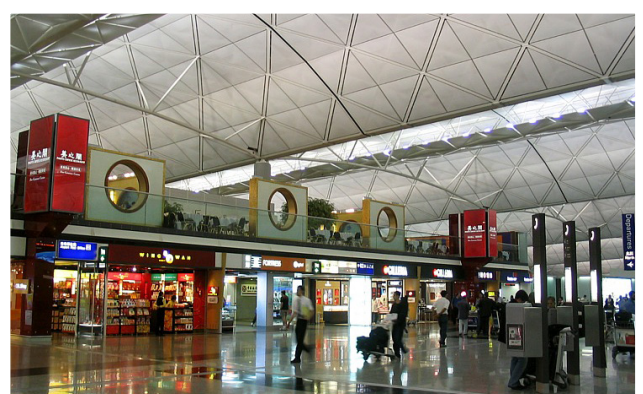

Figure 2.63

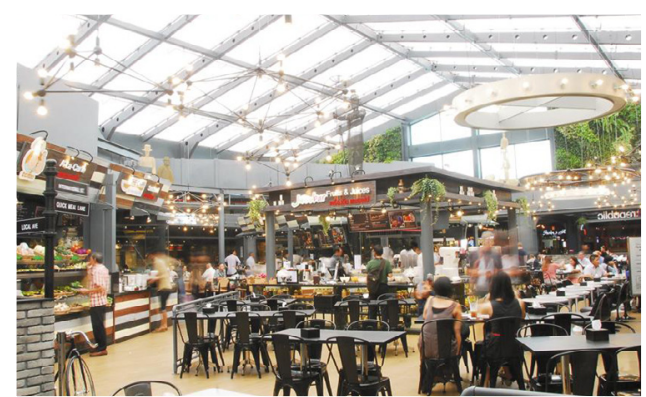

Figure 2.64

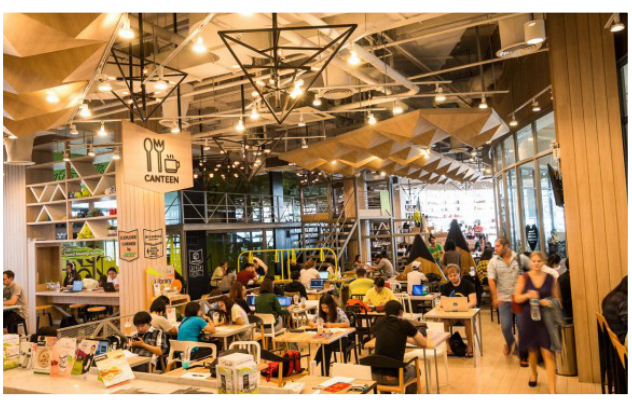

Figure 2.65 


\subsection{5 | A Scale and Rhythm of Users}

Cities have historically grown around the need and preference for consumption, and our cities today are continuously re-shaped by this culture. It has replaced most of our public spaces and has also been a strategy for urban revitalization. It recognizes the needs and preference of users in both subtle and transformative ways. We may not notice it, but our cities are now shaped by our consumption patterns. The mall has essentially replaced the town square and shopping is also an excuse for social life and gregarious connections.

However, beyond the goal of encouraging consumption, retail spaces illustrate the potentials and importance of catering to specific user scales and rhythms. A study of retail spaces and typologies reveal a strategy of simulating scale and rhythm of public street life to maintain shopper engagement. Strategies of successful retail spaces reduce storefronts to modest scales and proportions that encourage slow movement and browsing through simulated diversity, creating different places within a place. These are social spaces that spatialize a desire for the public activity and liveliness in the traditional marketplace. Retail also successfully translates user rhythms into architectural environments, being a more authentic and considerate way to engage users. Thus, the same strategies of scale and rhythm can be used in architectural design to create spaces that are enjoyable to all users. 


\section{6 | Beyond Superficial Entertainment}

Although entertainment architecture has driven contemporary architecture toward a preference and tendency for superficial spectacles, there are still lessons to be learned from entertainment architecture that can be applied to contemporary architecture in positive ways. The values of education, experience, and scales of entertainment architecture begins to mitigate issues of superficiality that we see in contemporary architecture today. Addressing issues of insensitivity toward architecture's program, context, and users, contemporary architecture today fails to communicate or express its purpose or function, is insular and disconnected from its context, and does not adequately address the scale of its users. Discussed throughout this chapter, the values of entertainment architecture provides us with opportunities to address these issues without resorting to spectacles or clichés (Figure 2.66, page 95).

Beyond its superficial appearance, entertainment architecture is structured and choreographed for authentically enjoyable and educational experiences. As places for entertainment, its architecture is in fact conducive to its use and can also address its context and users in more meaningful ways, catering to our basic need for leisure and entertainment. The spatialization of production found in the theme park attraction is a spatial organizational strategy for architectural design that can communicate and provoke an understanding of its use and production in a world of consumption, allowing a journey of discovery and revelation beyond themed artifices. The theme of the city allows us to reference an authentic context and history instead, where the architectural design emerges from and references place-based symbols of its surroundings that are relevant to its location and culture. Finally, beyond the act of shopping, a study of scale and rhythm of streetscapes and shopping centres reveal a strategy for design that accommodates social values of interaction and intimacy based on a scale and rhythm that is suitable for its users. Thus, understanding entertainment as experience, exemplified in the three typologies, these strategies form the basis for architectural design that can instead add value to contemporary architecture beyond visual excitement and iconic appeal, re-establishing a connection between program, context, and users of architecture.

As mentioned earlier, architecture should be able to communicate an appropriate expression with relation to the city and its users, where we can read and interpret a hierarchal system of significance through its built forms. The increasing types of architectural spectacles in the city has begun to homogenize our environments such that any typology is a self-proclaimed monument (Jencks, The Iconic Building 2005) that disregards its context and 
only attempts to capture public attention. At the same time however, this does not mean that non-cultural or "insignificant" buildings and typologies must adopt a mundane expression to be appropriate for the city. This thesis posits that there is an appropriate balance between the mundane and the spectacle that is offered by using strategies of entertainment architecture to authentically express an architecture that is informed by function, is sensitive to context, and adequately addresses the scales of its users.

To showcase the ways in which these strategies can be applied to contemporary architectural design, the thesis looks into non-cultural and non-entertaining typologies for a balance between the mundane and the spectacle. It attempts to articulate an appropriate expression for a typology that is typically utilitarian and unexciting, but civically and socially relevant that also deserves opportunities for flourish and spectacle, driven by the strategies found in entertainment architecture. Thus, a public service facility was chosen as the program to showcase the strategies outlined above and is located within the cultural context of Toronto, Canada. The next chapter will begin to define the parameters and context of the thesis project program and site. 


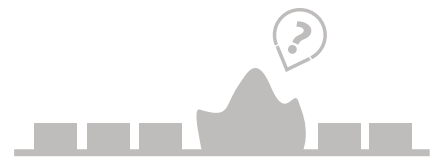

Unable to communicate purpose or function

Issue 1

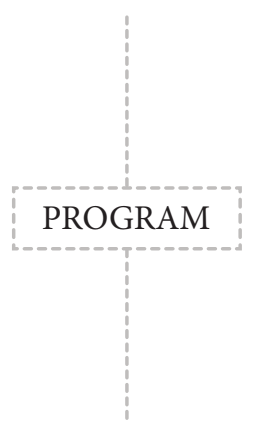

Strategy 1

An Architecture of Work

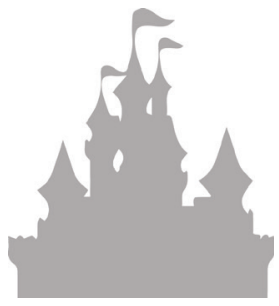

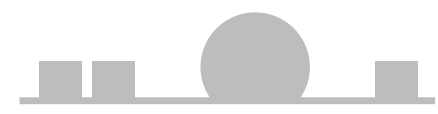

Insular and disconnected from its context

Issue 2

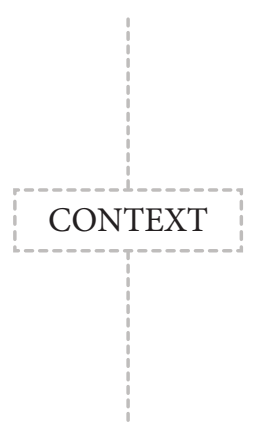

Strategy 2

Theme of the City

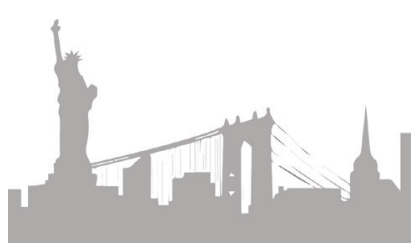

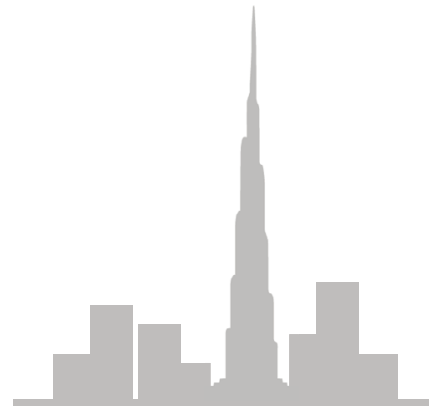

Does not adequately address the scale of its users

Issue 3

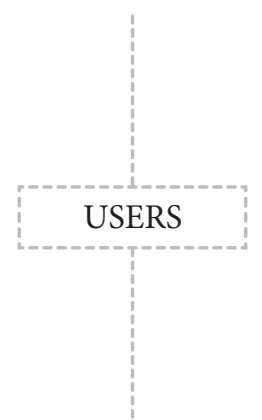

Strategy 3

Scale and Rhythm of Users

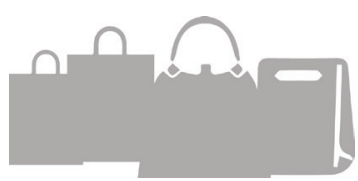

Figure 2.66: Issues and Strategies Relationship 


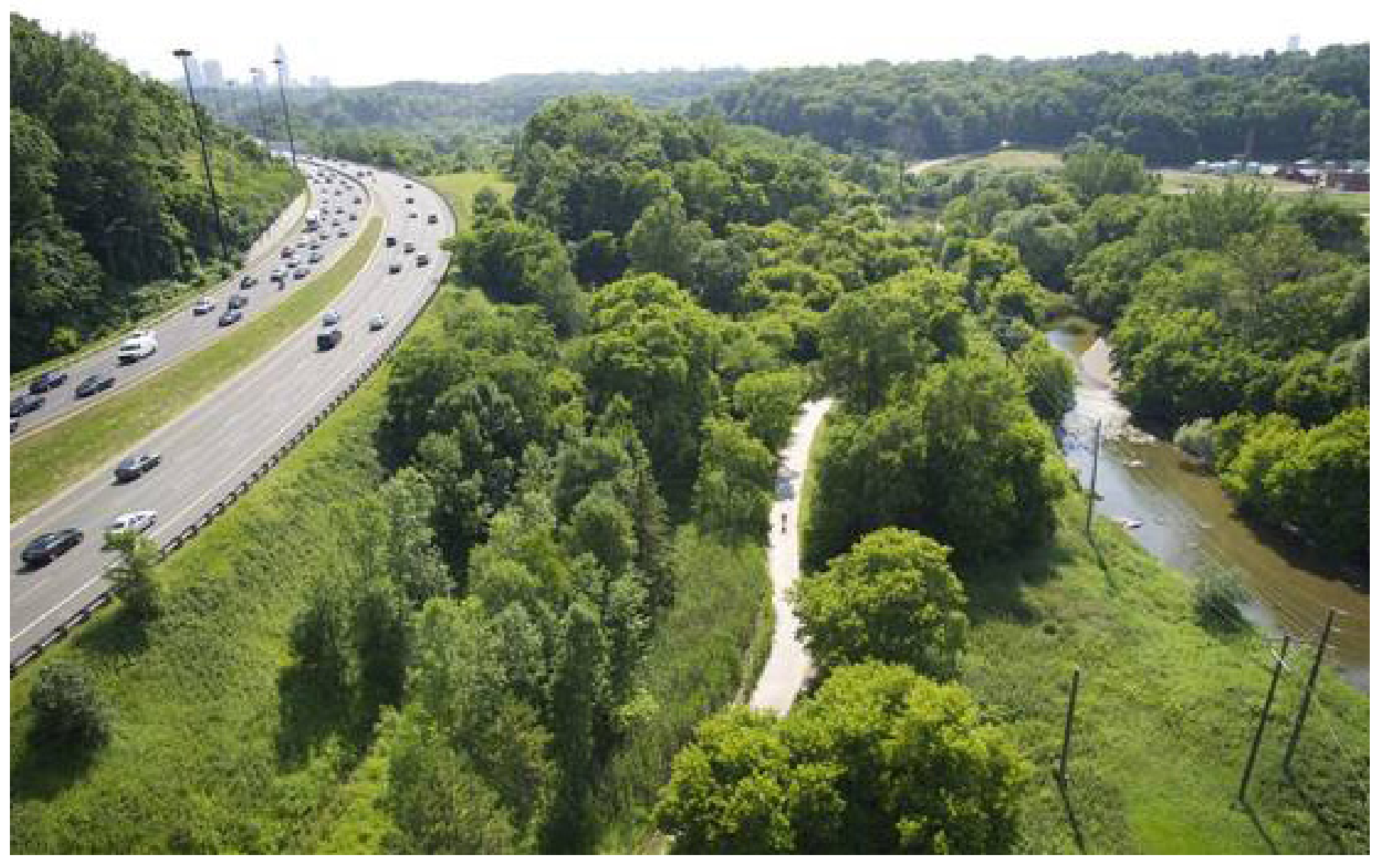


CHAPTER 3

DESIGN I

DEFINING PROJECT SITE, SCOPE, AND BACKGROUND 


\section{1 | Introduction}

\subsection{1 | Cultural and Architectural Context of Toronto}

Figure 3.1: (previous page) Don Valley, Toronto.

Figure 3.2: Map of Canada

Figure 3.3: Map of Downtown Toronto

Figure 3.4: Some of Toronto's different neighbourhoods
Toronto was the only Canadian city to rank in the top 20 global cities of 2014, gaining its leading role as an economic and cultural hub in Canada, ranking 13th overall (ATKearney 2014). In this context of globalization and competition however, Toronto is constantly attempting to define itself on the international stage. As a relatively young and very multi-cultural city, there are challenges of defining and identifying a unified culture and sense of place. As a result, Toronto also turns to the conspicuous consumption of architectural landmarks to establish authority and identity.

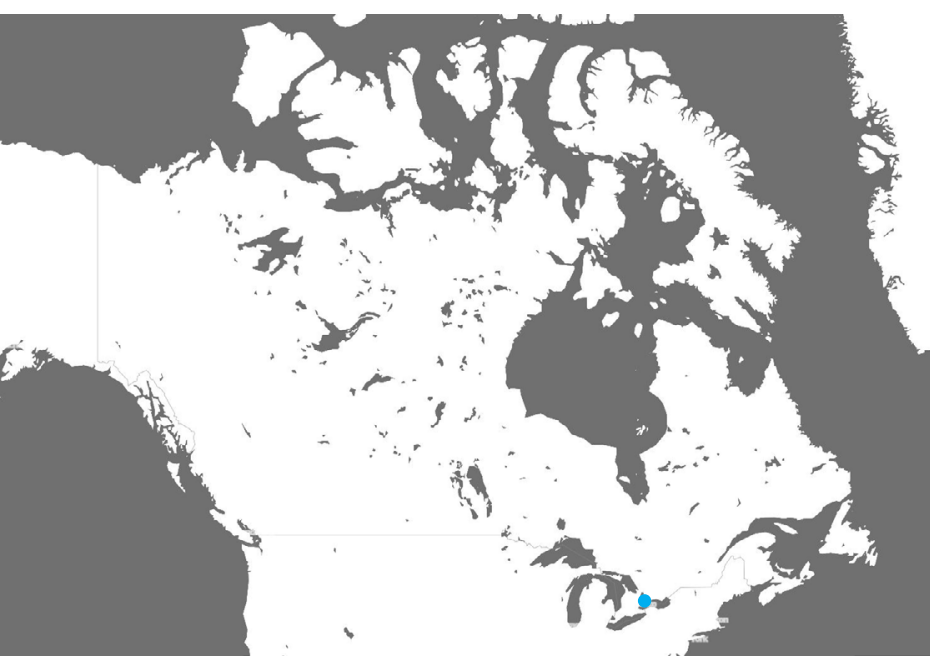

Figure 3.2

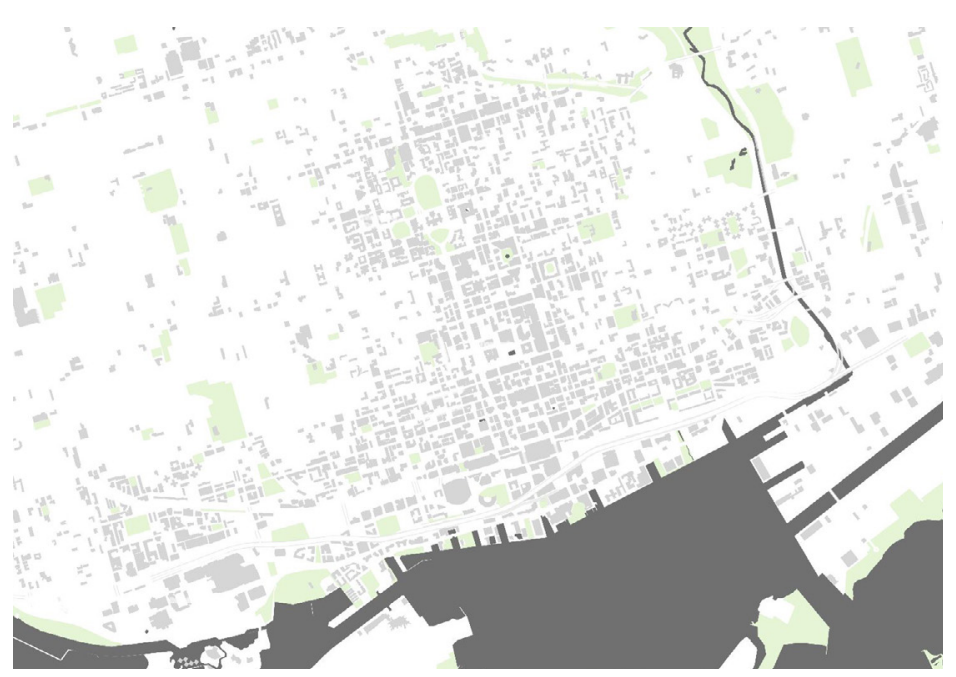

Figure 3.3 


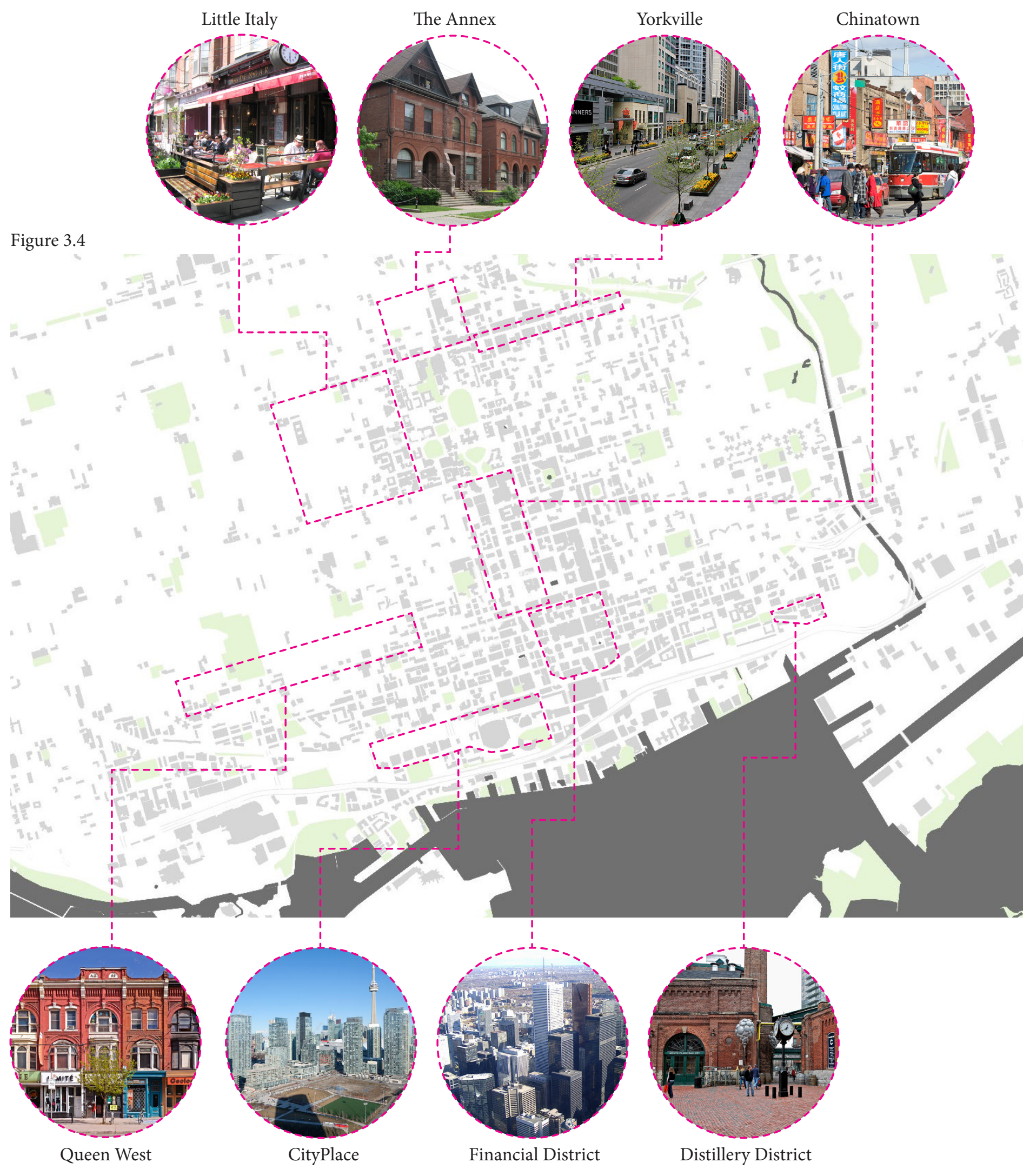




\section{The "Cultural Renaissance"}

As mentioned in previous sections, culture has become a commodity used to signify status and attract economic benefits. The impact of the Bilbao Effect can thus also be seen in Toronto, and the city is also guilty of participating in the conspicuous consumption of architectural commodities, under the title of cultural tourism (Jenkins 2005). Following the economic recession of the early 1990s, Toronto has since undergone economic and cultural transformation that is mirrored and propelled by its built environment. The city has dubbed this construction boom The Cultural Renaissance, aimed to elevate Toronto's economic and cultural status on the international stage (Jenkins 2005). Influenced by the economic success of Bilbao, Toronto's Cultural Renaissance involved all levels of government directing significant funds towards cultural construction projects that will become iconic landmarks and transformational agents in the city (Jenkins 2005). The projects are intended to boost the city's identity and reputation as an international economic and cultural capital, becoming a true 'global city', attracting both tourists and investors into the city. The Cultural Renaissance projects include the ROM, AGO, Canadian Opera Company, Royal Conservatory of Music, Canada's National Ballet School, Young Centre for the Performing Arts, Roy Thompson Hall renovations, and the Gardiner Museum and funded through a combination of public and private investment. International competitions attract starchitects and project publicity that helps add value to these public projects. Starchitects like Frank Gehry (AGO), Daniel Libeskind (ROM), and Will Alsop (OCAD) have each made their marks in Toronto's urban fabric (Figure 3.5).

Figure 3.5: (Page 101, top to bottom)

Art Gallery of Ontario by Frank Gehry, 2008. Toronto, Canada.

Royal Ontario Museum by Daniel Libeskind and $\mathrm{B}+\mathrm{H}$ Architects, 2007. Toronto, Canada.

National Ballet of Canada by KPMB, 2005. Toronto, Canada.

Canadian Opera House Four Seasons Centre by Diamond Schmitt Architects, 2006. Toronto, Canada.

Sharp Centre for Design (OCAD) by Will Alsop and Robbie/Young + Wright Architects Inc., 2004. Toronto, Canada.
Beyond cultural and educational institutions using starchitects to elevate their statuses, Toronto's skyline is also increasingly dominated by high-profile residential skyscrapers. Densification of the urban core brings people back to the downtown, but the massive block-scale private amenity podiums and corporate retail storefronts also displaces Toronto's small-scale neighbourhood character and local businesses. New and taller residential towers around the city are marketed as iconic real estate attractions that aim for distinction and uniqueness, disregarding any real connection to the streetscape. These statement buildings only aim to elevate the status of the possessor, which on one hand, drives housing prices up, and on the other, upsets the urban hierarchy by placing significant emphasis on residential towers

In a city where culture is becoming entertainment and everything aims to be iconic, there needs to be a more authentic and better integration of contemporary social and cultural values beyond program addition and visual appeal that relates to the city's needs for uniqueness, entertainment, leisure, and public space. As such, Toronto will serve as the site for exploration. 

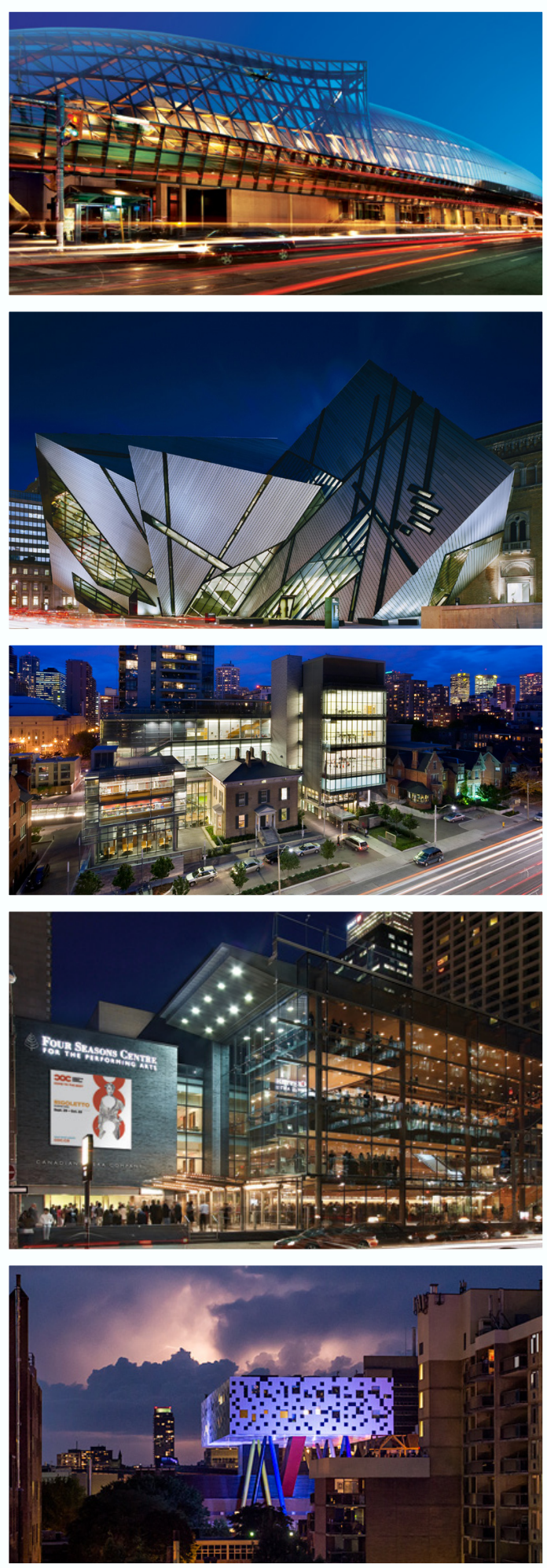

Figure 3.5 


\section{2 | Design Research and Design Project}

\subsection{1 | Iterations and Lessons Learned}

Using strategies of entertainment architecture outlined in the previous chapter, the initial stages of this thesis explored the realms of entertainment architecture that proposed to add additional meaning to entertainment architecture itself. It attempted to engage and infuse meaning to entertainment beyond the superficial façades. Working within the context of Toronto, the first design project looked at the potentials of converting Old City Hall into a shopping mall. The idea of commodifying history was briefly explored. However, the focus of the thesis is not in adaptive reuse or conversion of old landmarks, so this option was not pursued. The second design iteration explored the potential of connecting Toronto's underground PATH shopping system with the city above, establishing a connection between above ground street life and underground street life. The third design iteration looked at combining education and entertainment in the form of a theatre school on Yonge Street. The fourth design iteration explored the creation of a new typology of entertainment space informed by the digital gaming culture. Further elaboration of these design explorations and research can be found in Appendix A.

To summarize some main issues and revelations, entertainment typologies were initially used as a basis for design, and issues of appropriateness and the inevitability of superficiality emerged from the studies. As buildings for entertainment, its architecture inevitably tends toward the superficial, aiming to excite and capture the attention of users. These explorations were useful in understanding how to navigate the fine line between superficial expressions and subverted meaning. It was found that superficiality was in fact an appropriate response to entertainment typologies.

As such, the final exploration moved away from a reliance on entertainment as a typology and looked at civic relevance in the context of the Experience Economy. As mentioned in previous chapters, people engage in activities and places for experiences in order to define lifestyles and identity. Beyond entertainment, the contemporary urbanite seeks other cultural experiences that can contribute to establishing identity and enhance physical and mental well-being. Hence non-entertaining, but civically relevant typologies were examined, using architecture as a catalyst to rebrand certain stereotypes associated with public service facilities. Using the animal shelter as a site for exploration, this thesis presents a design that uses architecture to enhance and benefit the image of the facility. 

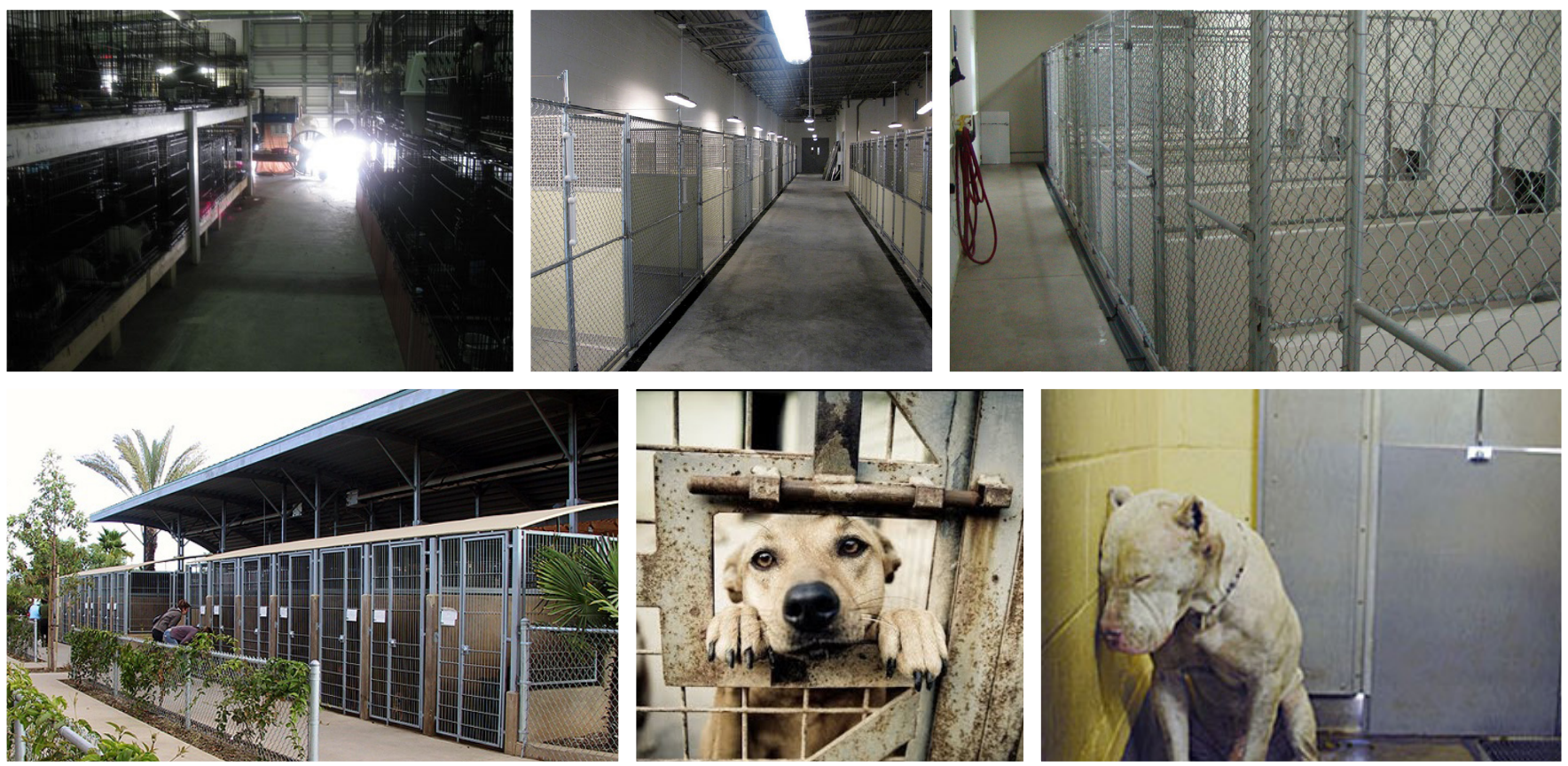

Figure 3.6:

\subsection{2 | Design Project}

The animal shelter, which is not considered a cultural building nor an entertaining facility, will be a site for showcasing the strategies for design outlined in the previous chapter. The thesis project is an exercise in rebranding through architectural design that turns the animal shelter into a place with social and cultural significance without resorting to superficial or cliché expressions.

Studies have shown that animals are a source of great comfort and companionship. Regardless of social class, a pet's playfulness, loyalty, and commitment are qualities that are therapeutic in nature. Pet ownership also establishes a certain lifestyle and enhances physical and mental well-being of highly stressful city-living. As facilities that aim to heal and help transitioning animals find permanent homes, the animal shelter can also benefit from a new image through architectural design. Since architecture is an artefact shaped by its cultural surroundings, it gives the shelter a renewed sense of appreciation and purpose it desperately needs. Using the existing Toronto Humane Society for both project site and program, the architectural manifestation will rebrand the stigma and stereotype of the animal shelter being perceived as merely a holding facility for unwanted, abandoned, and sick animals. The project will reimagine the facility as a place that can provoke and communicate more authentic and sincere relationships between its built forms and its use, context,

Figure 3.6: Typical animal shelter facilities 


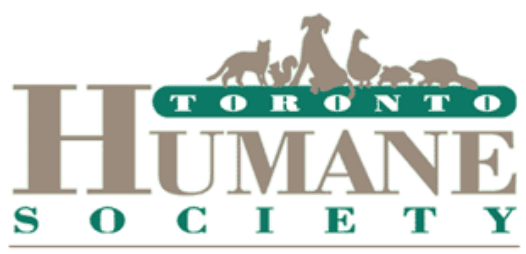

\subsection{2 | Toronto Humane Society}

\section{Introduction}

The Toronto Human Society (THS) was established in 1887 as an institution that promoted the humane treatment of both children and animals through regulations, laws and education for the prevention of cruelty. Today, the THS continues to run as a non-profit organization as an animal shelter and animal rescue center. The shelter now deals primarily with domestic animals (including dogs, cats, rabbits, hamsters, gerbils, turtles, lizards, and birds), either surrendered by owners or transferred from other shelters.

Their wildlife license was revoked in 2009 following an Ontario Society for the Prevention of Cruelty to Animals (OSPCA) raid for allegations of animal cruelty. The raid found poor management, understaffing and overpopulation of animals to be sources of cruelty and misery for the animals (Clark 2011). With a personal mission to accept any and all animals, the shelter's former CEO is found to have crowded the shelter to a point where it became inhabitable for animals and an unworkable environment for employees and volunteers. As such, the THS lost its affiliation with the OSPCA and can no longer accept stray animals and wildlife directly (O'Toole 2012). The shelter has since cleaned up its facilities, only accepting owner surrendered or shelter transferred animals for re-homing, keeping their numbers manageable. Yet, the THS still struggles with poor reputation and image after the seeming betrayal of public trust.

"A shelter is not meant to house animals. It should only be a way station"

Figure 3.7: First Headquarters of the Toronto Humane Society at the intersection of Bay Street and what is now Wellesley Street.

Figure 3.8: Current Toronto Humane Society Facility at Queen Street E and River Street.

\section{- veterinarian at THS (Clark 2011).}

The THS is not simply a place that takes in unwanted animals, but also ensures that each one's needs are attended to in order to ensure an appropriate quality of life and subsequent appropriate re-homing. Its current building communicates the exact opposite, presenting ominous and unwelcoming brick walls on all sides. Apart from the signage at the corner, the facility is unidentifiable and projects an image of solitude and confinement. Thus, the facility is in desperate need for an improved image, both in terms of operations and the way it presents itself to the public. It needs emphasis on transparency, humanity, and sanitary conditions that can educate and appeal to the public as well as attract investment and donations. 


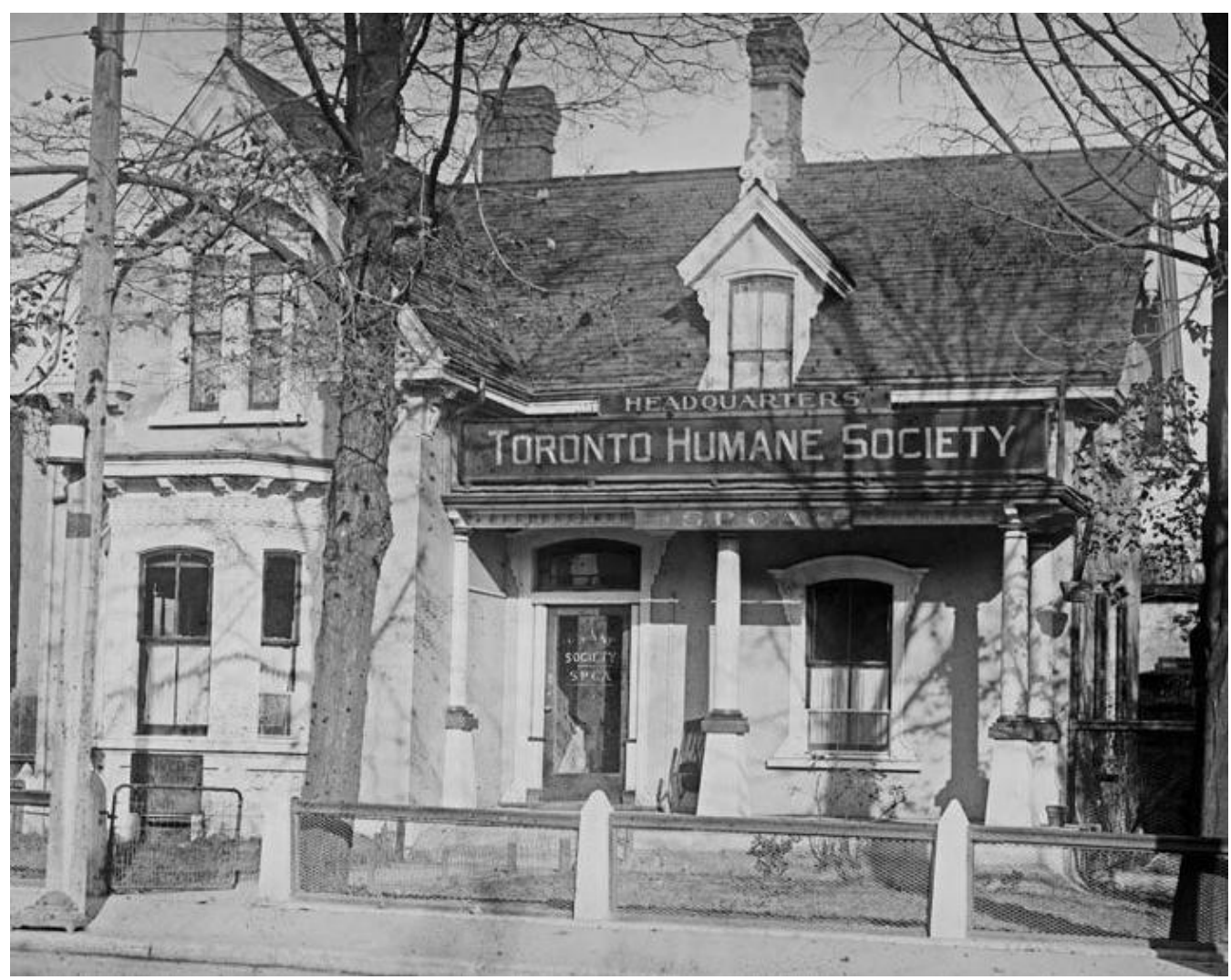

Figure 3.7

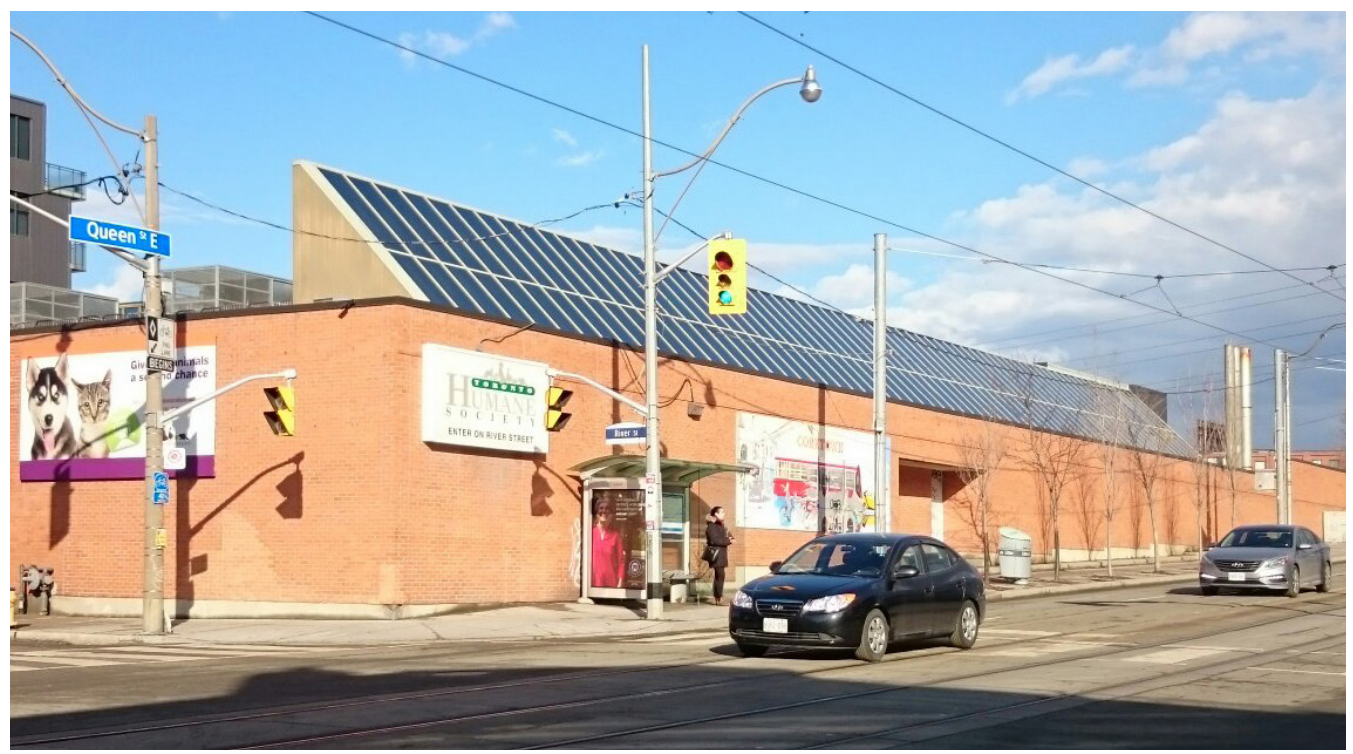

Figure 3.8 
Figure 3.10

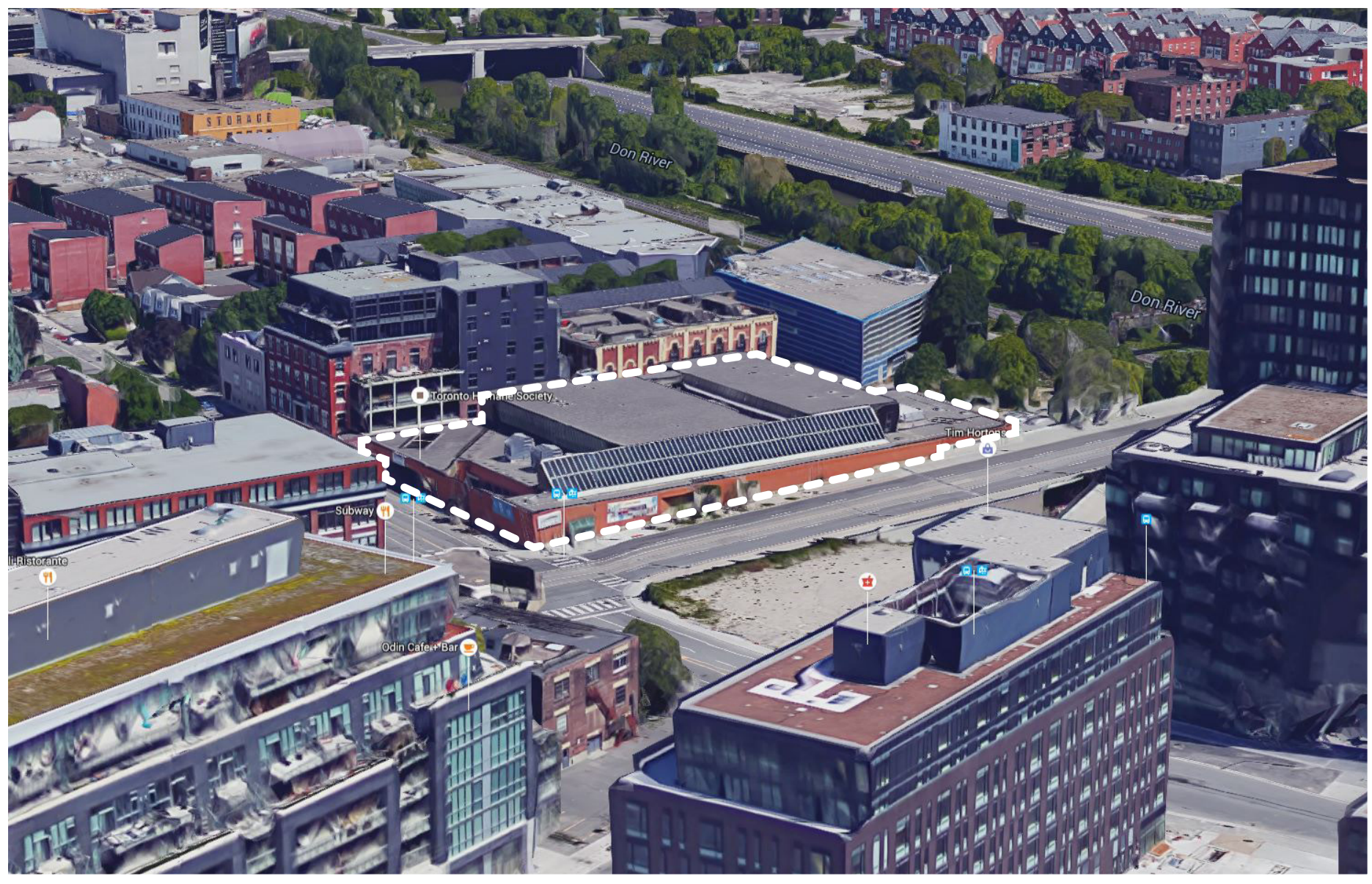

Figure 3.10: Aerial view looking northeast. 
Figure 3.11

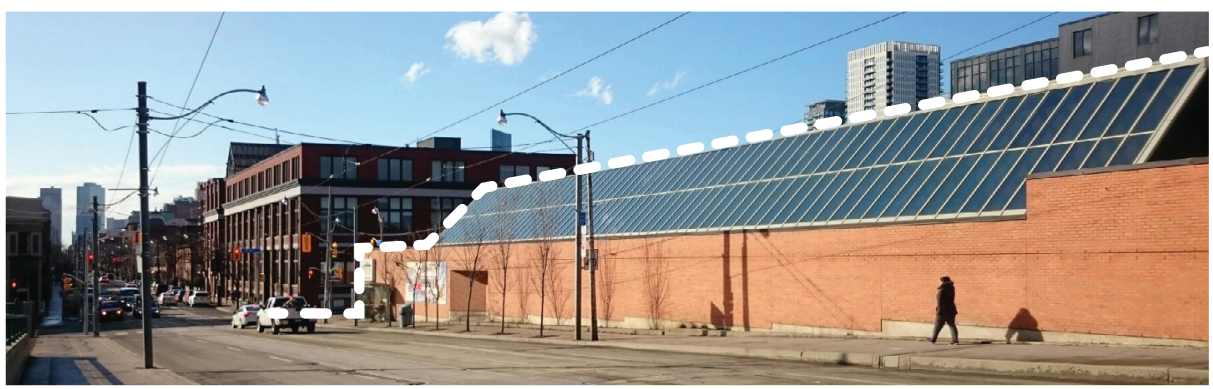

Figure 3.12

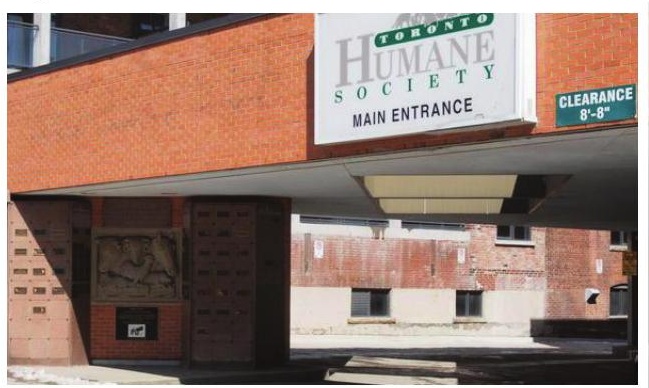

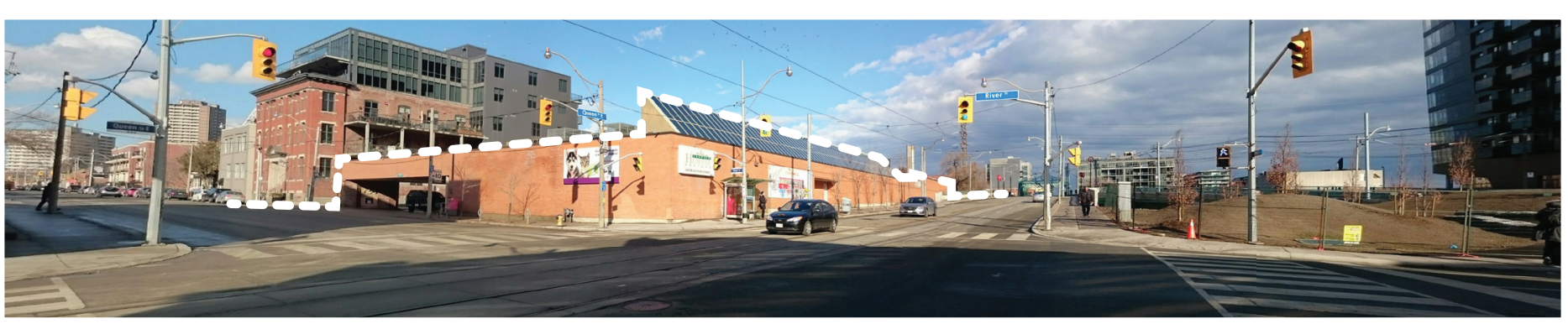

Figure 3.14

Figure 3.11: South facade of THS along Queen St E.

Figure 3.12: THS entrance and drop off.

Figure 3.13: Westbound 501 Queen streetcar stop in front of the THS.

Figure 3.14: View looking northeast at the corner of Queen and River Streets. 
The THS is currently located at the east end of downtown Toronto, between the neighbourhoods of Regent Park, Corktown, and South Riverdale. It sits at the northeast corner of River Street and Queen Street, bordering the Don River. Old Brewery Lane sits to the north and Bayview Ave to the east of the site (Figure 3.9, page 109).

The proximity to the new and redeveloping neighbourhoods of Regent Park, Corktown, Leslieville, and Lower Don River Trail provides amenities and people in its immediate context that allows for a diverse mix of people and nature that can benefit the shelter's program mission of raising awareness and visibility. The new neighbourhoods are expected to bring 80,000 new mixed income residents to the downtown, and this mix of housing types are also an ideal opportunity to accommodate different sized pets.

The site of the THS, at the western edge of the Queen Street Bridge, is also positioned as the gateway to the downtown core. The building, then, not only functions as an animal shelter, but can act as a locational signifier of this transition as well. The neighbourhoods of Corktown, West Don Lands, South Riverdale, and Regent Park converge at this point, and a pedestrian stair links the city above with the valley below. To understand the influence and growth of this context, an understanding of the changing perceptions of the Don River and Valley is needed.

Figure 3.15: Existing Site Plan

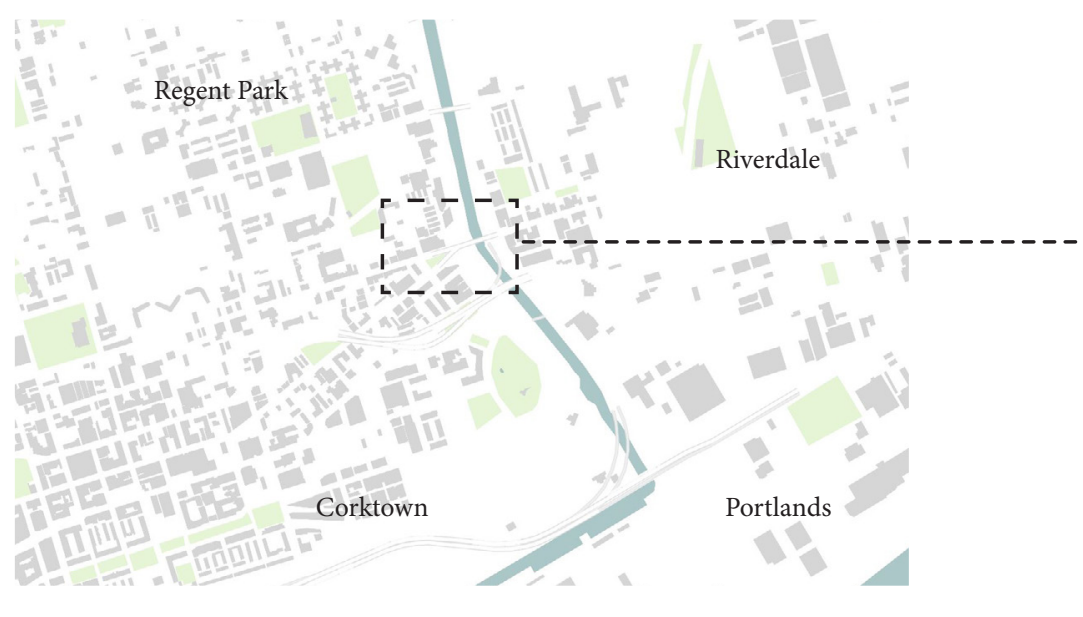


Figure 3.15

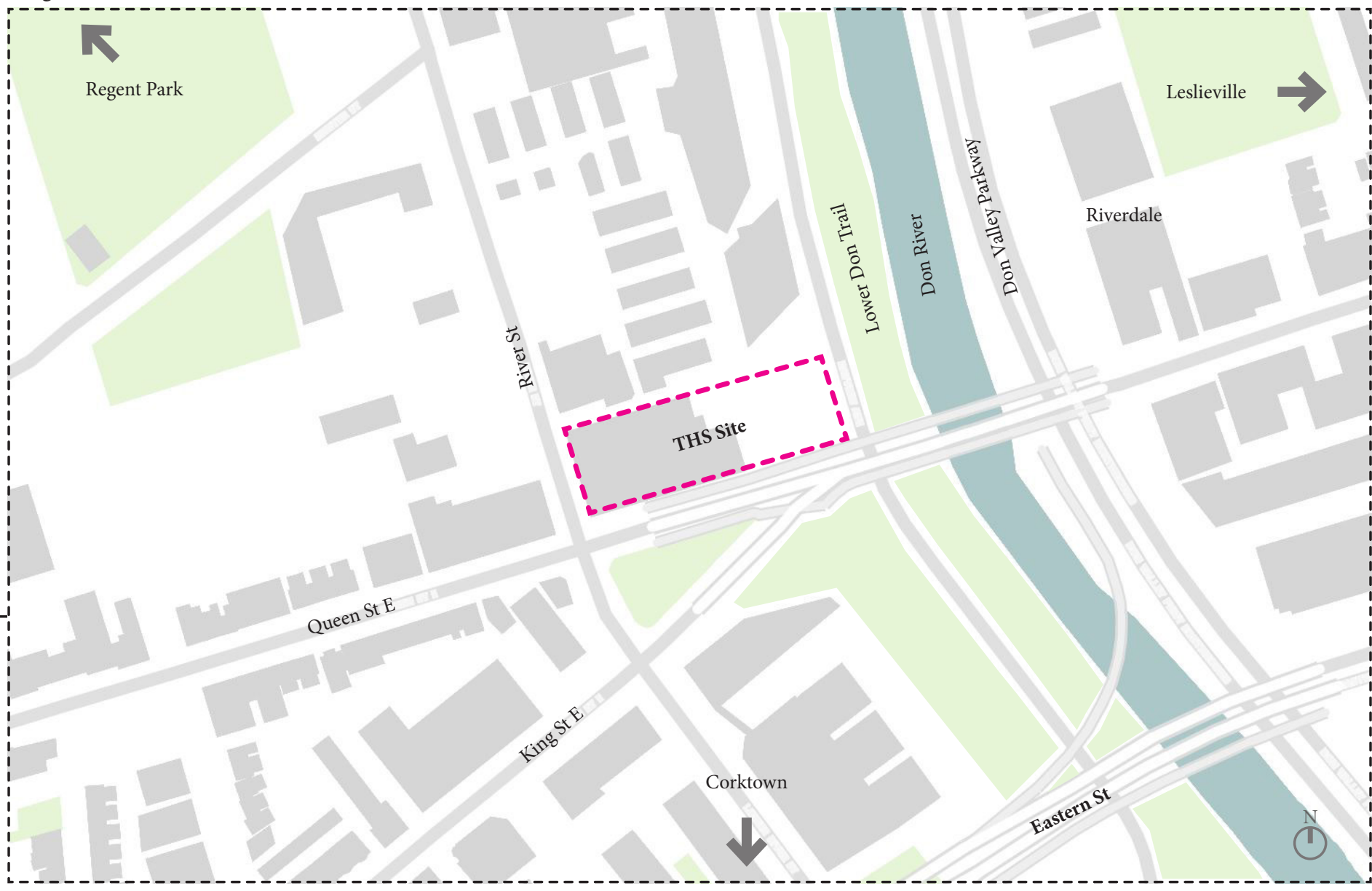




\subsubsection{The Don River Valley - History and Relevance}

The Don Valley is a landscape for recreation and leisure in the centre of the city. However, the Don Valley and River were not always enjoyed as recreational landscapes. We still experience the repercussions of heavy industrial use along lengths of the river, while rail and vehicular infrastructure constantly remind us of the impact of industrialization on the landscape. Yet, the neglect and pollution of the Don has been integral to the growth of the city, allowing Toronto to become the city it is today. An analysis and understanding of the history and development of the Don River and Valley was explored to get a sense of the site's history and significance. The works of historian Jennifer Bonnell (2014) and conservationist Charles Sauriol (1992) on the history and development of the Don River are understood and summarized in Appendix B, while some main points and themes are explained below. Figures 3.15-3.20 on page 111 summarize the physical changes to the river, valley system, and city throughout the years.

The Don River and its surrounding landscapes first attracted country estates for recreation and government use in the 1800s, but as it was increasingly exploited for industrial use, it quickly became unfit for habitation and heavy industries took over. This established the Don as the city's eastern margin, drawing industry and institutions (hospital, jails, and asylum) to its rural setting. The natural landscape was seen as a restorative force for physical and mental rehabilitation, as well as a provider of natural resources and a site for waste disposal. The straightening of the Don River in 1886 attempted to improve sanitary conditions and fill lands for more industrial use. However, this initiative only exacerbated flooding and pollution at the lower reaches of the river. The Don River and valley continued to support industrial activity until the 1950s. It had a poor reputation for being a magnet for social and industrial discards. Since the construction of the Don Valley Parkway in the 1950s-60s however, the experience and perception of the Valley has been recentered as a vital transportation corridor. It allowed the city's expansion into the suburbs, and the Don Valley became a natural and scenic backdrop for driving down the Parkway and a foreground to the Toronto skyline beyond. With this scenic backdrop, there has been a renewed appreciation for Toronto's urban green spaces. With a decommissioned industrial core, the rehabilitation of past industrial lands for public use can be seen along the valley, focusing on public recreation and urban space. While new and revitalized neighbourhoods of Regent Park, Leslieville, and Corktown are bringing more people into the area, the Valley is increasingly seen as Toronto's backyard, with potentials to provide much needed natural park and recreation space in the city. 


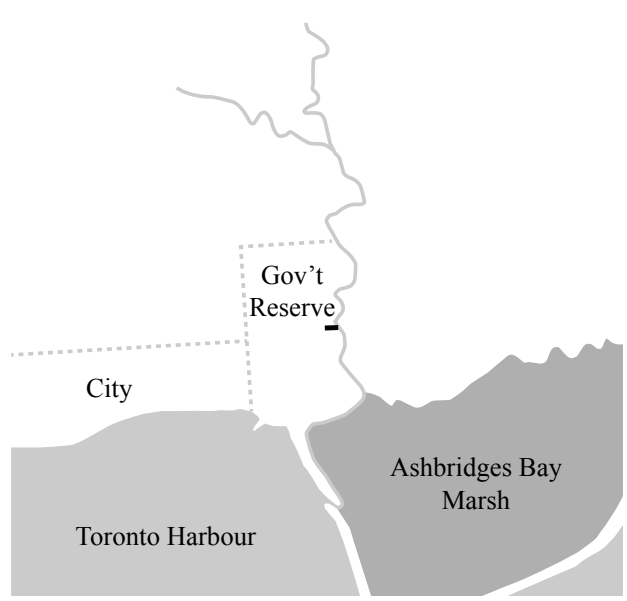

Figure 3.15: 1800-1840 plans for government reserve

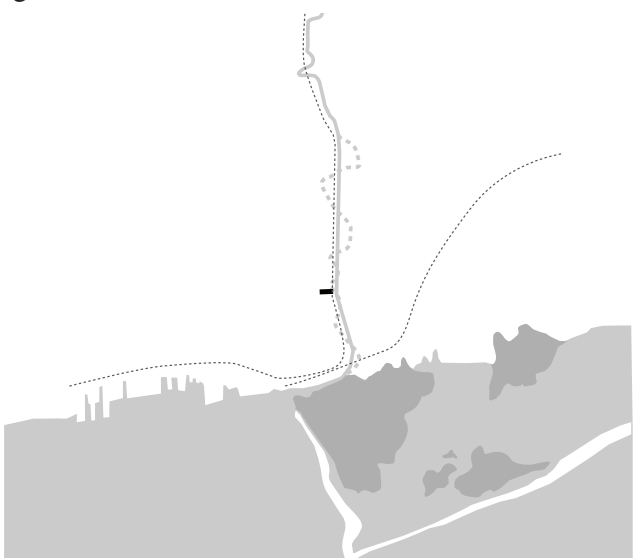

Figure 3.17: 1886 "taming" of the river and introduction of rail infrastructure

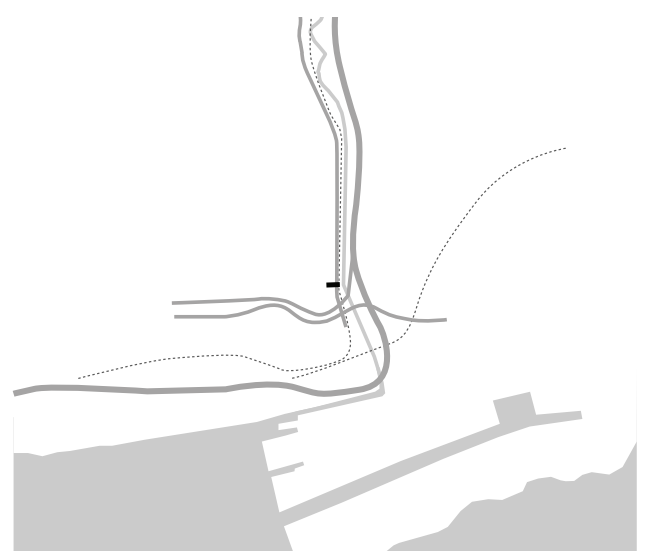

Figure 3.19: 1950-1960 introduction of the Don Valley Parkway as a civilizing force and transportation corridor that allowed expansion into the suburbs

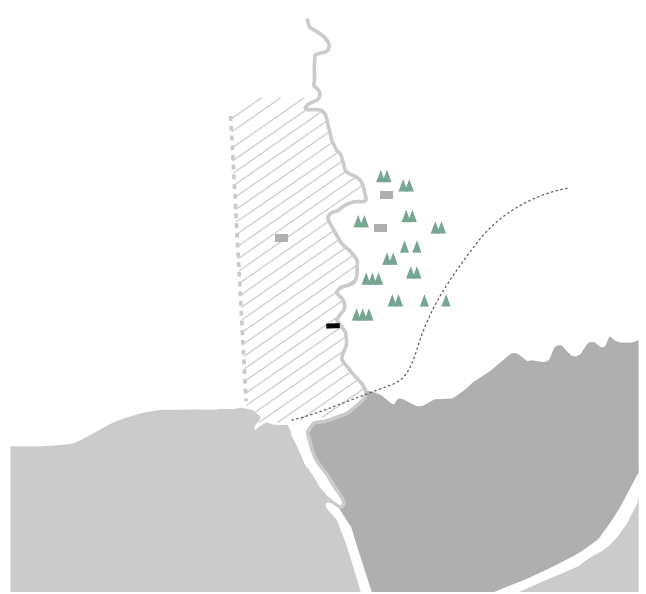

Figure 3.16: 1850-1880 industrial and rural landscapes

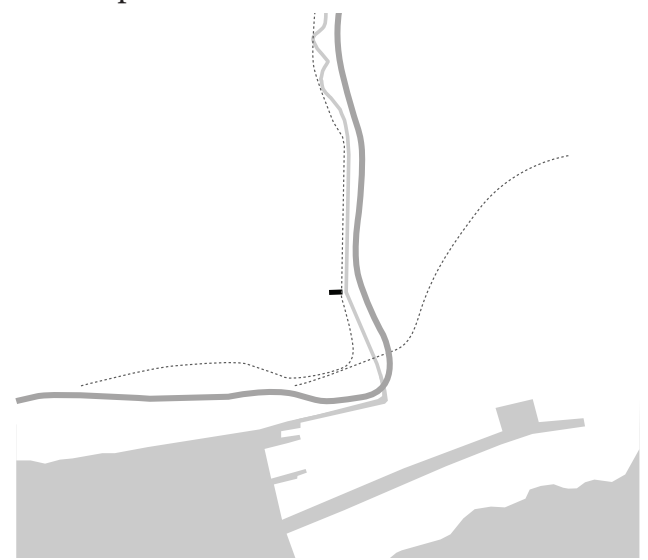

Figure 3.18: 1890-1940 Ashbridges Bay Marsh filled to reduce spread of disease in stagnant waters

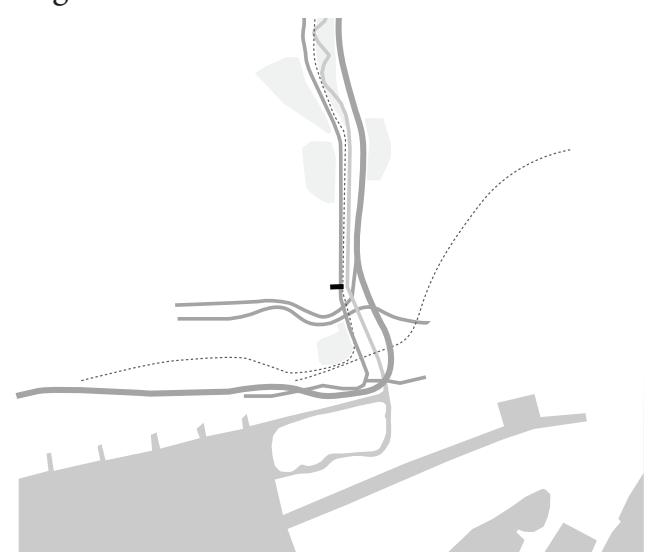

Figure 3.20: Today - reintroduced recreational landscapes along the valley. Future -Re-naturalize river mouth for flood protection and habitat creation 
Figure 3.21: Lithograph of the Don Brewery from 1887 by Peter A. Gross. City of Toronto Archives.

Figure 3.22: The Malthouse before conversion. 2010.

Figure 3.23: The Malthouse Lofts. 2012.

Figure 3.24: Queen Street E looking north with Queen City Vinegar Co on the left and the Malting House on the right. 1978.
The site of the THS at the lower reaches of the Don River was formerly the Don Brewery (Figure 3.21), one of the area's prominent distilleries in the 1800 s, drawing from the river for brewing and malting. The Davies family owned the brewery as well as the Don Valley Brickworks, and was responsible for building employee housing in most of the area, giving it the industrial character we see today. Prior to the straightening of the Don in the 1880s, the river's original course actually meandered through the site (Figure 3.27, 3.28 page 113). As such, the area (including portions of the Don Valley Parkway) still experience floods and drainage issues after heavy rainfall: a reminder that human interventions of 'taming' natural hydrology and river systems are not always possible.

The Don Brewery closed in the 1930s and the malting house has since been converted into residential lofts just north of the site (Figure 3.23) (Bonnell 2014). As a small urban waterway, the Don River has always been integral to the growth of Toronto. Recurring themes of recreation and modernization continuously change its landscape as it attempts to satisfy all the needs of a growing city. As it stands today, the valley is used as both recreation grounds to escape the city as well as a vital transportation corridor of the city. An interweaving of nature and infrastructure, the valley continuously supports both uses.
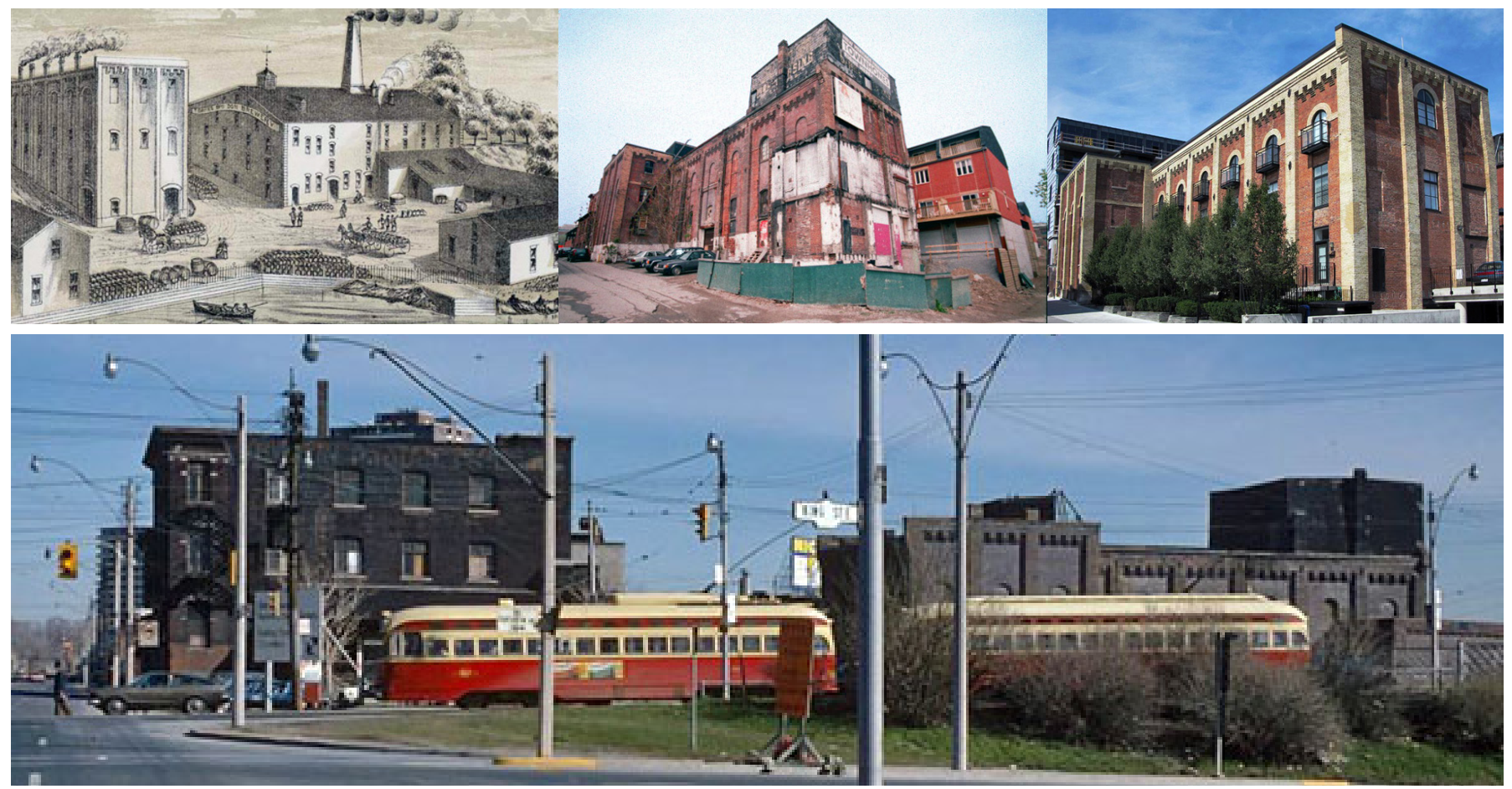

Figure 3.24 


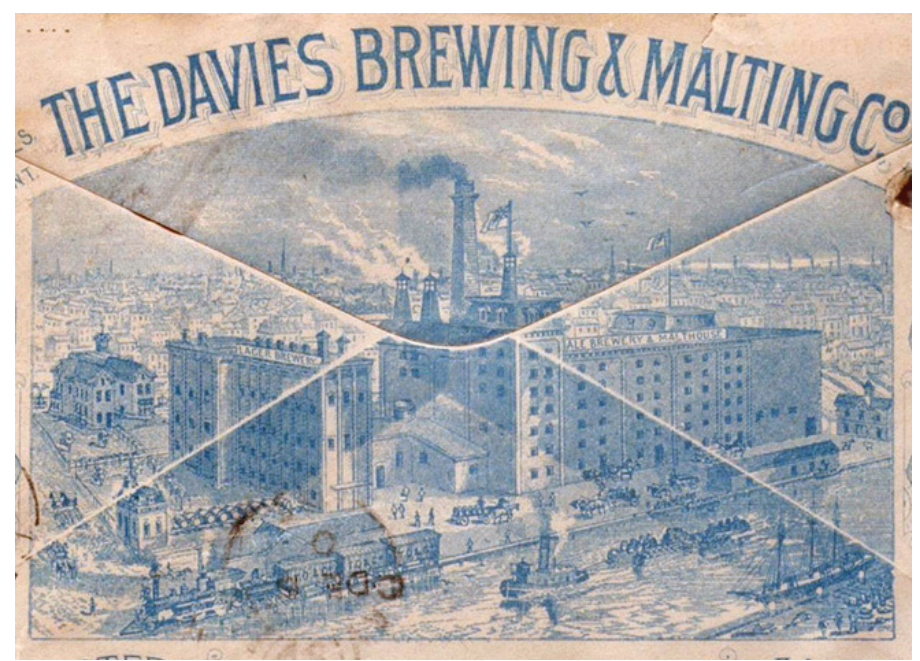

Figure 3.25

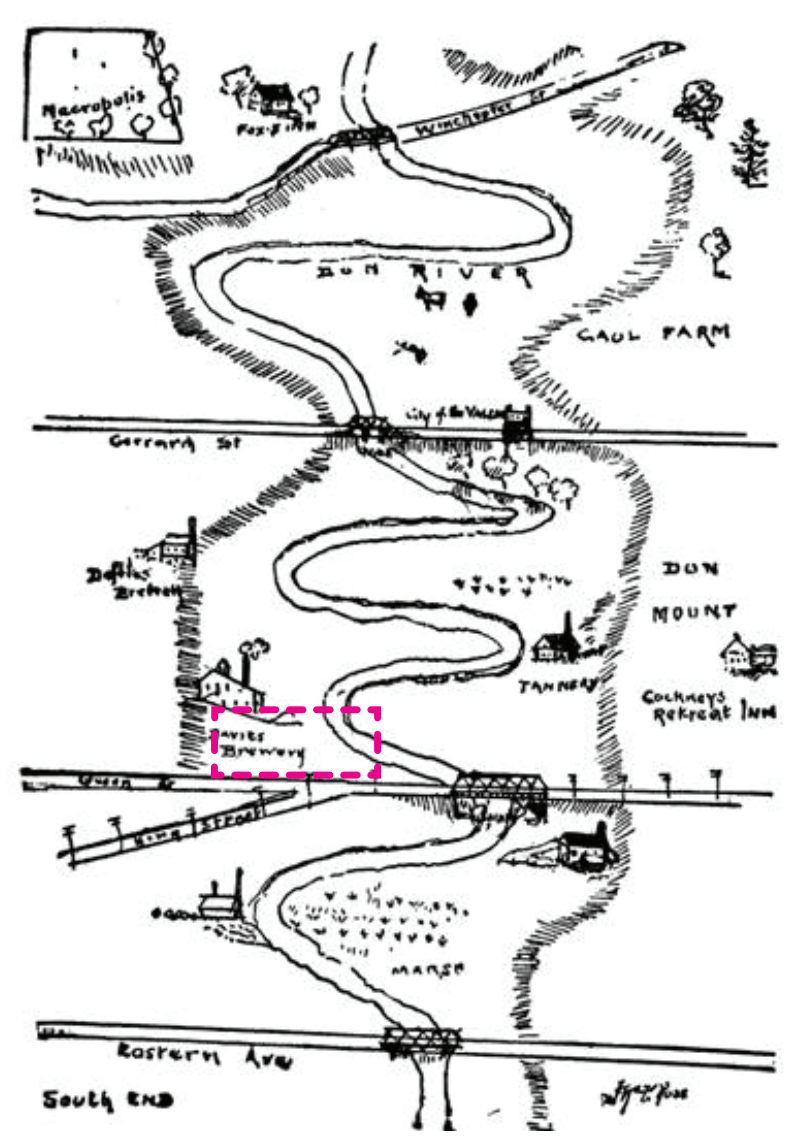

Figure 3.27

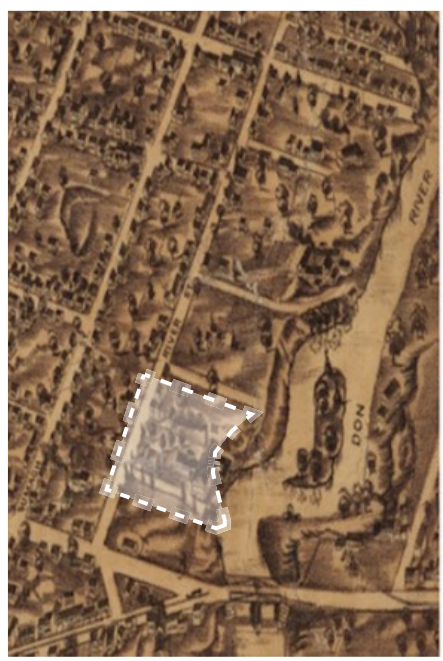

Figure 3.26
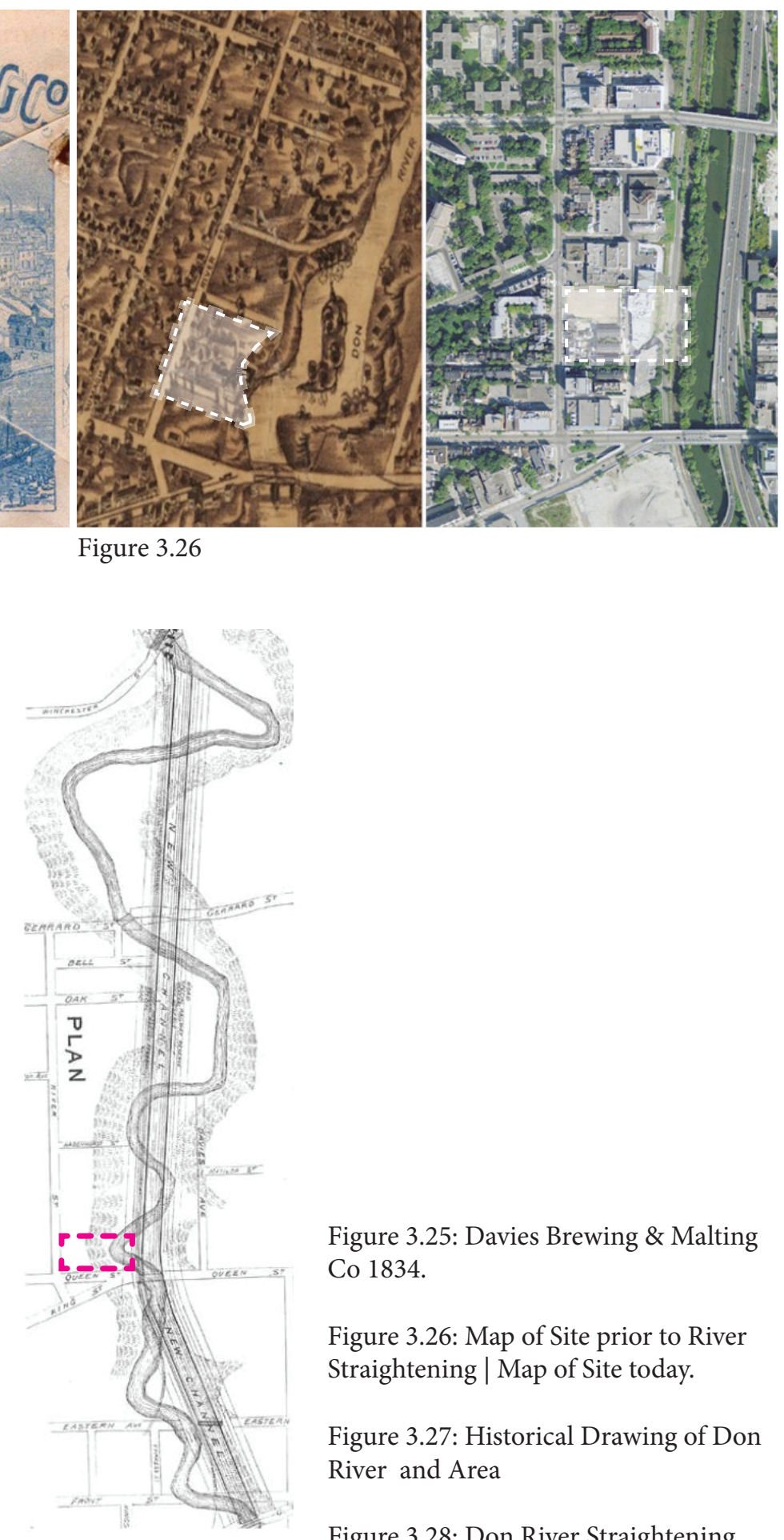

Figure 3.28
Figure 3.25: Davies Brewing \& Malting Co 1834.

Figure 3.26: Map of Site prior to River Straightening | Map of Site today.

Figure 3.27: Historical Drawing of Don River and Area

Figure 3.28: Don River Straightening Plan, 1886. 


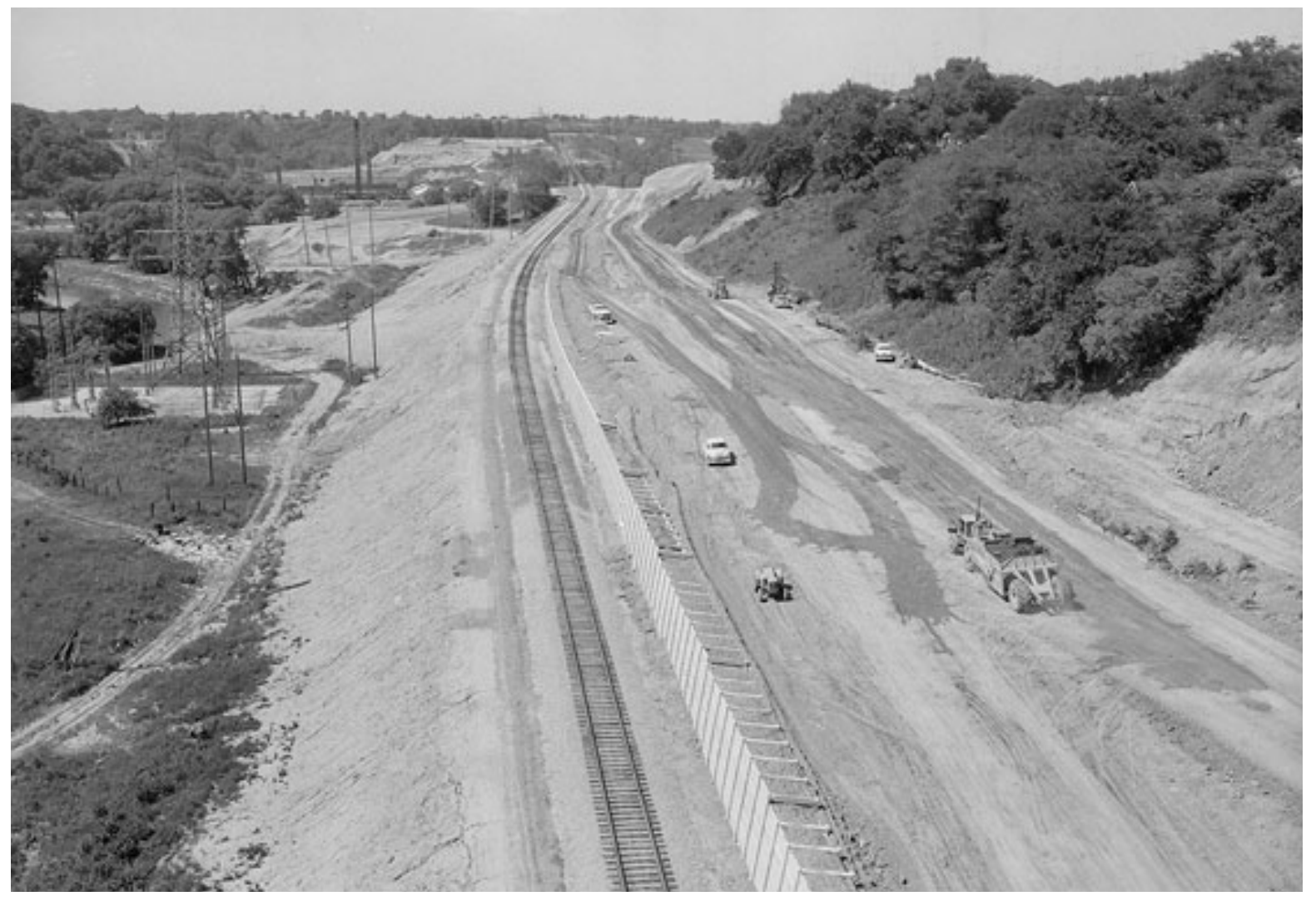

Figure 3.29

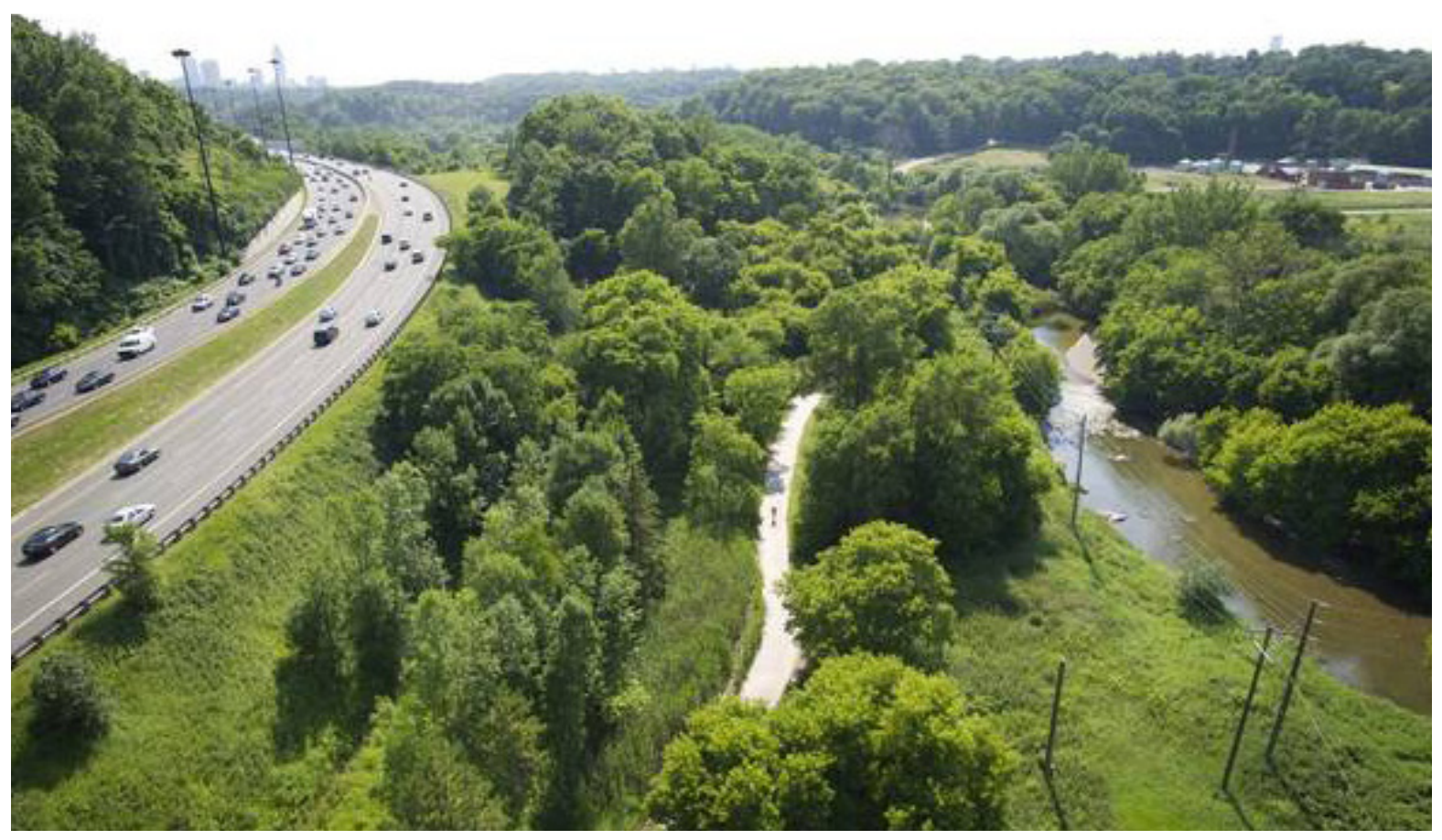

Figure 3.30 


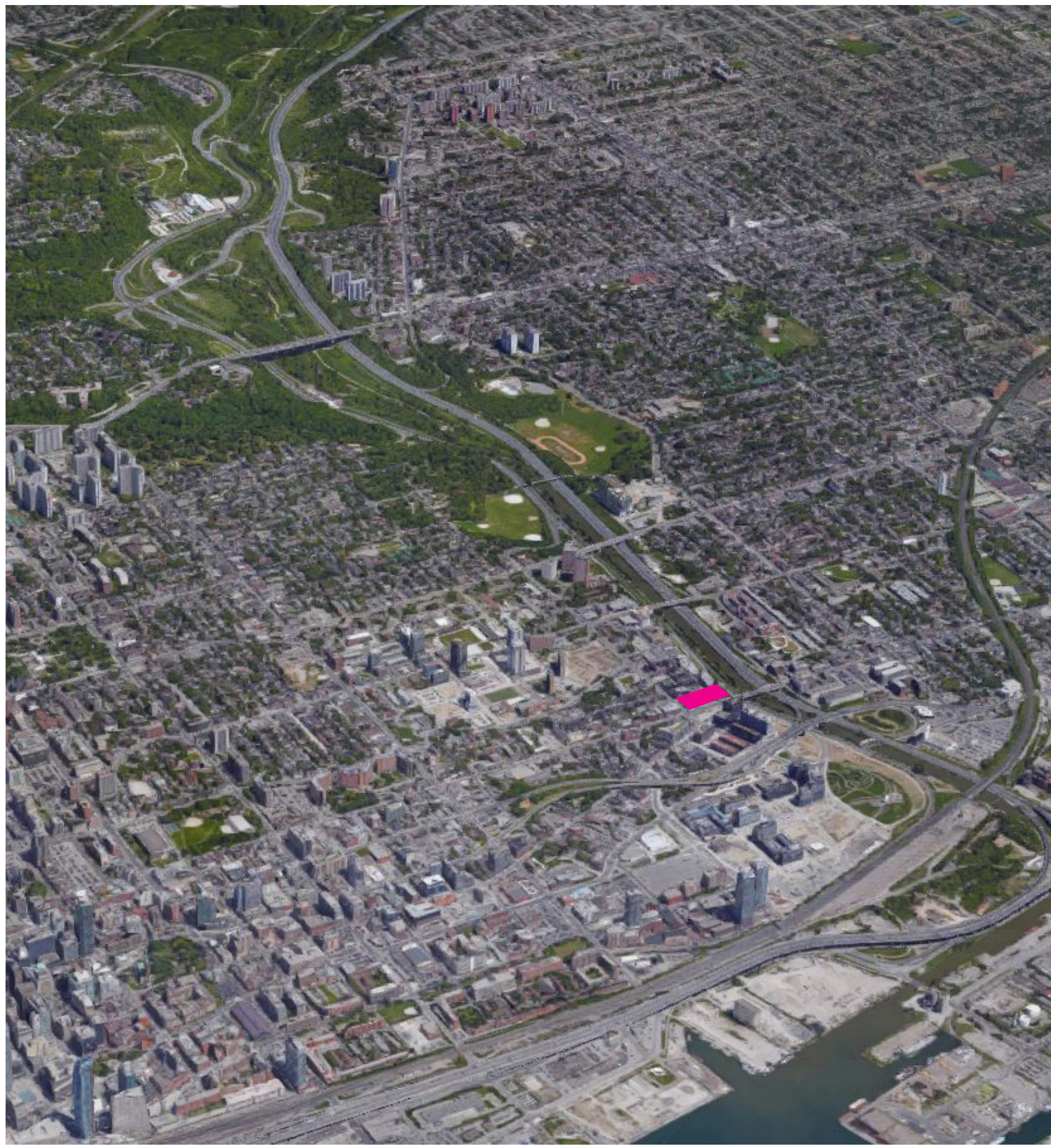

Figure 3.31 


\subsection{Redefining the Animal Shelter in Toronto}

As a public service facility, the Toronto Humane Society currently does not engage the public as much as it should. Its ominous exterior effectively shuts out the public both physically and visually, internalizing all its functions and services. As a facility that relies on public support (donations and adoptions), public awareness has been hard to achieve behind closed walls. Even though digital and social media can mitigate some effects, the building itself is still an effective communication tool.

As a thesis project, the facility is an appropriate site for showcasing how architecture can move away from superficial tendencies while still being expressive. Rather than simply creating superficial and obnoxious forms to draw attention to itself, the shelter's function and operations will inform its spatial configuration, context will inform its expression, and users will inform its experience.

As a point of departure, the thesis uses the existing THS program as the project brief. The THS currently runs a public spay/ neuter clinic and an adoption center (which has its own clinic, office, isolation area, and kennels). Program breakdown, analysis, and floor plans of the existing facility can be found in Appendix C. Other programmatic elements are added to enhance public engagement and revenue-generating options. Public dog parks become gathering places, appealing to people of all social classes and cultural backgrounds. Its architecture will project an image that is appropriate for its use, location, and people, achieving the goals of raising public awareness, increasing adoption rates, and providing an enjoyable and humane environment for both humans and animals.
Figure 3.29: Construction of Don Valley Parkway 1950s

Figure 3.30: Don Valley Parkway 2014

Figure 3.31: Aerial View of Lower Don River and Valley

Figure 3.32: THS Adoption Kennel 


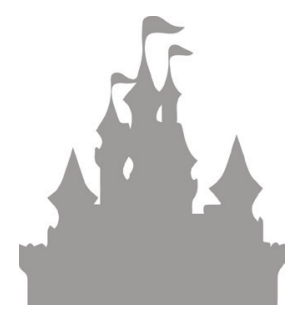

An Architecture of Work

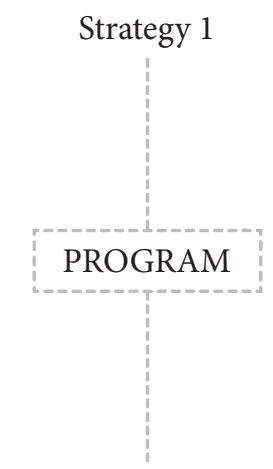

Rescue, Rehabilitate \& Re-Home

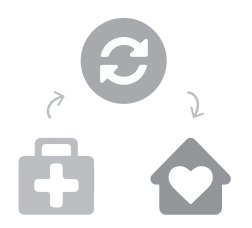

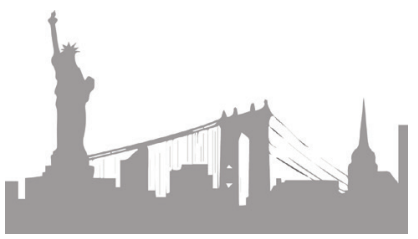

Theme of the City

Strategy 2

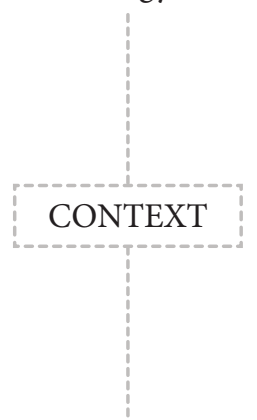

Toronto \& the Don Valley

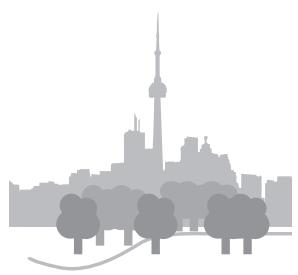

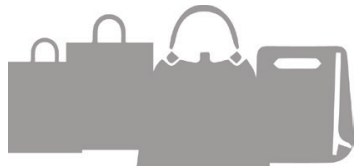

Scale and Rhythm of Users

Strategy 3

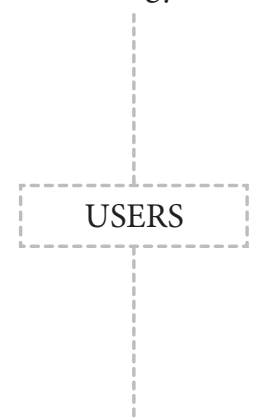

Animals \& People

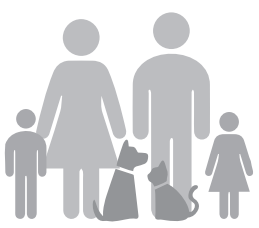

Figure 4.1: Strategies applied to design

\section{1 | Introduction}

This chapter begins to showcase how the strategies outlined in chapter 2 will be applied to the project brief and requirements of the THS.

Strategy 1: An Architecture of Work: To redefine the shelter's program by subverting some back-of-house functions as an authentic architectural narrative for organizing space.

Strategy 2: Theme of the City: To establish physical and symbolic connections between building and context by using its site conditions and local materials as a coherent theme throughout.

Strategy 3: Scale and Rhythm of Users: To design appropriate scales and senses for all users: animals, children, employees, volunteers, and visitors. 


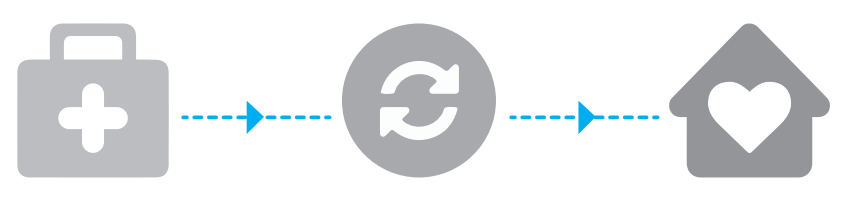

\section{2 | Strategy 1: An Architecture of Work}

To redefine the shelter's program by subverting some back-of-house functions as an authentic architectural narrative for organizing space.

In order to understand the ways in which the function of the building could inform new spatial organizations, a number of studies and explorations were made. First, a visit to the Toronto Humane Society provided a first-hand visitor experience of the shelter. A shelter tour was also arranged for a better understanding of the work involved beyond the adoption center. The guided tour took visitors through the clinic and service spaces, explaining the use and processes of the THS. Beyond a visit to the THS, a study of other animal shelters' layouts and designs provided additional insight on operational space relations. Next, a comparison of typical animal shelters with pet spas / daycares reveal different images and responses for animal spaces. Finally, based on these studies, a definition and subversion of "work" starts to form the architectural narrative and establishes a basis for design. 


\subsubsection{A Visit to the Shelter - Existing Conditions}

The THS has an adoption shelter component and a spay/neuter clinic component that are both open to the public between $10 \mathrm{am}$ and $6 \mathrm{pm}$. The main shelter entrance is tucked behind a chamfered corner on River Street with a small drop off area in the front. The clinic entrance is in the northeast corner beside the loading dock through a small door, not easily visible or accessible. Visitor parking is located in the back and visitors walk back along Old Brewery Lane to access the main entrance (Figure 4.2 and 4.3, page 123). A detailed review and documentation of the site visit and shelter tour can be found in Appendix D.

Overall, the visit into the adoption spaces simply showed animals that were available for adoption with a basic status chart on its cage. However, beyond visiting the adoption areas of the shelter, the THS also offers guided shelter tours through their shelter and facilities. After the OSPCA raid in 2009, this initiative attempts to spread awareness for the shelter to present itself as a clean, publically accessible facility. The first strategy for design, then, understands the guided tour as a narrative for spatial organization that integrates private and public spaces together in an authentic expression of work. 


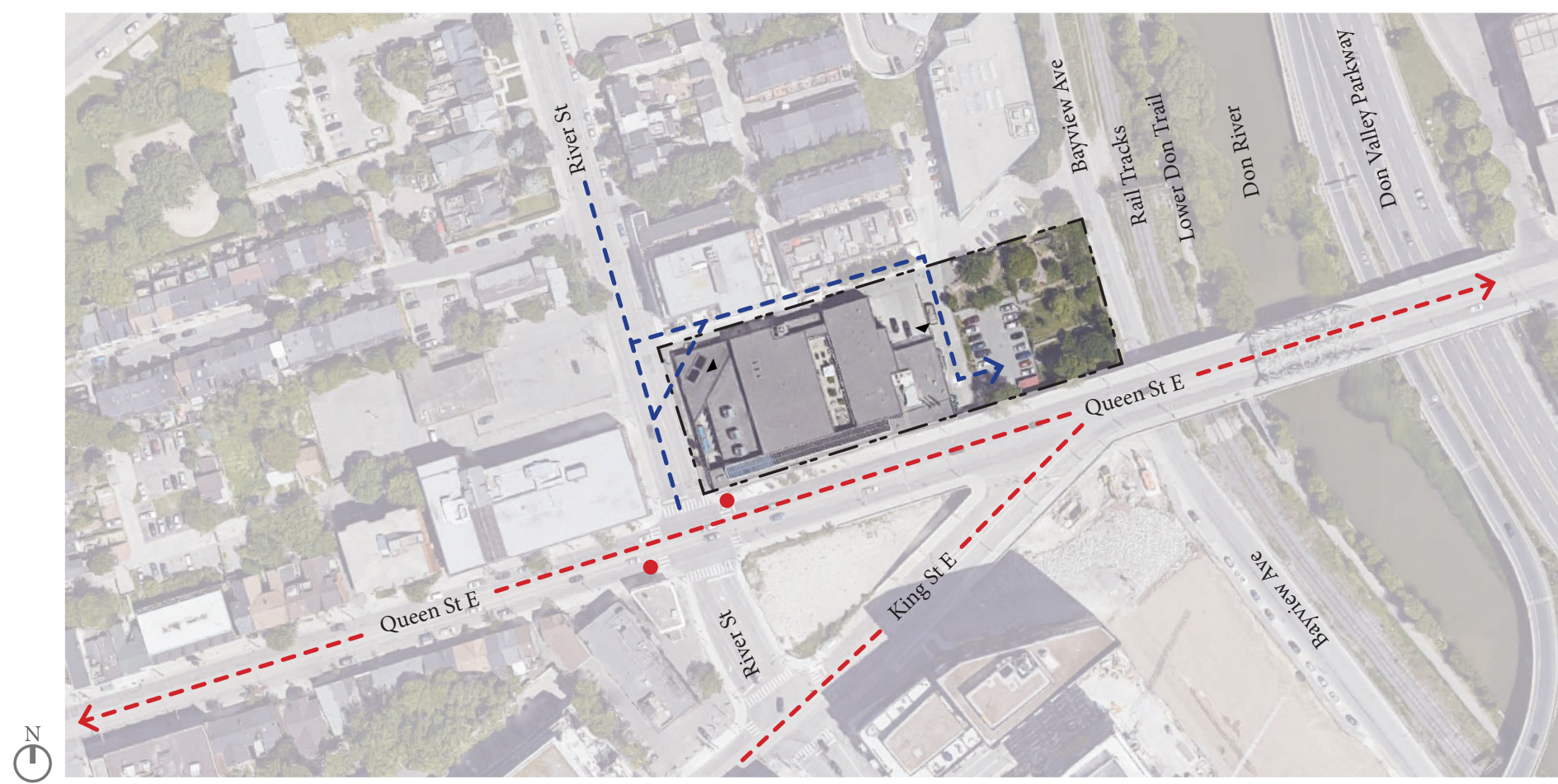

4.2: Aerial Map of Contextual Conditions and Site Access Diagram (NTS)

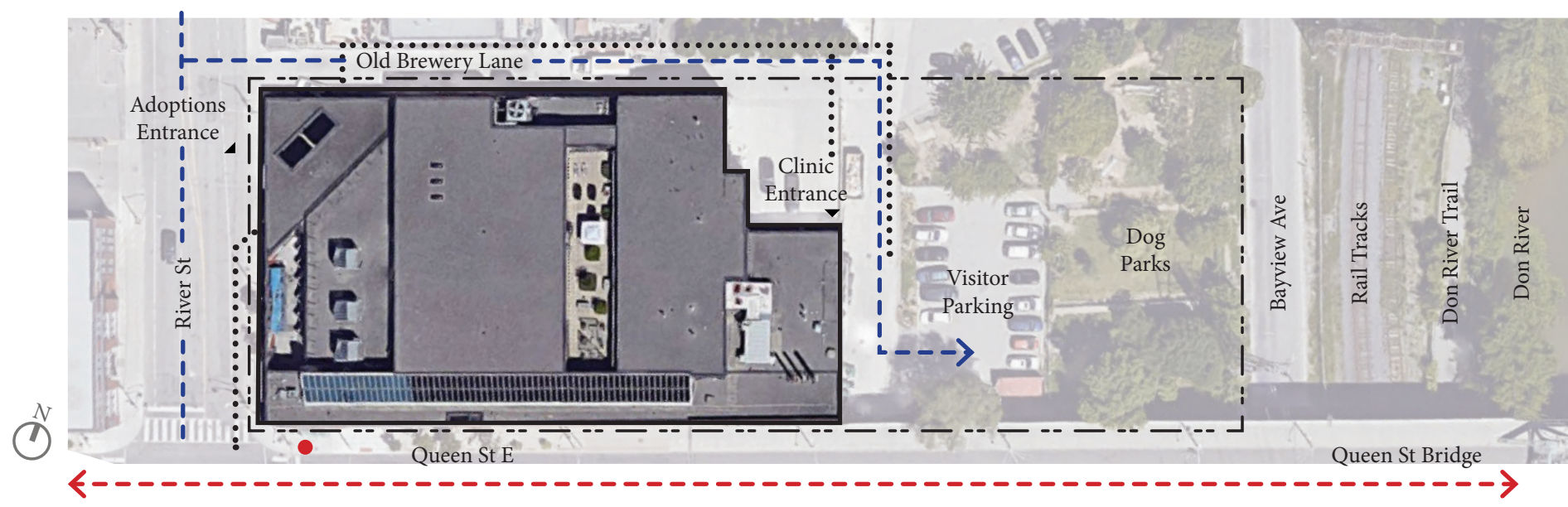

4.3: Circulation and Site Access of Existing THS Facility (NTS)

Legend

- Public Entrance

- Transit Stop

- - - - Property Line

$----\rightarrow$ Public Transit

$----\rightarrow$ Vehicular Access

........... Pedestrian Access 
The guided tour first takes visitors through the adoption kennels of the THS. The second part of the tour takes visitors behind-the-scenes into the clinic and administrative spaces. Without participating in the guided tour, public visitors are restricted to the kennel areas only. There is a strict separation between the public and private spaces (Figure 4.4).

Beyond the kennels, visitors in the tour are exposed to the laundry and loading facilities, food storage and prep areas, isolation rooms, clinic prep rooms, pre-op and post-op wards, and even operation rooms. The guide explains the processes and workings of the shelter. Beyond opening hours, they have 6 veterinarians, numerous technicians and assistants, administrative staff, call center staff, a communications and marketing department, over 500 volunteers and 250 foster parents, each working toward animal care and well-being. Animal intake and admissions are by appointment only, taking in animals transferred from other shelters or owner surrenders. All animals must be isolated for 10 days and examined prior to becoming adoptable. The clinic staff ensures all animals are free of health issues and are spayed or neutered before adoption. Animals with behavior issues work with specialists to correct bad behaviors in order to increase their chance of adoption. Volunteers help with activities ranging from animal enrichment and dog walking sessions to call center and administrative work. The shelter tour has been summarized with photos in Figure 4.5.

In the same way that the guided tour explains the inner workings of the shelter, the architectural manifestation and circulation should also be able to communicate this process without a tour guide to allow a better understanding and educational journey through the shelter. 


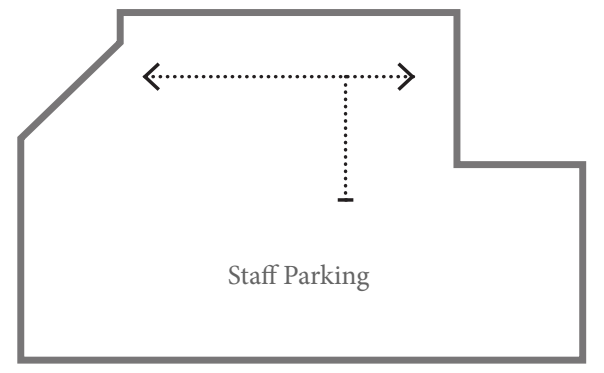

A

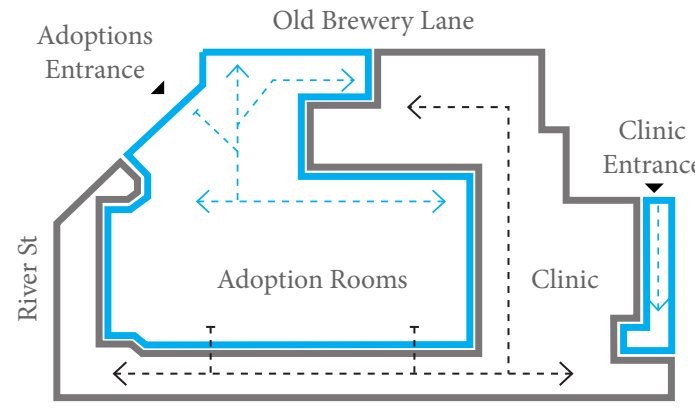

B

Queen St

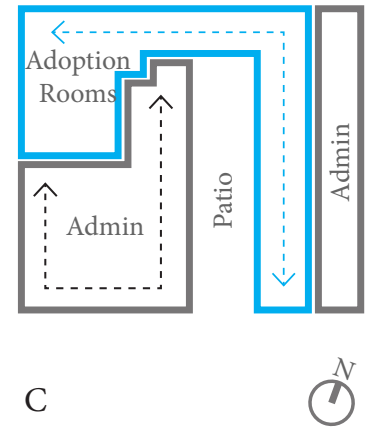

Legend

- Public Entrance Public Areas

Private Areas

(-...... P Public Circulation

<-------> Private Circulation

Figure 4.4: Diagram of Public versus Private Spaces of the Existing THS
A | Basement Level
B | Ground Floor Layout
C | Second Floor Layout 
| Beyond a set of double doors from the main lobby, the intake office handles owner surrenders, strays, and lost \& found. No windows or views to outside or rest of facility.

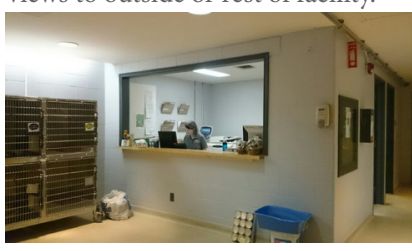
intake office

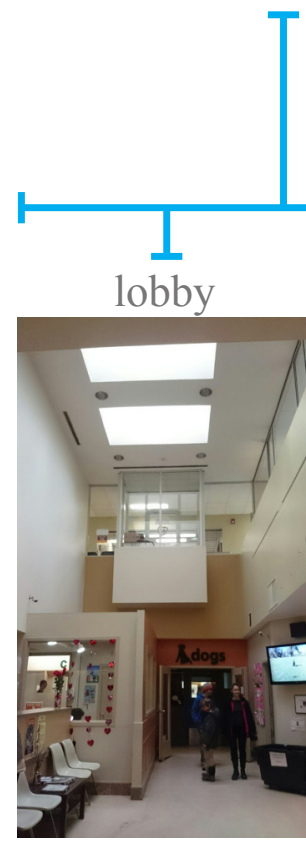

| Main entrance reception area has double height space and signs to direct visitors to kennels. Small retail area behind reception desk.

Figure 4.5: Photos and summary of THS Shelter Tour, taken Feb 3 2016, comparing public versus private spaces.

| 2nd level - Cat Rooms with movable cages. Volunteers are playing with cats for 'enrichment'.
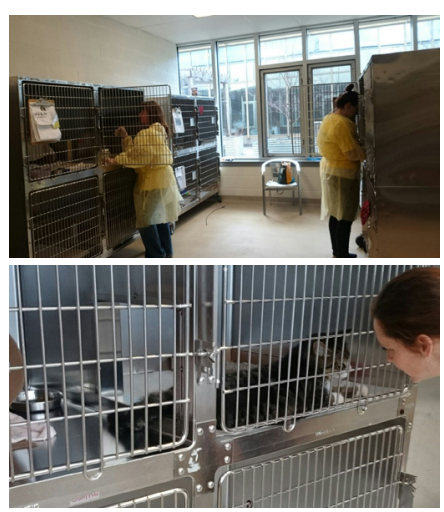

| 2nd level - Interior courtyard for volunteers and cat enrichment, also letting in natural light.
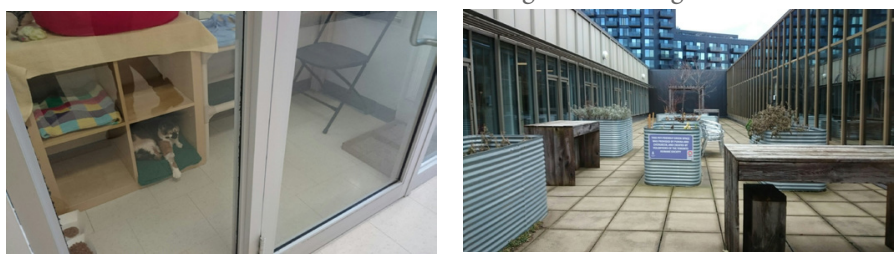

cats

T

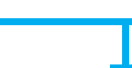

PUBLIC F = - = - =

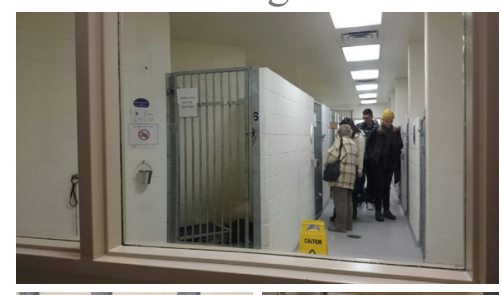

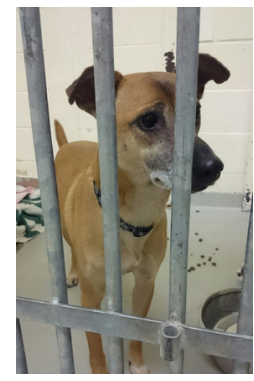

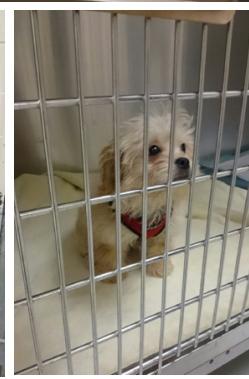

| 1st level - Dog Adoption Kennels - There are 4 main adoption rooms with 10-20 double sided runs each. Double sided runs allow ease of cleaning and separates food and resting area from elimination area. Dogs typically stay here for around 2 weeks before they get adopted. Concrete and metal finishes echo barks, voices, and footsteps. No windows or views out are provided.

\section{small animals}

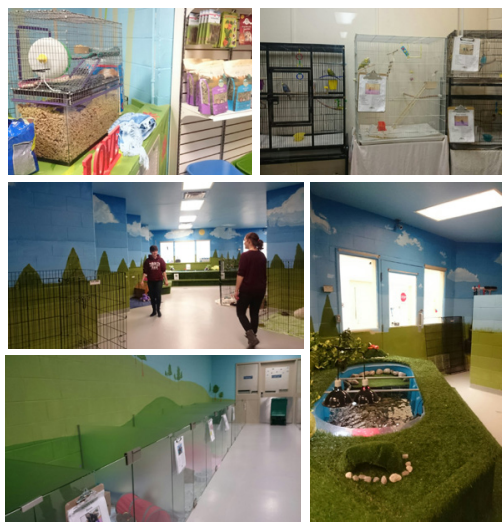

| 1st level - Small Animals Adoption Rooms. Cages are on the floor and painted murals attempt to stimulate the hamsters, gerbils, rabbits, and turtles. Birds are separated into a small room with no windows. 
| Isolation kennels

| Surgery Rooms. During time of visit, are rated by hazard. a shelter huskie was being prepped for dental surgery. The veterinarian briefly explained the procedure and background of the huskie.
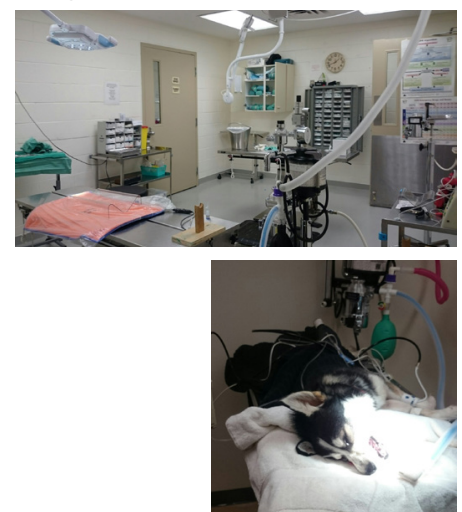
Protective gear must be worn to enter. Animals are isolated here for at least 10 days.

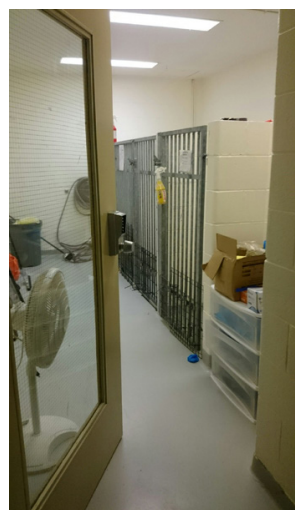

isolation \& clinic

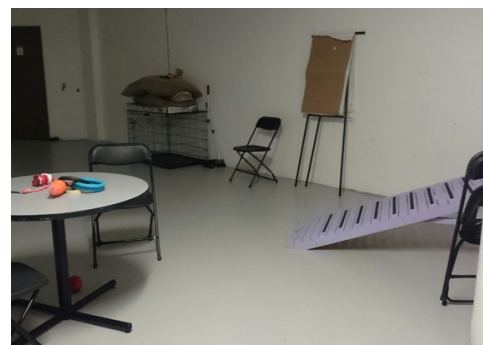

| Training facility for dogs with behavioural issues is located in the basement. Previously a storage room. Pet training classes for general public are held here.

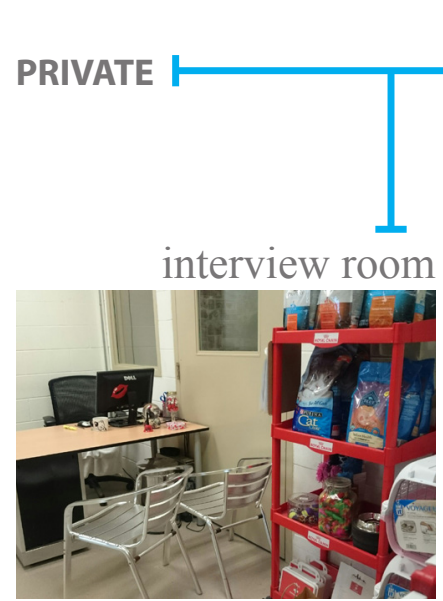

| 2nd Level Interview Room Potential adopters are interviewed by staff to discuss compatability and other responsibilities.

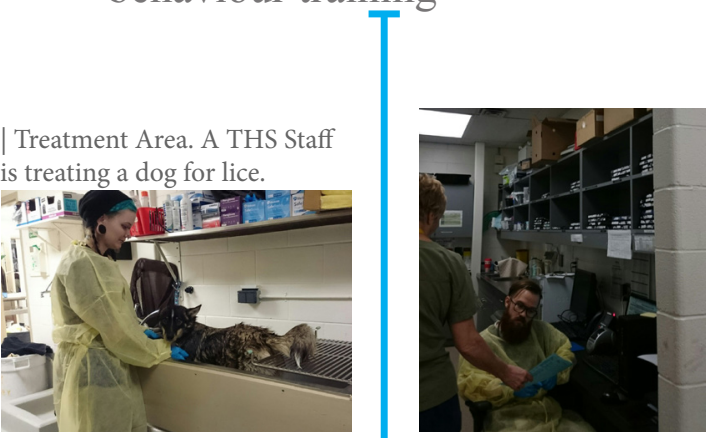

\section{behaviour training}

admin
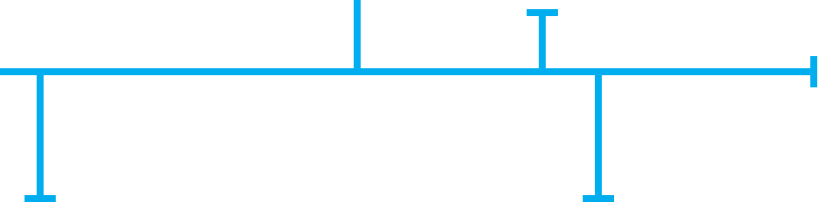

loading \& laundry

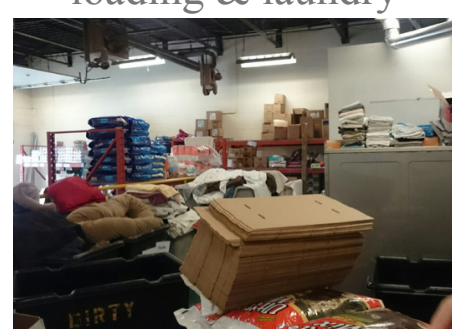

| 1st Level - loading area, dog food storage and laundry facilities combined.

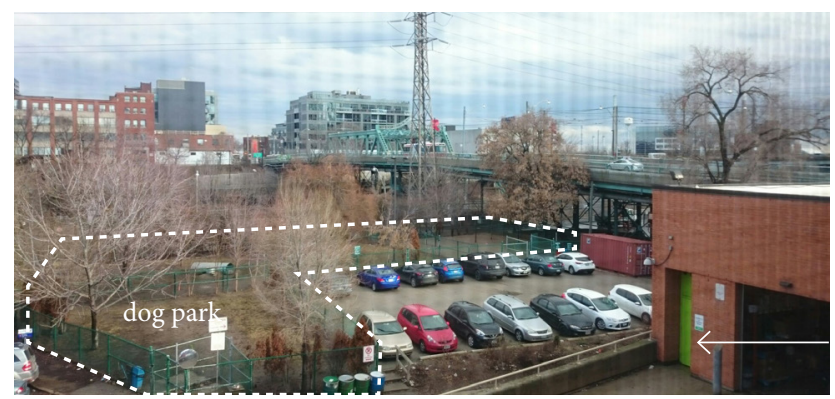

| Dog park, public parking lot, and public spay/neuter clinic entrance at back of building. Dogs are taken outside for 2 play groups per day.

Volunteers have to take dogs out through front entrance, around to the back and across the parking lot to access the parks.

| Entrance to public spay/neuter clinic 


\subsection{2 | Analysis of Other Shelters}

Beyond an analysis of the existing conditions and process at THS, a formal analysis of other shelters was conducted. The shelters' layouts showed that the separated shelter and clinic model are the most common (Figure 4.6, page 129), where public and private spaces are strictly segregated, restricting public access to the adoption kennels only. This maximizes efficiency by containing all intake and clinic facilities in one area. However, it fails to take advantage of integrating different users into the same space, and the shelter tour through the THS proved to be a more interesting and informative way of experiencing a shelter. The issue of workflow efficiency was a main concern for all the shelters, where the spaces are consolidated to minimize travel distance and reduce the spread of diseases. Where possible, kennels were located outdoors to take advantage of outdoor play areas and also to maximize air flow. It is also important for animals to have access to daylighting to understand day and night cycles, as animals require schedule and routine to stay healthy. At least 2 entrances were be provided to separate intake clinic from public adoption areas. The case studies of other animal shelters are summarized in Appendix E. 


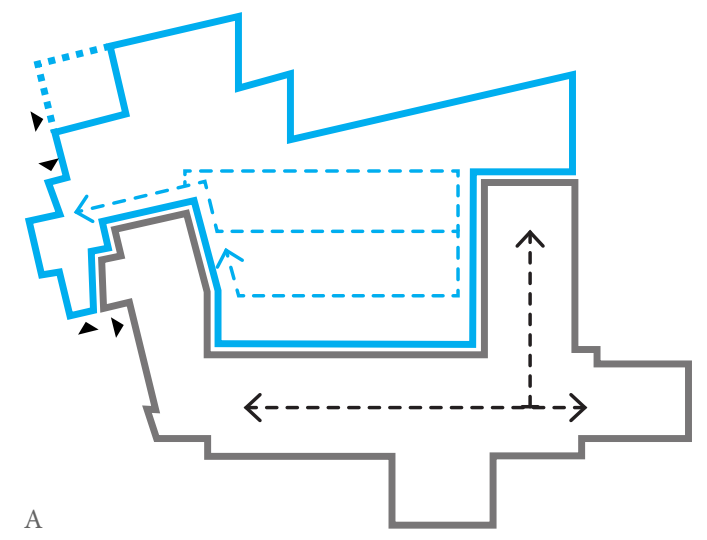

C
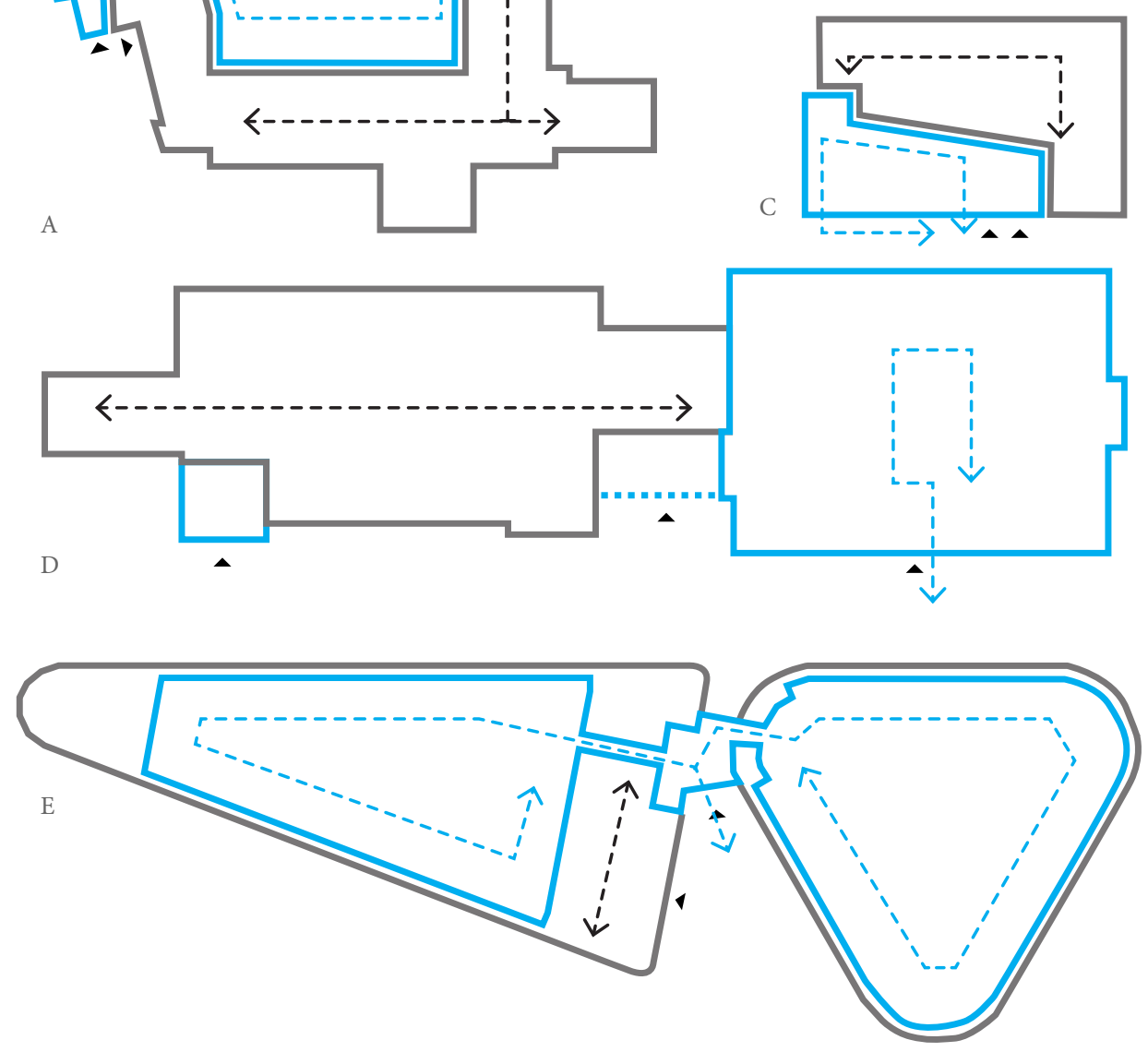

Legend

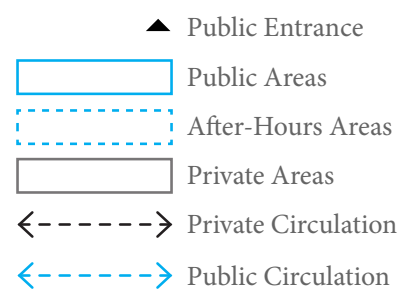

Figure 4.6:

Shelter Layout Diagrams Summary
A | Palm Springs Animal Care Facility B Staten Island Animal Care Center
C | Greenville Humane Society
D | Montgomery County Animal Services and Adoption Centre
E | Amsterdam Animal Refuge Center 


\subsubsection{The Two Extremes}

Comparing images of shelters and dog pounds with pet spas and daycares (Figures 4.7 and 4.8), there is a huge discrepancy in the way the animals are perceived by looking at the environments they are treated in. The pet spa or daycare imitates the superficial artifices of themed environments that appeal to the owner's preference for iconography and symbolism. It imitates "human" environments for the enjoyment of the owners, giving off the illusion of the animals being "treated like humans". The social constructs of some themes, like bone-shaped pools and painted fire hydrants, are excessive and unnecessary for animal comfort. It only fuels the conspicuous consumption behavior of the owners. Pets in these environments, however, are perceived to be better cared for and healthier. Shelters and dog pounds, on the other hand, present more utilitarian constructions of identical "cells" and cages of metal or concrete. Animals in these environments are perceived to have health and

Figure 4.7: Dog Pound and Shelters.

(Page 131)

Figure 4.8: Dog Daycare and Boarding Facilities. behavior issues that give them a negative image. Although this may sometimes be the case, most are recovering and healthy animals that are ready to be rehomed. Navigating between the two extremes, animals should be perceived as being treated humanely without resorting to clichés, simulations, or animalthemed environments.

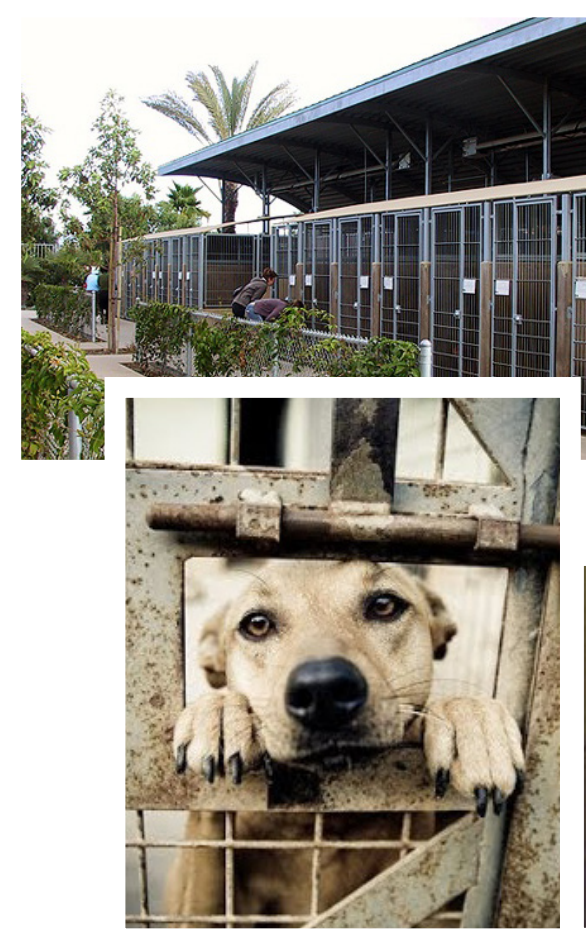

Figure 4.7
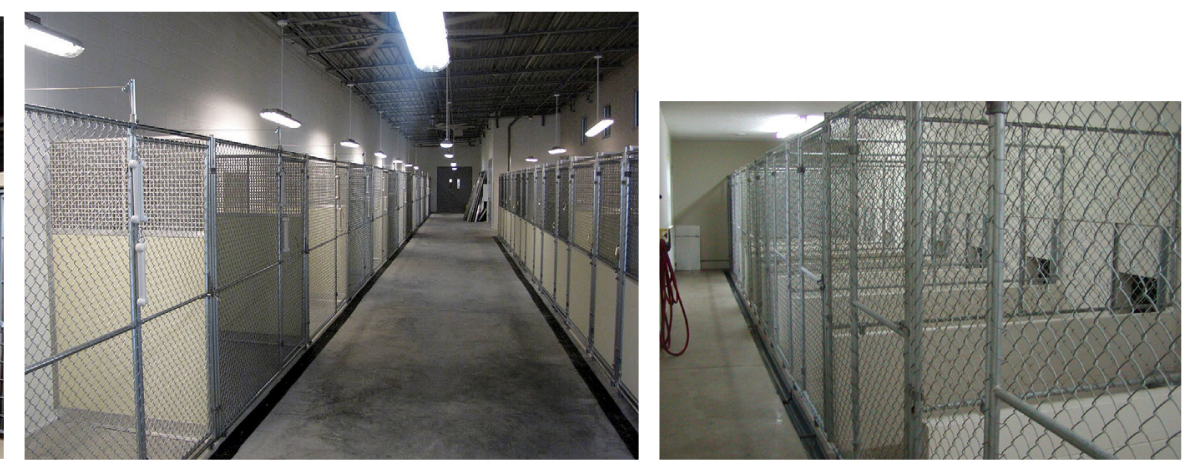

ANIMAL SHELTER | DOG POUND F - - - - - - - - - - - - - - - - - - - -
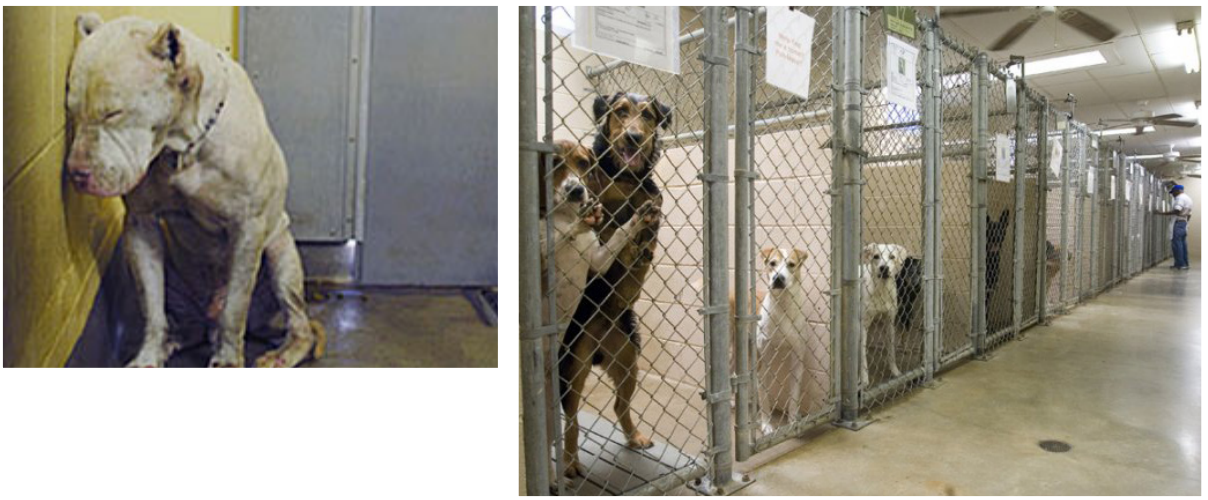


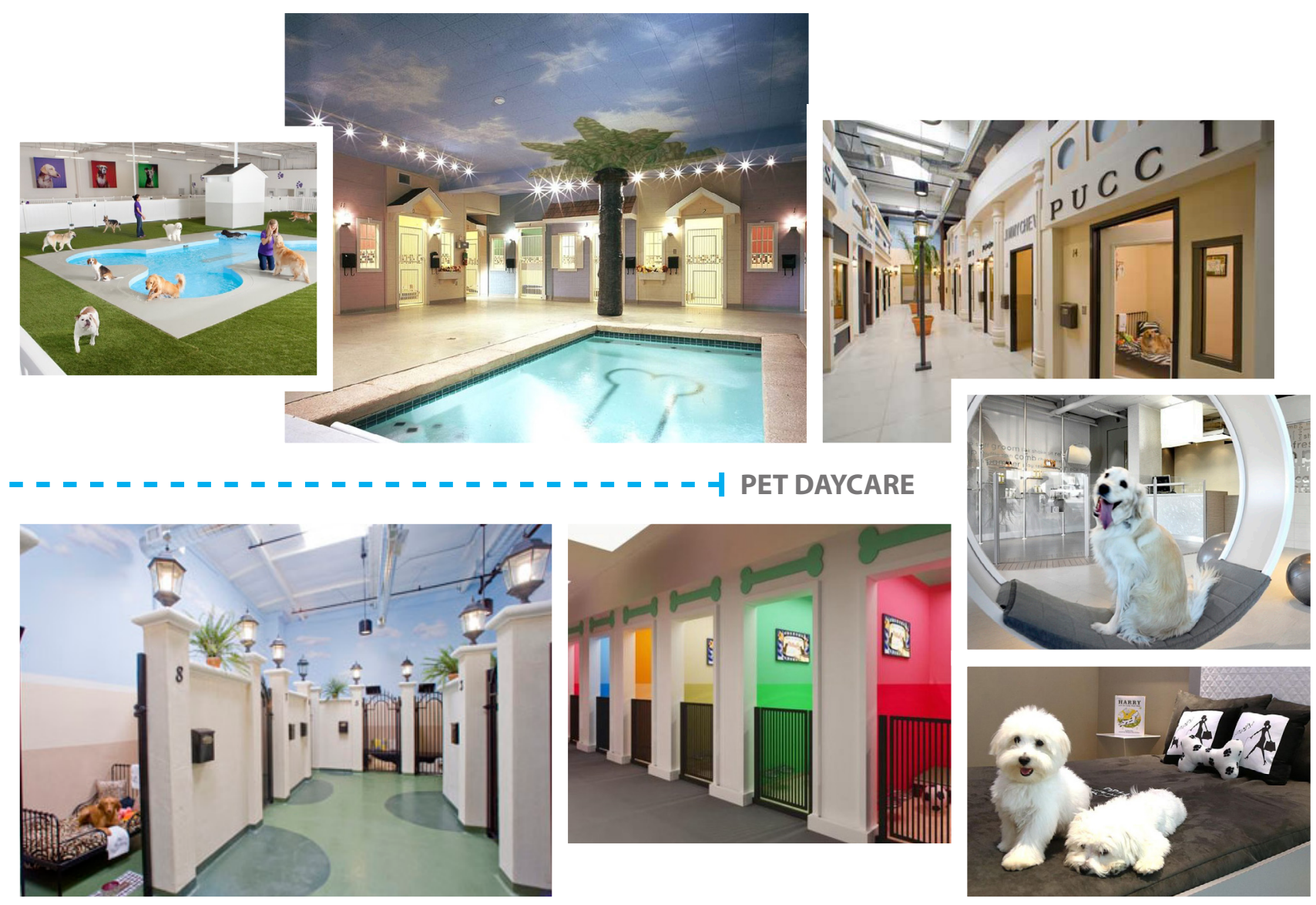

Figure 4.8 


\subsection{4 | Definition \& Subversion of Work}

\section{Introduction}

Beyond observation of the THS functions and analysis of precedent plans and layouts, the documentation of operational process of animal shelters, operational efficiencies, and standard shelter design guidelines were also studied.

The thesis examines the way an architectural narrative of work is used as a means of communicating the functions of a building. Thus, the design of specific clinic and treatment spaces are outside of the scope of this project. The workflow and spaces have only been considered in relation to each other to form part of an overall narrative and experience for the design. The design of individual clinic and kennel spaces are excluded in the work, and typical guidelines for clinic spaces and enclosure sizes has been used. Evident in the organization of other shelters, the 'back-of-house' work is often consolidated to maximize efficiency. The premise of the thesis attempts establish a different way of experiencing the shelter, so efficiency of operations is not a high priority for design.

The process and workflow of animal intake to adoption has been summarized in Figure 4.9 (Page 133), based on the requirements and guidelines found in Appendix F. This forms the overall architectural narrative, following an animal's path from intake to adoption. After identifying the process, spaces are assigned to each process or activity to understand space relations and requirements (Figure 4.10 Page 134). A hierarchy of private and public spaces is then established to define and understand the subversion of work. 


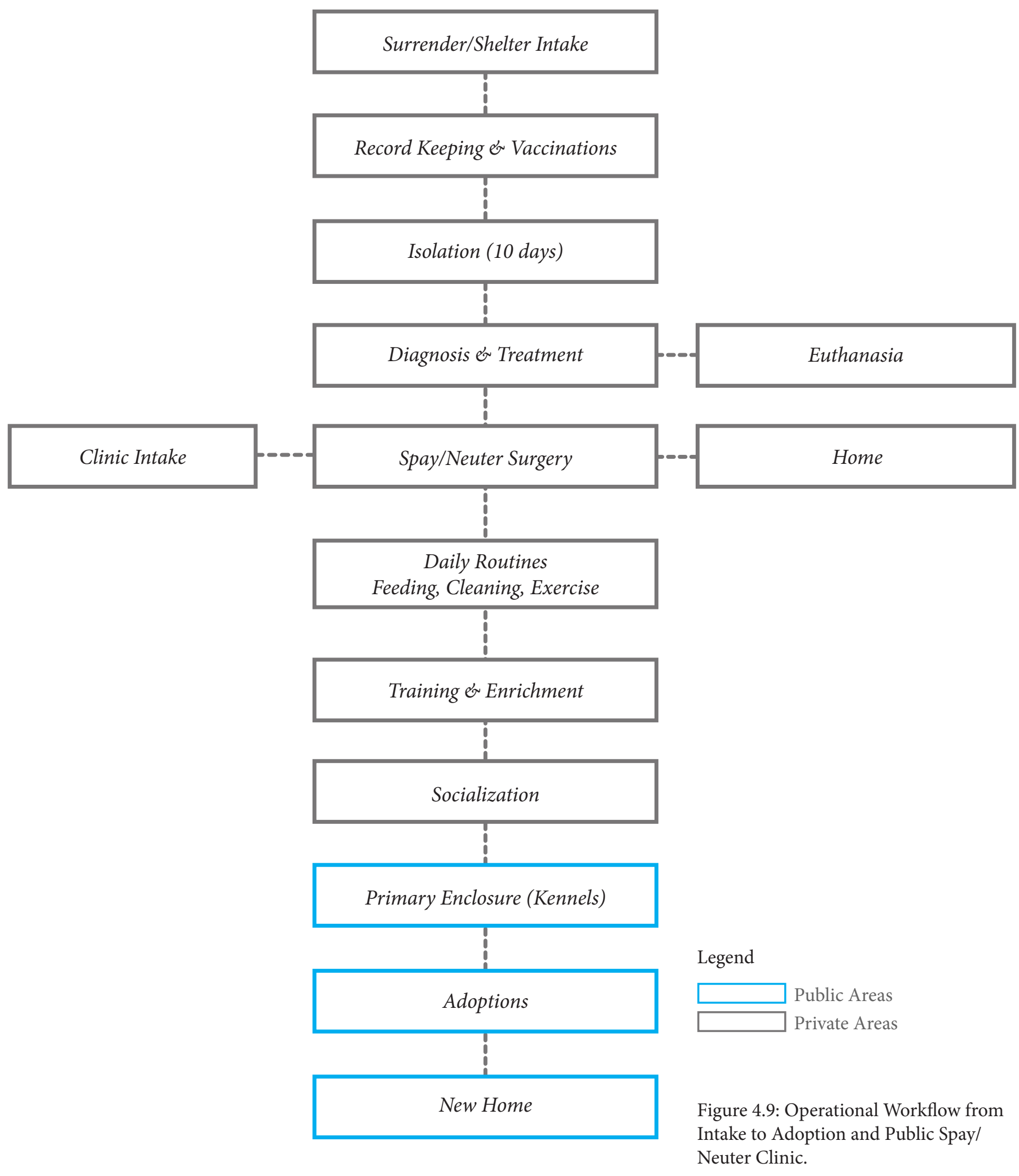


Workflow Process

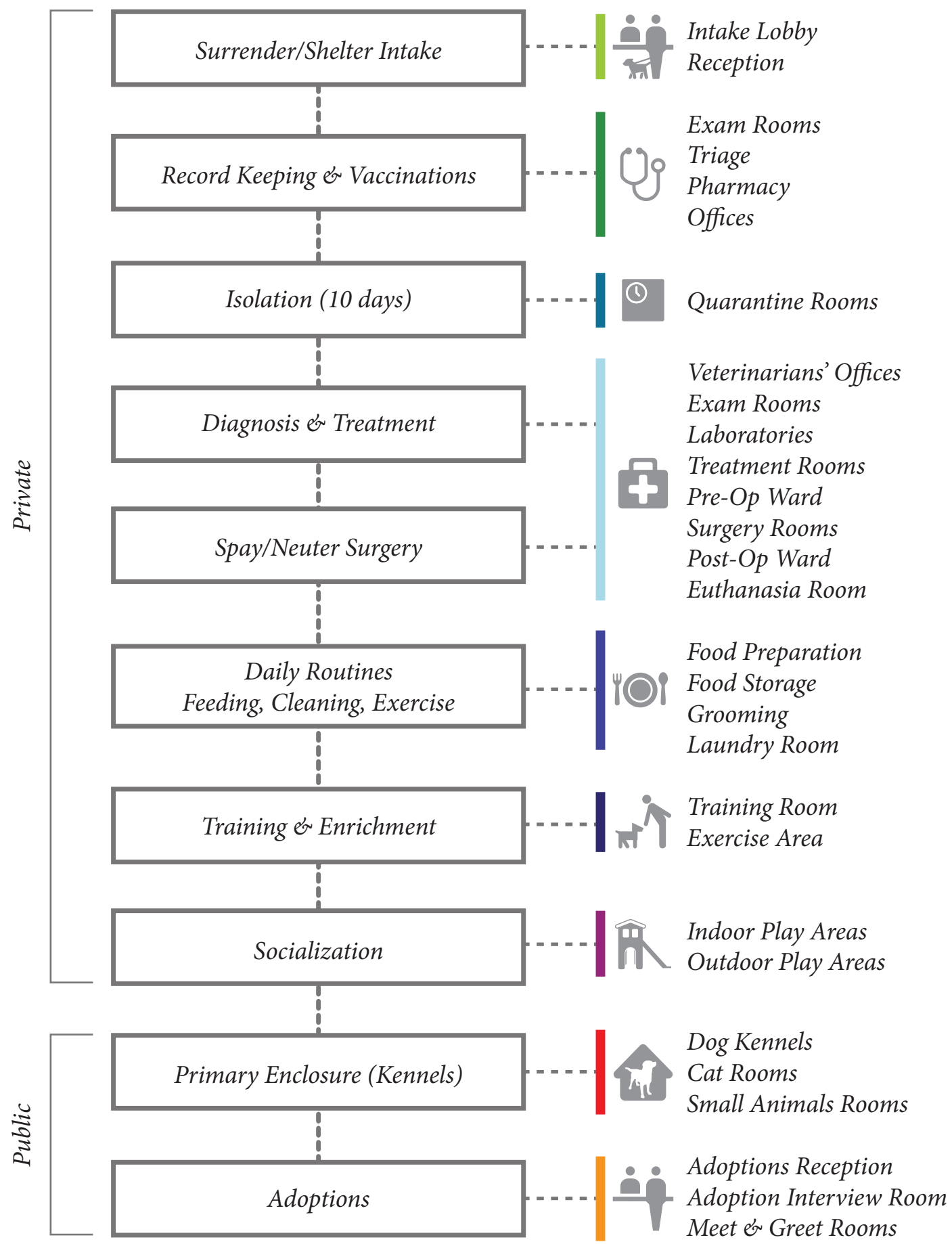

Figure 4.10: Intake Workflow and Associated Spaces 
Additional Support Spaces
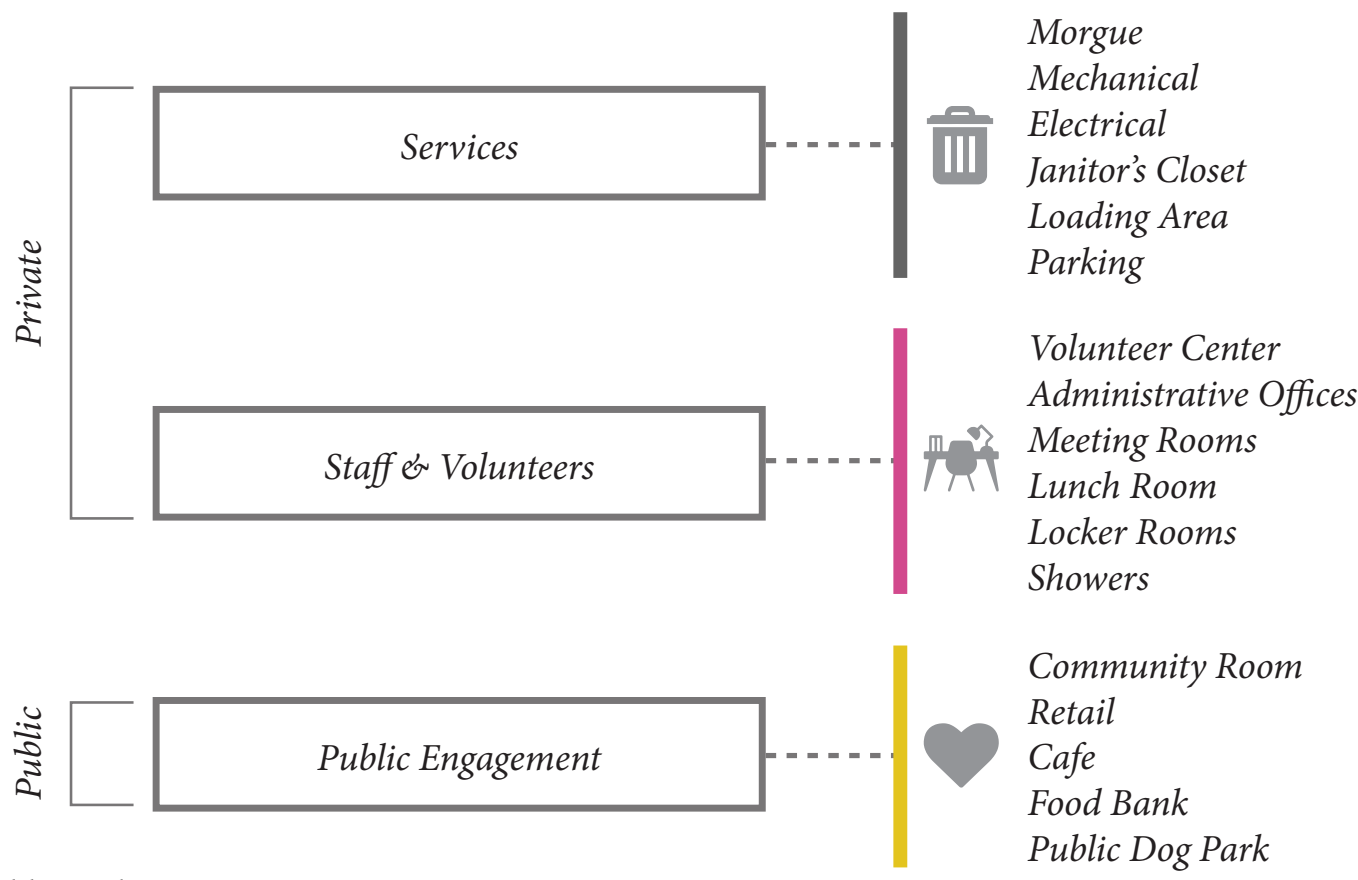

Figure 4:11: Additional Support Spaces

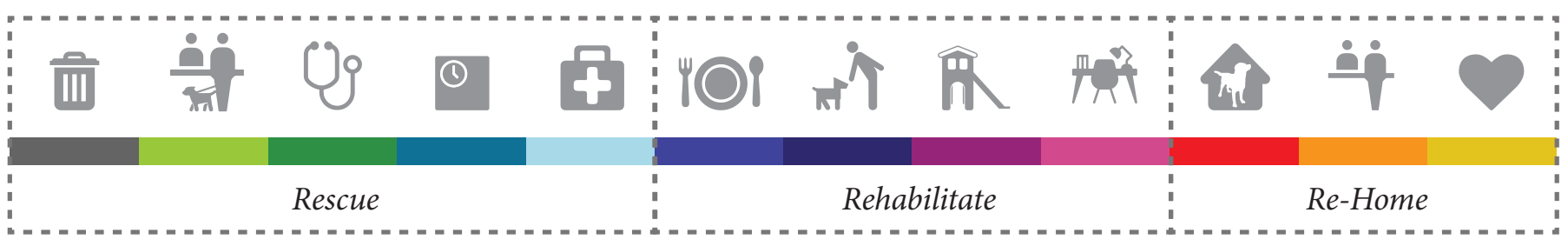

Figure 4.12: Workflow is identified as a process of Rescue, Rehabilitate, and Re-Home

The overall mission for the shelter can be identified as: rescue, rehabilitate, and re-home. Typically the public areas of a shelter are only limited to the sanitized "pet shop" portion, keeping the back of house out of sight. The subversion of work then exposes and integrates the behind-the-scenes rehabilitation work into public view, allowing for a more direct and transparent relationship between what we see and what the shelter is about. Visitors have direct or visual access to work spaces and kennels, visually integrating all users (visitors, pets, employees, and volunteers) into the same spaces, acting as a self-guided tour through the shelter without being too prescribed and one-directional. This restructuring of program contributes to an improved and more educational experience of the shelter, spatially communicating the back-of-house conditions.

The average length of stay for each animal will depend on the required treatment and attention that is needed. Thus, a variety of spaces should offer comfortable conditions for both short-term and long-term stays. All animals are required to be examined and then isolated for 10 days upon arrival, so the minimum length of shelter stay is $10-12$ days. The shelter should be a transition point, offering temporary yet comfortable living conditions and its architecture should reflect that transient nature as well. 


\section{The Shelter's Work}

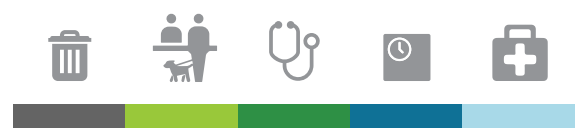

"Rescue" Work

Drawing the line between privacy and education.

Despite the overall idea to expose all back-of-house work as an educational journey, some parts of the shelter remain should completely private to respect the work of veterinarians and privacy of recovering animals. Functions like surgery rooms, laboratories, isolation areas, euthanasia room, the morgue, and staff locker rooms are not publically accessible. Other areas that support the building function such as mechanical, electrical, loading, and garbage rooms are also excluded.

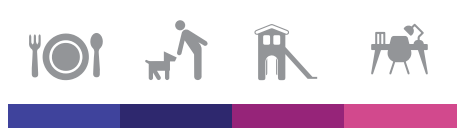

\section{"Rehabilitation" Work}

Rehabilitation involves the treatment, recovery, maintenance, and training of pets to be adoptable. Pets are either surrendered or transferred to the THS following various reasons such as abandonment, neglect, abuse, inhumane conditions, strays, etc., and often suffer behavioural or psychological issues that prevent them from being in a permanent home. The staff at THS work with these pets to overcome these issues so they become more adoptable. Owners will often surrender or return their pets due to lack of patience in training, deeming the pet "undesirable". Thus, communicating this necessity of patience is essential for understanding pet ownership. Basic training is usually needed to house-break or teach them to follow simple commands, and pets with anxiety or temperament issues will require more patience and time to train.

As experienced in the THS Shelter Tour, seeing and speaking to the trainers and maintenance staff is essential to understand the responsibilities of the shelter as well as responsibilities of pet ownership. The maintenance, feeding, cleaning, and training are thus included in the public sequence of spaces. Each type of domestic animal will have their own wards specific for their own needs, since visual and acoustical separation of animals is essential, but can share clinic facilities. Staff offices are also exposed to reveal additional work of the shelter. These spaces include marketing and communications, call center, and pet monitoring and filing.

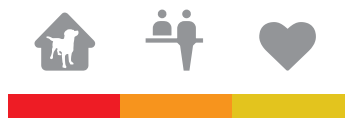

\section{"Re-home" work}

Potential adopter interview rooms and meet \& greet areas are also exposed to allow greater transparency of the process. As much as the shelter wants to re-home as many pets as possible, research must also be done on potential adopters to ensure both parties match. Visitors not only see the play areas and kennels (the fun part of owning a pet) but also reveal other processes as part of the experience, exposing the work and maintenance required to own a pet. 
Rescue, Rehabilitate, and Re-Home as Overall Theme

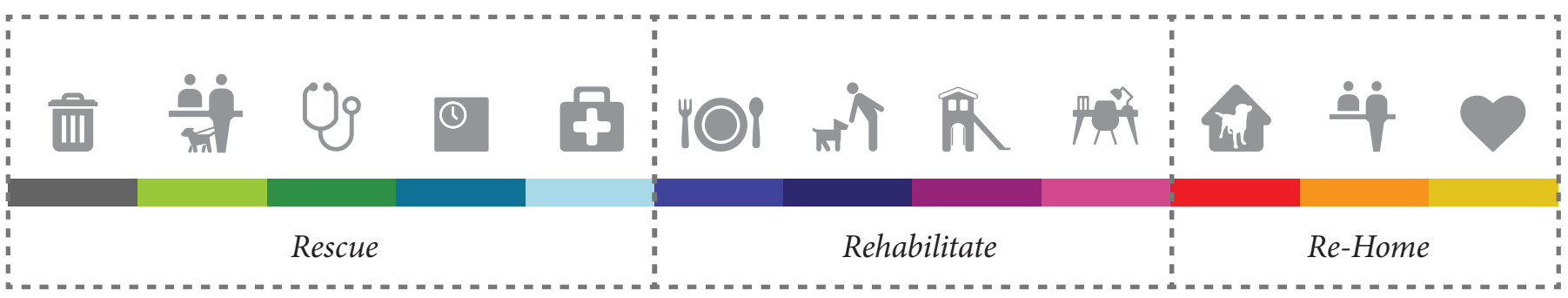

PRIVATE

PUBLIC

Figure 4.13: Overall Workflow and Theme of Shelter

Subversion of Workflow as Architectural Narrative

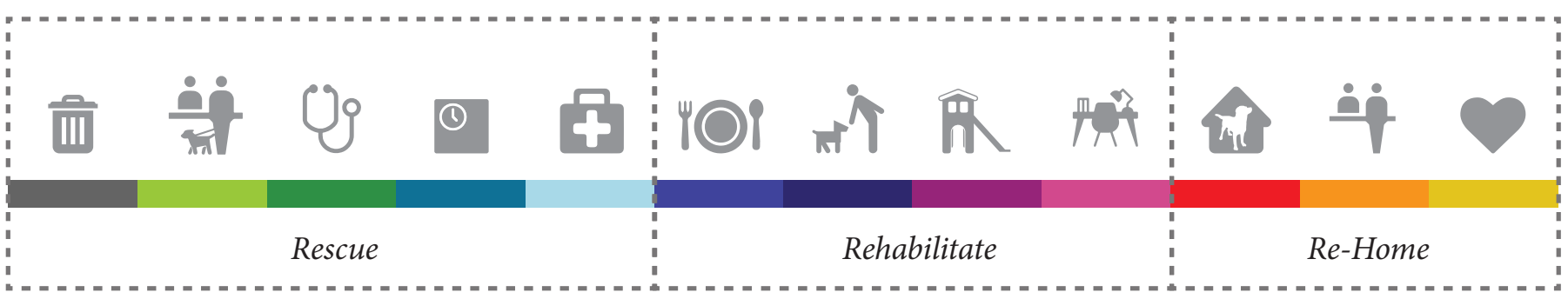

PRIVATE

\section{PUBLIC}

Figure 4.14: Subversion of Workflow as Architectural Narrative

Other Features:

Support and Public Space:

Public programs (community event space, education center, café, and an expanded retail component) are added to help support the facility's functions and can remain open beyond regular shelter hours, acting as public gathering space, event venue, and revenue generator for the shelter. To accommodate multiple uses in the same space, the public circulation can also double as a walking and leash training path for canines. 


\subsubsection{Program and Design Parameters}

Based on the analysis in previous sections, the following list of guidelines for program organization have been established. Figure 4.16 illustrates the program spaces reorganized around the overall architectural narrative of Rescue, Rehabilitate, and Rehome.

At least two entrances will be provided to separate intake reception from public adoption reception and public areas

Access to adoption kennels and shelter spaces are controlled at one point of entry for all visitors for security reasons, allowing for public functions to remain open after shelter hours.

Clinic and treatment areas are consolidated to facilitate workflow, but offers visual access to visitors

Visitors should be presented with a clear path of circulation that guides and directs access and engagement with staff, volunteers, and pets

3 distinct areas for canines, felines, and small animals are accessible off the main circulation route

Due to Toronto's extreme climate (both too hot and too cold), indoor exercise and socialization spaces should be provided for staff and animal comfort

Outdoor private and public dog parks should also be provided for training and public use

Animal housing should have access to daylighting and views outdoors where possible

Clarity in wayfinding is also an important aspect of consideration, ensuring visitors can navigate and understand the overall narrative, but also easily access the different animal spaces. The program spaces, narrative, and circulation is outlined in Figure 4.16 (Page 139). A centralized path defines the main circulation through the shelter and spaces unfold along its length to reveal different work processes. Animal spaces are divided into canines, felines, and small animals. 
Rescue

Intake Lobby
Reception
Exam Rooms
Triage
Pharmacy
Offices

(1) Quarantine Rooms

Veterinarians' Offices

Exam Rooms

Laboratories

Treatment Rooms

Pre-Op Ward

Surgery Rooms

Post-Op Ward

Euthanasia Room
Rehabilitate

Volunteer Center

Administrative Offices

Meeting Rooms

Lunch Room

Locker Rooms

Showers

Food Preparation

40 Food Storage

Grooming

Laundry Room

Training Room

Indoor Play Areas
Re-Home

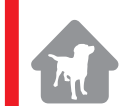

Dog Kennels

Cat Rooms

Small Animals Rooms

$\therefore$ Adoptions Reception

Adoption Interview Room Meet \& Greet Rooms

Community Room

Retail

Cafe

Food Bank

Public Dog Park

Figure 4.15: Program Spaces

Outdoor Play Areas

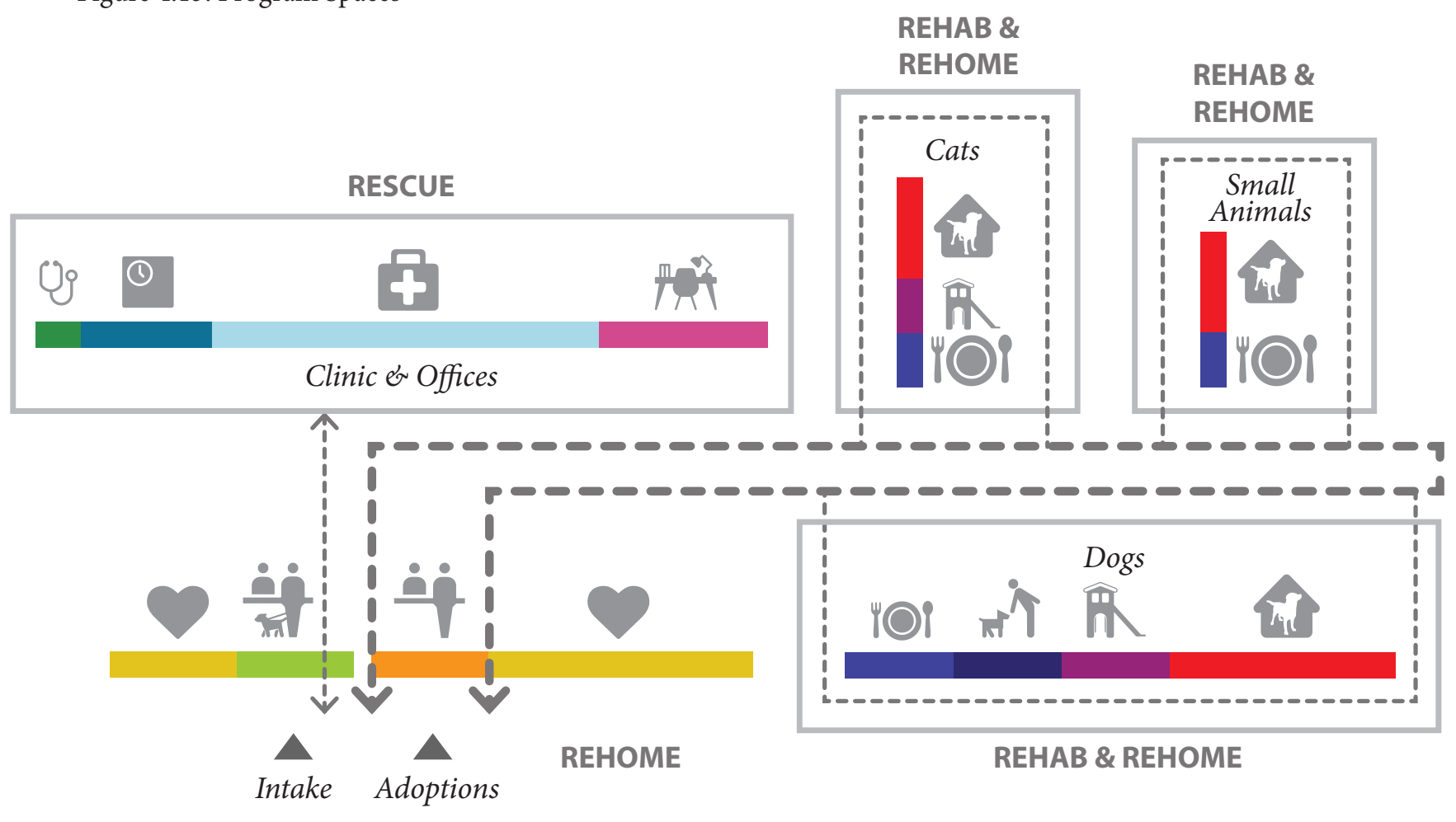

Figure 4.16: Program Spaces Organized Around Overall Architectural Narrative. 


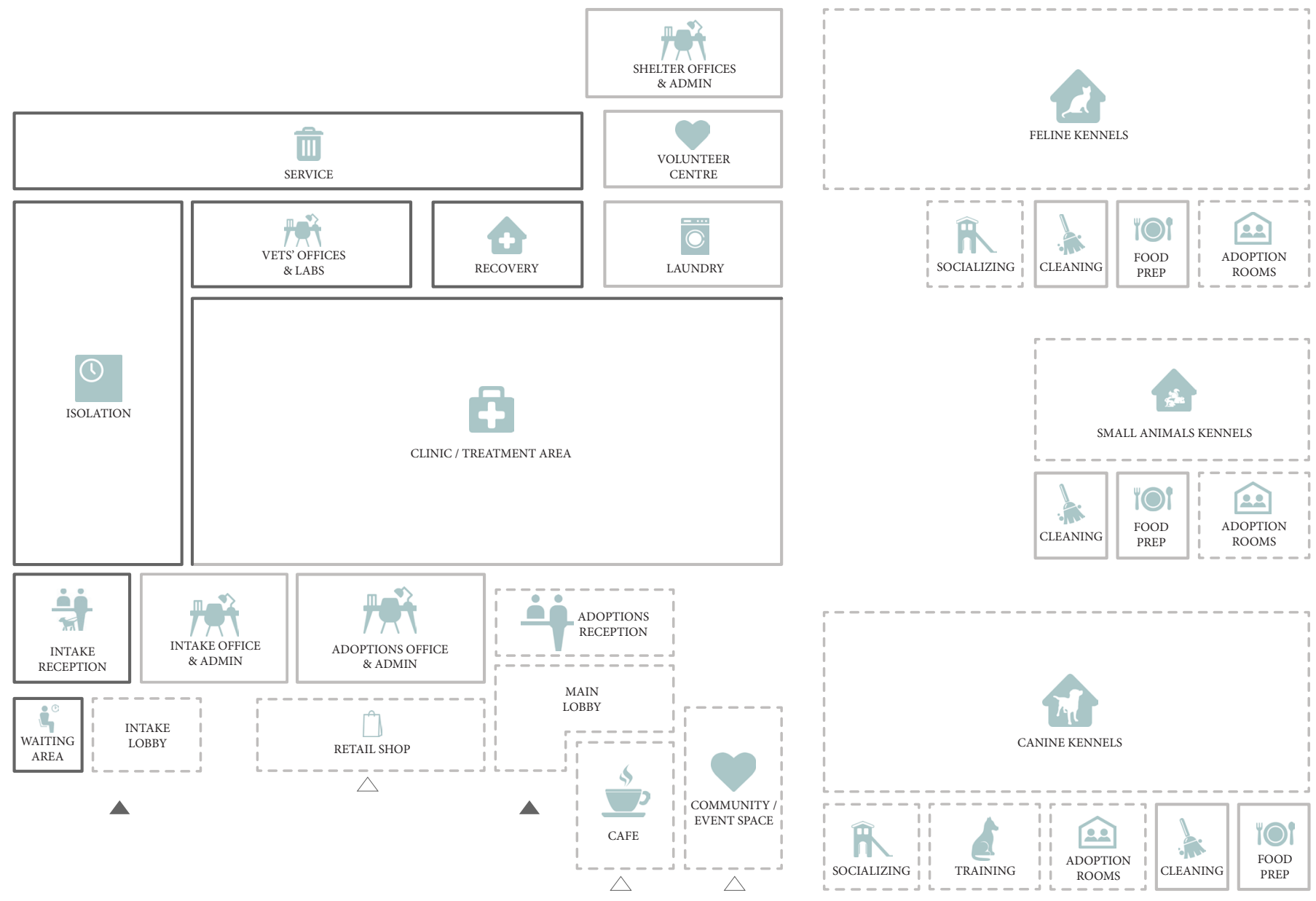

Legend

- Public Entrance

$\triangle$ Secondary/After-Hours Entrance Rescue Space Rehabilitate Space Re-home Space

\subsubsection{Program Adjacencies and Ciculation Patterns}

Based on the overall narrative, program adjacencies and circulation patterns are defined and showcased in Figures 4.17 and 4.18, establishing direct and visual access between the different program areas.

Figure 4.17 Program Adjacencies -

Subverting "Rehabilitation" Spaces into

"Re-home" Spaces. 


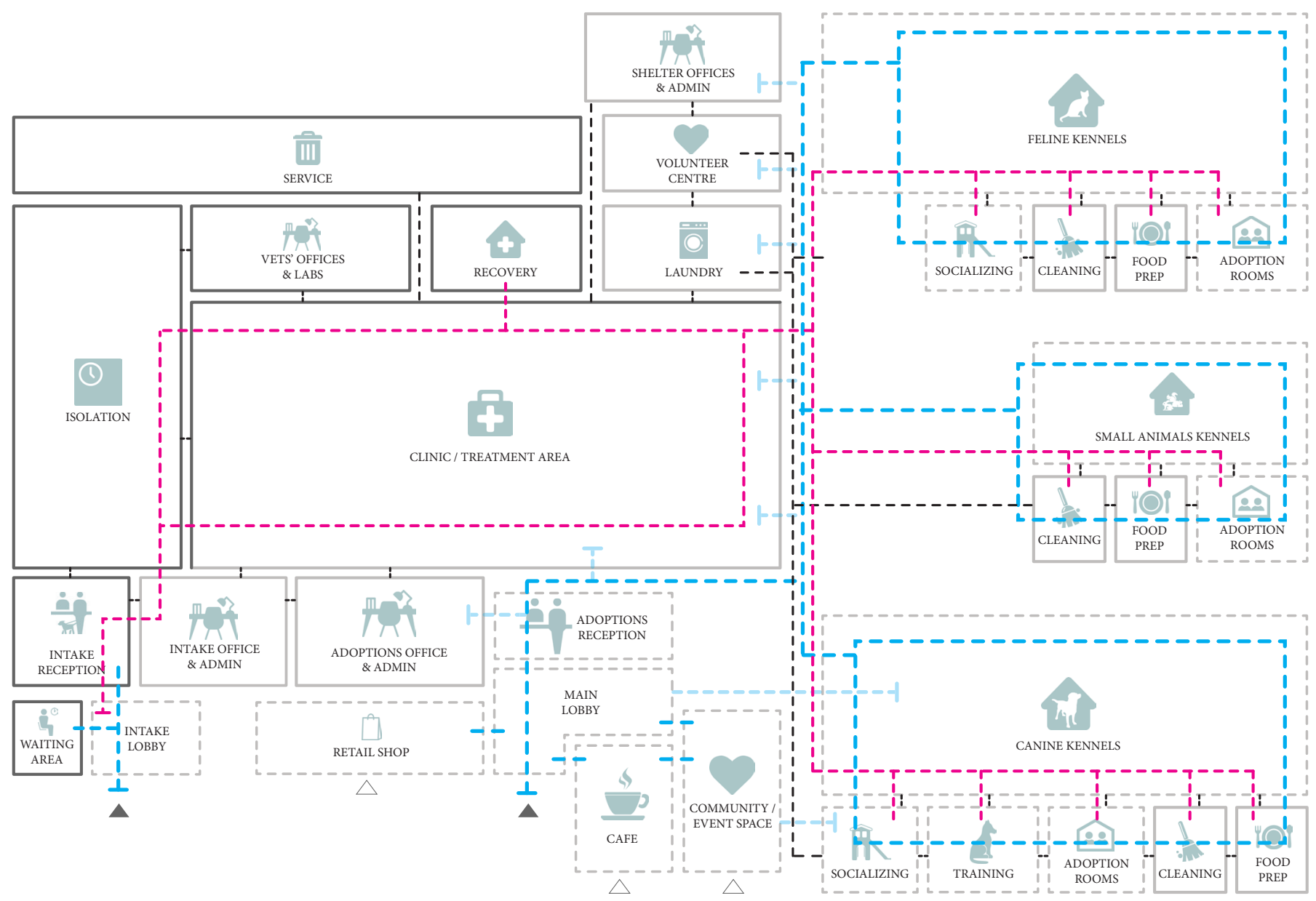

Legend

- Public Entrance

$\triangle$ Secondary/After-Hours

Entrance

- - - - Public Access

Visual Access

Pet Intake Process

Staff \& Volunteer Access

Figure 4.18: Program Adjacencies - Circulation Routes and Visual Connections 

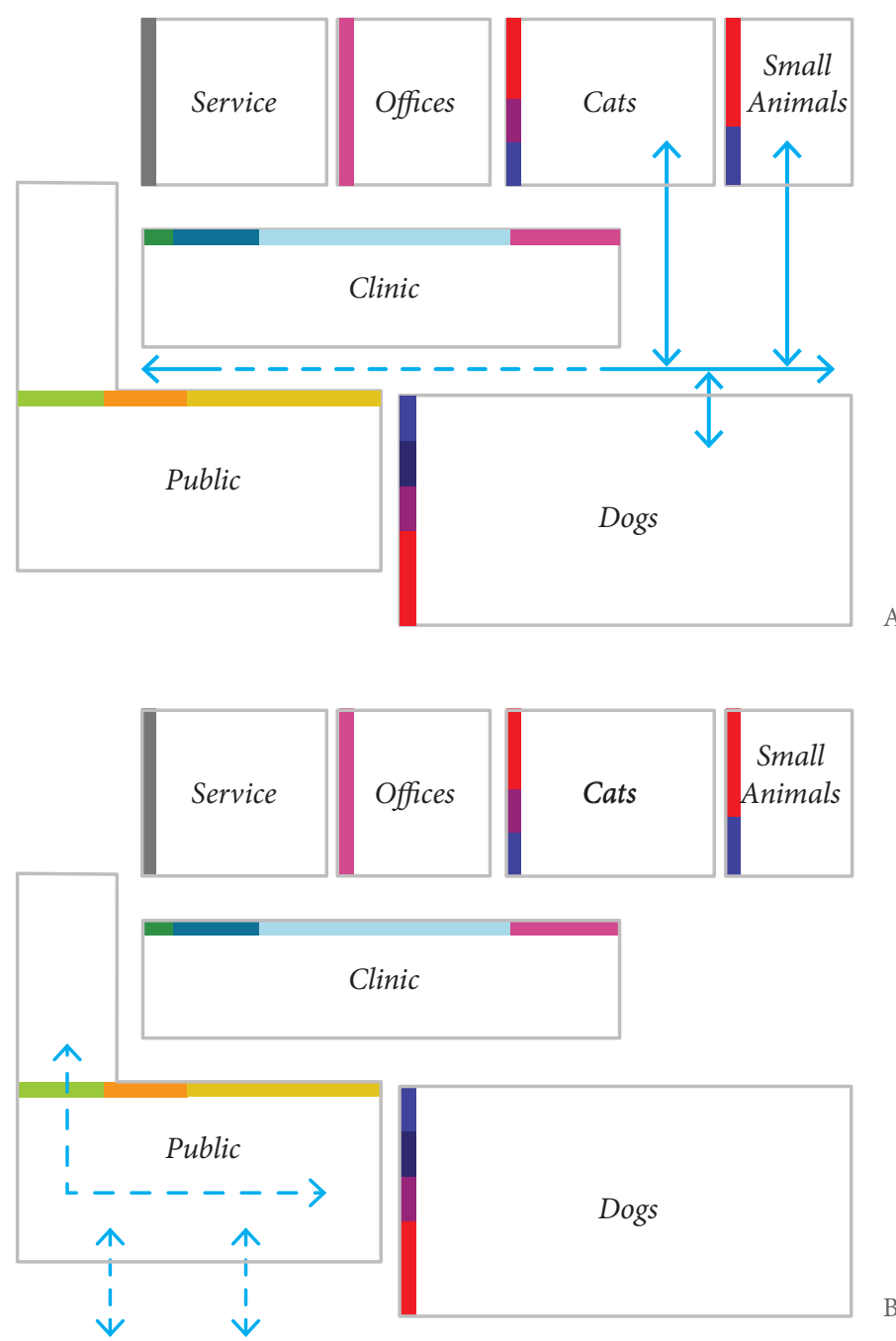

Figure 4.19: Program Organization and Circulation

A | Shelter Circulation

B | Public Engagement Circulation

C | Private Circulation

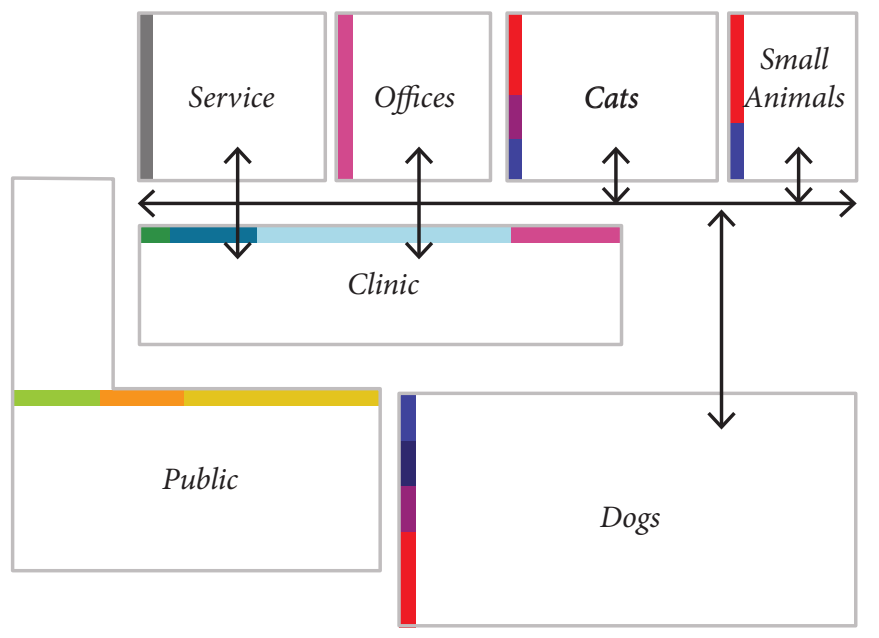




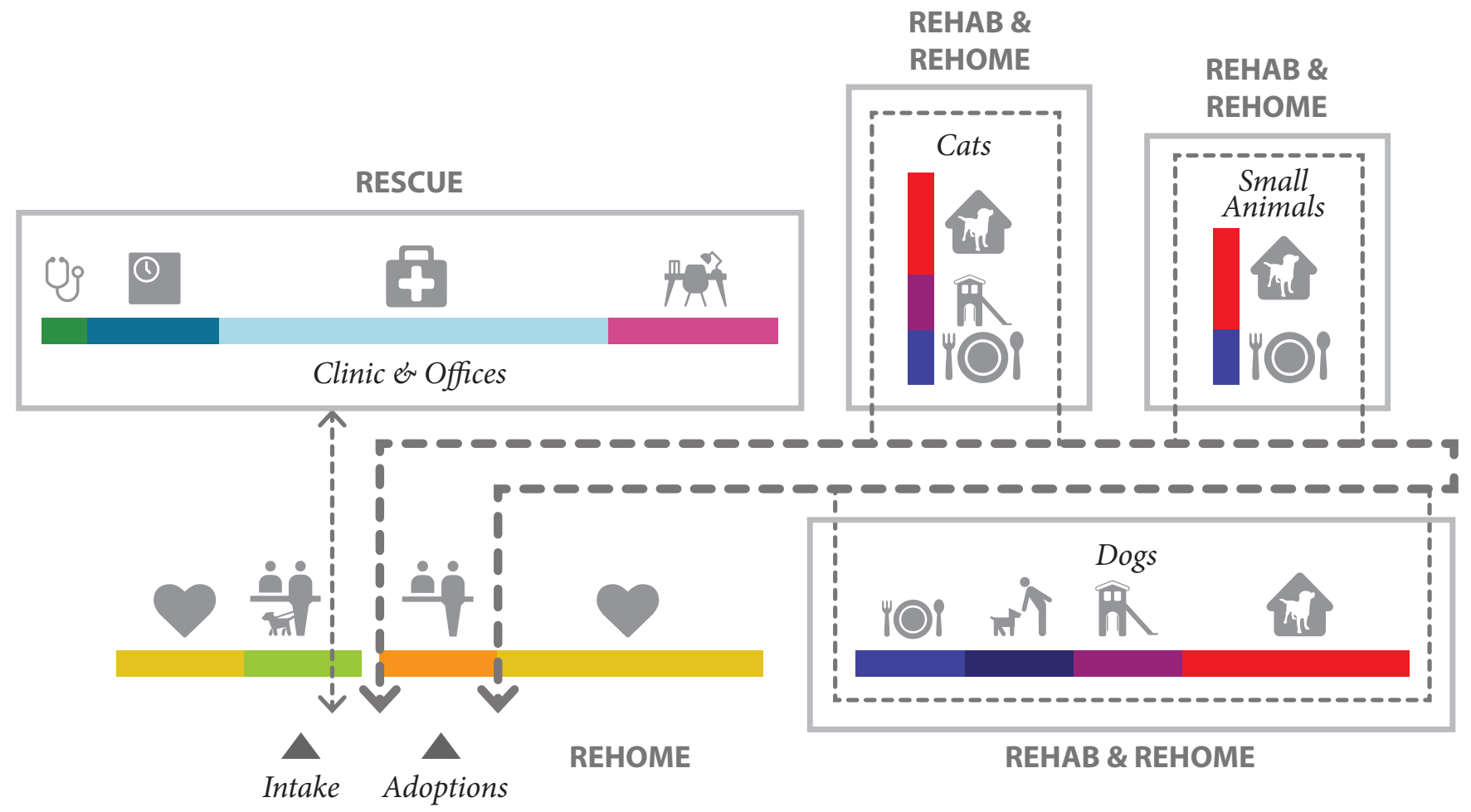

Program Spaces Organized Around Overall Architectural Narrative 


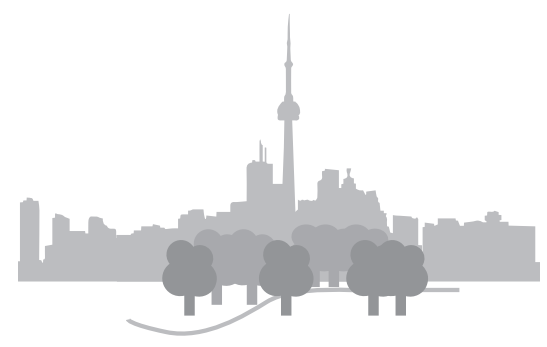

\section{2 | Strategy 2: The Context as Theme}

(Page 145)

Figure 4.20: Existing Site Plan (NTS)

Figure 4.21: Aerial View of THS looking Northeast \& THS Contextual Themes and Indicators: Don Brewery 1880s; Don Valley Parkway 1950s; Queen St Viaduct 1910; City of Toronto.
To establish physical and symbolic connections between building and context by using its site conditions and local materials as a coherent theme throughout.

The hierarchy and organization of spaces have been established in the previous section using the process of intake to adoption as the driver of design. Next, the surrounding context would inform how the spaces are placed in relation to each other on the site. Traffic patterns, solar orientation, sightlines, and access points are considered for visual and logical connection to the site and its surroundings. The Don Valley then serves as inspiration for material expression. The themes and symbols of nature, industry, recreation, and infrastructure form the basis for material studies appropriate for the site, and a hierarchy is established, defining and differentiating rescue, rehabilitate, and re-home programs. 


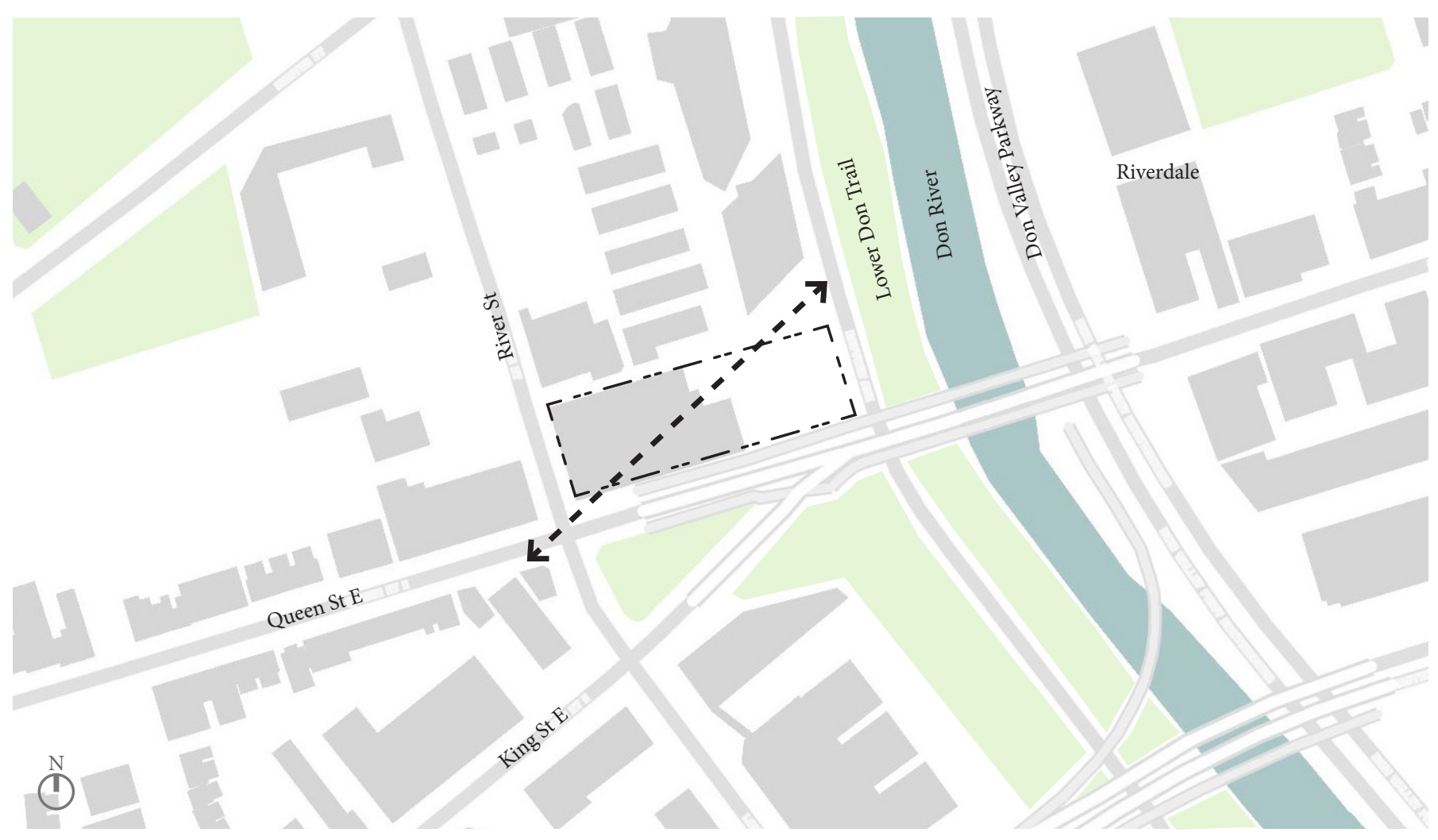

Figure 4.20
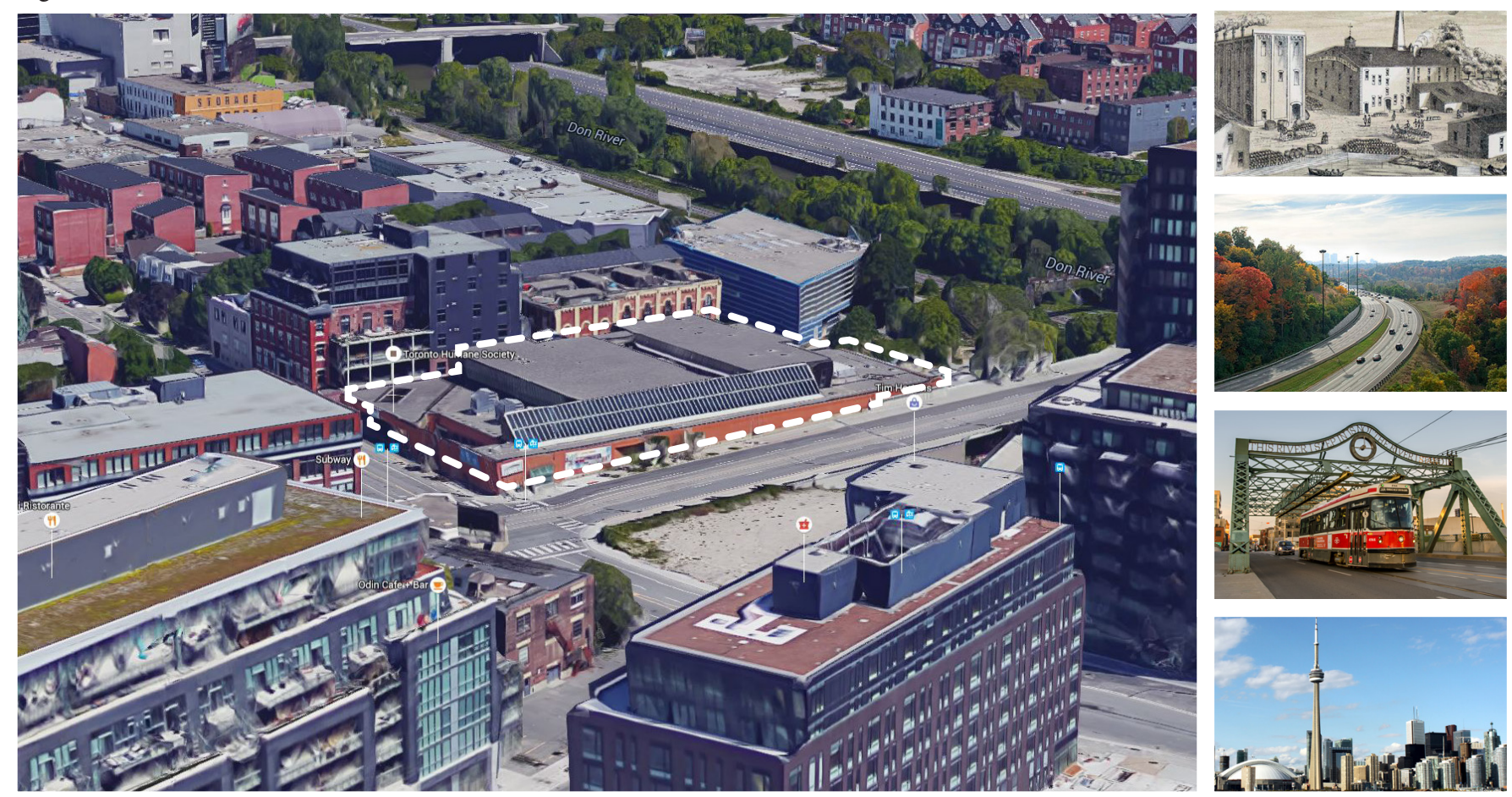

Figure 4.21 


\subsection{1 | Addressing the Immediate Context}

\section{Building Massing Responds to Site Conditions}

An interweaving of nature and city as theme, the building acts as a transition between city and valley. The form of the building responds to its surroundings by addressing and mediating between the two conditions from east (valley) to west (city) (Figure 4.22 previous pages).

Rather than a massive block at one end of the site (as the existing THS sits), the mass is divided to maximize daylighting and a diagonal split establishes visual connection between city and valley from the street corner (Figure 2.23). This opens the corner up for a public plaza, inviting people in from the streets. The building edge stops where the river used to meander through the site, maintaining the natural flood plain and providing additional park and exercise space for the shelter animals. It attempts to return this natural landscape for productive recreational use for the shelter (Figure 4.23). Although physically separated from the actual river and trail by Bayview Avenue and GO Train rail tracks, this park space symbolically serves as a reminder of the past, while respecting the infrastructural needs of the present. 
Figure 4.23: Massing Study Diagrams

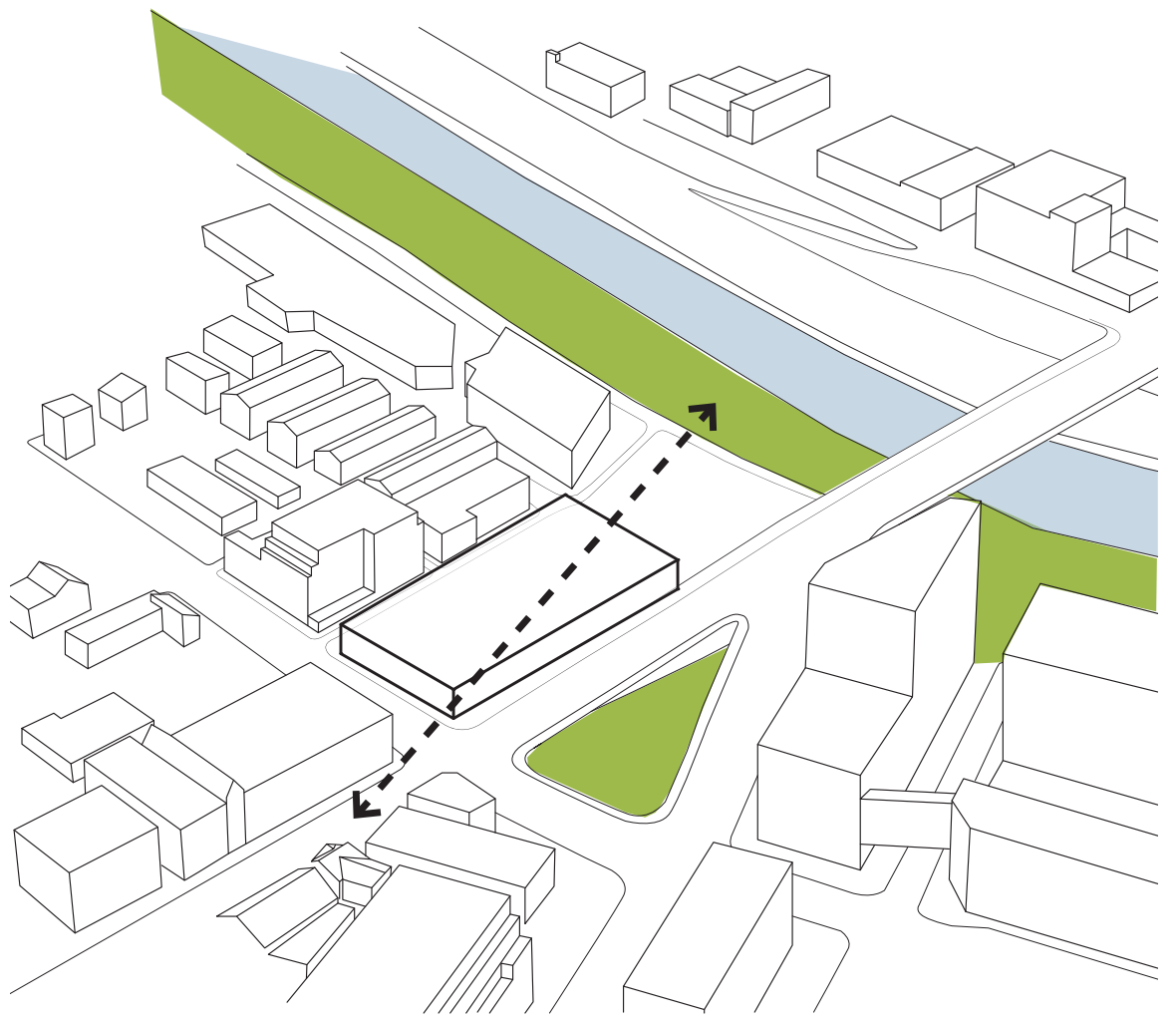

A | Overall massing idea

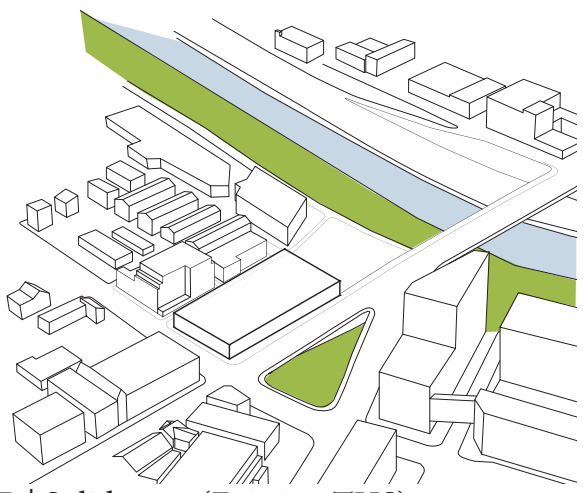

B | Solid mass (Existing THS)

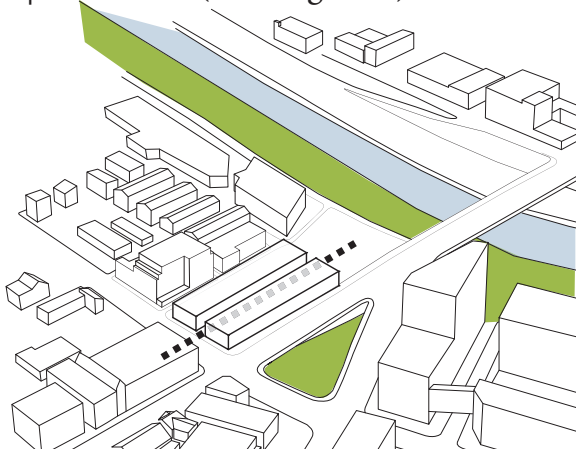

C | Divided mass to maximize daylighting

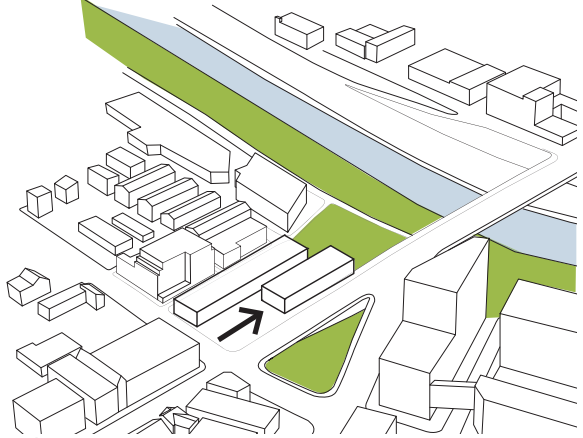

D | Southern mass reduced to open up corner at Queen St E and River St

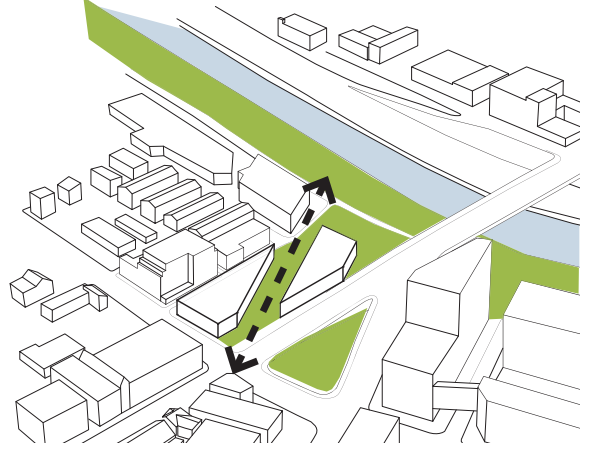

E | Diagonal split for visual connection to valley 


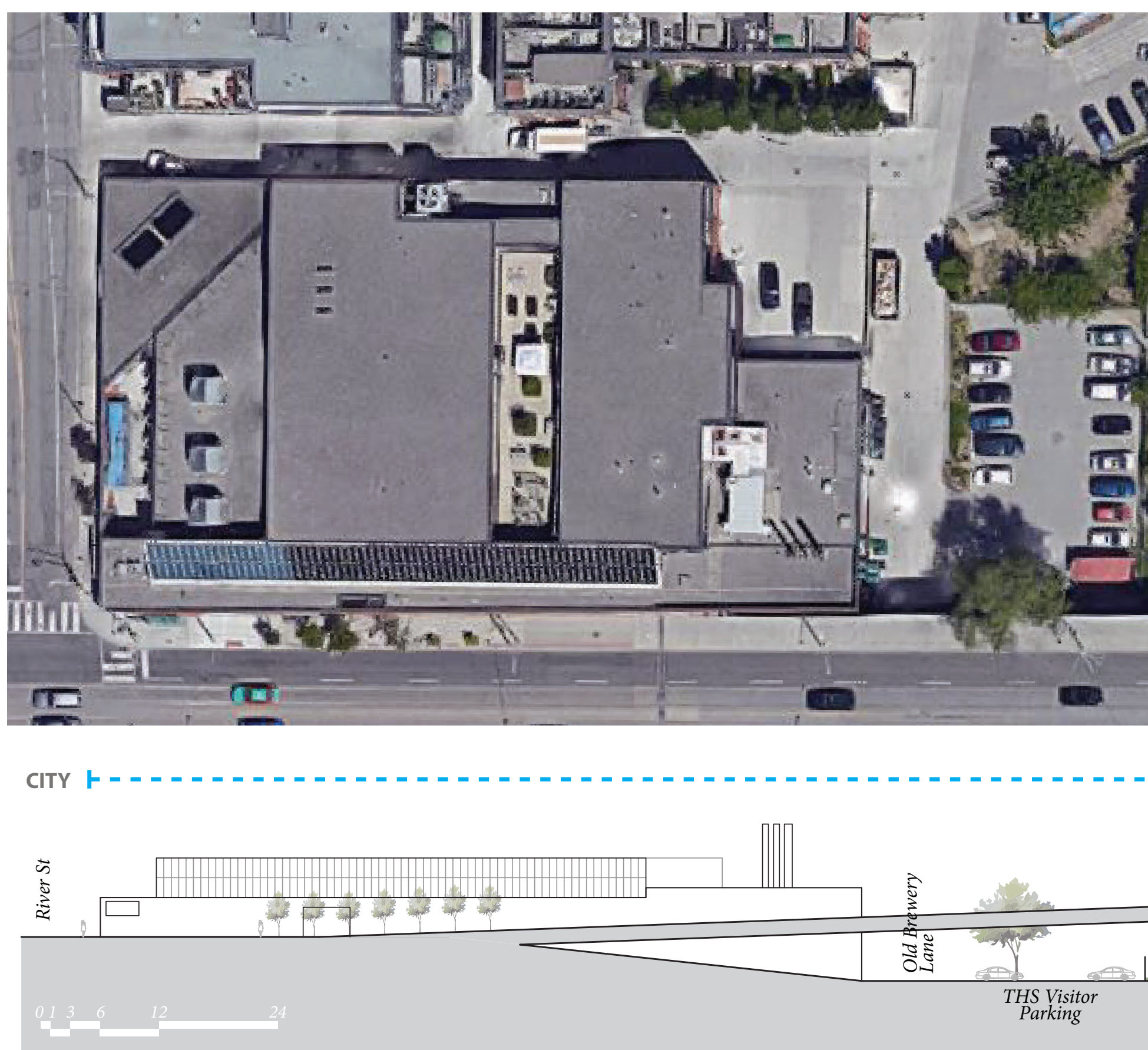

Figure 4.22 


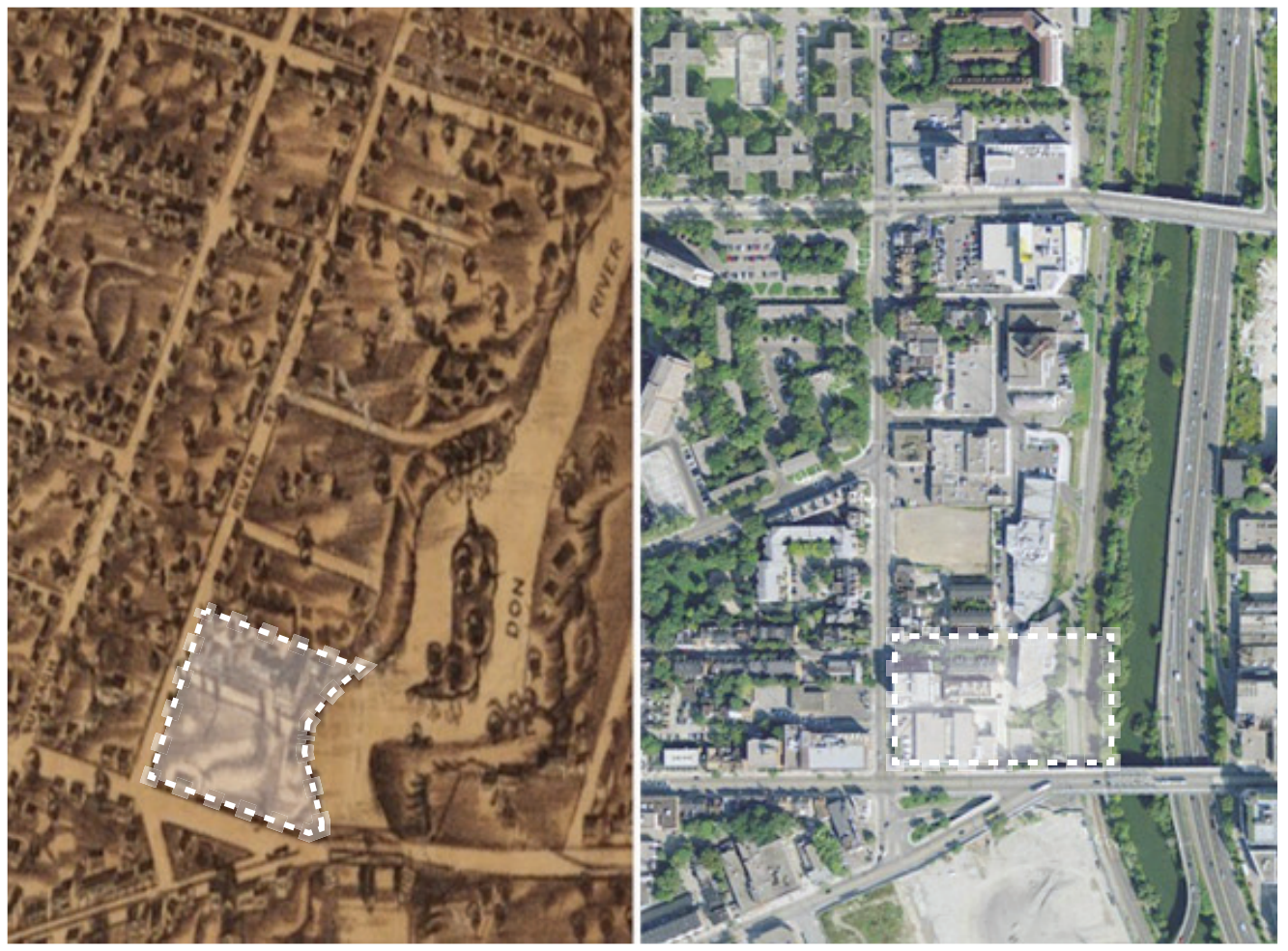

Figure 4.24: Map of Site prior to River Straightening | Map of Site today. 


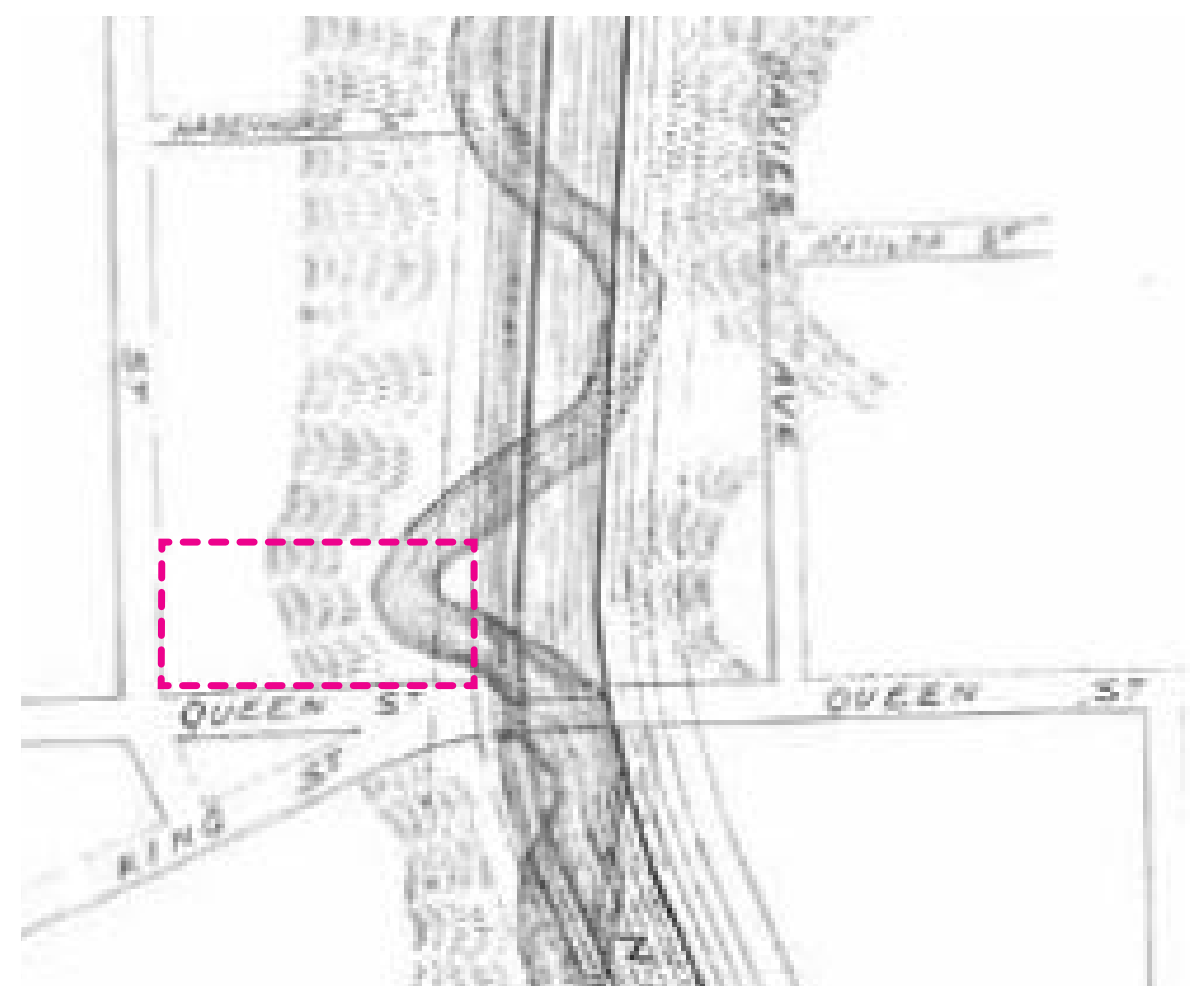

Figure 4.25: Don River Straightening Plan, 1886.

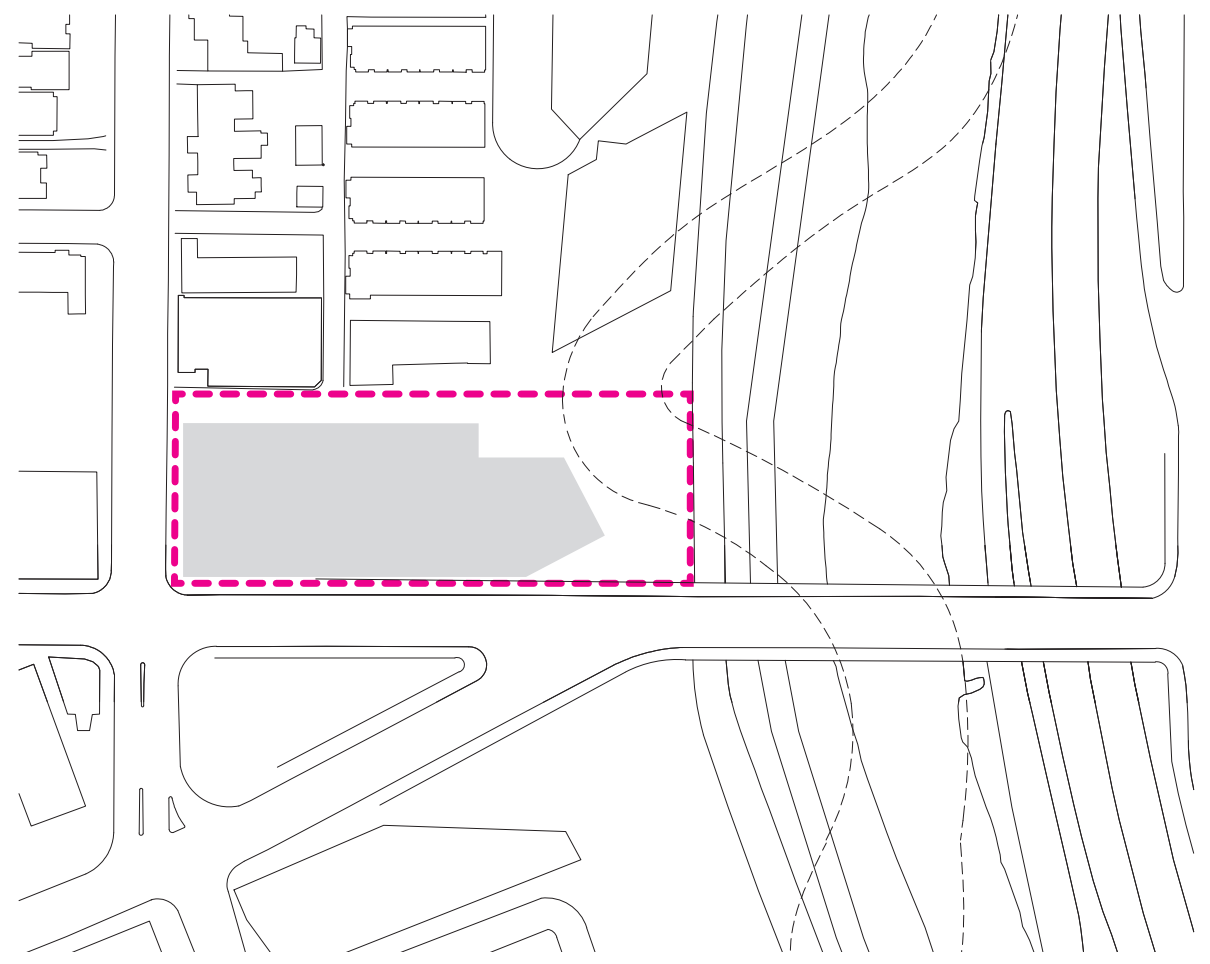

Figure 4.26: New Building Footprint on Site, showing original river course. 


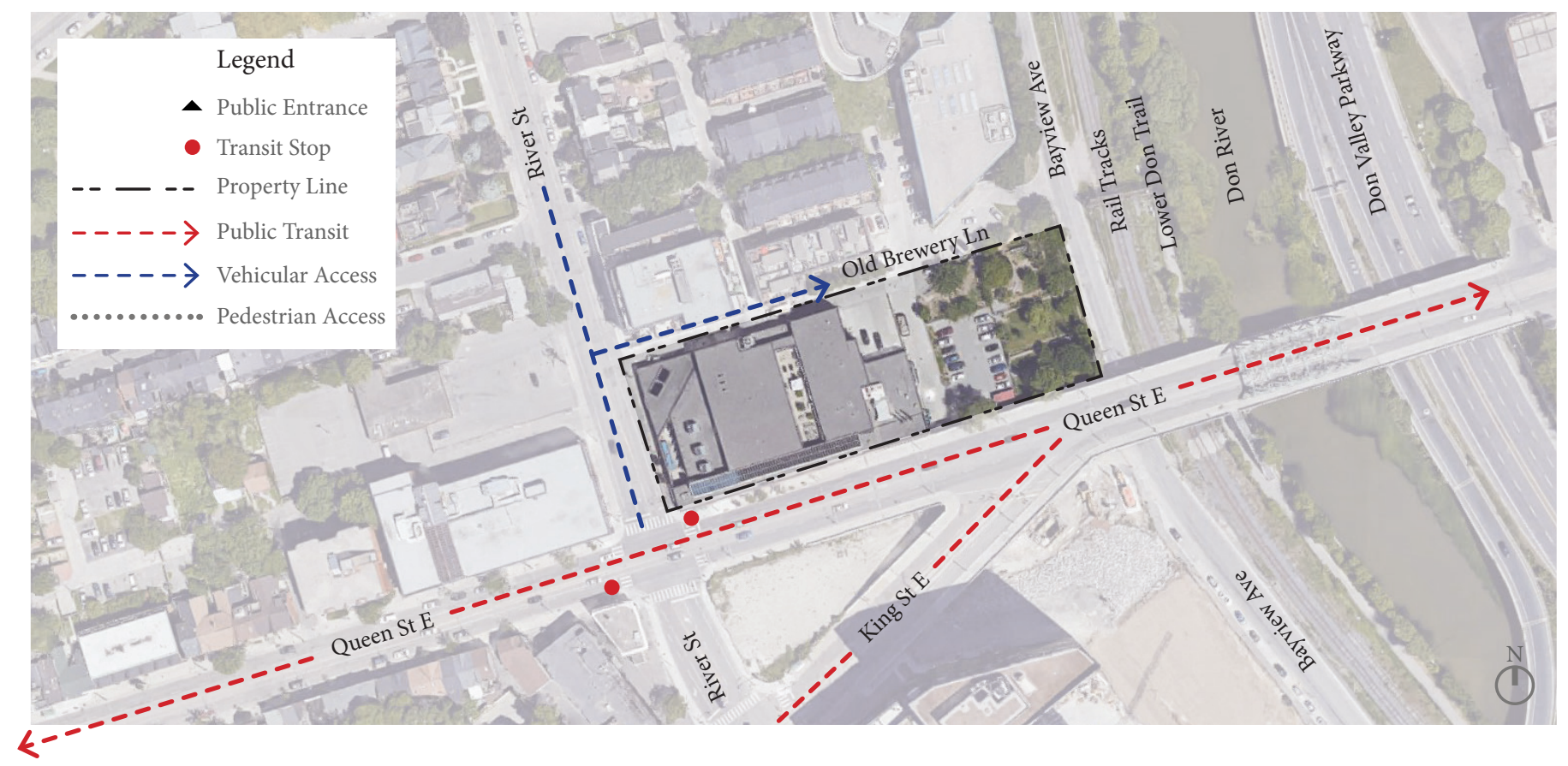

Figure 4.27. Existing Site Plan with Traffic and Circulation Patterns

\section{Program Distribution}

Public programs and entrances are positioned along River Street, Queen Street, and the public plaza, but also maintains partial street frontage for public access and closer relation to the street. The Intake and Clinic entrance is separated from the main Adoption Center entrance, where the Intake entrance is more private off River Street, and the Adoption entrance prominently faces Queen Street, signified as a centralized volume. The public programs of retail, café, and community spaces are clustered around the entrances, allowing program to spill out onto the public plaza in the summer months.

Private programs of the clinic and offices sit along the residential laneway on the north, allowing for easy service access and more privacy for treatment and administrative spaces. Diffused light from the north also allows for ambient lighting in these spaces. The site itself slopes down toward the river, and as such, mechanical and parking can be concealed underground on the western end of the site.

Adoption areas are divided into canine, feline, and small animals, each with their separate areas of living quarters, exercise and socialization spaces, and maintenance spaces. They are positioned around the clinic spaces for ease of access, but are physically and visually separated from each other. Roofscapes and the park on the east serve as private outdoor exercise and socialization spaces for the animals and staff, fully using all horizontal surfaces for the benefit of the shelter. 


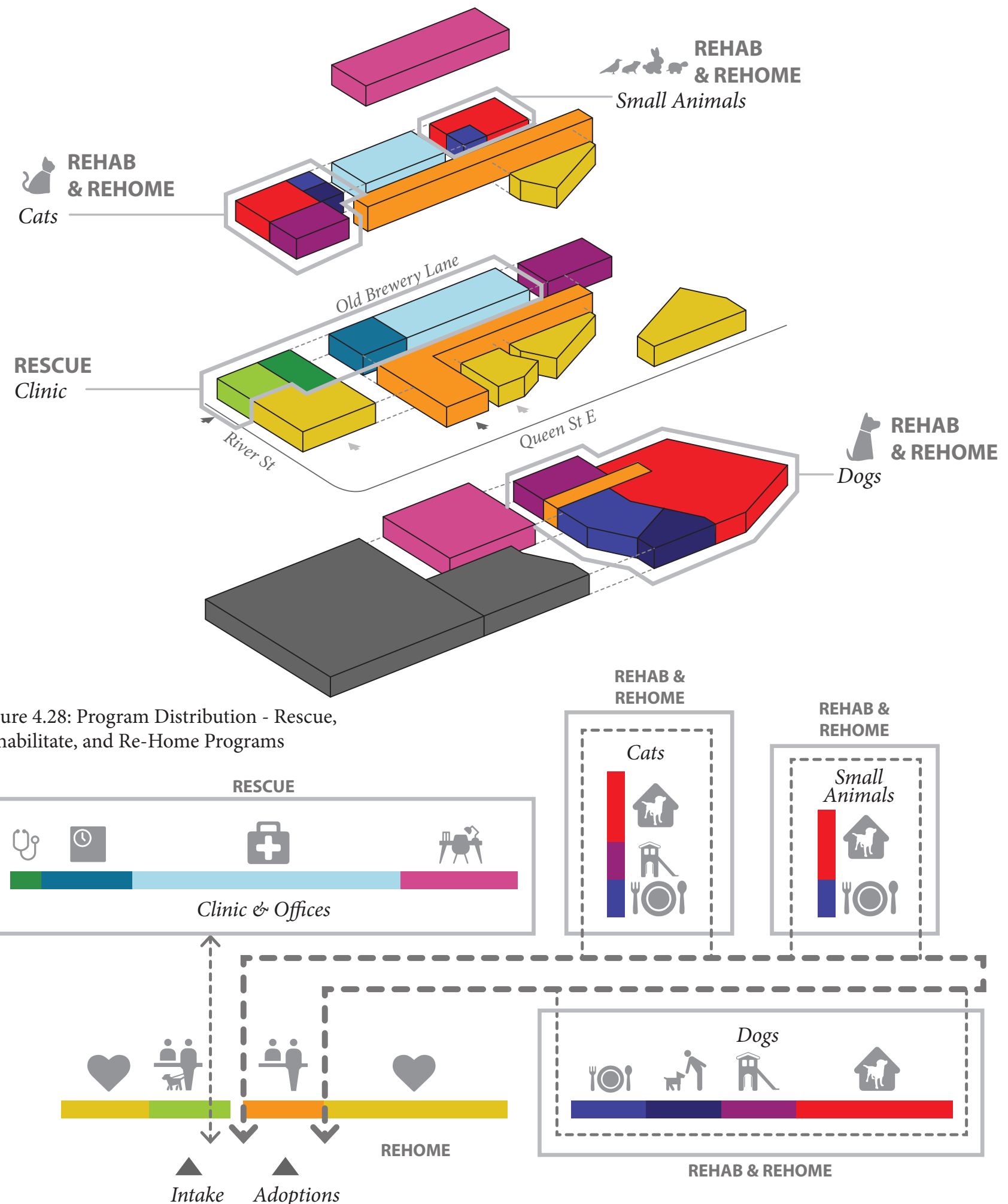

Figure 4.29: Overall Architectural Narrative 
3rd Floor +9500

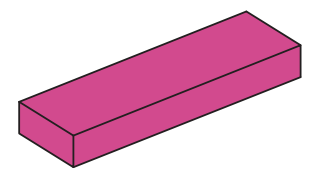

2nd Floor +5000

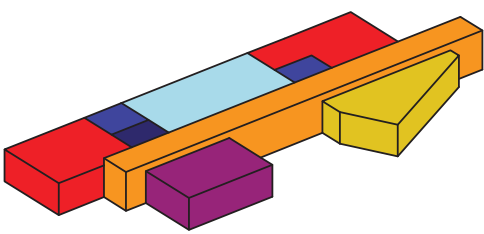

Intake Lobby

Reception

Lower Level -4500

Exam Rooms

Triage

Pharmacy

Offices

(1) Quarantine Rooms

Veterinarians' Offices

Exam Rooms

Laboratories

Treatment Rooms

Pre-Op Ward

Surgery Rooms

Post-Op Ward

Euthanasia Room

Morgue

Mechanical

Electrical

Janitor's Closet

Loading Area

Parking

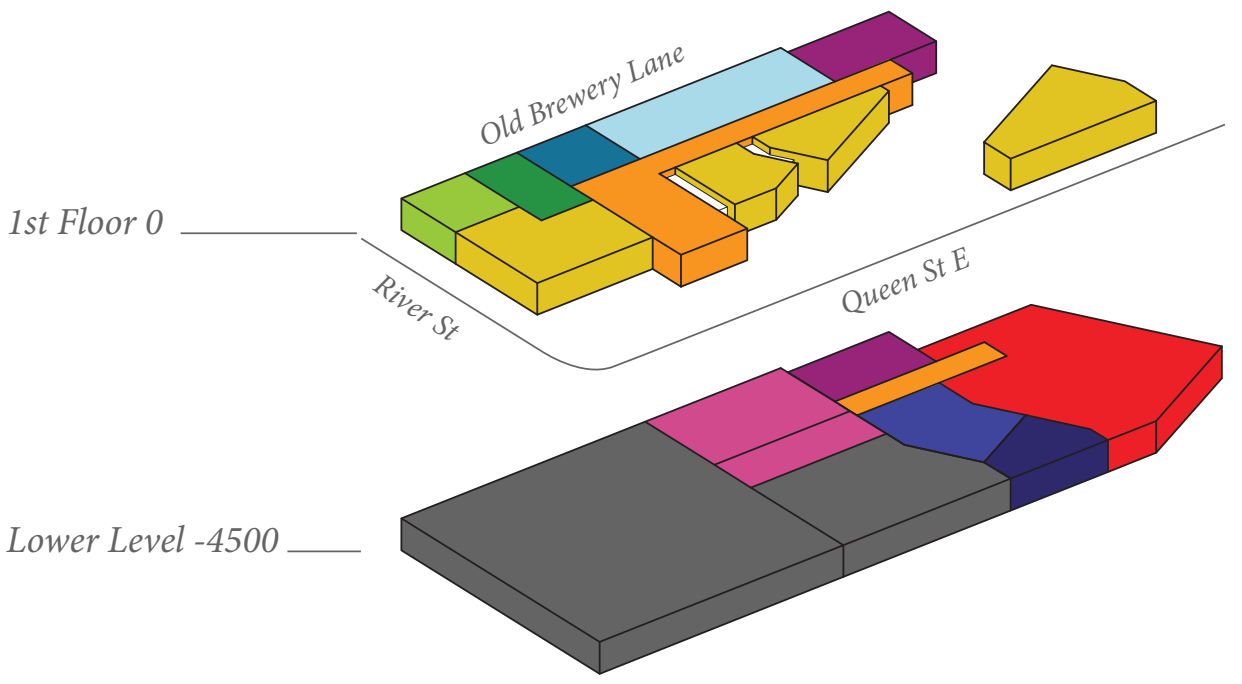

Food Preparation

Food Storage

Grooming

Laundry Room

Thercise Area

Indoor Play Areas

Outdoor Play Areas

Volunteer Center

Administrative Offices

Meeting Rooms

Lunch Room

Locker Rooms

Showers
Figure 4.30: Overall Program

Distribution.
Dog Kennels

Cat Rooms

Small Animals Rooms

Adoptions Reception

Adoption Interview Room

Meet \& Greet Rooms

Community Room

Retail

Cafe

Food Bank

Public Dog Park 


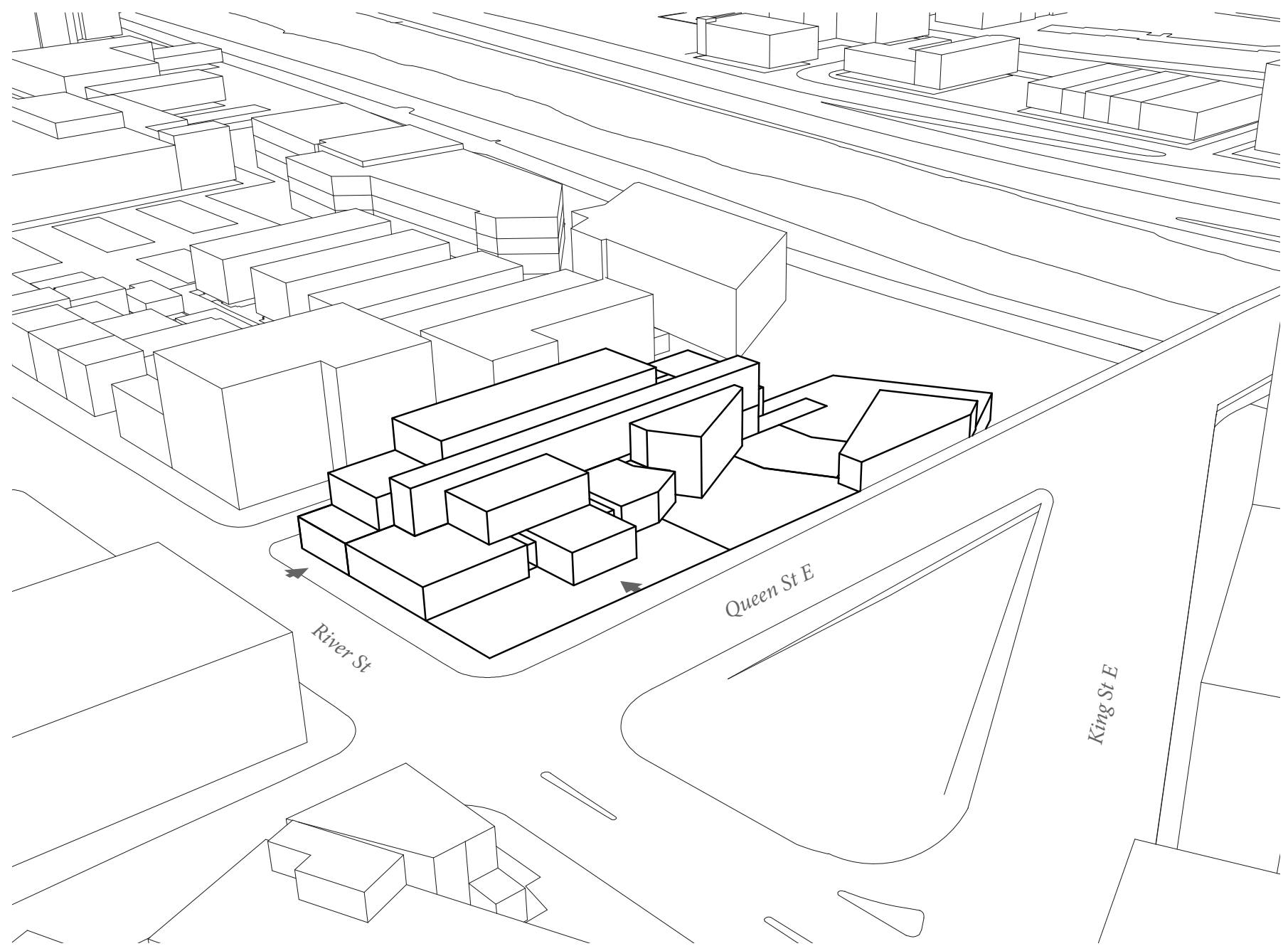

Figure 4.31: Overall Massing on site. Aerial view looking northeast. 


\subsubsection{Signs and Symbols of the Don Valley}

The perception of the Don River and Valley system has continuously shifted throughout the city's history. At first, the valley was seen as a picturesque landscape and country retreat for recreation and leisure. Industrial activity of the late 1800s transformed it into a landscape of waste and pollution, attracting unsightly industries and urban discards, becoming the physical and social fringe of the city. However, additional transportation infrastructure in the 1900s astoundingly changed the valley's perception to that of a vital and productive landscape. The Don Valley Parkway's meandering roads imitate the natural curves of the valley, taking drivers on a picturesque tour of the valley's landscape, renewing people's appreciation of urban parks. Thus, the themes and symbols of nature, industry, recreation, and infrastructure form the basis for material studies appropriate for the site. Addressing both its industrial past and recreational future, brick, wood, steel, and glass form the primary material palette for the design.
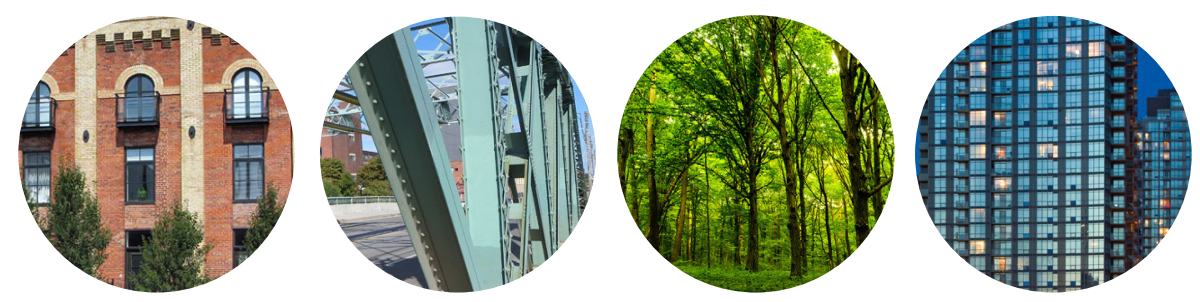
Remnants of Toronto's industrial past can be spotted throughout the Don Valley and the city. The Don Valley Brickworks (now an environmental center) used to produce and supply most of the brick for the city's buildings. The valley itself supplied the necessary clay, shale, sand, and water for the production of bricks that literally built Toronto's appearance and character since the 1800s. As such, brick, as an expression of history and industry, is an appropriate material for the shelter.

The site of the THS and the area just north of it was the site of the Don Brewery, one of the largest breweries in 19th Century Toronto. The Davies family owned the brewery as well as the Brickworks, and was responsible for building employee housing in Corktown too. The brewery was shut down in 1910 following a massive fire, and only the Malthouse remained, later designated as a heritage building in 1996. It features buff brick pilasters, decorative corbelling, and rounded arches that define the Victorian Industrial Era. The Malthouse has since been converted into residential lofts. Queen St Vinegar Co, just west of the Malthouse, is also indicative of the past. These buildings give us a hint of the past industrial character of the site.

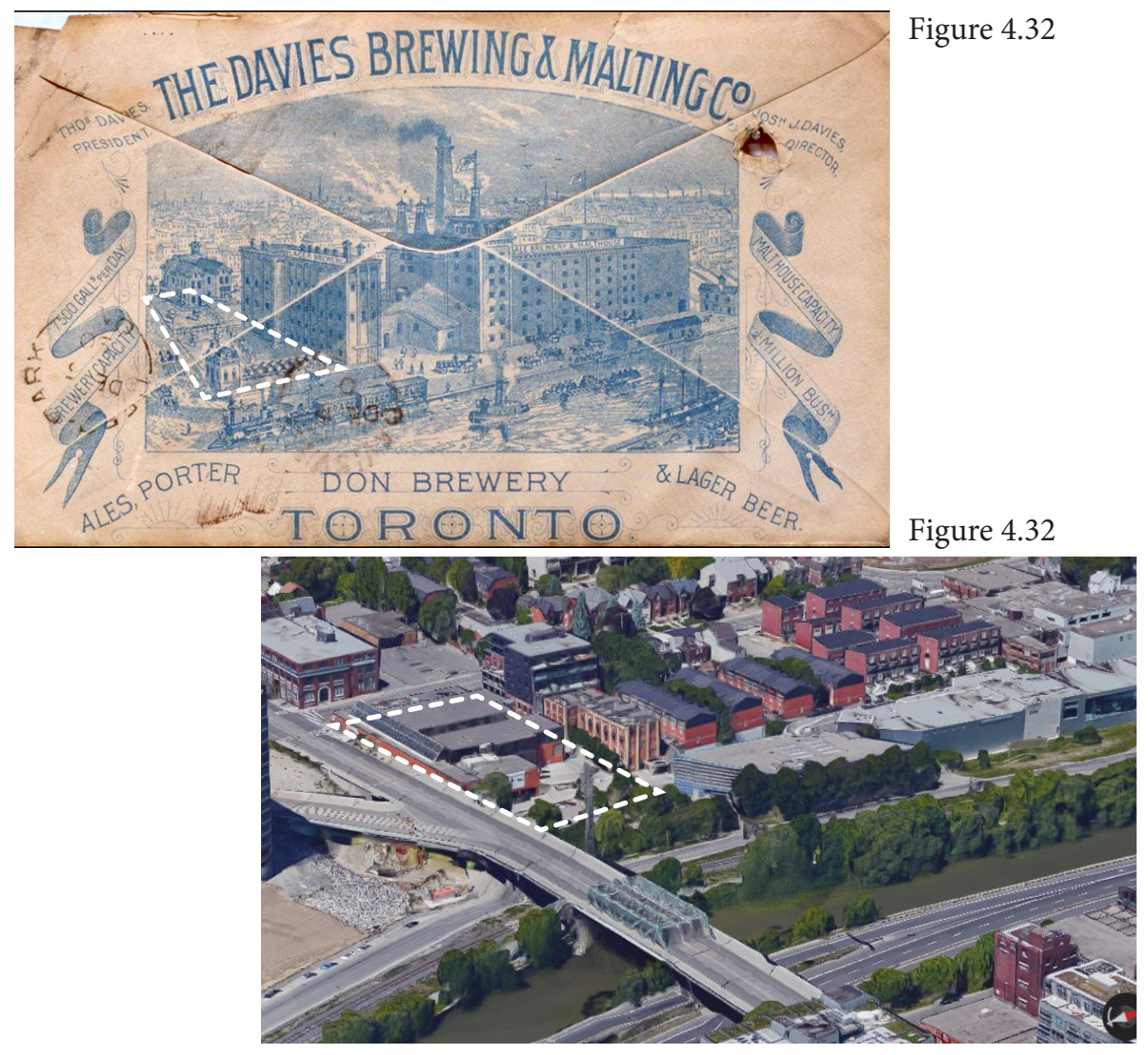

Figure 4.32: The Davies Brewing \& Malting Co. 1890s Drawing. Aerial View looking northwest.

Figure 4.33: Current Aerial View of former Davies Brewery site looking northwest. 
Figure 4.34
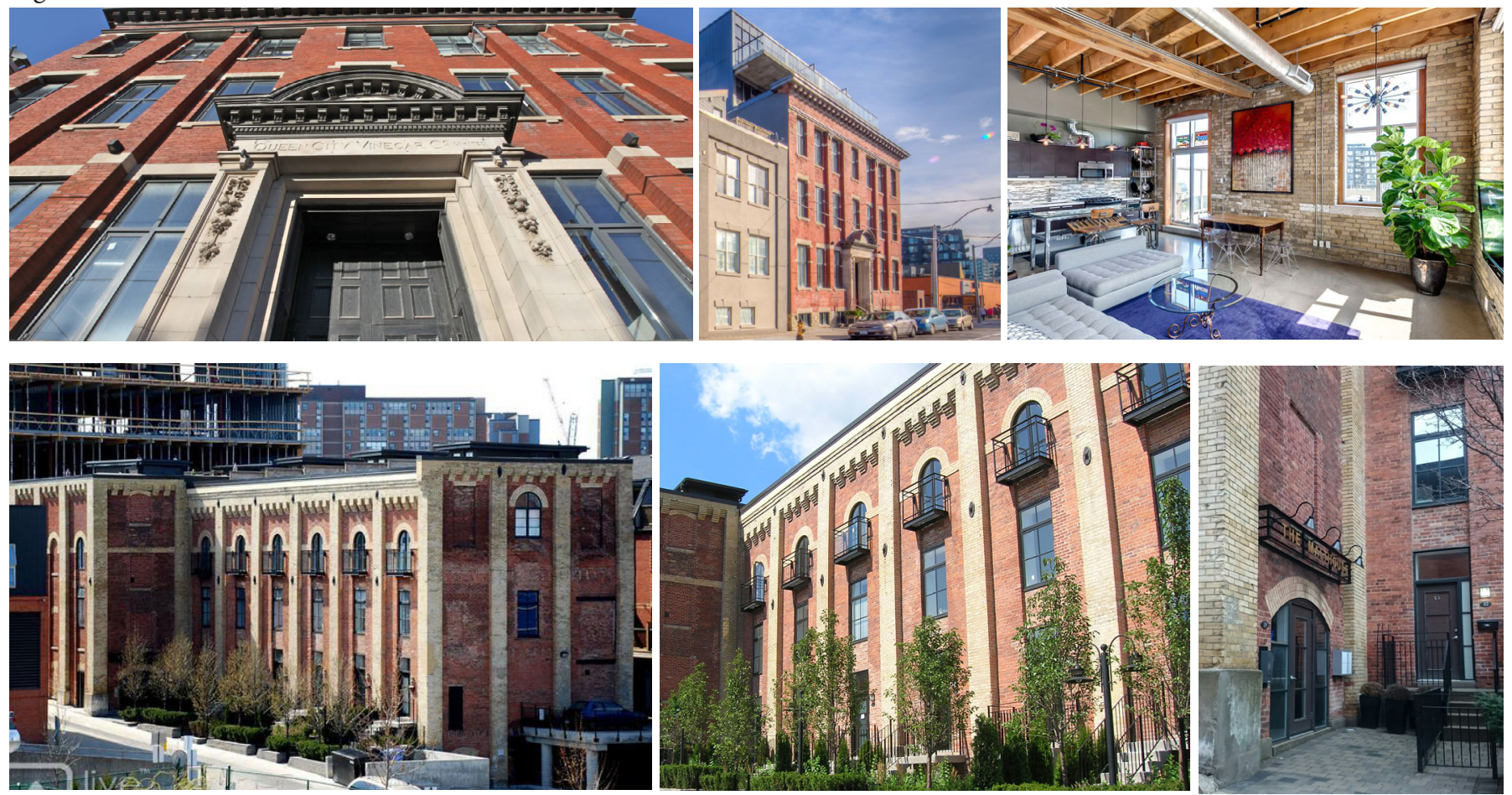

Figure 4.35

Figure 4.34. (Left to Right) Queen City Vinegar Co. Front Elevation; Along River Street with THS in the background; Interior

Figure 4.35. (Left to Right) The Malthouse Lofts. Aerial View looking northwest; South Elevation facing THS; Entrance along Old Brewery Lane. 

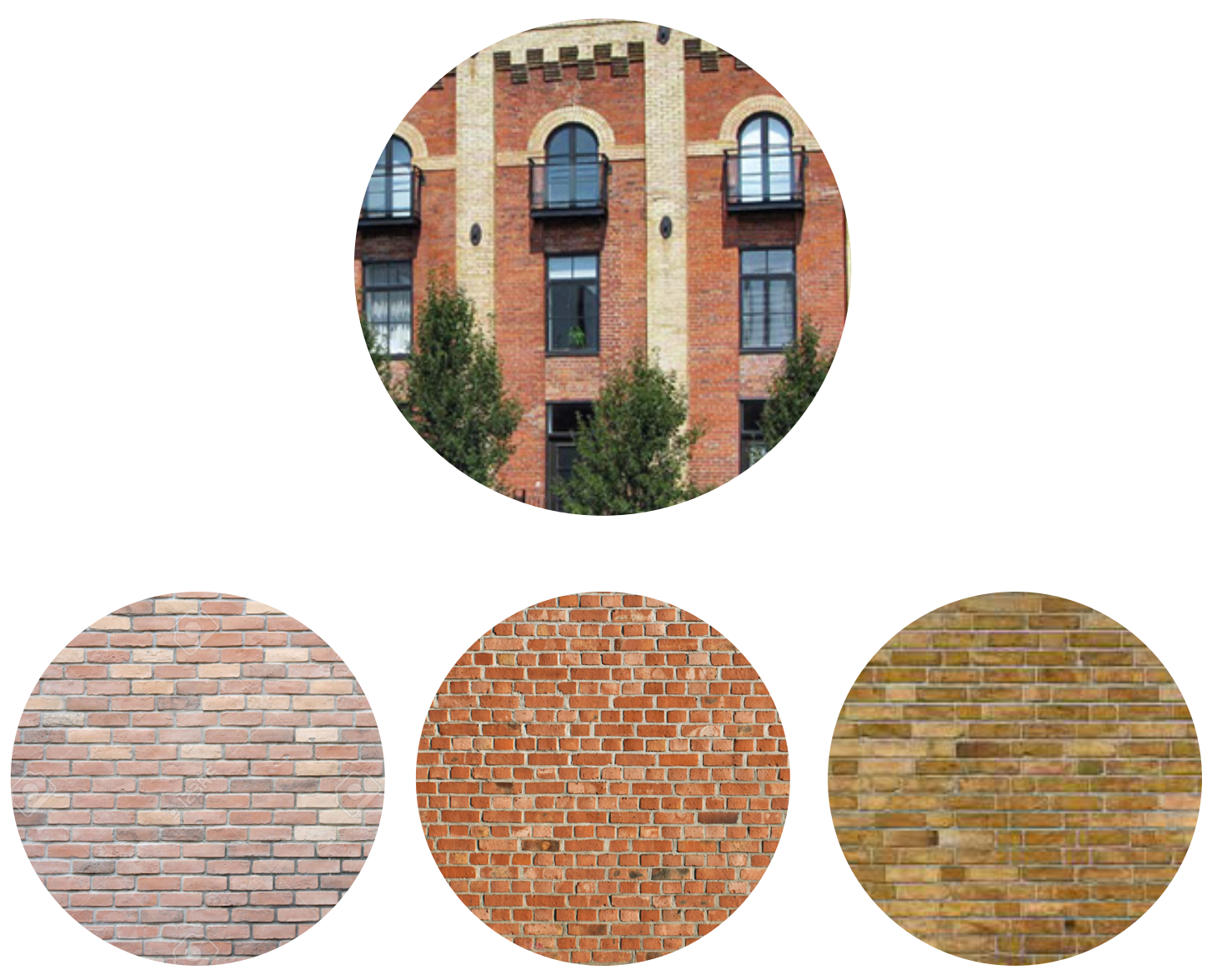


\section{Steel - Queen Street Bridge}

Immediately southeast of the site is the Queen Street Bridge, one of few steel truss bridges in the city. Built in 1911, the bridge was a prominent crossing raised well above the river. The bridges prior to this one were lower and made of wood, which frequently collapsed during floods. Today, the truss acts as a gateway entering and exiting the city as experienced by walking, biking, driving or taking the streetcar across the bridge. The trusses extend to the ground underneath the bridge adjacent to the THS site, and are clearly visible from the park. Thus, the structure for the shelter will also use steel to symbolically reference this adjacent landmark and industrial past.

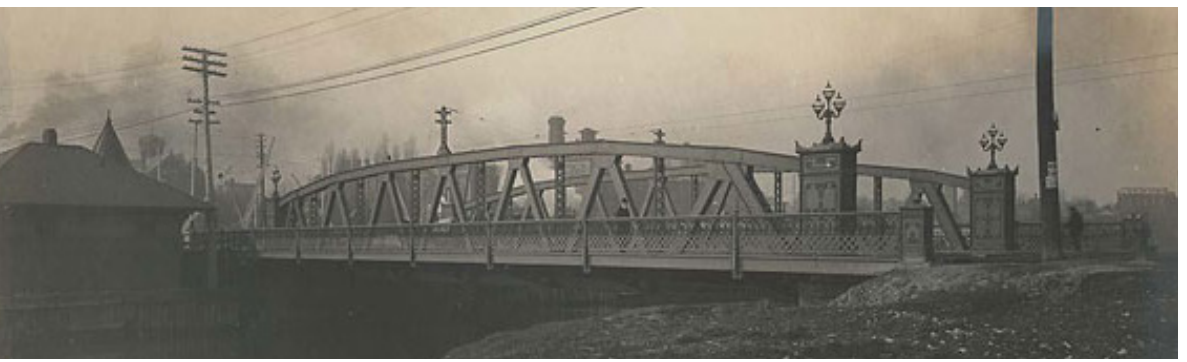

throughout the years. (Top to bottom):

Queen St Bridge 1880s;

Queen St Bridge 1910; Queen St Bridge today after 1996 Renovation and Artwork Addition.

Figure 4.38: Queen Street Bridge from the THS. (Top to Bottom): Structural Support Below the Queen Street Bridge; Lower Level of the THS adjacent to the Queen Street Bridge

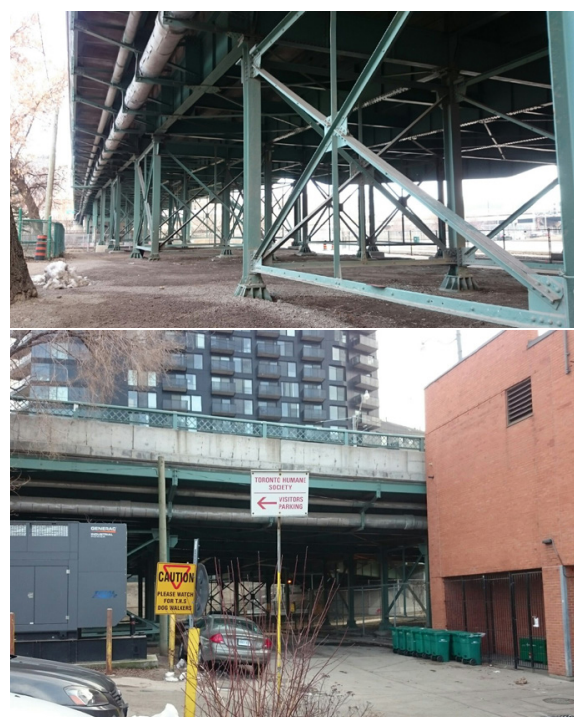

Figure 4.38
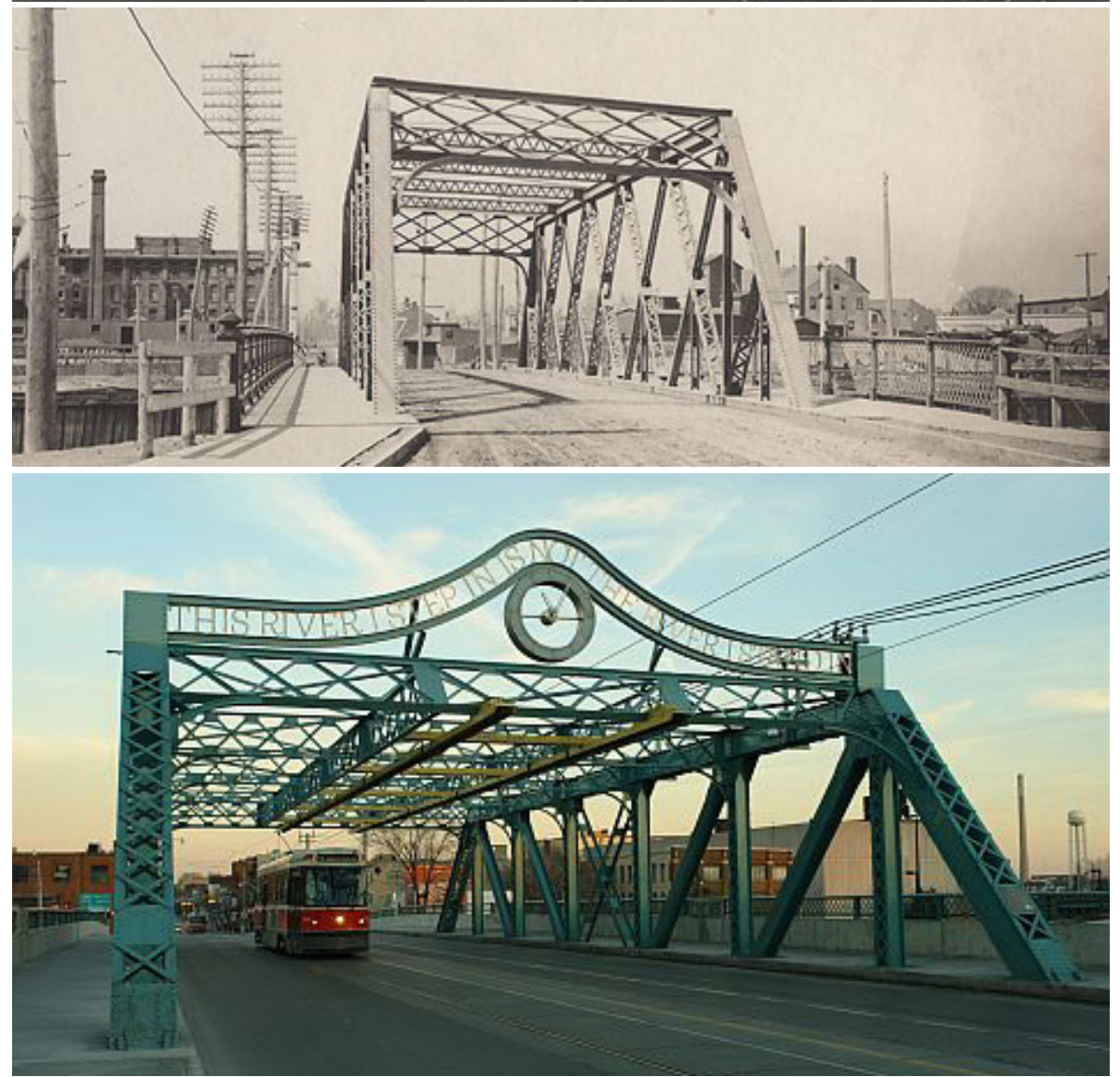

Figure 4.37 

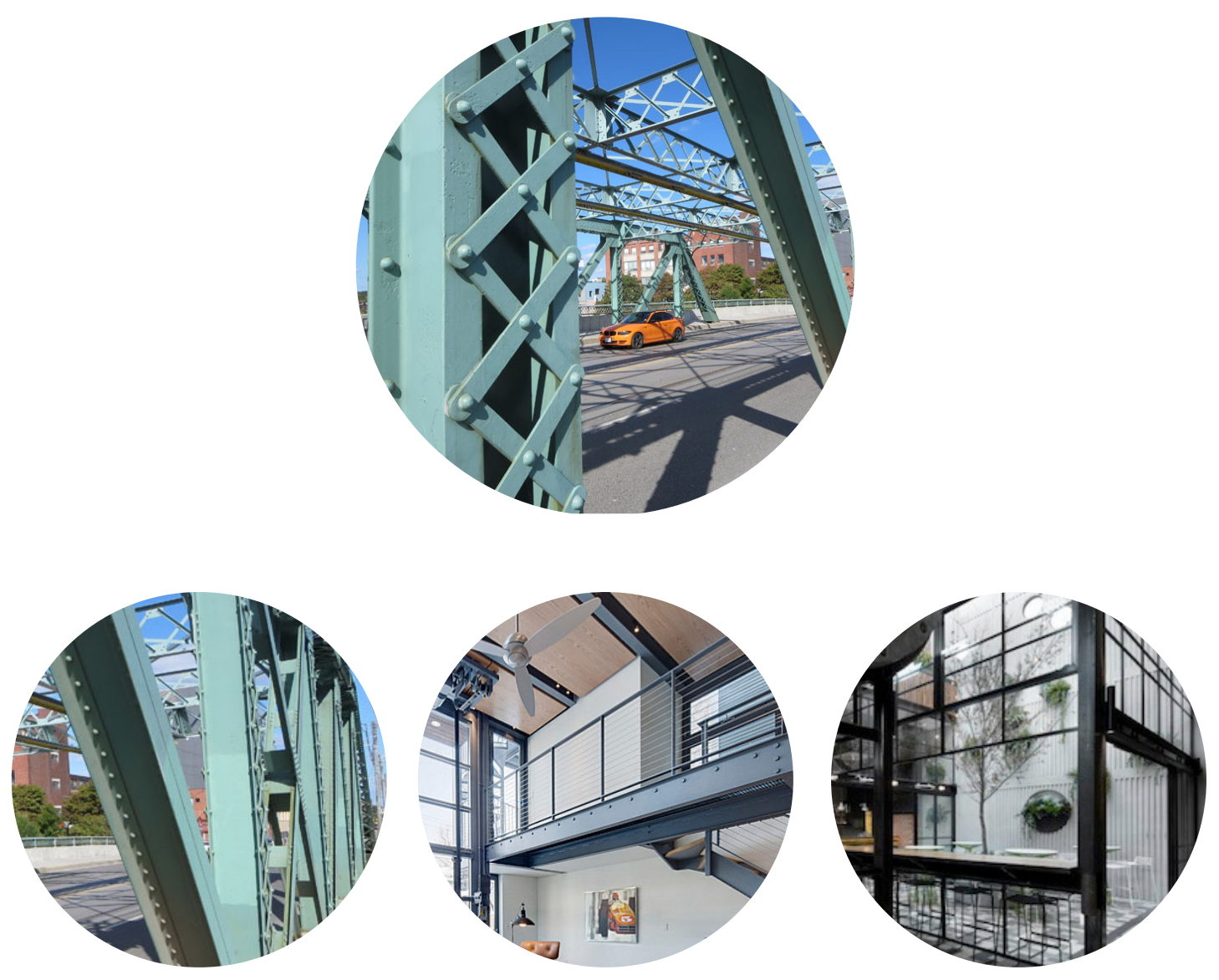
As a natural material and a frequent structural material of industrial architecture, wood features and finishes also evoke the warmth and natural feel of trees and landscape of the valley.

In addition to structural use, the use of wood screens to provide shading and privacy is also explored. Symbols and patterns of trees and leaves are investigated to provide different levels of shading, interesting shadows, and both reveal and conceal certain areas of the shelter.

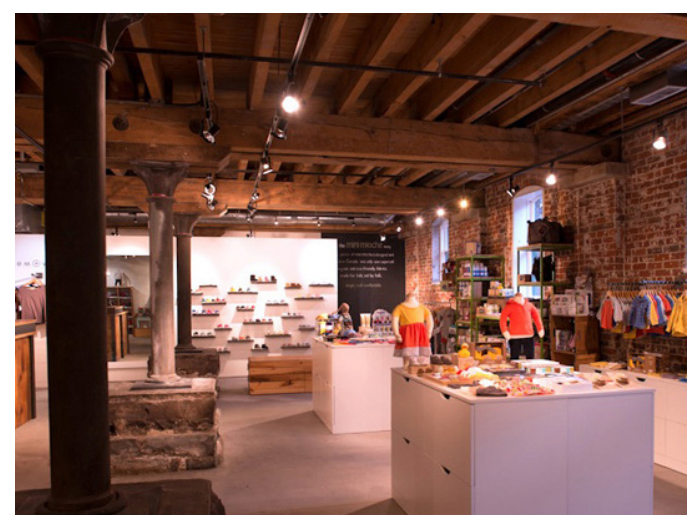

Figure 4.39
Figure 4.40
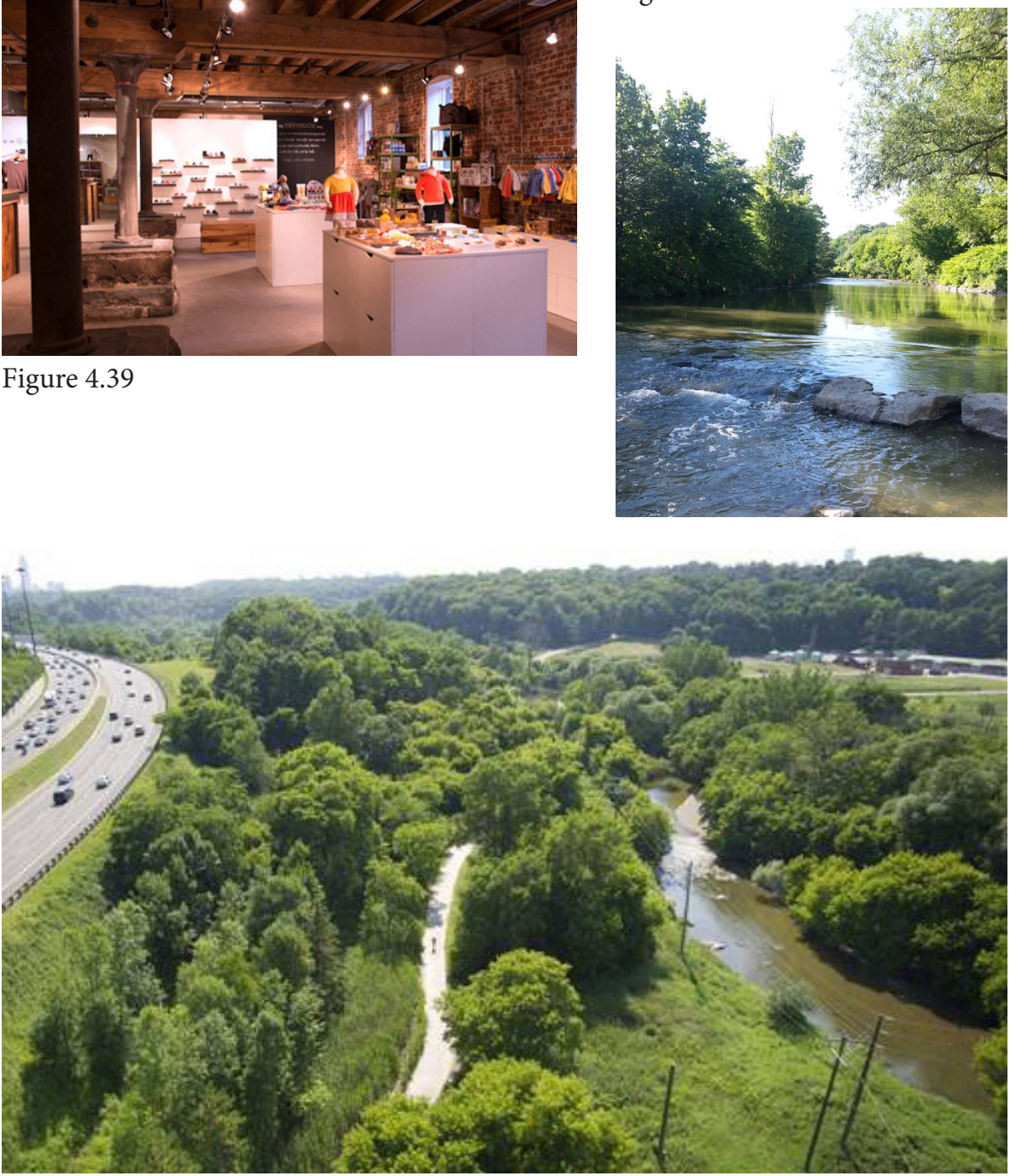

Figure 4.41
Figure 4.39: Reclaimed Industrial Interiors, featuring wood beams and ceilings.

Figure 4.40: The Don River

Figure 4.41: The Don Valley Parkway, Valley, Trail, and River Landscape 

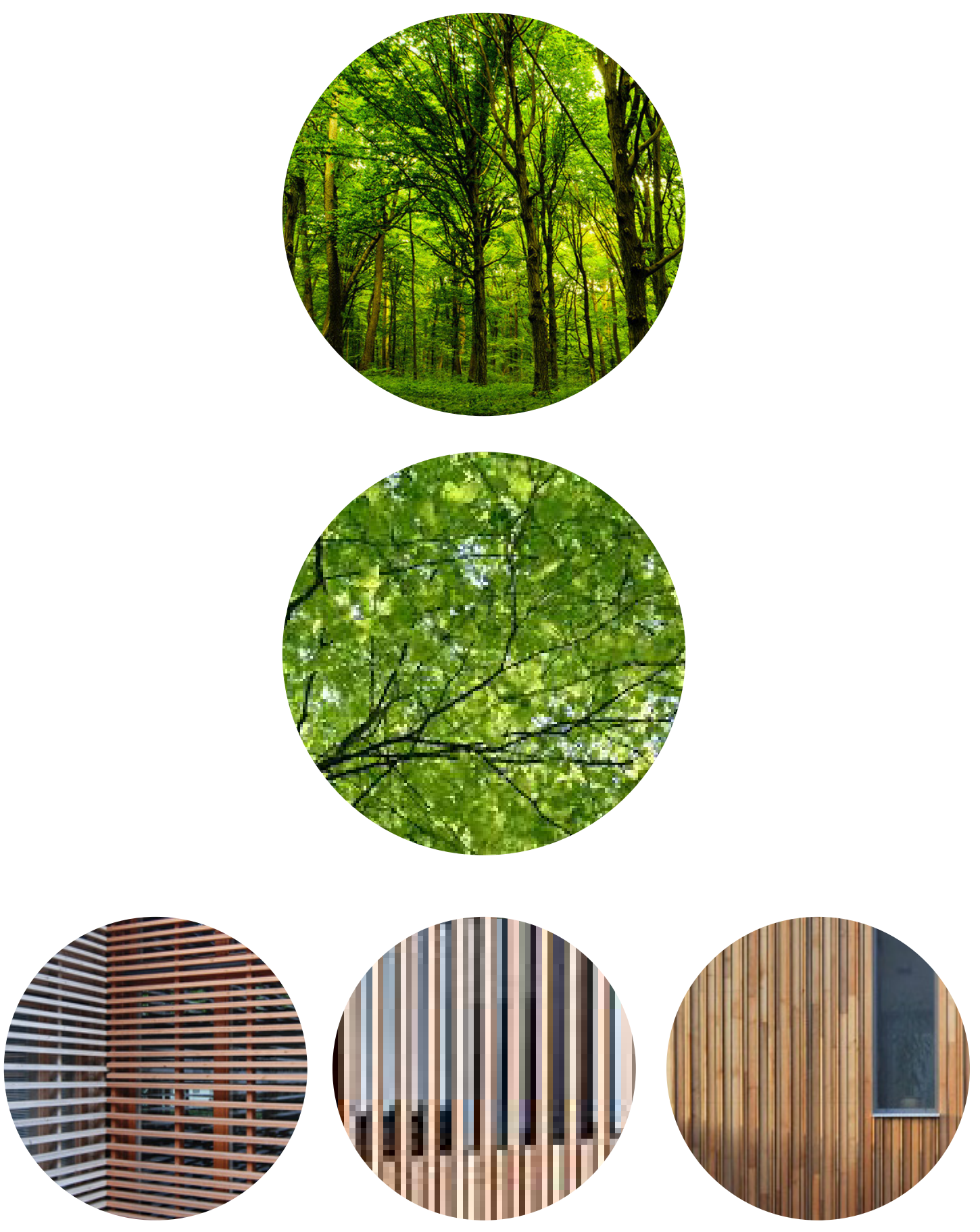


\section{Glass - Visibility \& Transparency}

The city is increasingly dominated by glass towers, but the transparency of the glass allows vistas and views inside and out. Views inside and out are beneficial to the THS to communicate an image of openness and transparency, giving people a sense of what goes on inside the shelter. Different levels of transparencies and glass patterns are explored to signify and differentiate areas and functions. 

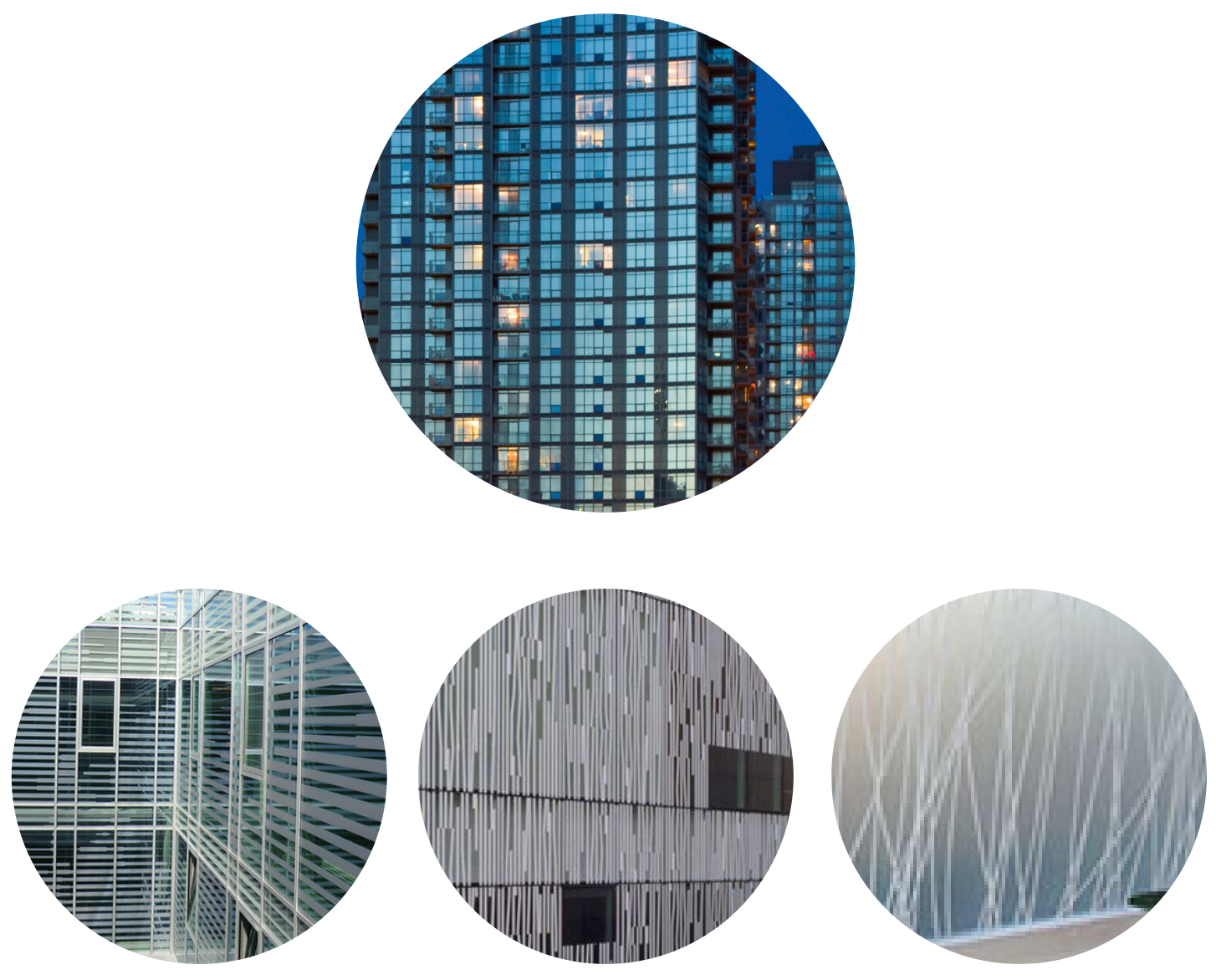


\subsubsection{A Hierarchy of Spaces and Coherent Theme Throughout}

Thus, the symbolic and pragmatic values of each material communicate a theme of the city and valley that addresses its natural character, industrial past, and current surroundings. Using the material palette as a tool for differentiating spaces, a hierarchy is established, defining and differentiating rescue, rehabilitate, and re-home programs.

Public areas are highly transparent, while animal spaces are translucent and let in natural light without being too exposed. The use of wood screens, lattices, and slats control visual and solar access to animal spaces. The rehabilitation spaces are a median between the public spaces and animal kennel spaces, and thus, the screens are less dense, but also revealing at some points.

The private areas of the shelter (the clinic and admin spaces) are signified by brick, respecting the residential lofts to the north, and communicating a solid and productive workspace. However, there will still be visual access to these spaces as outlined in the overall architectural narrative. Openings to the north imitate and reflect the rhythm of windows on the residential lofts.

Private - Clinic \& Admin

Animal Space - Kennels ¿ Support Spaces

Public - Adoptions \& Community Space

Figure 4.42: Hierarchy of Spaces defined by materials

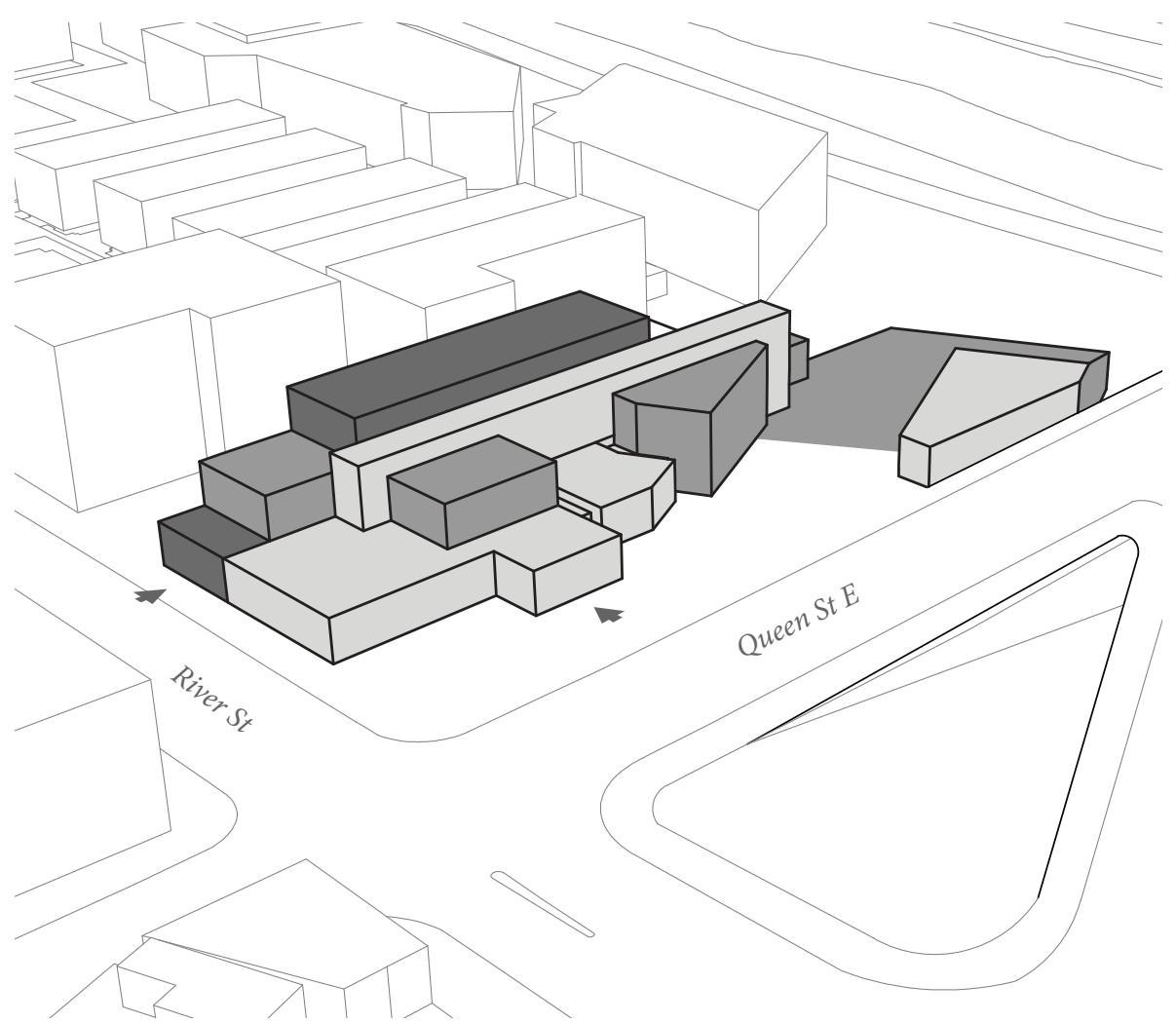



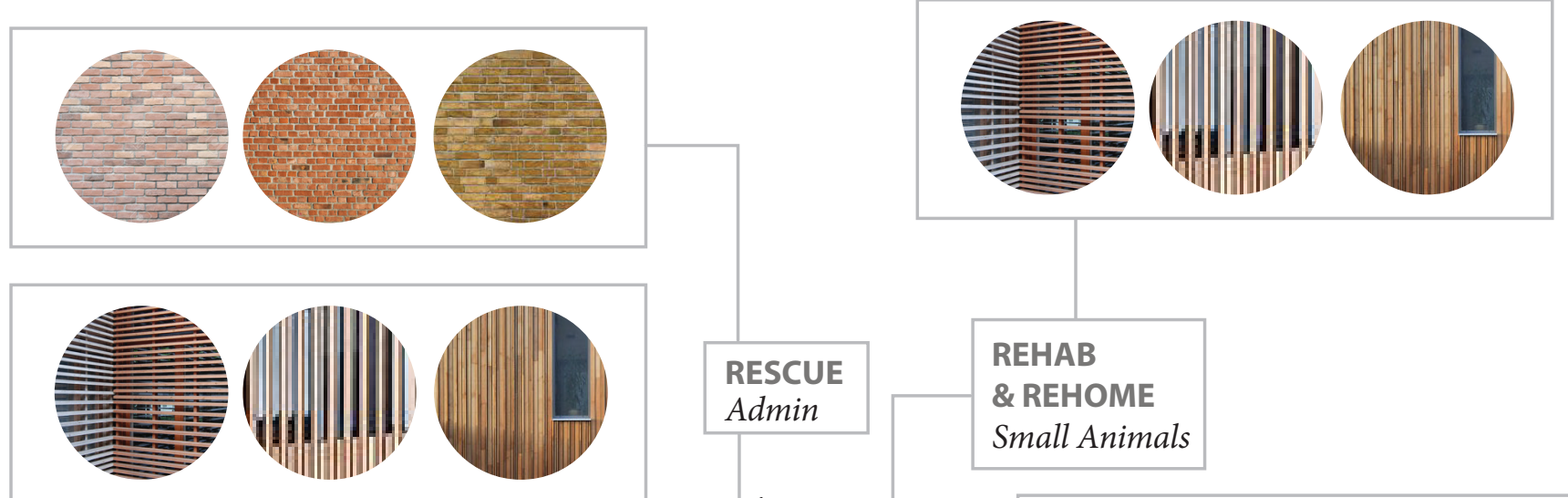

\section{REHAB \\ \& REHOME \\ Small Animals}

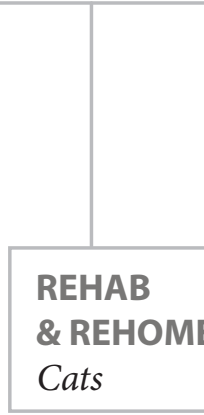

\section{RESCUE} Clinic
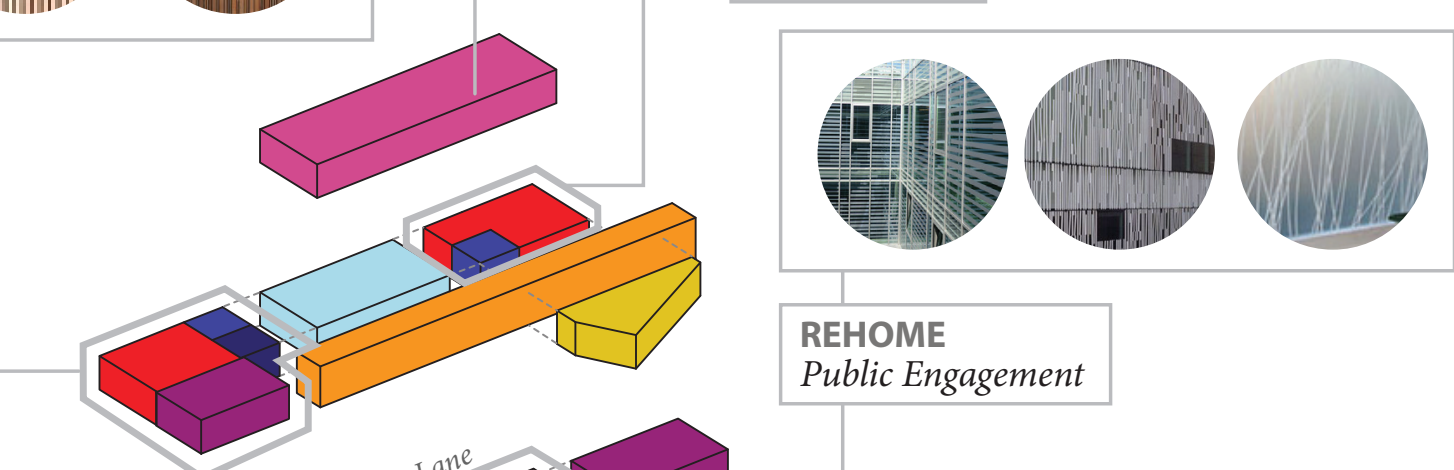

REHOME

Public Engagement

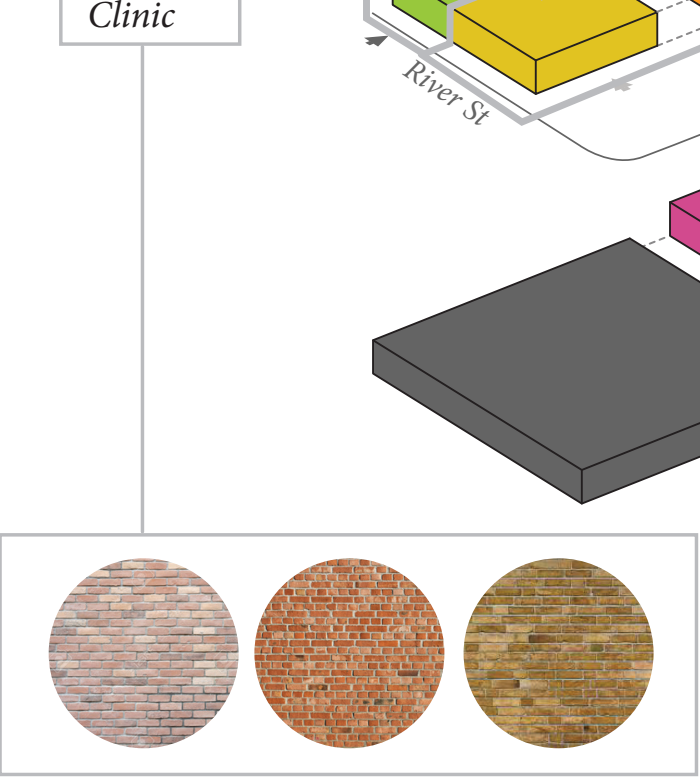

Figure 4.43: Breakdown of Program Spaces and Material Palette

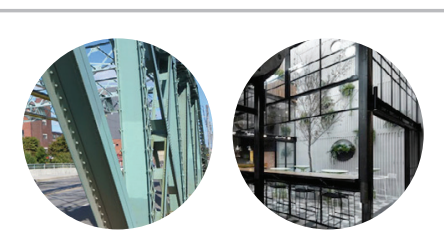

Structure 


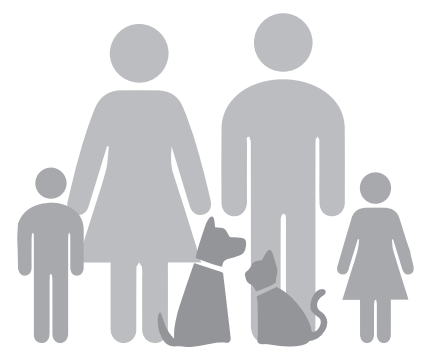

\section{3 | Strategy 3: Social Scale and Rhythm of Users}

To communicate a sense of scale and engage in senses appropriate for the shelter's users.

Informed by the way shopping successfully appeals to the scales and rhythms of various consumer lifestyles and routines, this strategy understands the scales and rhythms of the shelter's users as a main factor for design. A study of routines and rhythms of each user of the shelter provides an understanding of the different scales and senses in architectural design that can encourage interaction and engagement of all users. Since the routine for shelter staff has already been established in Section 4.1 as an overall architectural narrative, this section will look at animals and visitors as other users of the shelter to compliment the rescue, rehabilitate, and re-home work. 


\subsection{1 | Animals}

Establishing regular routine and schedules for pets are important for their well-being, and the environment can help facilitate and indicate some of these routines. Animals, particularly cats and dogs, are essentially only in a few different situations, and these areas should be very different from each other for animals to understand how to behave in these environments. Tracking daily routines of the animals establishes a rhythm of movement and behaviours in different program spaces. These activities and behaviours are addressed in each of the spaces to communicate the different needs of the animals (Figures 4.44 and 4.45).

\begin{tabular}{|c|c|c|}
\hline Location & Activity & Desired Behaviours \\
\hline $\begin{array}{l}\text { Primary Enclosure } \\
\text { (Kennels) }\end{array}$ & $\begin{array}{l}\text { Sleep } \\
\text { Feed \& Drink } \\
\text { Cleaning \& Grooming } \\
\text { Rest }\end{array}$ & $\begin{array}{l}\text { Calm, Relaxed, Clean, } \\
\text { Rested, Meeting Potential } \\
\text { Adopters }\end{array}$ \\
\hline Play Area & Socialize & Playful, Friendly \\
\hline Trails \& Paths & Exercise & Playful, Energized \\
\hline Training Room & Training & Obedient \\
\hline
\end{tabular}

Figure 4.44: Animal Spaces, Daily Activities, and Desired Behaviours in the Spaces
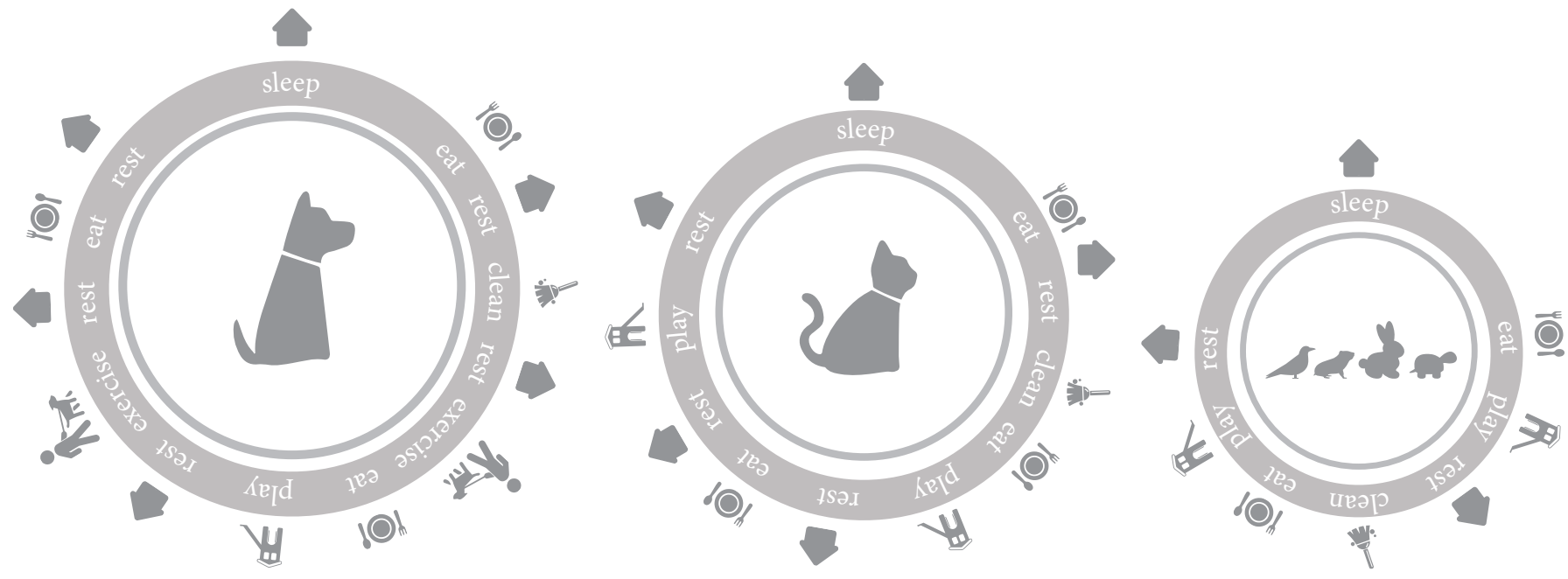

Figure 4.45: Daily Routines and Activities of Canines, Felines, and Small Animals 
Primary Enclosures - Kennels, Cattery, and Cages

For the purposes of understanding basic pet kennel space requirements, the following is a list of guidelines based on research and guidelines in Appendix F. As mentioned earlier, the individual spaces will not be designed beyond sizing and placement in relation to overall narrative.

Each pet type should be visually and acoustically separated from one another

A variety of sizes and types of spaces should be provided to accommodate different sizes and preferences of animals - a mix of individual, pair, or group housing will be provided

Kennels should have ample resting and exercise space, allow for opportunities of retreat, concealment or interaction, and have access to or a view of the outdoors and daylighting

Canine kennels should be compartmentalized to separate feeding and resting areas from elimination areas

Feline kennels should provide perching and hiding spaces, separating feeding and resting area from litter box

Play Areas - Socialization

These spaces are important for animals to understand and get along with other people and animals, giving them a chance to play and explore.

Exercise (Dogs)

Indoor circulation path doubling as leash training path.

Outdoor trail in park is a continuation of the walk.

Training (Dogs)

Minimize distractions and excitement so the animal can focus on learning. 
Canine Kennels

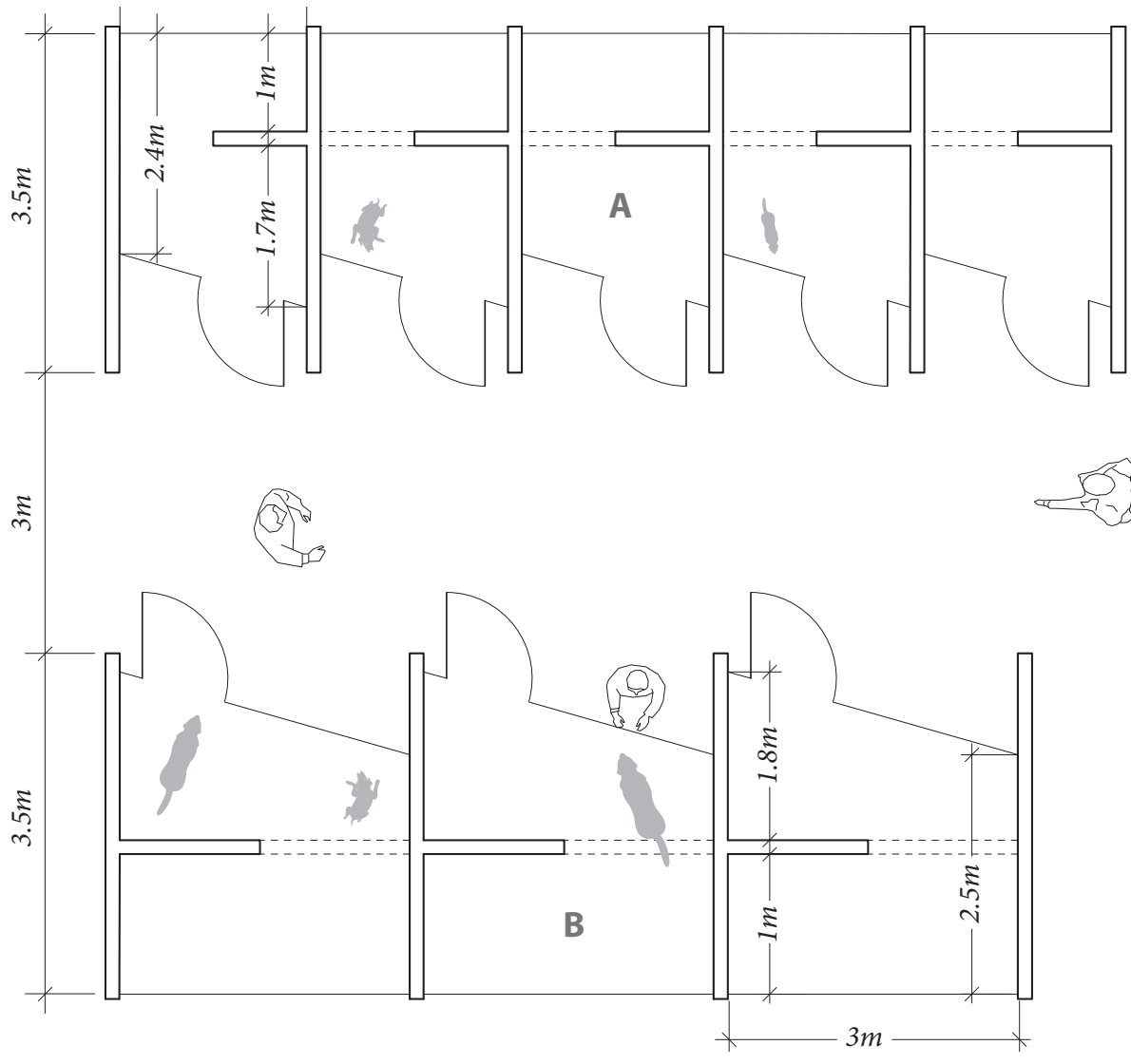

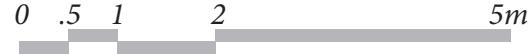

Figure 4.46: Typical Double Compartment Canine Kennel Layouts. A. Individual or Small Dogs Unit. B. Group or Big Dogs Unit

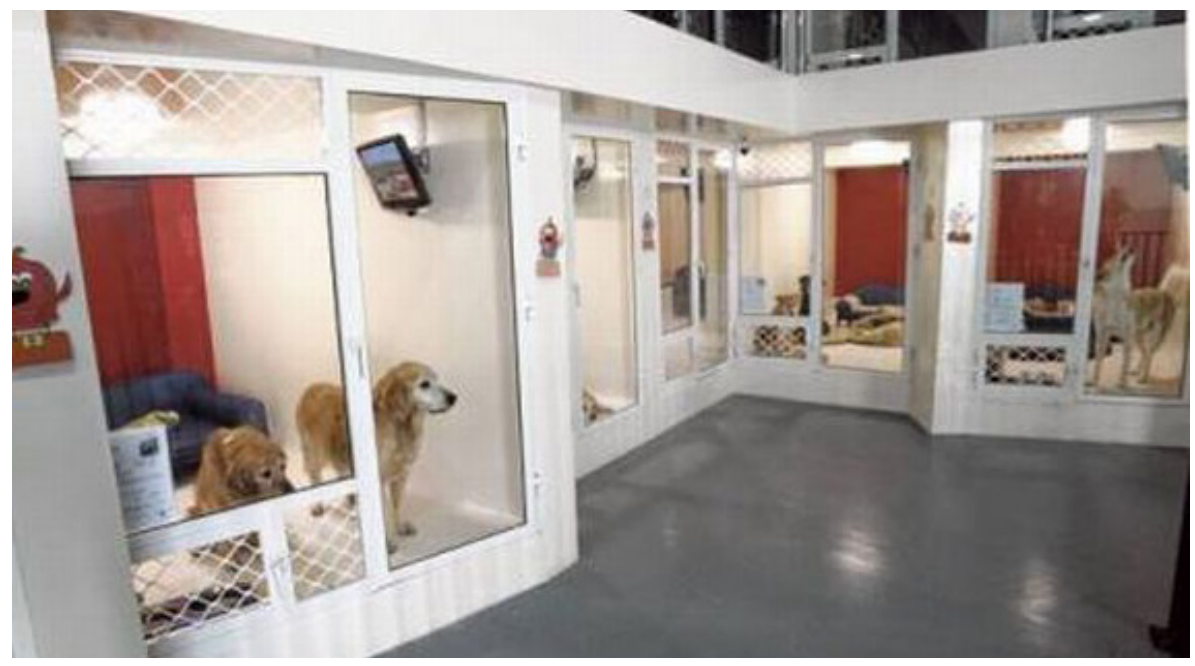

Figure 4.47: Canine Kennels

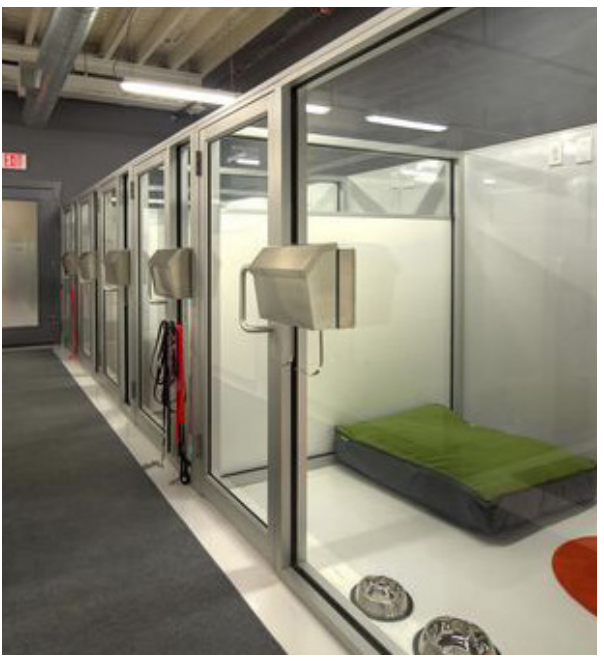

Figure 4.48: Canine Kennels 


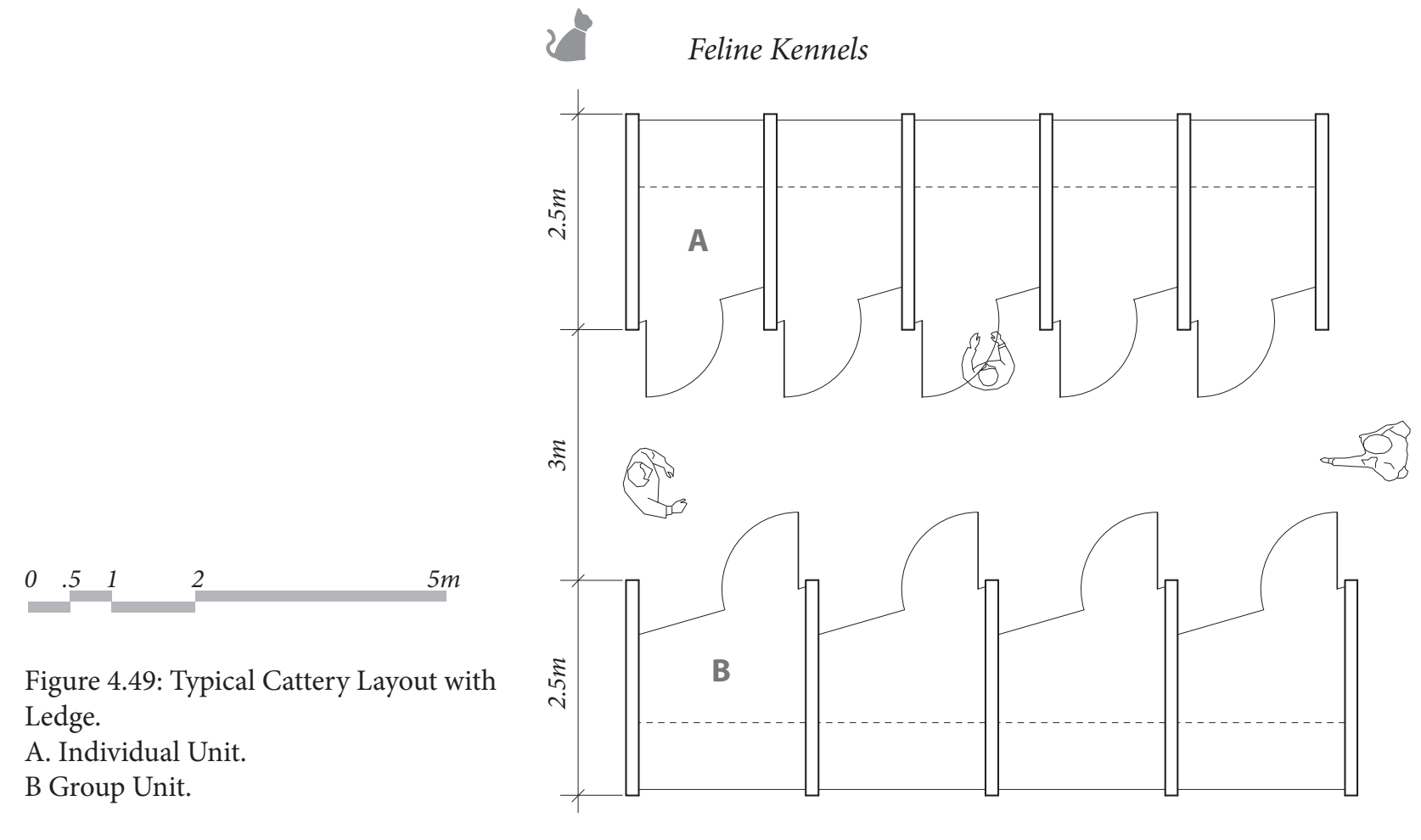

Figure 4.50: Cattery

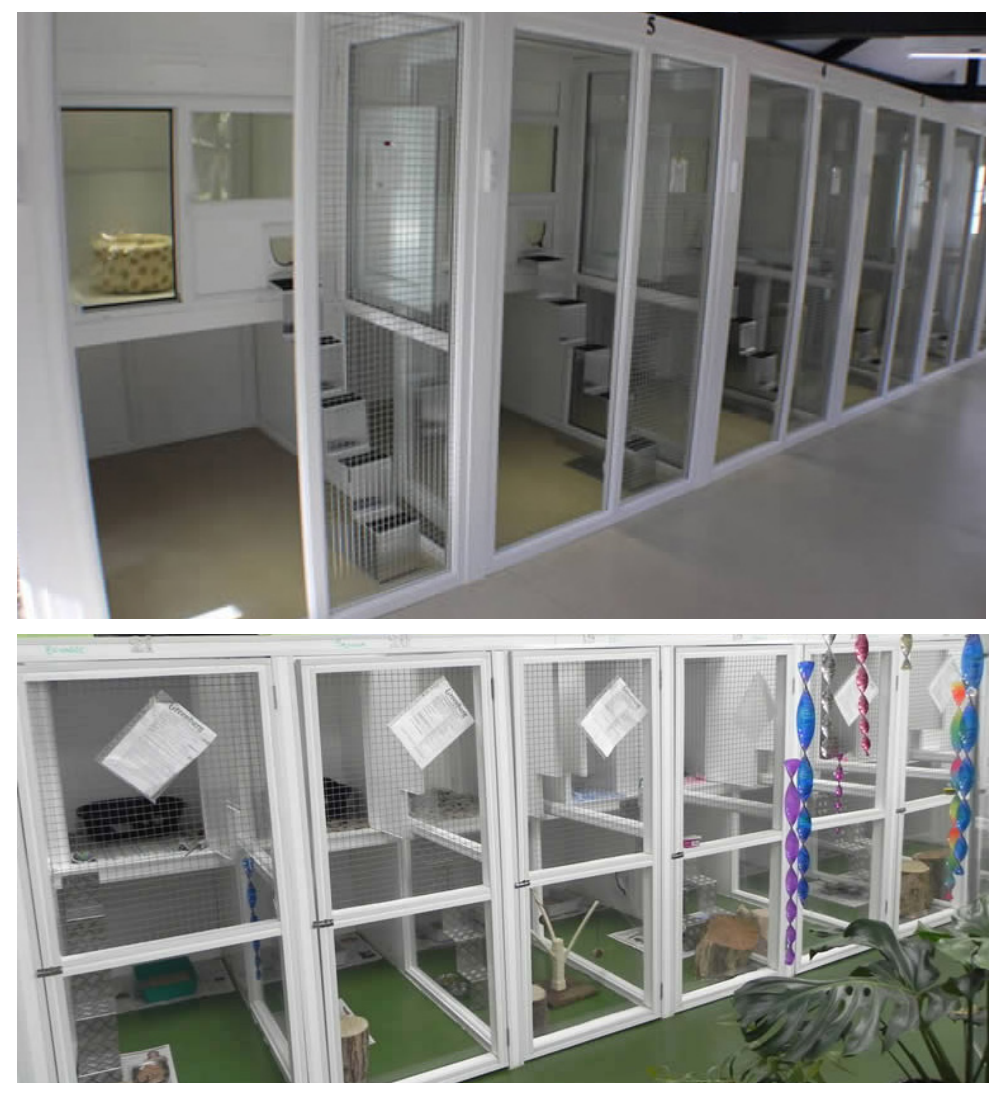

Figure 4.51: Cattery 
Small animals are accommodated for in moveable cages instead, reflecting the transient nature of the shelter. More permanent habitats and enclosures are discouraged as it communicates a long-term stay at the shelter. This would also deter potential adopters. Beyond cages, it's hard for potential adopters to commit finances towards permanent structures. Thus, open areas with cages will define the small animals' area. However, the different animal types will be divided into separate dedicated areas.
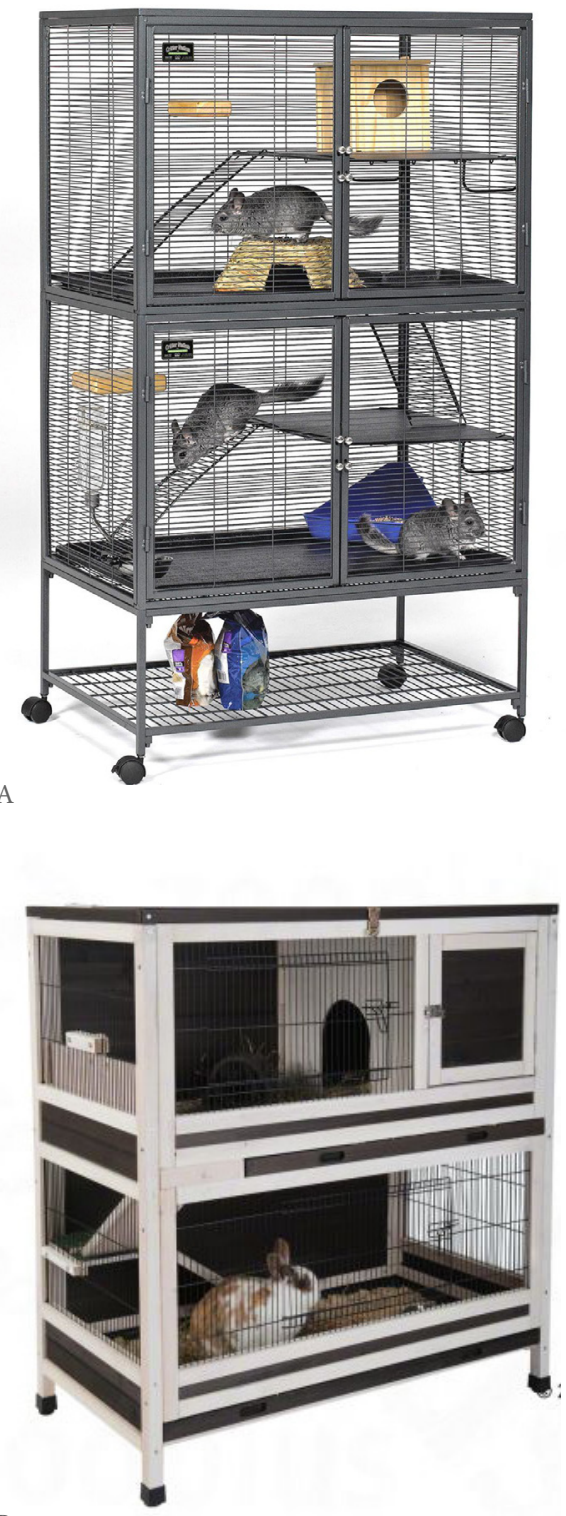

C

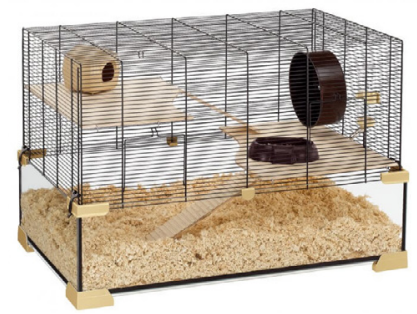

$\mathrm{D}$
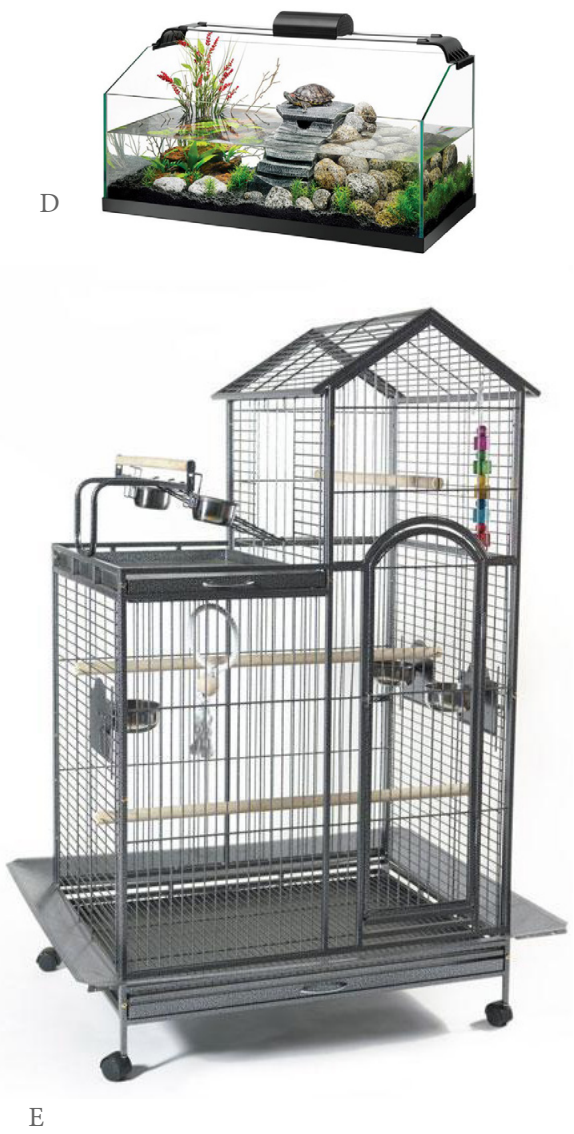

Figure 4.52: Small Animal Primary Enclosures

A | Guinea Pigs

B | Rabbits

C | Hamsters

D | Turtles

E | Birds 
Figure 4.53: Socialization Spaces Canine

Figure 4.54: Socialization Spaces - Feline
Play Areas - Socialization

\section{Canine - Outdoor}
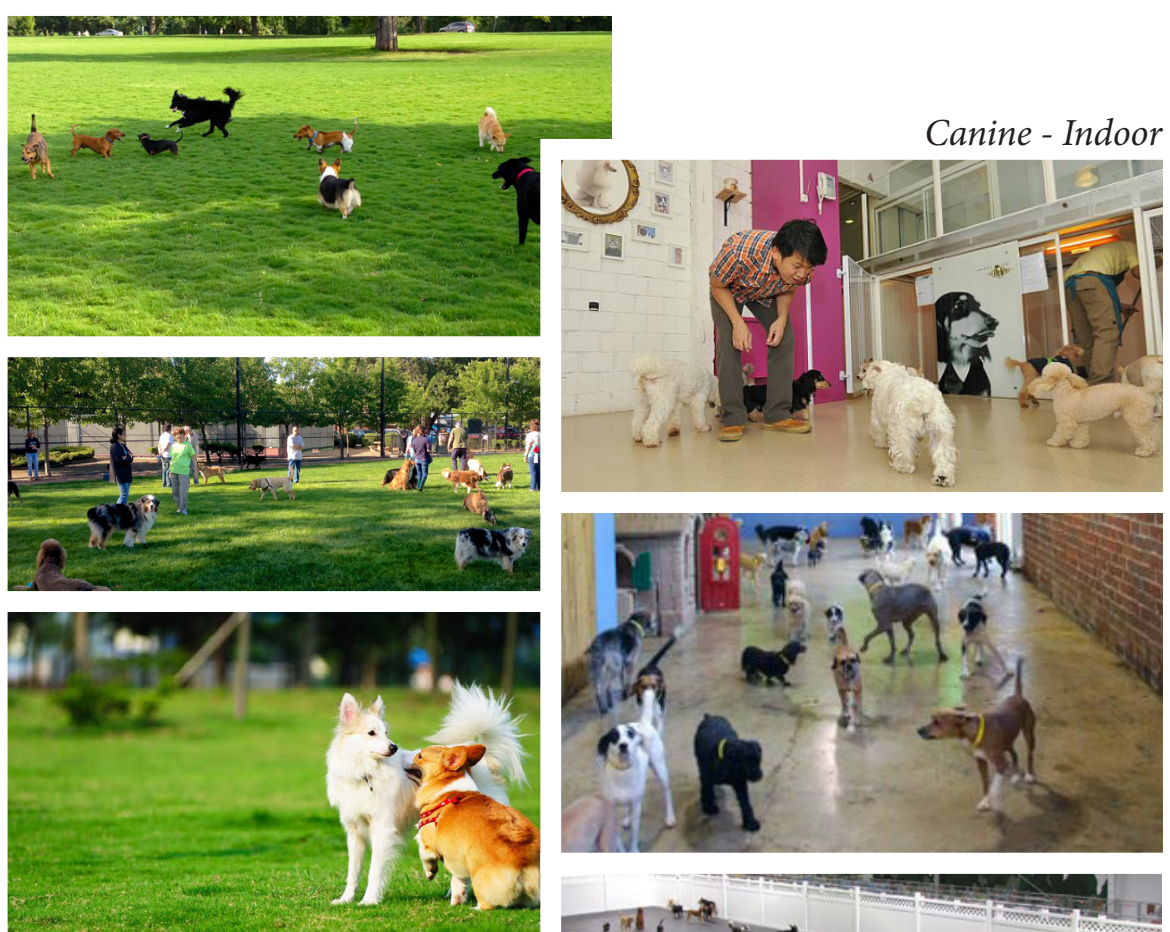

Emphasis on open space

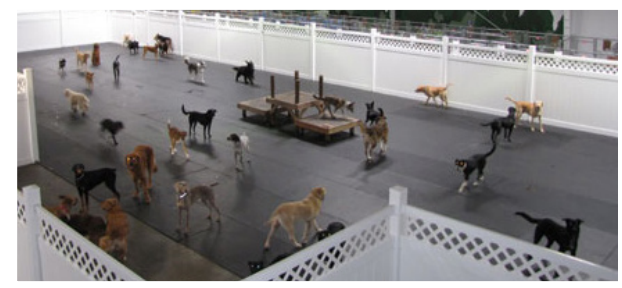

Feline - Indoor
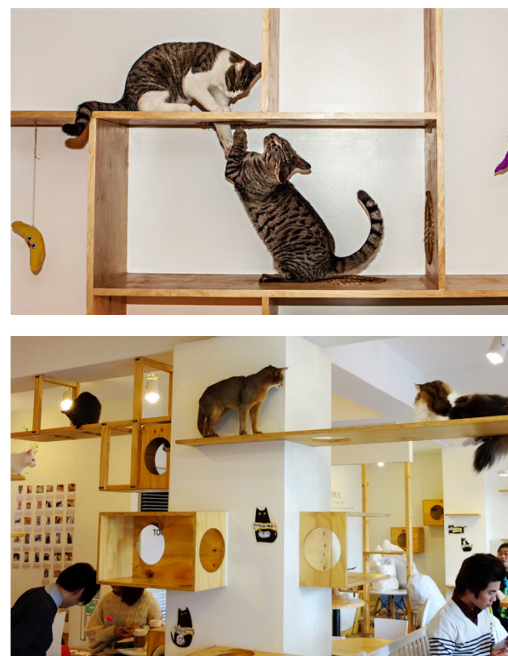

今

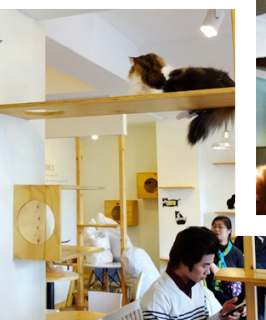

1. Emphasis on vertical climbing space 


\section{Scales and Senses}

Due to their small sizes, their visual realm is limited to the bottom 2 feet. However, animals, like humans, experience their surroundings using their other senses as well, and the design should also address these senses.

Visual

Emphasize bottom 2 feet to provide interest for animals, informed by the material studies in the previous section. A change in levels and heights can allow multiple viewpoints and visual connections. Certain views can be revealed or concealed to engage or discourage access.

\section{Acoustics}

The animals' primary enclosures (kennels) should be quiet and comforting. Echoes and unknown sounds should be minimized to reduce stress.

\section{Touch}

In addition to creating visual variety for the animals, changing levels also brings animals closer to humans for interaction (touching, petting, and sniffing).

Different surfaces can be provided in different areas to understand the functions of each area (E.g. grass $=$ outdoor, concrete $=$ cleaning, tiles $=$ resting, soft area $=$ bed)

\section{Olfactory}

An animal's sense of smell is an important way for them to understand the world around them, and as such, animals tend to sniff everything they encounter.

Landscaping and nature can be used as olfactory indicator of different areas. Play or exercise spaces incorporate natural elements, whereas the absence of landscape indicates resting quarters. 


\subsection{2 | Scale and Rhythm Exploration}

Appealing to the scales and rhythms of the different animal types, different densities and patterns of wood screens begin to define and differentiate between canine, feline, and small animals. An exploration of simple patterns led to the use of vertical slats as a means for screening. The vertical slats provide a coherent theme throughout the shelter, but are then adjusted to create different patterns that reflect the different animal types (Figure 4.58, Page 178).

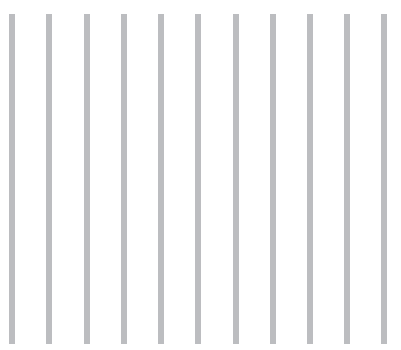

\section{Dogs}

The vertical slats allow for a wall that constantly changes views. At the scale of the canine walking along a hall or edge, the wall appears solid from an angle. However, when approached and looked at closer or at a perpendicular angle, views and openings allow visual or direct access, generating interest and surprise for both visitors and canines. A change in levels and heights also changes the perspective and engagement level. (Figure 4.55)

\section{Cats}

Feline areas are defined with a pattern that

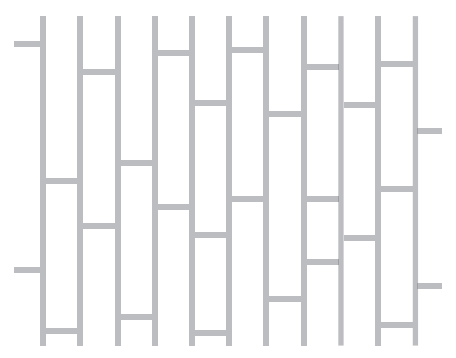
expresses the preference and movement of cats. Where dogs need expansive horizontal space for running and playing, cats use vertical surfaces for climbing and perching. Steps and ledges in the vertical slats start to create a rhythm of movement to define these areas. This preference for climbing and vertical movement also connects different floors, visually guiding visitors through the shelter. (Figure 4.56)

\section{Small Animals}

The density and pattern here reflect the size

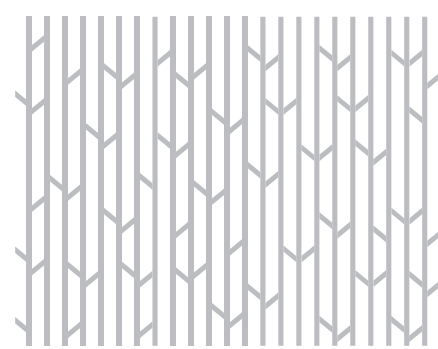
of the small animals, becoming denser and take on "tree-like" forms to imitate natural screens. As light passes through the screens, it casts shadow patterns that change throughout the day, imitating filtered light through leaves and tree cover. (Figure 4.57). At the current small animals ward at the THS, painted murals imitate natural settings in a very superficial manner that doesn't allow any light or views in or out. 


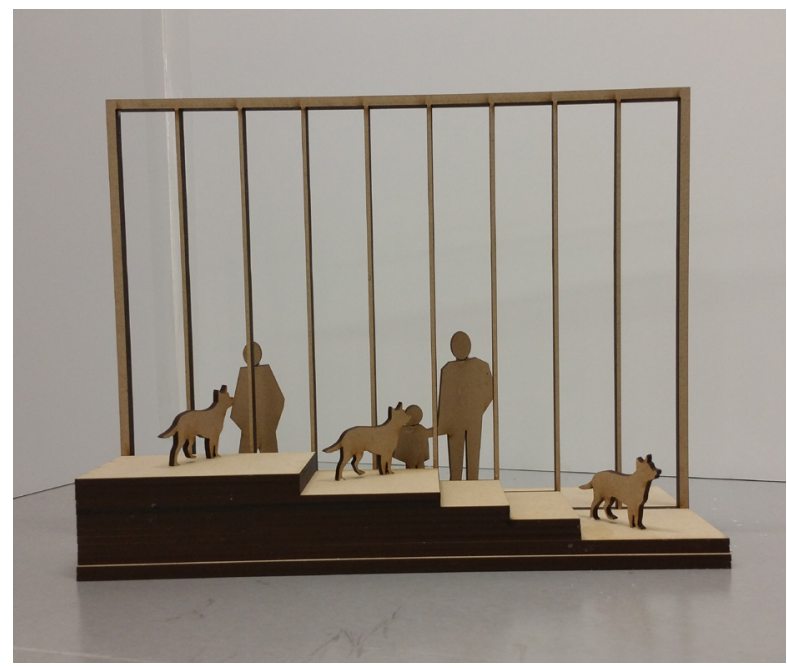

Figure 4.55: 1:20 Scale Model - Canine Screen

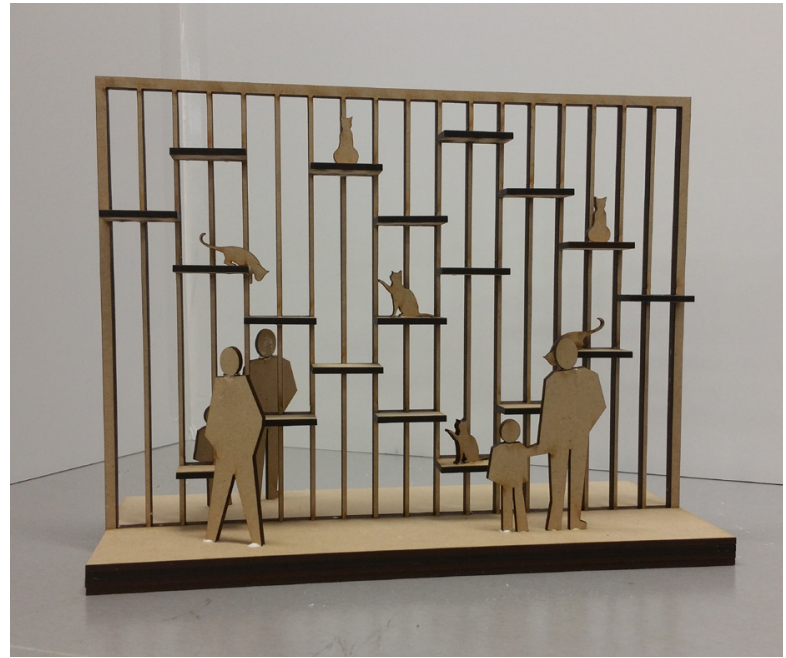

Figure 4.56: 1:20 Scale Model - Feline Screen

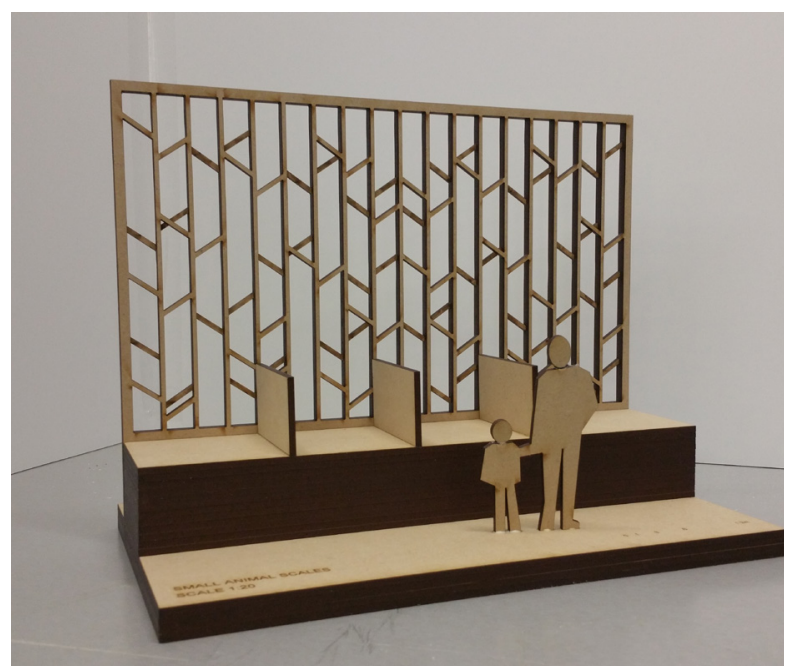

Figure 4.57: 1:20 Scale Model - Small Animals Screen 


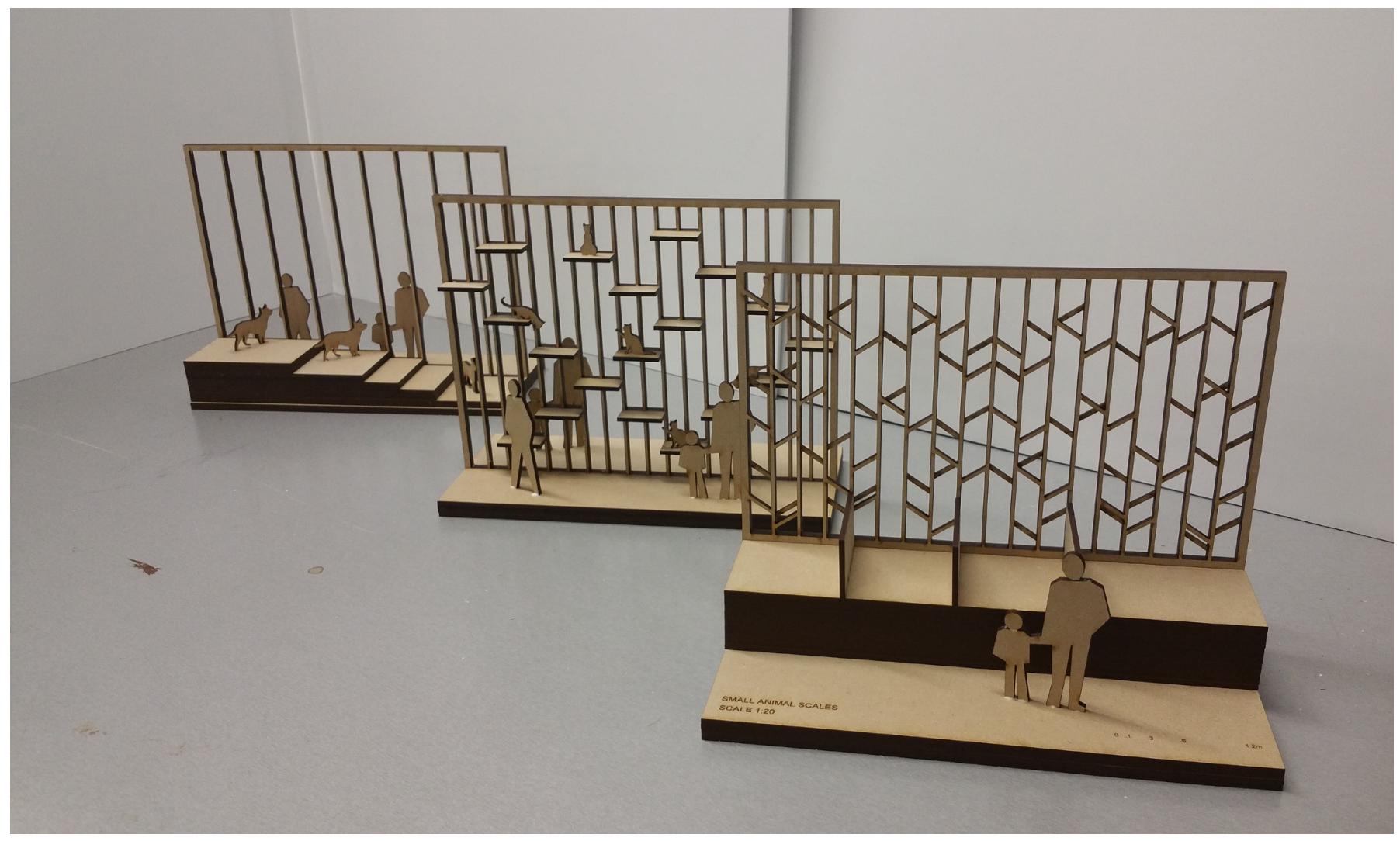

Figure 4.58: 1:20 Scale models of the different animal type screens 


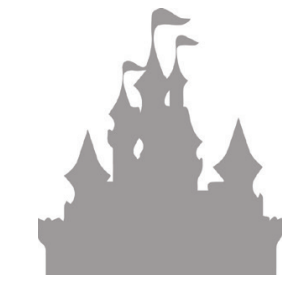

An Architecture of Work

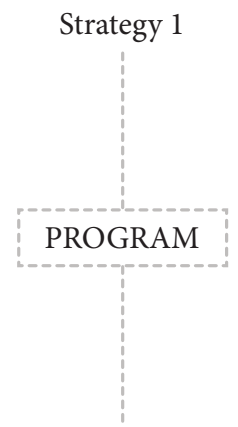

Rescue, Rehabilitate \& Re-Home

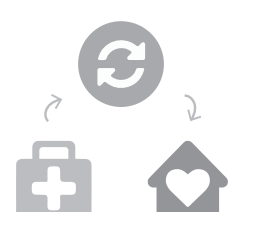

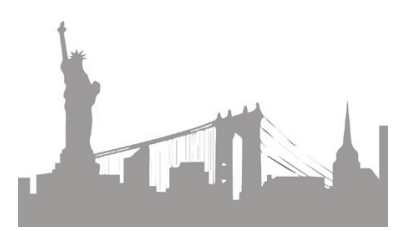

Theme of the City

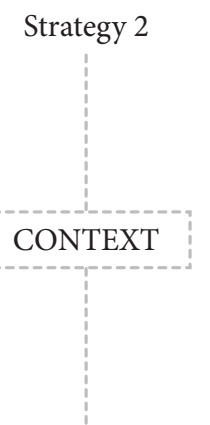

Toronto \& the Don Valley

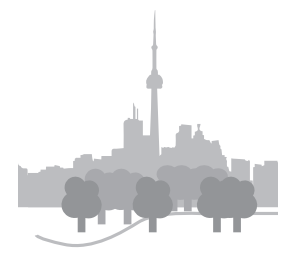

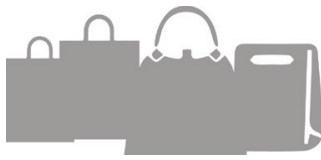

Scale and Rhythm of Users

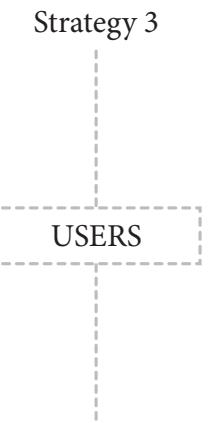

Animals \& People

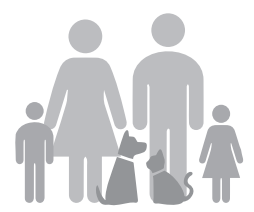

Figure 4.59: Strategies applied to design project

\subsection{Strategies and Tactics Applied to the Animal Shelter}

As such, the outlined strategies and tactics studies use program, context, and users to form the basis for an architectural design and expression that is authentic and relevant to users and the public. An architecture of work determines the shelter's story as "rescue, rehabilitate, and re-home", allowing the subversion of work spaces to inform spatial re-organization. Next, the theme of the city and valley uses ideas of nature and industry to inform contextual connections, material choices, and establishes a hierarchy of spaces. Finally, a study of scales and rhythms cater to specific needs, scales, and senses of staff, animals, and visitors. Altogether, the three strategies lead to an architectural expression that is appropriate for its use, context, and people, redefining the way the animal shelter is experienced and perceived. The final design is presented in the next chapter as an amalgamation of the above 3 strategies. 


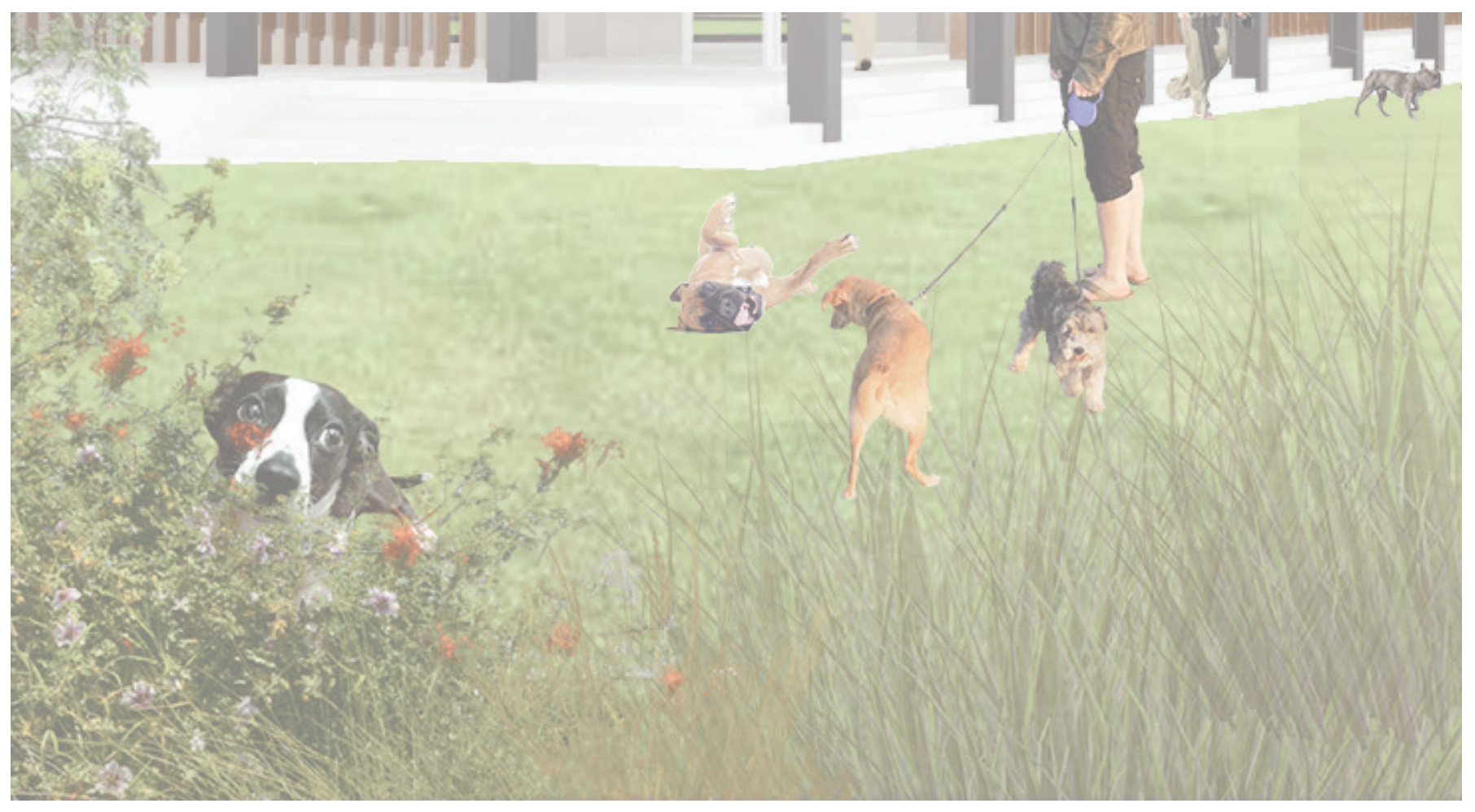




\section{1 | Introduction}

This thesis posits that there is an appropriate balance between the mundane and the spectacle that is offered by using strategies of entertainment architecture to authentically express an architecture that is informed by its function, is sensitive to contextual conditions and history, and adequately addresses the scales of its users. To showcase the ways in which these strategies can be applied to contemporary architectural design, this chapter presents a design for the Toronto Humane Society Animal Shelter and Public Clinic in Toronto, Canada that balances between the mundane and the spectacle. It attempts to articulate an appropriate expression for a typology that is typically utilitarian and unexciting, but civically and socially relevant that deserves opportunities for flourish and spectacle. As a public service facility and a place of healing and rescue, there is a serious and institutional aspect of the shelter that is communicated through a more corporate and rectilinear expression on the northern edge of the site. The southern portion on the other hand, presents a more playful and interesting form that invites and welcomes the public into its spaces. The formal expression is thus both simple and interesting without being a spectacle or cliché in the urban landscape. It does not attempt to compete for attention yet also does not dissolve into the background, being an appropriate expression for a public service facility that relies on public visibility and engagement (for donations and adoptions). 


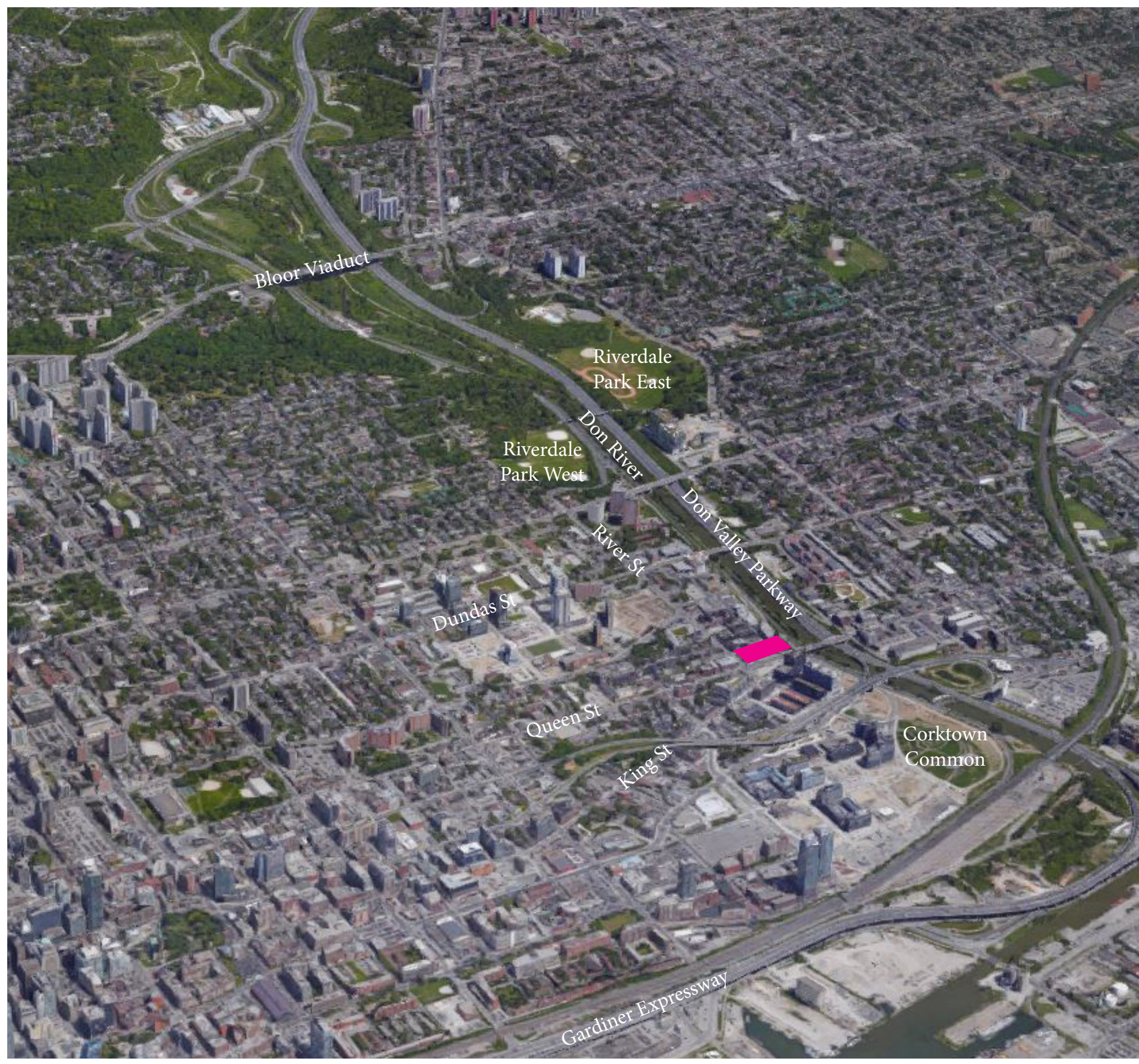

Figure 5.1: Project Site and Surroundings 

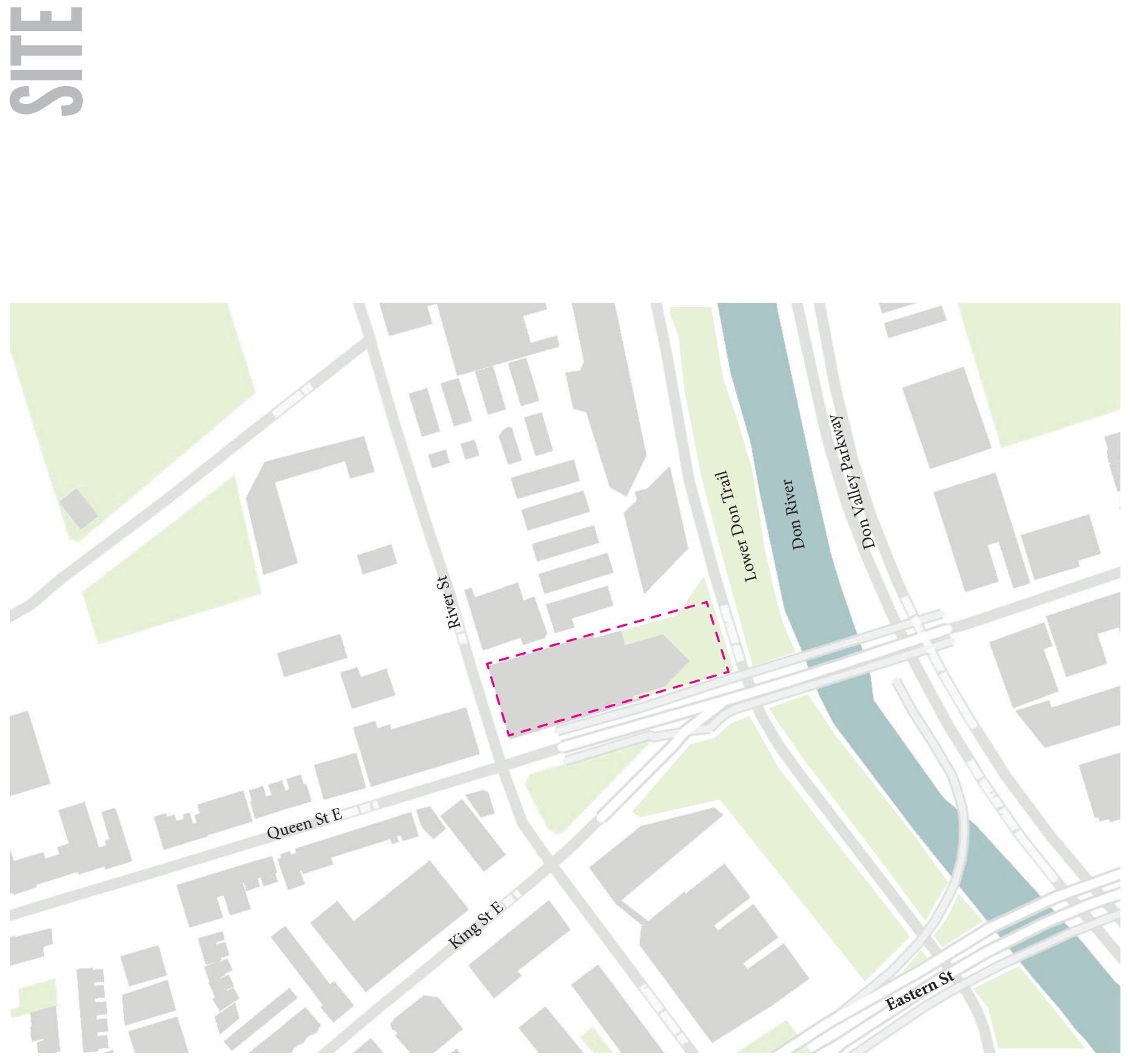

$\stackrel{\infty}{10}$

Figure 5.2: Project Site and Context (NTS) 

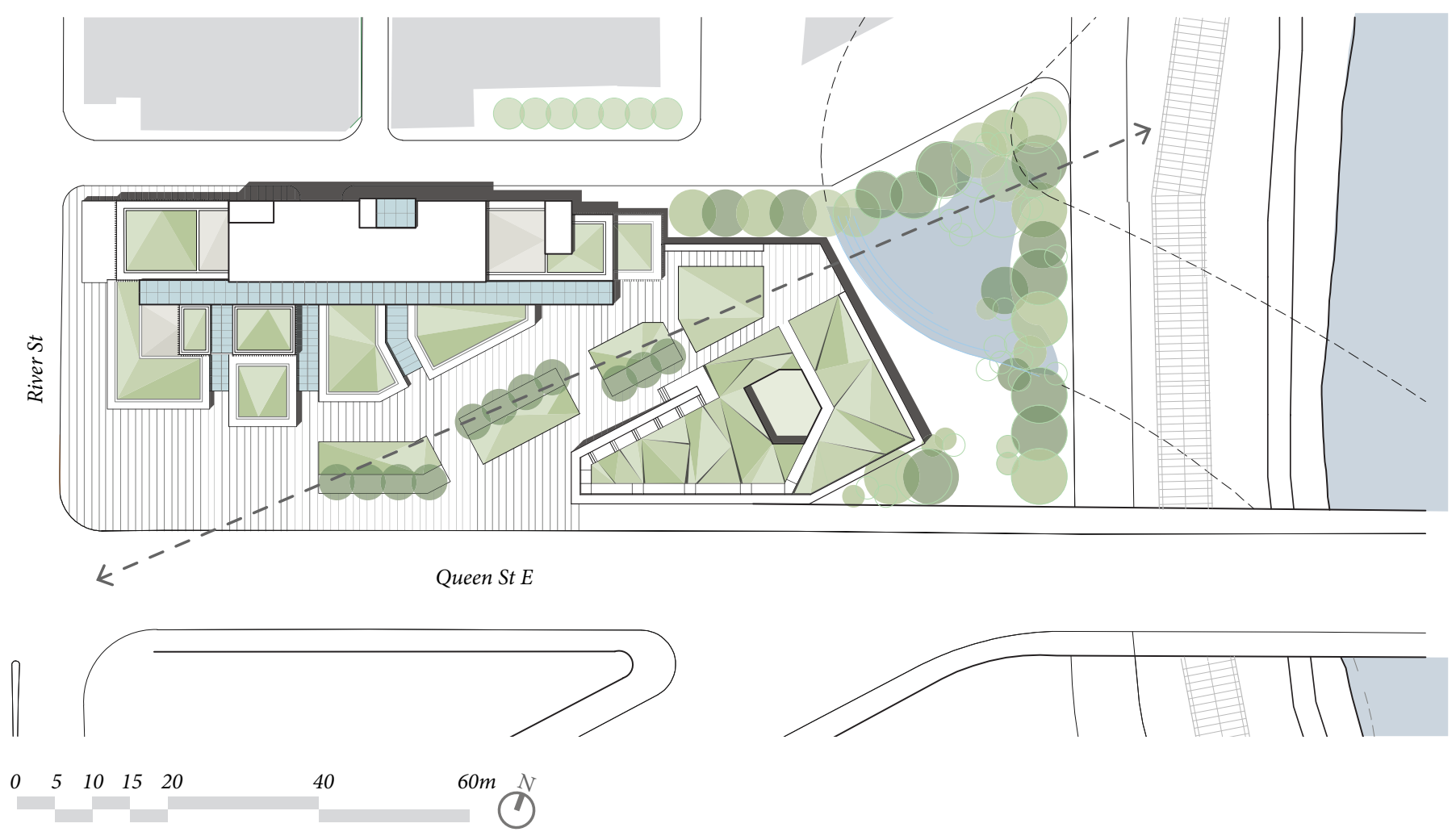

Figure 5.3: Project Site Plan

The new Humane Society frames a view and establishes a visual connection from the city street corner to the Don River and Valley. Its southern portion has a public plaza and parkspace that acts as a buffer and interstitial space between the Humane Society and the street.

The building itself stops short at the river's original course, respecting the natural hydrology of the site. The park below becomes a private retreat for the animals on site. 


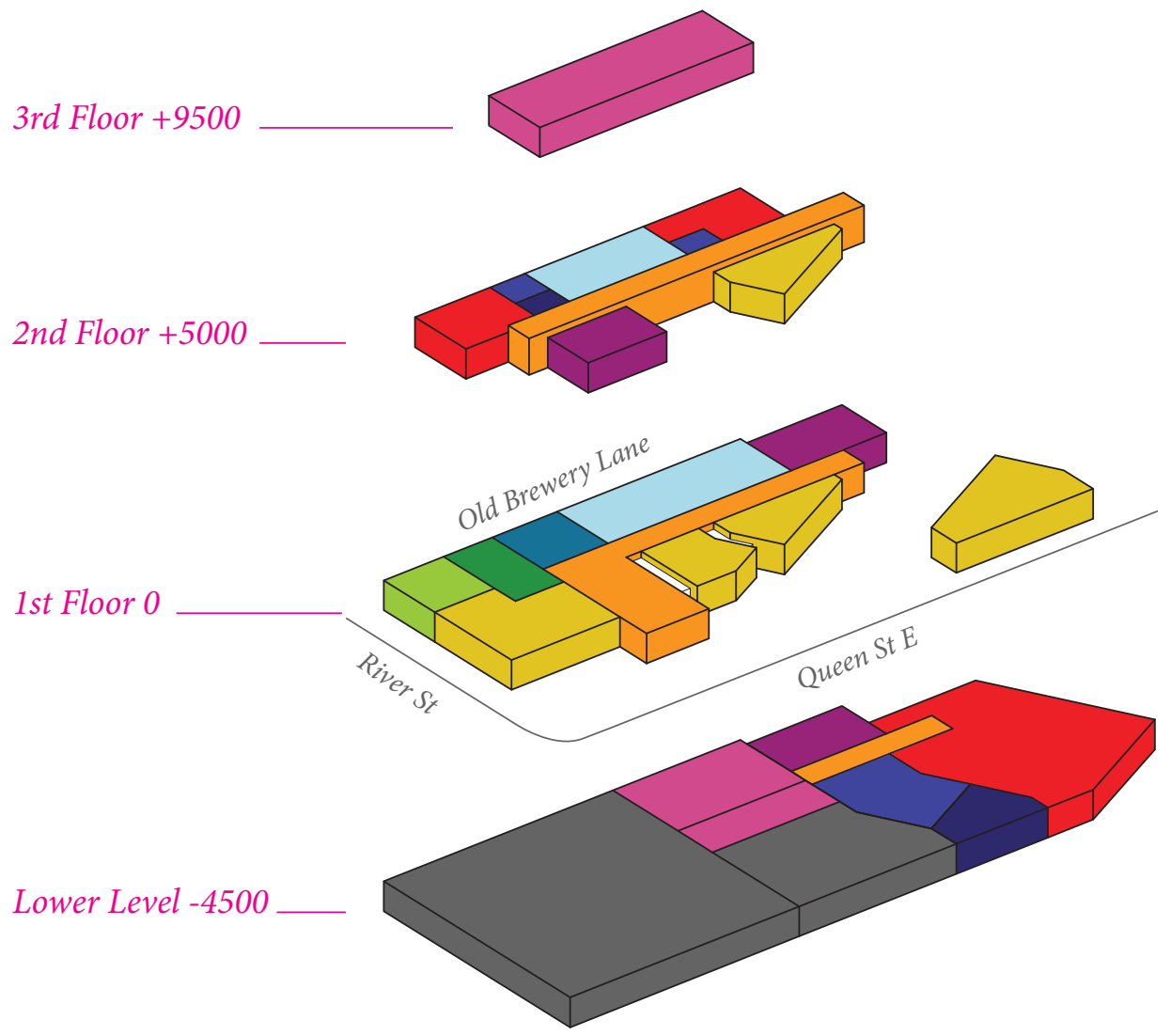

Offices

(1) Quarantine Rooms

Veterinarians' Offices

Exam Rooms

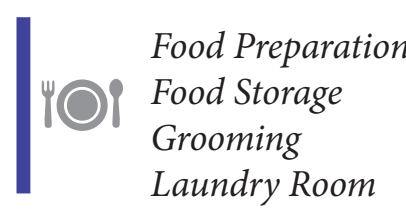

Laboratories

Treatment Rooms

Pre-Op Ward

Surgery Rooms

Post-Op Ward

Euthanasia Room

Training Room

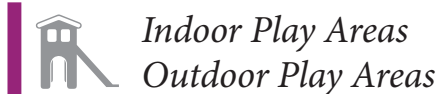

Morgue

Mechanical

Electrical

Janitor's Closet

Loading Area

Parking
Volunteer Center

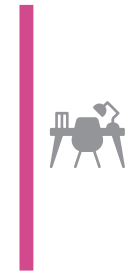

Administrative Offices

Meeting Rooms

Lunch Room

Locker Rooms

Showers
Dog Kennels

Cat Rooms

Small Animals Rooms

Adoptions Reception

Adoption Interview Room

Meet \& Greet Rooms

Community Room

Retail

Cafe

Food Bank

Public Dog Park

Figure 5.4: Overall Program Distribution 


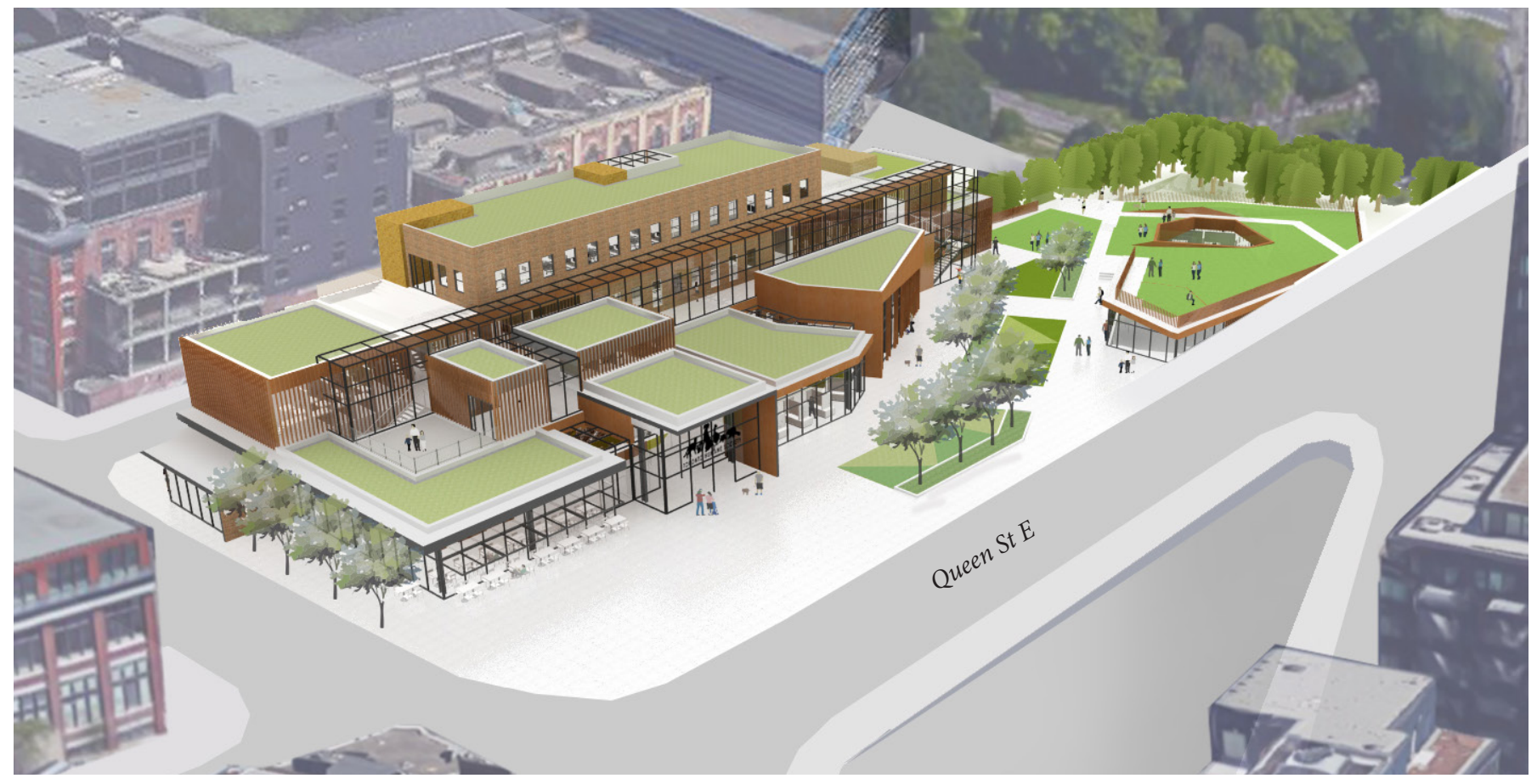

Figure 5.5: Aerial View Looking Northeast

Public programs of cafe and retail frame the main entrance, which has been centralised to draw visitors towards the park space. The Adoptions Hall is a prominent axial feature that also symbolically acts as a transition between public and private space. Spaces unfold around this central circulation spine, as it illustrates the process from intake to adoptions. 


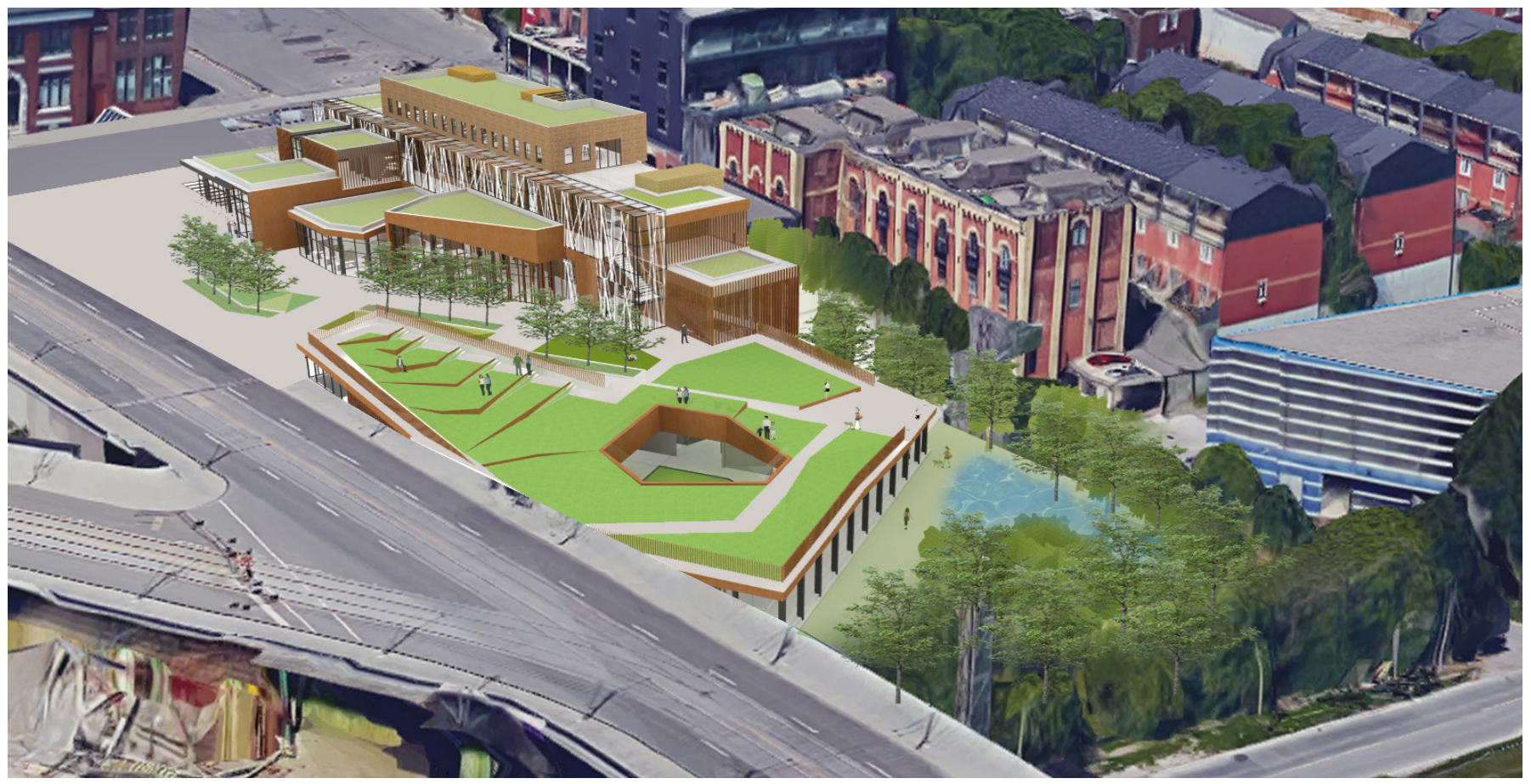

\section{Figure 5.6: Aerial View Looking Northwest}

Public and private outdoor spaces are differentiated vertically, where public is at street level and private is below. A private and more secluded park at the lower level serves as additional park and amenity space for canine exercise and socialization. The water feature outlines the original course of the Don River, and can be seen from street level. 

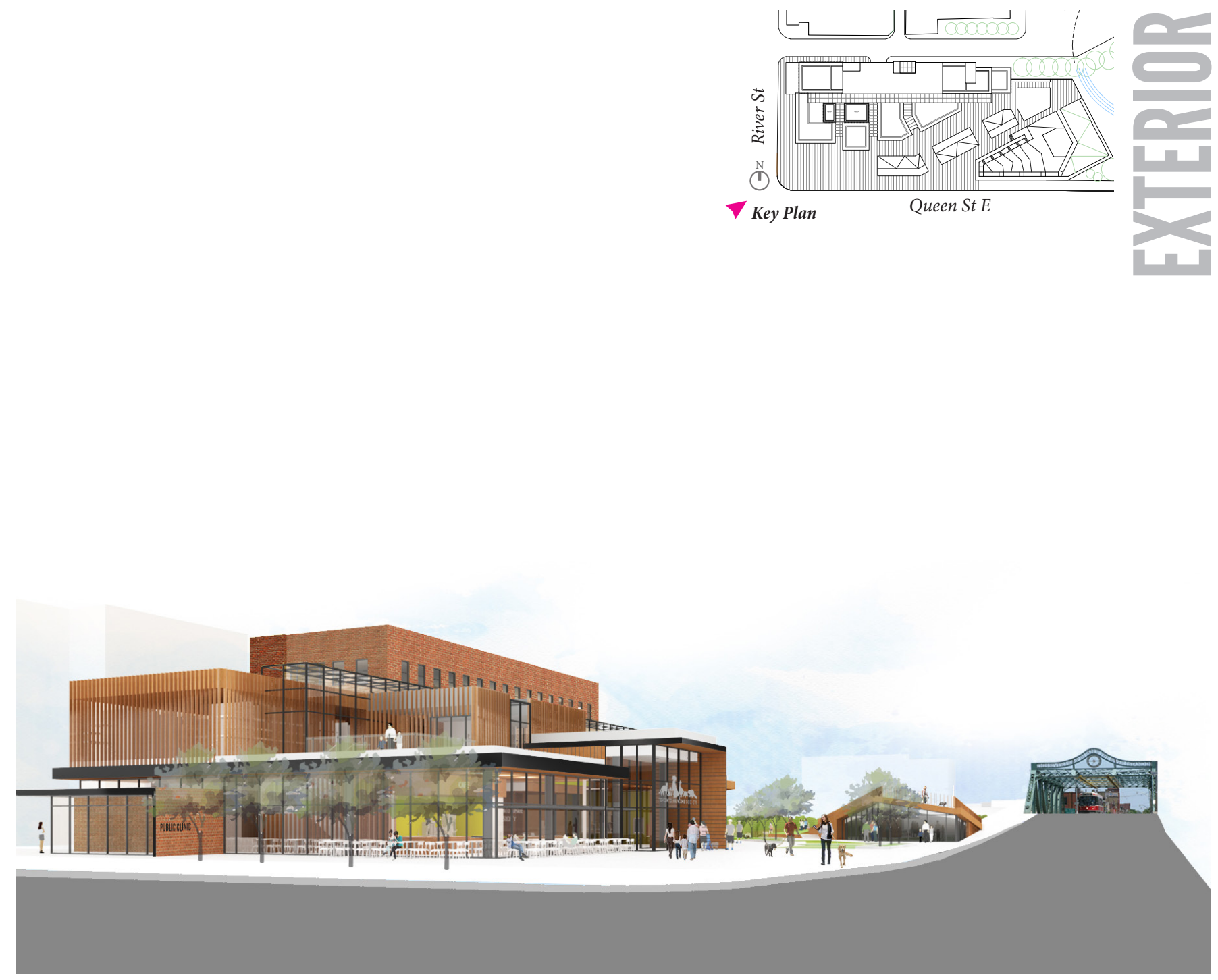

Figure 5.7: View from Street Corner

The main entrance is signified with a higher volume facing Queen Street, visible from both the east and west. Approaching from the corner, we have a visual connection to valley the beyond, drawing visitors into the park space. The intake and clinic entrance is accessible through a more private entrance off River Street. 

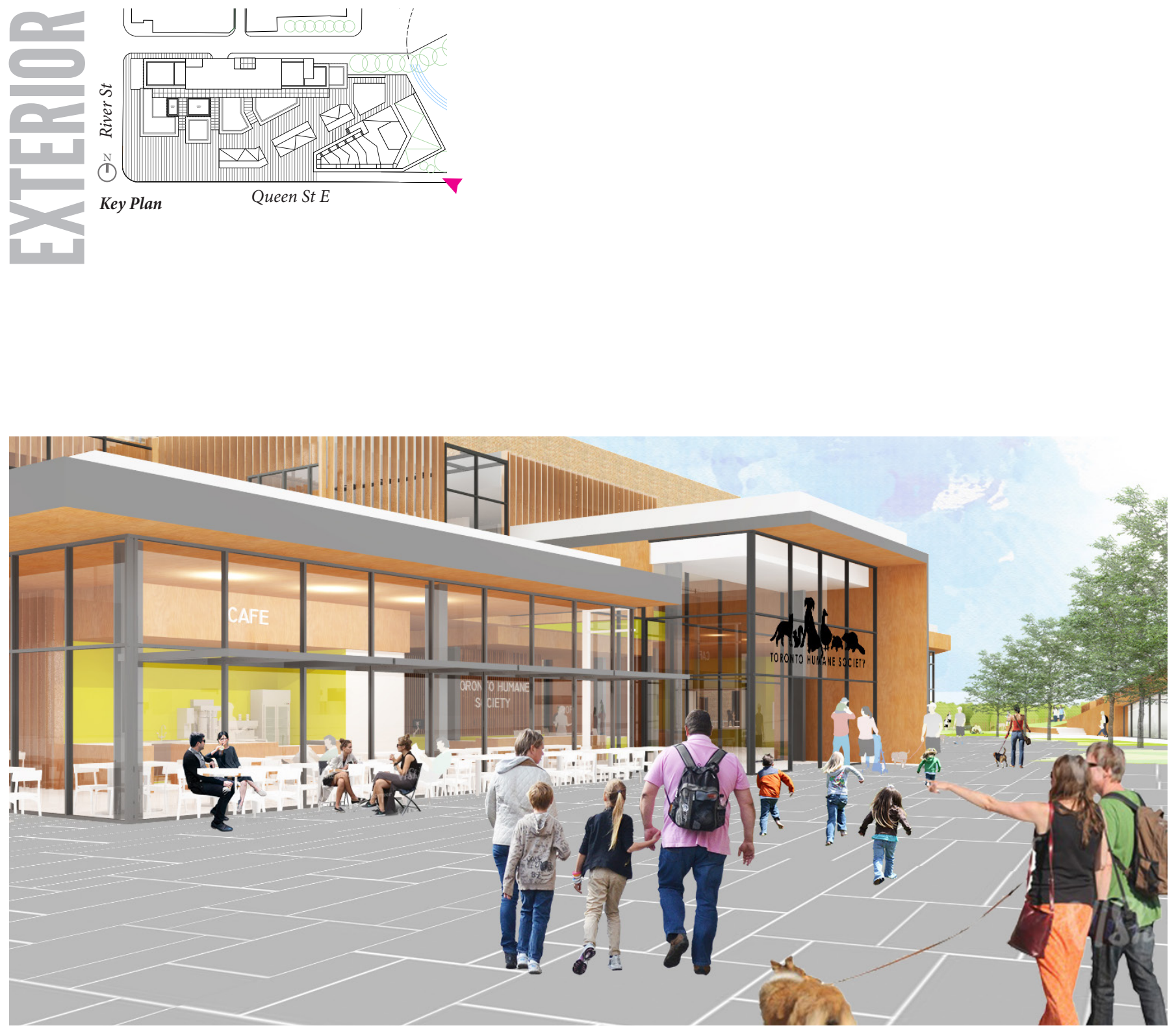

Figure 5.8: Main Entrance

The highly transparent ground floor is set back to draw in and invite visitors to linger in its public spaces, benefitting the city and complimentary to the Don Valley trail. 

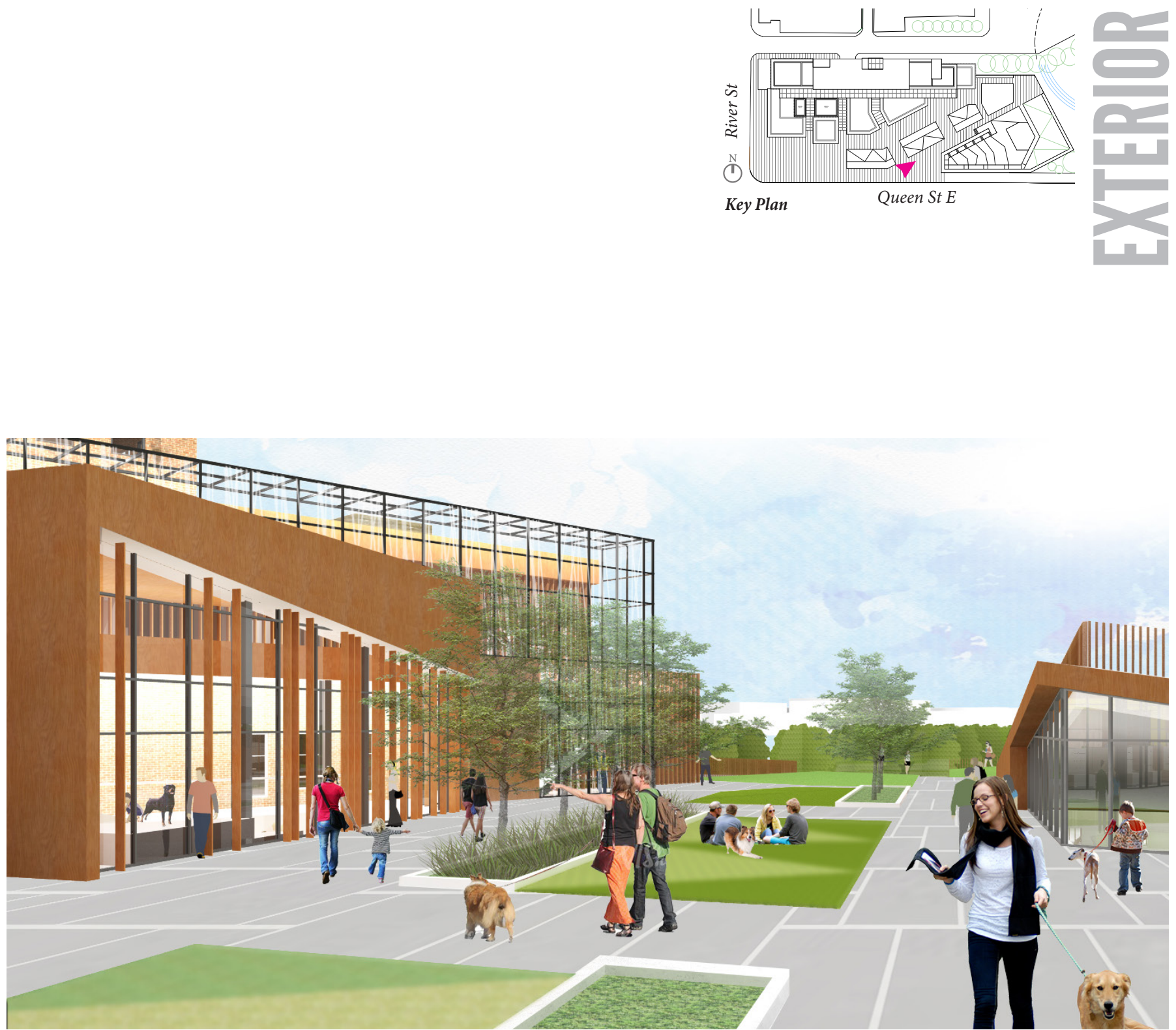

Figure 5.9: Public Park

From the outside, the public gets partial views into the different spaces of the shelter. The adoptions hall is expressed as a main feature, suggesting a way of moving through the shelter, and also serves to differentiate the shelter's public versus private spaces. 

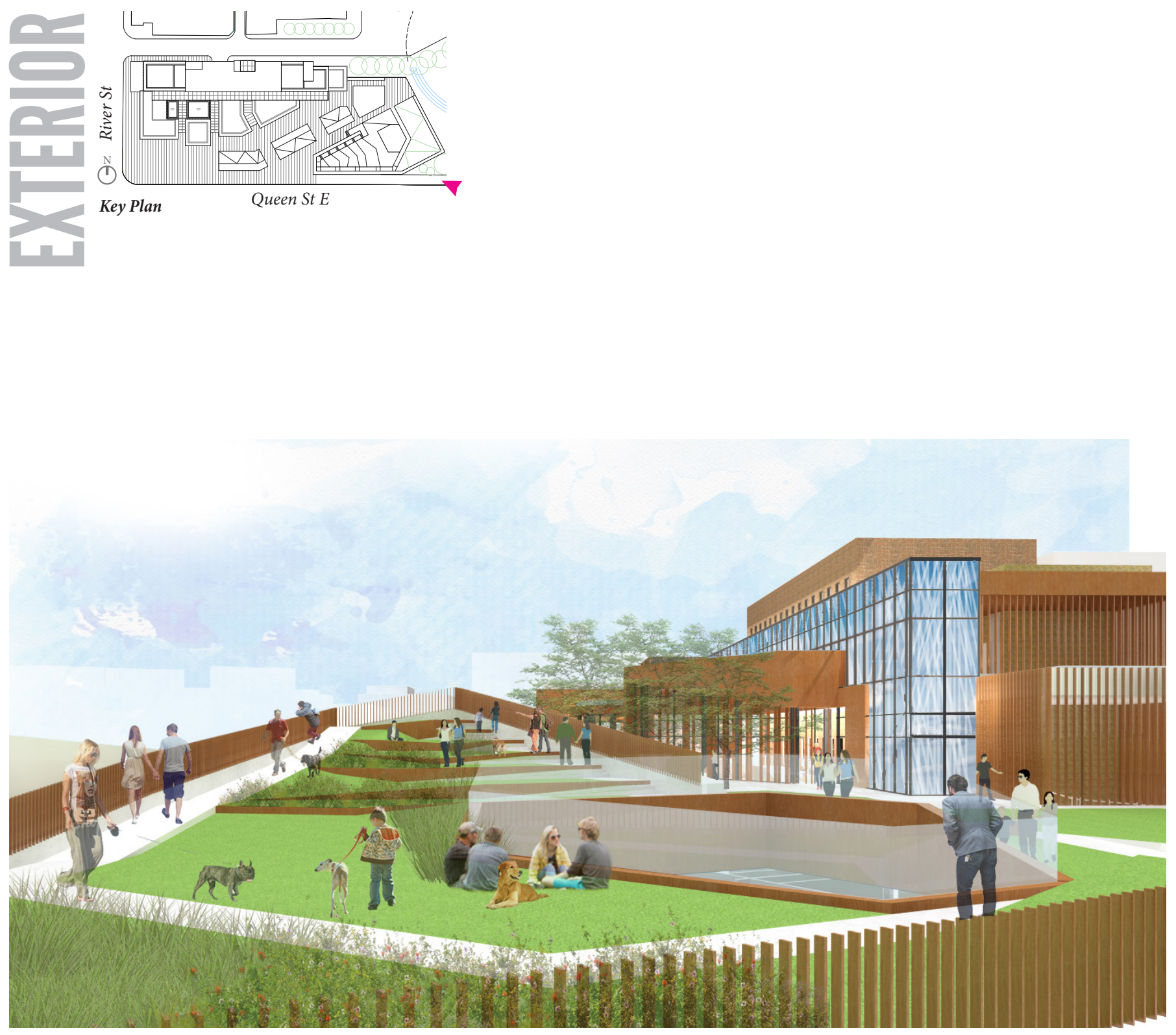

Figure 5.10: Public Park

The roofscape becomes a public amenity and urban greenspace for both pet owners and the general public. It allows users to interact with each other around playing animals in a landscaped setting. The terraced roof elevates users from the street level and provides a certain level of privacy although being completely public. 

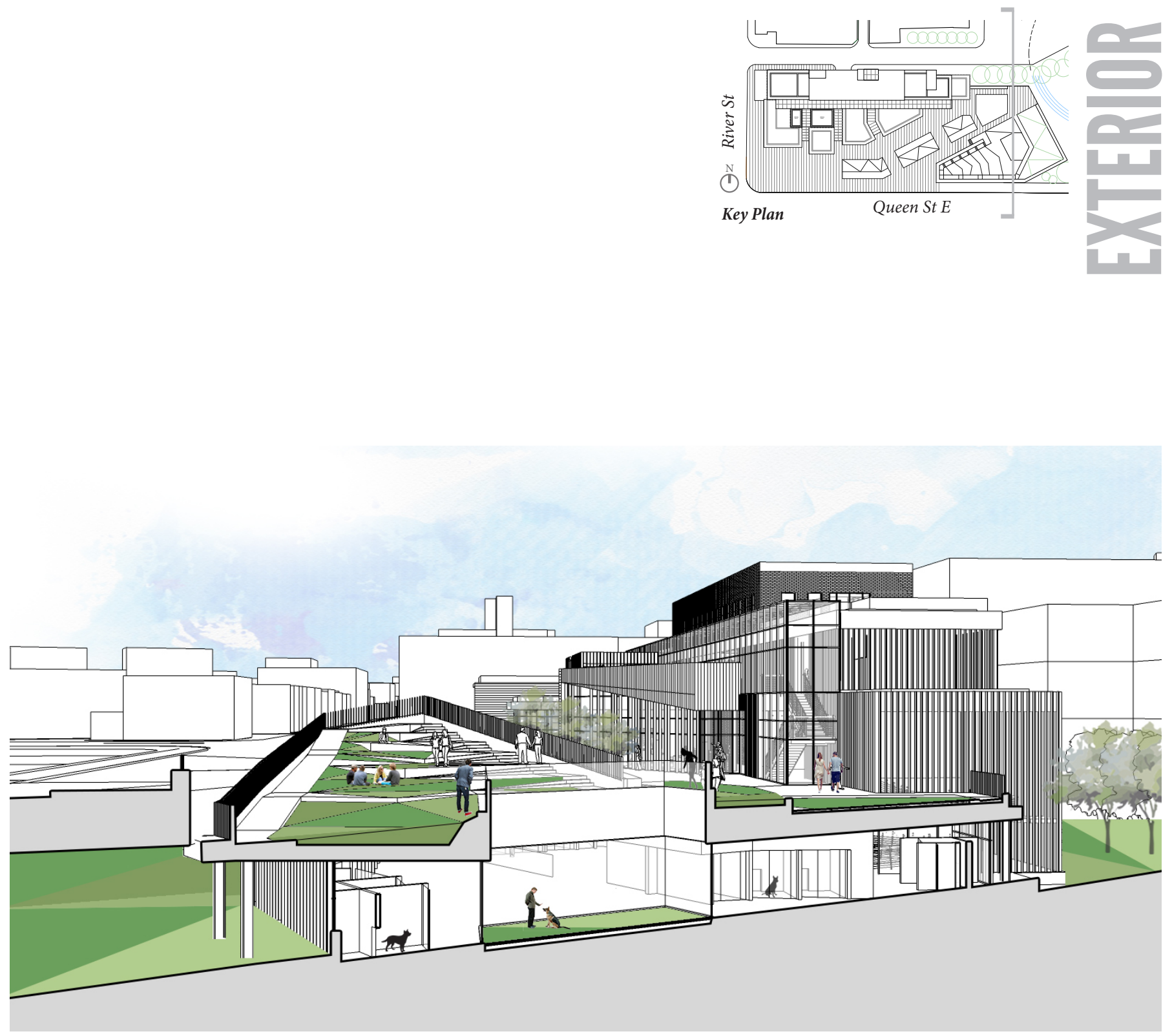

Figure 5.11: Public Park

Within the public terraced park, a courtyard below is seen from above, giving the public glimpses into the canine kennels below. 

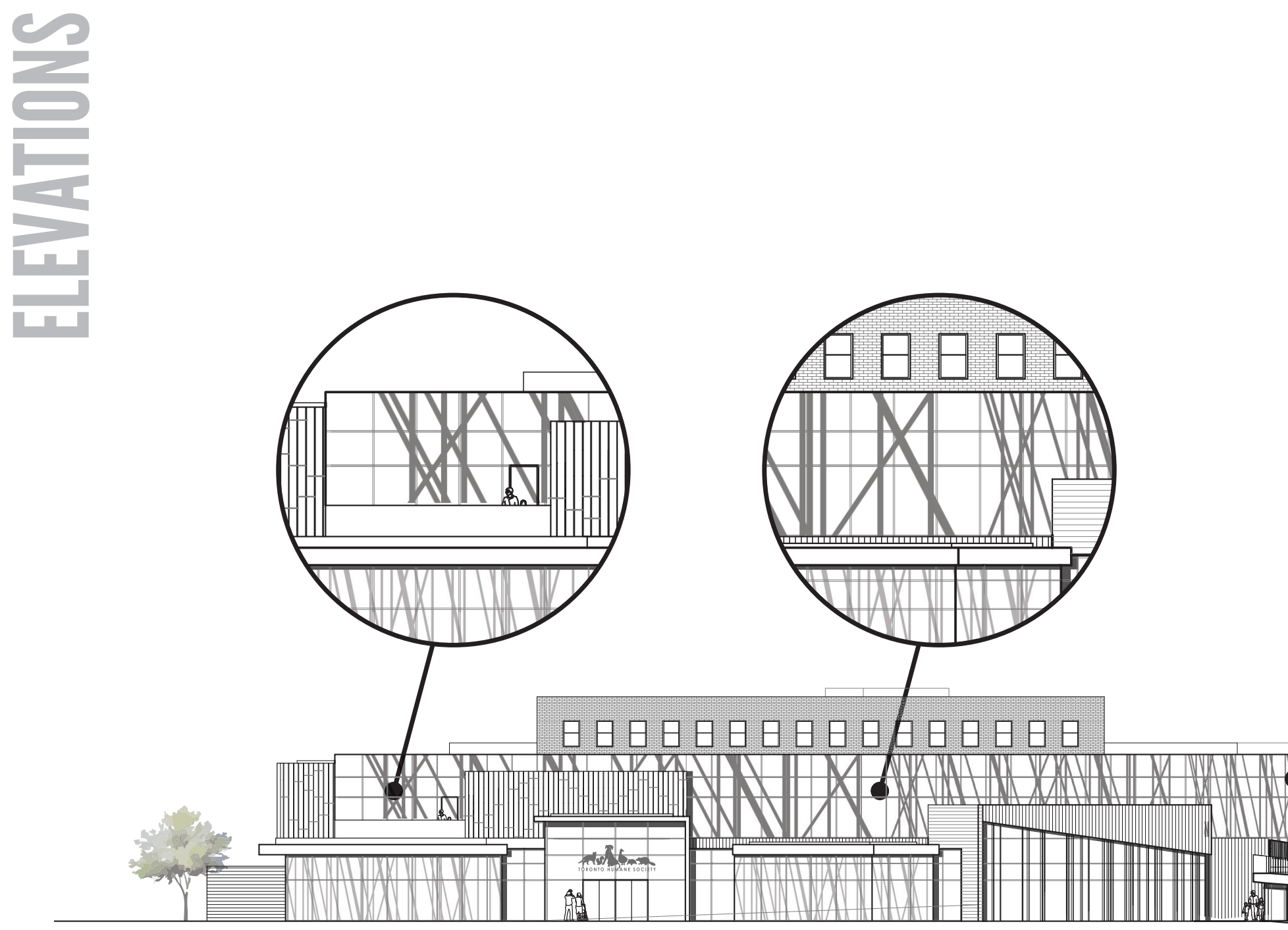

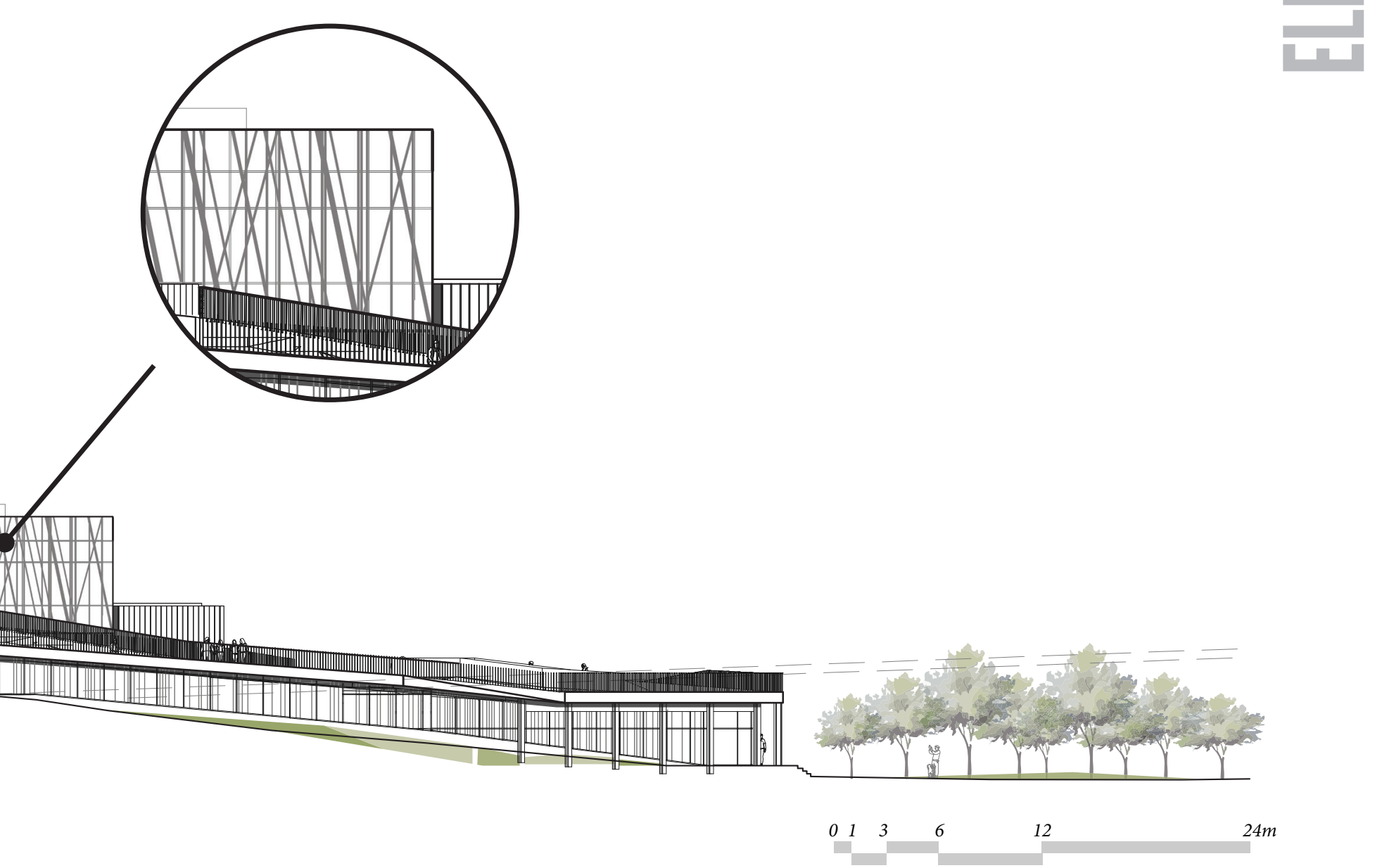

Figure 5.12: South Elevation

The south elevation suggests a way of moving through the shelter, and also divides the shelter's public versus private spaces. To control glare and visual access, a frit pattern throughout the façade changes in density as it changes from city to valley, being more dense as it goes from west to east, public to private. 

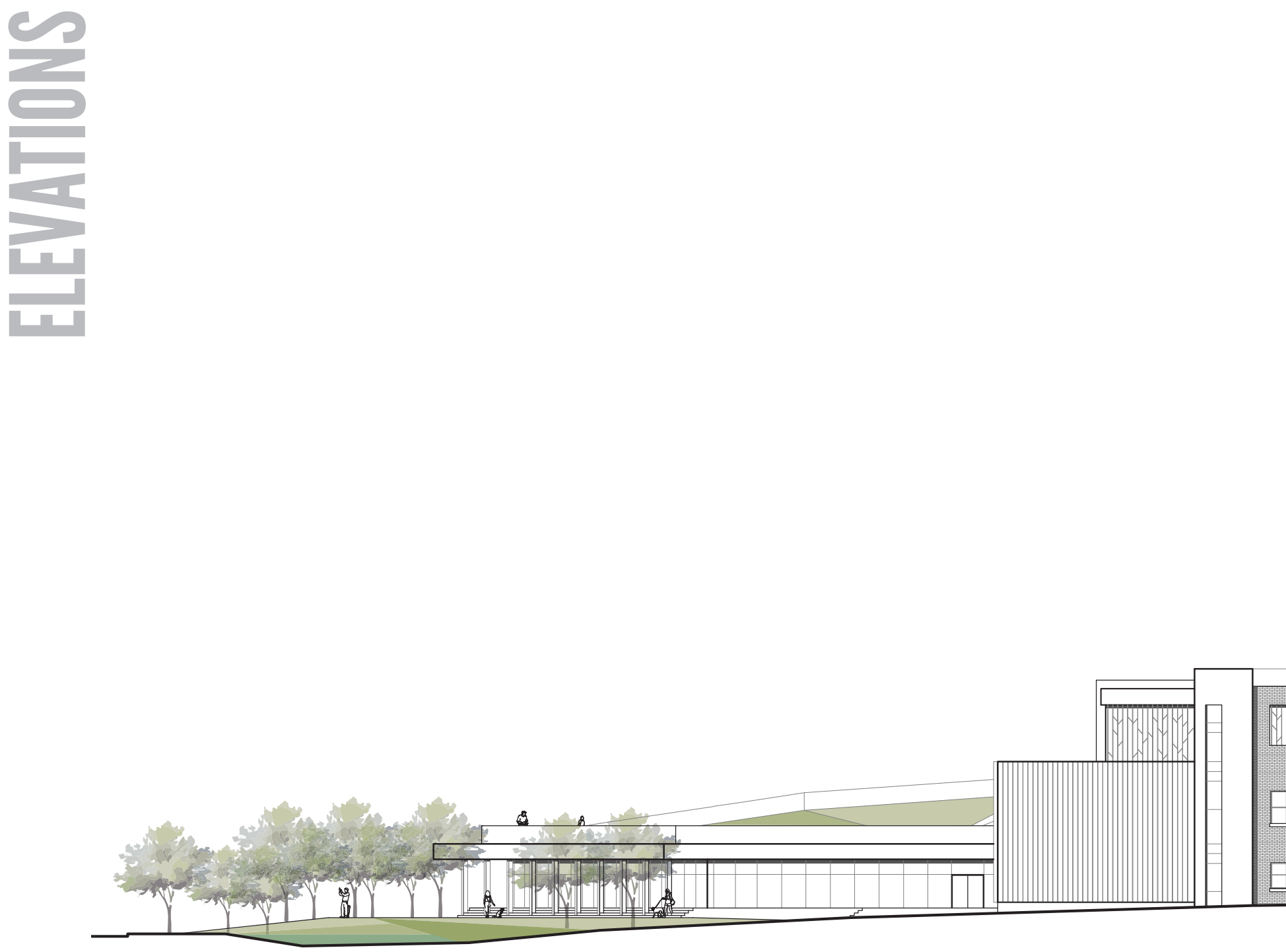

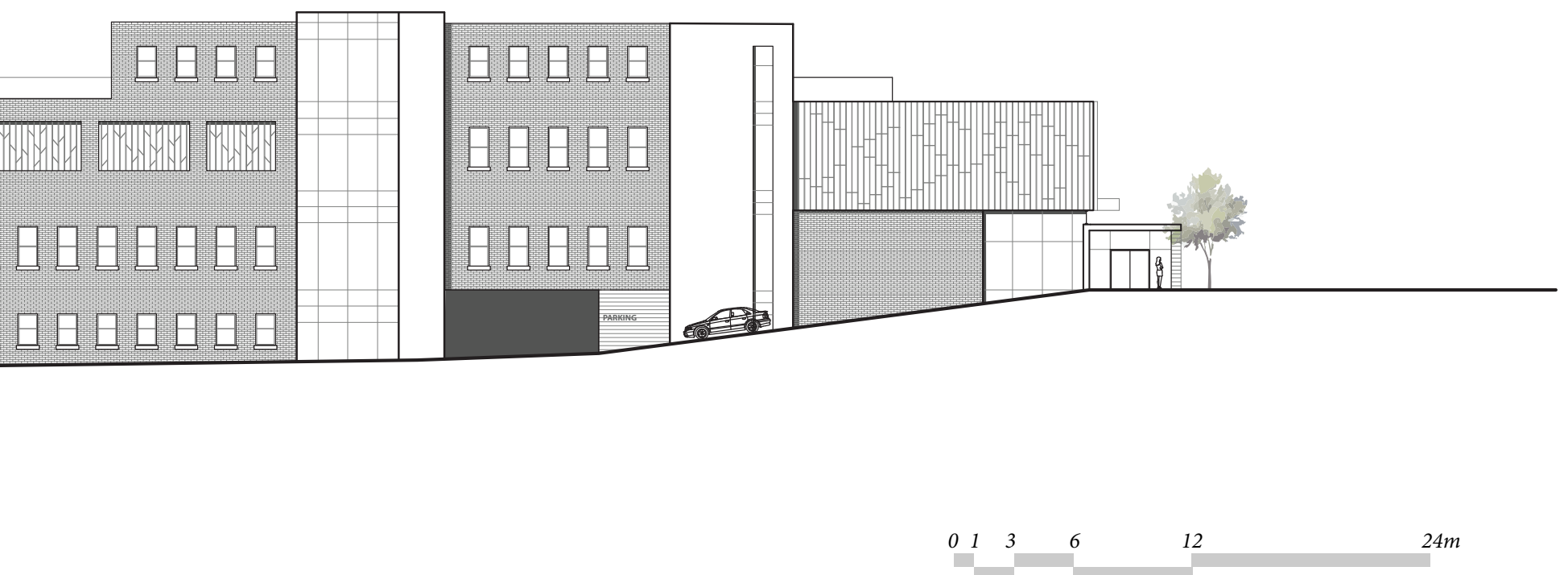

Figure 5.13: North Elevation

The north elevation, on the other hand, expresses a more private and institutional character that respects materials and scales of the residential lofts to the north. 


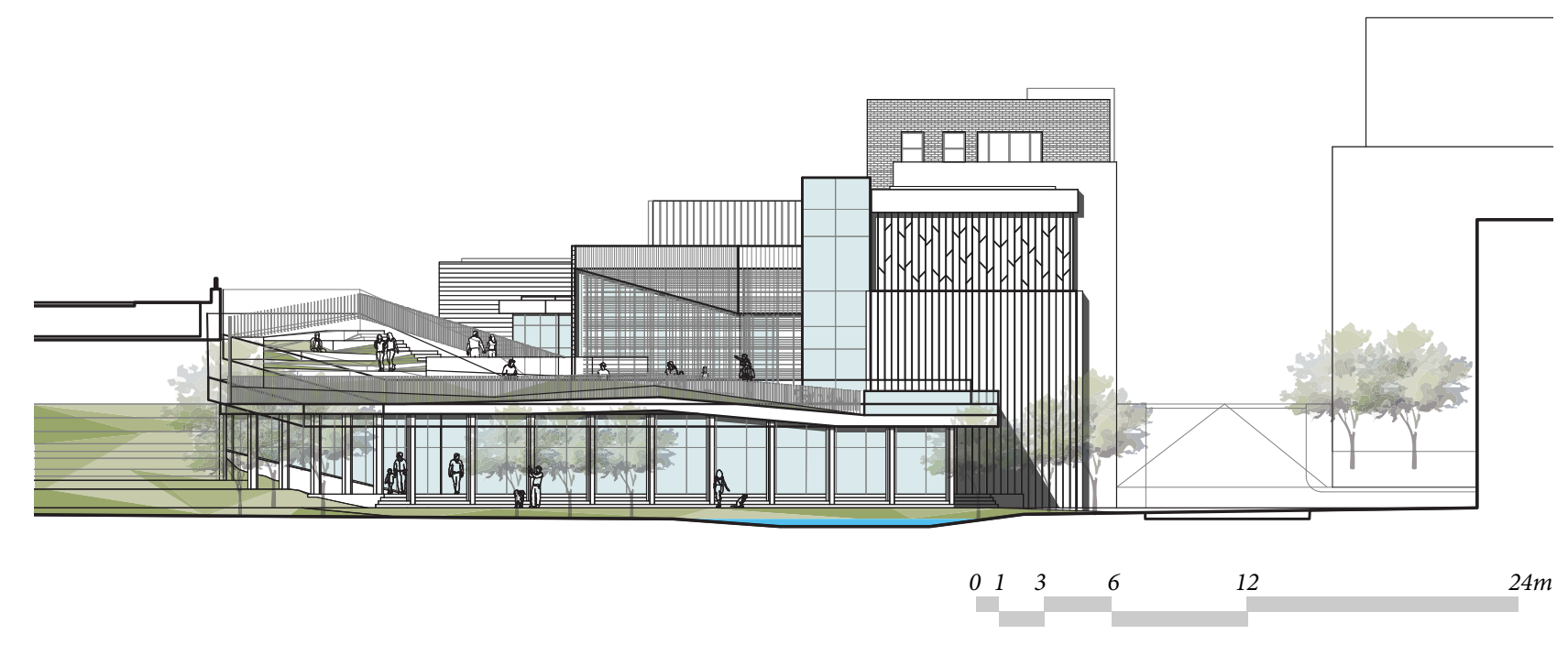

Figure 5.14: East Elevation

The east elevation presents a park-like setting that is reminescent of the Don Valley, where the west elevation is highly transparent to appeal to the city. 

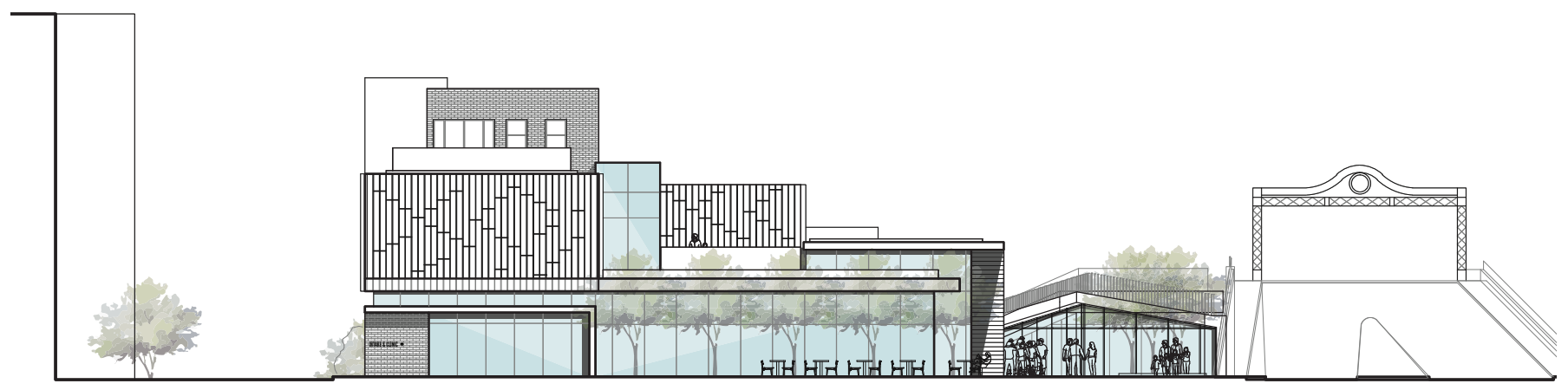

$\begin{array}{lll}0 & 1 & 3\end{array}$

6

12

$24 m$

Figure 5.15: West Elevation 

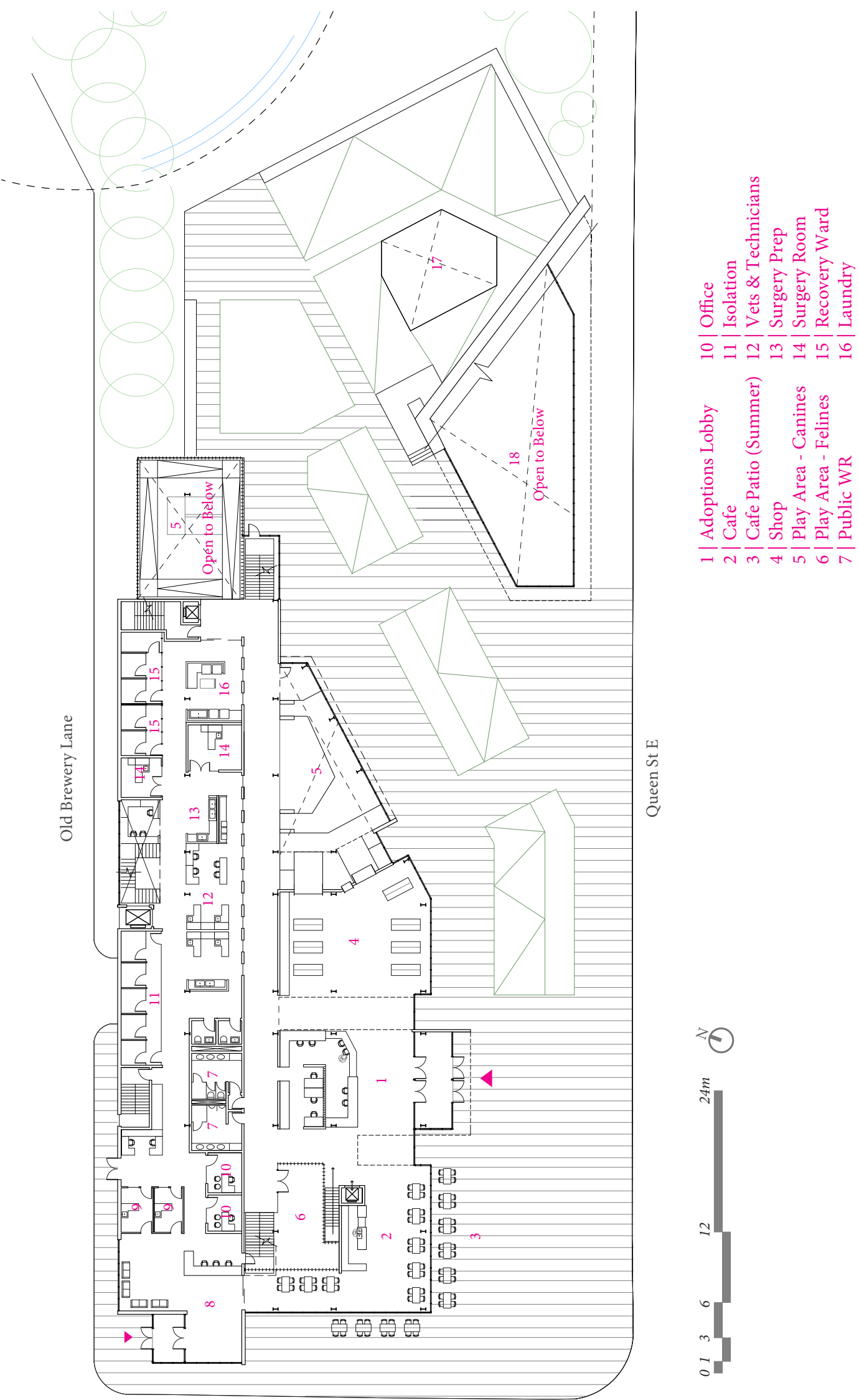

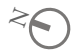
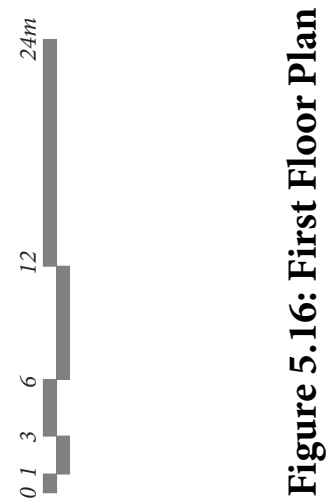

IS เәАІч 


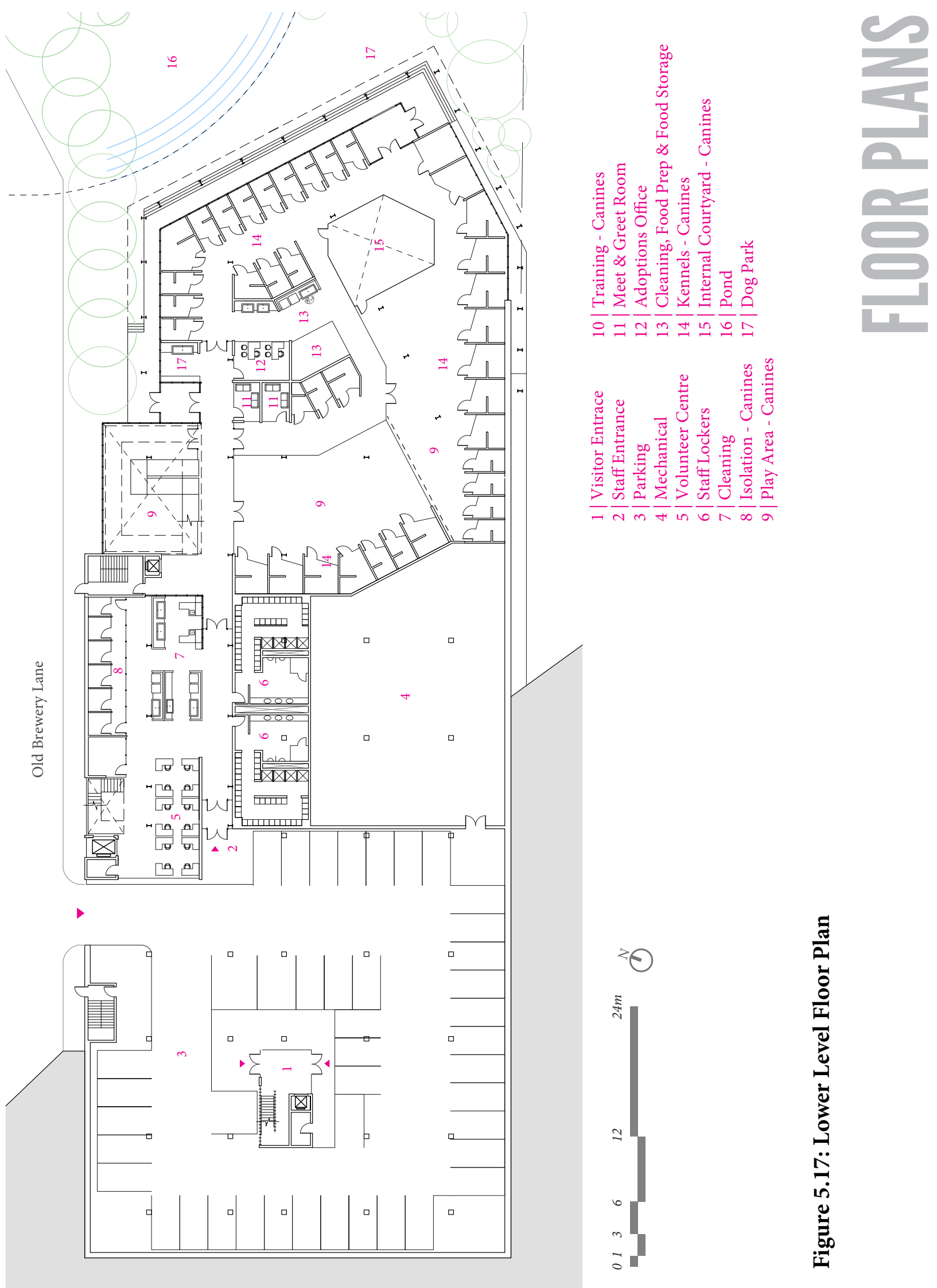



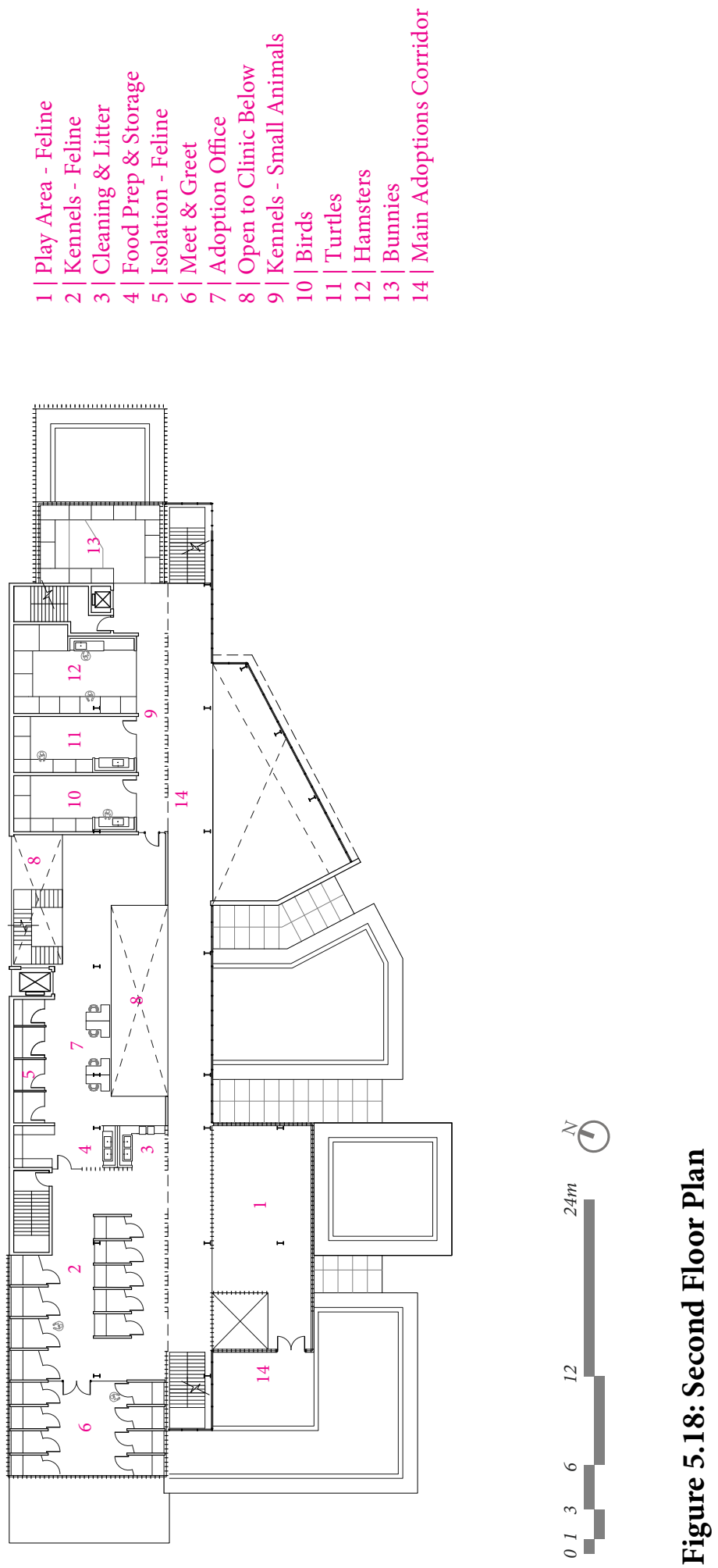

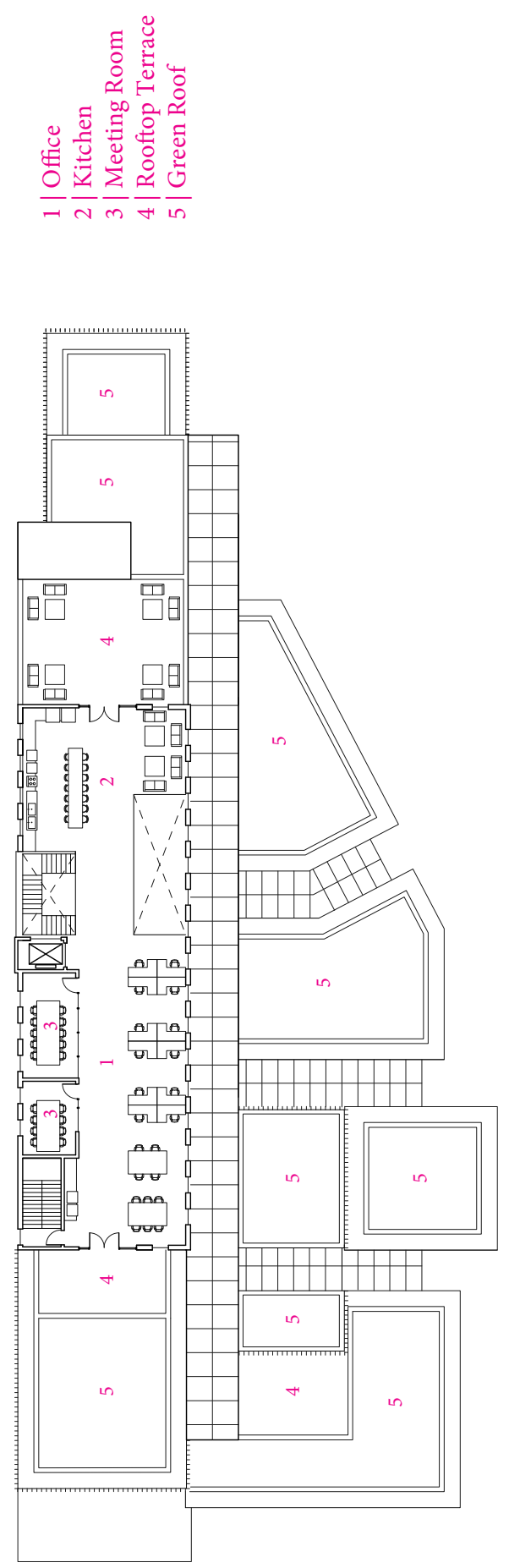

$>0$

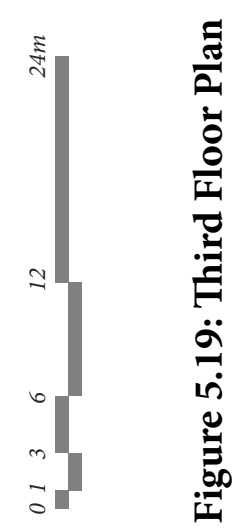



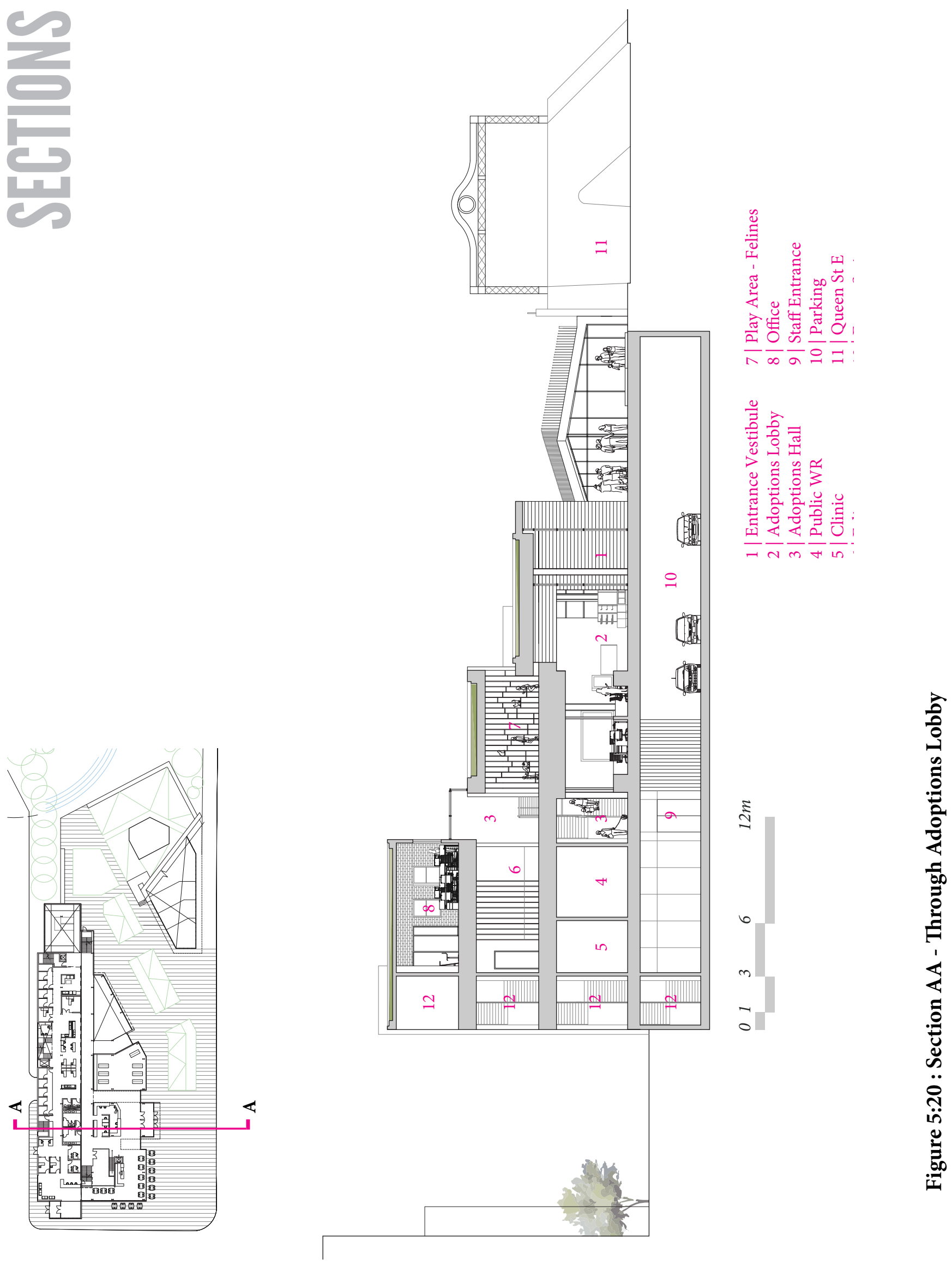

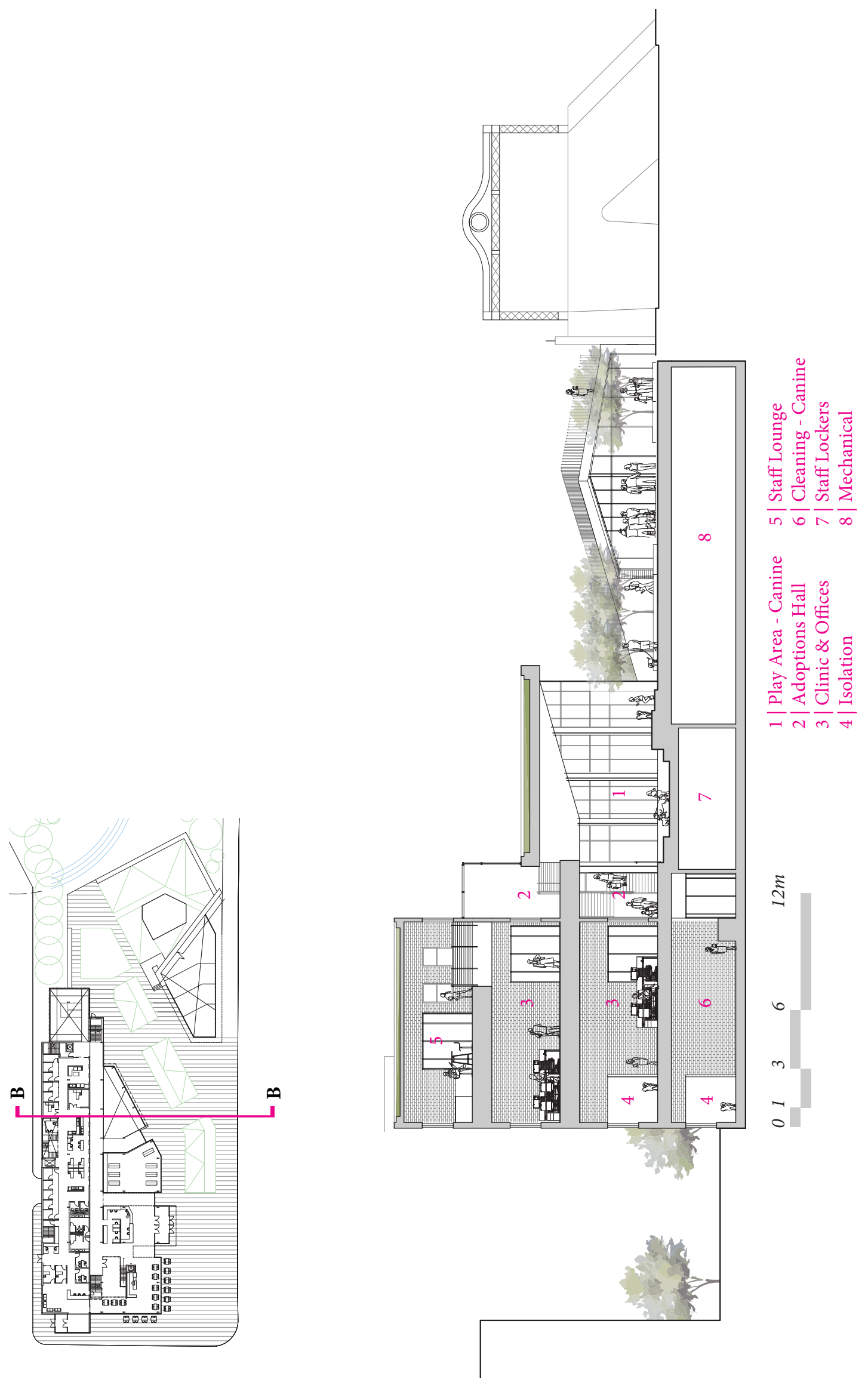

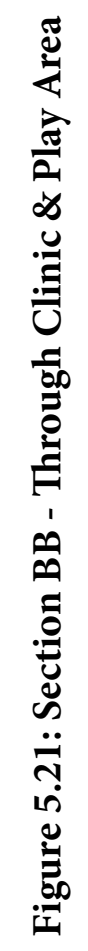



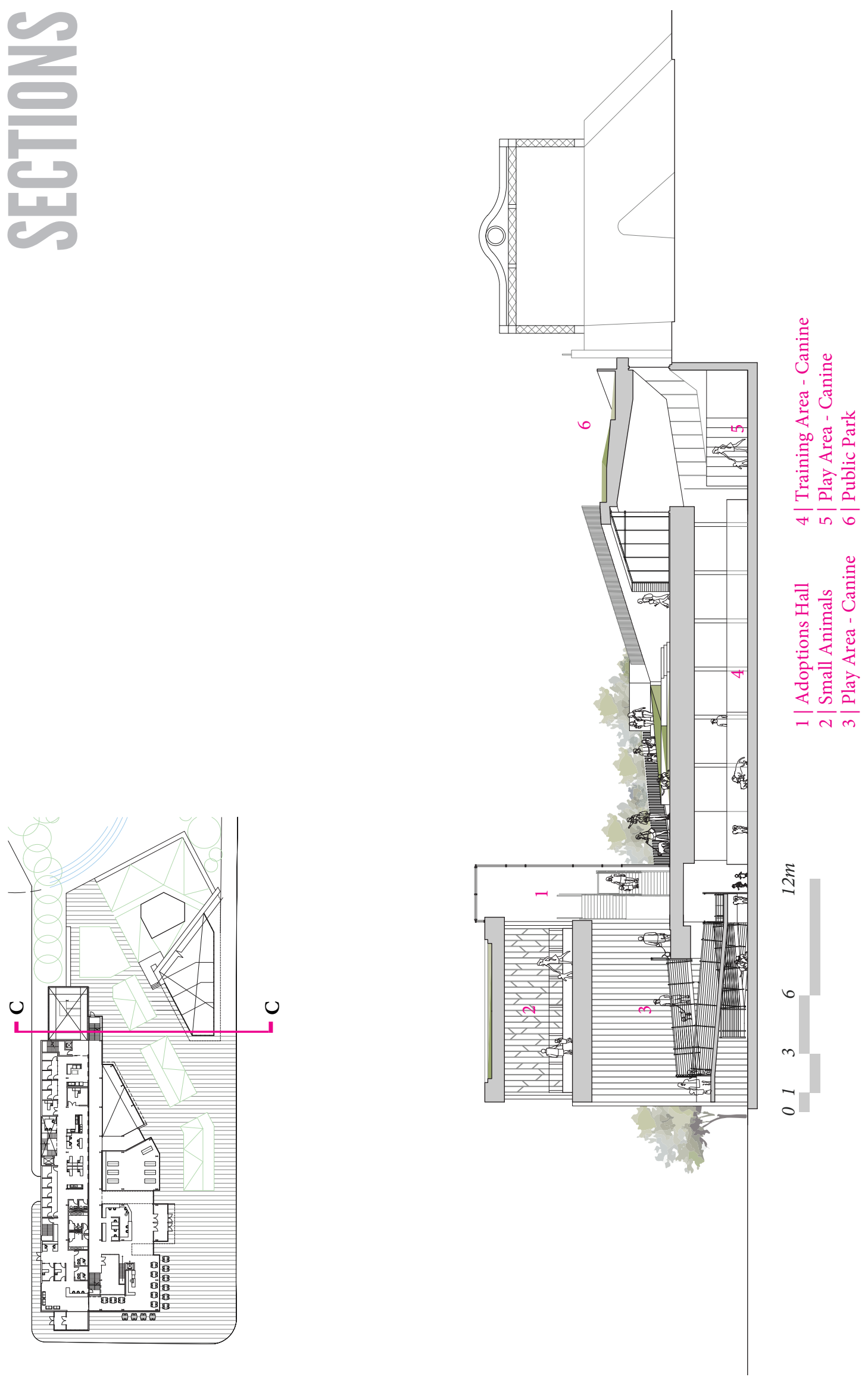

हี 

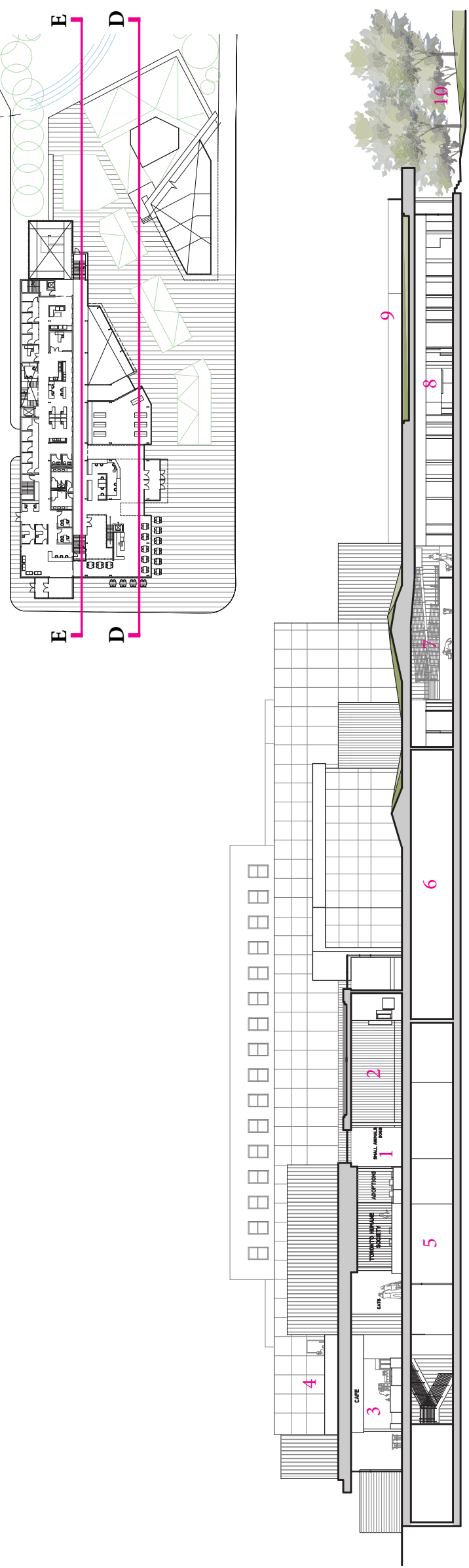
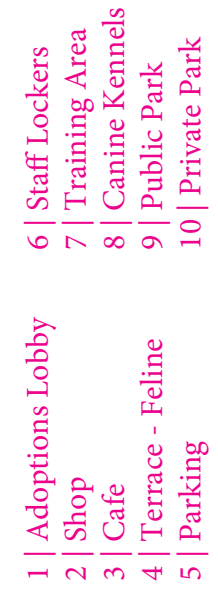

焉 00 㐘 寻芩苋 ज्ञ $\frac{1}{6} \frac{2}{1} \frac{2}{\infty} \frac{2}{a}$

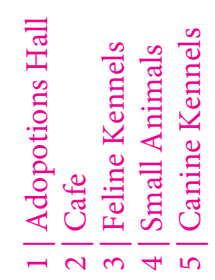

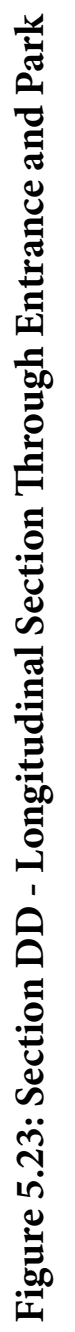

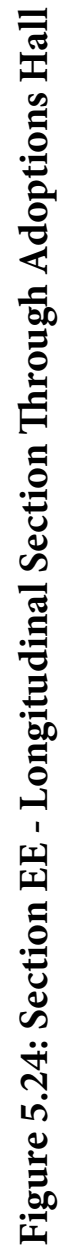




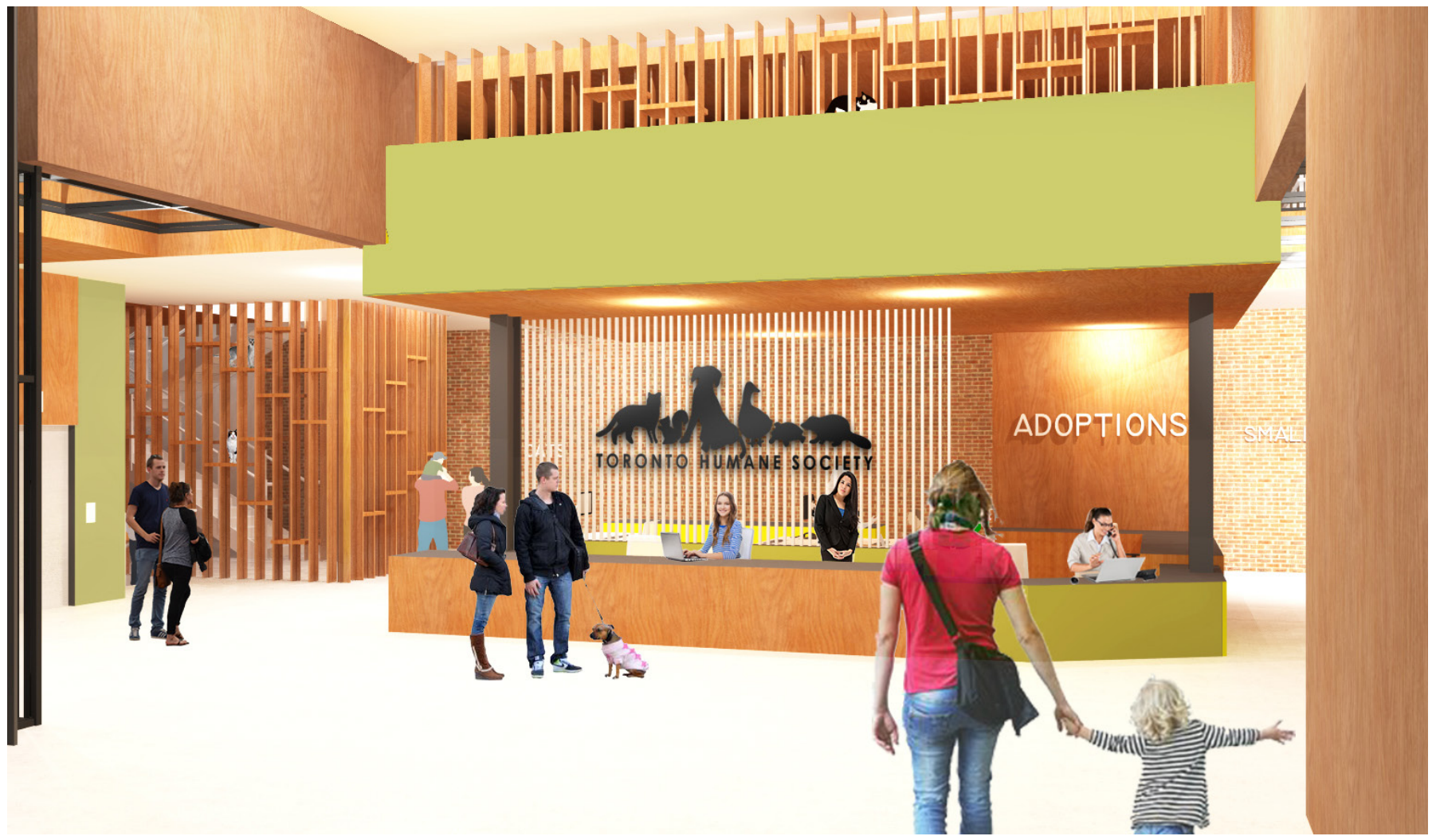

\section{Figure 5.25: Main Adoptions Lobby}

Once inside the shelter, the Adoptions Reception is centralized and surrounded by public programs of the shop and café. Yet from here, we still get glimpses of the animal spaces beyond, where cats are seen on the left, and dogs to the right (Figure 5.25)

Key Plan - First Floor

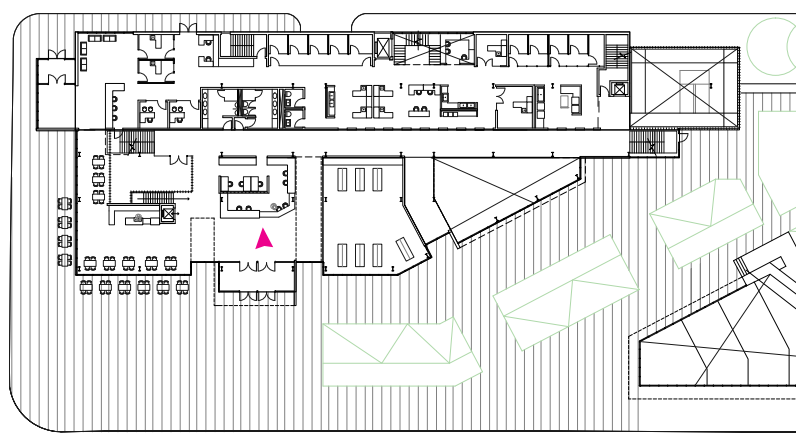




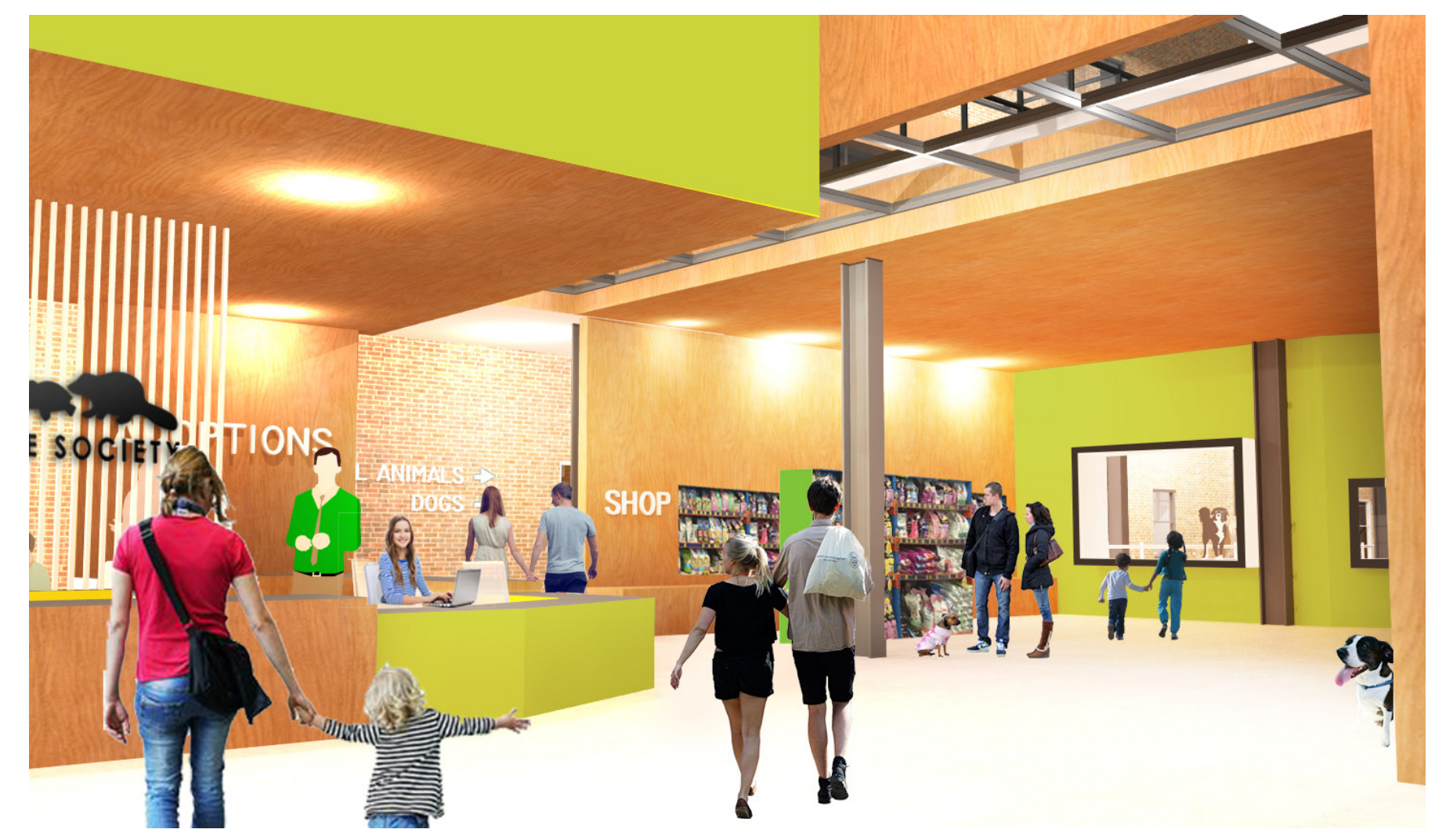

Figure 5.26: Main Adoptions Lobby

Key Plan - First Floor

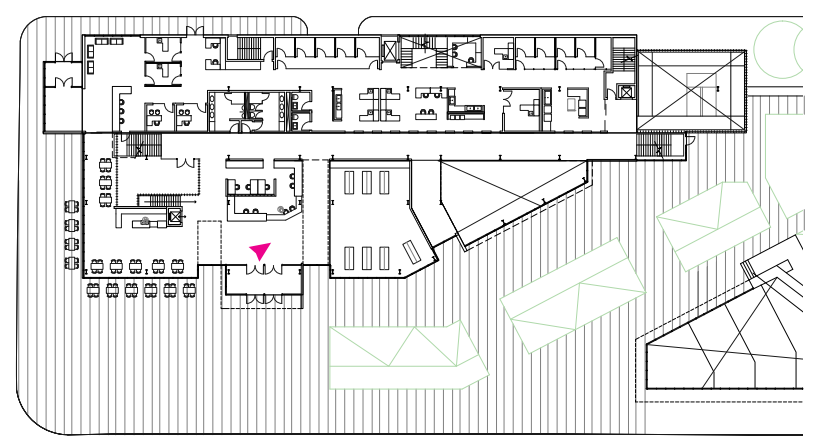




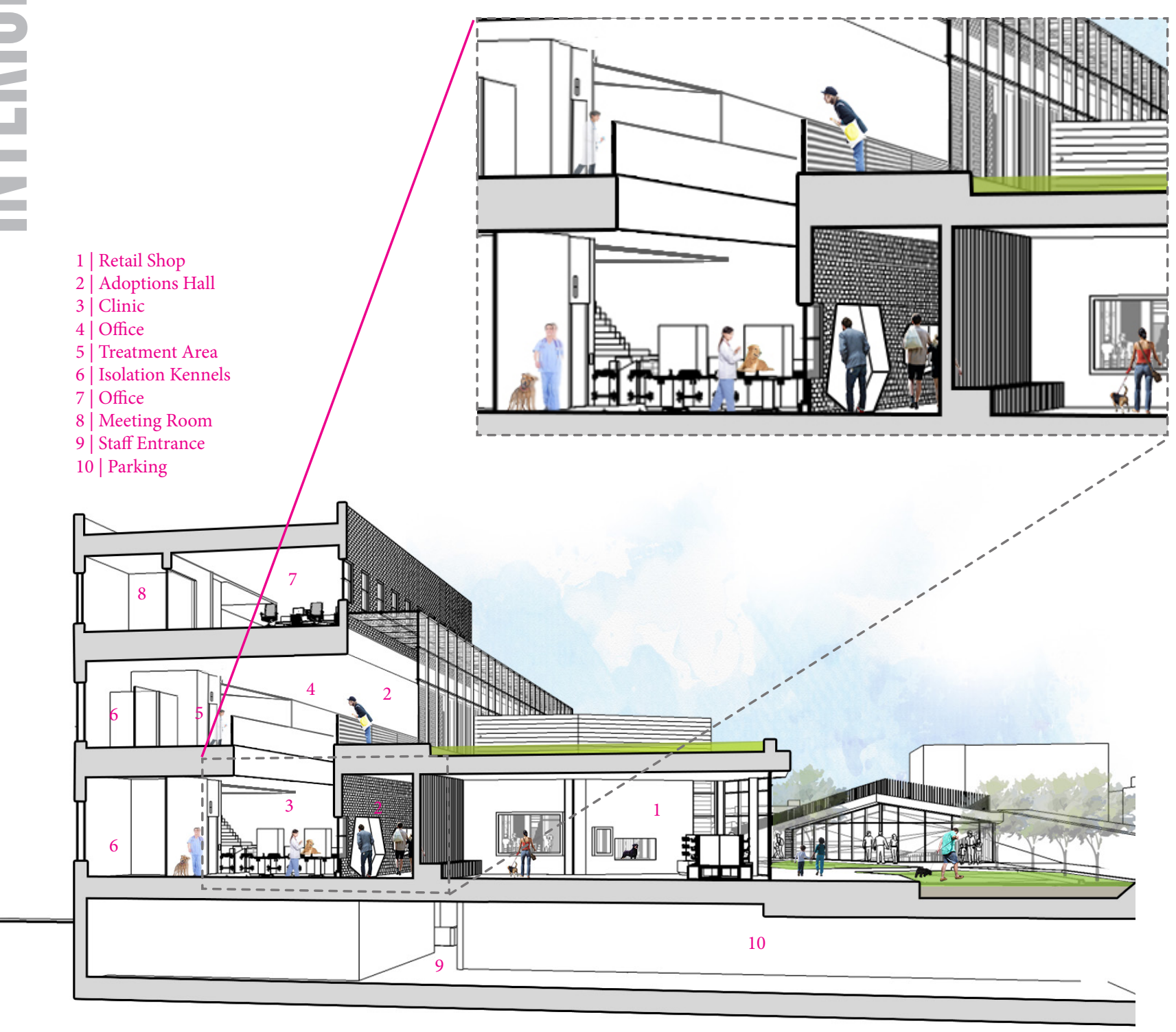

Figure 5.27: Sectional perspective through entrance and clinic

The intake and treatment process is laid out along the north and visitors get views into the space along the adoptions hall.

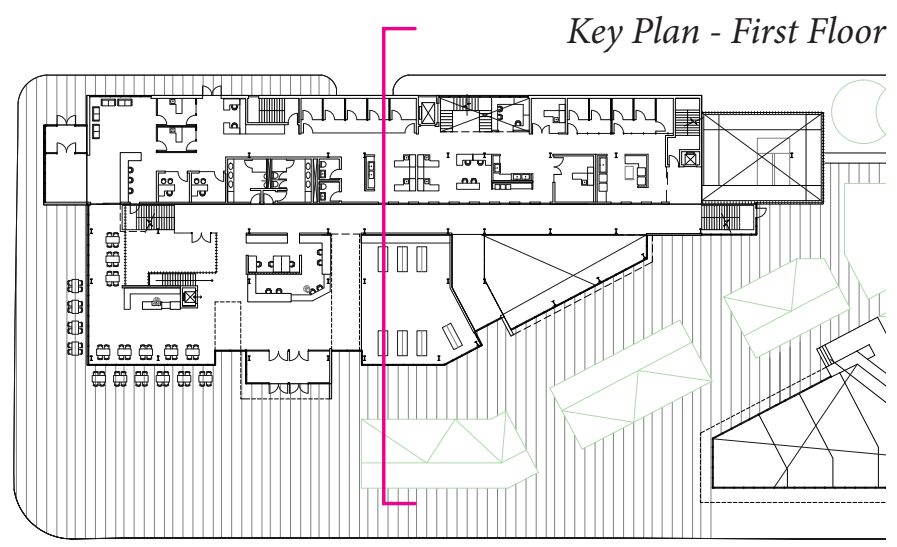




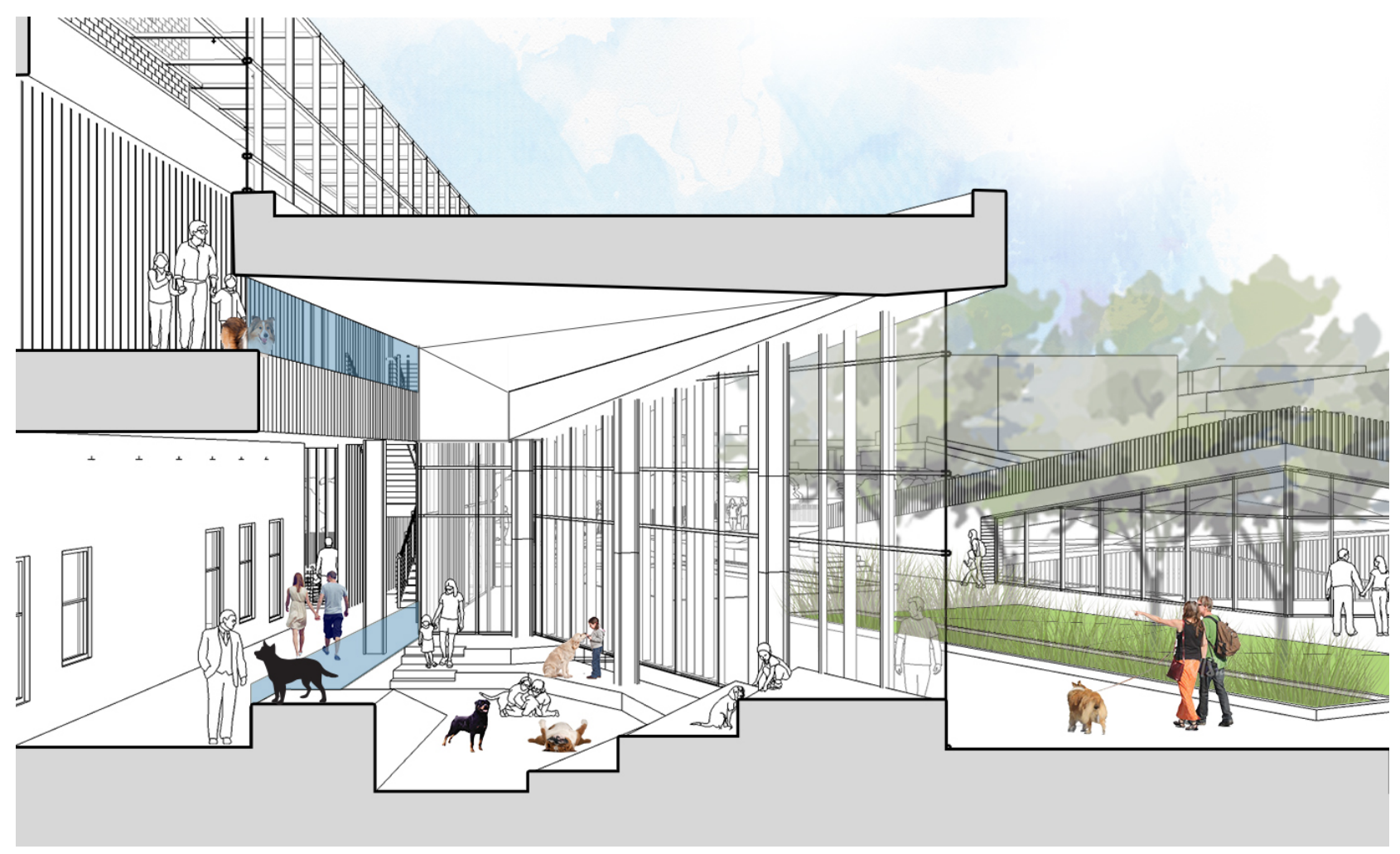

Key Plan - First Floor

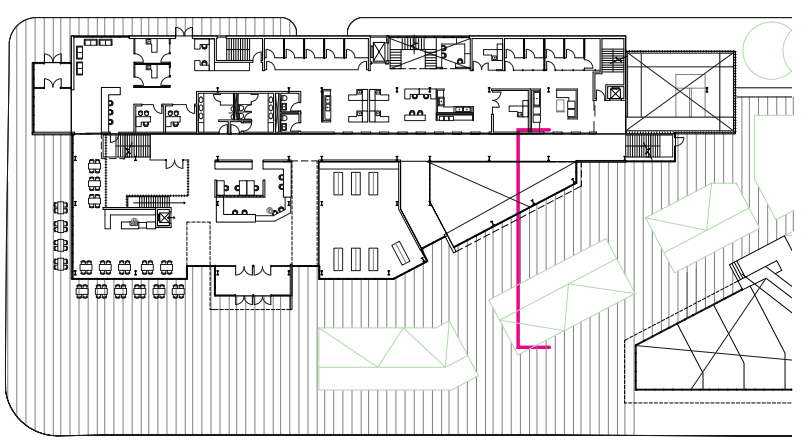

Figure 5.28: Sectional perspective through main canine play area and public park

As visitors move along the hall, other spaces seen earlier begins to open up. Varying levels and heights elevate and provide diversity for both animals and children. The sight, sounds, and ability to touch and engage with each other allows for a more social and experiential dynamic between users in these socialization and play spaces. 


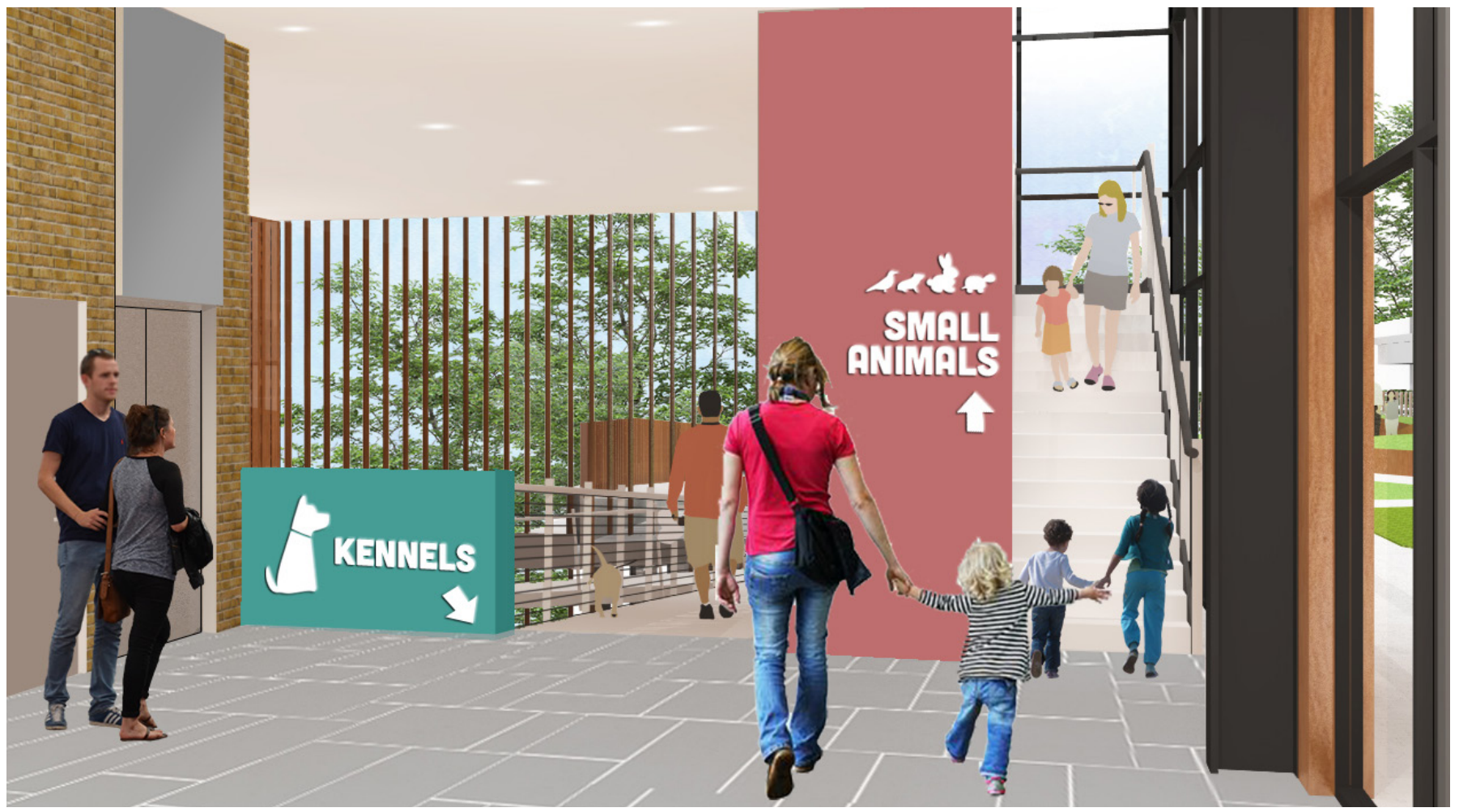

Figure 5.29: Adoption Hall - First Floor

The end of the adoptions hall directs visitors upstairs Key Plan - First Floor to small animals or down to canine kennels and training spaces. A ramp spirals down and around a canine play area, but views to the outside indicate a more private and park-like setting, as the ramp slowly descends into the canine kennel and rehabilitation areas (Figure 5.29).

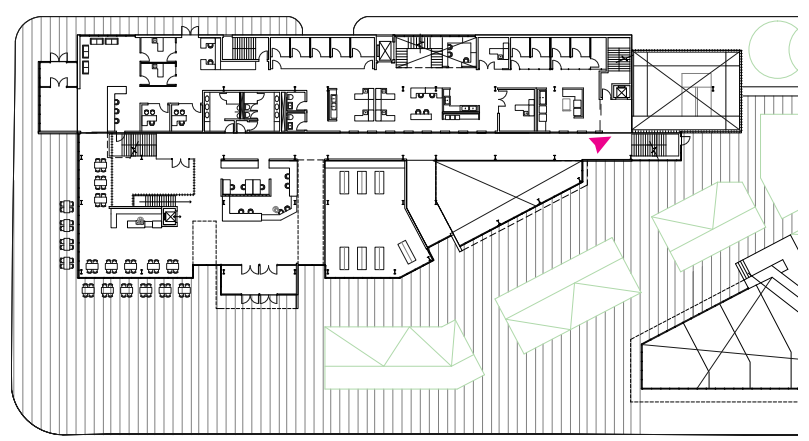




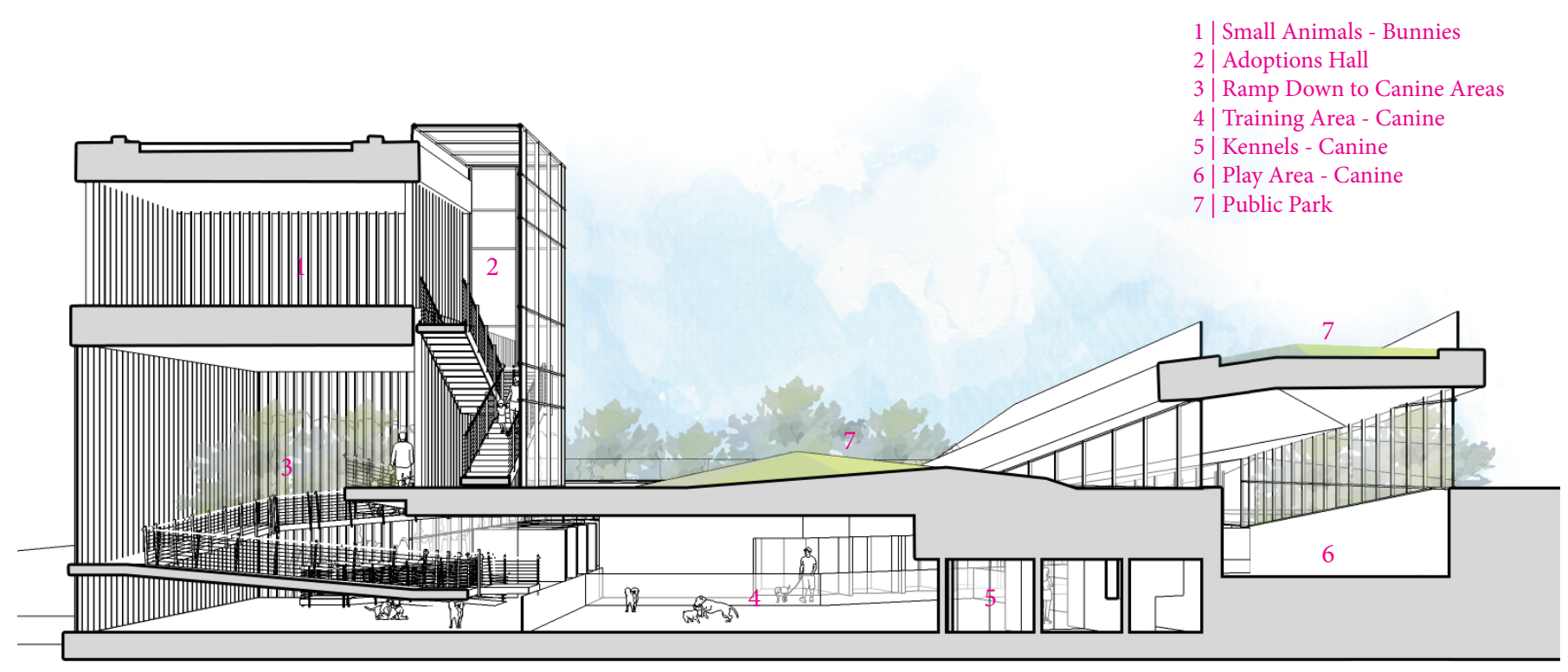

Figure 5.30: Sectional Perspective Through Canine Areas

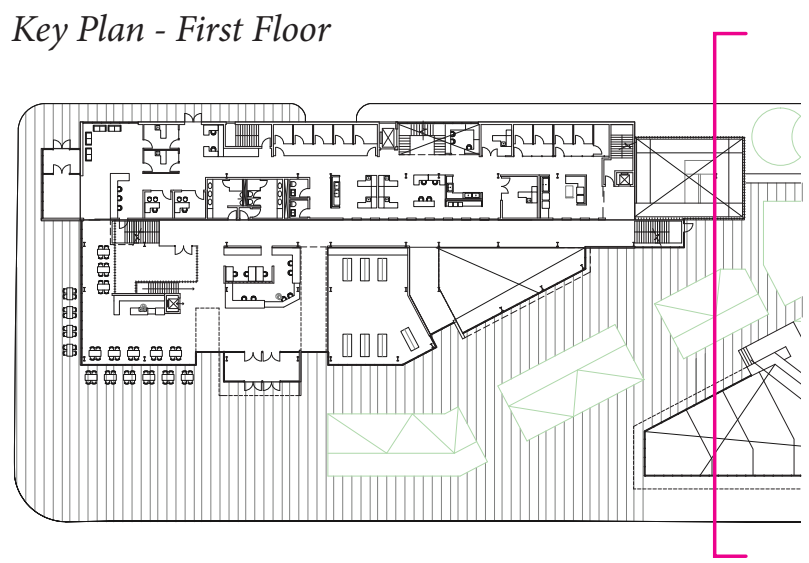



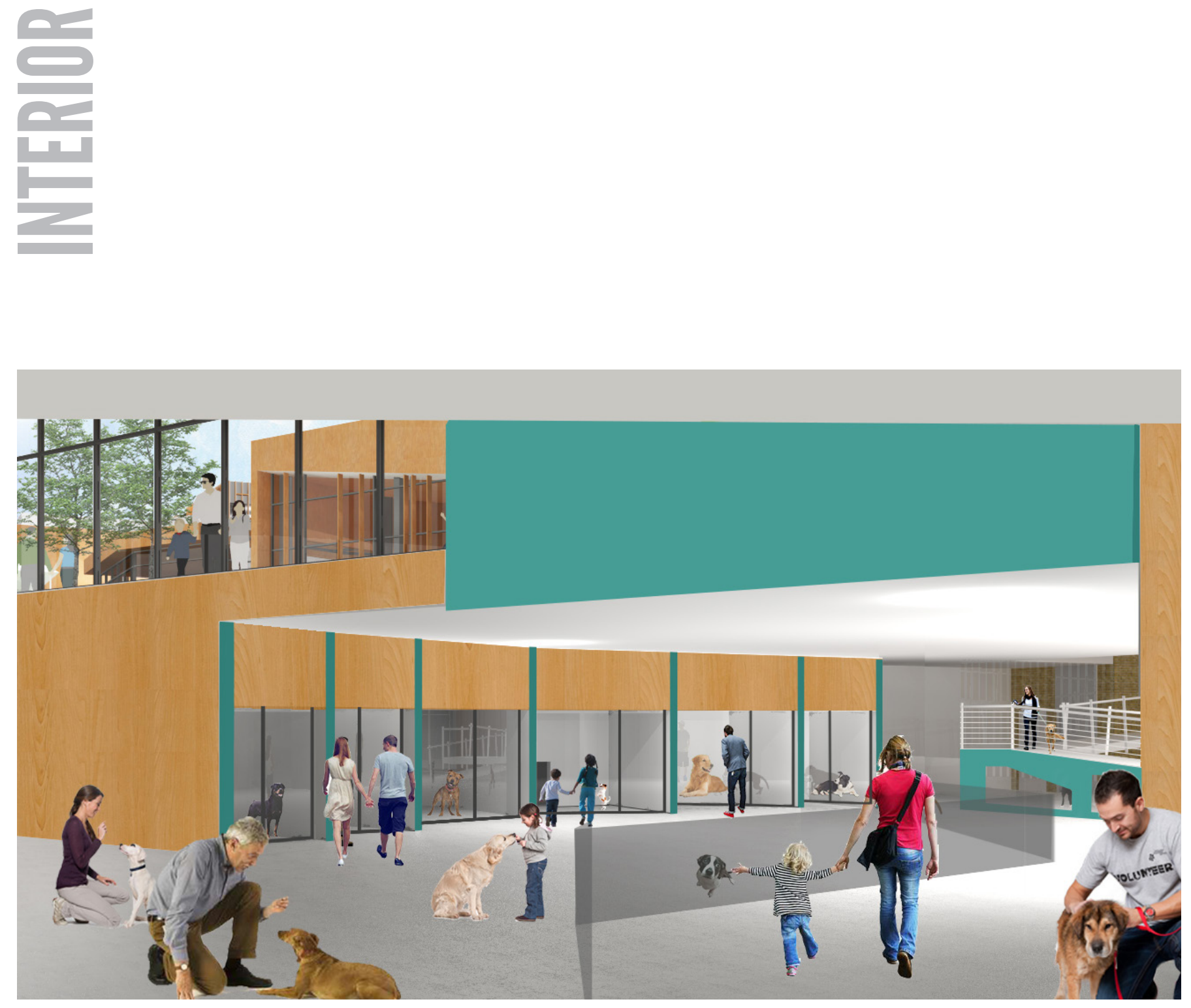

Figure 5.31: Canine Kennels and Training Area

Kennels are arranged along the perimeter while training, cleaning, maintenance, food preparation areas, and adoption meeting rooms are centralized among the kennels and circulation path. Visitors walk through the training areas, with views up to the public park above.

Key Plan - Lower Level

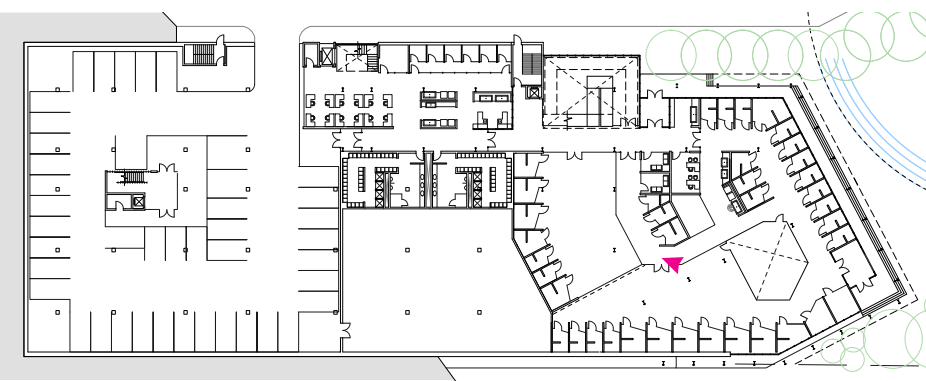




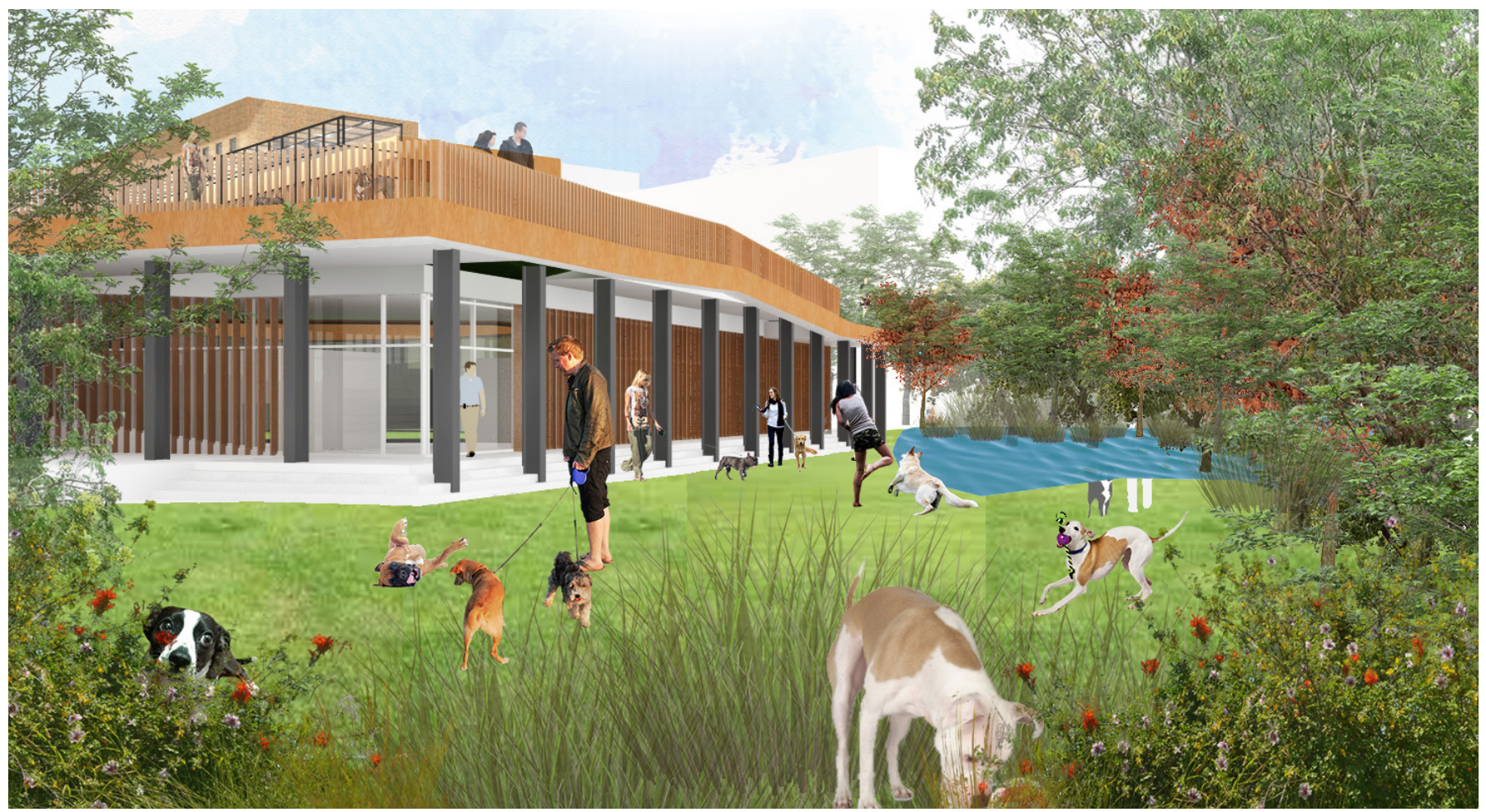

Figure 5.32: Private Dog Park

Key Plan - Site Plan

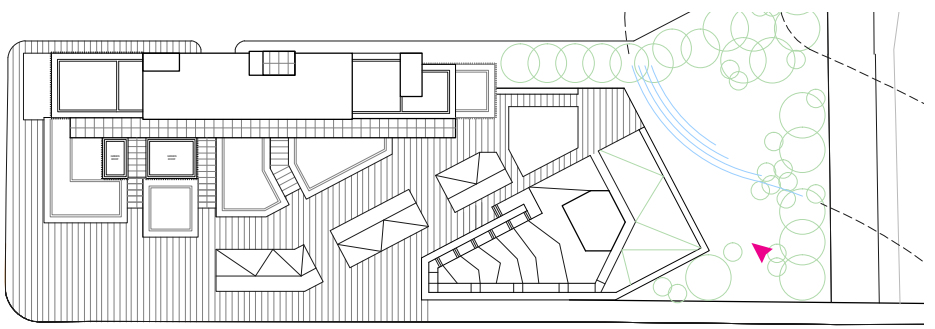

The park to the east is used as an additional exercise space to walk and train dogs to distinguish between inside and out, and between hardscapes and landscape. 


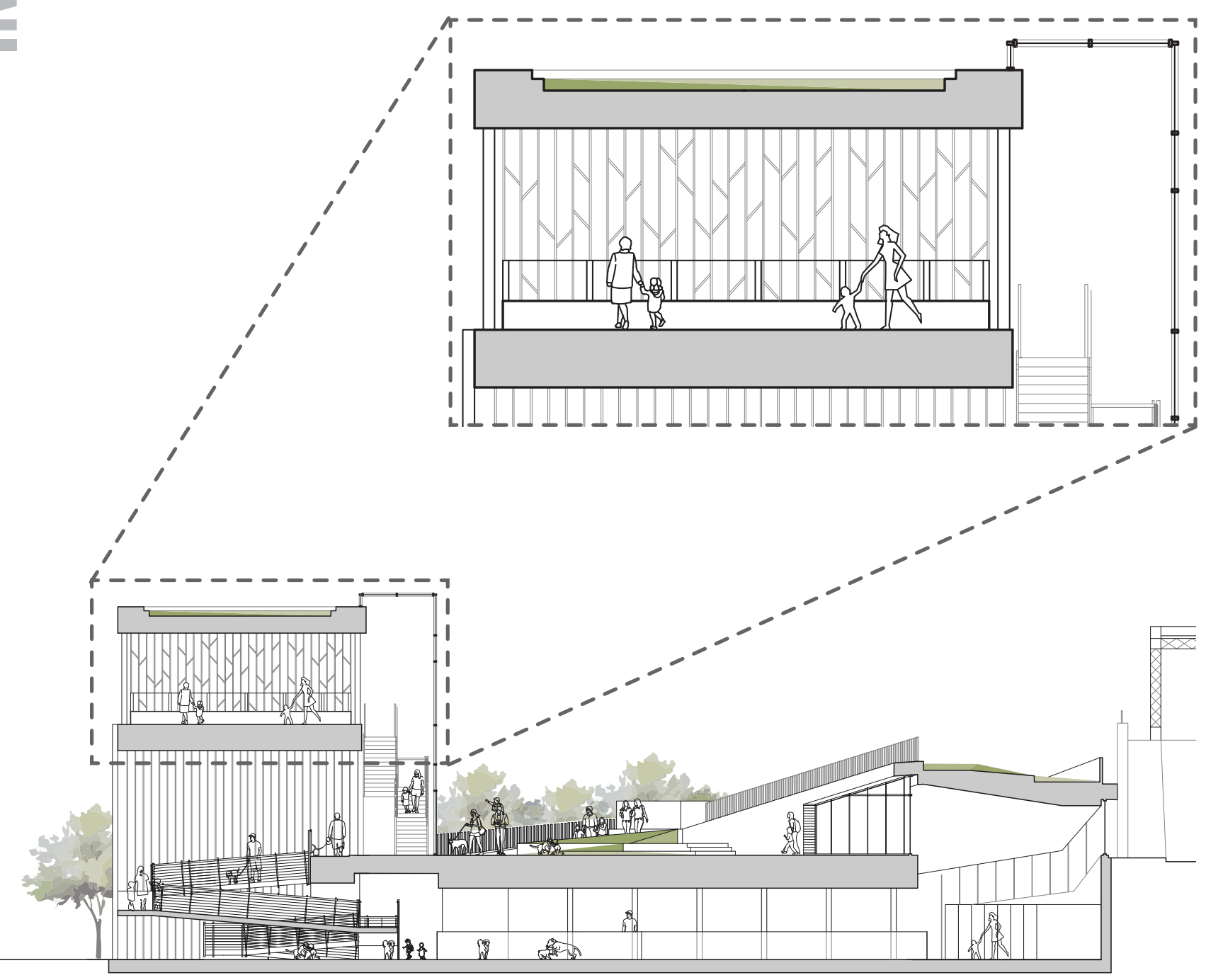

Figure 5.33: Small Animal Area on Second Floor

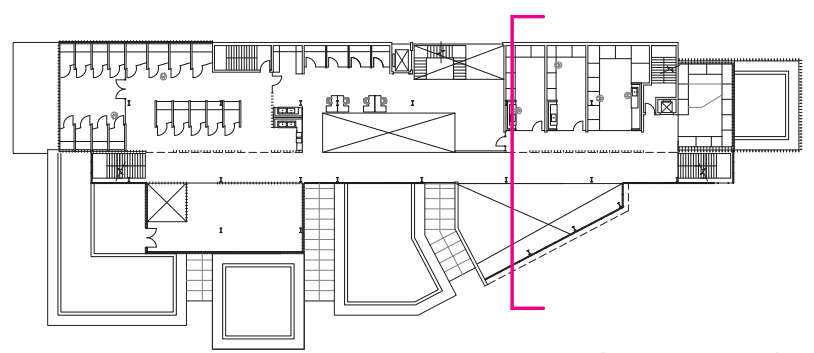

Key Plan - Second Floor 


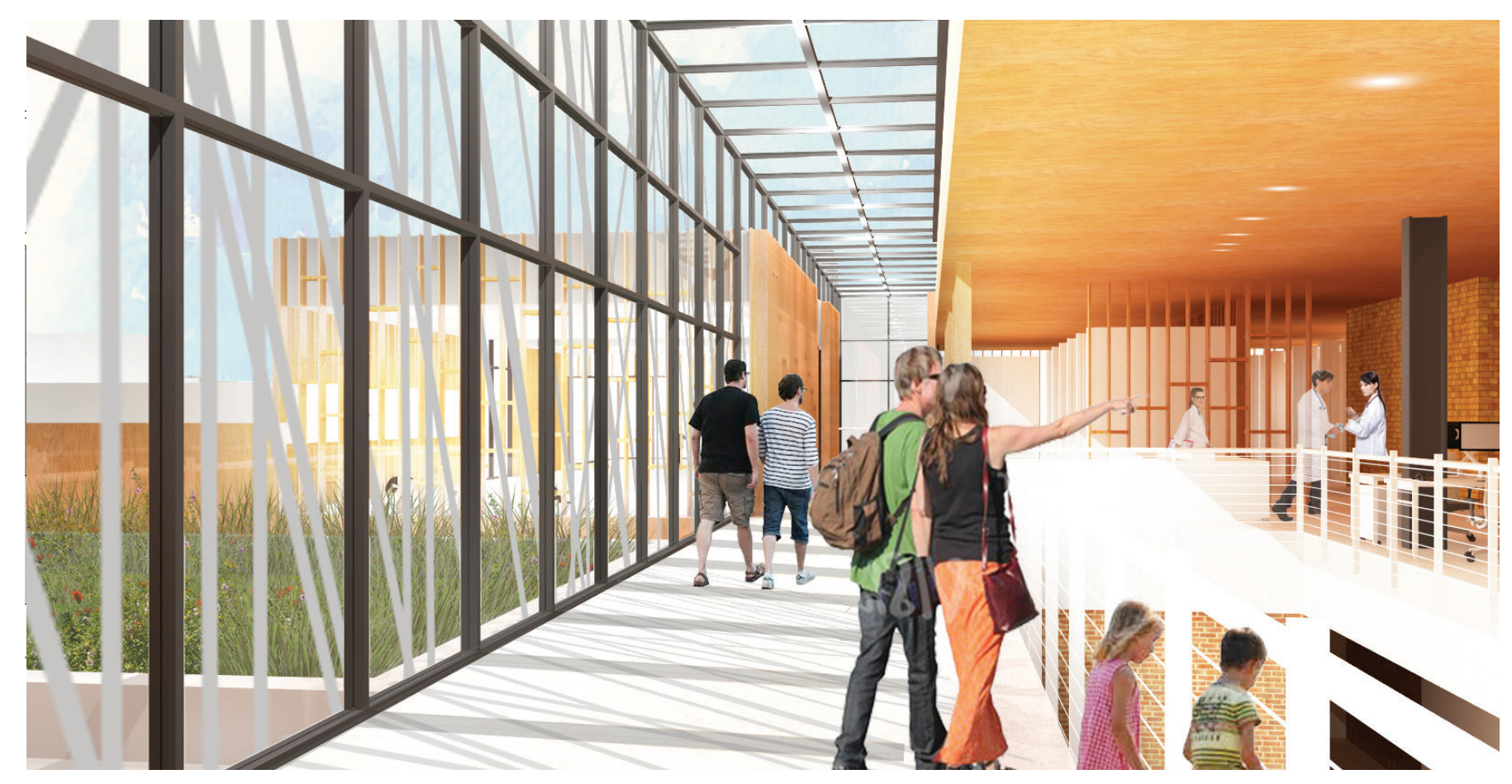

Figure 5.34: Adoptions Hall - Second Floor

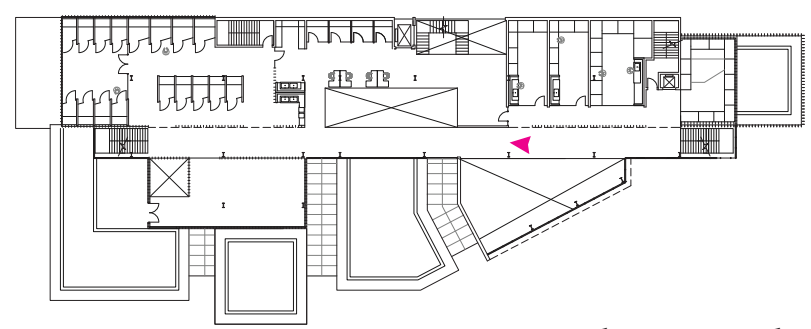

As one move along the adoptions hall on the second floor, they get views into the same clinic and admin spaces from above.

Key Plan - Second Floor 


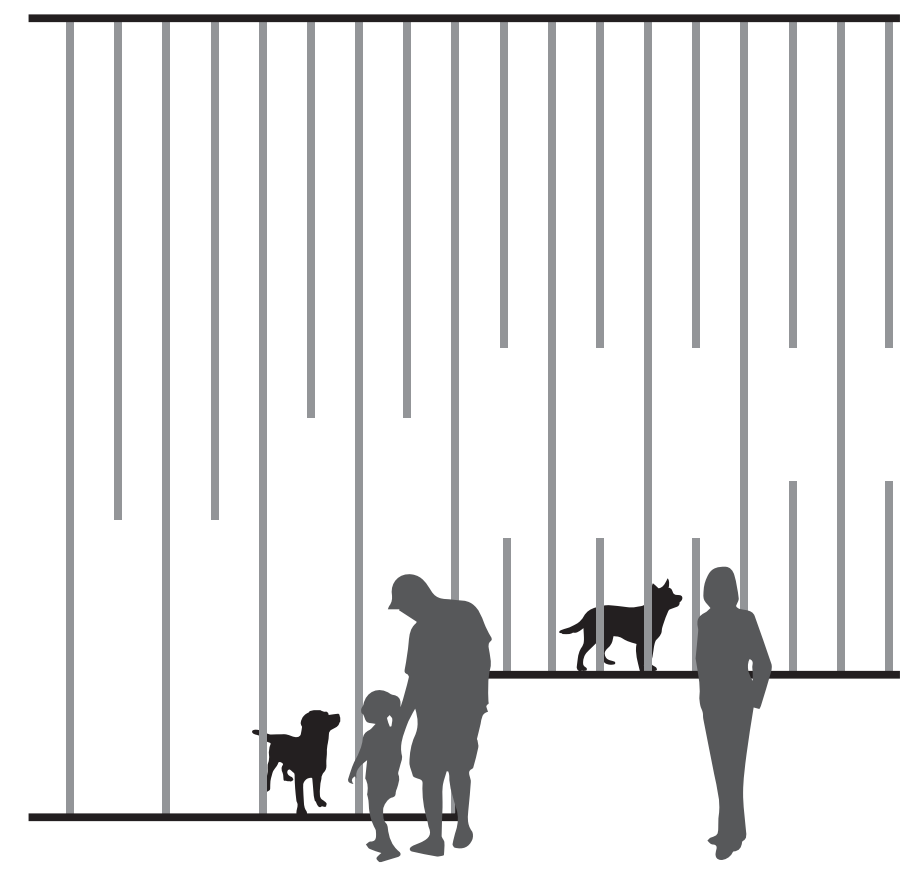

Figure 5.35: Canine Scales
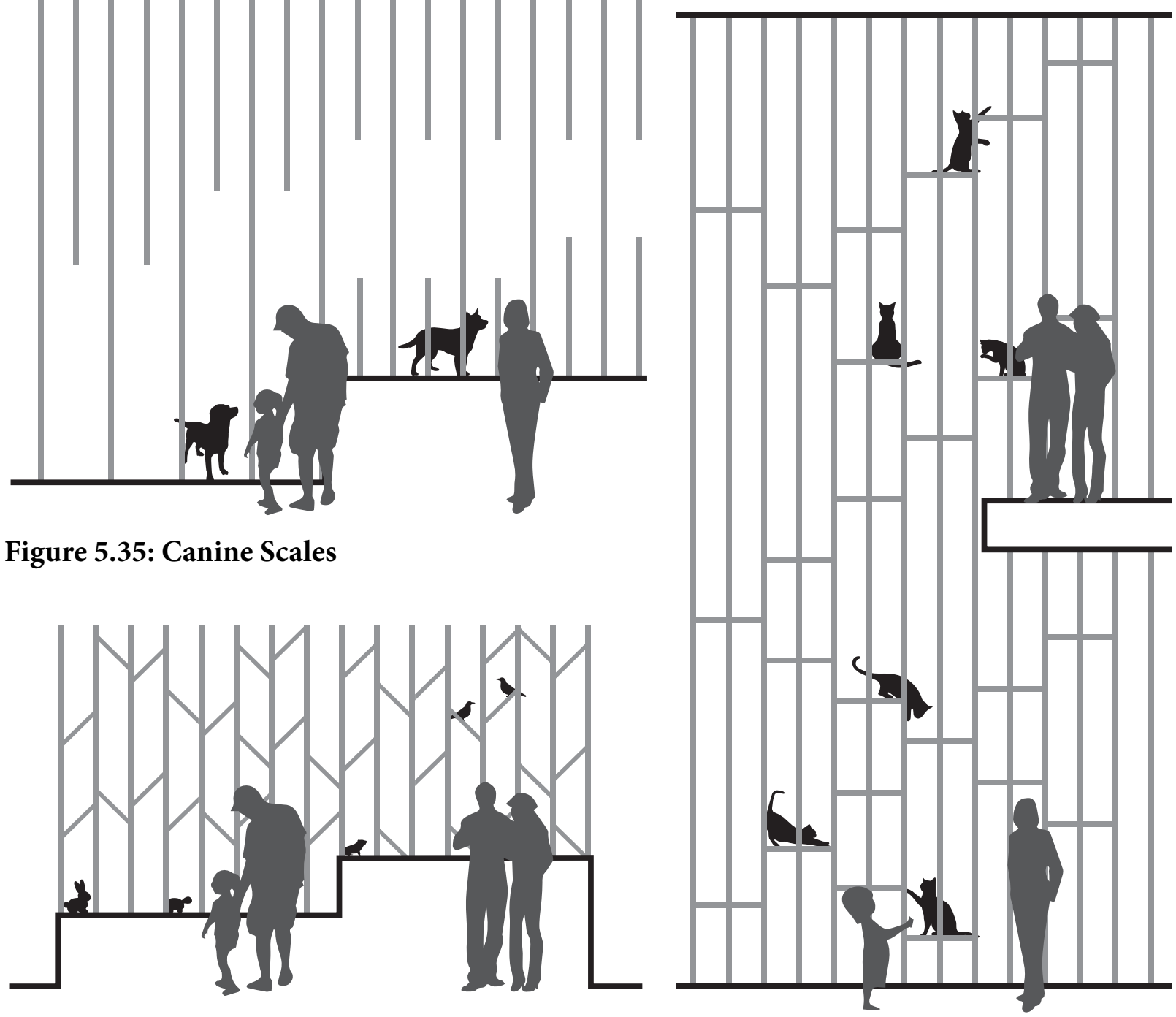

Figure 5.36:

Small Animals Scale

Figure 5.37: Feline Scales 


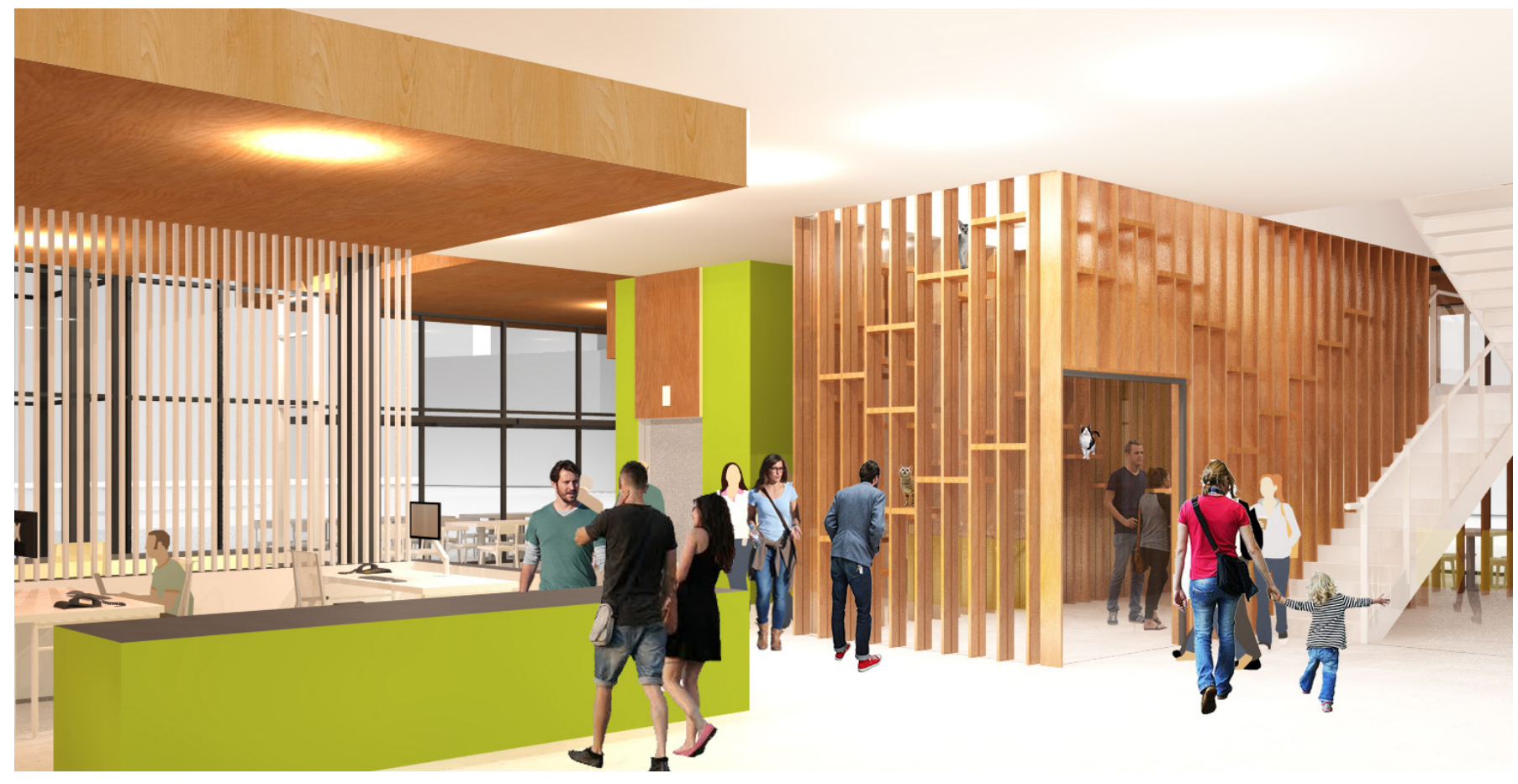

Figure 5.38: Adoptions Hall and Reception on First Floor

Key Plan - First Floor

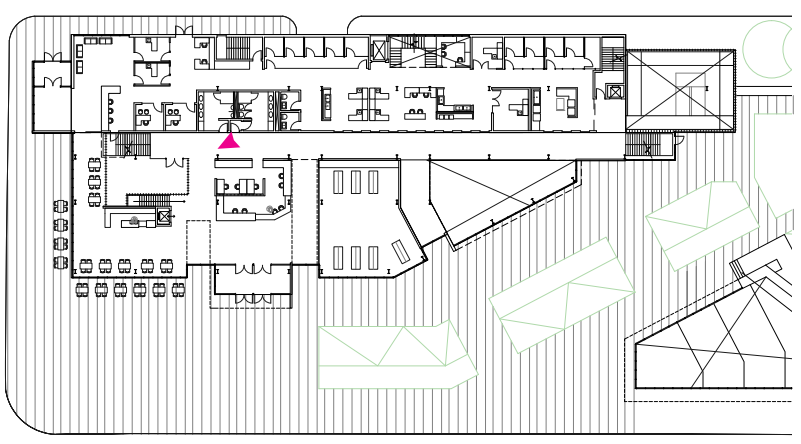

The area for cats are defined with a pattern that expresses the preference and movement of cats. Where dogs need expansive horizontal space for running and playing, cats use vertical surfaces for climbing and perching. Steps and ledges in the vertical slats start to create a rhythm of movement to define these areas. This preference for climbing and vertical movement connects the play area to the first floor, bringing the visitor back to the main entrance. 



\section{CONCLUSION}




\section{Conclusion}

Contemporary architectural solutions have tended towards the instant gratification of the spectacle, slowly losing its value and connection with people and place. The rise of an ocular-centric society, the dominance of economy, and the effects of globalization have pushed architecture into a commodified object that glorifies an architecture of excess. However, by navigating beyond the flaws and superficiality of entertainment architecture, it is found that enjoyable leisure experiences and strategies can provoke a better connection between people, architecture, and the city.

The strategy of work as an architectural narrative, derived from the theme park typology, understands operation and production processes as essential elements to architectural narrative and spatial organization. The theme of the city strategy found in Las Vegas Casinos looks at using contextuallybased icons, symbols, materials, and construction for architectural expression. Lastly, the scale and rhythm of users and their daily routines establishes patterns of movement and intimate relations between architecture and people.

As a public service facility, the Toronto Humane Society currently does not engage the public as much as it should. Its ominous exterior effectively shuts out the public both physically and visually, internalizing all its functions and services. As a thesis project, the facility was an appropriate site for exploration and a showcase of how architecture can move away from superficial tendencies while still being expressive, improving the shelter's image as a whole. Rather than simply creating superficial and obnoxious forms to draw attention to itself, the shelter's function and operations determined its spatial configuration and architectural narrative, is sensitive to and informed by its context, and the users' scales add experiential senses and qualities.

The final architectural manifestation projects an image that is appropriate for its use, location, and people. It expresses the institutional aspects of clinical treatment and healing, but also the dynamic playfulness of the animals and visitors, providing and projecting an enjoyable and humane environment for both humans and animals. It sits between the two spectrums of pragmatism and spectacle, expressing the facility as both a place of serious work (healing, treatment, euthanasia, etc.) and a place that is approachable and fun without being a spectacle in the landscape. 
Informed by the processes of work, site surroundings, and user scales, the excess can thus express program, context, and users beyond superficial and visual delight, provoking an understanding of architecture's place in the city. It begins to mitigate the effects of globalized and insular architectural spectacles that has plagued our contemporary cities. Yet if architecture is always shaped and informed by its cultural context, this thesis posits that we must learn to navigate and investigate within this very context. The landscape of consumer culture and conspicuous consumption has informed the nature of this study, and the thesis proposes that there is an appropriate balance between the mundane and the spectacle that is offered by using strategies of entertainment architecture to authentically express an architecture that is informed by its function, is sensitive to contextual conditions and history, and adequately addresses the scales of its users. 



\section{APPENDIX A}

Design Research. Iterations and Lessons Learned. 


\section{Introduction}

The initial stages of this thesis explored the realms of entertainment architecture that proposed to add additional meaning to entertainment architecture itself. It attempted to engage and infuse meaning to entertainment beyond the superficial façades. Working within the context of Toronto, the first design project looked at the potentials of converting Old City Hall into a shopping mall. The idea of commodifying history was briefly explored. The second design iteration explored the potential of connecting Toronto's underground PATH shopping system with the city above, establishing a connection between above ground street life and underground street life. The third design iteration looked at combining education and entertainment in the form of a theatre school on Yonge Street. The fourth design iteration explored the creation of a new typology of entertainment space informed by the digital gaming culture. 


\section{thestar.com}

\section{GTA}

News / GTA

\section{From Old City Hall to mall? Century-old Toronto building could undergo transformation}

The 116-year-old building, which currently houses provincial courthouses, was analyzed by Avison Young, a real estate brokerage firm.

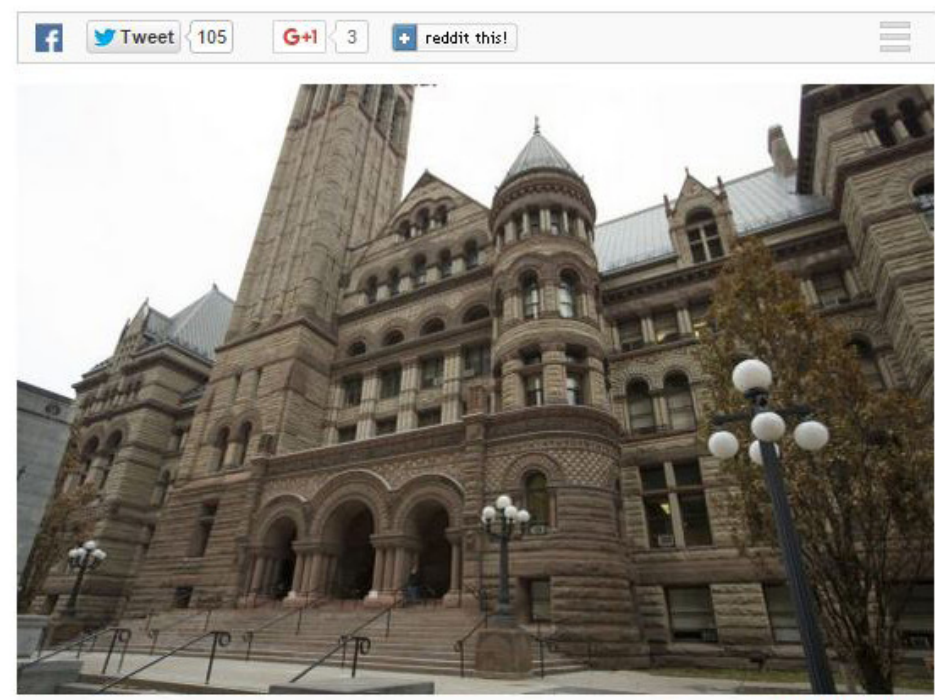

CHRIS SO/TORONTO STAR Order this photo Toronto's Old City Hall was declared a National Historic Site in 1989 and was also proposed as the location for a potential city of Toronto museum

By: Dan Taekema Staff Reporter, Published on Tue Sep 292015

Old City Hall could be transformed into a new city mall in as little as five years.

The city's Government Management Committee will consider a city staff report next Monday which recommends that "the highest and best use for Old City Hall would be conversion to a retail centre that contains a mix of food service, leisure, event and civic uses."

The 116-year-old building, which currently houses provincial courtrooms, was analyzed by Avison Young, a real estate brokerage firm, in order to propose tenant options after the courts leave by Dec. 31, 2021.

The firm snofested the cite wnuld he ideal for an "estahliched resnerted and

"... the highest and best use for Old City Hall would be conversion to a retail centre that contains a mix of food service, leisure, event and civic uses"

Figure 1: The Star Article as inspiration for design proposal. Taekema, Dan. TheStar.com. Sept 29 2015. Retreived Oct 2 2015. https://www.thestar.com/news/ gta/2015/09/29/torontos-old-city-hall-could-become-a-mall.html 
Working within the context of Toronto, the first design project looked at the potentials of converting Old City Hall into a shopping mall. The idea of commodifying history was briefly explored. The inevitability of entertainment and retail infiltrating historic landmarks was an interesting but controversial topic. However, since the focus of the thesis is not in adaptive reuse or conversion of old landmarks, this option was not pursued beyond initial site and program analysis.

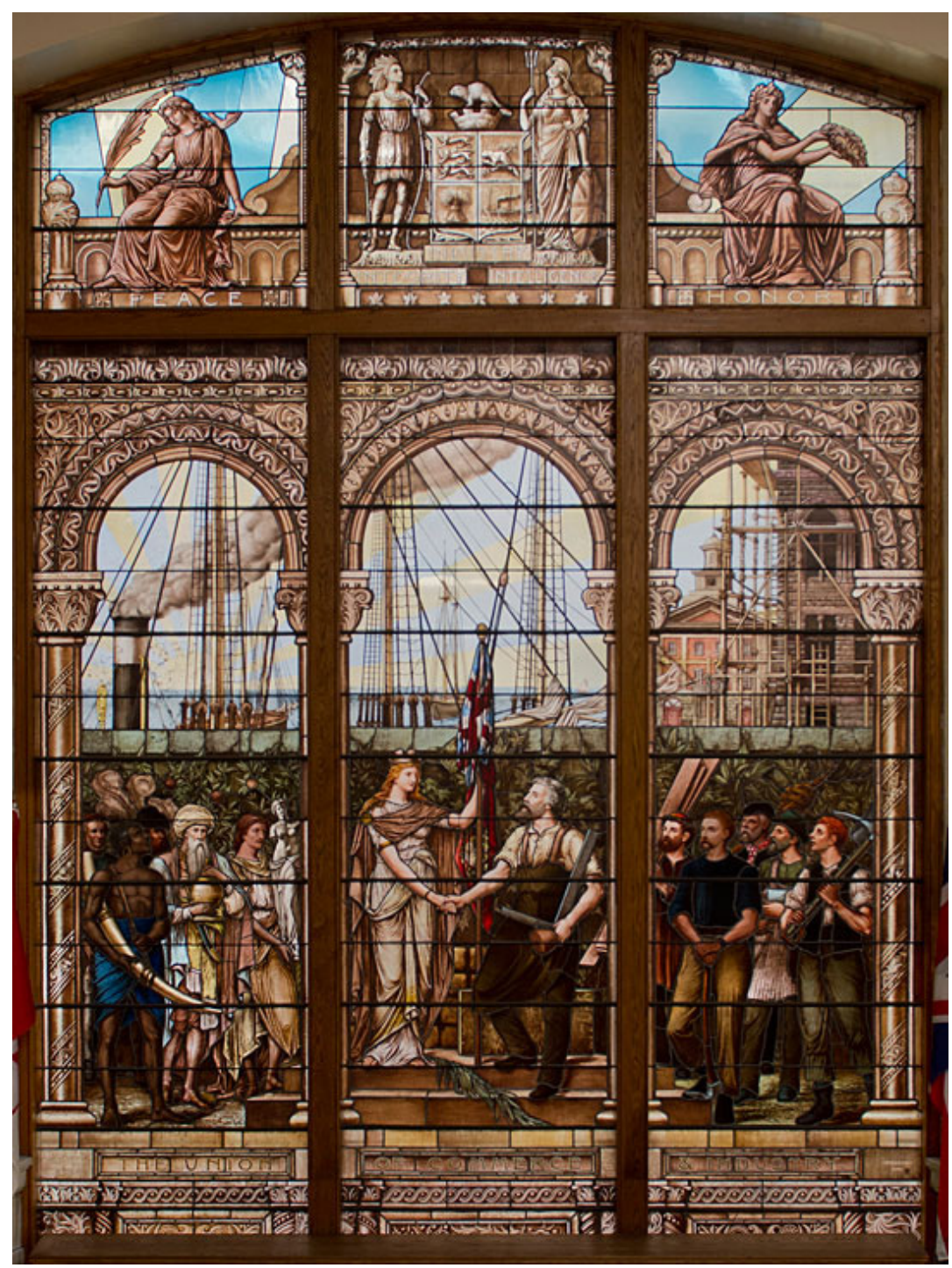

Figure 2: Stained Glass Art inside Old City Hall: "The Union of Commerce and Industry" https://c1.staticflickr.com/4/3784/14274743304_5e3bb90689.jpg 
The second design iteration explored the potential of connecting Toronto's underground PATH shopping system with the city above, establishing a connection between above ground street life and underground street life. It attempted to express and accentuate the transition between the two very different conditions: corporate blandness above ground and entertainment and retail below grade, attempting to create a more meaningful dialogue between the two. However, the non-site-specific design imposed a foreign form that was not an adequate mediator between the two, and was in fact a spectacle that exaggerated an entrance.

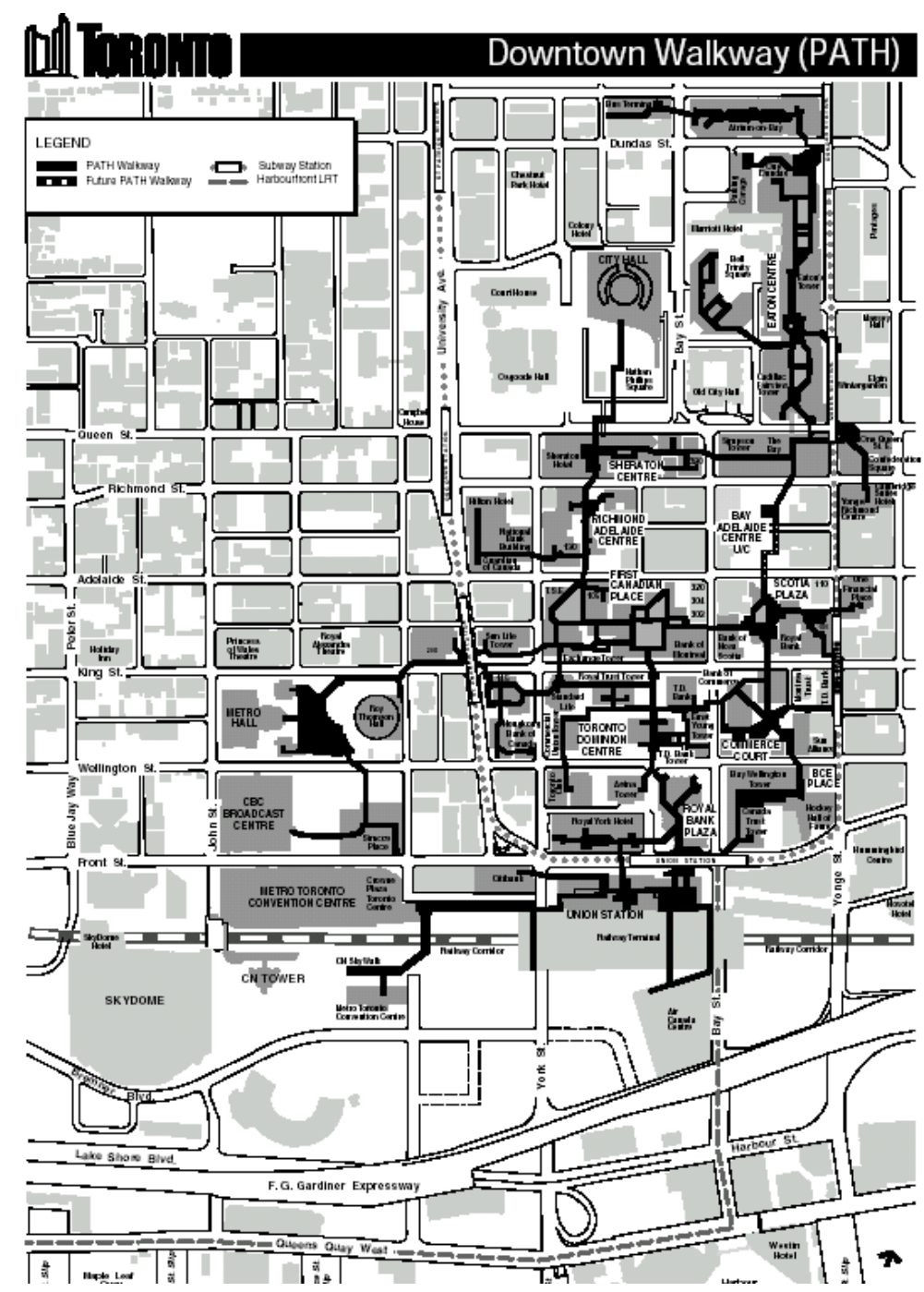

Figure 1: Map of PATH System

http://toronto.ontariotenants.ca/path-map.gif 


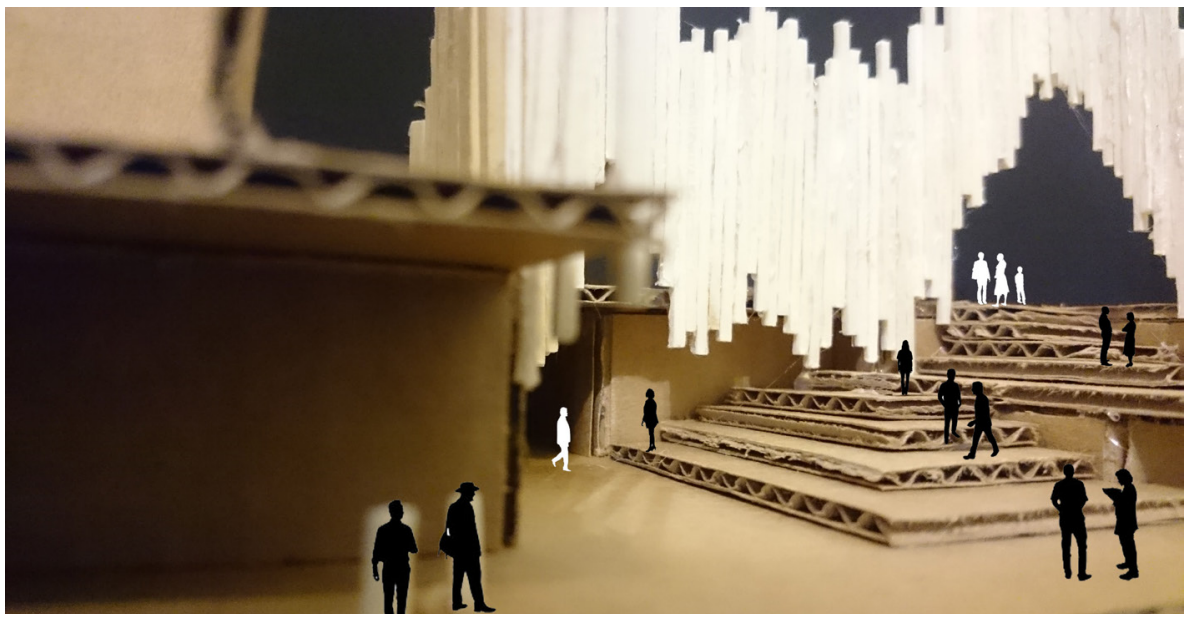

Figure 2: Creating a meaningful transition from PATH to city

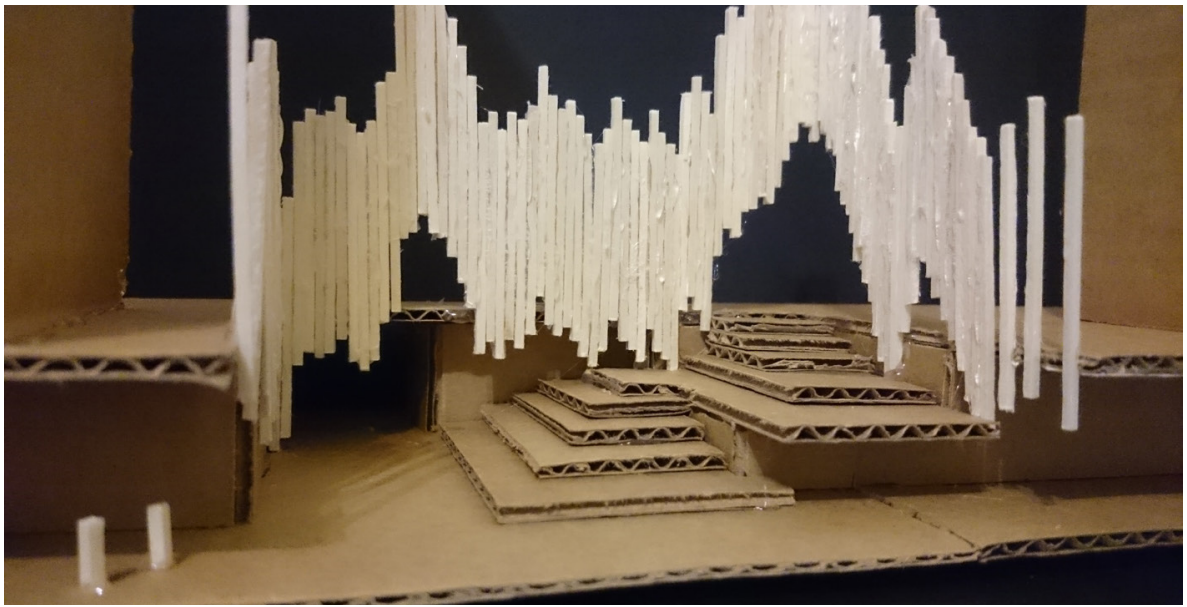

Figure 3: Transition from underground to aboveground

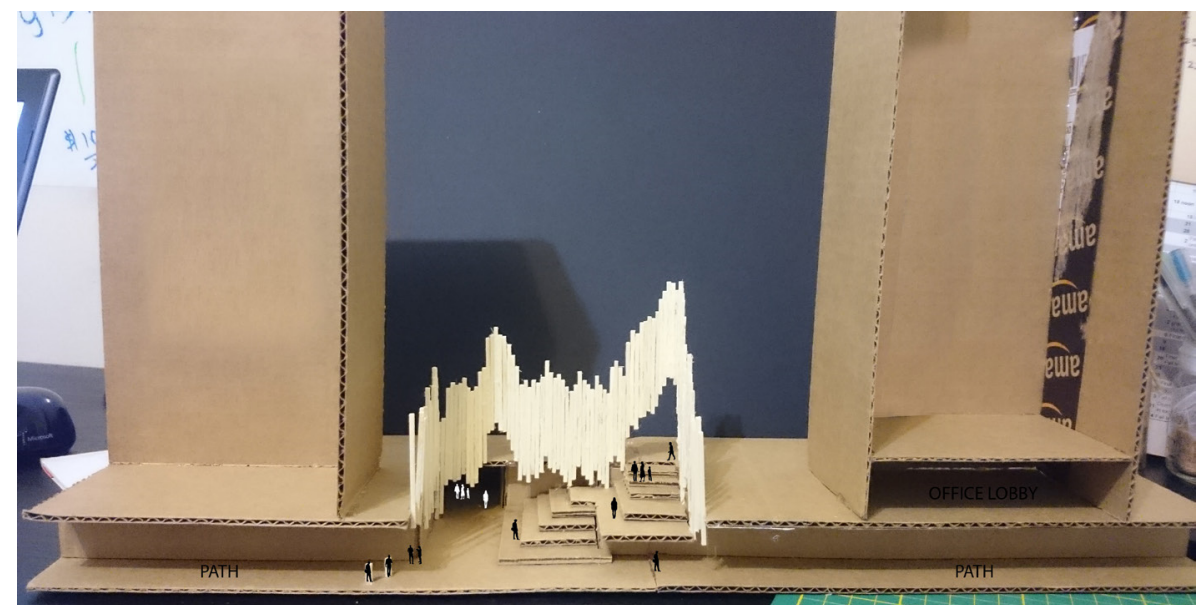

Figure 4: Section through entrance 
The third design iteration looked at combining education and entertainment in the form of a theatre school on Yonge Street. Yonge Street has historically been Toronto's main street for leisure and entertainment, with its numerous restaurants, theatres and retail shops along its length. This particular site was chosen for its proximity to historically significant entertainment venues: the Elgin and Winter Garden Theatre and Massey Hall. It is also directly across from the Eaton Center. An institutional typology was chosen to integrate learning and entertainment together in one space by exposing and expressing the story of a theatre school. However, the complexity of the program became problematic and difficult to navigate and understand each of its components as it relates to the thesis.

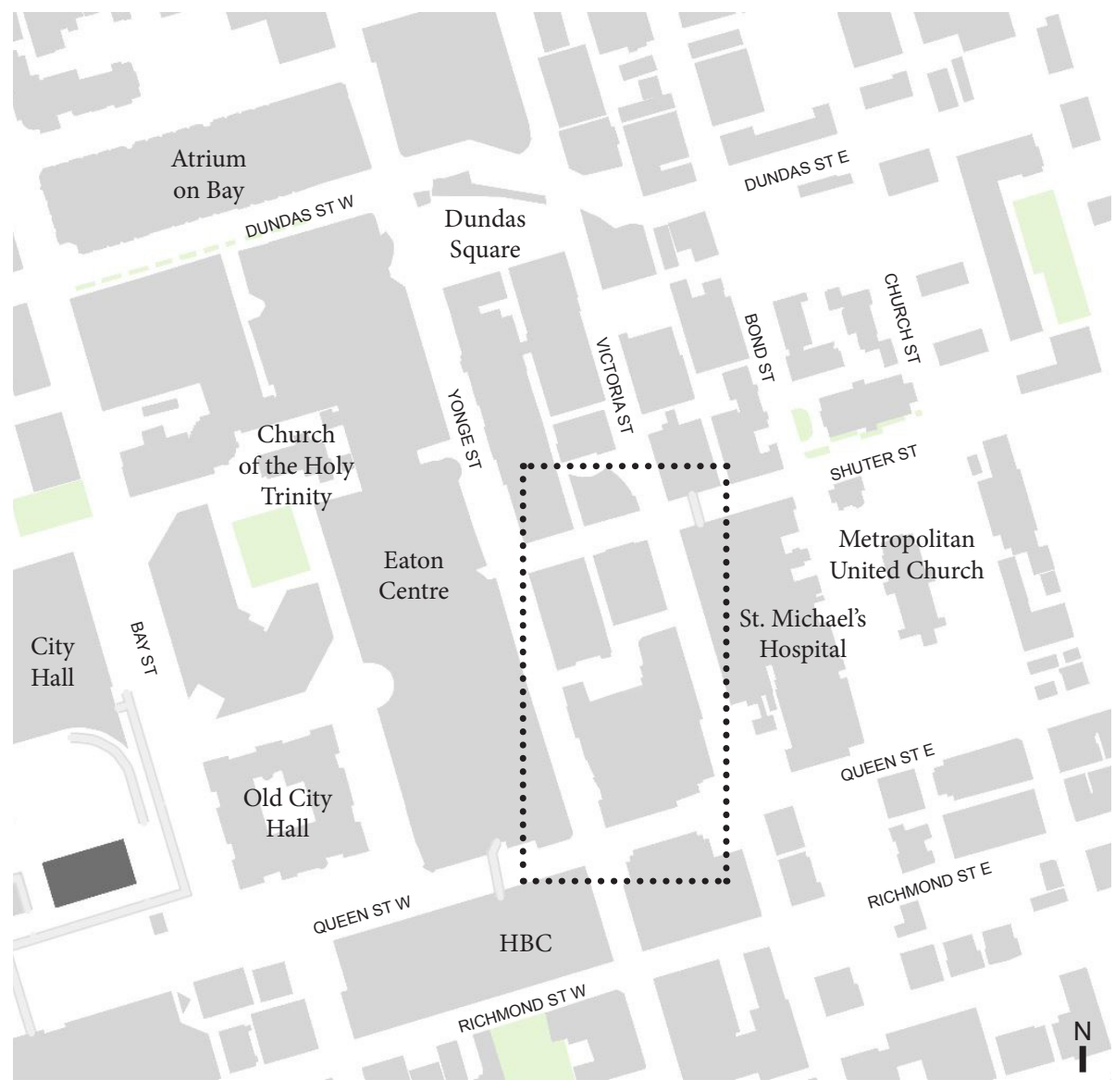

Figure 1: Context Plan.

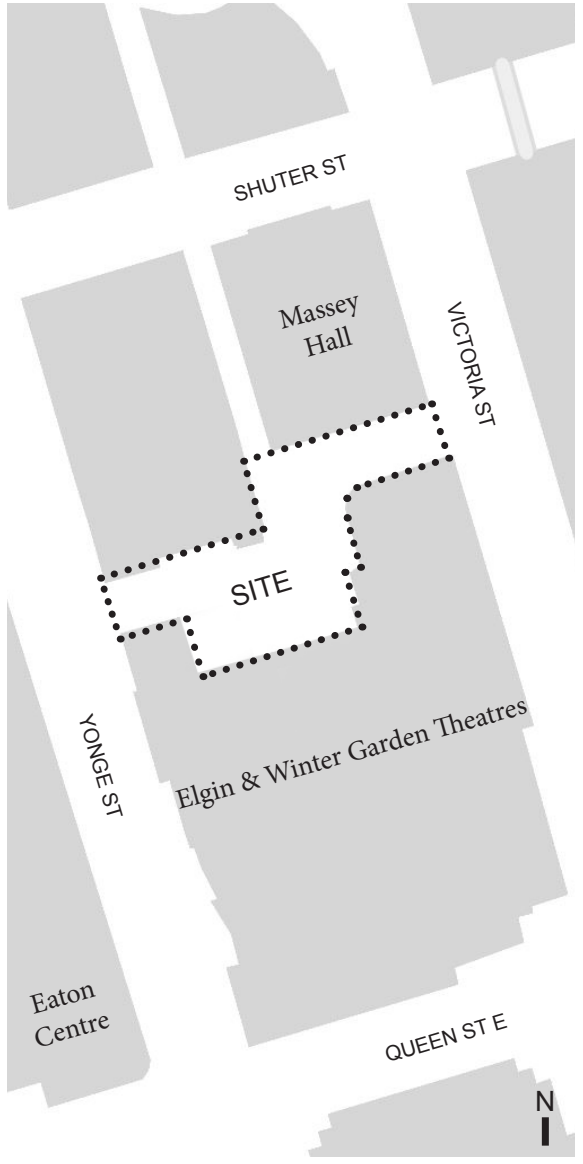

Figure 2: Project Site 
Design Iteration 3 - Theatre School on Yonge Street
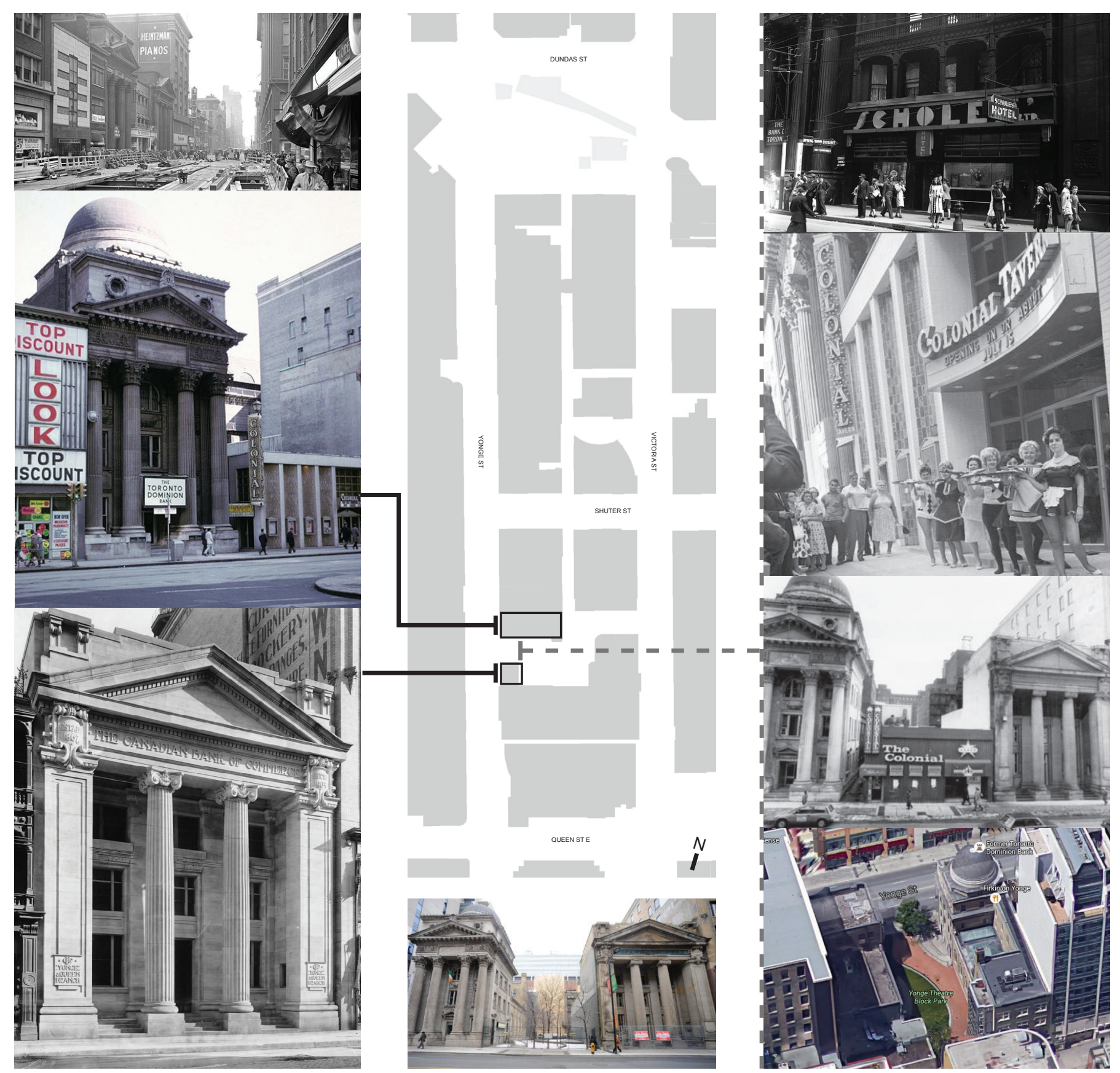

Figure 3: Context Buildings 
Design Iteration 3 - Theatre School on Yonge Street

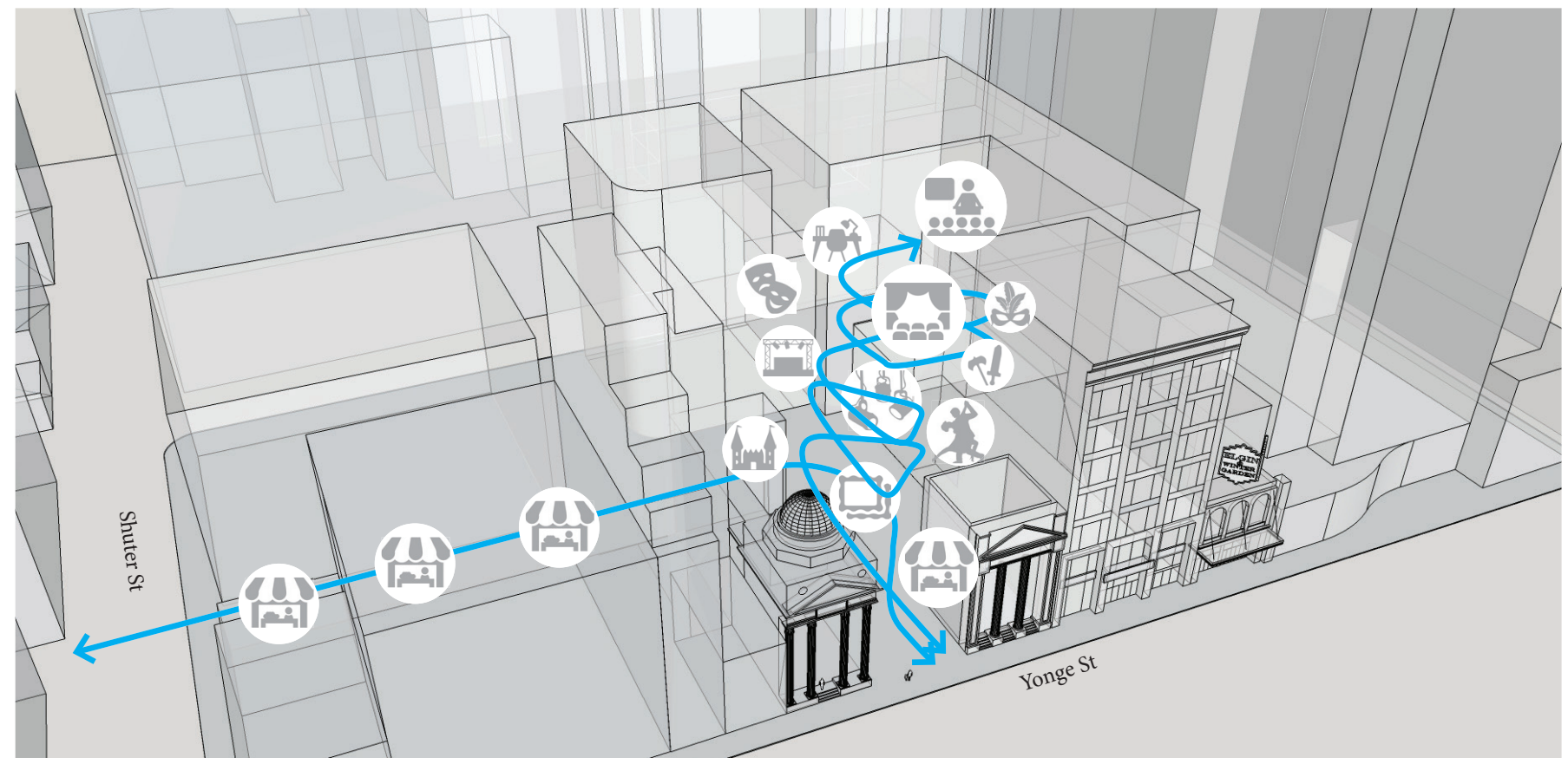

Figure 4: Circulation Studies

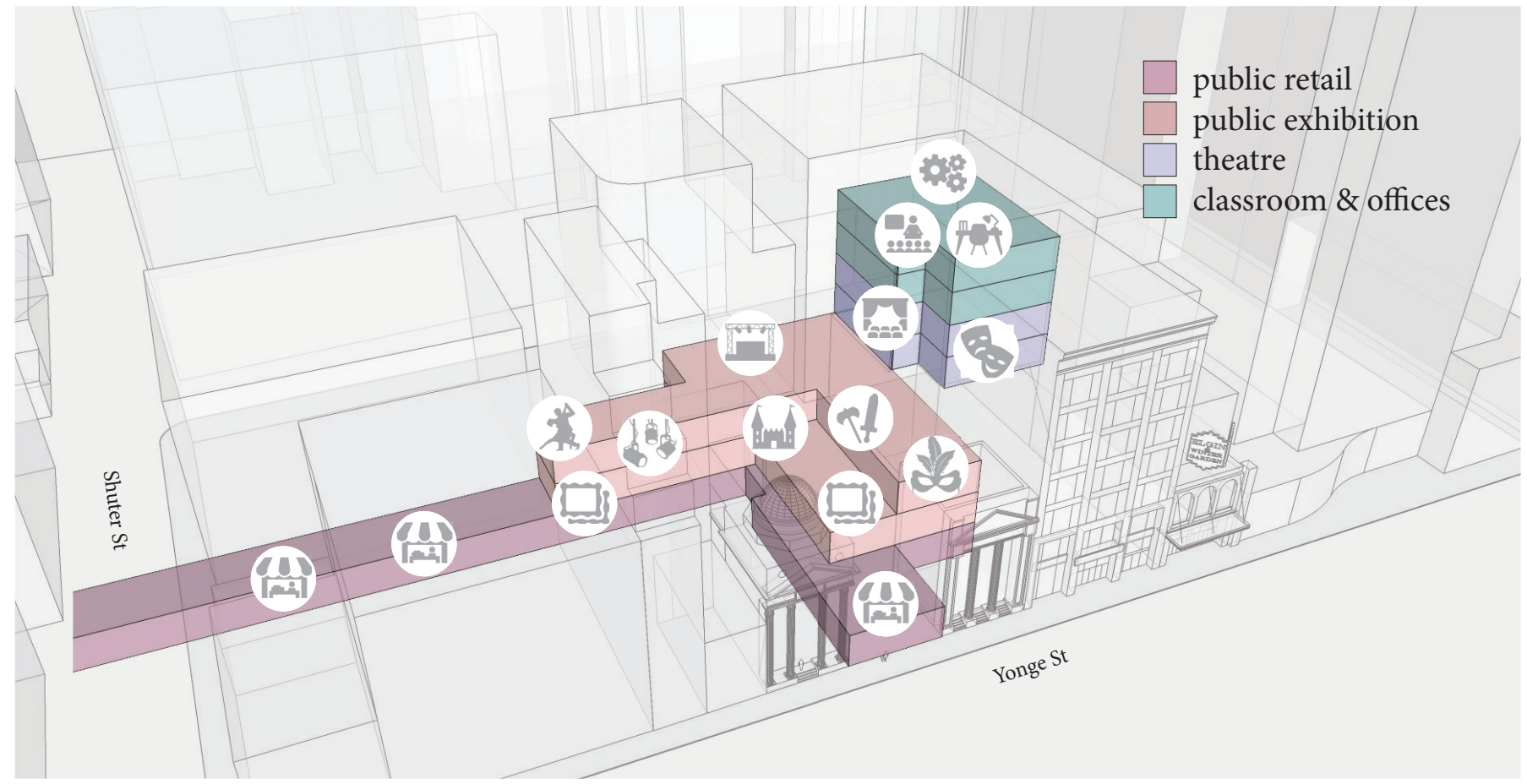

Figure 5: Program Distribution 

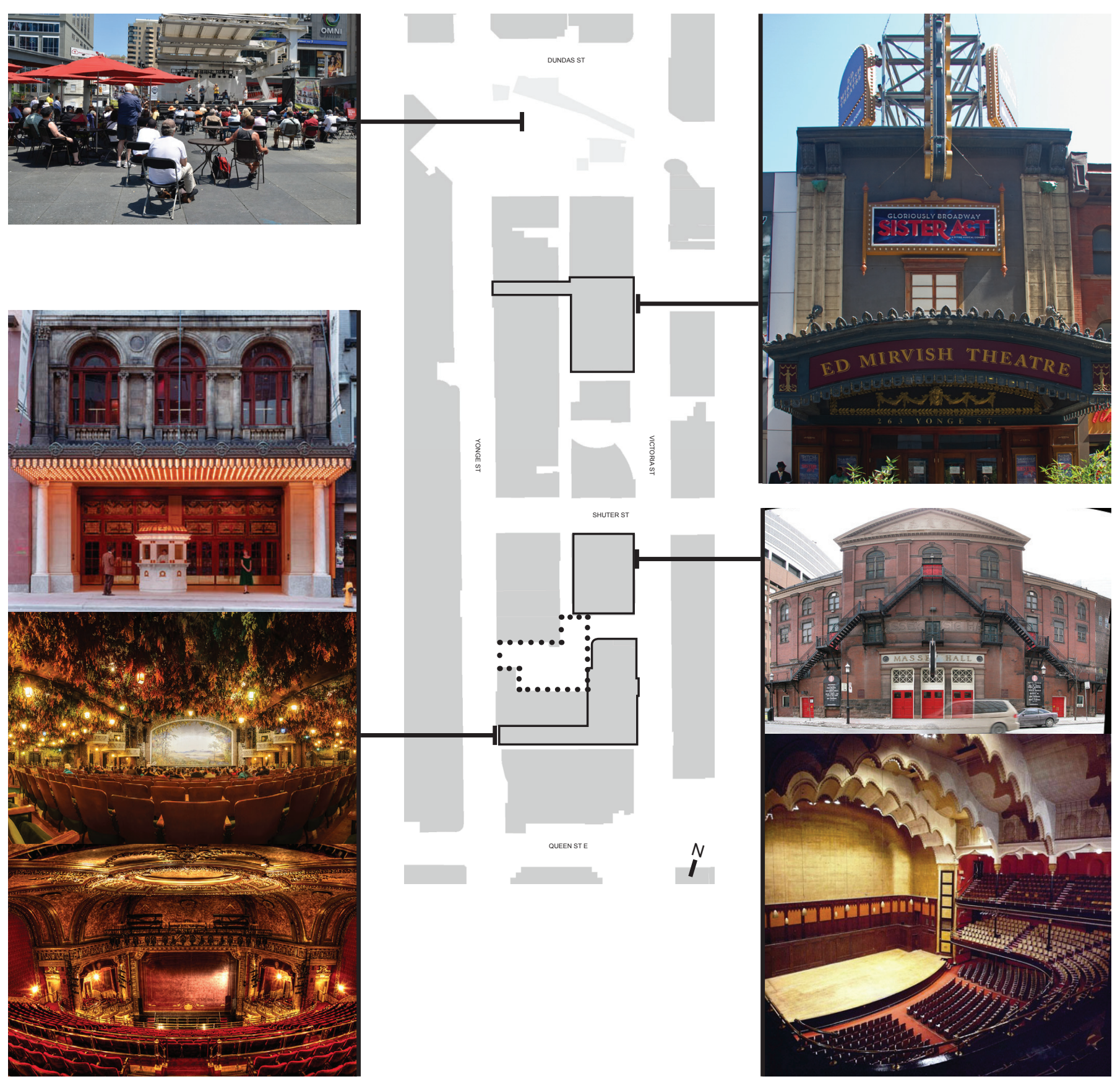

Figure 6: Contextual relationship with other theatres 
The fourth design explored the creation of a new typology of entertainment space informed by the digital gaming culture. As a new form of entertainment and a means to bridge digital and physical space, the typology was an interesting attempt to navigate between the digital and physical. As video gaming begins to become a dominant form of entertainment in our digital age, its identity and expression is still ambiguous and foreign. The design, then, attempted to establish meaning and identity for this particular entertainment typology by exposing its inner workings to the public. However, the thesis began to deviate from addressing the issues established in Chapter 1 and attempted to resolve the connection between the digital and physical realms. It was acknowledged that entertainment typologies actually must rely on the spectacle as a means of expression. It is thus appropriate for an eSports Event Center to be ostentatious to attract attention.
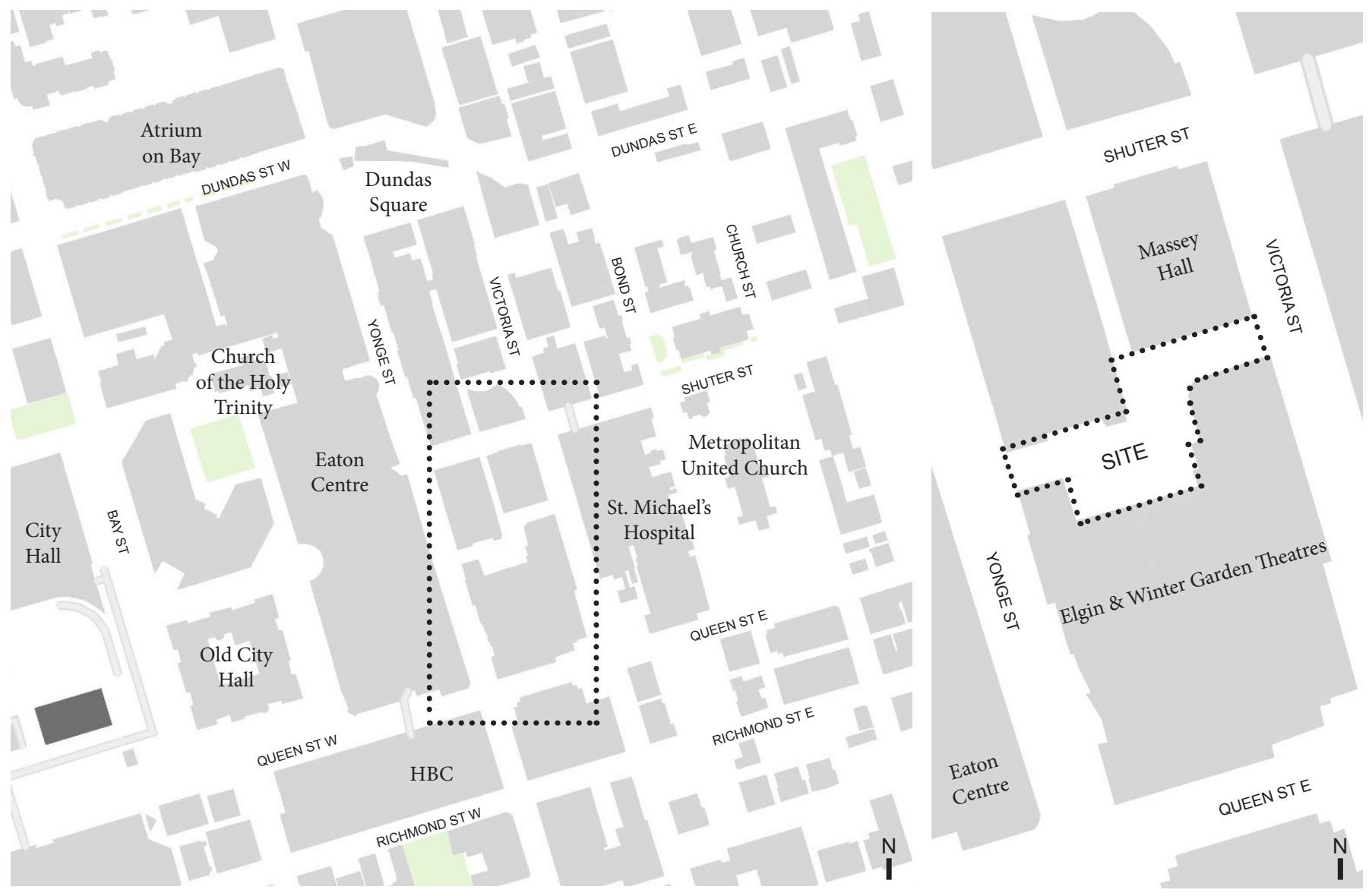

Figure 1: Context Plan

Figure 2: Project Site 
program
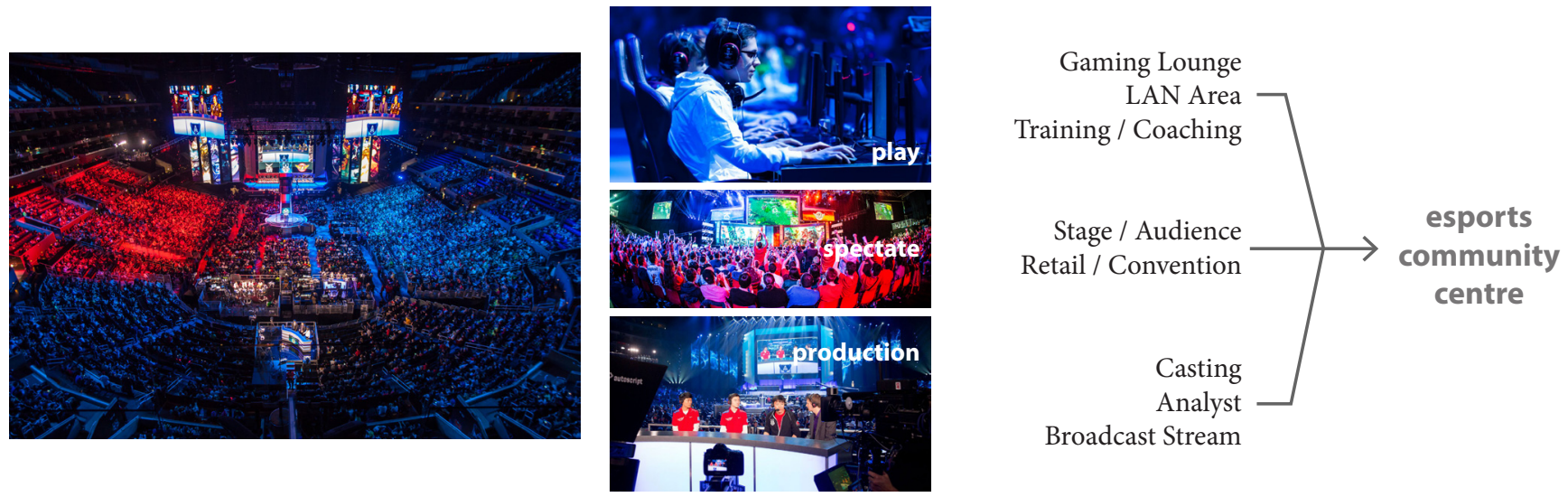

Figure 3: New age of digital entertainment: video gaming spectacle (esports)

production of the spectacle

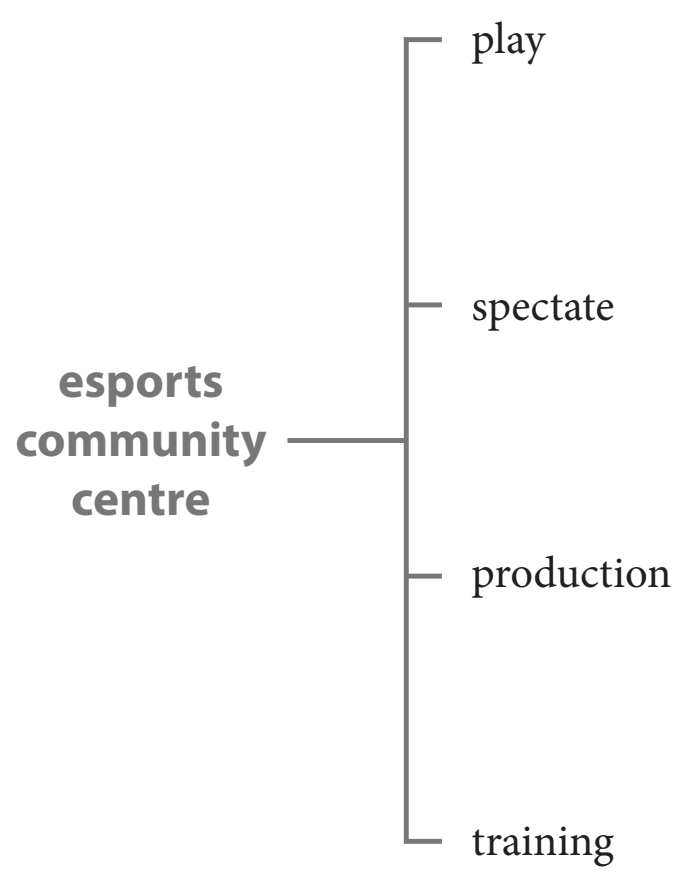

Figure 4: Production behind the entertainment and spectacle gaming lounge

LAN area

console area

audience space screens/projectors retail

exhibitors

stage

analysts

casters

broadcast/stream

training space

coaching

meeting rooms 


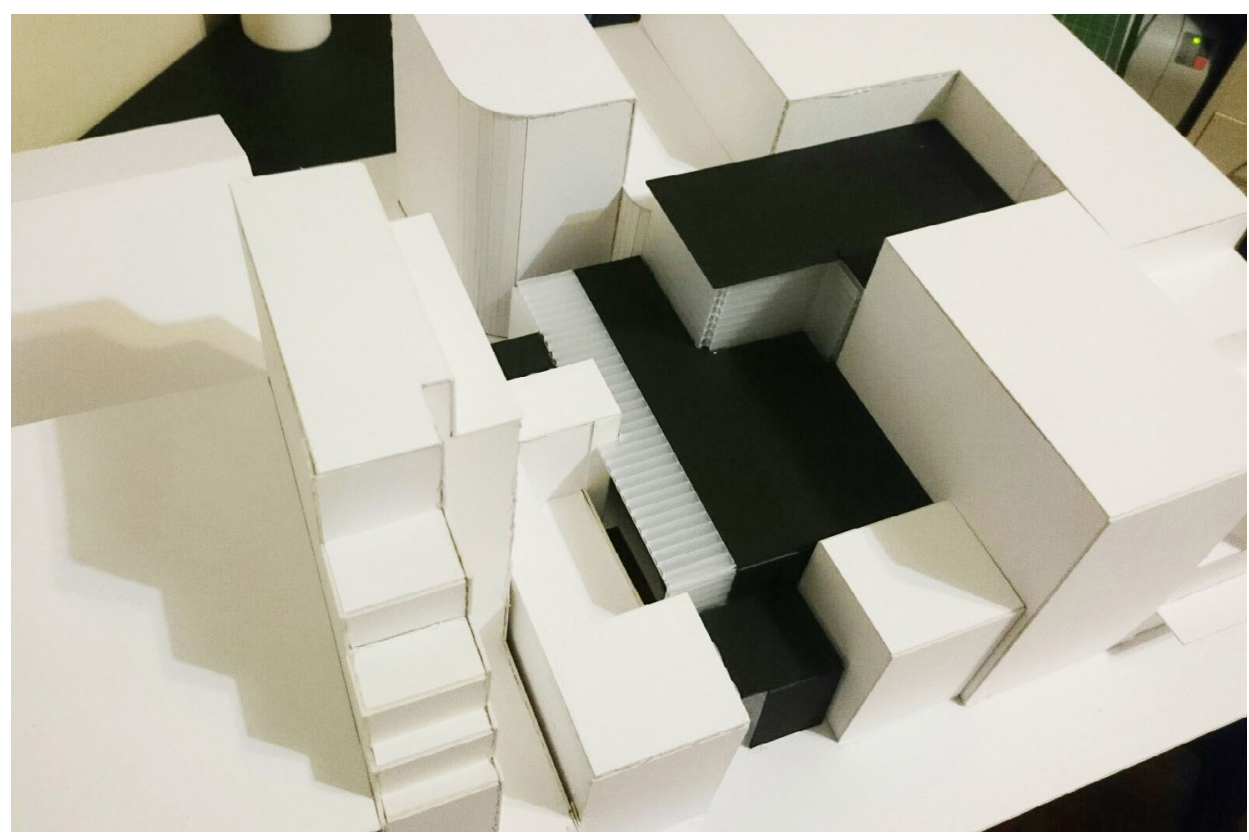

Figure 5: Massing Study 1

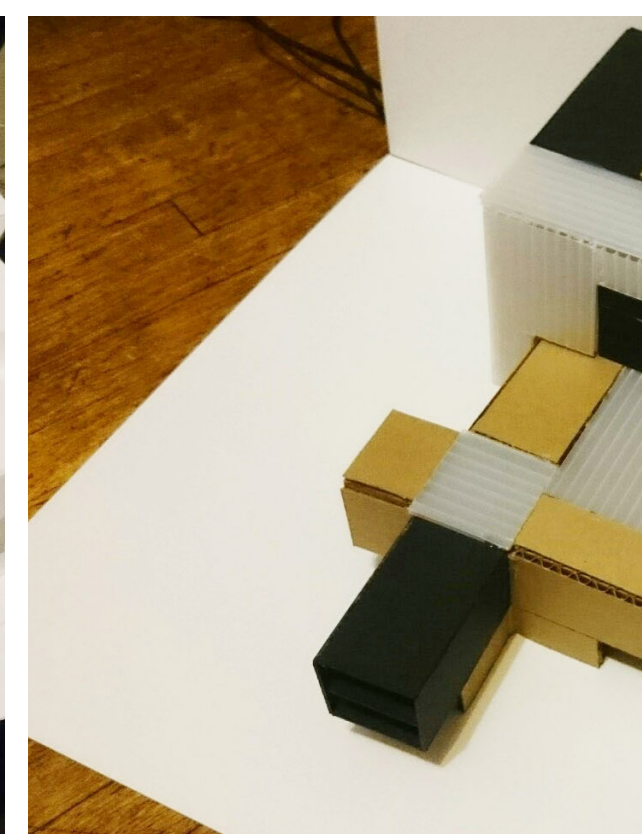

Figure 6: Massing Study 2 
Design Iteration 4 - Esports Event Center
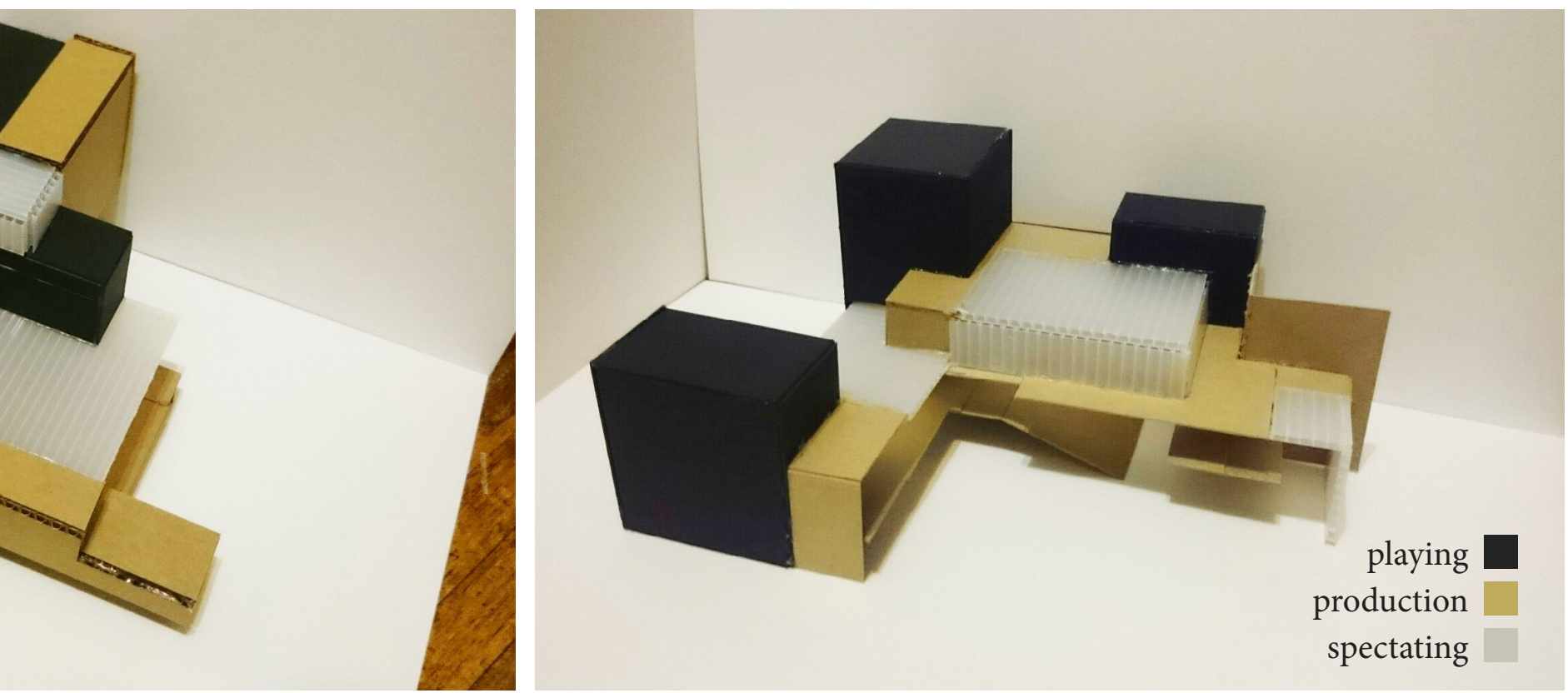

Figure 7: Massing Study 3 


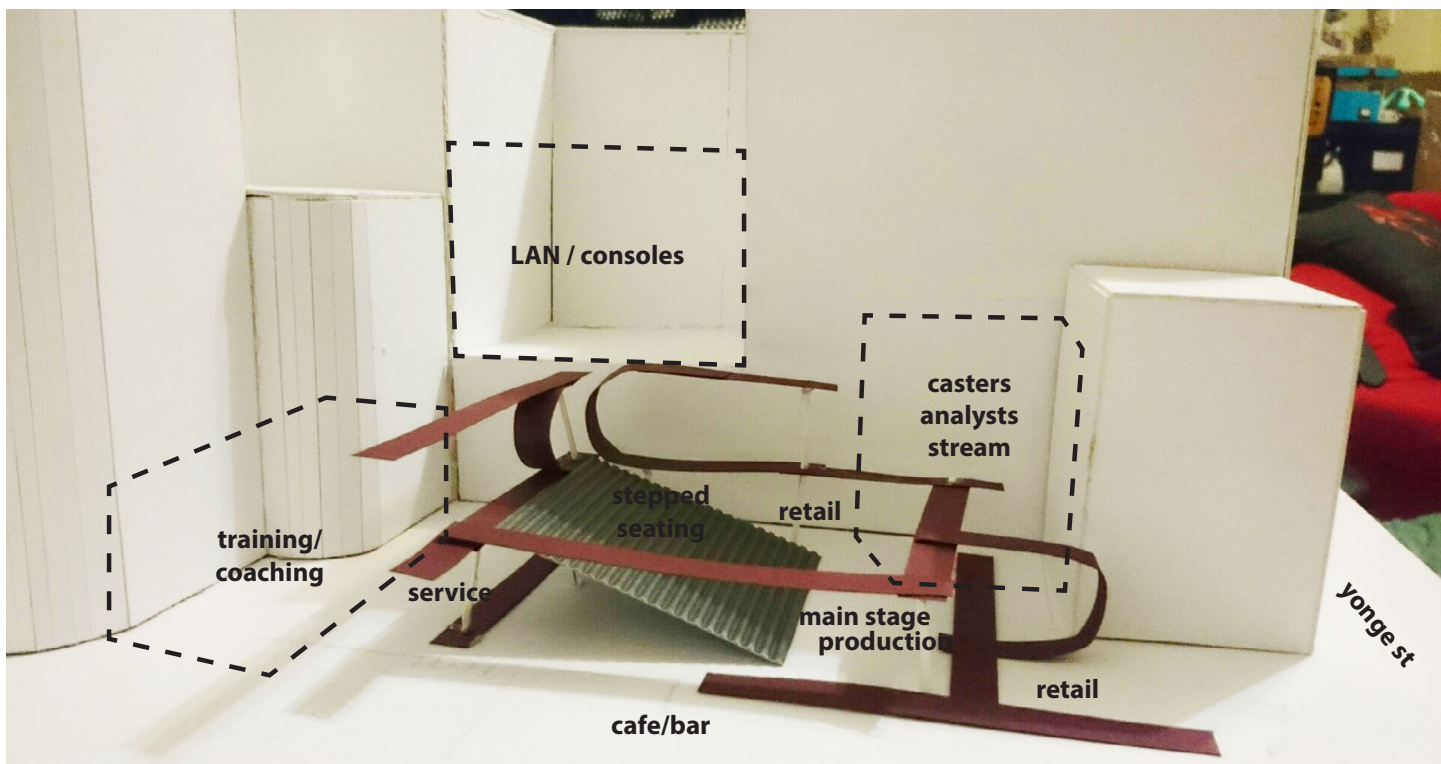

Figure 8: Circulation Study

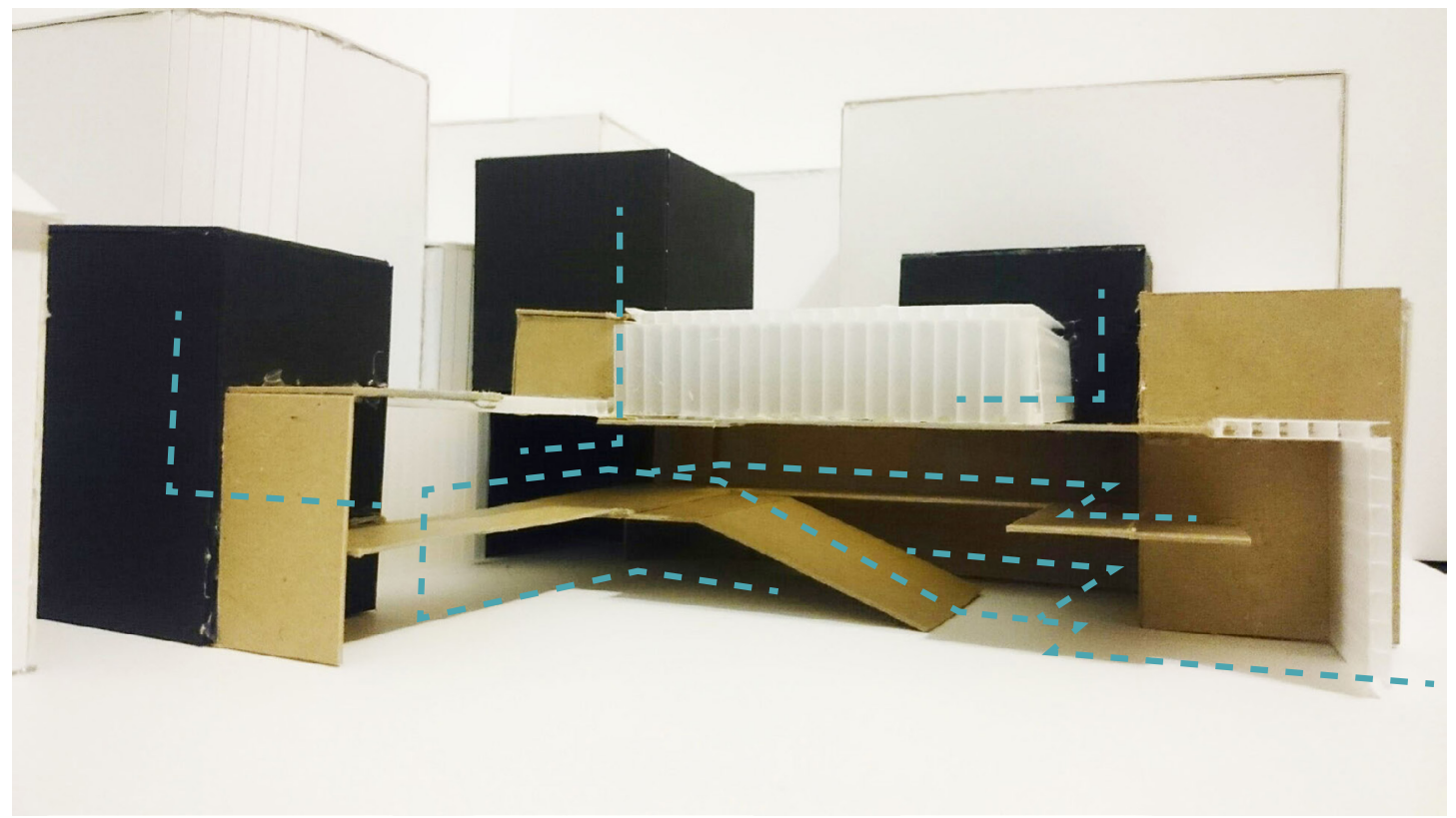

Figure 9: Circulation Study 2 


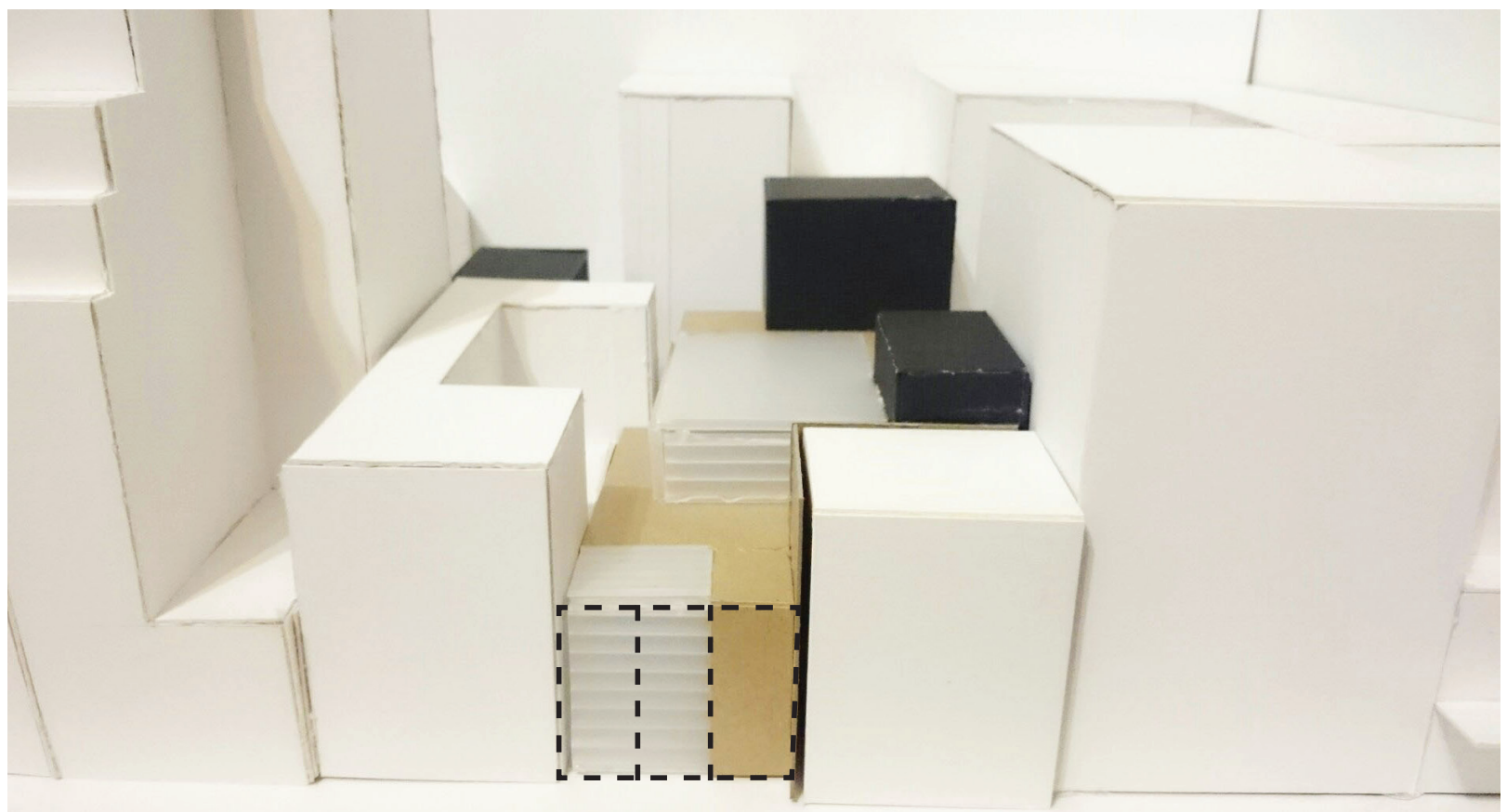

Figure 10: Yonge Street facade rhythm

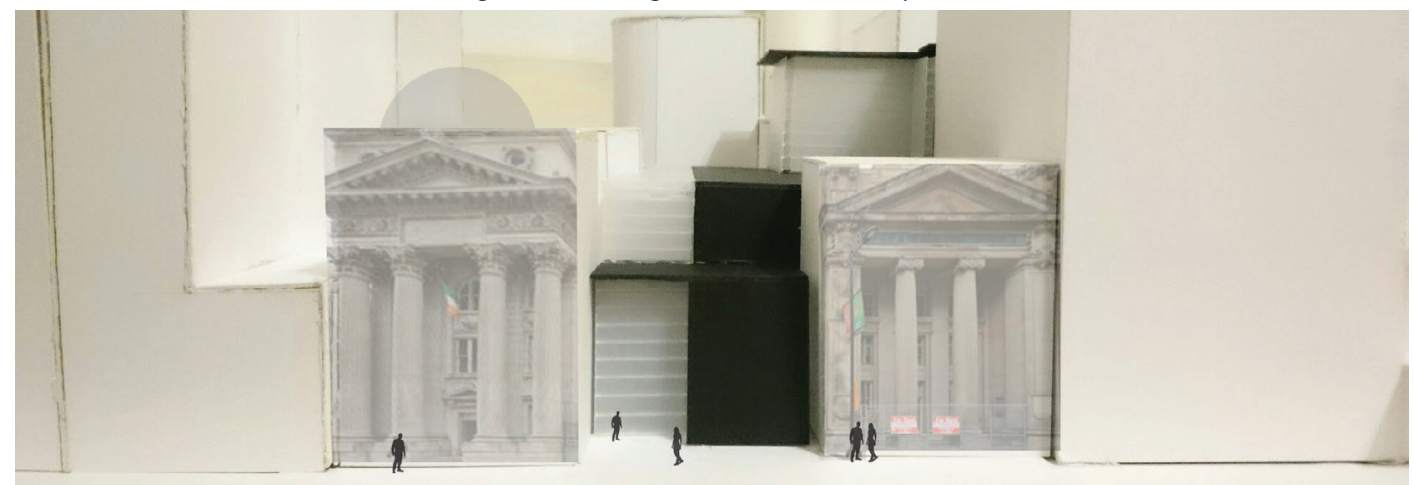

Figure 11: Yonge Street elevation

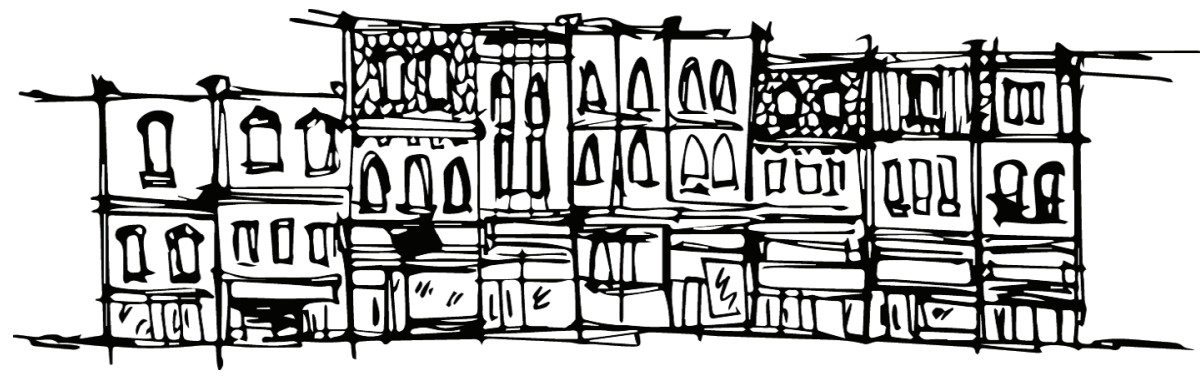

Figure 12: Sketch of Yonge Street scale and rhythm 


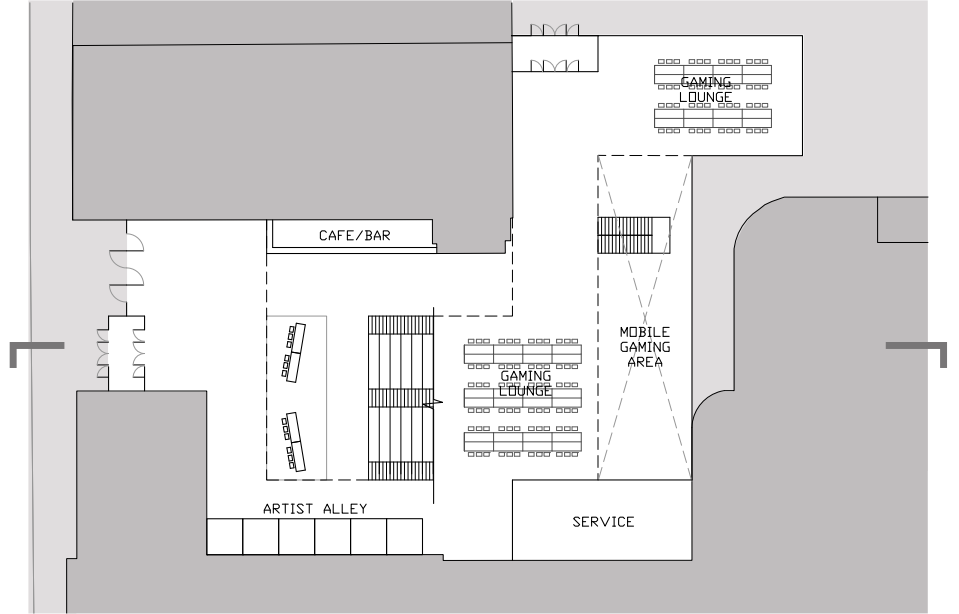

i

Figure 13: Ground Floor Plan - Public Spectacle

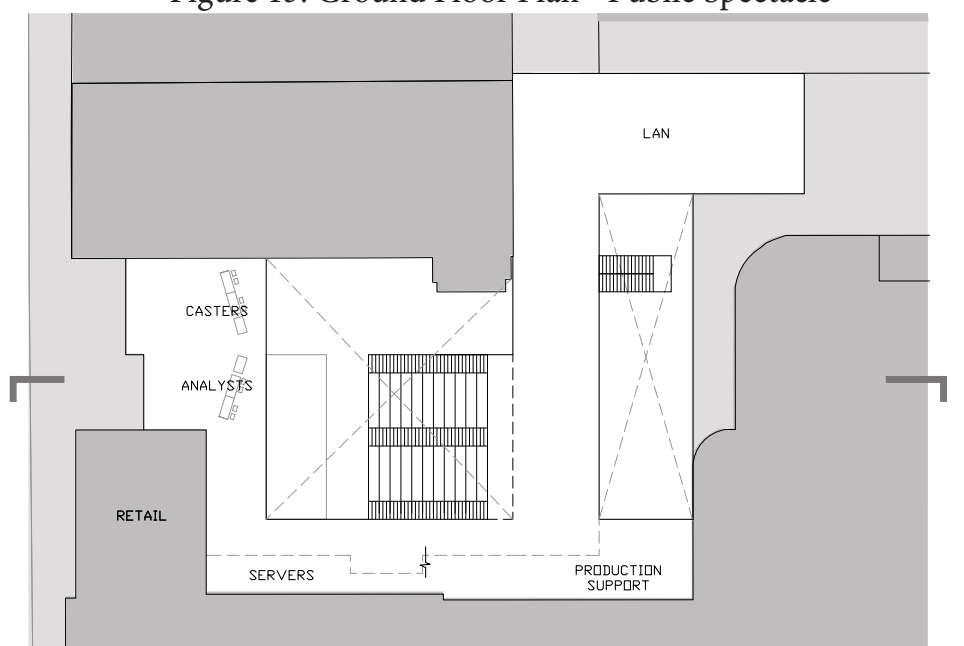

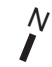

Figure 14: 2nd Floor Plan - Production of the Spectacle

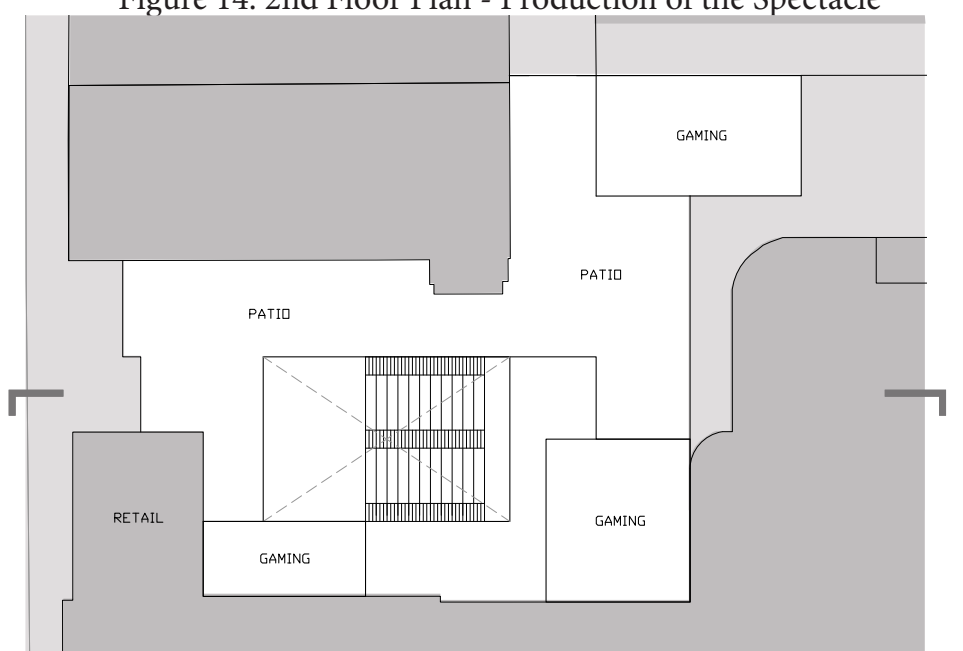

Figure 15: 3rd Floor Plan - Intersection of Gaming ccxl 


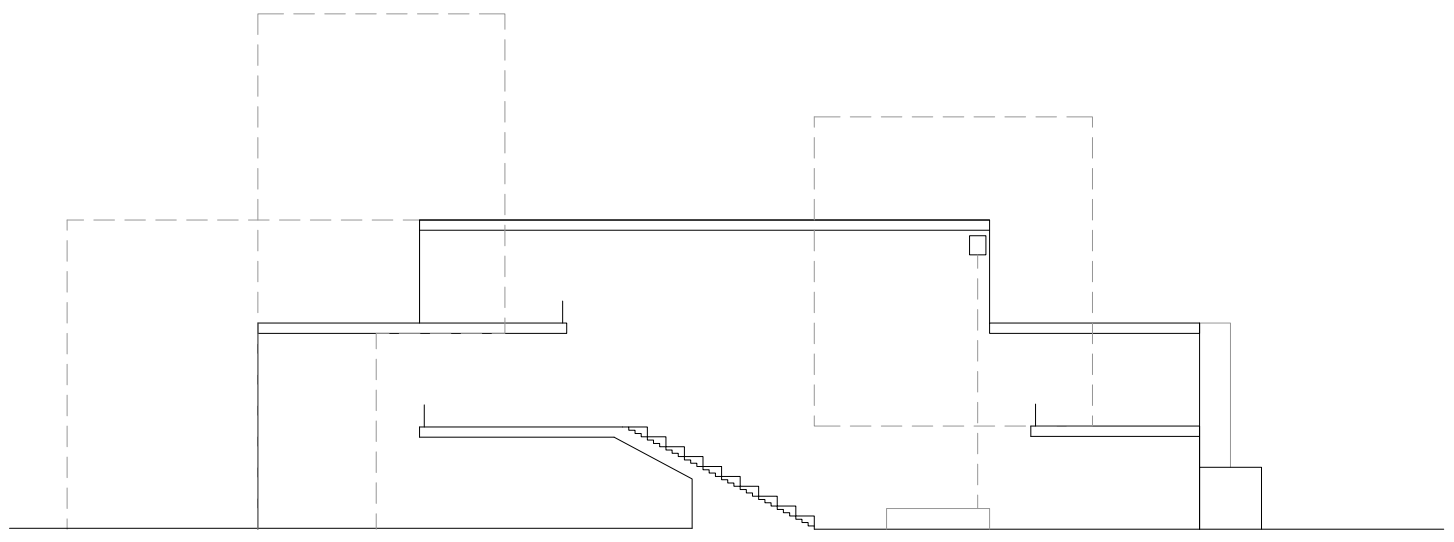

Figure 16: Section looking south

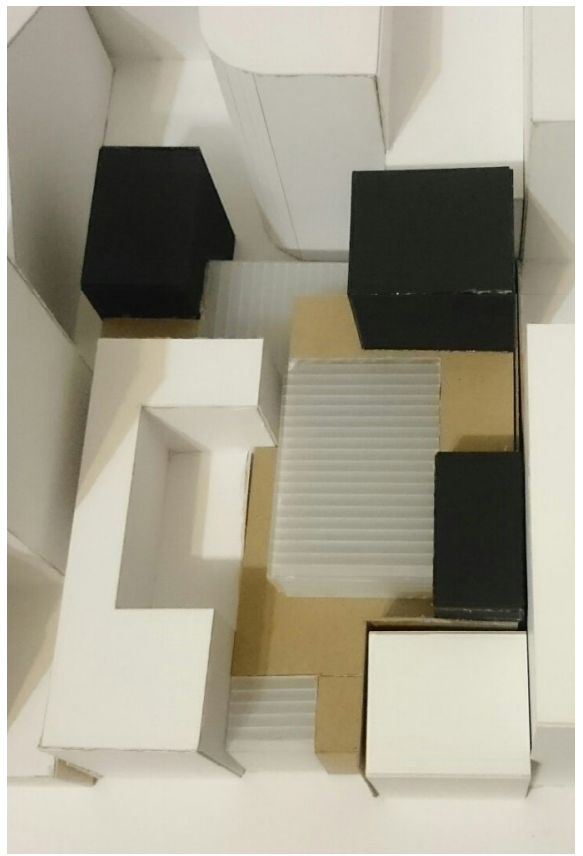

Figure 17: Sketch Model

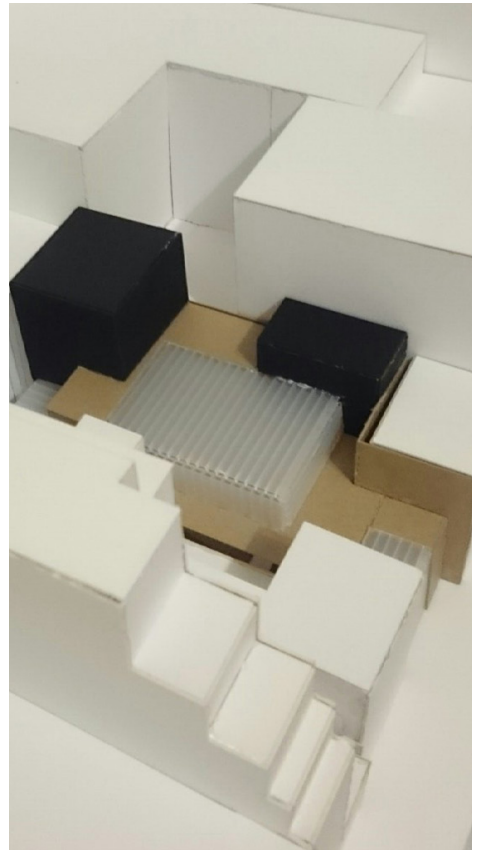

Figure 18: Sketch Model

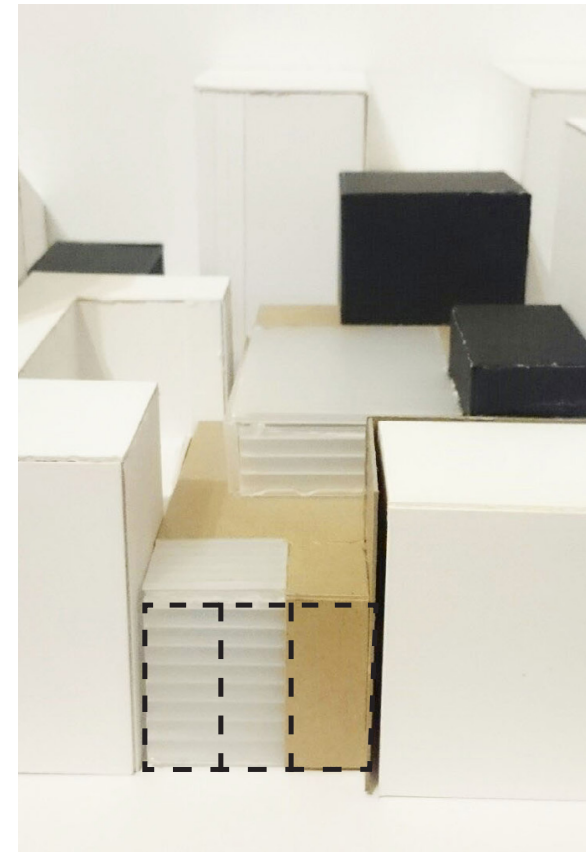

Figure 19: Sketch Model - Yonge Street 
ccxlii 


\section{Conclusion}

To summarize, entertainment typologies were initially used as a basis for design, but issues of appropriateness and the inevitability of superficiality emerged from the studies. As buildings for entertainment, its architecture inevitably tends toward the superficial, aiming to excite and capture the attention of its users. These explorations, however, were useful in understanding how to navigate the fine line between superficial expressions and subverted meaning. It was found that superficiality was in fact an appropriate response to entertainment typologies.

As such, the final exploration moved away from a reliance on entertainment as a typology and looked at civic relevance in the context of the Experience Economy. Non-cultural and non-entertaining, but civically relevant typologies were examined, using architecture as a catalyst to rebrand certain stereotypes associated with public service facilities. Using the animal shelter as a site for exploration, this thesis presents a design that uses architecture to enhance and benefit the image of the facility. 



\section{APPENDIX B}

History and Relevance of the Don River and Valley 


\section{Introduction}

The Don Valley can be interpreted as Toronto's backyard, a landscape for recreation and leisure in the centre of the city. However, the Don Valley and River were not always seen as recreational landscapes. We still experience the repercussions of heavy industrial use along lengths of the river, while rail and vehicular infrastructure constantly remind us of the impact of industrialization on the landscape. Yet, the neglect and pollution of the Don has been integral to the growth of the city, allowing Toronto to become the city it is today.

\section{Past Initiatives}

1800-40 - Establishing Toronto close to the Don, protected by Toronto Harbour, John Graves Simcoe envisioned the Don Valley and river system as a retreat and provider of natural resources. Lands by the river were set apart as government park reserve and country estates. Government houses were planned at the river mouth, while industries (lumber, clay, mills, salmon and trout fishing) took advantage of the natural resources and river flow to set up operations.

1850-80s - As industrialization became the established economy of the new city, exploitation and pollution of the Valley's resources rendered it an undesirable landscape for agriculture and recreation. The Ashbridges marsh at mouth of river became a breeder of diseases and the city expanded westward instead, abandoning its Government retreat plans. The Don River then became the official eastern margin of the city, dividing the city east-west. Cheap lands around the Don attracted unsightly industries (loud, dirty, odours, and toxic industries) to use the river as a waste disposal method, pushing these industries out of sight out of mind. This marginality attracted the city's institutions (hospital, jail, and asylum: essentially those in need of mental and physical rehabilitation) to the valley as well, since rural lands were seen as wild and restorative forces. The Don Valley then became an urban fringe both physically and socially. At the same time, however, it was seen as an acceptable price to pay for prosperity and habitability of the rest of the city. 


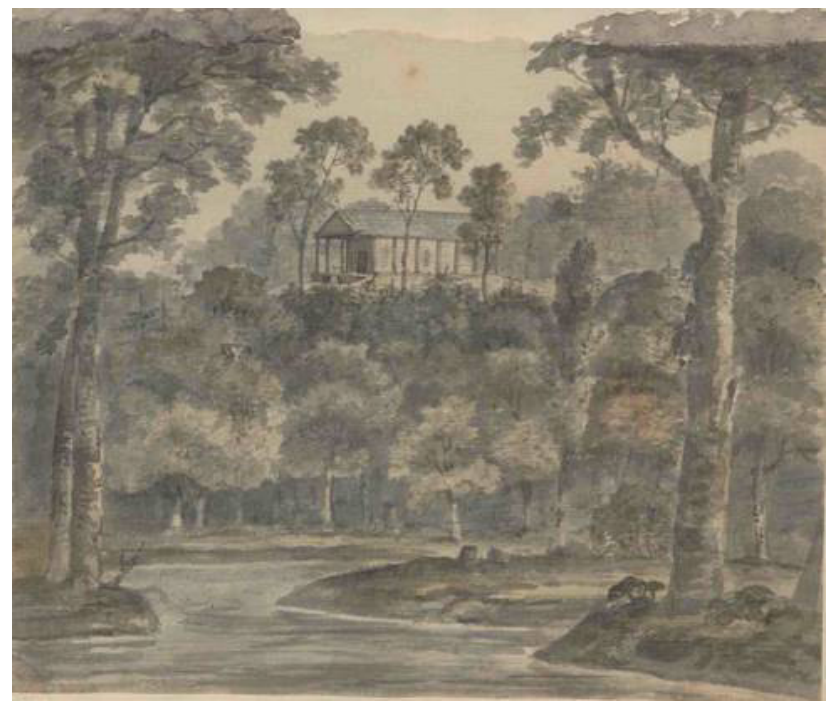

Figure 1: Castle Frank 1796

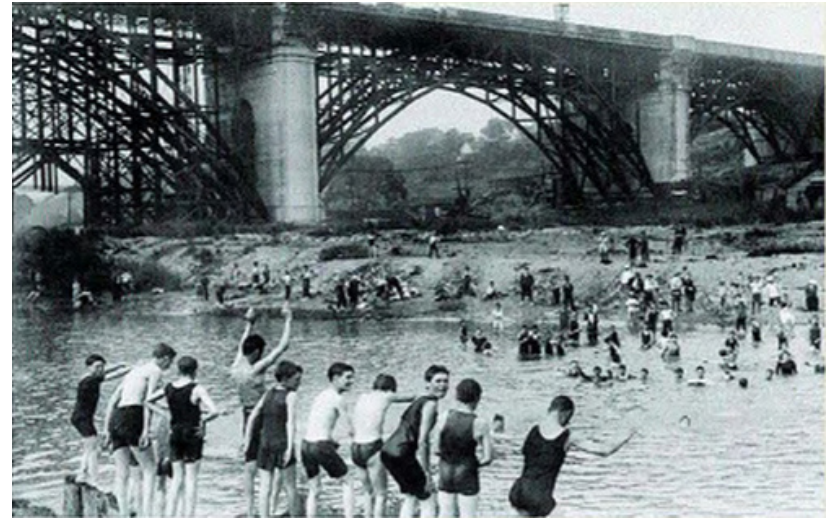

Figure 2: Recreation in the Don River 1920s

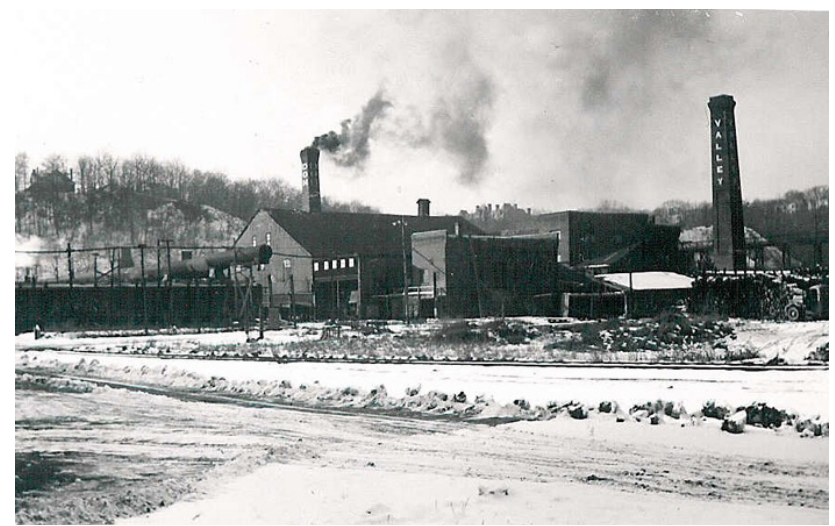

Figure 3: Don Valley Brickworks 1800s 


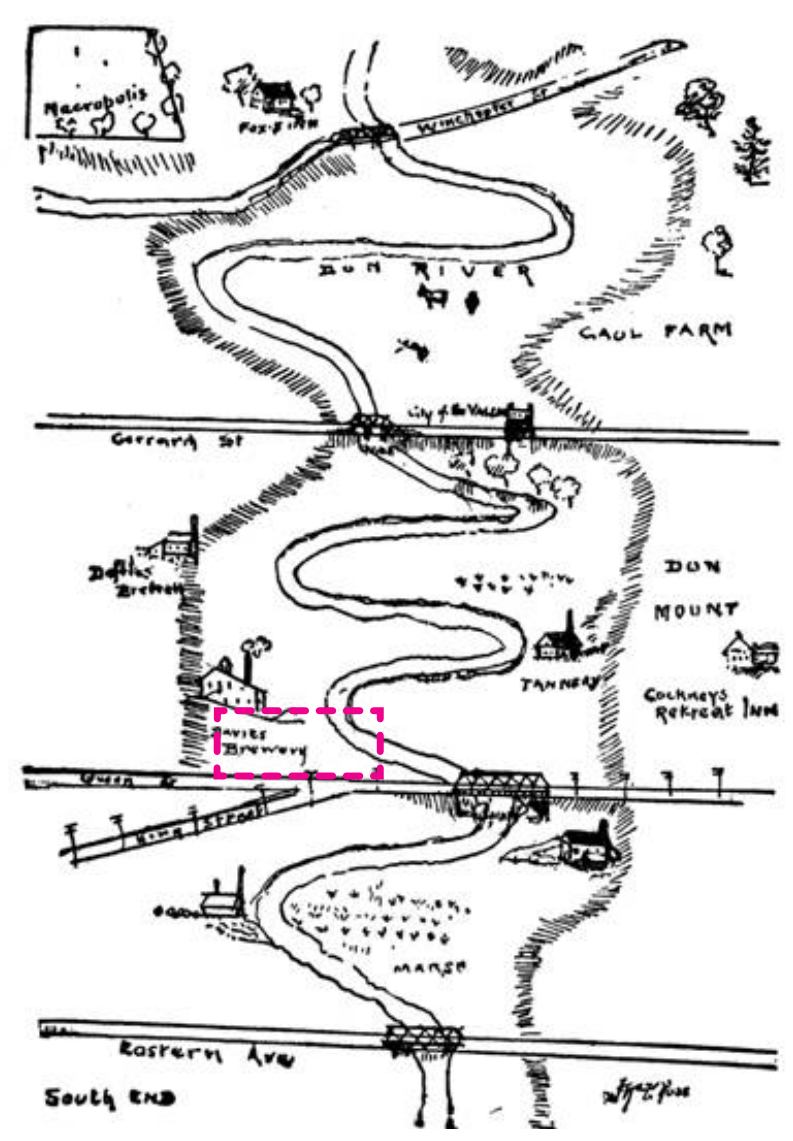

Figure 4: Historical Drawing of Don River and Area

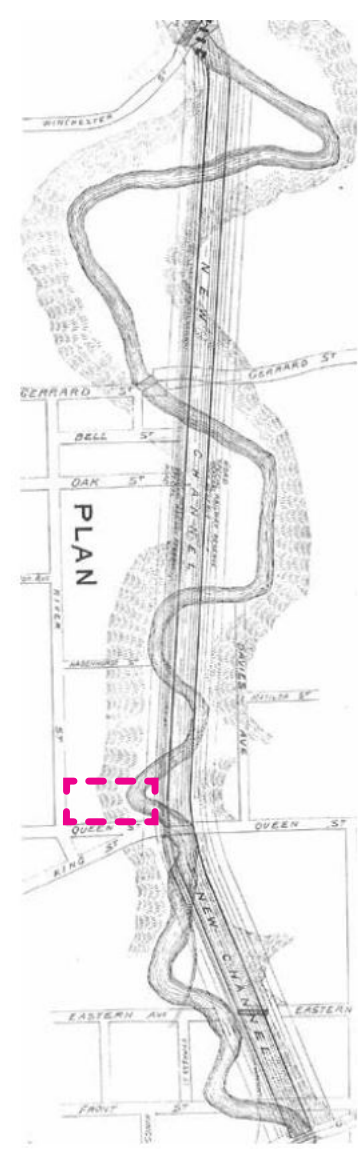

Figure 5: Don River Straightening Plan, 1886.

1886 - Fed up with diseases, pollution, and constant flooding, the "Don Improvement Project" of the 1880s straightened the Don River south of Winchester Street, attempting to "improve" sanitary conditions, allow ship access, and fill lands for more industrial use. This initiative also saw the introduction of a railway corridor along the valley floor, allowing more industrial development in the area. Prior to the Don Improvement Project in the 1880s, the river actually meandered through the THS site, where the former Davie's Brewery used to run their operations. The Davies family also ran the Don Valley Brickworks, supplying most of the bricks used in Toronto's early buildings. Straightening the Don freed up land for more industrial development. 
1890-1940s - With increased industrial activity in the area, the marshes at the river mouth were filled in to create the Portlands we see today. It attempted to 'tame' the marshy, disease-ridden waters at the river mouth. However, the 90 degree outlet only caused siltation build-up and costly maintenance.

1950-60s - The Don Valley Parkway was one of four expressways into the downtown core envisioned by Gardiner. It was a modern solution to congestion, but in a nostalgic slow moving character of a parkway, weaving modern roads into a traditional landscape. The parkway was seen as a 'civilizing force' to convert unruly, dangerous, and filthy landscapes into scenic backdrop for the experience of driving. The other expressways never materialized and the DVP did not alleviate traffic, but become a central transportation corridor that allowed Toronto's expansion into northeastern suburbs, ironically increasing traffic. With the valley as a picturesque backdrop to driving, this new experience of the valley redefined and rediscovered its natural beauty.

1970s - Highway problems, bringing noise, traffic, people, pollution; floods - barrier to east west movement; declining industries, abandoned industrial buildings 


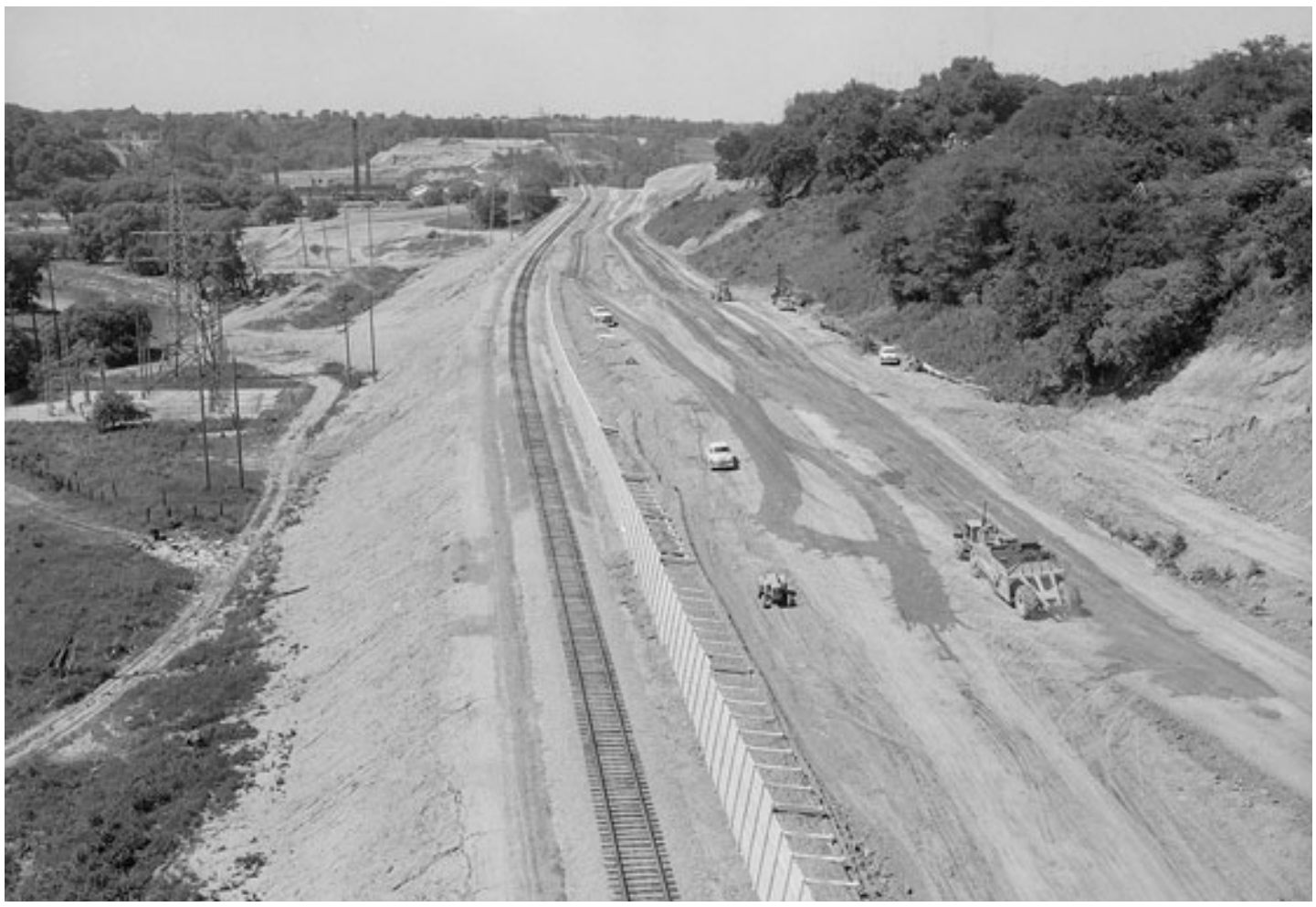

Figure 6: Construction of Don Valley Parkway 1950s

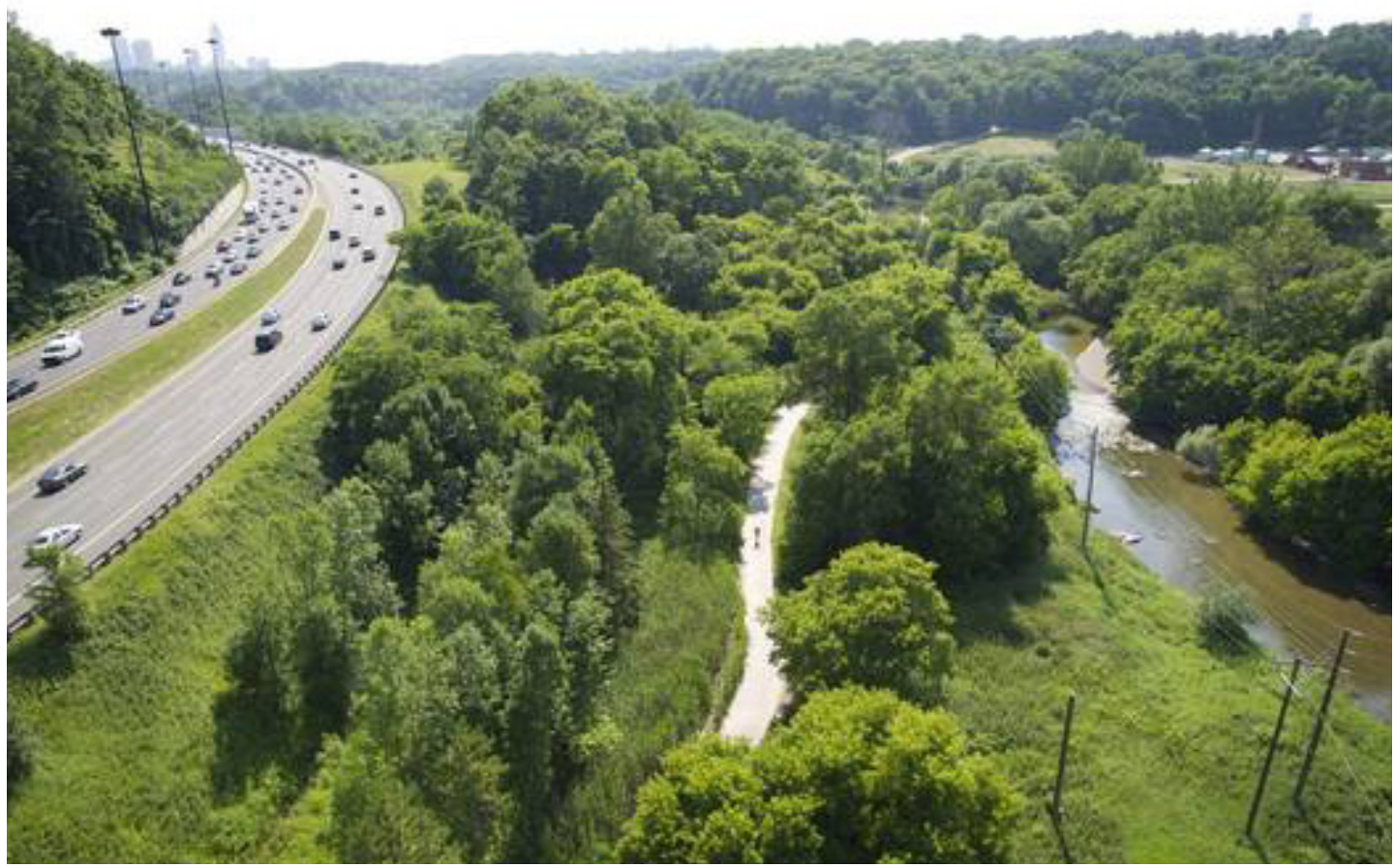

Figure 7: Don Valley Parkway 2014 


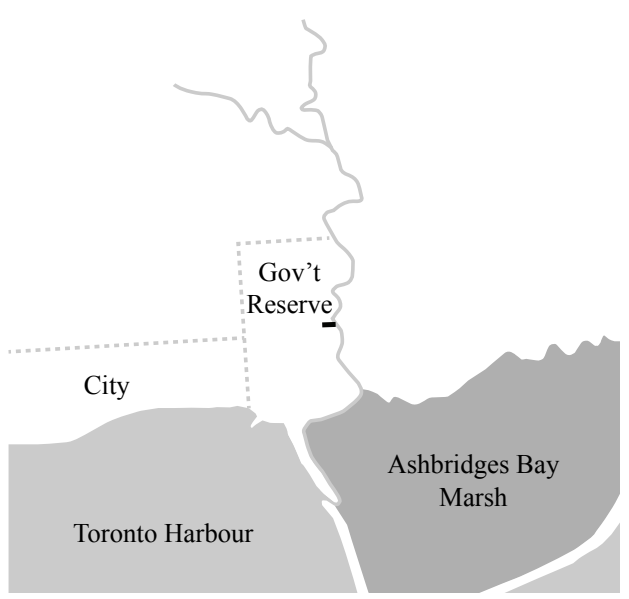

Figure 8: 1800-1840 plans for government reserve

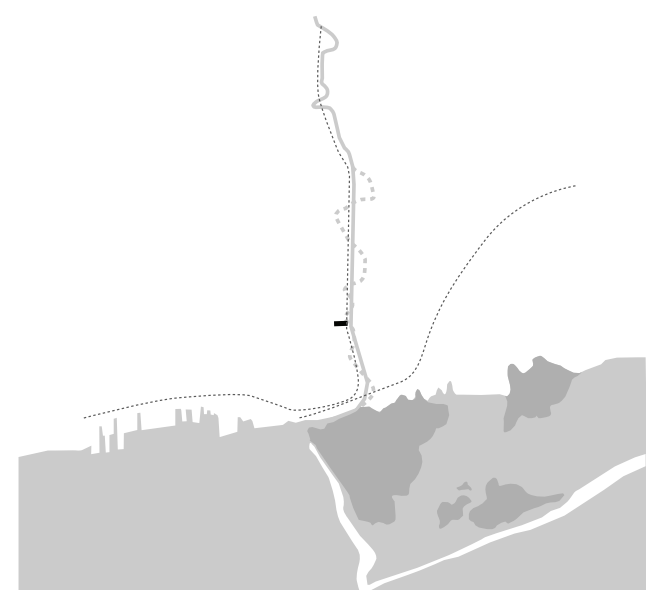

Figure 10: 1886 "taming" of the river and introduction of rail infrastructure

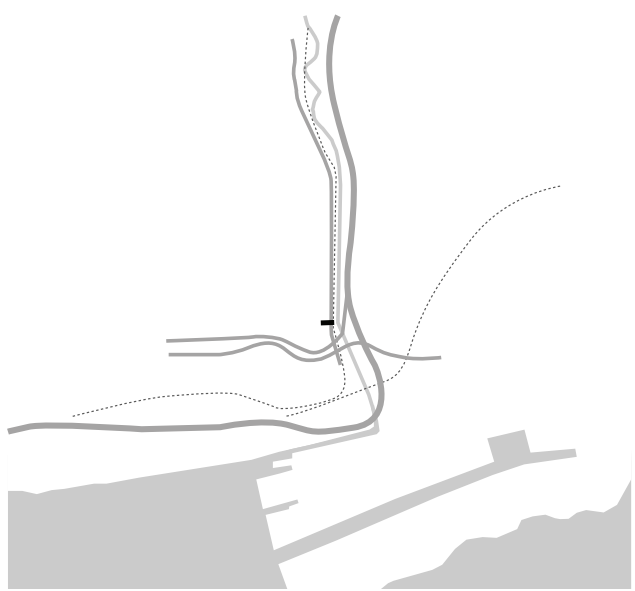

Figure 12: 1950-1960 introduction of the Don Valley Parkway as a civilizing force and transportation corridor that allowed expansion into the suburbs

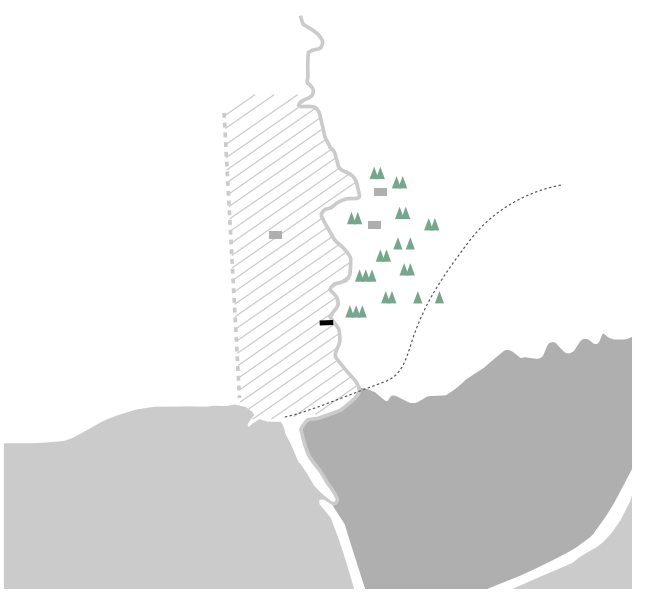

Figure 9: 1850-1880 industrial and rural landscapes

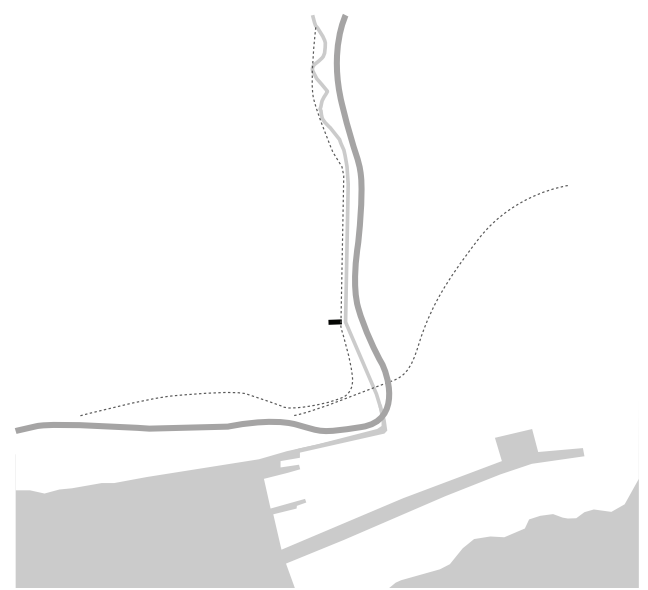

Figure 11: 1890-1940 Ashbridges Bay Marsh filled to reduce spread of disease in stagnant waters

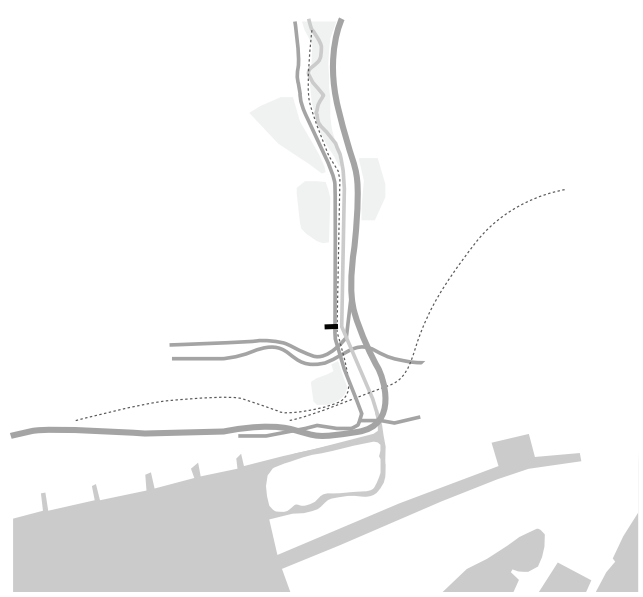

Figure 13: Today - reintroduced recreational landscapes along the valley. Future -Re-naturalize river mouth for flood protection and habitat creation 
Since the construction of the Don Valley Parkway in the midcentury, the experience and perception of the Valley has since been re-centered as a vital transportation corridor, experienced through the windshield on our daily commutes downtown. The valley slopes become a natural and scenic backdrop for driving, being the foreground to the Toronto skyline beyond. Driving down the Don Valley has become a visually enjoyable and pleasant way of entering the city despite the heavy traffic. With this scenic backdrop, there has been a renewed appreciation for Toronto's urban green spaces.

With a decommissioned industrial core, Toronto's urban spaces are slowly being revitalized and redeveloped to attract people back into the downtown. The rehabilitation of past industrial lands for public use can be seen along the waterfront and the revitalization of the Don River Trail, focusing on public recreation and urban space. The Lower Don River Trail stretches from Pottery Road south to Cherry Street offering a trail for walking and cycling through the Valley floor.

Environmental concerns of the 1990s began to acknowledge the importance of conservation efforts in our cities, refusing to accept environmental degradation as a product of society (Bonnell 2014). Canadian naturalist and long-time Don Valley conservation advocate Charles Sauriol actively pushed for the conservation and restoration of the valley grounds. The Don Valley Brick works, formerly a brick quarry that supplied most of the brick for Toronto's buildings, has been restored as an environmental community centre, cultural centre, and public park including naturalized ponds and hiking trails. Riverdale Farm and its parks offer ample recreation space and sweeping vistas of the downtown skyline. Regardless of the conservation efforts however, the Don still experiences flooding at its lower reaches, particularly after periods of heavy rain. The new Corktown Commons Park attempts to mitigate the effects of flooding by naturalizing and berming its park features near the river mouth. 


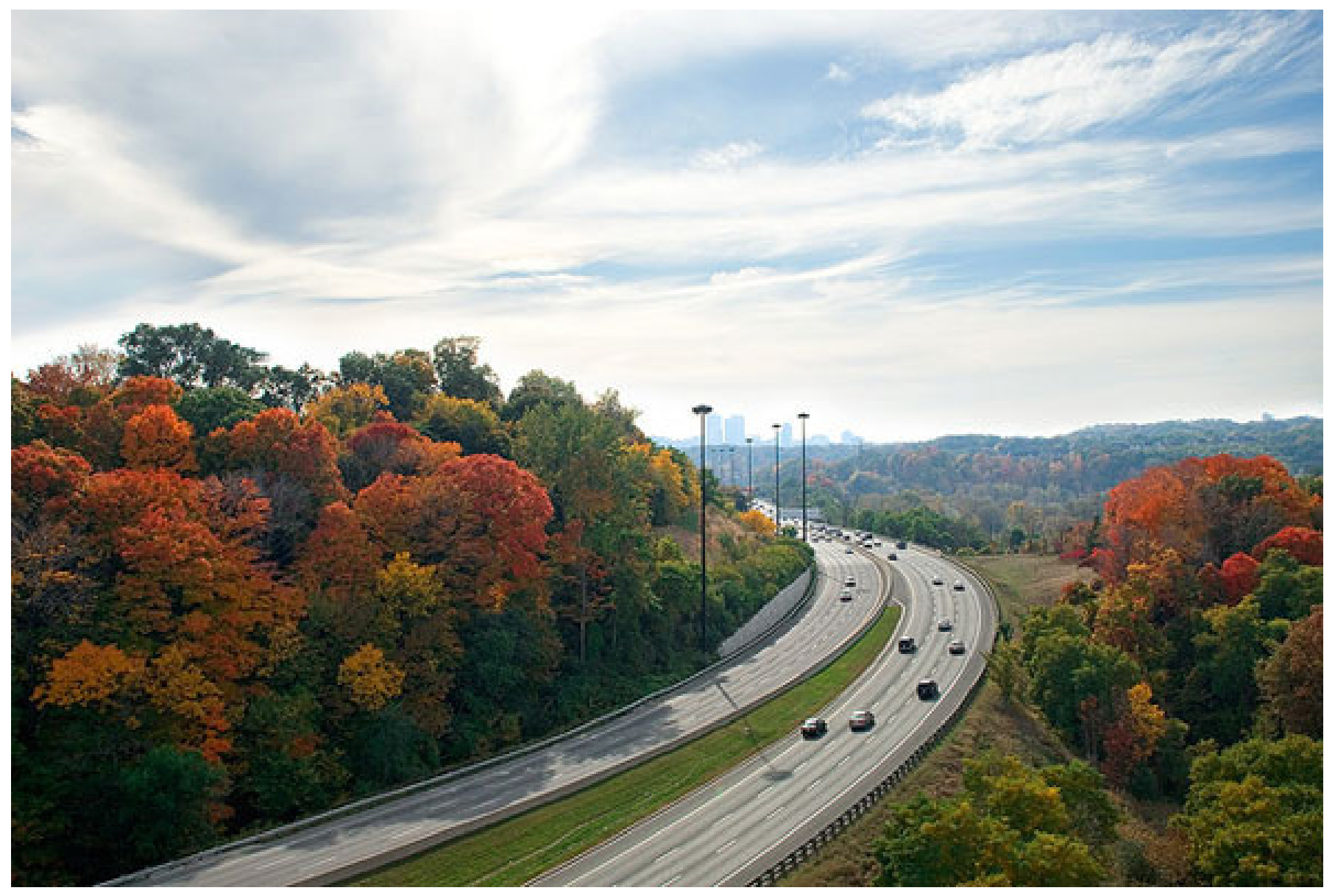

Figure 14: Don Valley Parkway 2014 
Figure 15: Renaturalized Don Valley Brickworks

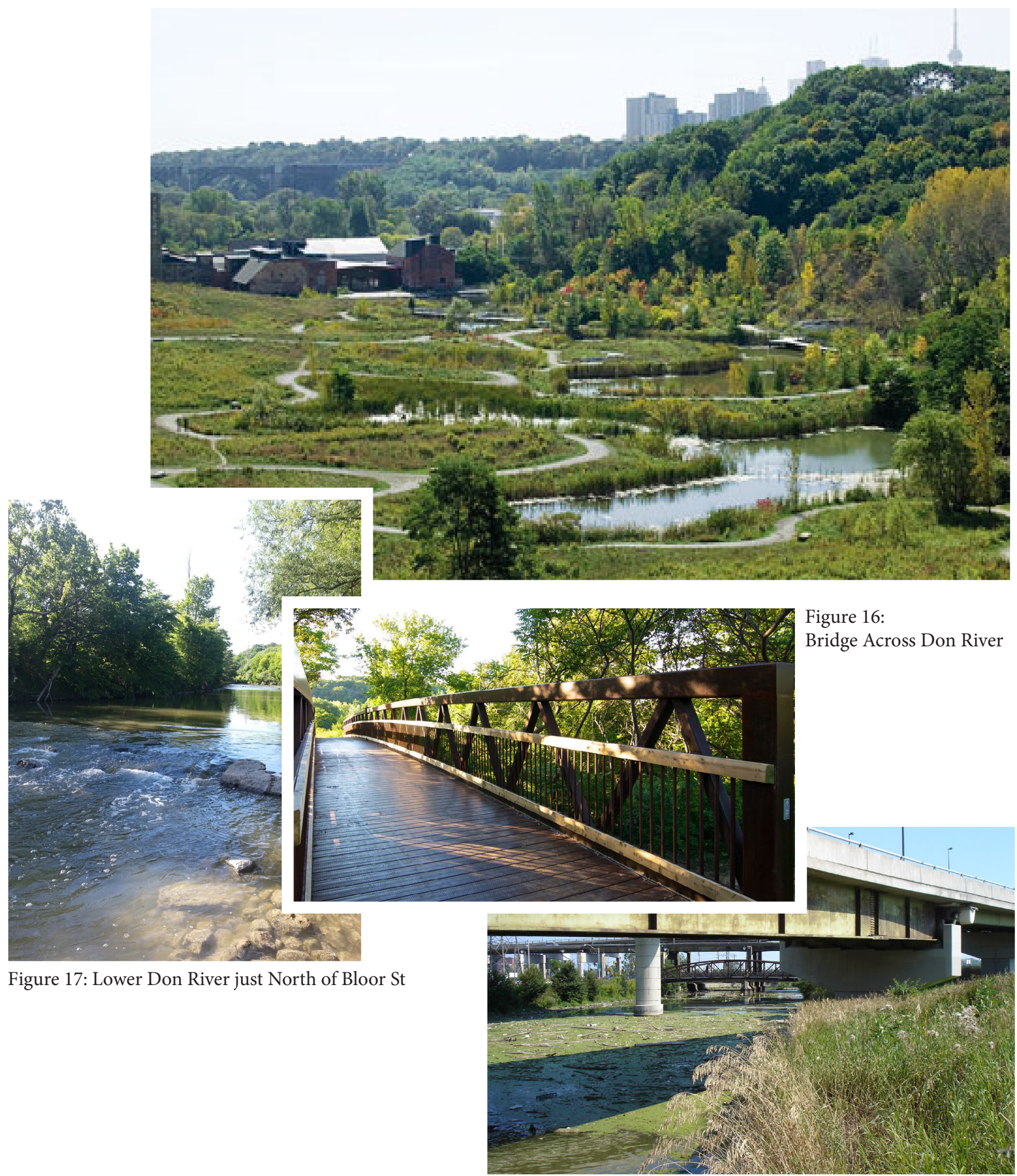

Figure 18: Lower Don River at Eastern Ave ccliv 


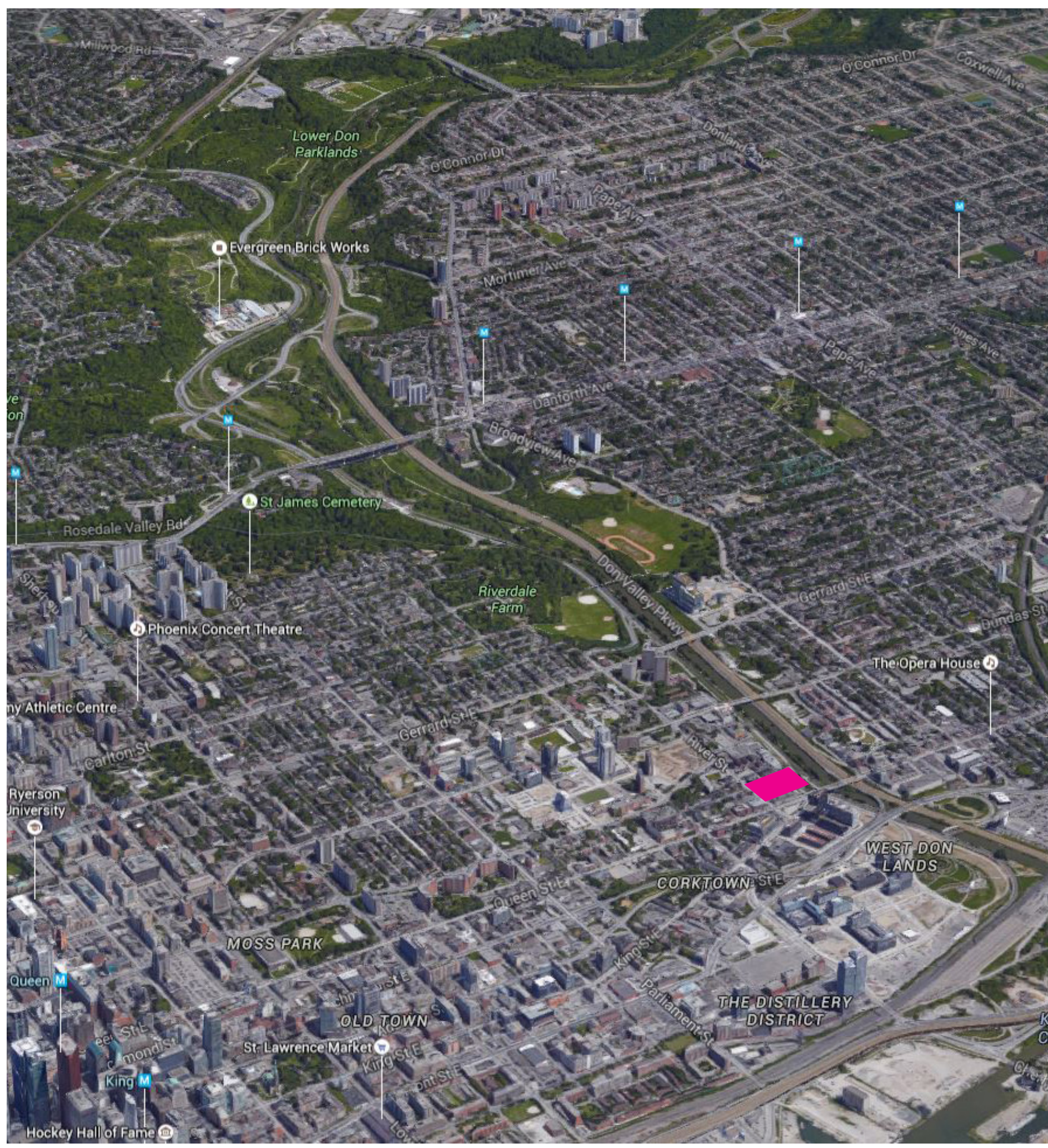

Figure 19: Aerial View of Lower Don River and Valley 


\section{Considering Future Growth}

While new and revitalized neighbourhoods of Regent Park, Leslieville, and Corktown are bringing more people into the downtown, the Valley is increasingly seen as "Toronto's backyard", with potentials to provide much needed natural park and recreation space in the city. The site of the THS on the valley, however, has lost all of its natural character to industrial development. The straightened length of the river between Winchester St and the river mouth remains the most unpleasant strip of the trail, appropriately named the Don Narrows. This section of the Don River and trail is the most constrained due to its narrow, heavily infrastructural nature, which hinders re-naturalization. Along this stretch Bayview Avenue, the rail tracks, trail path, Don River, and DVP are tightly parallel, restricting connections and flood mitigation efforts.

DTAH's masterplan to revitalize the Lower Don Trail aims to shift the perception of the valley as a poorly defined in-between space into a recreational destination of its own. Their strategies aim to increase accessibility and entry points to allow greater access to this prime resource in downtown Toronto, but also aims to simultaneously protect and enhance its natural environment. The plan proposes to simply widen trail width, add additional stair entrances, add benches along its path, and incorporate a public art fence between the trail and rail tracks. Although these tactics are an improvement to the existing conditions, it only provides utilitarian items of connection and amenity, lacking identifiability and connection to context. This stretch connects developments north and south of the site (Don Valley Brickworks and Riverdale Parks with Corktown Commons and the Lower Don Lands. The last major restoration vision for the Don River connects the river to the greater waterfront masterplan. In an international competition, MVVA's Don Mouth Naturalizing Project, proposed in 2015, attempts to reinstate a natural outlet from the Don River into Toronto Harbour. The current 90 degree river mouth at Keating Channel abruptly changes the flow of the river, adding to its siltation, pollution, and flooding problems, and MVVA proposes an alternative exit for the river. The proposal keeps the existing Keating Channel, but envisions the Lower Don Lands as an urban estuary for flood mitigation, wildlife habitat restoration, and new neighbourhood creation. New woodlands and marshes create an aesthetic and functioning ecosystem environment for flood protection, habitat restoration, and recreational use. It attempts to 
transform the area from an obsolete landscape of industrial production to a landscape of consumption by creating an iconic identity for the river mouth. However, cost of implementation remains a major barrier to this vision.

\section{Other Initiatives}

An alternative proposed intervention in the valley in 2016 sees it as a tourist attraction with the least impact to the natural landscape. A privately funded proposal suggests a "recreational infrastructure" of gondolas that connect the Prince Edward Viaduct to the Don Valley Brickworks. Because of the tough accessibility from the Castle Frank subway exit to the Brickworks, the gondolas become an accessibility feature, another traffic solution, as well as a tourist attraction, allowing an experience of the valley from above. It gives people greater access to the ravines without being too obtrusive (Kalinowski 2016).

As a small urban waterway, the Don River has always been integral to the growth of Toronto. Early visions of the valley being a retreat and agricultural site was quickly taken over by industrial activity, and has since propelled the city economically but destroyed the natural landscape of the valley. However, the natural hydrology of the river has always prevailed over any infrastructural "taming" of it, and the "Don Problem" has persisted to this day, recognizing that rational human efforts are only secondary to natural forces.

\section{Conclusion}

As a small urban waterway, the Don River has always been integral to the growth of Toronto. Early visions of the valley being a retreat and agricultural site was quickly taken over by industrial activity, and has since propelled the city economically but destroyed the natural landscape of the valley. However, the natural hydrology of the river has always prevailed over any infrastructural "taming" of it, and the "Don Problem" has persisted to this day, recognizing that rational human efforts are only secondary to natural forces. 

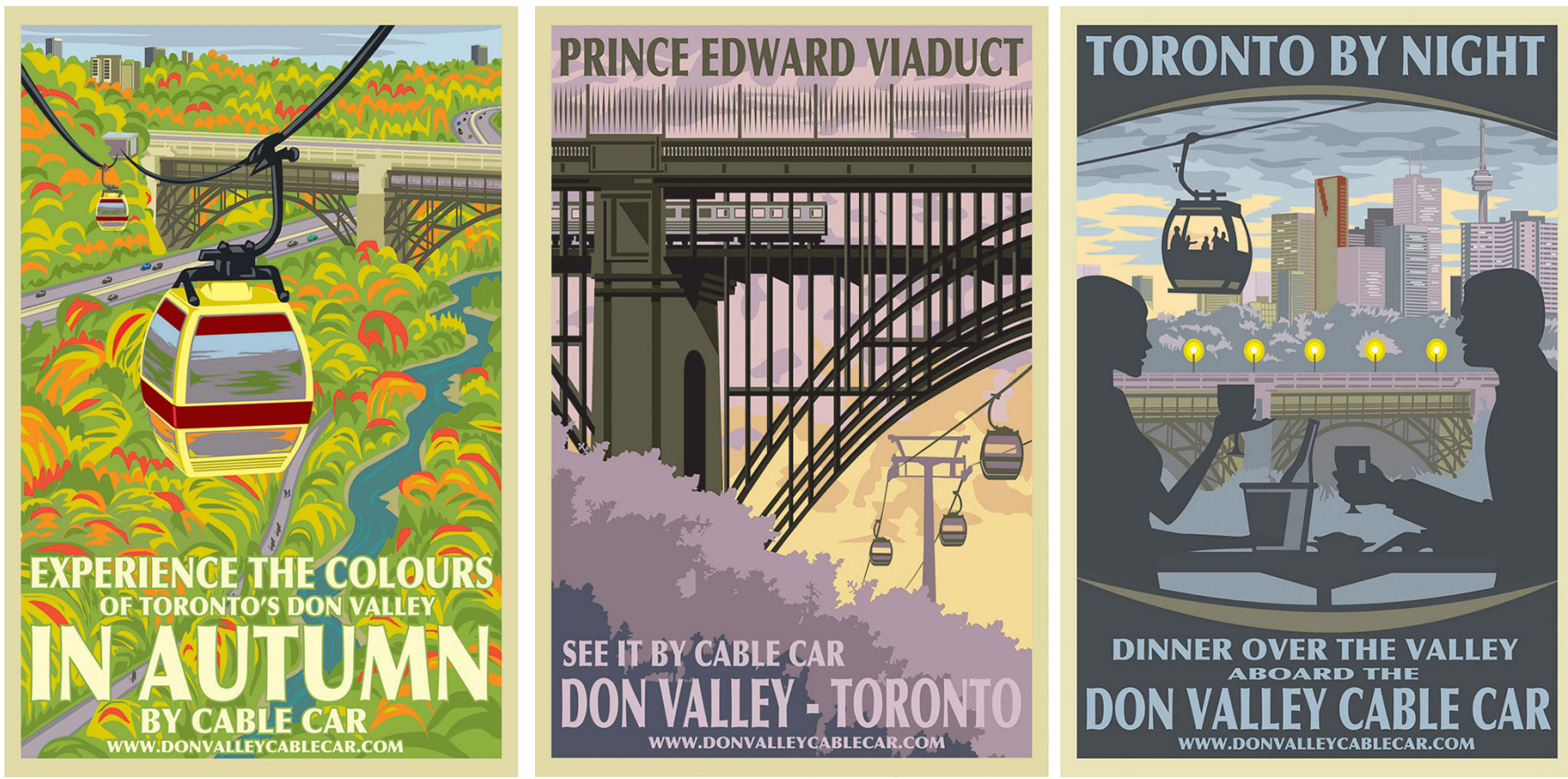

Figure 25: Promotional posters for Don Valley Cable Car Proposal. 2016 


\section{LIST OF FIGURES}

Figure $1 \quad 1796$ Sketch of Castle Frank by Elizabeth Simcoe https://maps. library.utoronto.ca/dvhmp/poi-template_clip_image002_0000.jpg

Figure 2 Recreation in the Don River 1920s

Figure 3 Don Valley Brickworks 1800s. https://maps.library.utoronto.ca/ dvhmp/don-valley-brickworks.html

Figure 4 Historical Drawing of Don River and Area

Figure 5 Don River Straightening Plan, 1886.

Figure 6 Don Valley Parkway Construction http://www.blogto.com/ city/2013/08/that_time_toronto_opened_the_don_valley_ parkway/

Figure 7 Don Valley Landscape http://www.blogto.com/city/2014/09/10_ quirky_things_to_know_about_the_don_valley/

Figure $8 \quad 1800-1840$ plans for government reserve. Made with maps from Bonnell, 2014.

Figure 9 1850-1880 industrial and rural landscapes. Made with maps from Bonnell, 2014.

Figure $10 \quad 1886$ "taming" of the river and introduction of rail infrastructure. Made with maps from Bonnell, 2014.

Figure 11 1890-1940 Ashbridges Bay Marsh filled to reduce spread of disease in stagnant waters. Made with maps from Bonnell, 2014.

Figure 12 1950-1960 introduction of the Don Valley Parkway as a civilizing force and transportation corridor that allowed expansion into the suburbs. Made with maps from Bonnell, 2014.

Figure 13 Today - reintroduced recreational landscapes along the valley. Future -Re-naturalize river mouth for flood protection and habitat creation. Made with maps from Bonnell, 2014.

Don Valley Parkway http://www.blogto.com/city/2014/09/10_ quirky_things_to_know_about_the_don_valley/

Figure14 Don River Trail Bridge

Figure 15 Renaturalized Don Valley Brickworks http://www.evergreen.ca/ images/site/i-quarry2005.jpg

$$
\text { cclx }
$$




\section{LIST OF FIGURES}

Figure 16 Bridge Across Don River https://www.likealocalguide.com/media/ cache/da/03/da03628ead6c570104161f49d688282e.jpg

Figure 17 Lower Don River just North of Bloor St. Photograph by author.

Figure 18 Lower Don River at Eastern Ave. https://upload.wikimedia.org/ wikipedia/commons/f/fd/Foot_of_the_Don_River,_Toronto.jpg

Figure 19 Aerial View of Lower Don River and Valley. Google Maps 2015.

Figure 20 DTAH Masterplan for Don Valley Trail. From DTAH, 2013.

Figure 21 DTAH Masterplan for the Don Narrows. From DTAH, 2013.

Figure 22 DTAH Masterplan for Dundas Street Connection. From DTAH, 2013.

Figure 23 DTAH Masterplan for the Don Narrows. From DTAH, 2013.

Figure 24 MVVA's Masterplan Vision for the Don River Mouth. http:// archleague.org/main/wp-content/uploads/2013/06/r_MVVA_ Lower-Don-Lands_Aerial-Plan_credit-MVVA.jpg

Figure 25 Promotional posters for Don Valley Cable Car Proposal. 2016. http://donvalleycablecar.com/ 
cclxii 


\section{REFERENCES}

Bonnell, Jennifer L. 2014. Reclaiming the Don: An Environmental History of Toronto's Don River Valley. Toronto: University of Toronto Press.

DTAH. 2013. "Lower Don Trail. Access, Environment + Art Master Plan." City of Toronto and the Toronto and Region Conservation Authority. http://dtah.com/project/lower-don-trail-master-plan/.

Kalinowski, Tess. 2016. Don Valley gondola could lift Toronto tourism. Toronto: The Star, February 19. Accessed February 26, 2016. http://www.thestar.com/news/gta/transportation/2016/02/19/ don-valley-gondola-could-lift-toronto-tourism.html.

Sauriol, Charles. 1981. Remembering the Don. A Rare Record of Earlier Times Within the Don River Valley. Toronto: Consolidated Amethyst Communications Inc. 



\section{APPENDIX C}

The Toronto Humane Society

cclxv 
The Toronto Human Society (THS) began as an institution that promoted the humane treatment of both children and animals through regulations, laws and education for the prevention of cruelty. Along with an anonymous \$2 donation, a Toronto resident asked the question: "Why don't we have a society for the prevention of cruelty?" referring to a then common sight of overworked horses on the streets of Toronto, lacking access to rest stations and drinking fountains. It was acknowledged that Toronto lacked a force that fought for the prevention of cruelty, and in 1887 the Humane Society was established with the following objectives:

Stop cruelty to children

Rescue children from vicious influences and remedy their conditions Put humane literature into schools and homes

Induce children to be humane

Encourage everybody to practice and teach kindness to animals and others

Stop the beating of animals

Stop overloading street cars and wagons (which were then pulled by horses)

Stop the working of old horses

Stop driving galled and disabled animals

Introduce drinking fountains for horses

Prevent the clipping of horses, docking of tails

Prevent the use of check rein/burr bit

Prevent the exposure of uncovered horses in cold weather

Prevent the under-feeding and over-driving of horses and cattle

Provide better laws

The Children's aid society eventually became its own separate organization in 1891 and the THS continues to run as a non-profit organization as an animal shelter and animal rescue centre. The shelter now deals primarily with domestic animals (including dogs, cats, rabbits, hamsters, gerbils, turtles, lizards, and birds), either surrendered by owners or transferred from other shelters (Northern Ontario, Quebec). Their wildlife license was revoked in 2009 following an Ontario Society for the Prevention of Cruelty to Animals (OSPCA) raid for allegations of animal cruelty. The raid found poor management, understaffing and overpopulation of animals to be sources of cruelty and misery for the animals. With a personal mission to accept any and all animals, the shelter's former CEO is found to have crowded the shelter to a point where it became inhabitable for animals and an unworkable environment for employees and volunteers. As such, the THS lost its affiliation with the OSPCA and can no longer accept stray animals and wildlife directly 
(O'Toole 2012). The shelter has since cleaned up its facilities, only accepting owner surrendered or shelter transferred animals for re-homing, keeping their numbers manageable. Yet, the THS still struggles with poor reputation and image after the seeming betrayal of public trust.

"A shelter is not meant to house animals. It should only be a way station" veterinarian at THS (Clark 2011).

The THS is not simply a place that takes in unwanted animals, but also ensures that each one's needs are attended to in order to ensure an appropriate quality of life and subsequent re-homing. The facility in desperate need for an improved image, focusing on transparency, humane and sanitary conditions that can educate and appeal to the public as well as attract investment and donations. 


\section{Existing THS Floor Plans}

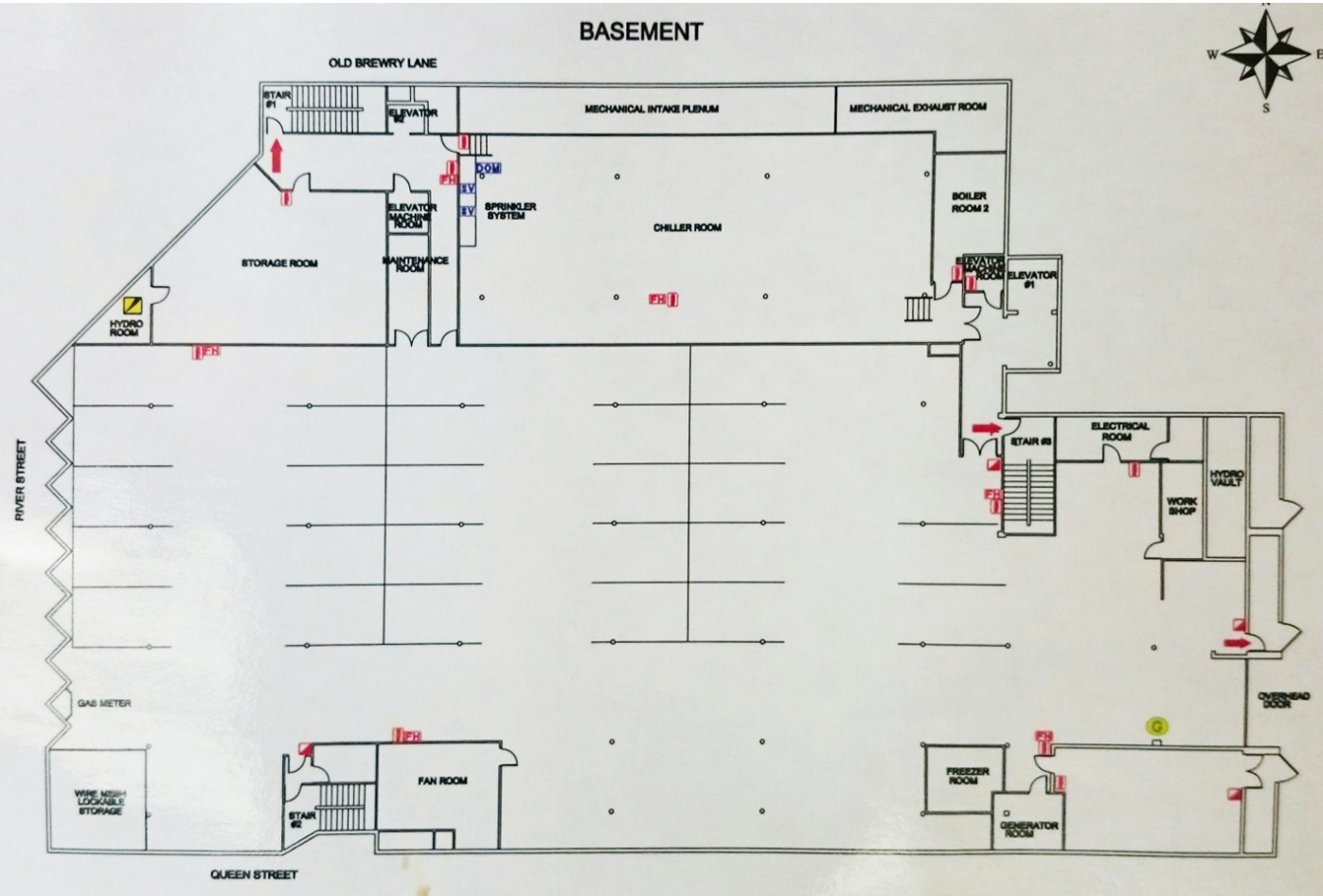

Figure 1: Basement Plan

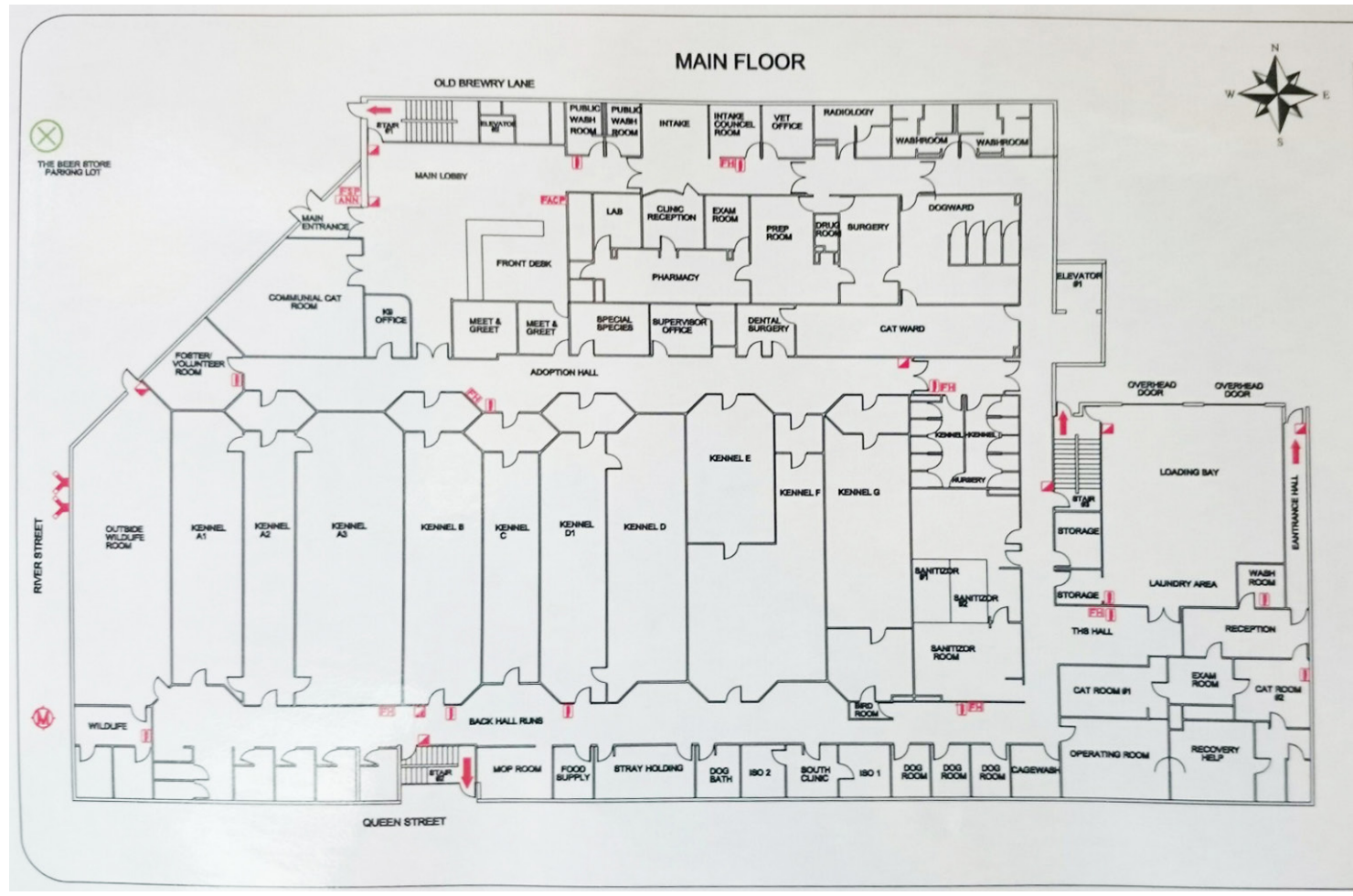

Figure 2: Ground Floor Plan

cclxviii 


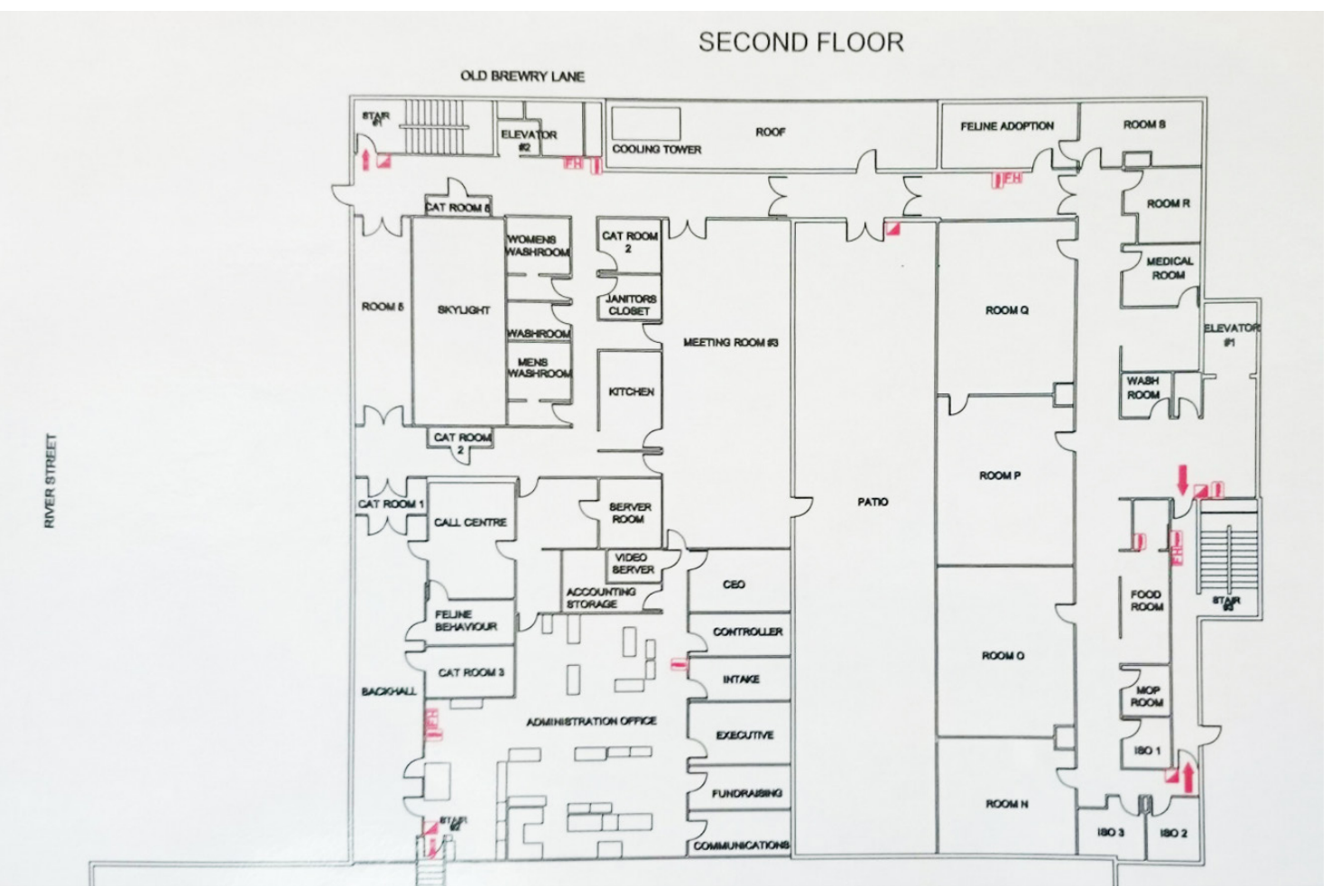

Figure 3: Second Floor Plan 


\section{Program Breakdown of Existing THS Facilities}

\section{PRIVATE}

Program Breakdown

Offices

Volunteer Check-in

Dog Support

Dog Training

Dog Isolation

Cat Behaviour Training

Cat Exam Room

Food Prep

Intake Counseling Office

Exam Room

Pharmacy

Lab

Veterinarian's Office

Prep Room

Surgery Room

Radiology

Dog Ward

Cat Ward

Wildlife Room

Sanitizer Room

Spay/Neuter Clinic Reception

Exam Room

Operating Room

Recovery Room

Cat Room

Admin Offices

Kitchen

Staff Washroom

Loading

Mechanical

Generator Room

Storage

Laundry

Janitor Closet

Patio

28 Staff Parking

\section{PUBLIC}

Program Breakdown

Sq.m

Lobby

Front Desk

Public Washroom

Dog Kennels

Meet and Greet Rooms

Cats

Cat Adoption Rooms

Cat Isolation

Small Animals

Bird Room

Intake Lobby

Intake Counseling Office

Reception

Wildlife Room

Sanitizer Room

Spay/Neuter Clinic Reception

Public Washroom

20 Visitor Parking 


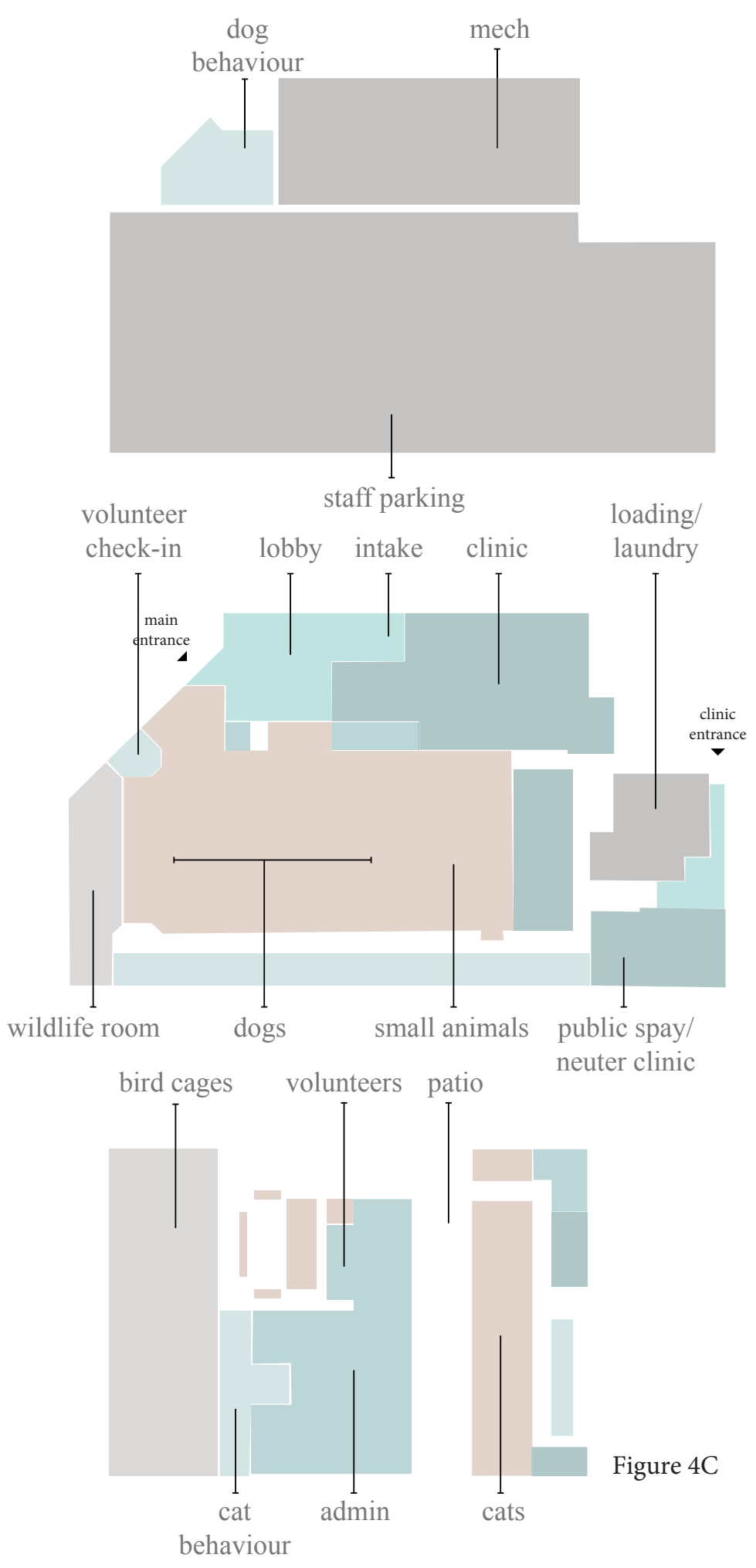

Figure 4A

Figure 4B

Figure 4: Program Blocking Diagram of Existing THS Program
A | Basement Level
B | Ground Floor
C | Second Floor

cclxxi 
Figure 5: Corner of River and Queen Streets

Figure 6: Corner of River and Queen Streets

Figure 7: Southern elevation along Queen Street
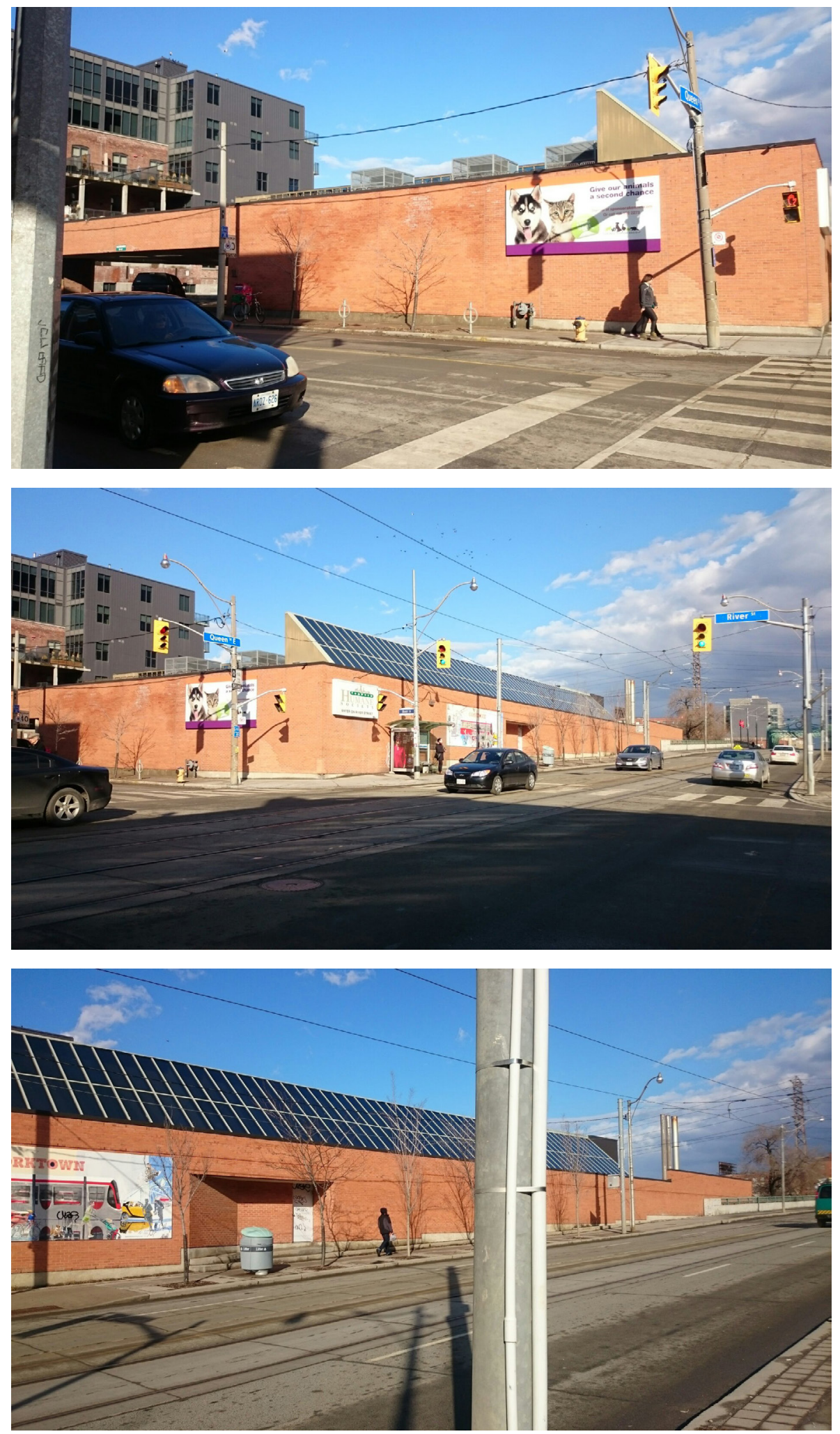

cclxxii 

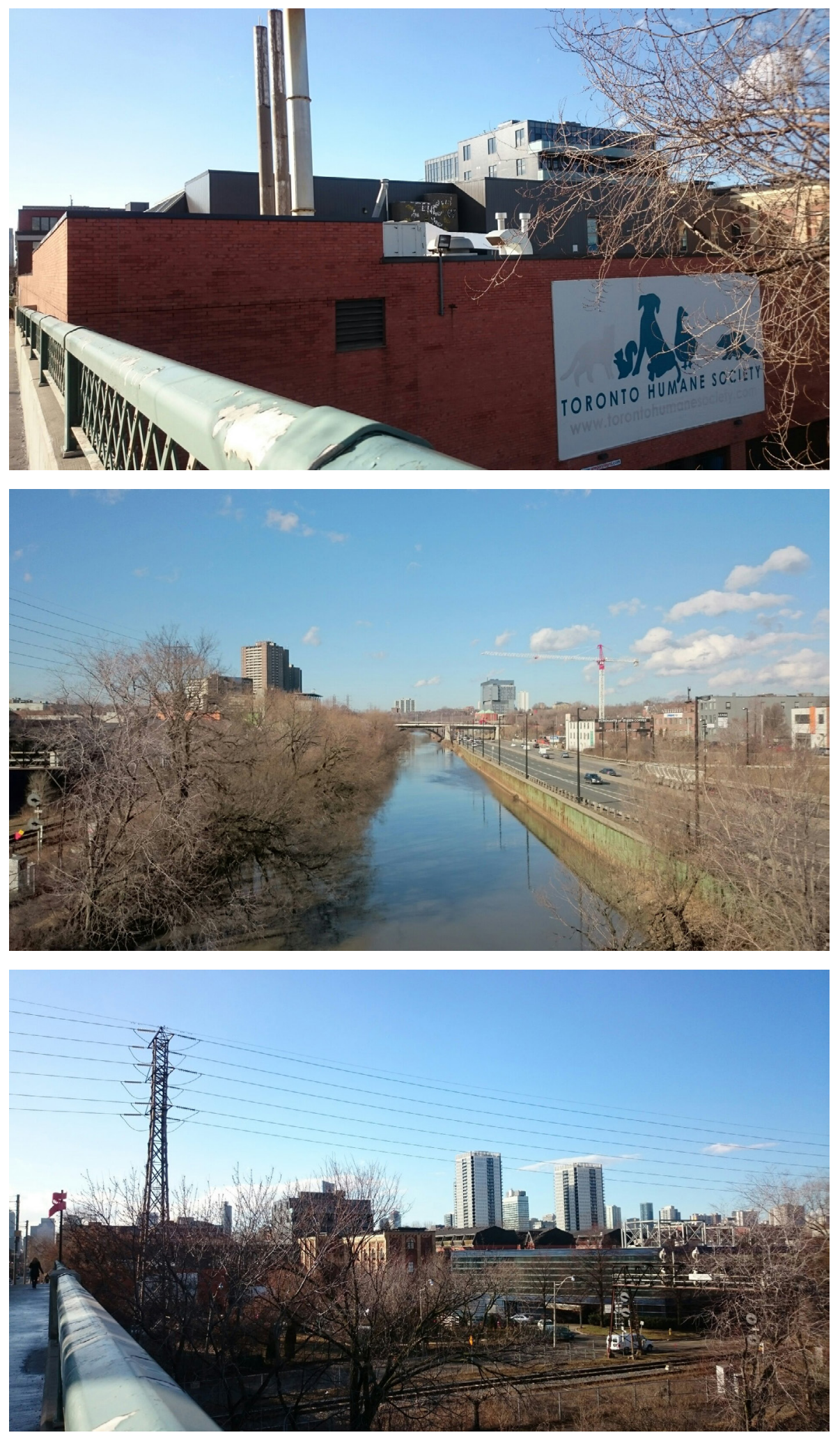

Figure 10: Looking west long Queen St bridge

Figure 8: East elevation of THS from Queen St bridge

Figure 9: Don River and Don Valley looking north on the Queen St bridge

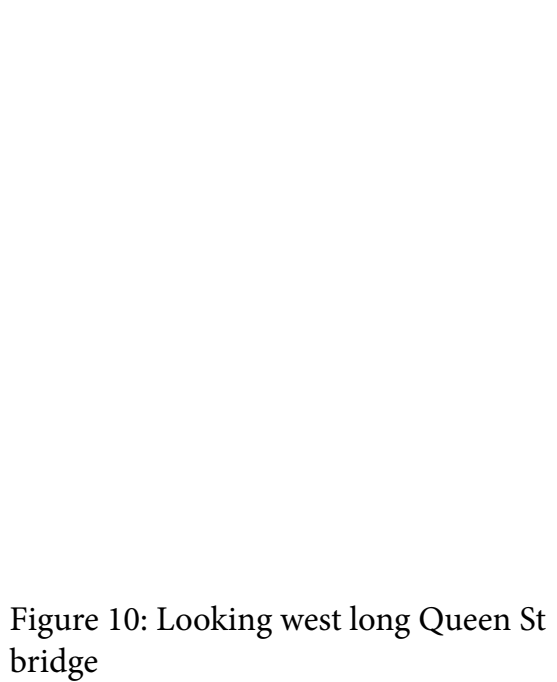


Figure 11: Canine Kennels

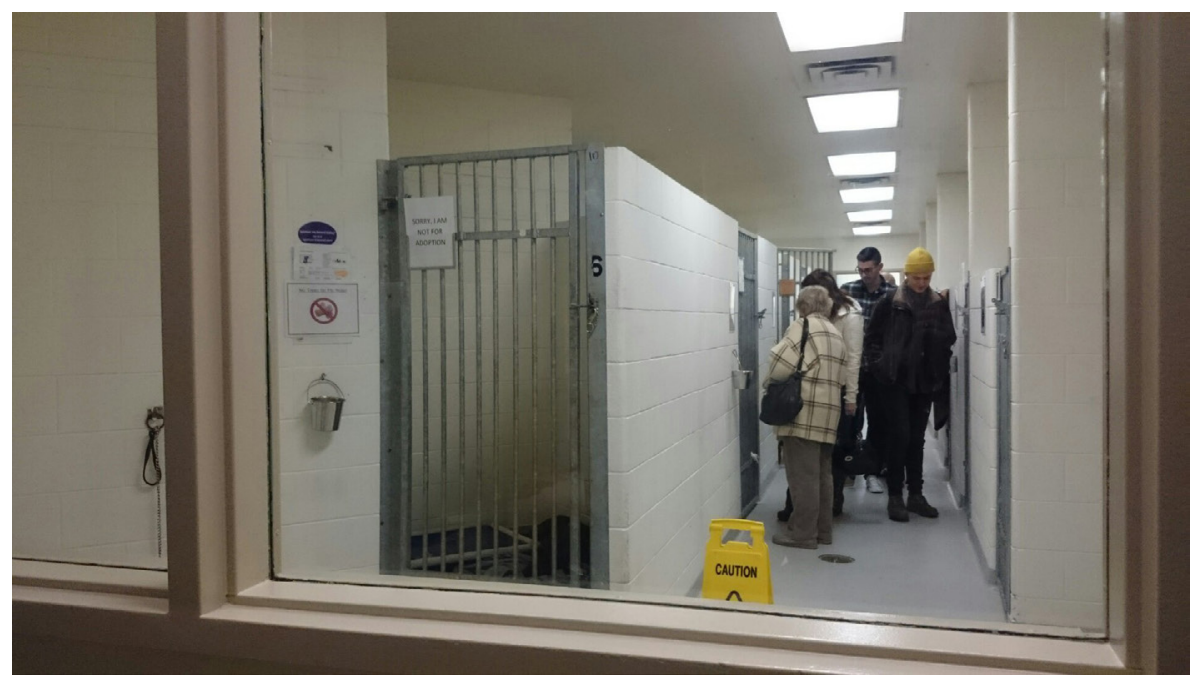

Figure 12: Feline Adoption Rooms Volunteer enrichment
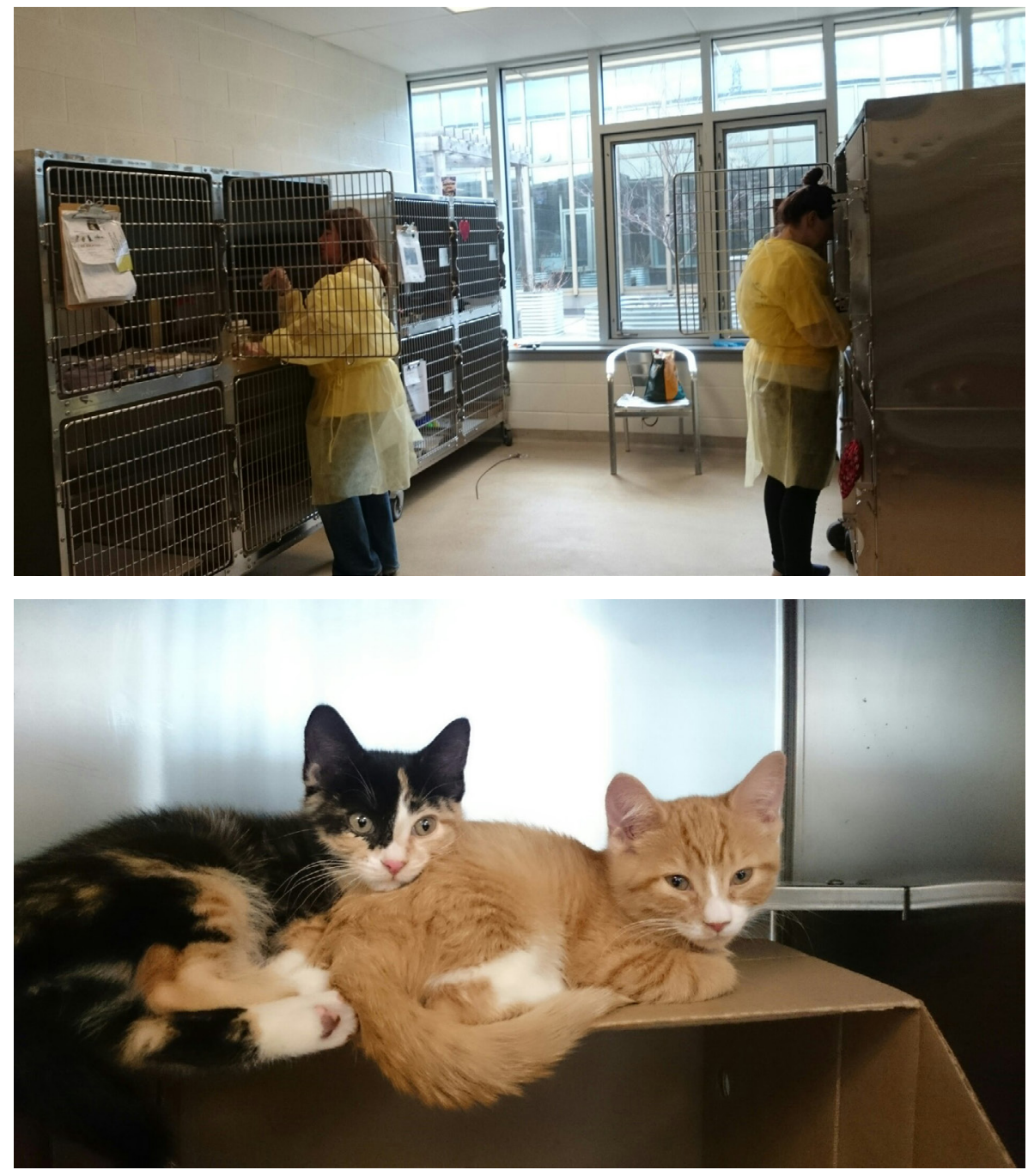

cclxxiv 

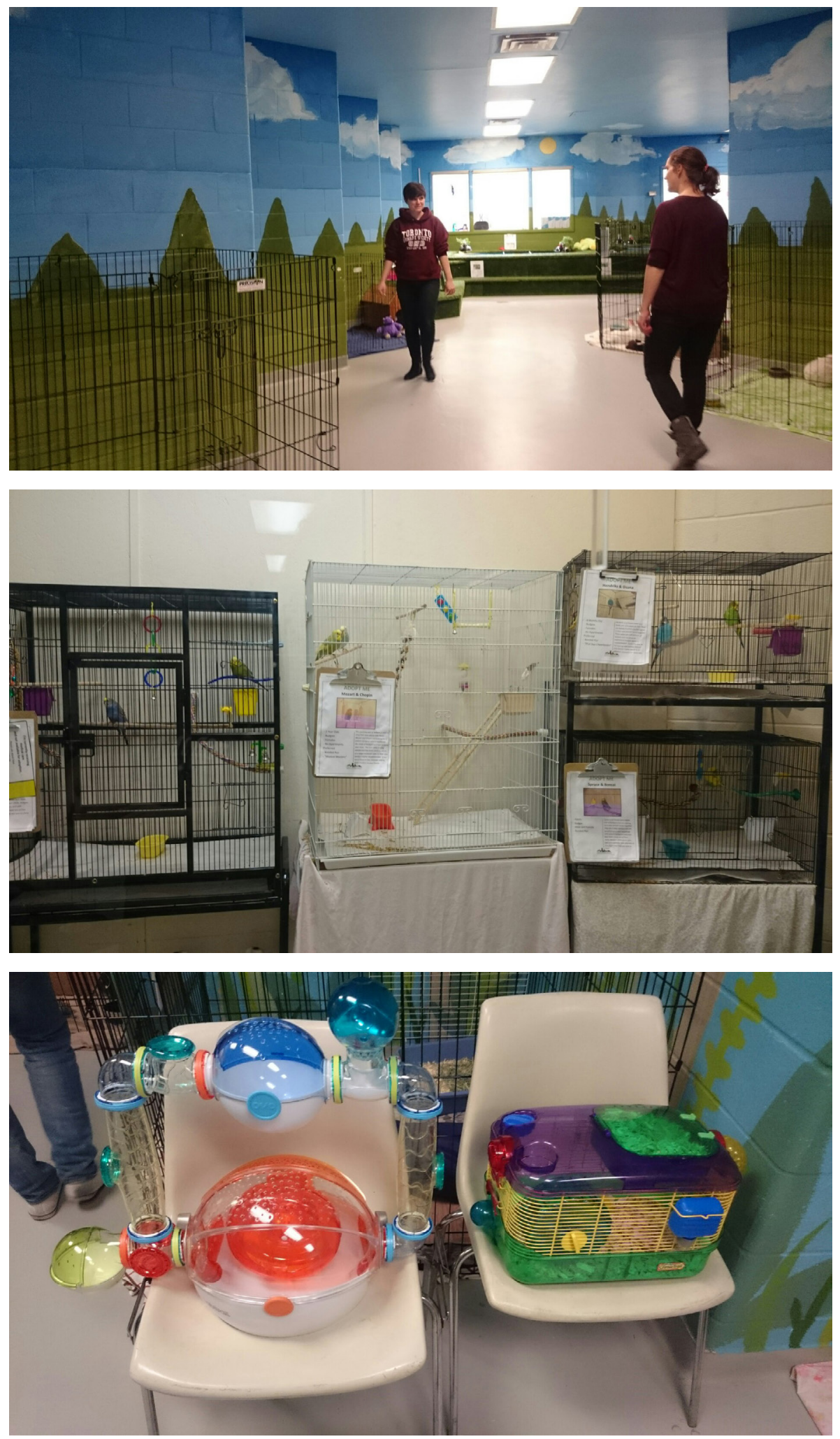

Figure 16: Small Animals' cages (THS retail)

Figure 14: Small Animals Adoption Room

Figure 15: THS Bird Room

cclxxv 


\section{REFERENCES}

Black, Debra. 2009. SPCA raids Toronto Humane Society. The

Toronto Star. Published June 2 2009. https://www.thestar.com/ news/crime/2009/06/02/spca_raids_toronto_humane_society. html. Accessed Jan 2016.

Hammer, Kate. 2009. Toronto Humane Society officials arrested, facing animal cruelty charges. The Globe and Mail. Published Nov 26 2009. http://www.theglobeandmail.com/news/toronto/ toronto-humane-society-officials-arrested-face-animal-crueltycharges/article1347595/. Accessed Jan 2016.

Toronto Humane Society Official website. http://www.torontohumanesociety.com/

Photographs and diagrams by author unless otherwise noted. 



\section{APPENDIX D}

Site Visit to the Toronto Humane Society 


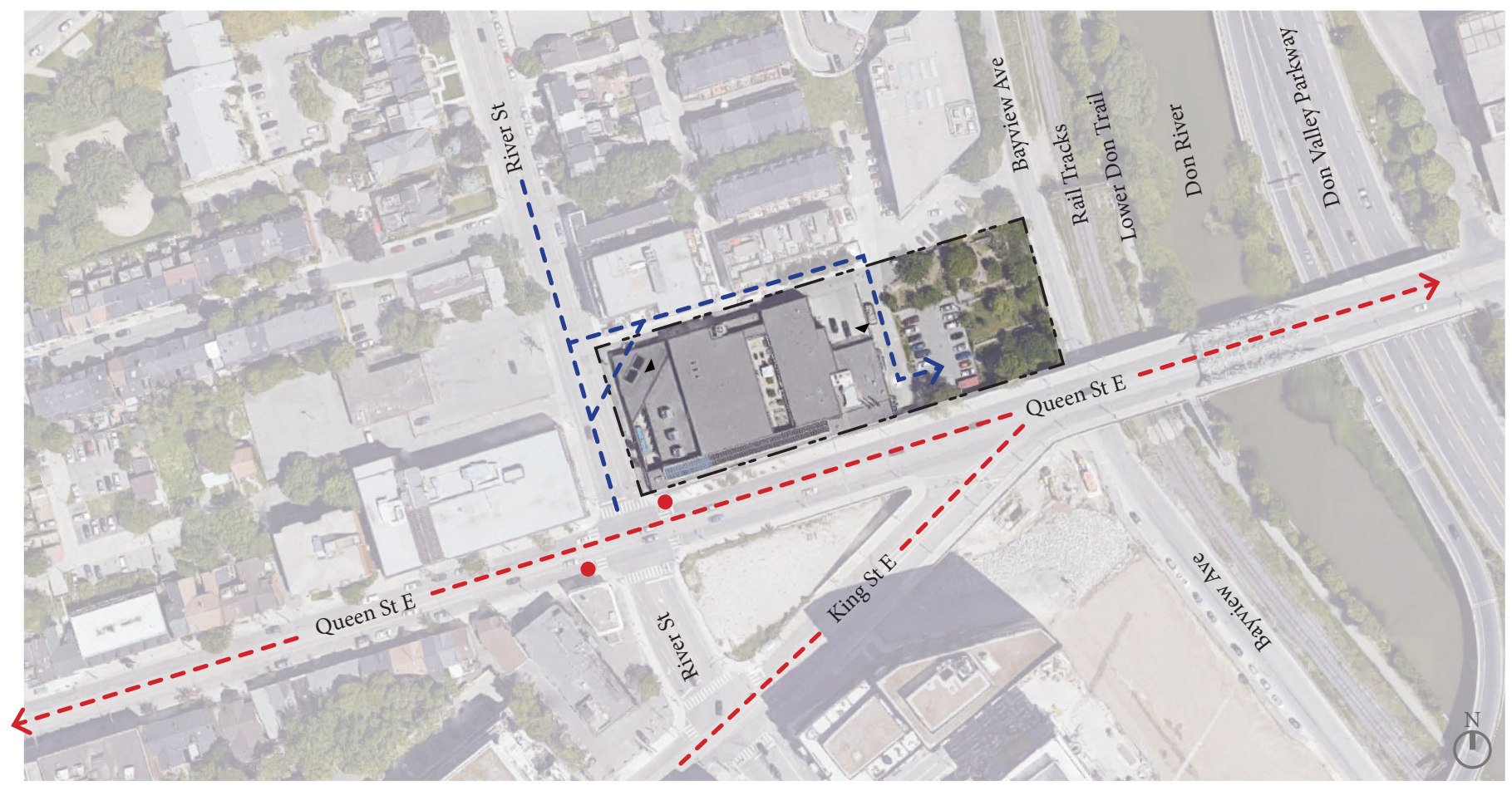

Figure 1 (NTS)

Figure 1: Aerial Map of Contextual Conditions and Site Access Diagram

Figure 2: Circulation and Site Access of Existing THS Facility

Figure 3: Entrace to THS. http://www. digitaljournal.com/img/9/5/5/2/8/2/ i/8/5/5/p-large/DMB_1094.JPG

Figure 4: Entrancealong River Street looking north

Figure 5: Main Entrance and Drop Off

Figure 6: Double Height Lobby

\section{A First-Hand Visitor Experience - Observations of Existing Conditions}

The THS has an adoption shelter component and a spay/neuter clinic component that are both open to the public between $10 \mathrm{am}$ and $6 \mathrm{pm}$, and the entrances to each are separated. The main entrance is tucked behind a chamfered corner on River Street with a small drop off area in the front (Figures 3-5). The clinic entrance is in the northeast corner beside the loading dock through a small door, not easily visible or accessible. Visitor parking is located in the back and visitors walk back along Old Brewery Lane to access the main entrance. The westbound 501, 502, and 503 Queen Streetcar stops right in front of the building at the corner of Queen and River Streets and the eastbound streetcar stops at the opposite corner. Bicycle parking is available along River Street. (Figures 1 and 2). 


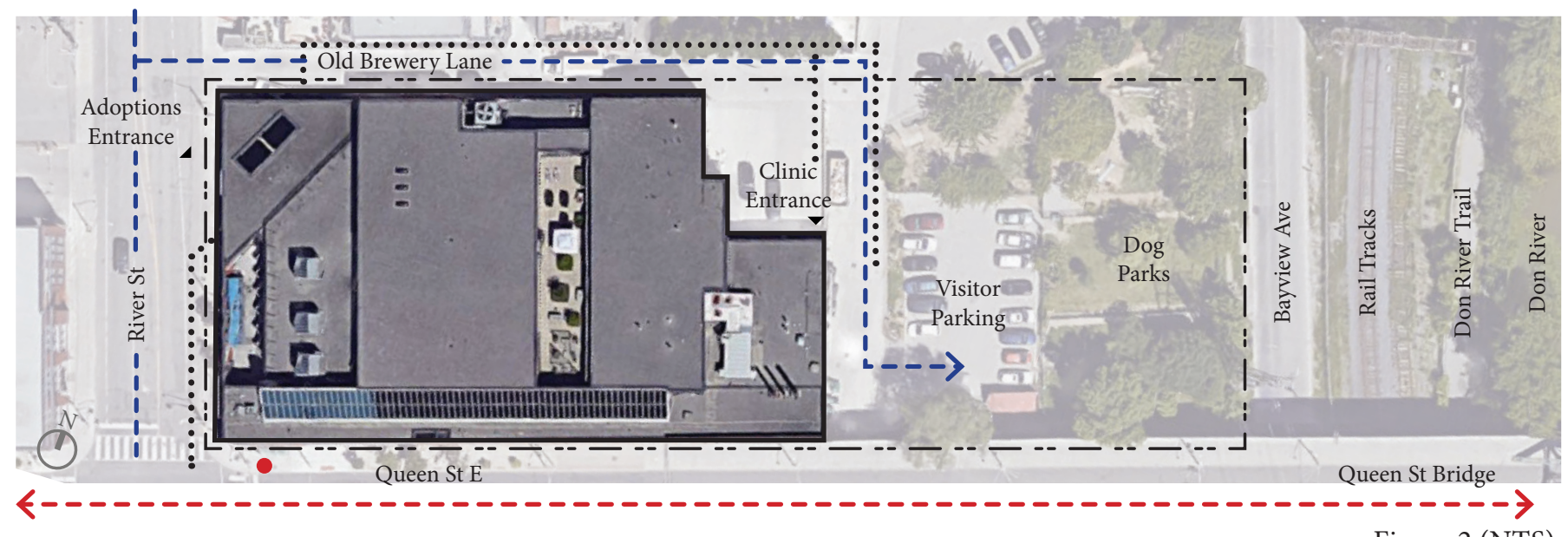

Legend

- Public Entrance

- Transit Stop

- - _ - - Property Line

- - - $\rightarrow$ Public Transit

- - - - $\rightarrow$ Vehicular Access

......... Pedestrian Access

Figure 3
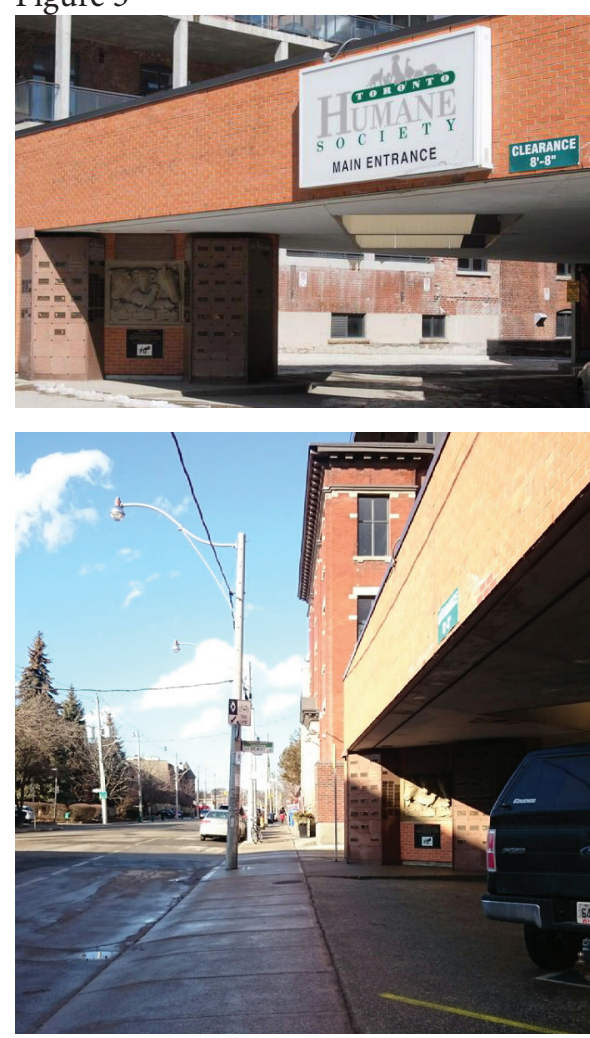

Figure 4
Figure 5

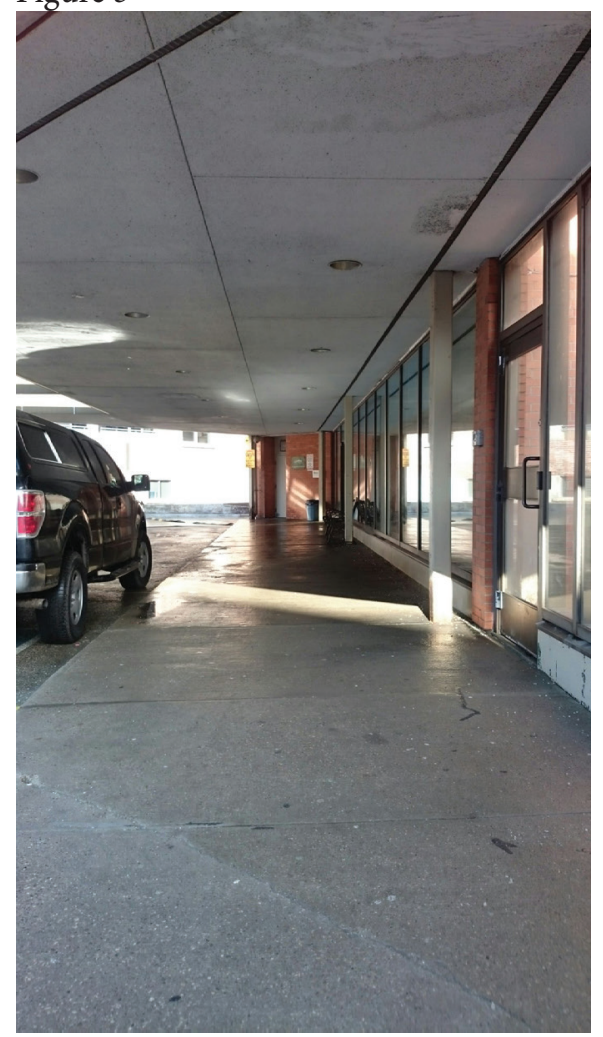

cclxxxi
Figure 6

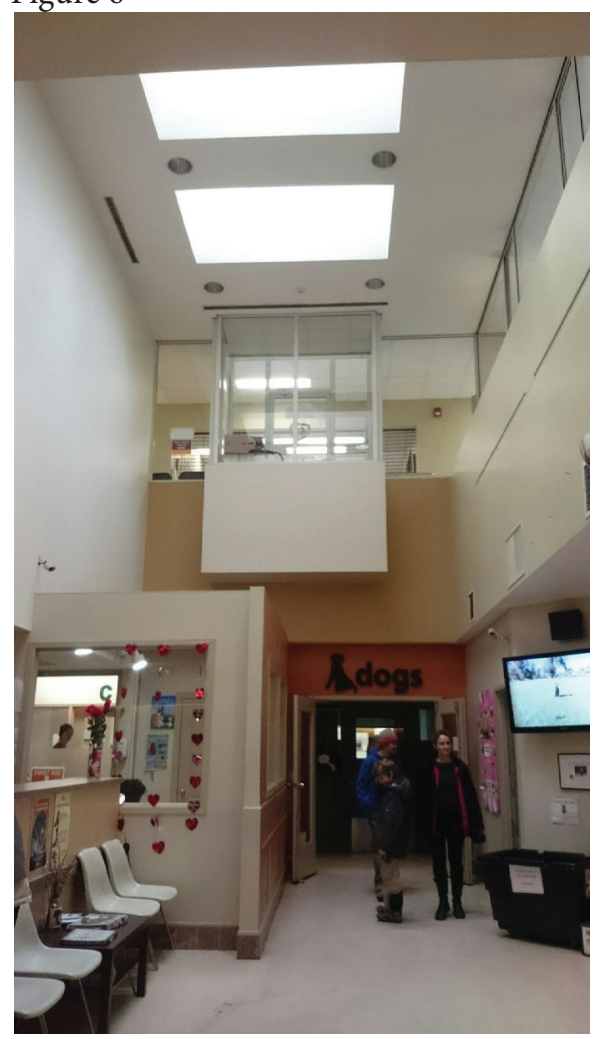


Figure 7: Public Areas of the THS
A: Lobby
B: Intake Reception
C: Small Animals
D: Turtle Pond
E: Bird Room
F: Dog Kennels http://www. jeffreyalanpayne.com/wp-content/ uploads/2014/08/Toronto-Humane- Society-Kennels.jpg
G: Dog Kennels
H: Volunteer Dog Walker
I: Cat Room
J: 2nd Floor Courtyard

Upon entry visitors sign in at the front desk prior to visiting the adoption kennels (Figure 7A). The front desk offers general information, adoption application forms, a food bank and some THS merchandise is available for purchase. There is a "communal cat room" in the front with windows out to the drop-off where mass intake cats are "isolated" but still adoptable. The intake reception and office is beyond a set of double doors behind the front desk. Adoption areas are indicated as "dogs" down one corridor and "cats" upstairs. The canine kennels are divided into 4 "rooms", each holding 10-20 dogs individually (Figure 7F and 7G). These rooms are sandwiched between the main public corridor and the private service corridor without access to any views or daylight. The concrete and metal finishes reverberate and increase barks, footsteps and voices, making it an unpleasant place to stay. Volunteers were seen taking dogs out on walks through the front entrance and around to the parking lot in the back (Figure $7 \mathrm{H}$ ). There is no direct access from the kennels to the dog parks in the back. The last 2 rooms hold small animals such as rabbits, guinea pigs, mice, hamsters, gerbils, turtles, and birds (Figure 7C, $7 \mathrm{D}, 7 \mathrm{E}$ ). These rooms are painted in a mural of rolling hills and blue skies, attempting to liven up the concrete walls. Cats, administrative spaces, and an outdoor courtyard are located on the second level. Cats are contained in moveable cages that can be easily wheeled around (Figure 7I). The courtyard has a garden of crops growing and also brings in plenty of natural light to the cat spaces. Staff and cats use this space in the summer months (Figure 7J). Overall, the visit into the adoption spaces simply showed animals that were available for adoption with a basic status chart on its cage. If visitors wanted any additional information, they would have to wait to ask a staff member at the front desk or fill in an application form and wait for contact. 
A
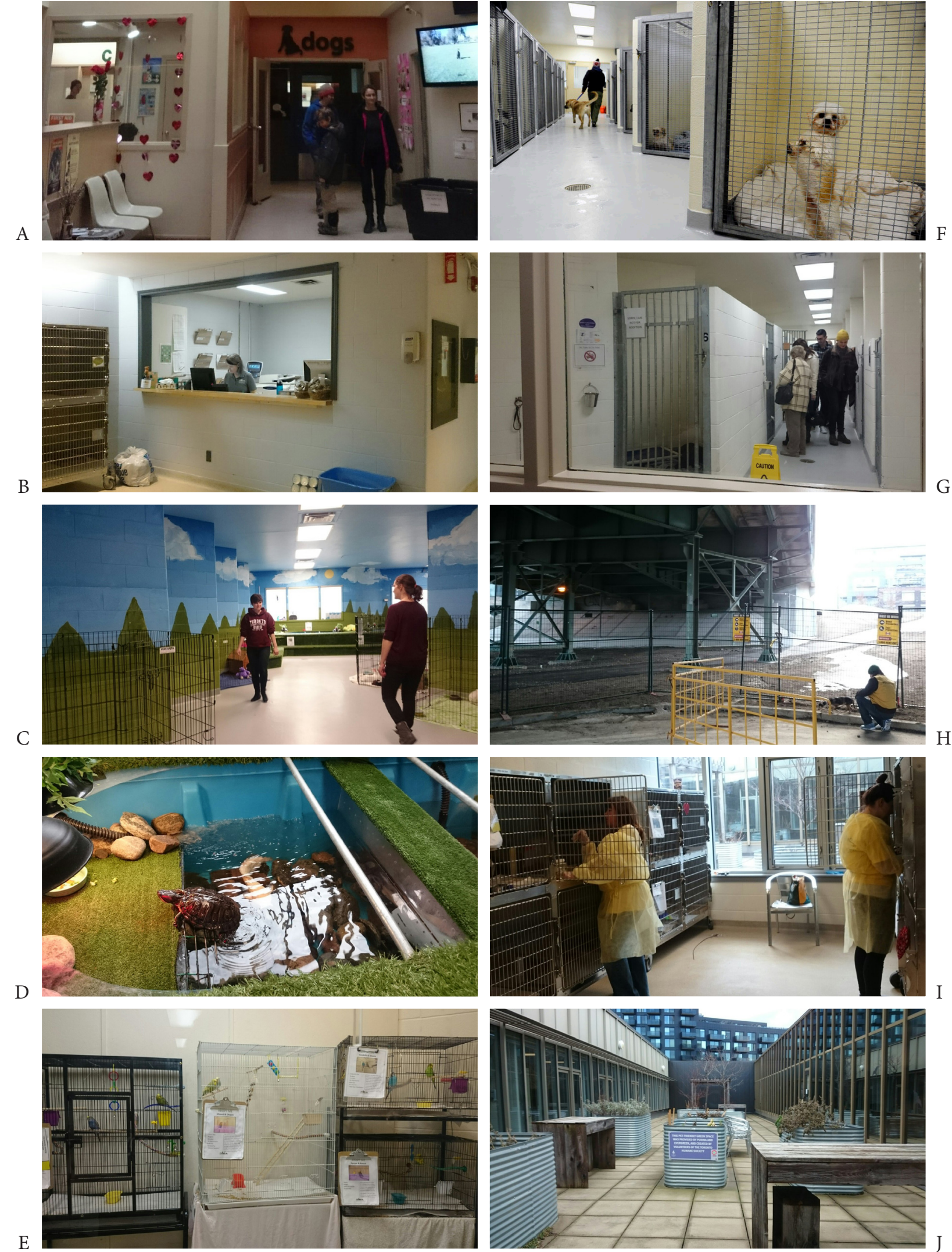

Figure 7

cclxxxiii 


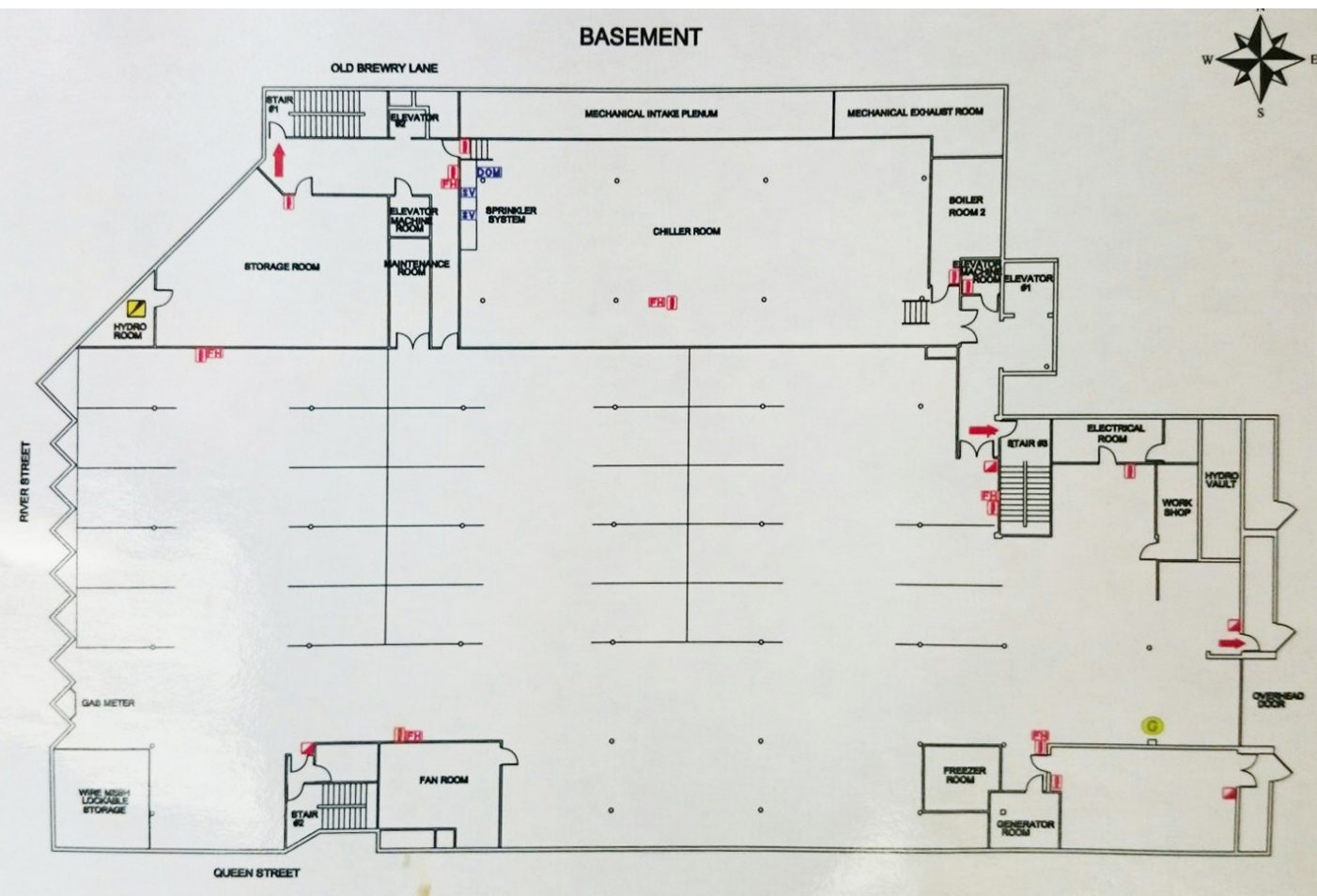

Figure 1: Basement Plan

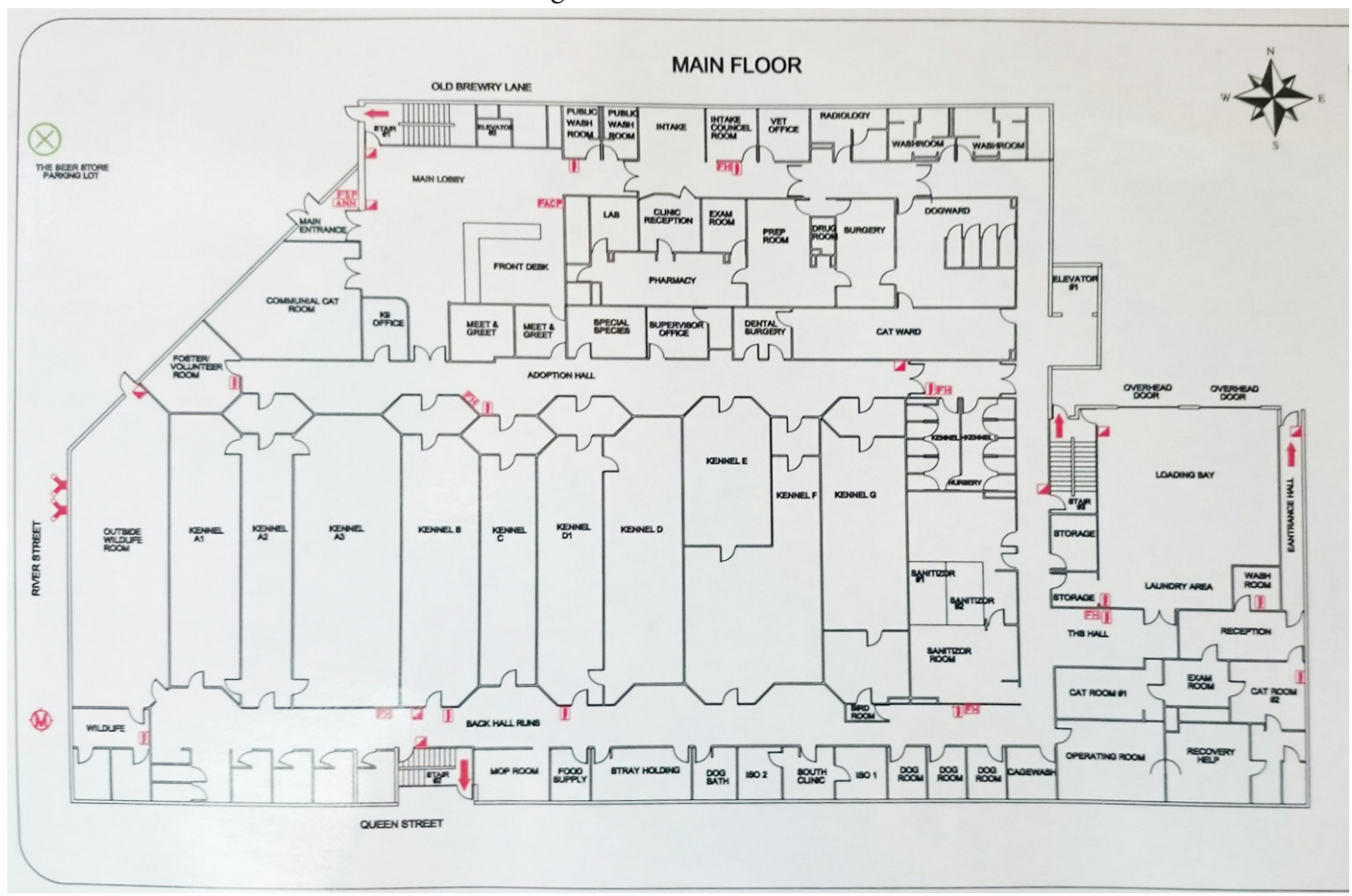

Figure 2: Ground Floor Plan

cclxxxiv 


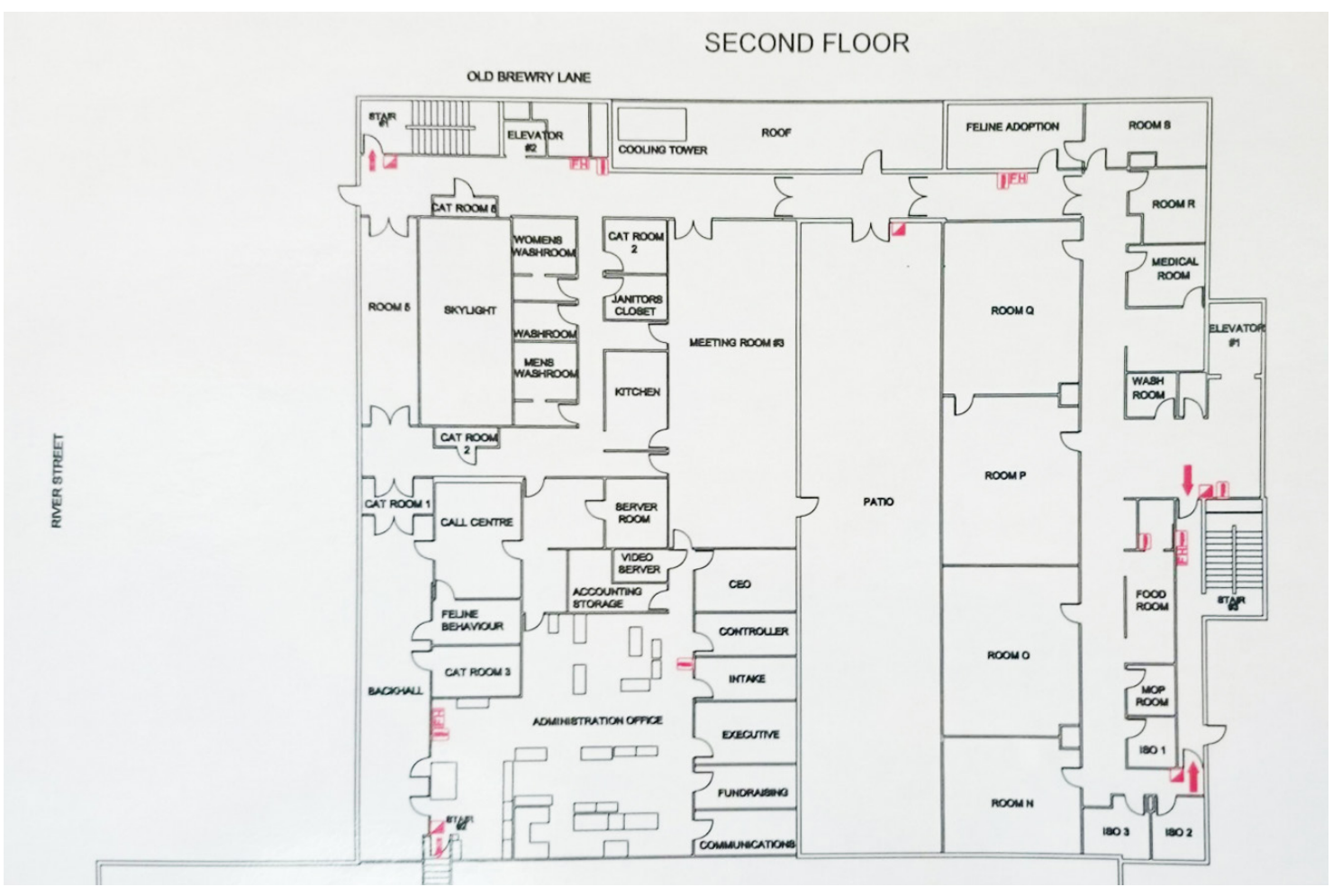

Figure 3: Second Floor Plan

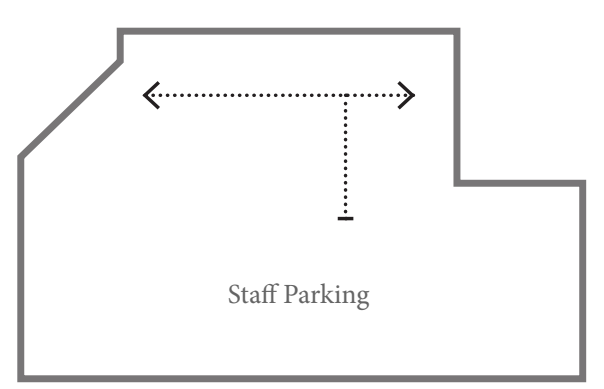

A

Legend

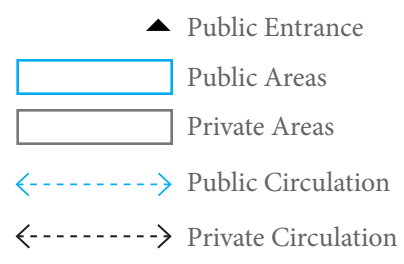

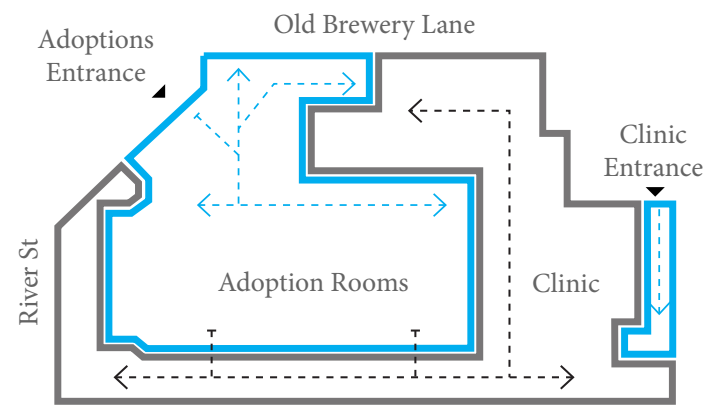

B

Queen St

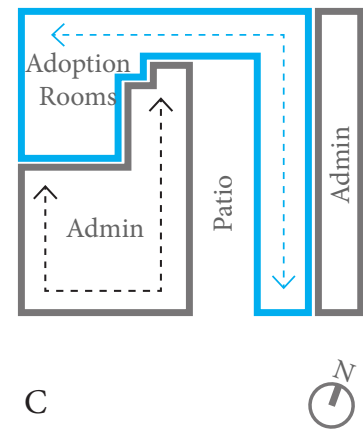

$\stackrel{N}{O}$
Figure 11: Public versus Private Spaces of the Existing THS
A | Basement Level
B | Ground Floor Layout
C | Second Floor Layout 
Beyond visiting the adoption areas of the shelter, the THS also offers guided shelter tours through their shelter and facilities. After the OSPCA raid in 2009, this initiative attempts to spread awareness for the shelter to present itself as a clean, publically accessible facility.

The guided tour first takes visitors through the adoption kennels, explaining the history and mandate of the THS. The second part of the tour takes visitors behind-the-scenes into the clinic and administrative spaces. In here, visitors are exposed to the laundry and loading facilities, food storage and prep areas, isolation rooms, clinic prep rooms, pre-op and post-op wards, and even operation rooms. The guide explains the processes and workings of the shelter to allow visitors a chance to understand the shelter beyond its adoption kennels. Public adoption and shelter visiting hours are between 10am to 6pm. Beyond those hours though, they have 6 veterinarians, numerous technicians and assistants, administrative staff, call center staff, a communications and marketing department, over 500 volunteers and 250 foster parents, each working toward animal care and well-being. Animal intake and admissions are by appointment only, taking in animals transferred from another shelter (typically from Northern Ontario reserves, Quebec, or California) or owner surrenders. All animals must be isolated for 10 days and examined prior to becoming adoptable. The clinic staff ensures all animals are free of health issues and are spayed or neutered before adoption. Animals with behavior issues work with specialists to correct bad behaviors in order to increase their chance of adoption. Volunteers come in 5 shifts from 7am to $10 \mathrm{pm}$ every day, helping with activities ranging from animal enrichment and dog walking sessions to call center and administrative work. Figures 12-14 show clinic and other administrative spaces. A summary with photographs of the entire tour is outlined in Figure15.

\section{REFERENCES}

THS Shelter Tour conducted on February 32016.

Photographs and diagrams by author unless otherwise noted. 

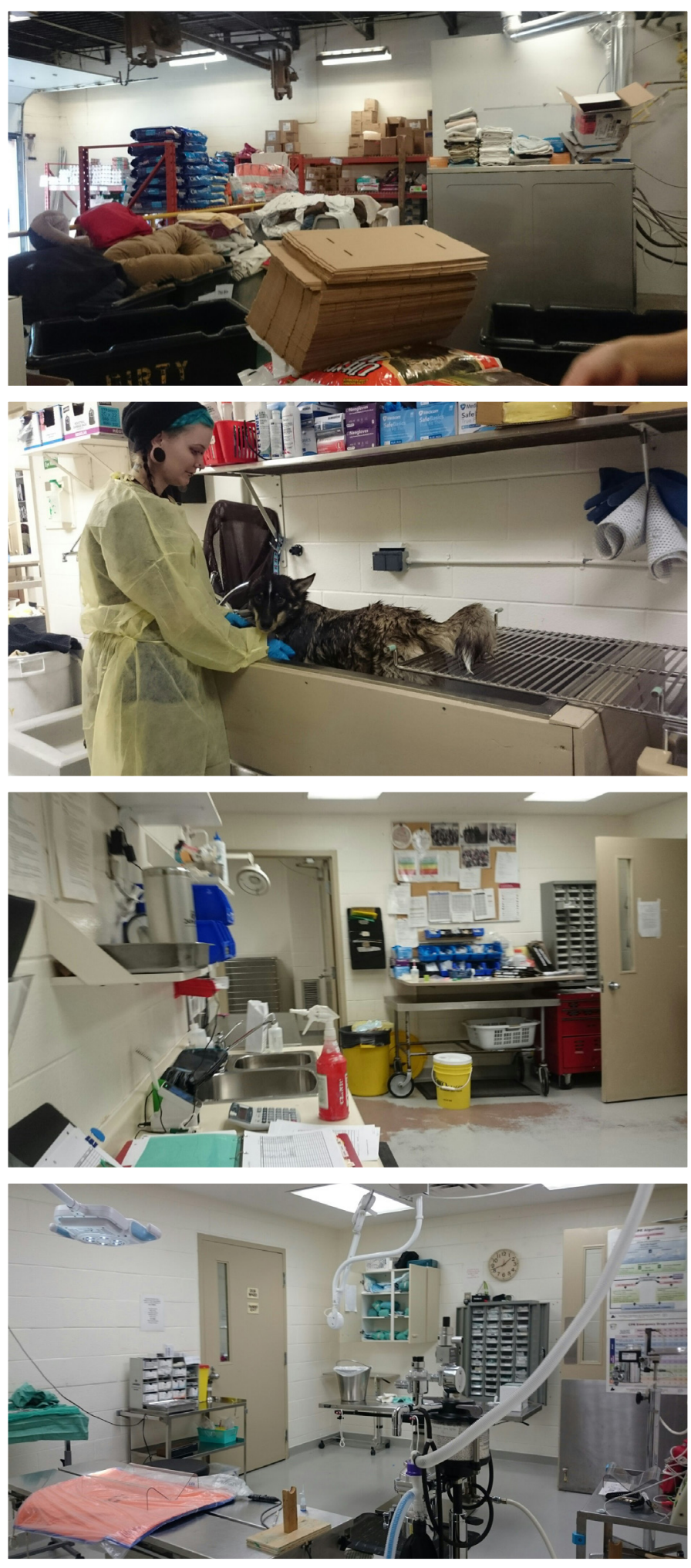

cclxxxvii
Figure 12: Laundry and Loading Area

Figure 13: THS Staff treating a dog for fleas

Figure 14: Treatment and Triage Area

Figure 15: Surgery Room 
Figure 16: Isolation Room
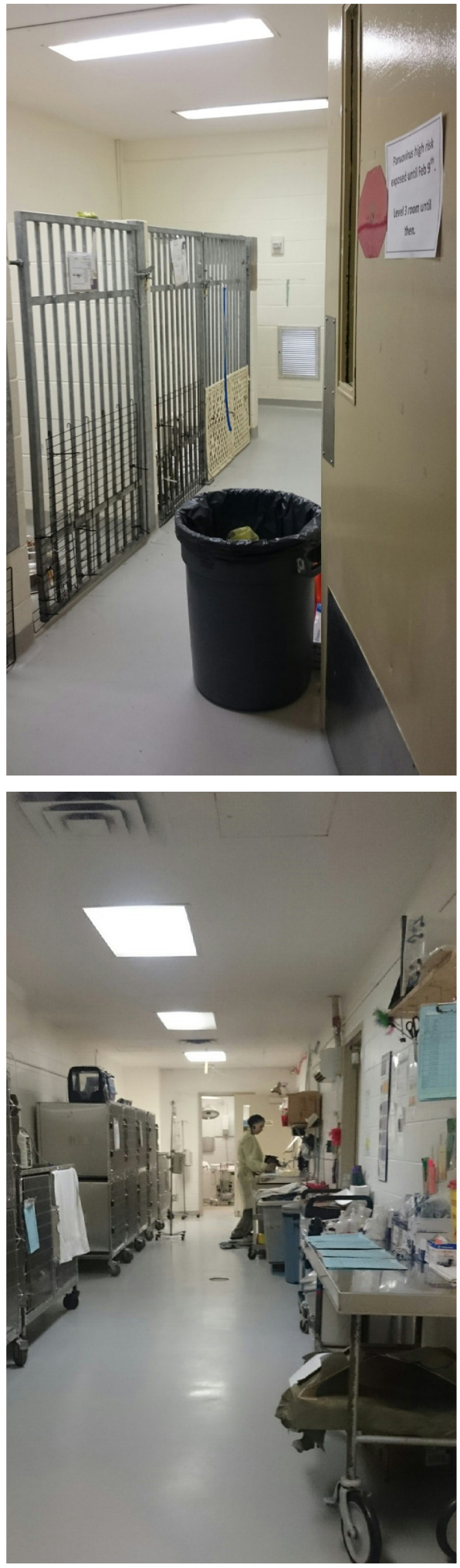

Figure 19: Treatment Area
Figure 17: Surgery Room
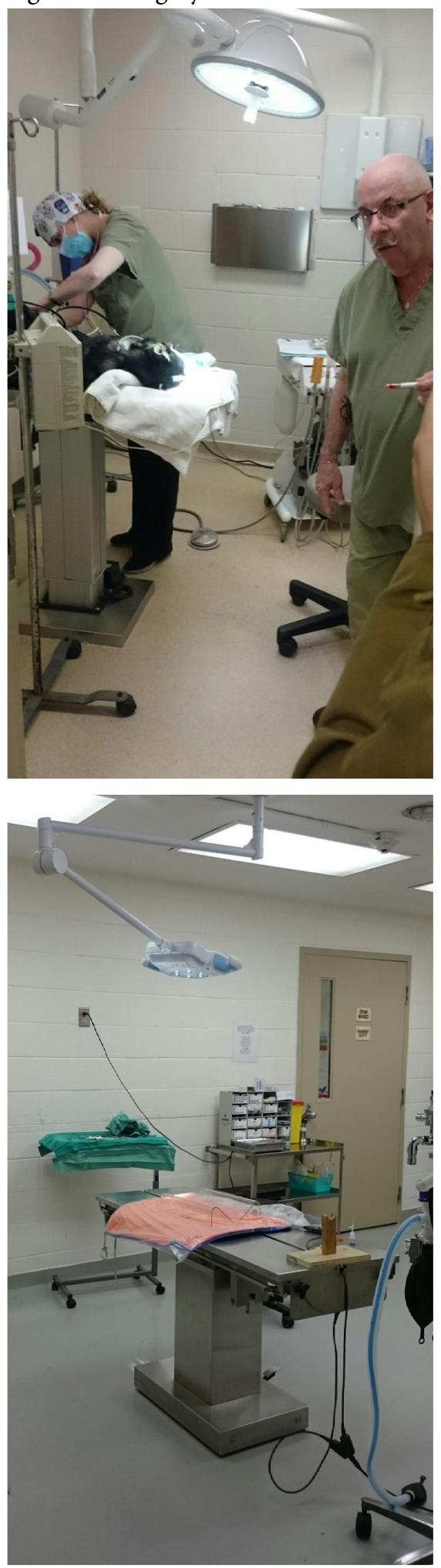

Figure 20: Surgery Room

cclxxxviii
Figure 18: Husky prepared for surgery
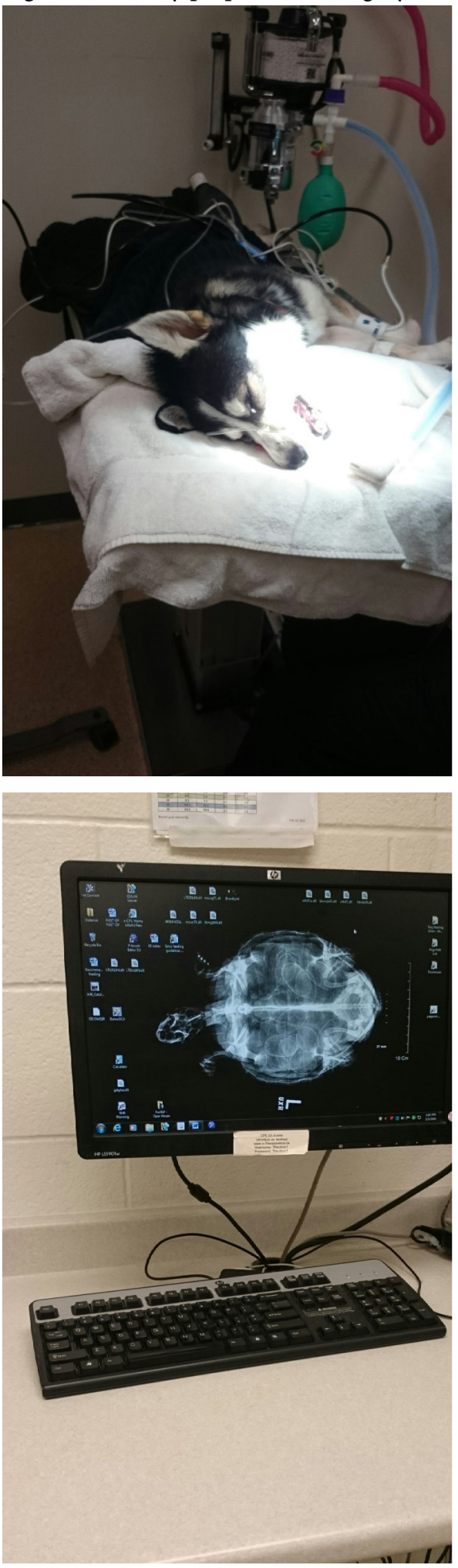

Figure 21: THS Systems 


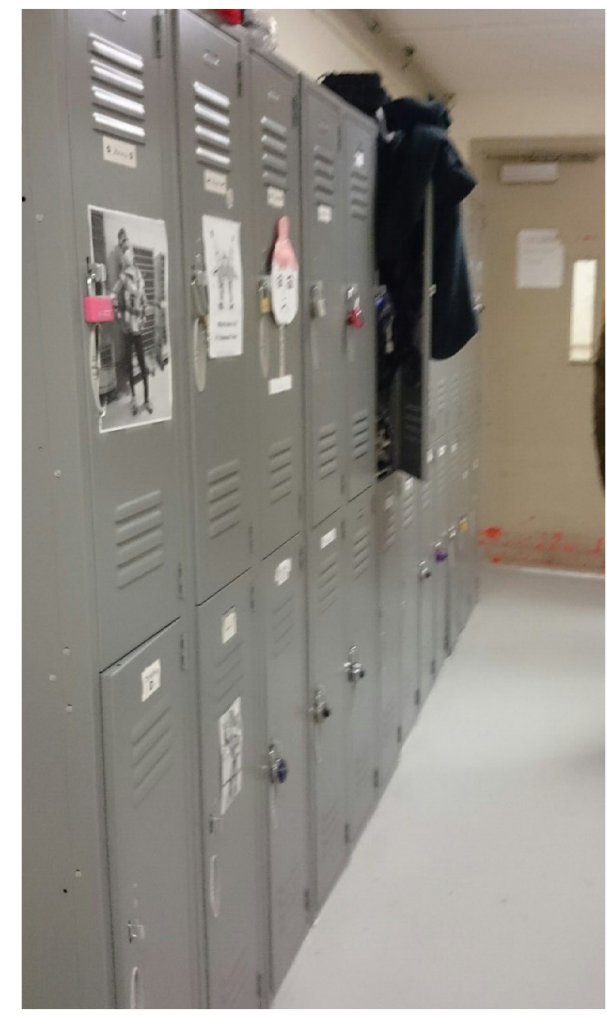

Figure 22: THS Staff Lockers
Figure 23: Feline Adoption Interviews
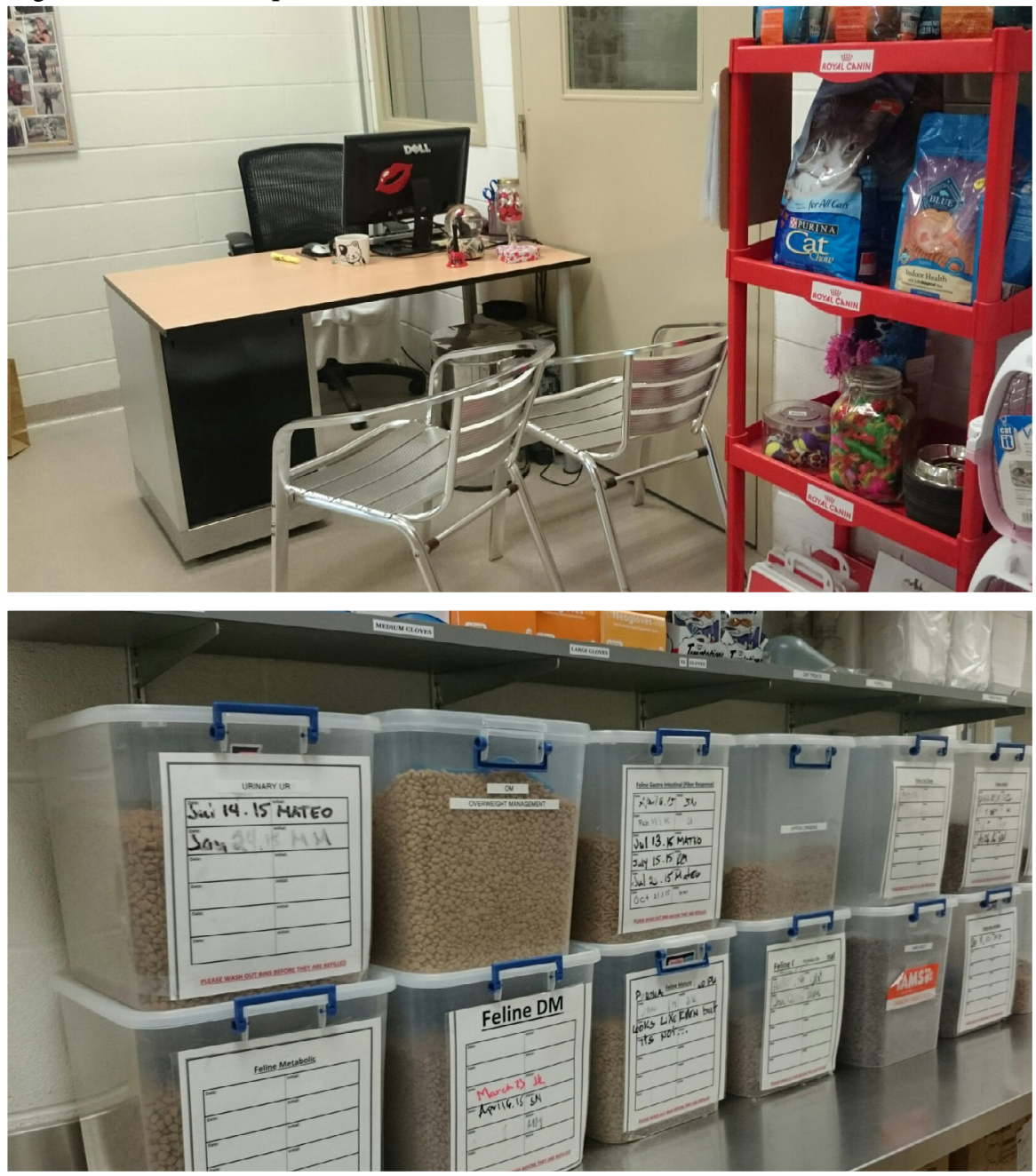

Figure 24: Feline Food Storage

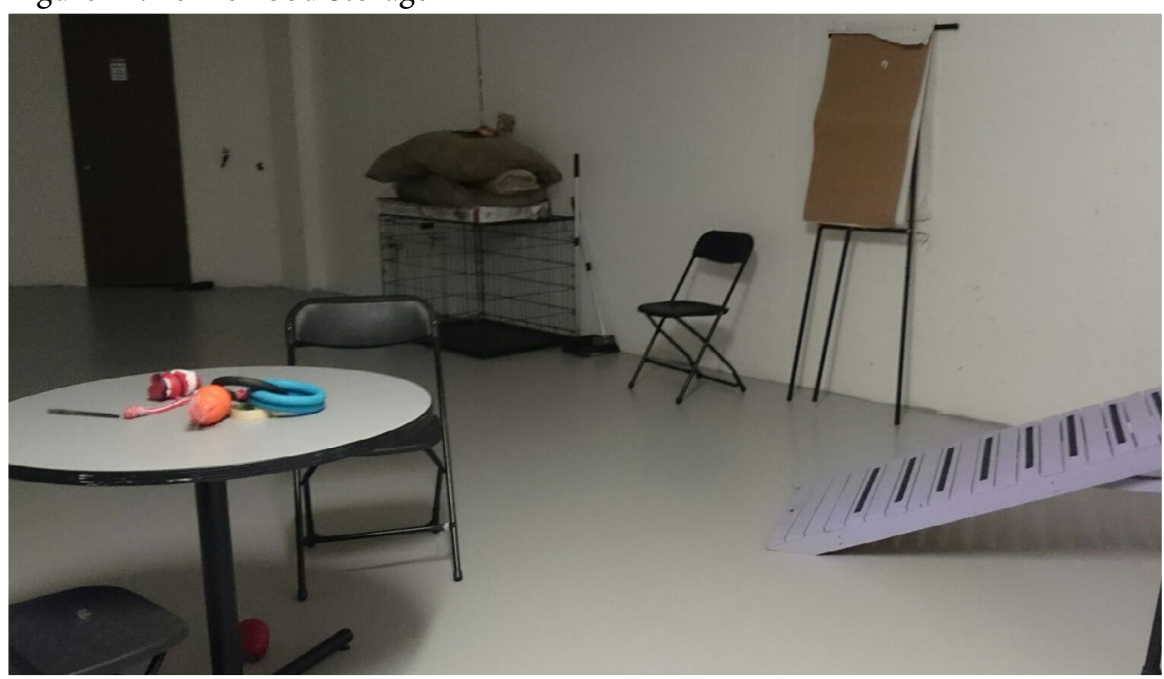

Figure 25: Canine Training Room

cclxxxix 
| Beyond a set of double doors from the main lobby, the intake office and lost $\&$ found. No windows or views to outside or rest of facility.

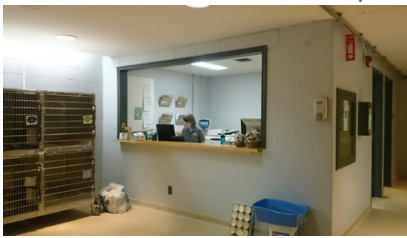

intake office

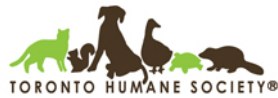

TORONTO HUMANE SOCIETY

Figure 26: Photos and summary of THS Shelter Tour, taken Feb 3 2016, comparing public versus private spaces.

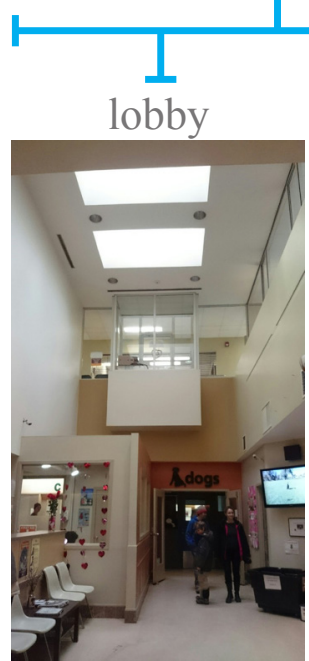

| Main entrance reception area has double height space and signs to direct visitors to kennels.

Small retail area behind reception desk. handles owner surrenders, strays,

| 2nd level - Cat Rooms with movable cages. Volunteers are playing with cats for 'enrichment'.
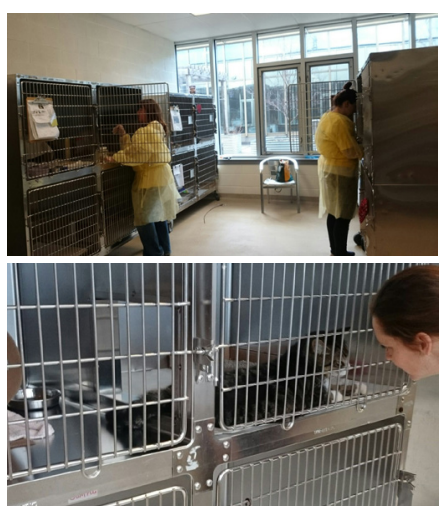

2nd level - Interior courtyard for volunteers and cat enrichment, also letting in natural light.
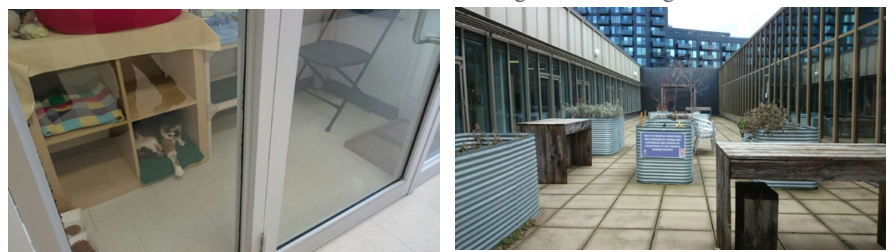

\section{cats}

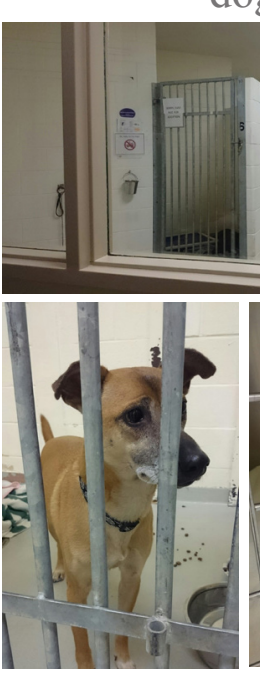

dogs
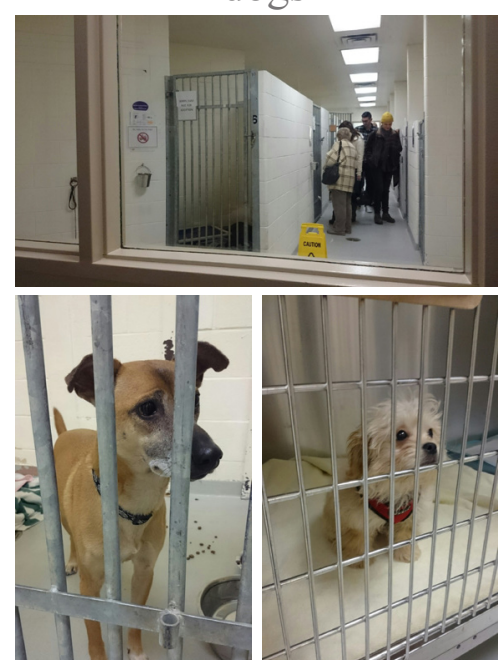

| 1st level - Dog Adoption Kennels - There are 4 main adoption rooms with 10-20 double sided runs each. Double sided runs allow ease of cleaning and separates food and resting area from elimination area. Dogs typically stay here for around 2 weeks before they get adopted. Concrete and metal finishes echo barks, voices, and footsteps. No windows or views out are provided.

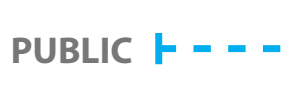

\section{small animals}

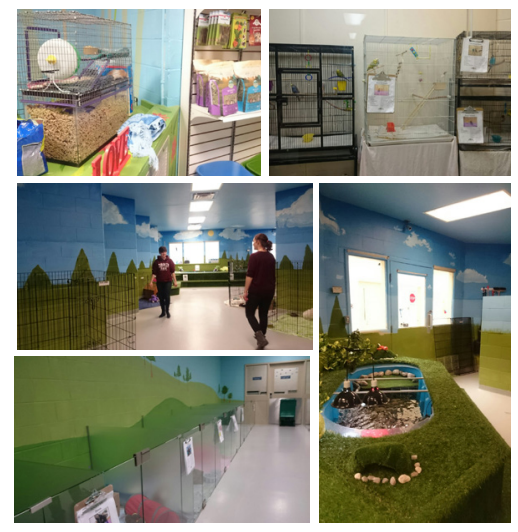

| 1st level - Small Animals Adoption Rooms. Cages are on the floor and painted murals attempt to stimulate the hamsters, gerbils, rabbits, and turtles. Birds are separated into a small room with no windows. 
| Isolation kennels

| Surgery Rooms. During time of visit, are rated by hazard. a shelter huskie was being prepped for dental surgery. The veterinarian briefly explained the procedure and background of the huskie.
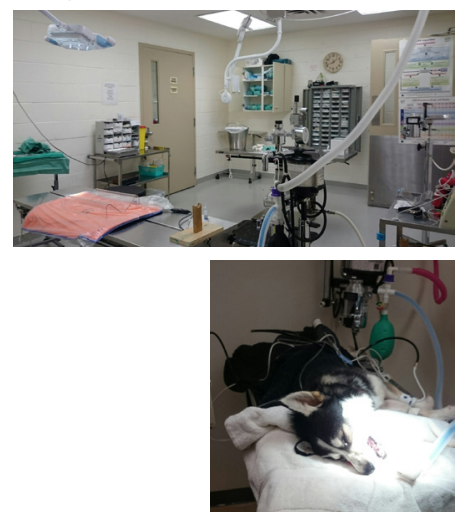

Protective gear must be worn to enter. Animals are isolated here for at least 10 days.

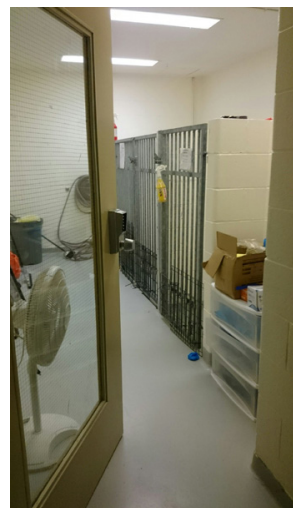

isolation \& clinic

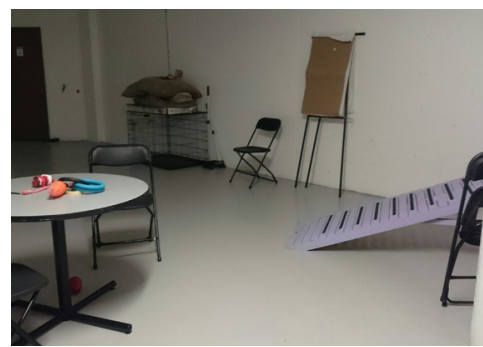

\section{behaviour training}

Treatment Area. A THS Staff is treating a dog for lice.
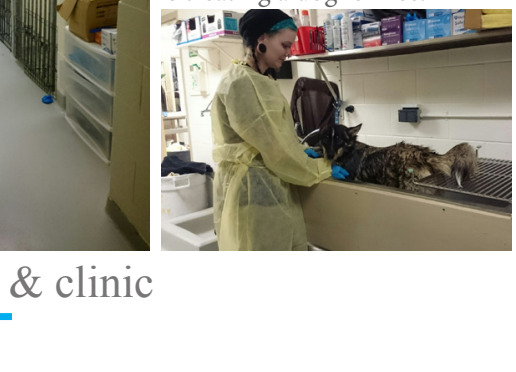

\section{PRIVATE}

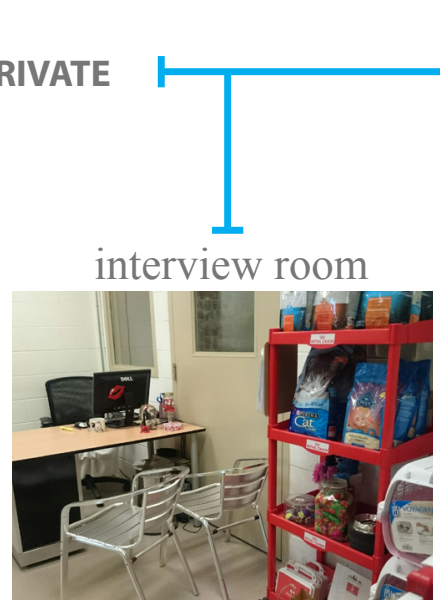

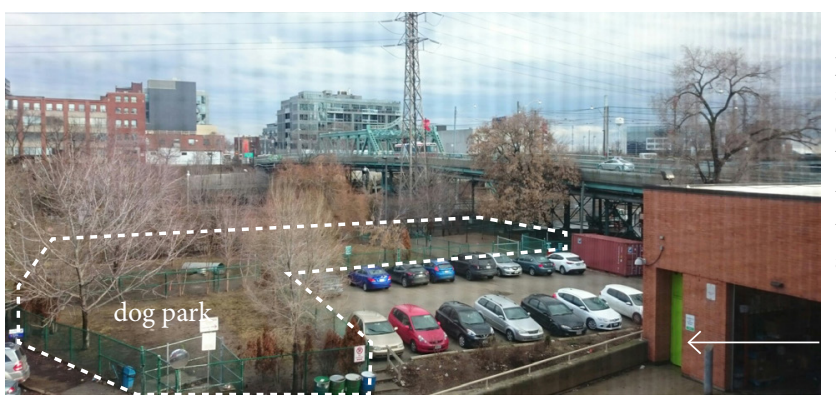

| Dog park, public parking lot, and public spay/neuter clinic entrance at back of building. Dogs are taken outside for 2 play groups per day. Volunteers have to take dogs out through front entrance, around to the back and across the parking lot to access the parks.

| Entrance to public spay/neuter clinic
| Training facility for dogs with behavioural issues is located in the basement. Previously a storage room. Pet training classes for general public are held here. 2nd Level Interview Room

- Potential adopters are interviewed by staff to discuss compatability and other responsibilities. and storage of cat food. Staff prepare food based on health and diet requirements.
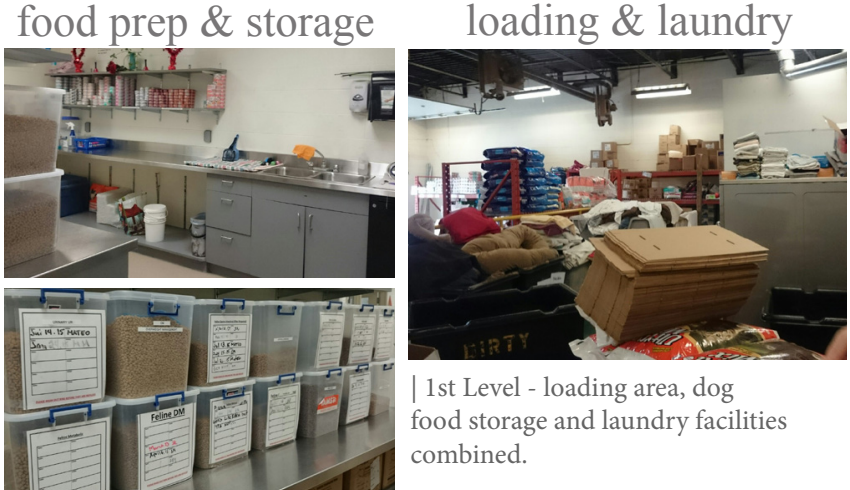

| 1st Level - loading area, dog food storage and laundry facilities combined. 


\section{APPENDIX E}

Animal Shelter Precedent Studies 


\section{Case Study 1:}

Palm Springs Animal Care Facility, Palm Springs, California. 2002. Swatt | Miers Architects $21,000 \mathrm{SF}$

The facility is designed to maximize operational efficiency by condensing the clinic, treatment, and isolation areas to one end of the building and allowing public access from the other end. Due to its climatic conditions, the facility can allow for centralized indoor and outdoor adoption kennels, giving animals the ability to be outdoors to maximize air flow through the kennels. Its setting in the park allows for a single storey facility with ample daylighting and views to the surrounding mountains. Movement and access through the shelter is straightforward, taking visitors directly into the adoption spaces, accessible through one main entrance. The facility also has an after-hours community education center for public engagement and is accessed through a third entrance.

Figure 1A: Palm Springs Animal Care Facility Entrance

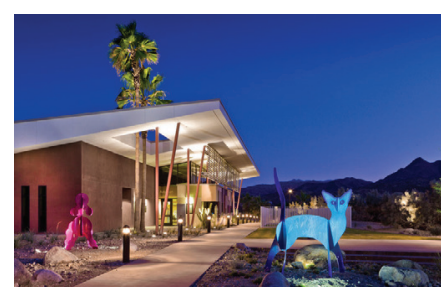

Figure 1B: Palm Springs Animal Care Facility Adoptions Lobby

Figure 1C: Palm Springs Animal Care Facility Public Hallway to Kennels
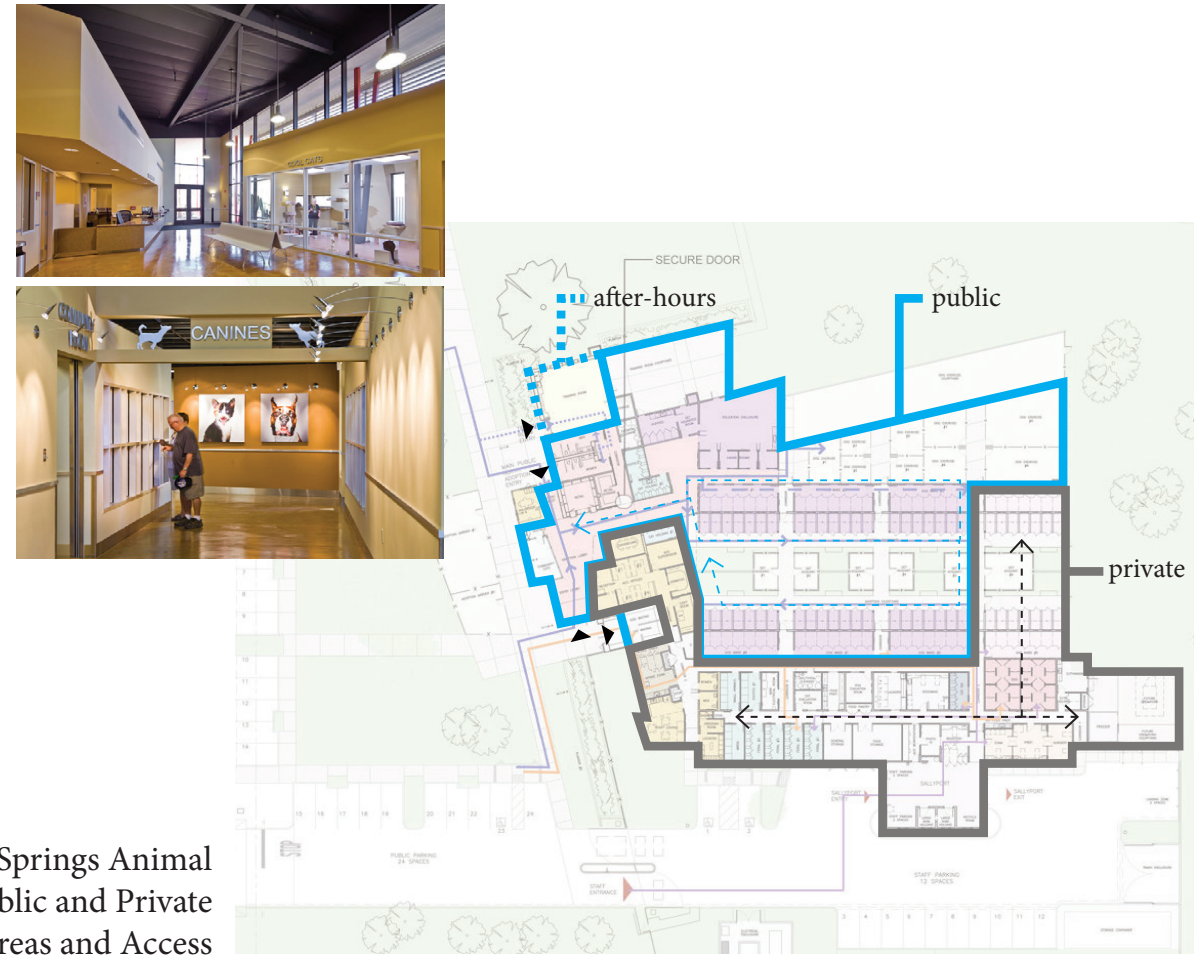

Figure 1D: Palm Springs Animal Care Facility Public and Private Areas and Access 


\section{Case Study 2:}

\section{Greenville Humane Society, Greenville, South Carolina.}

McMillan Pazdan Smith Architecture

$10,000 \mathrm{SF}$

The low budget warehouse renovation aims to rebrand the Greenville Humane Society in simple yet bold ways. Durable and readily available materials were used to keep costs down, and use of bright colour, bold typography, and large murals adds playfulness to the interiors (Figure 2C). The shelter accommodates around 60 cats and dogs and is also designed for other revenue-generating aspects like a retail shop, café, and salon. Two separate entrances for adoption center and clinic are located in the front, signified by a bright green wall (Figure 2B). The adoption lobby directs visitors straight to the kennels only. The grounds also feature dog parks and walking trails for the shelter's animals. The project simply and successfully brings in an element of playfulness and joy to the otherwise simple and pragmatic structure.

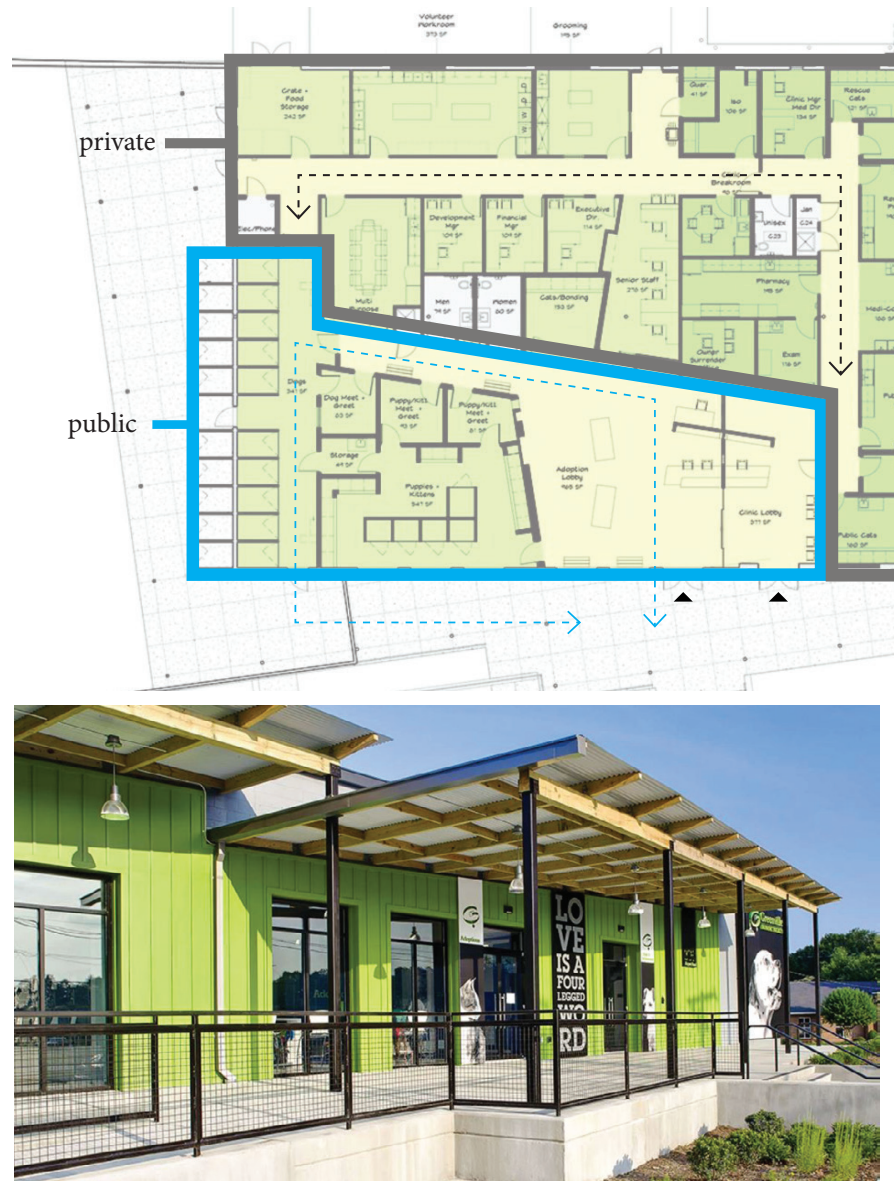

Figure 2B: Greenville Humane Society Entrance
Figure 2A: Greenville Humane Society Public and Private Areas and Access

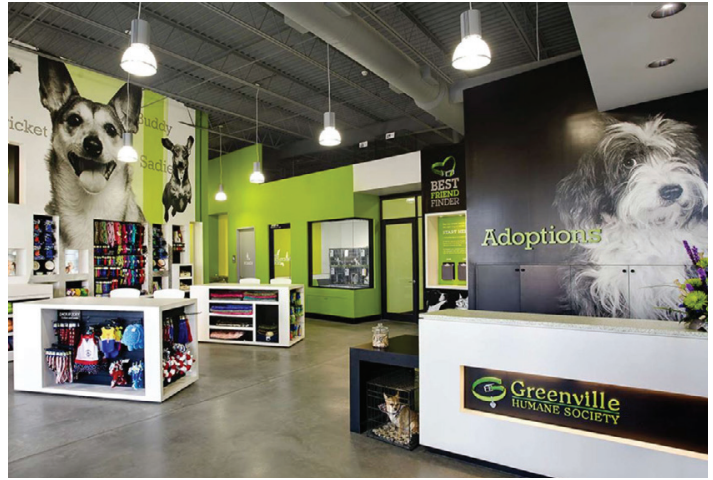

Figure 2C: Greenville Humane Society Adoptions Entrance Lobby 


\section{Case Study 3:}

\section{Montgomery County Animal Services and Adoption Centre, Montgomery \\ County, Maryland. 2014.}

Proffitt \& Associates Architects

$49,000 \mathrm{SF}$

The one and a half storey facility is designed as a linear mass meant to provide straightforward circulation and workflow. Workflow process from intake to adoptions is laid out in a linear manner, where each step in the intake process branches off this main circulation spine toward adoptions (Figure 3). This cuts down animal transport into shorter distances between stages, making it easy for staff to navigate and understand workflow. Adoptions and Animal Services share the facility and is clearly divided between public and private functions. Animal care and housing areas are all on the ground floor for ease of operations, with administrative offices on the second floor. The spaces are very simple and pragmatic, but presents a sterile and monochromatic appearance not unlike that of a hospital (Figures 3B, C, D).

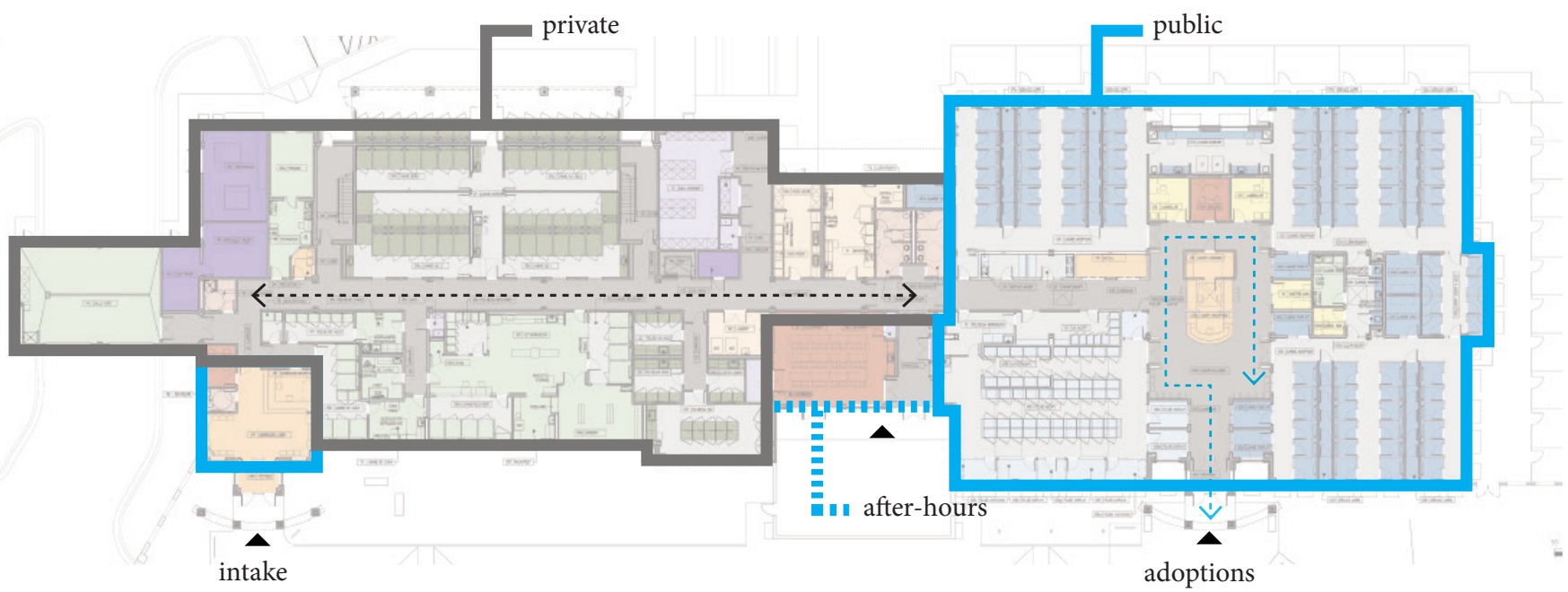

Figure 3A: Montgomery County Animal Services and Adoption Centre Public and Private Areas and Access

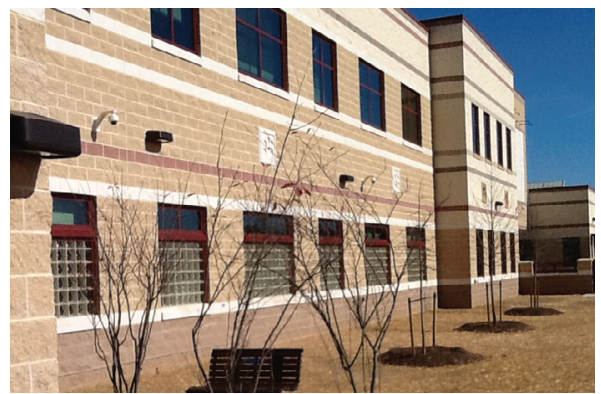

Figure 3B: Montgomery County Animal Services and Adoption Centre Building Exterior

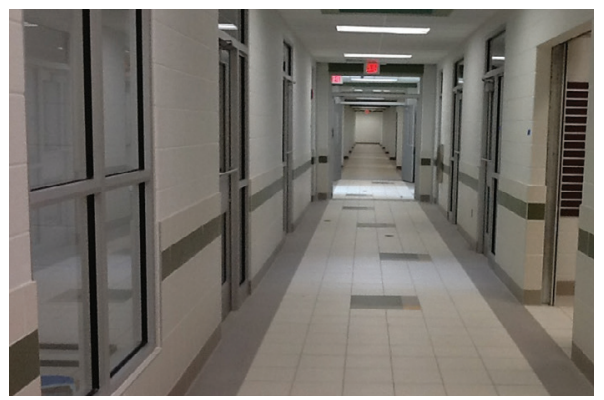

Figure 3C: Montgomery County Animal Services and Adoption Centre Central Circulation Corridor

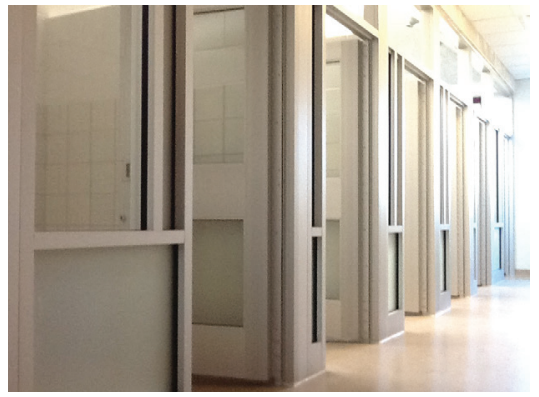

Figure 3D: Montgomery County Animal Services and Adoption Centre Kennels 


\section{Case Study 4:}

\section{Staten Island Animal Care Center, Staten Island, New York. Unbuilt.}

Garrison Architects

$5,000 \mathrm{SF}$
Figure 4:

Staten Island Animal Care Center
A | Outdoor Courtyard
B | Entrance Lobby
C | Public and Private Areas and Access

The design proposes an interesting reversal of the typical shelter plan, where the animal housing quarters are on arranged along the perimeter of the building for maximum visibility and daylighting. Offices and services are internalized instead, but maintains separation between public and private. The translucent façade lets in lots of natural light and the exterior is expected to be animated by the liveliness of the animals inside. This, however, puts the animals perpetually "on display". It gives them visibility to the public, but doesn't give them the option of concealing themselves, taking away some privacy and comfort.

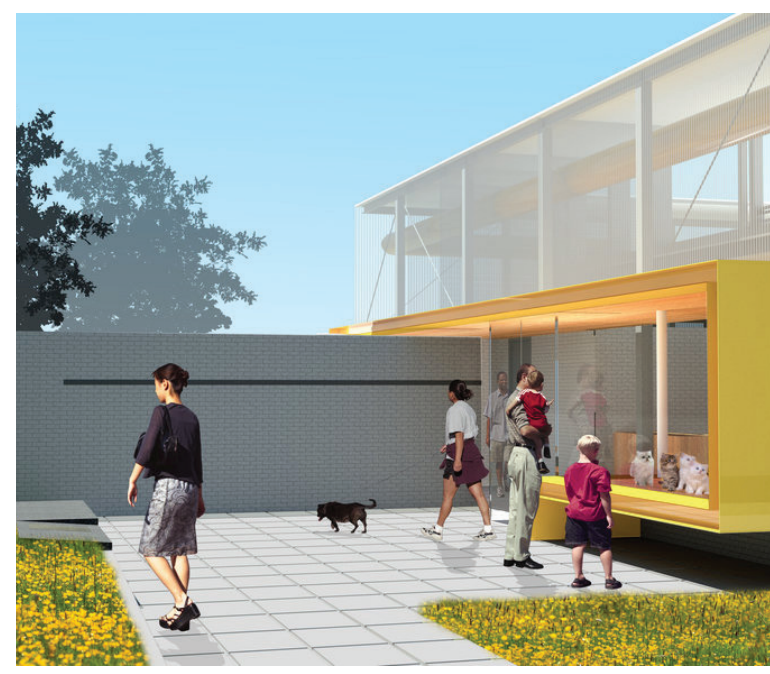

Figure 4A: Staten Island Animal Care Centre Outdoor Courtyard

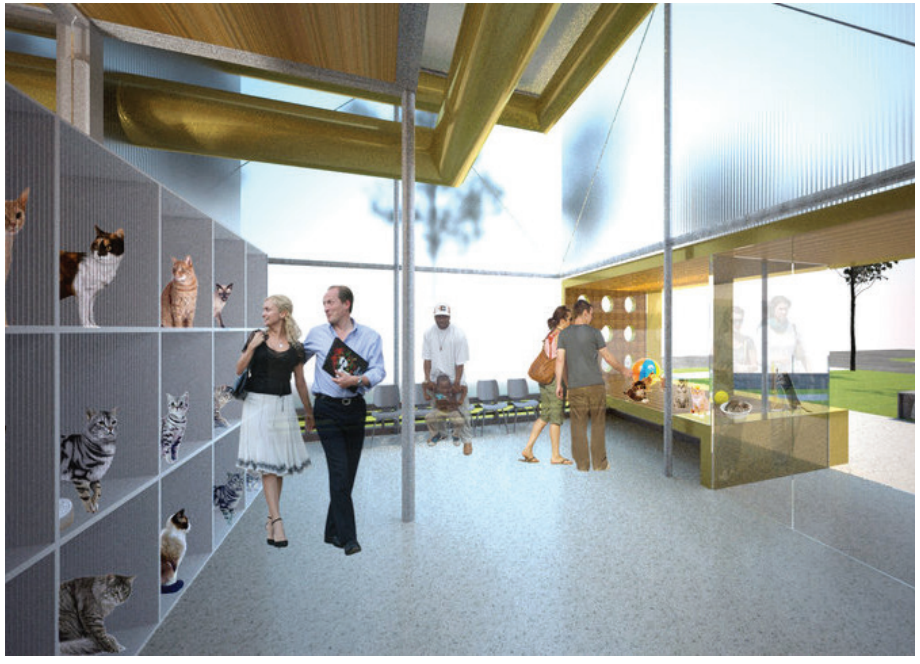

Figure 4B: Staten Island Animal Care Centre Entrance Lobby

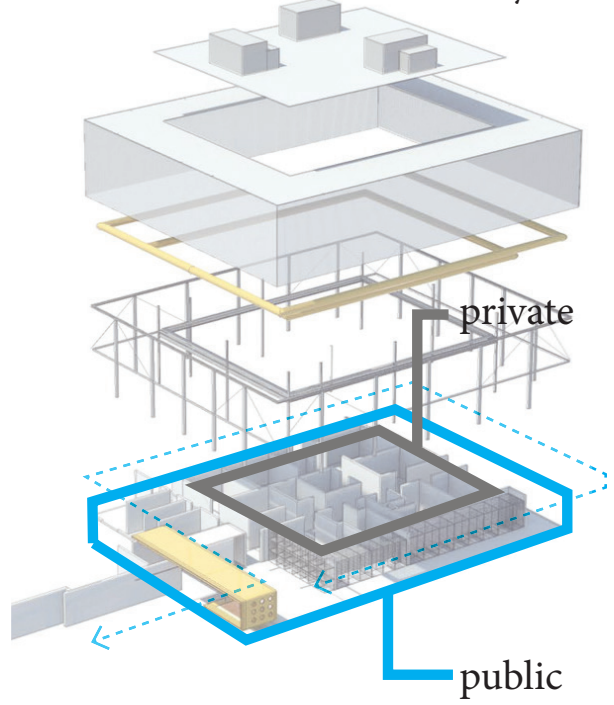

Figure 4C: Staten Island Animal Care Centre Public and Private Areas and Access 


\section{Case Study 5:}

Amsterdam Animal Refuge Center, Amsterdam, The Netherlands. 2007. Arons en Gelauff Architecten $62,000 \mathrm{SF}$

The facility is arranged tightly along its site boundaries defined by a waterway at the fringe of the city of Amsterdam. A ribbon of service corridors and dog kennels surround internal courtyards of smaller play spaces, internalizing all housing and public adoption spaces (Figure 5C). The climate allows for kennels and public adoption spaces to be outdoors. The building faces inwards in order to reduce noise levels for its neighbours and cat housing is located on the second level, providing another level of noise buffer. The main entrance, offices, clinics and service spaces are centrally located for ease of access to both kennel areas, and the shelter also provides daycare and grooming services. The exterior façade has minimal openings and seems to turn its back on its context, but also references it by resembling a pixelated graphic of grasses inspired by its site surroundings (Figure 5A). Once inside, visitors are surrounded by the animals on both levels, giving them maximum visibility. However, the colour and playfulness doesn't extend into the interior, and the cages and bars evoke a prison-like environment (Figures 5D and E).

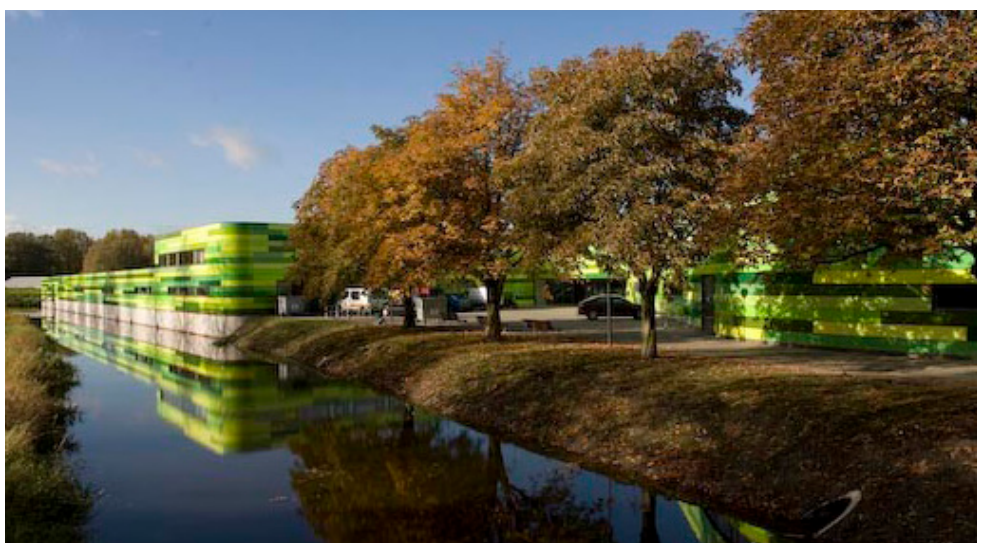

Figure 5A: Amsterdam Animal Refuge Centre Building Exterior

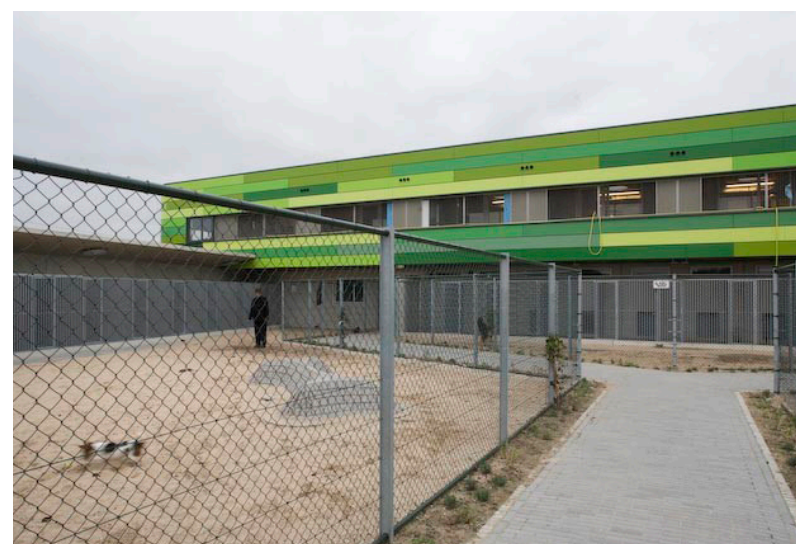

Figure 5B: Amsterdam Animal Refuge Centre Internal Courtyard Play Space 
Figure 5C: Amsterdam Animal Refuge Centre Entrance Lobby

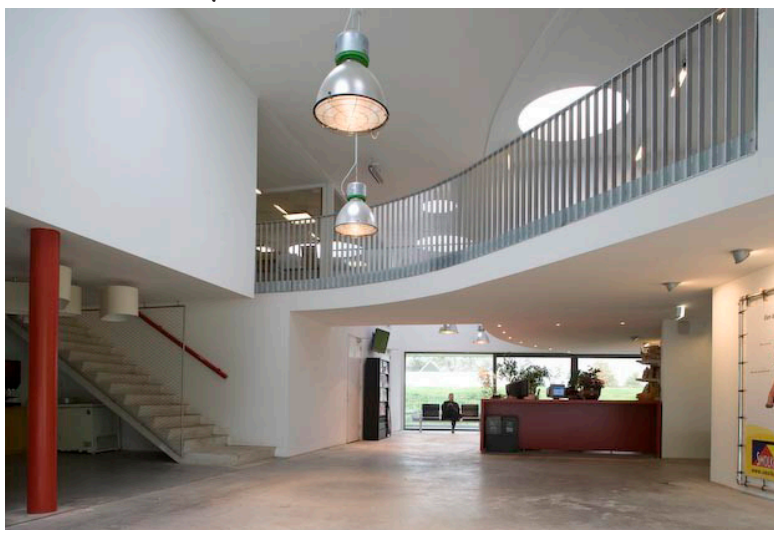

Figure 5D: Amsterdam Animal Refuge Centre Kennels and Outdoor Space
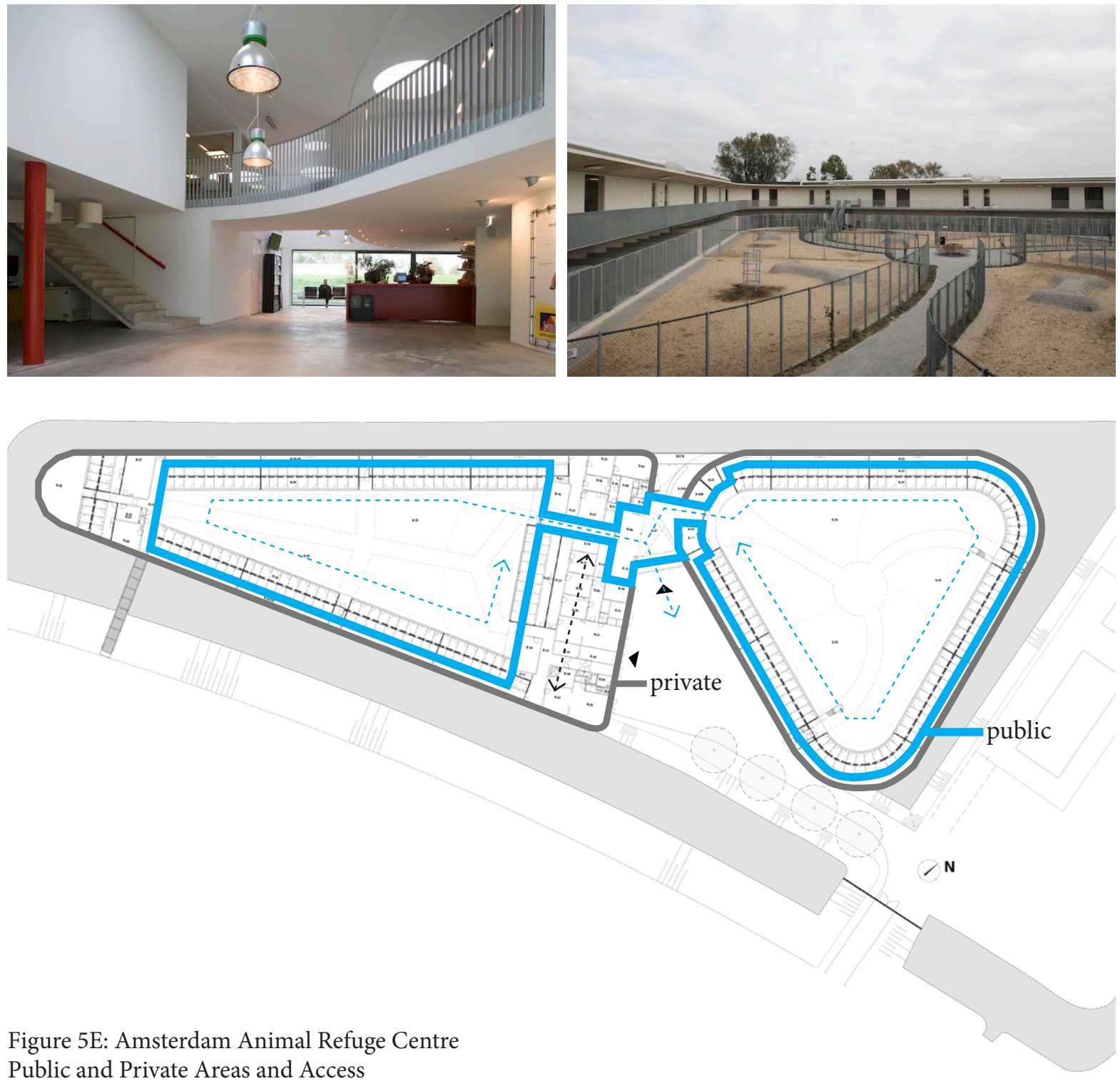

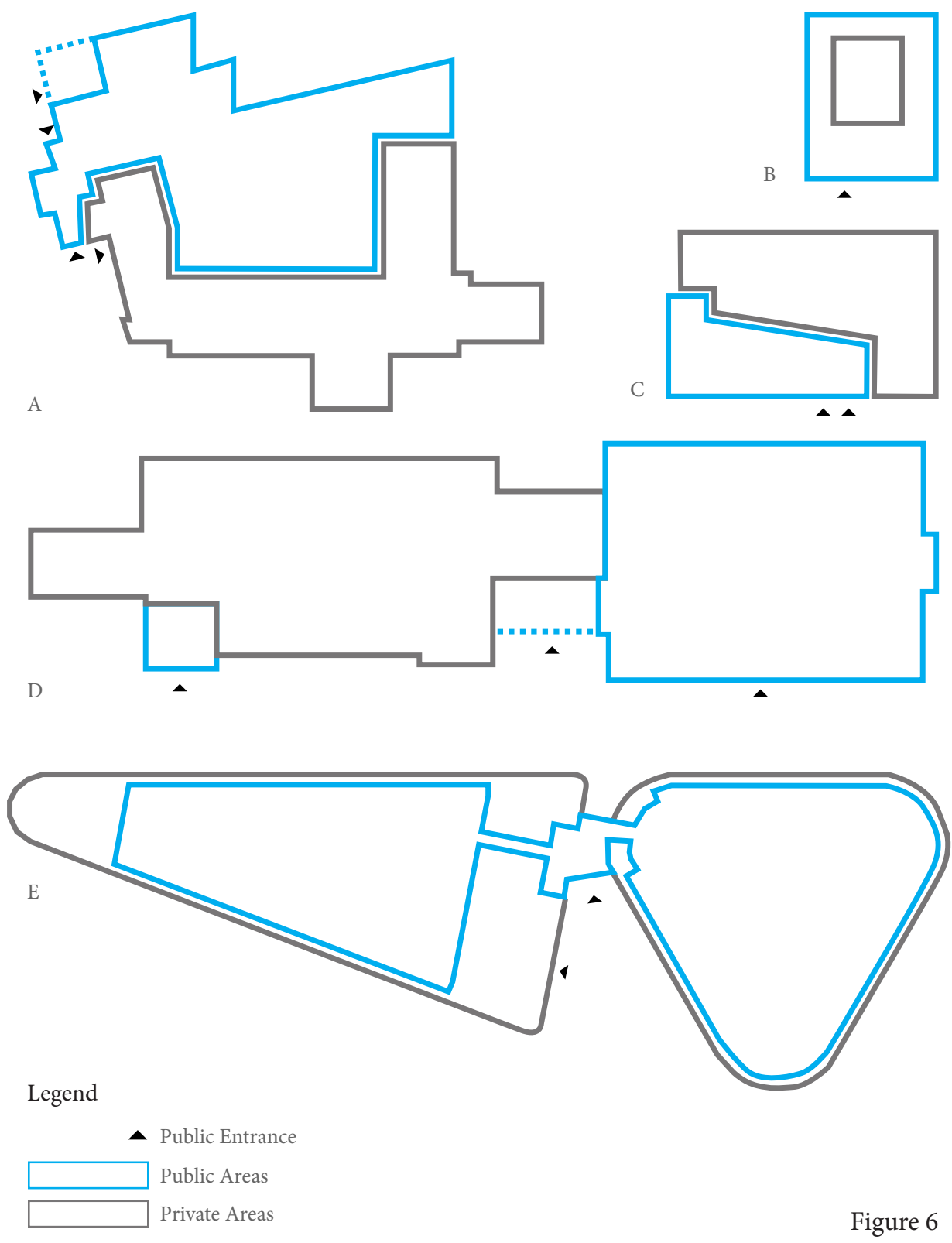

Figure 6:

Shelter Layout Diagrams Summary
A | Palm Springs Animal Care Facility
B Staten Island Animal Care Center
C | Greenville Humane Society
D | Montgomery County Animal
Services and Adoption Centre
E $\mid$ Amsterdam Animal Refuge Center 


\section{REFERENCES}

Case Stuy 1: Palm Springs Animal Care Facility, Palm Springs, California. 2002 Swatt | Miers Architects

http://www.archdaily.com/237233/palm-springs-animal-care-facility-swattmiers-architects

http://mobile.swattmiers.com/palm-springs/

Case Study 2: Greenville Humane Society, Greenville, South Carolina. McMillan Pazdan Smith Architecture

http://architizer.com/projects/greenville-humane-society/

Case Study 3: Montgomery County Animal Services and Adoption Centre, Montgomery County, Maryland. 2014.

Proffitt \& Associates Architects http://www.montgomerycountymd.gov/DGS-BDC/MMC/470400.html http://www.montgomerycountymd.gov/animalservices/

Case Study 4: Staten Island Animal Care Center, Staten Island, New York. Unbuilt.

Garrison Architects

http://www.garrisonarchitects.com/projects/buildings/staten_island_animal_ care_center

http://www.archdaily.com/121670/in-progress-staten-island-animal-care-centergarrison-architects

Case Study 5: Amsterdam Animal Refuge Center, Amsterdam, The Netherlands. 2007.

Arons en Gelauff Architecten http://www.archdaily.com/2156/animal-refuge-centre-arons-en-gelauffarchitecten

http://www.arch2o.com/amsterdam-animal-refuge-centre-arons-en-gelauffarchitecten/

http://www.doamsterdam.nl/EN/hoofdmenu_intro_asiel_en.htm 


\section{APPENDIX F}

Shelter Design Guidelines and Operational Efficiencies 


\section{Introduction}

Beyond observation of the THS functions and analysis of precedent layouts, the operational process of animal shelters, operational efficiencies, and standard shelter design guidelines were also studied. These guidelines and manuals are taken from various agencies such as the Canadian Federation of Humane Societies (CFHS), British Royal Society for the Prevention of Cruelty to Animals (RSPCA), The Association of Shelter Veterinarians, etc.

\section{Overall Goals and Missions}

The Five Freedoms for Animal Welfare

1. Freedom from Hunger and Thirst

2. Freedom from

Discomfort

3. Freedom from Pain, Injury or Disease

4. Freedom to Express Normal Behavior

5. Freedom from Fear and Distress by ready access to fresh water and a diet to maintain full health and vigor

by providing an appropriate environment including shelter and a comfortable resting area

by prevention or rapid diagnosis and treatment

by providing sufficient space, proper facilities and company of the animal's own kind by ensuring conditions and treatment which avoid mental suffering 


\section{Overall Shelter Design Considerations}

Primary Enclosure

Area of confinement where an animal eats, sleeps, and spends majority of its time in. (More details below)

Surface and Drainage

Non-porous surfaces, easily disinfected

Heating, Ventilation, and Air Quality

Ambient temperatures above 15.5 degrees $\mathrm{C}$ and below 26.6 degrees $\mathrm{C}$

Relative humidity 30-70\%

Fresh air or adequate ventilation

Olfactory separation between each animal type

Light

Maximize natural light, but also provide areas of darkness for preferences

Natural light helps animals understand day and nigh cycles

Sound Control

Acoustic isolation of each animal type to reduce stress 


\section{THE BUILDING - LAYOUT}

When deciding the layout of your shelter, preventing the spread of disease must be your first priority. Incoming animals must be quarantined away from animals that are ready for rehoming. Isolation and quarantine areas must not be accessible to the general public.

\section{STAFF AND PUBLIC SPACES}

1. RECEPTION AREA: You must consider every procedure and activity regularly undertaken here, including the traffic flow of people using this area. The reception area should give a good first impression and will therefore need to communicate a sense of order, and be light and clean.

2. ADMINISTRATIVE OFFICE: This is the control centre for the shelter, and it should have direct access both to the reception area and the animal quarters. You will need to keep accurate records of all animals entering and leaving your shelter, so you must allow sufficient space for the storage of records, including future growth.

3. MEDICAL/EUTHANASIA ROOM: This should be adjacent to the isolation/quarantine facility to allow the easy movement of sick and recovering animals. There should be a separate entrance from outside and clear access for vehicles. There should be a separate ventilation system for this area, and there should be isolation units that prevent any physical contact between animals.

4. CARCASS ROOM/COLD STORAGE: This should be adjacent to the euthanasia room - a cold room, refrigerator or freezer may be required. Before deciding on the method that you will use to dispose of carcasses, you must check with the local authorities for any health and pollution regulations that may affect your choice. If you are going to have a crematorium on site, then a dedicated space must be set aside for this purpose. If disposal is to take place off the premises, then a larger cold storage room will be needed.

5. ANIMAL FOOD PREPARATION: This area will require a sink with hot and cold running water and a refrigerator. You should ensure that there is an area to disinfect feeding bowls, and that you have sufficient counter space on which to place the bowls. The food storage should be adjacent, and all food should be stored off the floor in vermin-proof containers.

6. HYGIENE AREA: Staff will require a wash area and toilets, together with a shower area if possible.

\section{ANIMAL SPACE}

1. FLOORS: To guard against infection, all floors should have a smooth impervious surface e.g. tiles. Concrete can be used if it is hardened and treated to be impervious. In outside areas, gravel flooring is preferable to grass or earth, but must be thoroughly washed frequently. Wood is not advised as it deteriorates and paving is also difficult to keep clean.

2. WALLS: These should be sealed e.g. with chlorinated rubber paint, so that they can be properly cleaned. There should be no gaps or cracks that can harbour disease.

3. DRAINAGE: Floors should slope towards a drain that is outside the animal living areas. A drain opening of not less than $20 \mathrm{~cm}$ diameter is recommended and it should be covered by a strainer grid. The provision of mains sewers, a cesspit or septic tank is essential.

\section{DOGS}

The following are minimum standards based on RSPCA experience.

1. INDIVIDUAL OR QUARANTINE KENNELS: Each dog should have a minimum of $2 \mathrm{~m}^{2}$ covered and draft-free accommodation. It should have a raised bed surface. The minimum temperature is $10^{\circ} \mathrm{C}$ and the maximum is $26^{\circ} \mathrm{C}$. Sleeping quarters must be ventilated and have both natural and supplementary light.

Each dog requires a minimum of $2.5-3.5 \mathrm{~m}^{2}$ of open exercise run. Fencing should be at least $2 \mathrm{~m}$ high and be made of weld mesh. It should slope inwards at the top to stop dogs climbing. Animals must always have a view outside the kennel.

2. GROUP HOUSING: This is not suitable for ill, injured or nursing animals, or in shelters with a high turnover. Minimum space requirements for dogs in group housing are the same as in individual kennels per dog. Dogs should only be put into group housing after spending 10 days in quarantine. Care must be taken to match compatible animals. In group housing you must have a policy of sterilisation or strict separation of the sexes.

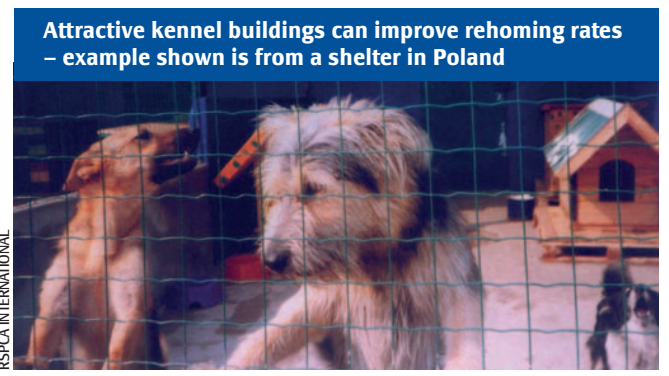

Guidelines for the design and management of animal shelters 


\section{CATS}

The following are minimum standards based on RSPCA experience.

1. Quarantine or individual cages: Cubicles plus exercise area should be a minimum of $2.2 \mathrm{~m}^{3}$ with an open mesh front. Each cubicle should have a bed, a dirt/ litter tray and space for food and water bowls. Good ventilation is essential and where cubicles face each other, they should be separated by at least $2 \mathrm{~m}$ to prevent the spread of disease.

2. Group housing: Good ventilation is even more important in group housing. Cats need access to covered, draft-free accommodation with a bed space. Bedding is not required, nor is it recommended because of the spread of infection. The minimum temperature is $10^{\circ} \mathrm{C}$ and the maximum should not exceed $26^{\circ} \mathrm{C}$. The outdoor space must be totally enclosed in weld mesh, but can have a solid roof. A sufficient number of dirt/litter trays to allow one per cat are required. The absolute maximum size of a group is 50 , but much smaller groups are recommended. In group housing you must have a policy of sterilisation or strict separation of the sexes.

\section{LARGE ANIMALS}

You may occasionally be called upon to take large animals such as horses. However, unless you have staff who are trained to deal with large animals, horses should only be accepted in an emergency, and kept for as short a time as possible before being taken to an alternative site where more specialised care is available. You will therefore need to identify specialists nearby that would be able to help you by 'fostering' large animals.

When making arrangements make sure you:

- check the standard of care provided will be adequate

- agree the price you will be charged

- discuss whether you will be responsible for transporting the animal to the specialist, or if they can collect

- draw up a legal contract covering all the points discussed.

\section{MISCELLANEOUS SMALL ANIMALS}

Most shelters find that they receive a variety of small animals other than cats and dogs. A multi-purpose block can be built, but bear in mind that since it is not a specialist unit, the length of time animals stay should be as short as possible. You should try and avoid having to provide this additional accommodation by identifying people who are prepared to 'foster' these animals until new homes can be found for them. The same conditions for fostering should apply as for large animals. The small animals block will need to be equipped with appropriate food and equipment, e.g. cages.

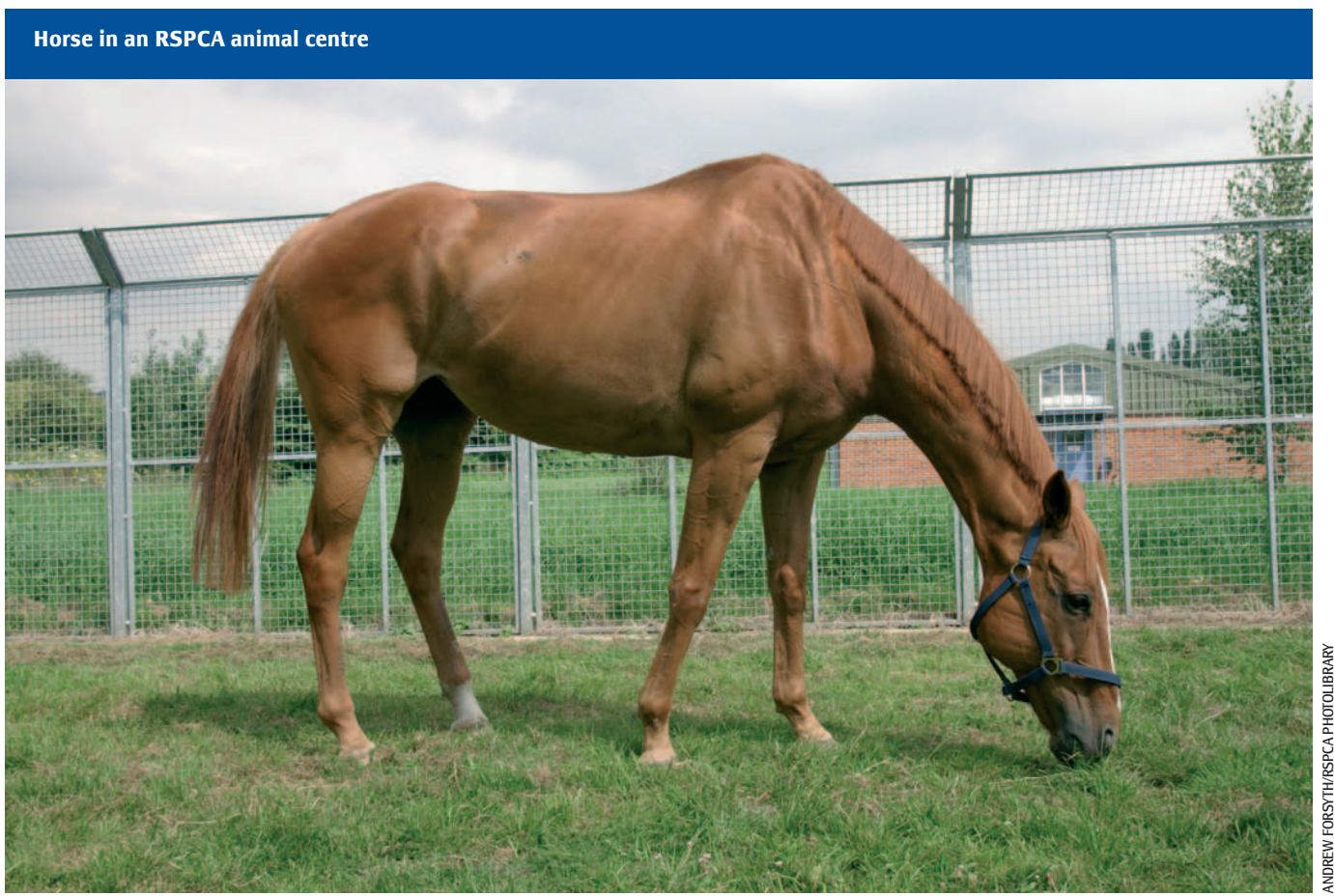

SECTION 3

Guidelines for the design and management of animal shelters

Royal Society for the Prevention of Cruelty to Animals. Guidelines for the design and Management of Animal Shelters. http://www.icam-coalition.org/downłoads/Shelter\%20guidelines.pdf 


\section{Intake Process and Procedures}

\section{Intake Record Keeping}

Medical History (if available) - from previous owner or shelter

Evaluate and Monitor Health Status

Behaviour Evaluation

\section{Vaccinations}

All animals must be vaccinated with core vaccinations at intake

\section{Isolation}

Separate entering animals - by species, age, physical and behavioural health

\section{Diagnosis}

Emergency Medical Care - for animals who are injured, in distress, or show signs of significant illness

Pain Management - Recognize and alleviate pain if needed

\section{Monitoring and Daily Rounds}

Check animals in isolation at least once every 24 hours to monitor

\section{Nutrition}

Determine appropriate diet and food requirements of each animal

7. Spay/Neuter Surgery

Medical History

Surgery and Anesthesia

\section{Euthanasia}




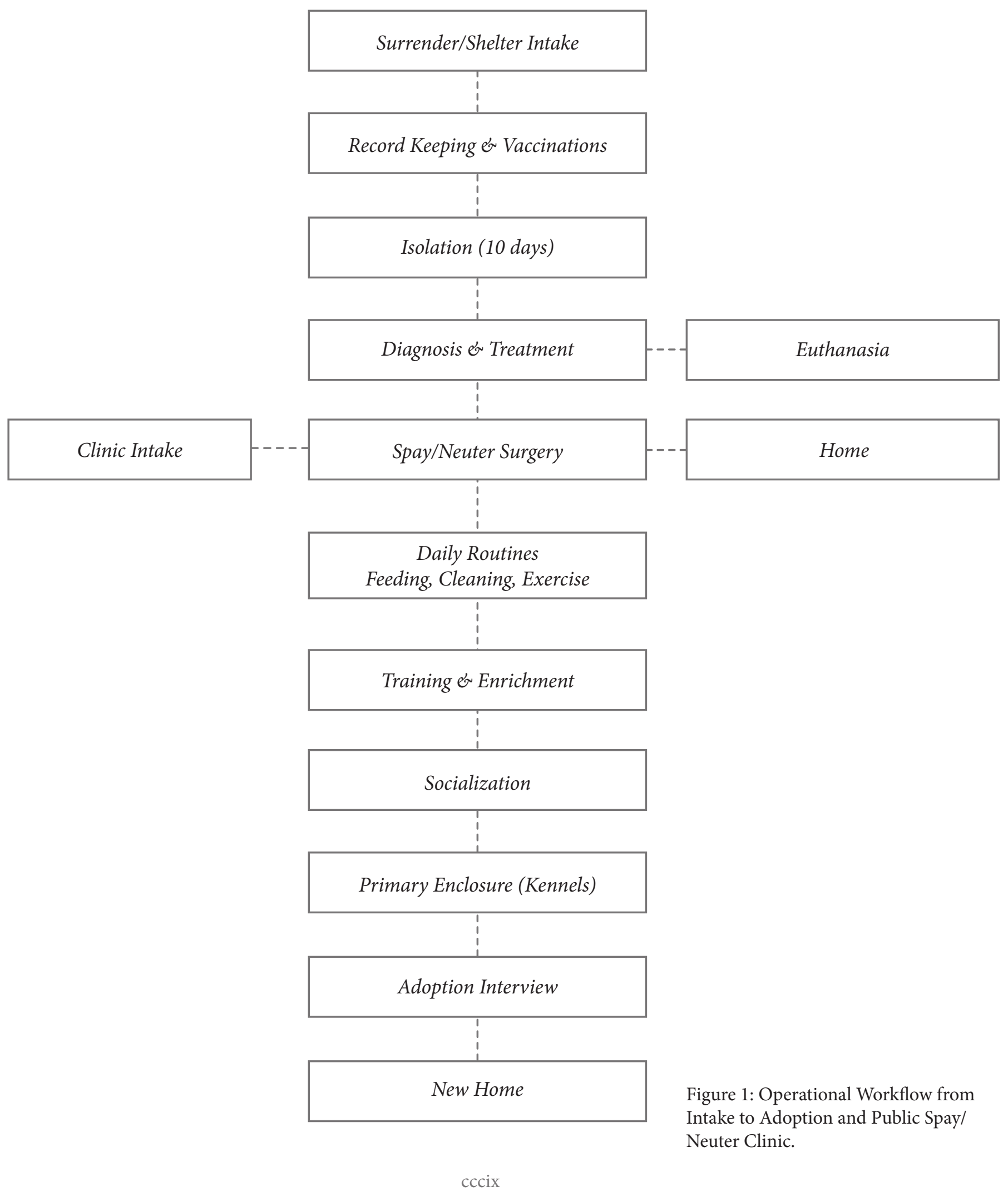




\section{SECTION 4: ESTABLISHING SHELTER ROUTINES}

The establishment of effective routines is an important part of running a shelter. Well-designed routines help an organisation to run smoothly and consistently achieve set standards. Routines also help to ensure that all staff are aware of their responsibilities. Routines should be established for admitting animals, rehoming procedures and daily tasks.

\section{INCOMING ANIMALS}

Dogs and cats must be quarantined on arrival for a minimum of 10 days. This timeframe can be adjusted according to incubation periods of common infectious diseases seen in your shelter or area. It is important that you have a dedicated quarantine area at your shelter. No contact between animals in quarantine or between quarantined animals and those ready for adoption should be allowed. All animals should be examined by a vet or an experienced member of staff within 24 hours of their arrival at the shelter, or sooner if there is any sign of injury or disease. Animals should also be vaccinated and wormed on arrival.

The time in quarantine gives an opportunity to assess the animal for any clinical or behavioural problems. This will help in rehoming and/or mixing appropriate animals together, particularly in communal kennels or catteries. Information gathered at arrival and during quarantine should be recorded in paper or electronic form (see Record keeping below).

Upon arrival all animals should be:

1. quarantined

2. examined by a vet

3. wormed

4. vaccinated

Dogs should be kept in quarantine for seven to 10 days and cats for 14 days.

\section{REHOMING}

The purpose of an animal shelter's rehoming programme should be to find responsible, life-long homes for animals.

Your organisation will need to establish a routine for rehoming. For instance, will you ask prospective adopters to fill in a questionnaire? Will you interview them?

To ensure an appropriate match between animal and adopter, it is important to know the needs of both the animal to be placed and their prospective adopter. Spending time refining your rehoming policy and routines will help to ensure the placement is long-term and does not increase your workload because the animals are subsequently returned, or cause undue stress to the animal.

It is important to carry out a formal assessment of animals before adoption so that:

- animals and adopters are suitably matched

- animals of unsound or questionable temperament are not rehomed.

Only healthy animals that are known not to have exhibited abnormal aggression or other serious behavioural disorders should be made available for adoption.

Example of RSPCA's rehoming process

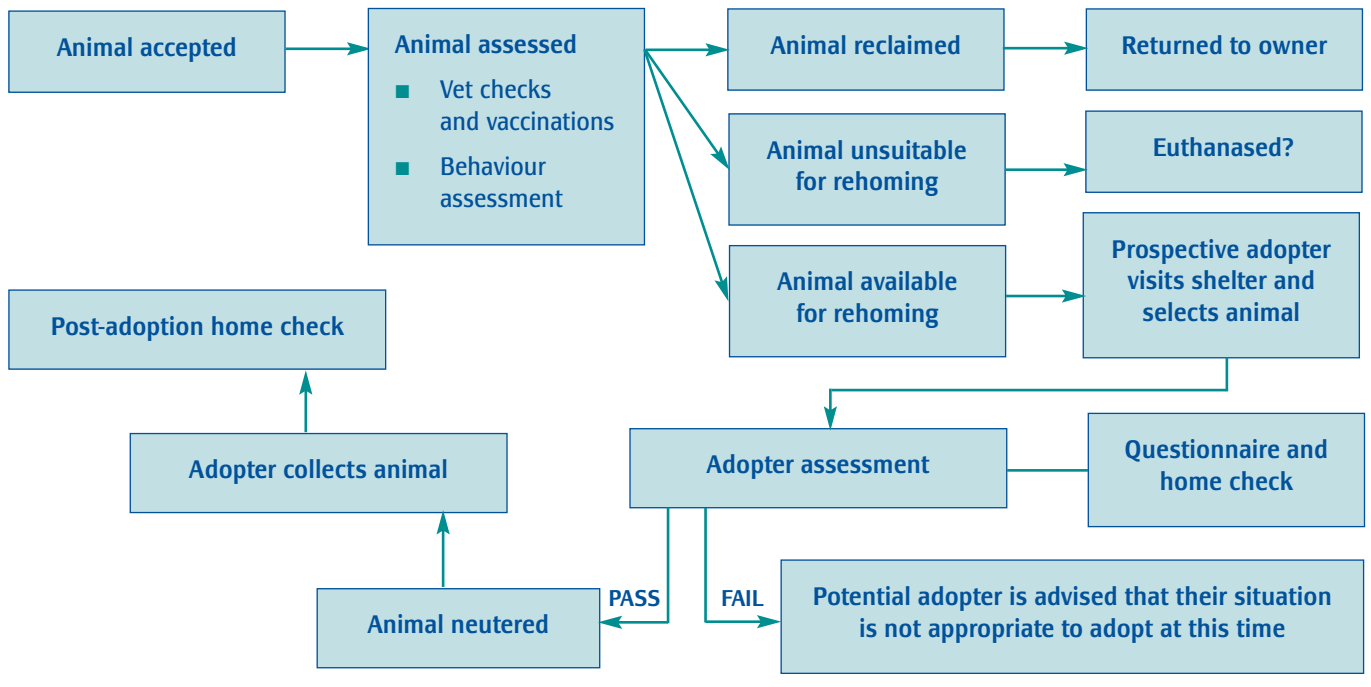

Royal Society for the Prevention of Cruelty to Animals. Guidelines for the design and Management of Animal Shelters. http://www.icam-coalition.org/docenloads/Shelter\%20guidelines.pdf 
Rehoming key points

1. The purpose of an animal shelter's rehoming programme is to find responsible, life-long homes for animals.

2. It is important to establish a routine for rehoming, so that staff and volunteers know the procedures to follow.

3. The written outline of the routine should state what forms are used, the sequence of the process and what fees, if any, are charged.

4. Responsible rehoming policies and procedures will help your organisation make the best decisions for the animals being adopted.

5. Use a pre-adoption questionnaire to learn as much as possible about the potential adopter's lifestyle, knowledge and commitment.

\section{DAILY ROUTINES}

It is important that routines are established and adhered to for feeding, cleaning and record keeping. This will ensure that fewer mistakes are made and that all essential tasks are completed properly. As part of the daily work routine, each shelter should detail the times by which these duties/tasks must be completed and the names of the staff responsible. A basic daily routine would be as follows.

1. Check all cages and inspect animals.

2. Adjust ventilation and heating.

3. Clean and disinfect kennels, cattery and service buildings.

4. Clean and disinfect feeding utensils.

5. Prepare food and feed animals.

6. Each animal should be exercised and groomed every day.

7. Attend to members of the public.

8. Allow time for staff breaks.

9. Bed down animals, adjust heating and ventilation.

10. Secure all buildings.

Ideally as many cleaning tasks as possible should be completed before the shelter is opened to members of the public.

You may need to draw up different routines for the weekends, holidays, etc., but all of the tasks will still need to be fulfilled, and preferably with the minimum of disruption to the normal routines for the animals.

\section{FEEDING}

The feeding regime should be set out clearly. Feeding times should be regular and adhered to, and concise written instructions should be available for staff. Frequent changes are unsettling for animals and should be avoided.

It is a good idea to have a wipeable white board in the food preparation area, showing the dietary requirements of each animal. The feeding products should not be changed too frequently since this can cause digestive upsets in some animals.

Food supplies must be regular and cost should take second place to quality, availability and sustainability.

The principles below should be considered when feeding:

- ensure you provide a balanced diet

- fresh clean water should be available at all times

- do not organise exercise sessions for the animals immediately after eating

- avoid sudden changes in diet

do not overfeed.

The food preparation area must be kept clean and orderly. Utensils should be practical and readily at hand. It is advisable to buy good quality products, as these will prove cheaper in the long run. Try to keep the food preparation time to a minimum since the time would be better spent socialising with the animals.

Tinned food provides a complete balanced meal, but animals produce looser stools, which may result in longer kennel cleaning times.

Dry food (either moistened or dry) provides a complete high protein, balanced meal. Stools will be very firm - the RSPCA uses dry food where possible.

Other foods. Avoid using leftovers, if possible. The potential for disease with this food is high and the nutritional value is often low, as well as being unreliable.

\section{HYGIENE AND CLEANING}

Systematic cleaning routines are essential to control the spread of disease. By establishing a set routine for cleaning, tasks are less likely to be forgotten and the control of disease will therefore be more effective. Cleaning routines for tasks which are to be done on a daily, weekly and monthly basis should be established and reviewed periodically to check that they are effective.

Daily cleaning:

- all occupied kennels must be cleaned daily

- animals must be moved out of the way while the cage/kennel is being cleaned, as should any moveable objects such as feeding/water bowls, dirt trays etc

- floors and walls should be thoroughly cleaned.

Royal Society for the Prevention of Cruelty to Animals. Guidelines for the design and Management of Animal Shelters. http://www.icam-coalition.org/downloads/Shelter\%20guidelines.pdf 


\section{In-Shelter Care - Summary of Considerations}

\section{Environment}

Enclosures \& Separation

Cats:

Clear 28" x 30" floor space (> 11 sqft); 30" height with shelf for perching

11 sqft includes bed, food and water dishes, litter box, and carrier or hiding box

Group housing - at least 18sqft of floor space per cat; less than 8 cats per group; double door entry

Dogs:

60-120sqft room

Double-sided runs to separate eating and resting area from elimination area, also convenient for facilitating daily cleaning procedures

Opportunities for retreat or interactions - give them control over their visual interactions. Sights of other dogs provide visual stimulation and comfort, discourages unnecessary barking, and encourages dogs to the front of their kennel which in turn facilitates adoption

Kennels should not face a blank wall - opportunities to look or access outdoors

Group housing - gives social dogs the opportunity to play and interact with each other in a larger space

Other considerations:

Hiding Places: All animals should be provided with appropriate places for concealment which comfortably allows them to avoid visual contact with people or other animals

Hard and Soft surfaces: Preference and options for resting on different surfaces

Interaction with potential adopters - petting through cages, interactive toy, or allow visitors to physically enter the kennel

"Real life rooms" - simulate house-like conditions with furniture so pets can adapt to new living conditions 
2. Daily Routine

3. Enrichment and Socialization

Interactions with people

Interactions with other animals

Enrichment

Exercise 
From: Koret Shelter Medicine Program. Facility Design and Animal Housing. 2015 http://www.sheltermedicine.com/library/facility-design-and-animal-housing

\section{Single Animal Housing Considerations}

\section{Adequate floor space and height}

One study found that cats were less stressed when given 11 square feet of floor space compared with animals given only 7.5 square feet. Our recent research, "Environmental and Group Health Risk Factors for Feline Respiratory Disease in Animal Shelters" documented lower risk for upper respiratory infection (URI) in shelters that provided housing with $>9$ square feet of floor space compared to shelters that provided less than 8 square feet.

In order to allow cats to assume most normal postures, housing needs to provide at least $28^{\prime \prime}$ by 30 " of clear floor space (e.g. excluding space occupied by bed, food and water dishes and litter boxes). In order to accommodate a carrier or hiding box, this generally means a width of $>3$ feet for a main compartment.

The height should be high enough to allow the cat to stand on their hind legs and fully extend their front legs without touching the roof of the enclosure, at least 30 " with a shelf or other elevated perching space.

Additionally, cages should be of sufficient size to accommodate a carrier which can be used to move the cat safely throughout the facility (and can double as the hiding space within the cage).

Although there are no studies documenting the specific space requirements for dogs, the same functional parameters should be met: sufficient floor space and height to allow the dog to assume all normal postures and engage in normal behaviors such as playing and moving about. Dog runs should be of sufficient size and height to permit human entry for cleaning and interaction, and should ideally be large enough to accommodate a human sitting in a chair to foster quiet interaction.

\section{Hiding area/carrier}

All animals should be provided with appropriate places for concealment which comfortably allow them to avoid visual contact with people or other animals8. These can be arranged such that staff can look in on an angle for identification and monitoring.

For cats and other small pets, cages should be of sufficient size to accommodate a carrier which can be used to move the animal safely throughout the facility (and can double as the hiding space within the cage). A carrier ideally stays with the cat throughout its shelter stay, from transport to intake, through stray holding, surgery, in get acquainted and play areas, to and from foster care, etc. If an airline type carrier or cardboard "Hide Perch and Go" type box is used, this can even go home with the cat to ease the transition to its new environment.

If floor space is insufficient to include a hiding box and still allow the cat to assume 
normal postures including laying down at full extension, providing a solid hiding box that takes up much of the floor space may do more harm than good. In such cases, the long term goal should be increasing cage size via installation of a portal or purchasing larger cages to provide sufficient floor space and a hiding box or carrier.

In the short term it is a better option to provide a hiding option that does not clutter limited floor space, such as a towel draped over a shelf or bed or a cage cover (these can be tailored to allow some concealment while still providing good air flow and visual access). If cats are housed in small cages, carriers should be stored outside the cage but still used for transport through the facility and remain with the cat throughout its shelter stay. Recognize that small cage housing has limited use and should not be used for long term housing of cats.

Dogs also benefit from the opportunity for concealment and some control over their environment. Crates for dogs can be more unwieldy due to their larger size, but in some cases the benefit will outweigh the trouble, especially for small dogs, frightened dogs, and those staying longer term. Providing crates models this helpful tool for the public as well as providing a bed, concealment and even a place to perch on top (some dogs, like many cats, prefer to sit up high). Crates should be sent home with the adopter or thoroughly sanitized between dogs and discarded if they are chewed to bits. The design of the run itself can facilitate opportunities for retreat or interaction as well. Double sided runs, runs designed on an angle, and furniture in "real life rooms" also offer some opportunities for retreat.

\section{Double-compartment.}

In addition to providing housing that allows for efficient and easy cleaning and daily care without animal disruption(critical for reducing handling stress for animals and reducing disease risk throughout the facility), double compartment cages meet animals need by providing distinct separation between elimination areas and feeding/resting areas.

Environmental control such as that afforded by compartmentalized housing can even promote friendlier behavior that may increase likelihood of adoption9.

For cats, litter should be in a separate compartment from the main food and resting area. The litter compartment may be smaller than the main living compartment but should be at least 15 " wide to accommodate a litter box and allow easy access for cleaning.

Alternately, very large single compartment housing can function adequately, providing size is sufficient for a person to walk in and clean without disrupting the cat, and greater than 3 feet is maintained between food and litter. In these cases, a carrier should still be provided so that the cat can be comfortably confined if necessary while its quarters are tidied.

For dogs, double compartment housing (ideally separated by a guillotine door that can be operated from outside the run) is critical to allow safe, efficient cleaning and care. Cleaning dog runs is a splashy wet business and it is difficult to avoid spraying dogs in adjacent runs; thus when cleaning a row of kennels, all dogs should be 
moved to the other side of a double compartment kennel and the guillotine door closed during the cleaning process.

Tying dogs out or keeping them in common areas during cleaning is not a viable solution, as this practice promotes disease transmission and fighting between incompatible dogs thrown together.

Double compartment housing is also necessary to provide clear separation between elimination and sleeping areas, a foundation for housebreaking (see Dog Elimination Preference chart above). Even in shelters with robust dog walking programs, it is likely that dogs will sometimes be left in the run for longer than they can hold their bowels or bladder (especially those who are not trained to take advantage of outdoor elimination opportunities whenever they have the chance).

Minimal visual stressors and provision of visual choices.

Animals in normal environments choose to spend a significant amount of time in visual contact with other animals or looking out windows. Visual access to other housed dogs has not been shown to increase barking, and allowing dogs the option of visual access to others (as long as they also have the option to retreat and not see or be seen by other dogs) may provide visual stimulation and encourage dogs to the front of cages, which in turn can facilitate adoption.

Animal housing should not face a blank wall if possible.

If cage banks or kennels face each other, part of the front should be covered so that animals can choose their level of visual contact, and some housing should be available for individual dogs that get overstimulated by exposure to another dog across the way.

Hard and soft surfaces.

Animals prefer soft sleeping surfaces over harder surfaces such as metal. Firm, cool surfaces benefit animals' ability to thermoregulate and gives them choices in their environment - e.g. soft bedding should be provided, however the entire cage surface should not be taken up with soft bedding.

Opportunity for potential adopters to make physical contact with adoptable animals

This can happen by petting them through cage bars, an interactive toy, or the opportunity to physically enter a large kennel

Many adopters report that physical contact is an important factor in adoptiondecision ("the cat chose me"). The risk of infectious disease transmission amongst healthy adoptable animals by visitors is likely minimal compared to the benefit of improving the chances and speed of adoption.

Hand sanitizers and hand washing stations should be provided, and unsupervised contact with infectious, sick animals prevented by housing these animals in separate areas. 
Enrichment within the cage and opportunity for out-of-cage time.

Provide animals with a variety of toys and offer cats a scratching post or pad. This can enhance opportunities for adoption as well as providing enrichment; even if toys are not played with, they can attract the attention of adopters.

Once screened for health, provide individually housed animals with an opportunity for out of cage time unless kennel size is sufficiently large to permit running, jumping, predatory-play behavior, lap-sitting, ball chasing and other normal behaviors. This can be accomplished in a separate, easily cleaned room or large pen placed off to the side or in the center of a room.

Do not allow animals to run loose in a room as a method of enrichment during cleaning, as litter, hair and debris and other potentially infectious material tends to accumulate on the floor in front of cages and may transmit infection.

\section{Outdoor space if possible.}

Animals benefit from the choice of exposure to sunlight and fresh air within their primary enclosure. Outdoor sections of enclosures can also be a cost effective means of substantially improving air quality.

For dogs, this is accomplished through double sided, runs, whether connected to an interior run or room. These can be separated by a guillotine door as described above to facilitate care without having to enter the run (especially beneficial for newly admitted, aggressive, or juvenile dogs). Alternately a door with a dog door can be used.

This design is also beneficial for cats; a human-sized door as well as a cat door will facilitate retrieving cats from the outdoor run sections. 
From: Koret Shelter Medicine Program. Facility Design and Animal Housing. 2015 http://www.sheltermedicine.com/library/facility-design-and-animal-housing

\section{Group Housing Considerations}

\section{Cats: group housing}

At least 18 square feet $(1.8 \mathrm{~m} 2)$ of floor space per cat.

Cats also need the opportunity to maintain a distance of 3-10 feet (1-3 meters) distance between themselves and other cats.

This does not include perches or walkways, but in temperate climates can include outdoor areas provided cats have 24 hour access.

Group size of 2-4 animals.

Addition of new animals to a group can result in more frequent aggression and can even cause sufficient stress to activate feline herpesvirus infection

In order to prevent frequent regrouping and to allow periodic complete emptying and disinfection of group rooms, more small rooms are greatly preferable to a few larger group rooms.

Dog runs no longer in use can be nicely converted to serve as small feline "group rooms" for this purpose

At maximum house no more than 8-10 cats per adequately sized group room.

Ample hiding and resting areas.

There should be at least as many hiding areas and elevated resting surfaces (at least 12 " wide) for the number of animals plus one

Ample litter and feeding stations.

While it may not be practical or desirable to provide each cat with a litter box, even in small rooms housing only 2-4 animals there should be at least 2 non-adjacent litter boxes and feeding/watering stations to prevent guarding by any one cat As the cat numbers increase the number of feeding stations and litter boxes will also need to increase

Daily monitoring is required, especially at feeding time, to ensure each cat has access to food and water. Periodic examination and weight monitoring can be very helpful in insuring health

Enrichment materials such as scratching posts, perches and furniture that can be readily disinfected or discarded from time to time.

Double doors at entry/exit points if possible.

This is especially important in larger group rooms to prevent feline escape when human visitors come in and out. At minimum, group room doors should not open directly to the outdoors. 


\section{Dogs: group housing}

\section{Sufficient space for each dog.}

No studies are available documenting space requirements per dog, but each dog should be able to move about freely without encountering another dog, with enough additional room that each dog can have its own resting place.

Pairs rather than group housing.

In addition to regrouping issues as for cats, dog feeding behavior is such that separation at feeding time is often required to ensure each dog has sufficient food. This can be easily accomplished if no more than two dogs are housed per double sided run.

If dogs are kept in larger groups, close monitoring of feeding is a must. If food guarding is observed provision must be made to segregate dogs at meal time.

Ample resting places and toys for each dog.

Although some dogs may choose to snuggle up together, there needs to be at least as many beds as there are dogs to prevent guarding by some preventing less dominant dogs from having access.

Double runs or rooms separated by a guillotine and/or full size door.

Since it is likely that some dogs will urinate and defecate in the run, daily cleaning is a must. It is not often practical to remove a herd of dogs daily for cleaning, so double sided runs are an important management consideration. This also provides dogs more flexibility to stay away from other group members if they so choose.

\section{All group housed animals}

Daily monitoring and removal of animals showing signs of social stress, including guarding of resources (e.g. food, beds, toys, litter, doorways or resting spots); frequent hiding; sitting with back turned to the group or hunched in a corner; decreased motor activity; or inappropriate elimination (e.g. eliminating on beds, cats eliminating outside of litter boxes)

Individual housing is the ideal option for any animal showing signs of stress in a group room, rather than repeatedly trying to house them with different, more compatible groups as the process of trying to find a compatible group is likely to afford numerous opportunities for stress and disease transmission.

A careful physical exam should also be performed to rule out medical causes for withdrawn or aggressive behavior 
Canine Kennels
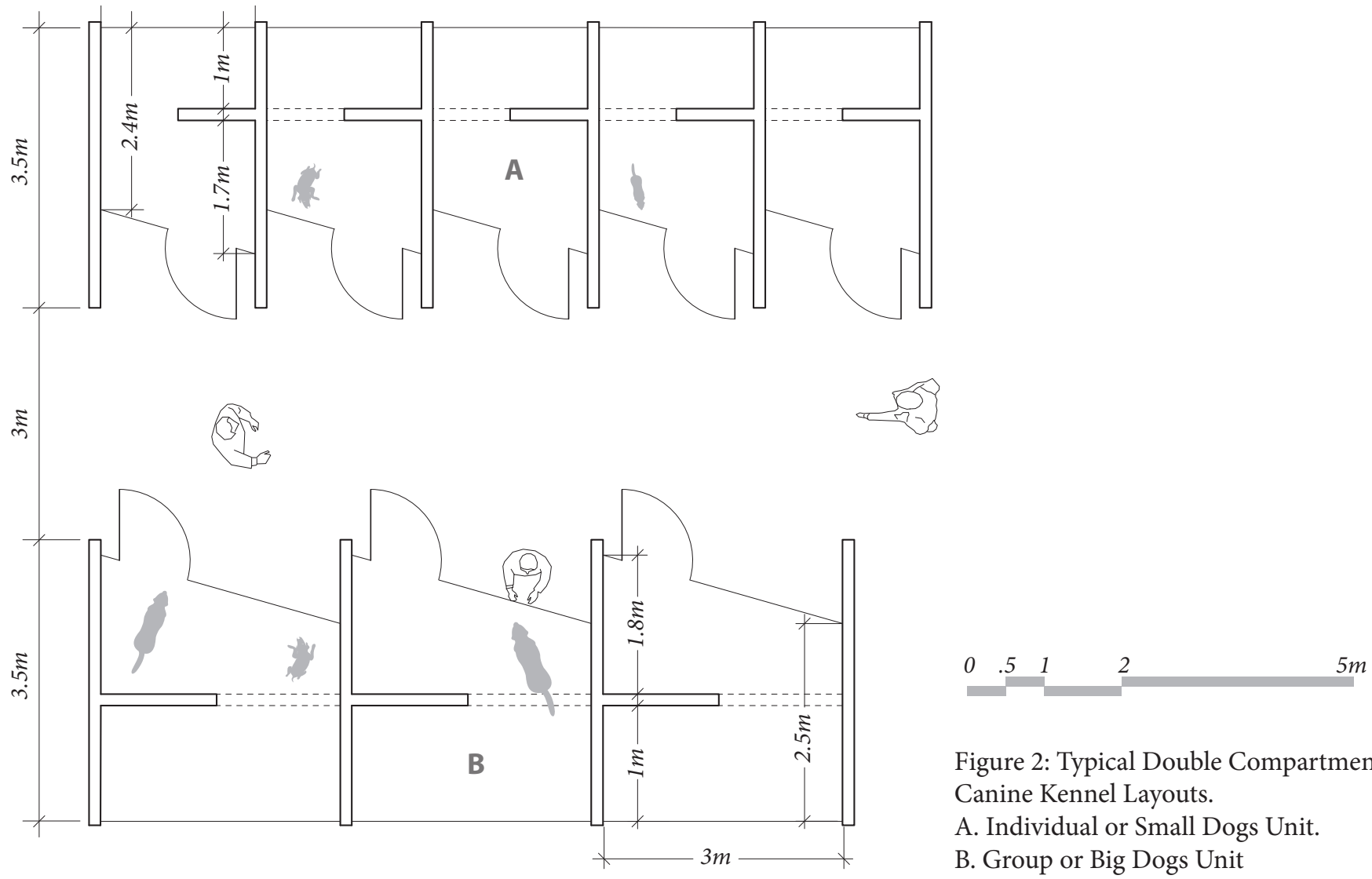

Figure 2: Typical Double Compartment Canine Kennel Layouts.
A. Individual or Small Dogs Unit.
B. Group or Big Dogs Unit

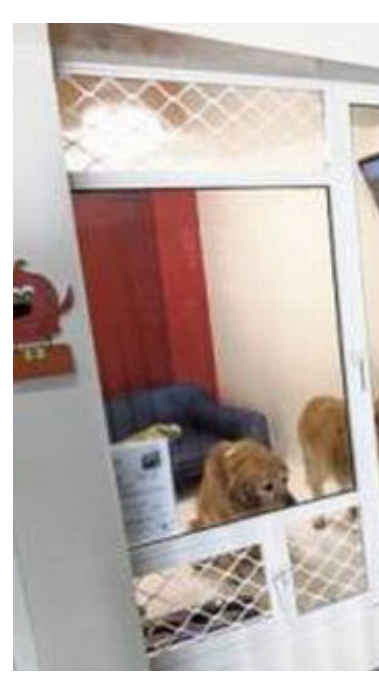

Figure 3: Canine Kennels

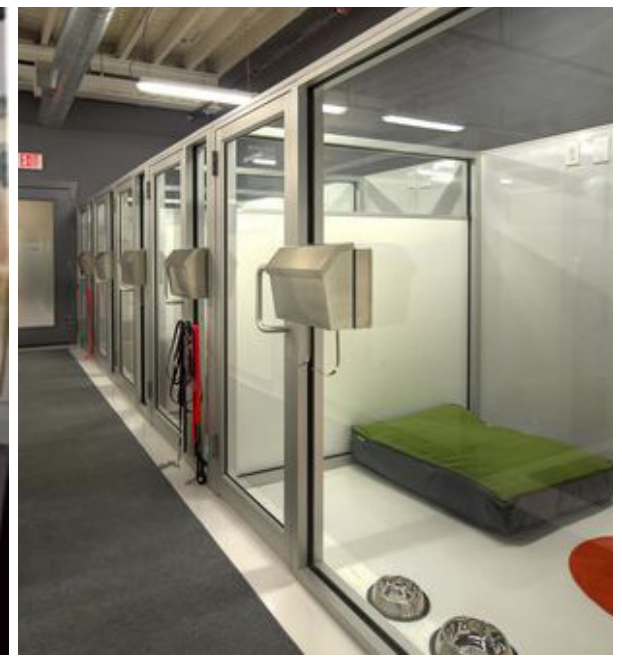

Figure 4: Canine Kennels 


\section{Feline Kennels}

$0 \quad .5$

\section{2}

Figure 5: Typical Cattery Layout with Ledge.

A. Individual Unit.

B Group Unit.

Figure 6: Cattery

Figure 7: Cattery
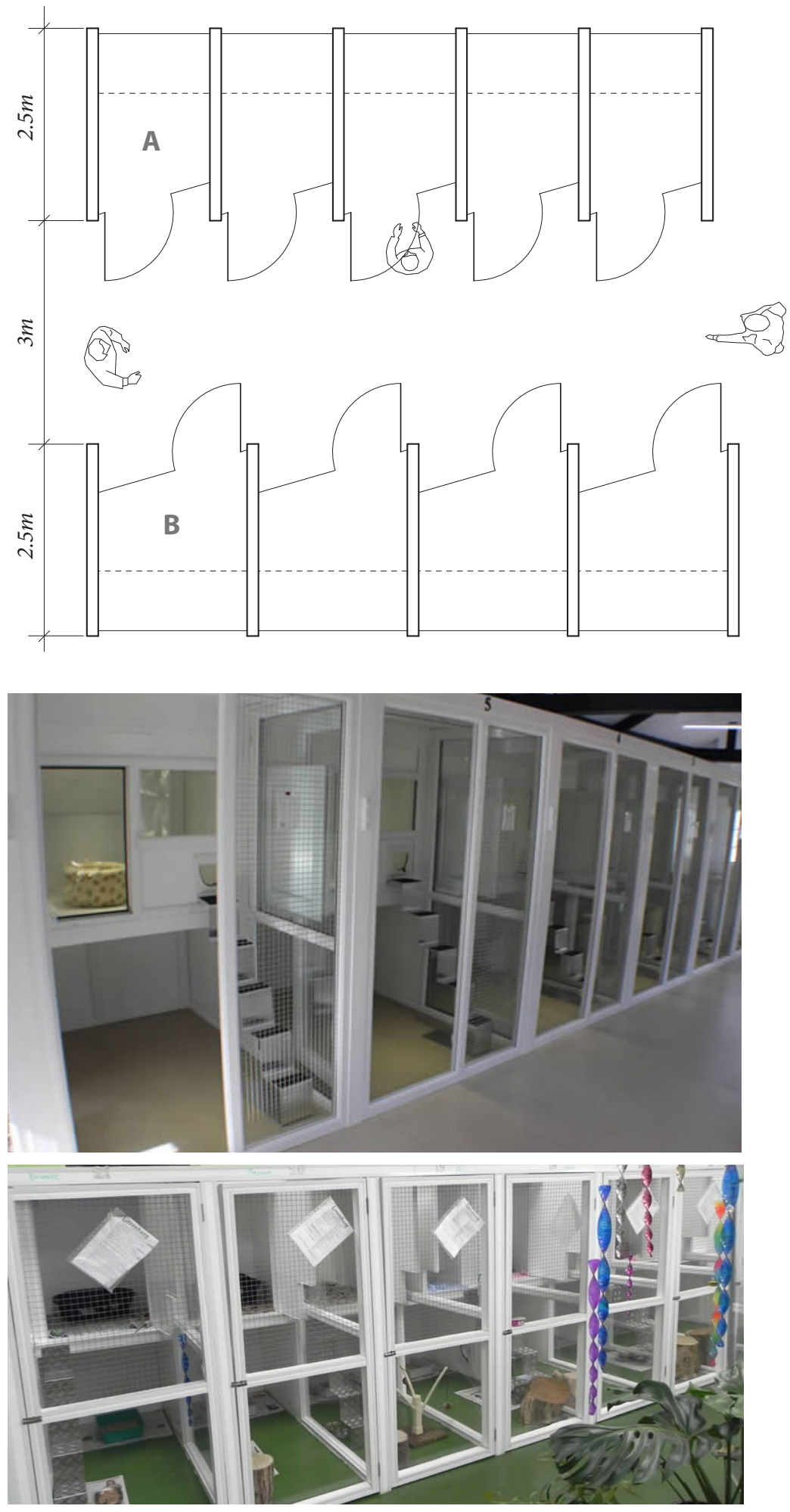

$\operatorname{cccxxi}$ 


\section{Sat Small Animals}

Small animals are accommodated for in moveable cages instead, reflecting the transient nature of the shelter. More permanent habitats and enclosures are discouraged as it communicates a long-term stay at the shelter. This would also deter potential adopters. Beyond cages, it's hard for potential adopters to commit finances towards permanent structures. Thus, open areas with cages will define the small animals' area.

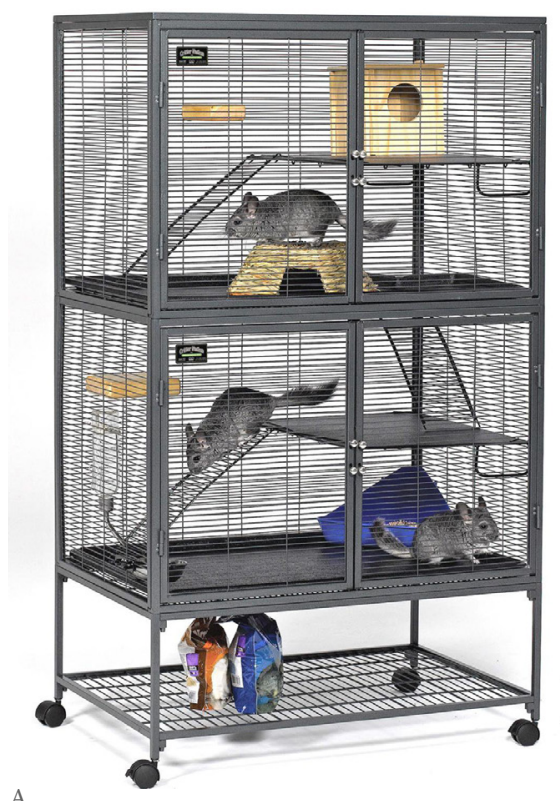

C

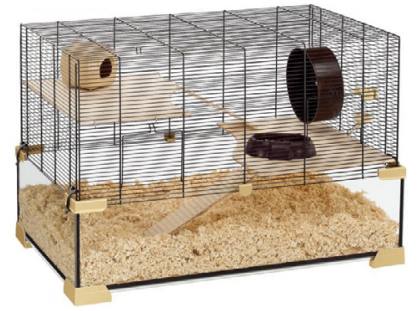

Figure 8: Small Animal Primary Enclosures
A | Guinea Pigs
B | Rabbits
C | Hamsters
D | Turtles
E | Birds

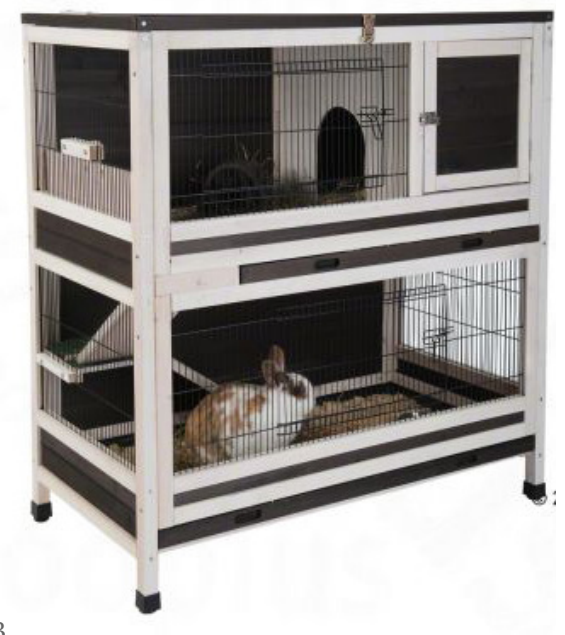

$\mathrm{D}$
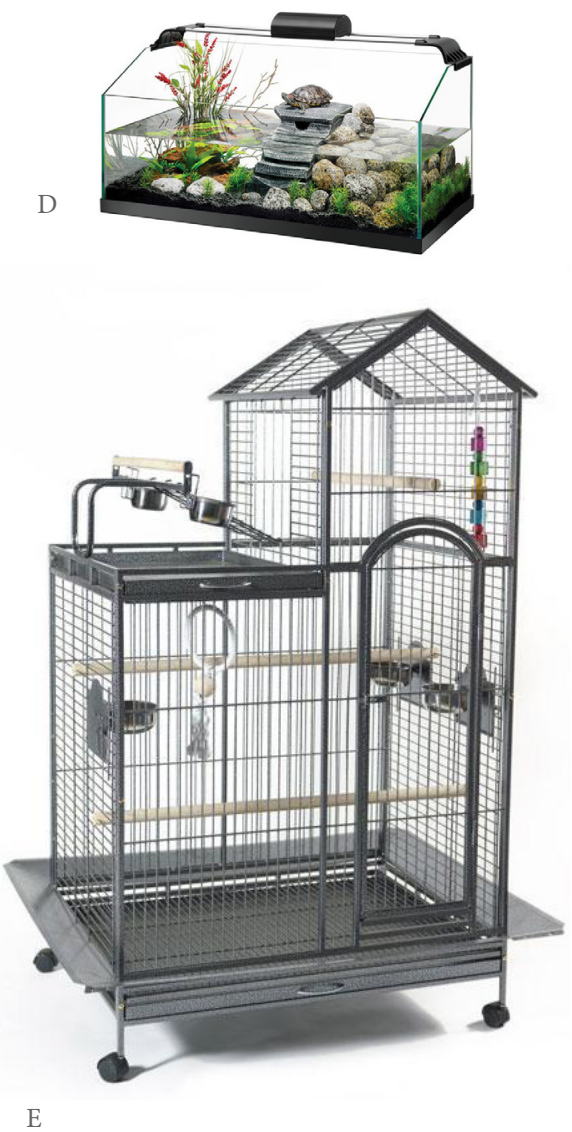

cccxxii 


\section{REFERENCES}

Association of Shelter Veterinarians. Guidelines for Standards of Care in Animal Shelters. 2010. http://ontariospca.ca/images/Shelter-Standards-Oct2011-from_ASV.PDF

Canadian Federation of Humane Societies. Standards of Care in Animal Shelters. 2010. http://cfhs.ca/athome/canadian_standards_of_care_in_animal_shelters/

Koret Shelter Medicine Program. Facility Design and Animal Housing. 2015

http://www.sheltermedicine.com/library/facility-design-and-animal-housing

Maddie's Fund. Design for Animal Shelters in a No-Kill World. 2003. http://www.

maddiesfund.org/design-for-shelter-animals.htm

Royal Society for the Prevention of Cruelty to Animals. Guidelines for the design and Management of Animal Shelters.

http://www.icam-coalition.org/downloads/Shelter\%20guidelines.pdf 


\section{BIBLIOGRAPHY}

ATKearney. 2014. Global Cities, Present and Future: 2014 Global Cities Index and Emerging Cities Outlook. April. Accessed Dec 14, 2015. https://www.atkearney.com/ research-studies/global-cities-index/2014.

Barthes, Roland. 1997. “Semiology and the Urban." In Rethinking Architecture: A Reader in Cultural Theory, by Neil Leach, 166-172. New York: Routledge.

Bonnell, Jennifer L. 2014. Reclaiming the Don: An Environmental History of Toronto's Don River Valley. Toronto: University of Toronto Press.

Bosker, Bianca. 2013. Original Copies: Architectural Mimicry in Contemporary China. Honolulu: University of Hawaii Press.

Boudrillard, Jean. 2006. Mass. Identity. Architecture. Architectural Writings of Jean Boudrillard. West Sussex: Wiley \& Sons Ltd.

—. 1988. Simulacra and Simulations. Edited by Mark Poster. Stanford University Press . http://www.egs.edu/faculty/jean-baudrillard/articles/simulacra-and-simulations/. Brightbill, C. 1961. Man and Leisure. New York: Prentice Hall Inc.

Brownlee, John. 2016. More Than A Beautiful Shell: Rebranding The World's Most Iconic Building. Feb 26. Accessed Mar 15, 2016. http://www.fastcodesign.com/3057144/morethan-a-beautiful-shell-rebranding-the-worlds-most-iconic-building.

Burke, Gerald. 1977. Towns in the Making. Edward Arnold.

2015. China "can't buy culture" with museum boom says critics. December. http://www. dezeen.com/2015/12/11/new-chinese-museums-construction-boom-opening-moneycant-buy-culture-china/.

Clark, Jane A. 2011. Urban Scrawl: Humane Society needs involvement now more than ever. Toronto: National Post, May 29. Accessed 02 10, 2016. http://news.nationalpost. $\mathrm{com} /$ posted-toronto/urban-scrawl-humane-society-needs-involvement-now-more-thanever.

Clave, Salvador Anton. 2007. The Global Theme Park Industry. UK: Biddles, Kings Lyn. Debord, Guy. 1977. The Society of the Spectacle.

Dezeen. 2015. China "can't buy culture" with museum boom, say critics. December 11. Accessed December 20, 2015. http://www.dezeen.com/2015/12/11/new-chinesemuseums-construction-boom-opening-money-cant-buy-culture-china/.

Dunlop, Beth. 1996. Building a Dream: The Art of Disney Architecture. New York: Harry N Abrams.

Eco, Umberto. 1997. "Function and Sign: The Semiotics of Architecture." In Rethinking Architecture: A Reader in Cultural Theory, by Neil Leach, 182-200. New York: Routledge.

Florida, Richard. 2002. The Rise of the Creative Class: And how its transforming work, leisure, community, and everyday life. New York: Basic Books. 
Frampton, Kenneth. 2005. “The Work of Architecture in the Age of Commodification.” In Commodification and Spectacle in Architecture, edited by William Saunders, ix - xviii. Minneapolis: The University of Minnesota Press.

Giedion, S. 1967. Space, Time, Architecture. Cambridge: Harvard University Press.

Goldberger, Paul. 2014. The Shape of Things to Come. January. Accessed September 2015. http://www.vanityfair.com/news/tech/2014/01/apple-facebook-google-headquartersarchitecture.

Gottdiener, Mark. 2001. The Theming of America. American Dreams, Media Fantasies, and Themed Environments. Westview Press.

Hardwickall, Jeffrey. 2003. Mall Maker: Victor Gruen, Architect of an American Dream. University of Pennsylvania Press.

Heathcote, Edwin. 2015. How celebrity architects are transforming New York's skyline. September 11 .

Heller, Steven. 2013. Duplitectural Marvels: Exploring China’s Replica Westen Cities. February 21. Accessed October 24, 2015. http://www.theatlantic.com/entertainment/ archive/2013/02/duplitectural-marvels-exploring-chinas-replica-western-cities/273366/.

Herwig, Oliver. 2006. Dream Worlds: Architecture and Entertainment. Munich: Prestal Verlag.

Huizinga, Johan. 1955. Homo Ludens: A Study of the Play Element in Culture. London: Routeledge \& Kegan Paul.

Jencks, Charles. 2005. The Iconic Building. New York: Rizzoli.

Jencks, Charles. 2006. “The Iconic Building is Here to Stay.” City (Routledge) 10 (1).

Jenkins, Barbara. 2005. “Toronto's Cultural Renaissance." Canadian Journal of Communication 30 (2). Accessed 02 18, 2016. http://cjc-online.ca/index.php/journal/ article/view/1417/1523.

Kalinowski, Tess. 2016. Don Valley gondola could lift Toronto tourism. Toronto: The Star, February 19. Accessed February 26, 2016. http://www.thestar.com/news/gta/ transportation/2016/02/19/don-valley-gondola-could-lift-toronto-tourism.html.

Kärrholm, Mattias. 2012. Retailising Space: Architecture, Retail and the Territorialisation of Public Space. Surrey: Ashgate Publishing Ltd.

Klein, Naomi. 2000. No Logo: Taking Tain at the Brand Bullies. Toronto: Vintage Canada.

Klein, Norman. 2004. The Vatican to Vegas: A History of Special Effects. New York: The New York Press. 
Klingmann, Anna. 2007. Brandscapes: Architecture in the Experience Economy. Cambridge: The MIT Press.

Koolhaas, Rem. 2002. “Junkspace.” October, Spring: 175-190. Accessed September 2015. http://www.jstor.org/stable/779098 .

—. 2001. The Harvard Design School Guide to Shopping . Taschen.

Lonsway, Brian. 2009. Making Leisure Work. Archtiecture and the Experience Economy. New York: Routledge.

Lukas, Scott A. 2007. The Themed Space: Locating Culture, Nation, and Self. Plymouth: Lexington Books.

Lukas, Scott A. 2008. Theme Park. Reaktion Books.

Marling, Karal Ann. 1997. Designing Disney's Theme Parks: The Architecture of Reassurance. Montreal: Canadian Centre for Architecture .

Mayor, Adam. n.d. "Architecture Critic Paul Goldberger on Silicon Valley, San Jose, and Apple."

Murphy, J.F. 1974. Concepts of Leisure. Philosophical Implications. New Jersey: San Jose State University Prentice Hall Inc.

O'Toole, Megan. 2012. Humane Society delays move to accept strays directly. Toronto: National Post, January 9. Accessed 02 10, 2016. http://news.nationalpost.com/postedtoronto/glut-of-stray-cats-puts-strain-on-animal-services.

Pallasmaa, Juhani. 2011. The Enbodied Image: Imagination and Imagery in Architecture. Wiley.

Pieper, Joseph. 1952. Leisure. The Basis of Culture. New York: Pantheon Books, Inc.

Pine, Joseph, and James H Gilmore. 1999. The Experience Economy: Work is Tehatre \& Every Business a Stage. Boston: Harvard Business School Press.

Poynor, Rick. 2005. "Hypernation Nation: Blurred Forms for a Blurred World." In Commodification and Spectacle in Architecture, edited by William Saunders, 34-46. Minneapolis: The University of Minnesota Press.

Related Companies. 2014. Zaha Hadid 520 West 28th. http://www.520w28.com/.

Society, Toronto Humane. n.d. Our History. Toronto. http://www.torontohumanesociety. com/about-us/history.

Sudjic, Deyan. 2005. The Ediface Complex: How the Rich and Powerful Shape the World. Penguin. 
Veblen, Thorstein. 2005. Conspicuous Consumption (Vol. 38). New York: Penguin Books Ltd.

Venturi, Robert. 1966. Complexity and Contradiction. New York: The Museum of Modern Art.

Venturi, Robert, Denise Scott-Brown, and Steven Izenour. 1977. Learning from Las Vegas. Cambridge: The MIT Press.

Zukin, Sharon. 1991. Landscapes of Power: From Detroit to Disney World. Los Angeles: University of California Press. 
